\title{
Ad valorem tariffs and customs valuation
}

Citation for published version (APA):

Macedo, L. C. L. (2020). Ad valorem tariffs and customs valuation: implications for the stability and predictability of national revenue from tariffs. [Doctoral Thesis, Maastricht University]. Maastricht University. https://doi.org/10.26481/dis.20201130lm

Document status and date:

Published: 01/01/2020

DOI:

10.26481/dis.20201130lm

Document Version:

Publisher's PDF, also known as Version of record

\section{Please check the document version of this publication:}

- A submitted manuscript is the version of the article upon submission and before peer-review. There can be important differences between the submitted version and the official published version of record.

People interested in the research are advised to contact the author for the final version of the publication, or visit the DOI to the publisher's website.

- The final author version and the galley proof are versions of the publication after peer review.

- The final published version features the final layout of the paper including the volume, issue and page numbers.

Link to publication

\footnotetext{
General rights rights.

- You may freely distribute the URL identifying the publication in the public portal. please follow below link for the End User Agreement:

www.umlib.nl/taverne-license

Take down policy

If you believe that this document breaches copyright please contact us at:

repository@maastrichtuniversity.nl

providing details and we will investigate your claim.
}

Copyright and moral rights for the publications made accessible in the public portal are retained by the authors and/or other copyright owners and it is a condition of accessing publications that users recognise and abide by the legal requirements associated with these

- Users may download and print one copy of any publication from the public portal for the purpose of private study or research.

- You may not further distribute the material or use it for any profit-making activity or commercial gain

If the publication is distributed under the terms of Article $25 \mathrm{fa}$ of the Dutch Copyright Act, indicated by the "Taverne" license above, 


\title{
Ad Valorem Tariffs and Customs Valuation
}

Implications for the stability and predictability of national revenue from tariffs

\author{
DISSERTATION
}

to obtain the degree of Doctor at Maastricht University, on the authority of the Rector Magnificus Prof. dr. Rianne Letschert in accordance with the decision of the Board of Deans, to be defended in public on 30 November 2020 at 16:00 hours

by

Leonardo Correia Lima Macedo 


\section{Reverse of title page}

\section{Supervisor:}

Prof. dr. Peter L.H. Van den Bossche

\section{Co-supervisor:}

Prof dr. Denise Prévost

\section{Assessment Committee:}

Prof. Raymond Luja (chairperson)

Dr Frank Nellen

Prof. dr. Hans-Michael Wolffgang, University of Muenster

Prof. dr. Santiago Ibanez Marsilla, University of Valencia 
To customs officers working at the borders and applying trade rules that do not align with their government's revenue goals and economic realities.

"True departure is return" (The Dispossessed, Ursula K. Le Guin) 


\section{Acknowledgements}

Writing this dissertation was a struggle, as I had difficulties to organize my thoughts and express my views in line with academic standards. This work connects my practitioner soul with my intellectual curiosity. As such, it is my central contribution, one that started with a master idea, each time progressing another step until I arrived at a satisfactory outcome. On this journey, I was extremely lucky to have Prof. Peter Van den Bossche and Dr. Denise Prévost.

My plans to work with Peter started in 2010 when I moved to Brussels. Our first meeting was canceled when he broke his foot in Maastricht and stayed in bed for a couple of weeks. Denise came to the rescue of his prospective students, and I was blessed to have her as my cosupervisor.

Peter is the ideal supervisor: internationally well known, always supportive, and easy-going. I remember his guidance about the expectations to innovate and the need to get the job done. Too high expectations are detrimental and might freeze the progress in the dissertation. Too low expectations result in a lousy job. One should find the balance to complete the work.

Denise was always on my side. During our meetings, I saw her clear guidance and strength, while juggling a successful professional career with family. She undertook the critical role of reading and commenting on the first drafts of the dissertation. For that, I am extremely grateful and acknowledge that this text is readable only because she read it first in great detail. Only half-way through the reading, she was already an expert on customs valuation and tariffs!

As a student, I benefited from the advice, comments, and suggestions of many. Some I met at the University, and others at work.

At Maastricht University, my sincere thanks to the Institute for Globalization and International Regulation, namely, Anselm Kamperman Sanders, Dalindyebo Shabalala, and Leila Choukroune. My gratitude to the administrative team: Licette Poll, Monique Laenen and Eva Rongen.

At work, I studied tariffs and customs valuation, taught, and worked both nationally and internationally. At the Brazilian Revenue and Customs Administration, I am grateful to those who introduced me to the world of customs: Clecy Lionço, Jose Barroso Tostes Neto, Ernani Checcucci and Tereza Christina Guimaraes. At the WCO, I owe thanks to the dedicated staff working at the organization and to the TCCV delegates who have shared ideas and friendship with me over several years: Ania Luniewicz (decd.), Eva Kralova, Guzmán Mañes Piñeiro, Holm Kappler, Hong Nguyen, Ian Cremer, Jan B Olsson, Jazmin Gonzalez Aguire, JeanFrançois Bédard, John Malone, Jože Tomažič, Kunio Mikuriya, Marcellin Laourou, Miia Kristiina Ainali, Monique Folcque, Paula Lopez Novella, Pierre Trudel, Ping Liu, Richard Soki, Rosalie Deegan, Sebastian Tschiderer, Sergio Mujica, Shigeaki Katsu, Sumit Dutt 
Majumder, Terdsak Suvarnamani, Timur Bektemirov, Uschi Krampe, Vicente Horacio, Wayne Baldwin, Yuliya Gulis, and many others.

From the WTO, I owe special thanks to Sheri Rosenow, Roy Santana, and Lisette Nonalaya, for their openness in exchanging views.

In 2017, I was lucky to be a visiting researcher at Georgetown Law University in Washington DC and to have access to its fantastic libraries' resources. For that, I am grateful to the Institute of International Economic Law (IIEL) team and to the administrative staff that supported my request: Christine Q. Washington, Mariah Strauch-Nelson, and Sandra Layton.

None of those mentioned above bear any responsibility for any error or omission in this dissertation. It is evident that any mistakes should be attributed to me only in my private capacity, and they do not represent the views of the people I met, nor the institutions I worked for during the past years.

Finally, I owe thanks to my beloved wife Maria Carmen and sons Rafael and Afonso for the time I took from them to research and write. They have always been supportive. Also, in the family, thanks to Alessandra and Tania, who insisted I should continue studying to get a Ph.D.

Leonardo Macedo 


\section{List of Abbreviations}

\begin{tabular}{|c|c|}
\hline AEO & Authorized Economic Operator \\
\hline AEOI & Automatic Exchange of Information \\
\hline AIA & American Importers Association \\
\hline ARO & Agreement on Rules of Origin \\
\hline ASP & American Selling Price \\
\hline ASYCUDA & Automated System of Custom Data \\
\hline AV & Ad Valorem \\
\hline AVE & Ad Valorem Equivalent \\
\hline $\mathrm{BDV}$ & Brussels Definition of Value \\
\hline BEPS & Base Erosion and Profit Shifting \\
\hline BREXIT & British Exit \\
\hline BRICS & Brazil, Russia, India, and China \\
\hline CBOT & Chicago Board of Trade \\
\hline CBP & Customs and Border Protection \\
\hline $\mathrm{CCC}$ & Customs Co-operation Council \\
\hline $\mathrm{CCV}$ & Committee on Customs Valuation \\
\hline CEE & Central and Eastern Europe \\
\hline CEEC & Committee of European Economic Co-operation \\
\hline $\mathrm{CFC}$ & Common Fund for Commodities \\
\hline CIF & Cost, Insurance, and Freight \\
\hline $\mathrm{CMC}$ & Carboxymethyl Cellulose \\
\hline CPIA & Country Policy and Institutional Assessment \\
\hline CRO & Committee on Rules of Origin \\
\hline CUP & Comparable Uncontrolled Price \\
\hline CVA & Customs Valuation Agreement \\
\hline CVM & Computed Value Method \\
\hline DG & Directorate-General \\
\hline $\mathrm{DS}$ & Dispute Settlement \\
\hline DSB & Dispute Settlement Body \\
\hline DSU & Dispute Settlement Understanding \\
\hline DVM & Deducted Value Method \\
\hline $\mathrm{EC}$ & European Community \\
\hline ECB & European Central Bank \\
\hline ECM & European Common Market \\
\hline ECOSOC & United Nations Economic and Social Council \\
\hline ECUSG & European Customs Union Study Group \\
\hline
\end{tabular}




\begin{tabular}{|c|c|}
\hline EEC & European Economic Community \\
\hline EFTA & European Free Trade Association \\
\hline ER & Exchange Rate \\
\hline EU & European Union \\
\hline FA & Formula Apportionment \\
\hline FAO & Food and Agriculture Organization of the United Nations \\
\hline FCS & Fragile and Conflict-Affected States \\
\hline FCTC & Framework Convention on Tobacco Control \\
\hline FEER & Fundamental Equilibrium Exchange Rate \\
\hline FOB & Free on Board \\
\hline FT & Financial Times \\
\hline FTA & Free Trade Agreement \\
\hline G20 & Group of Twenty \\
\hline GATS & General Agreement on Trade in Services \\
\hline GATT 1947 & General Agreement on Tariffs and Trade 1947 \\
\hline GATT 1994 & General Agreement on Tariffs and Trade 1994 \\
\hline GB & Global Britain \\
\hline GCC & Global Commodity Chain \\
\hline GIC & General Introductory Commentary \\
\hline GPN & Global Production Network \\
\hline GTAP & Global Trade Analysis Project \\
\hline GTFP & Global Trade Finance Program \\
\hline GVC & Global Value Chain \\
\hline HRO & Harmonized Non-Preferential Rules of Origin \\
\hline HS & Harmonized Commodity Description and Coding System \\
\hline IBRD & International Bank for Reconstruction and Development \\
\hline ICA & International Commodity Agreement \\
\hline ICB & International Commodity Body \\
\hline ICC & International Chamber of Commerce \\
\hline ICCICA & Interim Coordinating Committee for International Commodity Arrangements \\
\hline IEG & Independent Evaluation Group \\
\hline IFC & International Finance Corporation \\
\hline IFFs & Illicit Financial Flows \\
\hline IFIA & International Federation of Inspection Agencies \\
\hline IIEL & Institute of International Economic Law \\
\hline IMF & International Monetary Fund \\
\hline IPC & Integrated Programme for Commodities \\
\hline IPPC & International Plant Protection Convention \\
\hline
\end{tabular}




\begin{tabular}{|c|c|}
\hline ISG & International Study Group \\
\hline ITC & International Trade Center \\
\hline ITC & International Trade Commission \\
\hline ITO & International Trade Organization \\
\hline LDCs & Least Developed Countries \\
\hline MATGs & Multilateral Agreements on Trade in Goods \\
\hline MDGs & Millennium Development Goals \\
\hline MIP & Minimum Import Prices \\
\hline MIWI & Made-in-the-World Initiative \\
\hline MNC & Multinational Corporation \\
\hline MNE & Multinational Enterprise \\
\hline MOU/MOA & Memorandum of Understanding/Agreement \\
\hline $\mathrm{MU}$ & Memorandum of Understanding \\
\hline NAMA & Negotiating Group on Market Access for Non-agricultural Products \\
\hline NATO & North Atlantic Treaty Organization \\
\hline NAV & Non-Ad Valorem \\
\hline NTB & Non-tariff barrier \\
\hline NTM & Non-tariff measure \\
\hline ODC & Other duties and charges \\
\hline OECD & Organization for Economic Co-operation and Development \\
\hline OED & Oxford English Dictionary \\
\hline OIE & $\begin{array}{l}\text { World Organization for Animal Health (formerly the Office International des } \\
\text { Epizooties) }\end{array}$ \\
\hline OTC & Over the Counter \\
\hline PCA & Post Clearance Audit \\
\hline $\mathrm{PM}$ & Philip Morris \\
\hline PRS & Price Range System \\
\hline PSI & Pre-Shipment Inspection \\
\hline PTA & Preferential Trade Agreement \\
\hline QR & Quantitative Restriction \\
\hline RKC & Revised Kyoto Convention \\
\hline $\mathrm{RP}$ & Revenue Package \\
\hline SA & Separate Accounting \\
\hline SDGs & Sustainable Development Goals \\
\hline TA & Technical Assistance \\
\hline TCCV & Technical Committee on Customs Valuation \\
\hline TCRO & Technical Committee on Rules of Origin \\
\hline TFA & Trade Facilitation Agreement \\
\hline TIN & Taxpayer Identification Number \\
\hline
\end{tabular}




\begin{tabular}{|l||l||}
\hline TiVA & Trade in Value-Added \\
\hline TPR & Trade Policy Review \\
\hline \hline TPRM & Trade Policy Review Mechanism \\
\hline \hline TV & Transaction Value \\
\hline \hline UN & United Nations \\
\hline UNCTAD & United Nations Conference on Trade and Development \\
\hline \hline USITC & United States International Trade Commission \\
\hline \hline VAT & Value-Added Taxes \\
\hline \hline VC & Valuation Code \\
\hline \hline WB & World Bank \\
\hline \hline WCO & World Customs Organization \\
\hline \hline WEF & World Economic Forum \\
\hline \hline WHO & World Health Organization \\
\hline \hline WIOD & World Input-Output Database \\
\hline \hline WTO & World Trade Organization \\
\hline
\end{tabular}




\section{List of Tables}

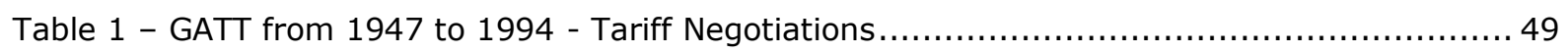

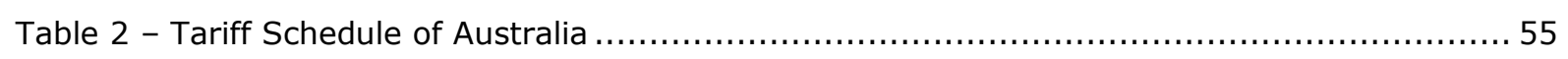

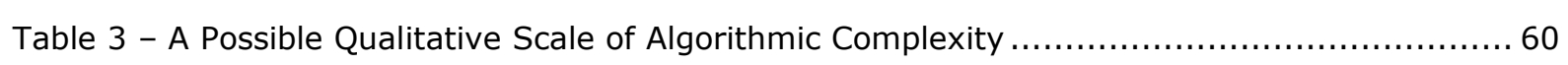

Table 4 - WTO Customs Valuation Agreement - Structure ........................................ 147

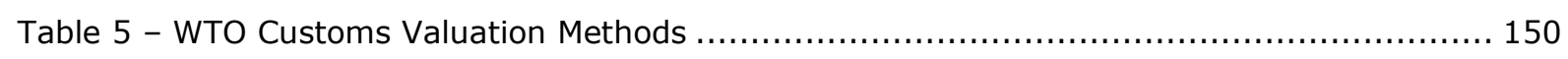

Table 6 - CCC/WCO Instruments on Royalties.................................................. 176

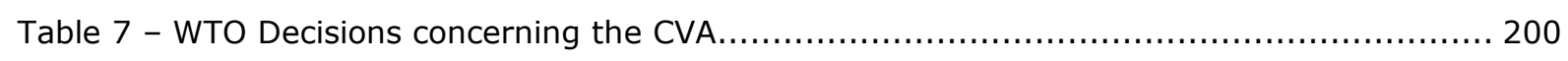

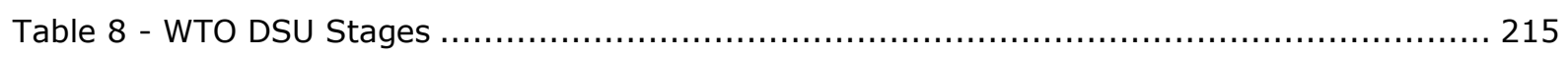

Table 9 - WTO DS Cases Art. VII - Number and Short Title ...................................... 217 


\section{List of WTO Cases}

The year in brackets following the short name of the case refers to the year in which the panel or Appellate Body report in that case was adopted by the DSB. For the cases that have no panel, the year used is the one referring to the consultations request or mutually agreed solution.

\begin{tabular}{|c|c|}
\hline Short title & Title and Status \\
\hline EC - Cereals (1995) & $\begin{array}{l}\text { European Communities - Duties on Imports of Cereals. Panel established on } \\
11 \text { October 1995, but subsequently not composed. (DS9) }\end{array}$ \\
\hline EC - Grains (1995) & $\begin{array}{l}\text { European Communities - Duties on Imports of Grains. Settled or terminated } \\
\text { (withdrawal, mutually agreed solution) on } 2 \text { May 1997. (DS13) }\end{array}$ \\
\hline EC - Rice (1995) & $\begin{array}{l}\text { European Communities - Duties on Imports of Rice. In consultations on } 3 \\
\text { October 1995. No dispute panel established and no withdrawal, or mutually } \\
\text { agreed solution notified. (DS17) }\end{array}$ \\
\hline $\begin{array}{l}\text { Argentina - Textiles and } \\
\text { Apparel (1998) }\end{array}$ & $\begin{array}{l}\text { Argentina - Measures Affecting Imports of Footwear, Textiles, Apparel } \\
\text { and other Items. Appellate Body Report adopted } 22 \text { April 1998. (DS56) }\end{array}$ \\
\hline US - Shrimp (1998) & $\begin{array}{l}\text { United States - Import Prohibition of Certain Shrimp and Shrimp } \\
\text { Products, Appellate Body report adopted on } 6 \text { November 1998. (DS58) }\end{array}$ \\
\hline $\begin{array}{l}\text { EC - Computer Equipment } \\
\text { (1998) }\end{array}$ & $\begin{array}{l}\text { European Communities - Customs Classification of Certain Computer } \\
\text { Equipment. Panel report adopted on } 22 \text { June 1998. (DS62) }\end{array}$ \\
\hline US - FSC (2006) & $\begin{array}{l}\text { United States - Tax Treatment for "Foreign Sales Corporations". Second } \\
\text { Recourse to Art 21.5 DSU Appellate Body report adopted on } 14 \text { March } \\
\text { 2006. (DS108) }\end{array}$ \\
\hline EC - Rice (1998) & $\begin{array}{l}\text { European Communities - Restrictions on Certain Import Duties on Rice. In } \\
\text { consultations on } 27 \text { May 1998. No dispute panel established and no } \\
\text { withdrawal, or mutually agreed solution notified. (DS134) }\end{array}$ \\
\hline $\begin{array}{l}\text { Brazil - Minimum Import } \\
\text { Prices (1999) }\end{array}$ & $\begin{array}{l}\text { Brazil - Measures on Import Licensing and Minimum Import Prices. In } \\
\text { consultations on } 14 \text { October 1999. No dispute panel established and no } \\
\text { withdrawal, or mutually agreed solution notified. (DS183) }\end{array}$ \\
\hline $\begin{array}{l}\text { Brazil - Minimum Import } \\
\text { Prices (2000) }\end{array}$ & $\begin{array}{l}\text { Brazil - Measures on Minimum Import Prices. In consultations on } 30 \text { May } \\
\text { 2000. No dispute panel established and no withdrawal, or mutually agreed } \\
\text { solution notified. (DS197) }\end{array}$ \\
\hline $\begin{array}{l}\text { Romania - Minimum Import } \\
\text { Prices (2001) }\end{array}$ & $\begin{array}{l}\text { Romania - Measures on Minimum Import Prices. Settled or terminated } \\
\text { (withdrawal, mutually agreed solution) on } 26 \text { September 2001. (DS198) }\end{array}$ \\
\hline Belgium - Rice (2001) & $\begin{array}{l}\text { Belgium - Administration of Measures Establishing Customs Duties for } \\
\text { Rice. Settled or terminated (withdrawal, mutually agreed solution) on } 18 \\
\text { December 2001. (DS210) }\end{array}$ \\
\hline $\begin{array}{l}\text { Argentina - Poultry } \\
\text { Anti-Dumping Duties (2003) }\end{array}$ & $\begin{array}{l}\text { Argentina - Definitive Anti-Dumping Duties on Poultry from Brazil. Panel } \\
\text { Report, Argentina - Definitive Anti-Dumping Duties on Poultry from } \\
\text { Brazil, WT/DS241/R, adopted } 19 \text { May 2003, DSR 2003:V, p. } 1727 \\
\text { (DS241) }\end{array}$ \\
\hline $\begin{array}{l}\text { Mexico - Customs Valuation } \\
\text { and Other Purposes (2005) }\end{array}$ & $\begin{array}{l}\text { Mexico - Certain Pricing Measures for Customs Valuation and Other } \\
\text { Purposes. Settled or terminated (withdrawal, mutually agreed solution) on } \\
29 \text { August 2005. (DS298) }\end{array}$ \\
\hline $\begin{array}{l}\text { EC - Approval and Marketing } \\
\text { of Biotech Products (2006) }\end{array}$ & $\begin{array}{l}\text { European Communities - Measures Affecting the Approval and Marketing } \\
\text { of Biotech Products, Panel report adopted on } 21 \text { November 2006. (DS291) }\end{array}$ \\
\hline $\begin{array}{l}\text { EC - Approval and Marketing } \\
\text { of Biotech Products (2006) }\end{array}$ & $\begin{array}{l}\text { European Communities - Measures Affecting the Approval and Marketing } \\
\text { of Biotech Products. Panel report adopted on } 21 \text { November 2006. (DS291) }\end{array}$ \\
\hline
\end{tabular}




\begin{tabular}{|l|l|}
\hline \multicolumn{1}{|c|}{ Short title } & \multicolumn{1}{c|}{ Title and Status } \\
\hline $\begin{array}{l}\text { Colombia - Customs Measures } \\
\text { (2006) }\end{array}$ & $\begin{array}{l}\text { Colombia - Customs Measures on Importation of Certain Goods from } \\
\text { Panama. Settled or terminated (withdrawal, mutually agreed solution) on 1 } \\
\text { December 2006. (DS348) }\end{array}$ \\
\hline $\begin{array}{l}\text { Colombia - Ports of Entry } \\
(2009)\end{array}$ & $\begin{array}{l}\text { Colombia - Indicative Prices and Restrictions on Ports of Entry. Panel } \\
\text { Report, WT/DS366/R and Corr.1, adopted 20 May 2009. Award of the } \\
\text { Arbitrator WT/DS366/13, 2 October 2009. (DS366) }\end{array}$ \\
\hline $\begin{array}{l}\text { Thailand - Cigarettes } \\
\text { (Philippines) (2011) }\end{array}$ & $\begin{array}{l}\text { Thailand - Customs and Fiscal Measures on Cigarettes from the } \\
\text { Philippines. Appellate Body Report, Thailand - Customs and Fiscal } \\
\text { Measures on Cigarettes from the Philippines, WT/DS371/AB/R, adopted 15 } \\
\text { July 2011. Art 21.5 DSU Panel report circulated 12 November 2018. } \\
\text { Second Recourse to Art 21.5 DSU Panel report circulated 12 July 2019. } \\
\text { (DS371) }\end{array}$ \\
\hline $\begin{array}{l}\text { Peru - Agricultural Products } \\
\text { (2015) }\end{array}$ & $\begin{array}{l}\text { Peru - Additional Duty on Imports of Certain Agricultural Products. } \\
\text { Appellate Body Report, WT/DS457/AB/R and Add.1, adopted 31 July } \\
\text { 2015. Art 21.3(c) DSU Arbitration award circulated 16 December 2015. } \\
\text { (DS457) }\end{array}$ \\
\hline $\begin{array}{l}\text { Russia - Tariff Treatment } \\
\text { (2016) }\end{array}$ & $\begin{array}{l}\text { Russia - Tariff Treatment of Certain Agricultural and Manufacturing } \\
\text { Products. Panel Report, WT/DS485/R, Corr.1, Corr.2, and Add.1, adopted } \\
\text { 26 September 2016. (DS485) }\end{array}$ \\
\hline $\begin{array}{l}\text { Colombia - Anti-Dumping } \\
\text { Colombia - Anti-Dumping Duties on Frozen Fries from Belgium, } \\
\text { Germany and the Netherlands. In consultations 15 November 2019. } \\
\text { (DS591) }\end{array}$ \\
\hline
\end{tabular}




\section{Prologue}

"The map is not the territory," said Alfred Korzybski, a Polish American scientist and philosopher, expressing the view that an abstraction derived from something is not the thing itself. Korzybski held that many people do confuse maps with territories, that is they confuse the models of reality with reality itself. In other words, economic models, books and agreements of international organizations are abstract idealizations of international trade, while actual trade is engaged in daily by traders through airports, ports and over land borders.

Trade theories cannot take political, cultural or religious divergences into consideration when talking about comparative trade advantages. For instance, there are cases where, for noneconomic reasons, nations avoid trade with neighbouring countries. Thus, trade theories are like maps and they fall short, missing relevant aspects of the reality, and therefore they are a precarious representation of real trade issues.

The United Nations (UN) and the World Trade Organization (WTO) recognize the difference between international trade textbook models and reality in the publication "A Practical Guide to Trade Policy Analysis".

It is a long way from the tariffs and quotas contained in international economics textbooks to the jungle of real world tariffs and non-tariff measures, and analyzing the effects of changing a tariff in an undistorted textbook market is very different from responding to the request of a minister who envisages opening domestic markets and who wants to know how this will affect income distribution. ${ }^{1}$

Thus, the objective of this dissertation is to challenge the UN and WTO policies in favour of the conversion of different types of tariffs into the ad valorem (AV) type, the reduction and the elimination of tariffs without proper revenue consideration, and the negotiation of a complex set of customs valuation rules.

Consequently, the dissertation supports the general argument that many trade liberalization models do not take account of the weakness of some countries' tax systems, nor do they fully reflect the importance of tariffs to support the countries' need for domestic resources, nor how value can differ according to social and economic realities, nor how value can be easily manipulated in cross-border trade.

An indicator of the weak institutional capacity is measured by the World Bank's Country Policy and Institutional Assessment (CPIA) score. Using the CPIA methodology, the IMF classified 39 countries that can be considered as Fragile and Conflict-Affected States (FCS). When referring to the revenue capacity of such group of countries that are in a conflict, disaster, post-conflict, post-disaster situation the IMF writes: "The inability of FCS to raise

\footnotetext{
${ }^{1}$ UN/WTO, 2012, p. 7
} 
sufficient tax revenue is strongly associated with the constraints they face in building resilience" 2

When reviewing the available literature, I noticed that most authors that produced works on tariffs and customs valuation take for granted the benefits of converting all tariffs into AV tariffs and determining the amount to be paid by applying the WTO rules on customs valuation. These authors assume that the technical understanding of the benefits of the AV type of tariff and the existence of rules about customs valuation helps countries succeed in trade liberalization, even though there is evidence that the implementation challenge has been evident for several decades without a foreseen solution.

Although I understand the works explaining the technical aspects of the GATT/WTO tariffication process and customs valuation rules, it is worth questioning the fundamentals of these ideas and their utility to achieve the goals of development and sustainable trade, for a considerable number of countries, particularly those classified as Fragile and ConflictAffected States (FCS). ${ }^{3}$

Are AV tariffs associated with WTO rules on customs valuation the best combination for international trade and countries' tariff revenue needs? The aim is to assess whether AV tariff conversion is the correct approach considering pre-GATT tariff theory, the countries' tax administration systems and global fiscal weaknesses. The dissertation questions fundamental beliefs about sustainable trade liberalization based on the perspective of converting all types of tariffs to $\mathrm{AV}$, which are applied in combination with customs valuation rules. Thus, the dissertation is ambitious, as it examines the tariff policy reasoning of the WTO to liberalize international trade.

Concerning methodology, the dissertation uses references from economics, history, and law. Beginning with history, the dissertation refers to pre-WTO materials to provide in depth knowledge of customs valuation and tariffs' functioning from the beginning of the XX century. In this aspect, it analyses specific documents in history that affected the GATT negotiations to establish a rule that is based on the transaction value. For example, the US congressional hearings that took place during the GATT Kennedy Round from 1964 to 1967 to explain why and how the WTO customs valuation rules were negotiated. The historical approach also takes some League of Nations documents, Bretton Woods 1944 discussions and the Convention of Brussels for Valuation of Goods 1953 meetings into consideration. As such, the dissertation comments on historical elements that are rarely found in the literature. It sheds light on significant pre-WTO materials to understand wider issues of trade negotiations.

\footnotetext{
${ }^{2}$ IMF (2020). Tax Revenues in Fragile and Conflicted-Affected States - Why Are They Low and How Can We Raise Them?. Prepared by Bernardin Akitoby, Jiro Honda, and Keyra Primus.

${ }^{3}$ There are 195 countries in the world today. This total comprises 193 countries that are member states of the United Nations and 2 countries that are non-member observer states: the Holy See and the State of Palestine. From the 193 countries, 39 were classified by the IMF as Fragile and Conflict-Affected States (FCS) which represents approximately $20 \%$ of the number of countries. The FCS classification indicates a weak institutional capacity to raise sufficient tax revenue.
} 
From an economics perspective, the dissertation verifies practical ideas supporting the theory of tariffs, the purpose of each different type of tariff, and the monetary and trade policies derived from the Bretton Woods Conference in 1944. It does so to confront the theory with the trade reality. A main difficulty here is to find literature that reflects the experience with the implementation of the WTO rules within countries. Most of the academic literature is based on theoretical assumptions and economic models, without reference to empirical evidence on implementation challenges. As such the dissertation researches and collects specific empirical material about countries that support a discussion on the wider application of ad valorem tariffs and WTO customs valuation rules. The dissertation also addresses the difficulties faced by nations to shift from trade taxation to domestic tax, the impact on customs valuation resulting from the end of the gold standard in 1971, and the extensive use of expansionist monetary policies after the 2008 global financial crisis.

Finally, from a legal perspective, the dissertation reflects on several aspects including, but not limited to: a) GATT/WTO rules on tariffs and AV conversion, including formulas, b) national legislation adopting AV tariffs and GATT/WTO customs valuation rules, c) international legislation dealing with the GATT/WTO customs valuation rules, d) WTO trade disputes involving tariffs and customs valuation, and e) countries legal manoeuvres to circumvent AV tariffs and GATT/WTO customs valuation rules. The legal perspective provides insights about the continuous challenges to implementing the WTO rules and the wider context of tax issues that surround countries. For instance, the fragility of the AV conversion formula with respect to revenue data and the discussion on trade disputes that challenge and the transaction value. All these points are important for the wider issue of long-term trade liberalization.

International economic law is the central area of study that guides this dissertation. Hence, history, economy, and law materials are interdependent in the context of international economic law.

Given the fact that AV tariffs and the WTO customs valuation rules create incentives for traders to manipulate the value of goods and circumvent government tax and trade barriers systems, the dissertation also reflects on whether trade statistics and economic policies are affected. The integrity of countries' trade databases providing reliable data is essential to guide economic policies. Thus, if the values are subject to manipulation, the quantitative and qualitative analysis based on such data may lead to wrong conclusions and actions.

For this dissertation, it is also important to note the relevance of trade taxation in supporting countries in their aim to attain the UN Sustainable Development Goals (SDG). ${ }^{4}$

\section{Research Process and Methodology}

\footnotetext{
${ }^{4}$ On September $25^{\text {th }}, 2015$, UN member countries adopted a set of goals to end poverty, protect the planet and ensure prosperity for all countries as part of a new sustainable development agenda. Each goal has specific targets to be achieved by 2030. The 17 goals are known as the Sustainable Development Goals (SDGs) with 169 targets and form part of the UN 2030 Agenda for Sustainable Development. United Nations, Resolution adopted by the General Assembly on 25 September 2015, 21 October 2015, Reference A/RES/70/1.
} 
This dissertation adds to the field of international economic law by juxtaposing the GATT/WTO tariffs AV conversion process, together with customs valuation rules, with trade liberalization assumptions and the purpose of national tax systems to ensure domestic resources.

This dissertation researches the relation between AV tariffs and trade revenue, together with liberalization policies through qualitative indicators that originated from historical documents, empirical evidence about countries' trade challenges, WTO disputes, and documents describing complex situations regarding the interpretation and application of the current rules. These qualitative indicators allow for the discussion of past and present rules in the context of international trade, allowing the reader to reflect on issues and problems related to tariffs and customs valuation concerning trade revenue.

The research question is whether AV tariffs, in combination with the WTO customs valuation rules, support trade revenue and liberalization policies. The most common definition of trade revenue comes from ordinary customs duties. However, for the purposes of this dissertation, the trade revenue affected by the WTO rules also includes domestic taxes that take into consideration the customs value. As for trade liberalization, economists often define it as the move towards freer trade through the reduction of tariff and other barriers. However, the dissertation asserts that the correct definition for trade liberalization should be aligned with fair tariffs. In other words, there can be trade liberalization, with trade growth, financial and social gains with tariffs that fulfill their roles. In fact, a working tariff is the best solution for long-term, sustainable trade liberalization.

In order to answer the research question, the dissertation addresses the following subquestions:

1. To what extent should the different types of tariffs be used?

2. To what extent are AV tariffs appropriate for all classes of goods?

3. To what extent can countries replace trade revenue derived from tariffs with other tax sources?

4. To what extent do the WTO goals on tariff simplification take the revenue derived from tariffs into consideration?

5. To what extent are the WTO customs valuation rules complex?

\section{Research Limitations}

A major limitation of the research was the limited sources of empirical material that derive from observation and experience when implementing the WTO rules, rather than based on theory or pure logic. While there is a vast source of theoretical material, it is difficult to find practitioners' reports on the challenges and utility of the rules.

Another main challenge was locating historical documents from times before the GATT.

These materials are available in only a few libraries and rarely in electronic format. As such, 
it is necessary to physically visit these libraries to research the material. Even at the WTO, these pre-GATT materials are challenging to locate.

Finally, it is worth mentioning that the researcher's empirical professional experience also guides his assessment of the efficacy and utility of existing WTO rules. Such experience was the basis for the enquiry conducted in this thesis and underlies some of the discussions contained therein. For example, it led the researcher to critically examine the promotion of tariffs conversions and reductions, without proper revenue assessment, for the achievement of trade growth. While insights gained in practice are reflected in the thesis, these aim to enrich the discussion, rather than to replace the rigorous academic analysis needed to answer the research question. 


\section{Table of Contents}

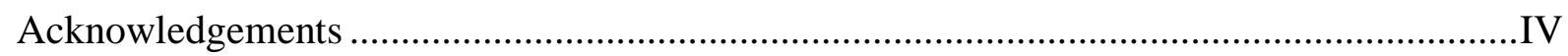

List of Abbreviations ....................................................................................................

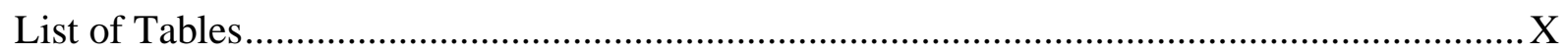

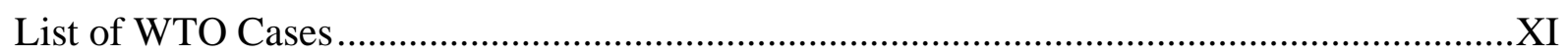

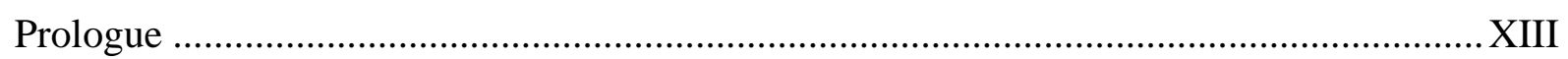

Introduction: Why Study Ad Valorem Tariffs and Customs Valuation?................................ 1

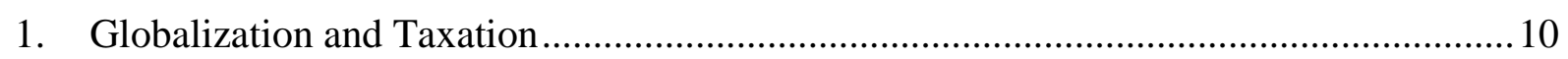

1.1 Economic Globalization and Global Value Chains................................................... 10

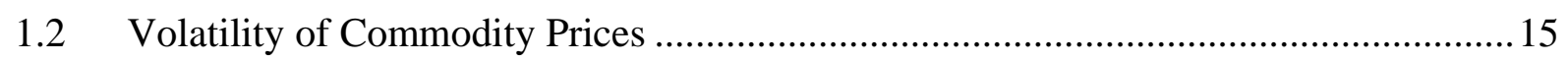

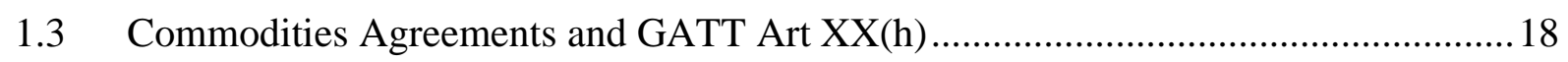

1.4 From Trade Revenue to Domestic Revenue .............................................................22

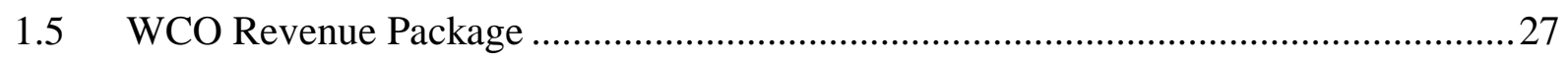

1.6 OECD BEPS Package - A Response to Tax Evasion.................................................28

1.7 UN - Addis Ababa Action Agenda (AAAA) and Tobacco..........................................35

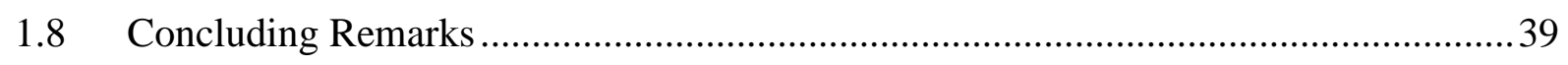

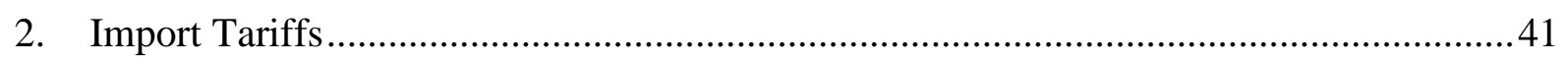

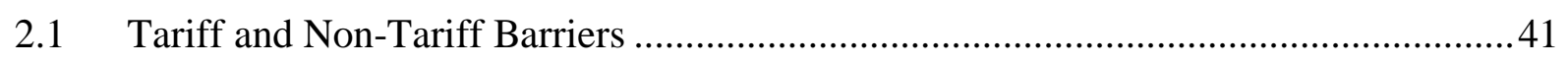

2.2 Focus on Ordinary Customs Duties, Regular Tariffs .............................................. 45

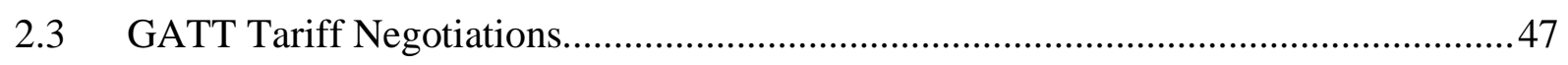

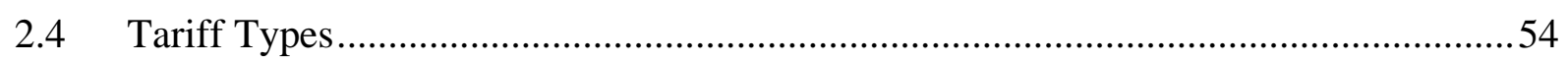

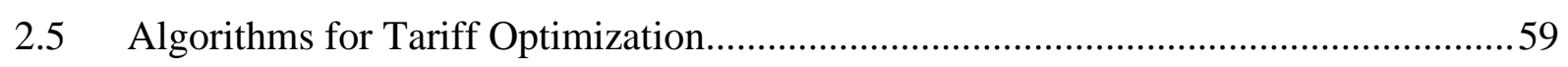

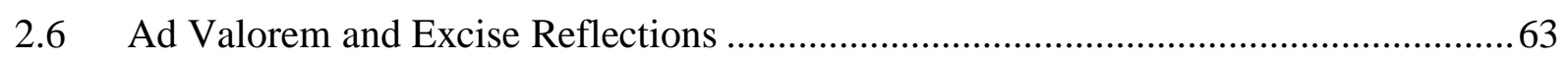

2.7 Non-Ad Valorem Conversion for Ad Valorem Equivalents ......................................67

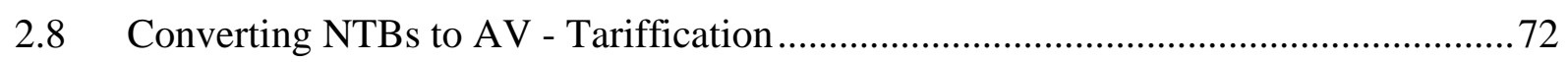

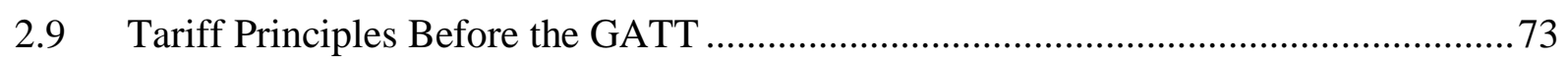

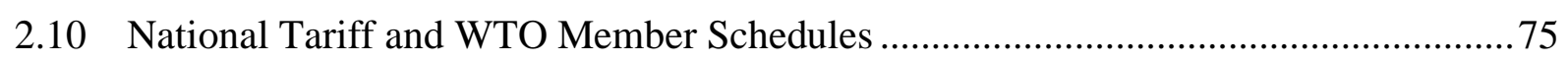

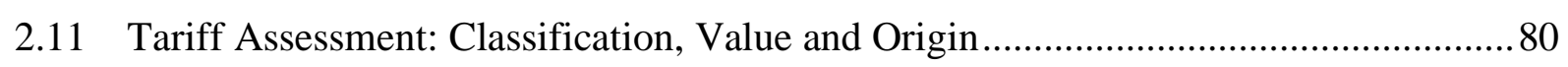

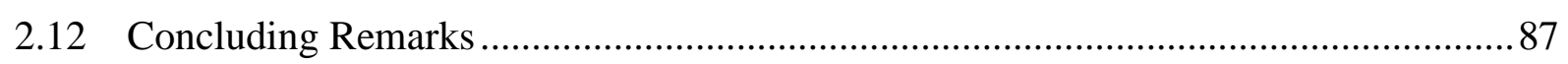

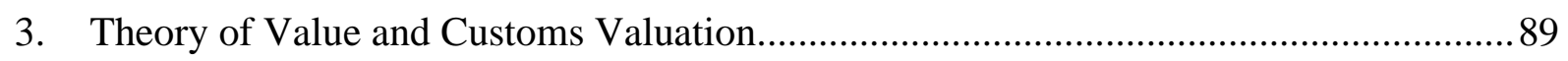

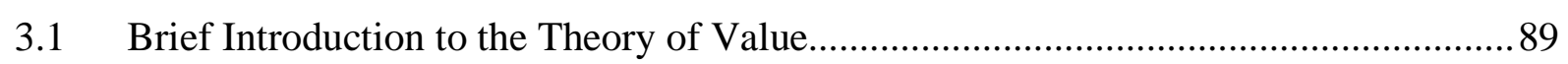

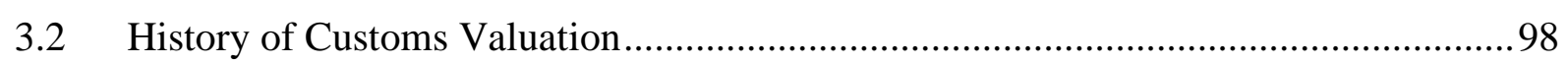

3.3 The Roaring 1920s - Trade Tariffs …................................................................. 101

3.4 League of Nations - Customs Valuation 1927 - 1930 ............................................... 102 


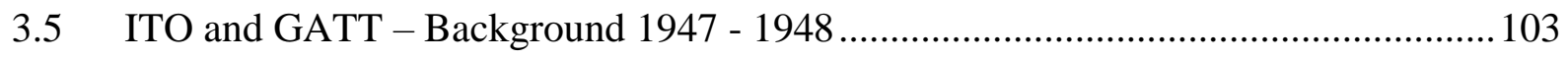

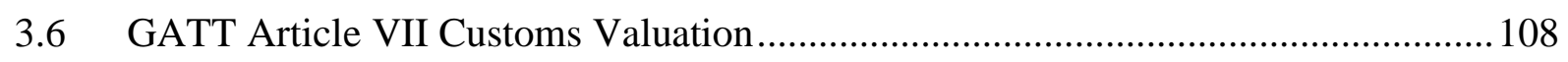

3.7 European Customs Union Study Group (ECUSG) - 1949 - BDV Convention ..........112

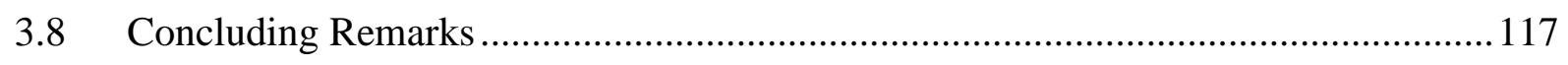

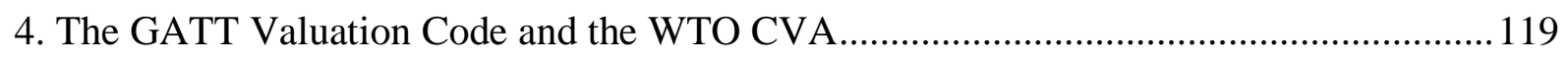

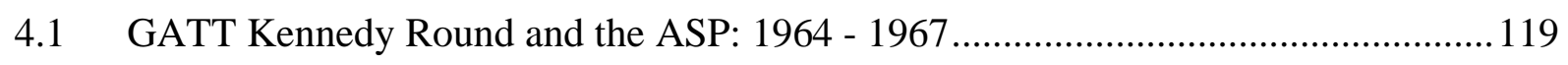

4.2 Introduction to the GATT Tokyo Round: 1972-1973 .............................................. 125

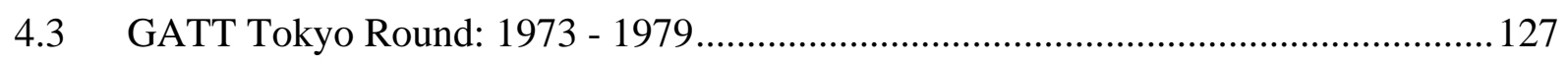

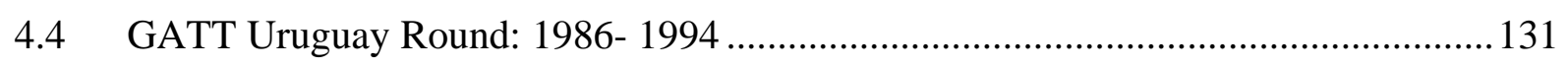

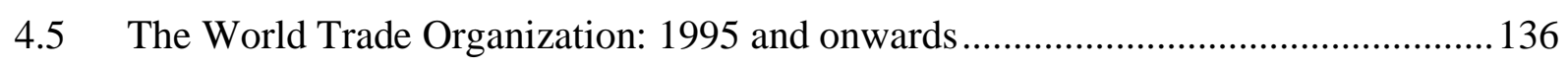

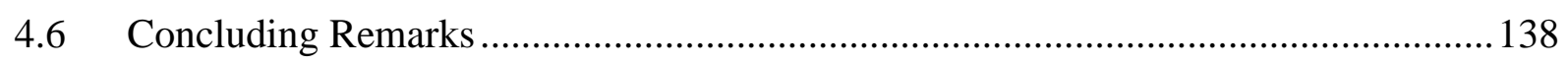

5. WTO Customs Valuation Agreement (CVA) .............................................................. 140

5.1 GATT Article VII and WTO Agreement - Hierarchy............................................. 140

5.2 WTO CVA Interpretation - Vienna Convention on the Law of Treaties ...................141

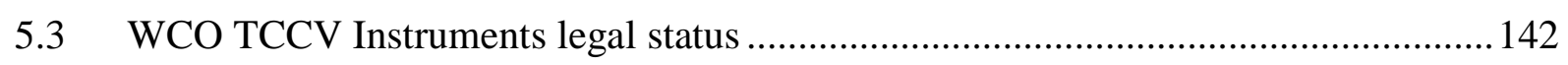

5.4 WTO CVA Part I - Rules on Customs Valuation..................................................... 147

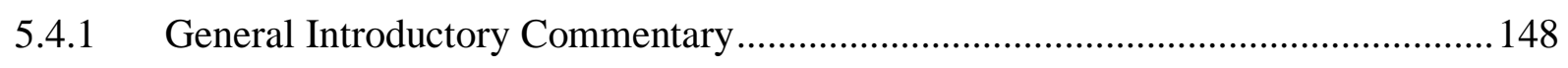

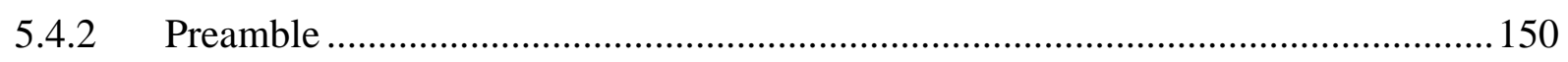

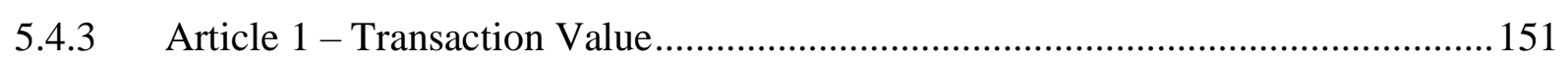

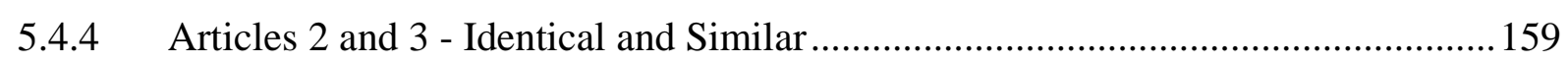

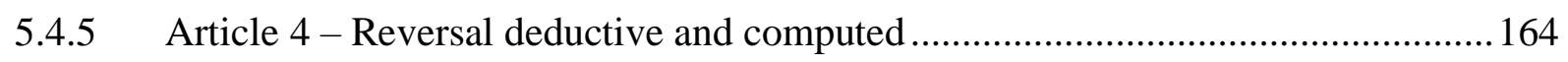

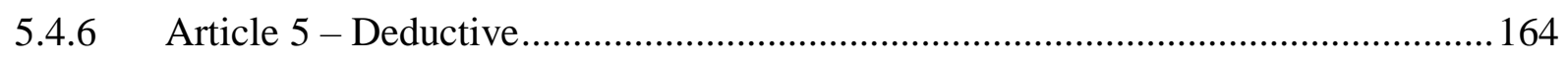

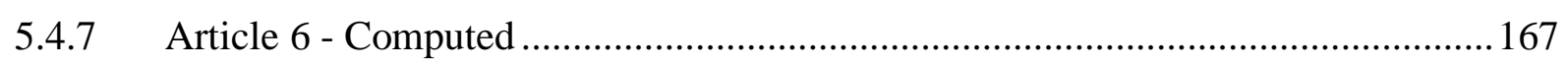

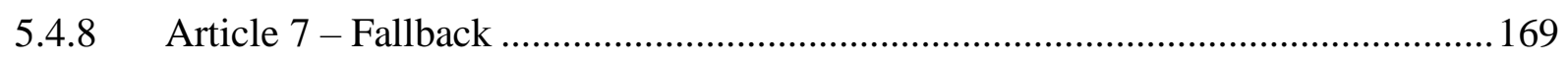

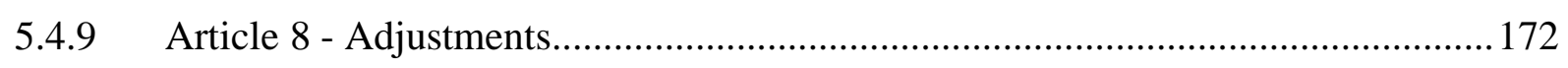

5.4.10 Articles 9 to 17 - - Currency conversion, confidentiality, and other issues ............183

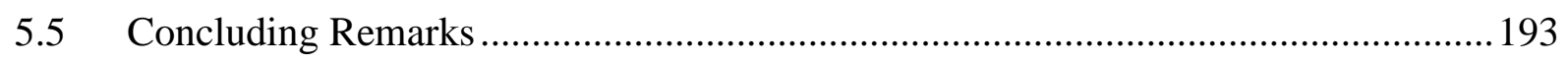

6. WTO CVA Part II - Administration, Consultations and Dispute Settlement ..................197

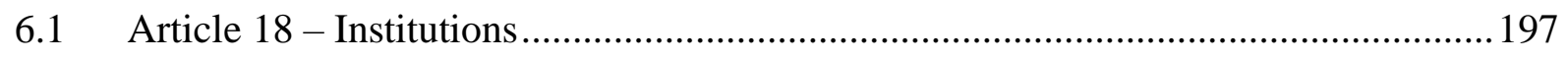

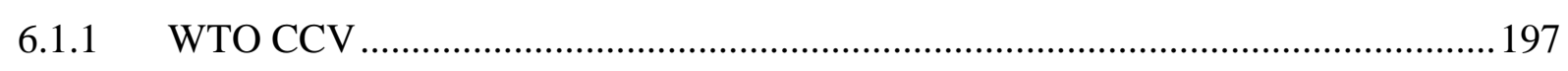

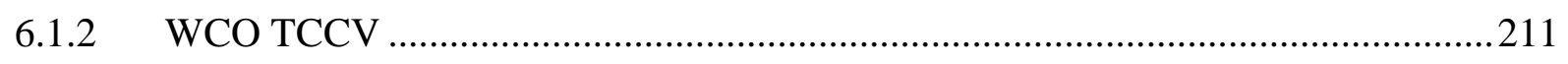

6.2 Article 19 - Consultation and Dispute Settlement...................................................213

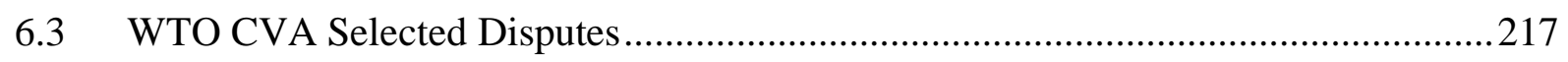

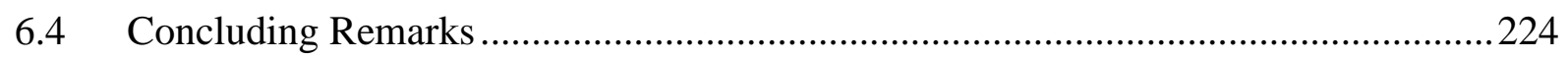

7. WTO CVA Part III - Special and Different Treatment..............................................228

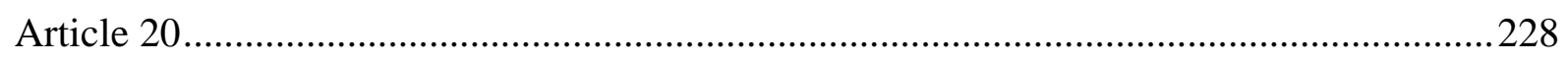




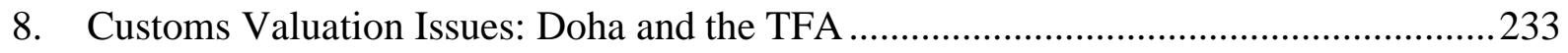

8.1 Doha Implementation Decision Paragraph 8 - Exchange of Information ...................233

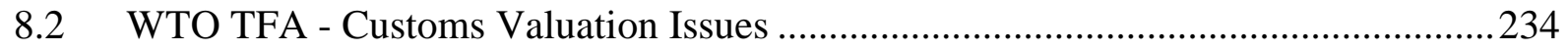

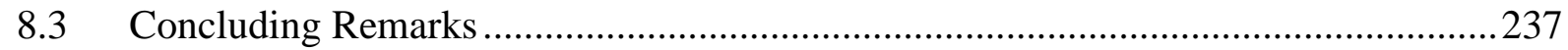

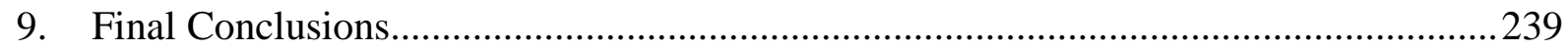

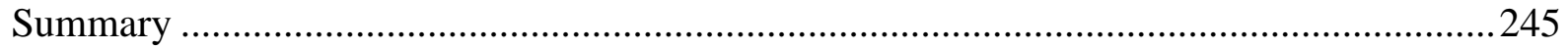

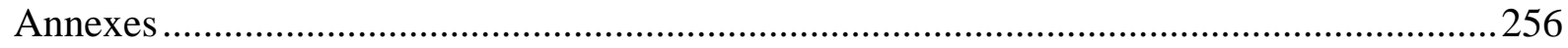

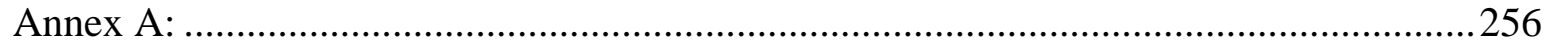

Havana Charter for an ITO - Customs Valuation and Commodities...............................256

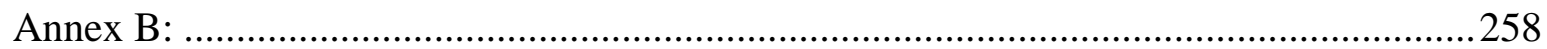

Havana Charter - Article 35 Valuation for Customs Purposes........................................258

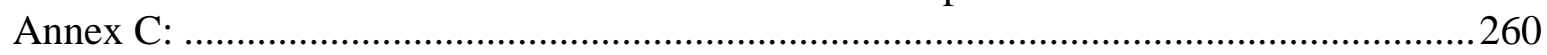

BDV - Convention on the Valuation of Goods for Customs Purposes .............................260

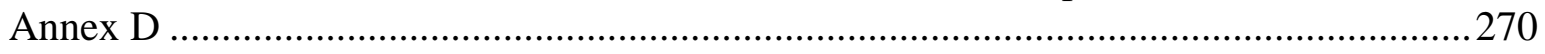

CCC/WCO BDV Convention Current Membership - 2017 .........................................270

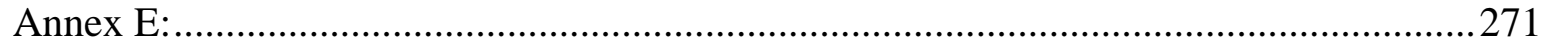

CCC/WCO BDV Convention - Model Withdraw Letter ...........................................271

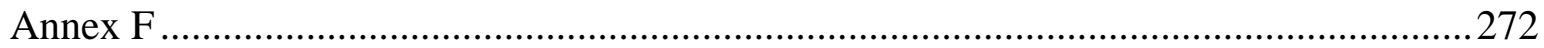

BDV - CCV - Dutiable Value of Computers and Carrier Media .....................................2272

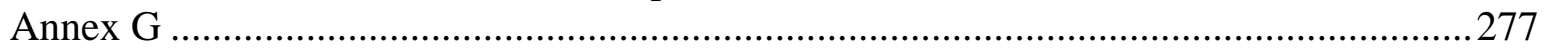

GATT Article VII and Interpretative Note Ad Article VII .............................................2. 277

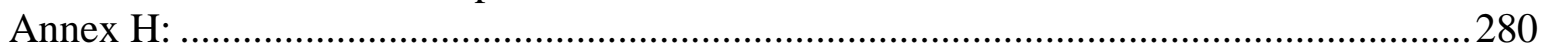

WTO Agreement on Implementation of Article VII of the General Agreement on Tariffs

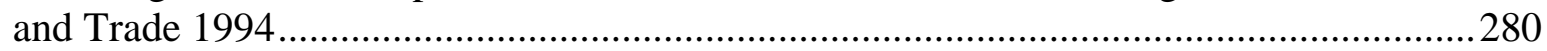

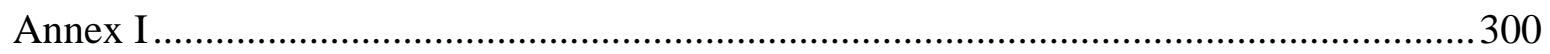

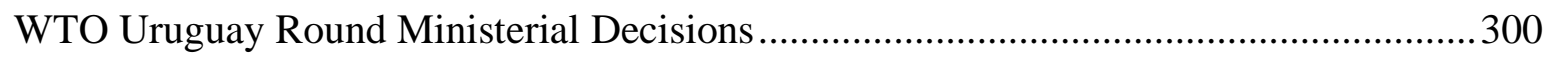

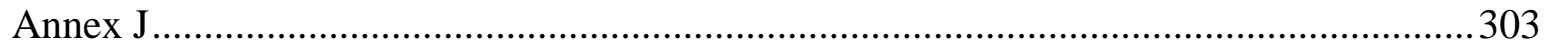

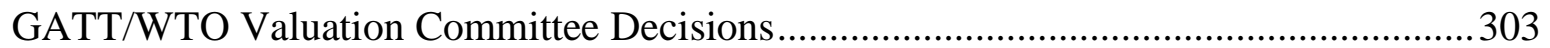

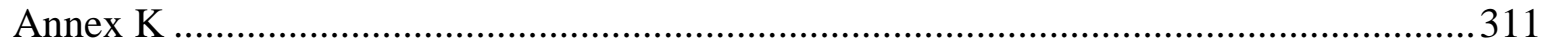

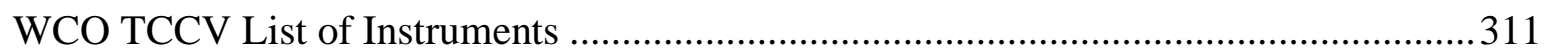

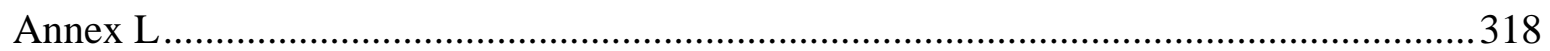

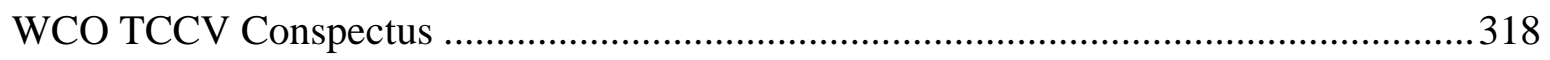

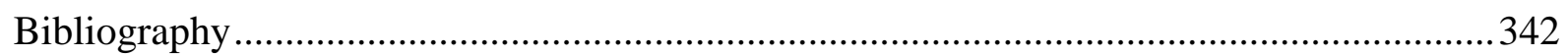

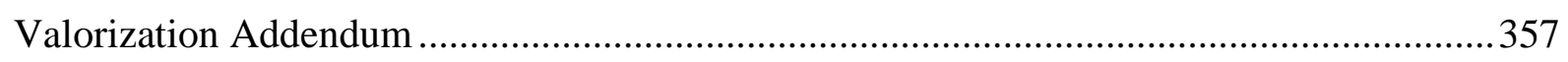

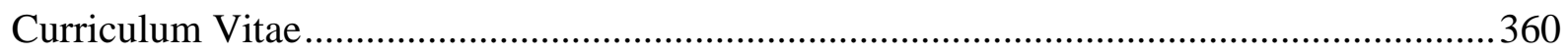




\section{Introduction: Why Study Ad Valorem Tariffs and Customs Valuation?}

Tariffs have been around for centuries. ${ }^{5}$ Most traded goods are subject to some sort of tariff when crossing the border. According to Asakura, the study of the Roman customs duty by R Cagnat shows that the first customs tariff was introduced in A.D. 136 in Palmyra, Syria.

(...). These studies tell us that diplomats were already being exempted from Customs duty in Greece, Rome and the Indian sub-continent at least as long as 2,000 years ago, that the first Customs tariff was drawn up in A.D. 136 in Palmyra, as oasis city in the Syrian desert, that a bamboo-shaped Customs laissez-passer with the King's instructions to Customs inscribed in golden characters was in use in China more than 2,000 years ago, and so on. ${ }^{6}$

Although there are various types of tariffs, AV duties are now the most commonly used type, where the duty is calculated based on the value, also known as the customs value, of the traded good. Thus, tariffs, and in connection with the AV type, the customs value, have been at the centre of the international trade debate for decades.

The predominant neo-liberal trade theory is against all sorts of trade barriers, including tariff barriers. Therefore, the substantial reduction or elimination of tariffs is considered a central pillar of the multilateral trading system.

For instance, Golt describes the central goal of GATT to eliminate tariffs as follows:

From the very beginning of the General Agreement on Tariffs and Trade (GATT), a central feature of its programme has been to sponsor a continuing series of multilateral negotiations with the objective of progressive mutual reductions of tariffs. It was never explicitly stated that the ultimate result would be the final elimination of tariffs or their reduction to levels where it would barely be worth while to retain them for the purpose of protection of domestic industry. But there was a tacit acceptance that this was, or might become, the theoretical end product of the process, at any rate as regards trade among the major industrialised countries. ${ }^{7}$

\footnotetext{
5 The terms "tariffs" and "customs duties" are usually used as synonyms in international trade. This dissertation opted to use tariffs whenever possible to avoid confusion.

${ }^{6}$ Asakura (2003), p.12

${ }^{7}$ Golt (1974), p.1
} 
As such, the final objective of the GATT was the reduction of tariffs to decrease their function of protecting domestic industry. Tariff cuts were and are still regarded as making a significant contribution to economic development. ${ }^{8}$

The GATT embraced the free trade theory opposing the mercantilist school and assumed that tariffs needed to be reduced or eliminated. Thus, to make the process of reduction or elimination easier, it was necessary to convert non-ad valorem (NAV) tariffs, such as specific, compound, mixed and technical types, into AV tariffs. The basic argument for the conversion of NAV into AV is the need for simplification to monitor and negotiate tariff percentages for all classes of goods. In this case, simplification means using the same type of tariff for all countries trading identical goods. It is supposedly the first step to control and negotiate tariff preferences when trying to eliminate tariffs in the long run.

Although I initially trusted the conversion from NAV into AV tariffs to be fair and to have only positive aspects, upon further examination of the different, and sometimes conflicting, trade realities of countries' tax systems caused me to question its validity. Tax avoidance, tax loopholes, poor fiscal discipline, inefficient tax administrations, imbalances in trade patterns, complex and restrictive customs valuation practices, barter, transfer pricing, among others were some of the factors that caused me to question the GATT policy for tariff simplification, reduction, and elimination. Moreover, the economic crises and governments' tax challenges of the last decade encouraged me to revisit tariffs and customs valuation to examine tariff systems to support countries' resource mobilization and trade liberalization.

When studying the function of tariffs, I learned that the conventional dual division of tariffs as intended either for revenue or for domestic protection required further investigation. Furthermore, such a distinction is dynamic and constantly changing according to the economic structure of a country, its trade partners, political scenarios, and environmental changes. As such, the line that distinguishes between tariffs is fuzzy, and trade negotiators are often missing the target. Regarding such a dim distinction between tariffs for revenue or domestic protection, Asakura notes:

\begin{abstract}
In this connection, it should be noted that although the textbooks distinguish between financial duty and protective duty, the dividing line is not always clear. For example, the Japanese Customs tariff used to impose a very high tariff of $355 \%$ ad valorem on tobacco, which was a monopoly product, and this tariff was generally regarded as a financial duty. However, the purpose of this
\end{abstract}

\footnotetext{
${ }^{8}$ According to preamble of the GATT, its purpose was the "substantial reduction of tariffs and other trade barriers and the elimination of preferences, on a reciprocal and mutually advantageous basis." The WTO also stresses in several publications that "Trade grows as tariffs decline" (e.g. WTO Trade and Tariffs, brochure 2015)
} 
Japanese tobacco duty seems to be quite similar to that of Ptolemaic duty on olive oil, which Rostovtzeff considered to be a protective duty. ${ }^{9}$

What Asakura notices is that authors are not sure about the function of tariffs. Tariffs are dynamic instruments, their function varying from generating revenue to protecting the domestic industry, depending on the country's economic circumstances, which are constantly changing. For instance, for a specific country, the tariff for a certain traded good can serve as a revenue instrument when there are no domestic traders to be protected or it can act as a protective barrier to level prices for domestic traders to remain competitive, as well as play dual role, partly capturing revenue and partly protection, depending on the scenario and point in time that it is studied.

These conclusions have significant implications for "tariff simplification" policies, which, for the WTO, means the conversion of NAV into AV types of tariffs to control and manage preferences. For instance, the modalities of the agricultural tariff negotiations in the context of the Doha Round mainly address tariff simplification.

Revised Draft Modalities for Agriculture

\section{Tariff simplification}

98. No tariff shall be bound in a form more complex than the current binding.

99. [At least [90] per cent of] [All] bound tariffs on products in a Member's Schedule shall be expressed as simple ad valorem tariffs. Where a Member already has at least [90] per cent of its bound tariffs expressed in simple ad valorem terms, that Member shall convert no less than [50] per cent of the remaining non-ad valorem tariffs into simple ad valorem tariffs. All tariffs within a 4-digit HS heading shall be expressed in the same form.

100. This tariff simplification shall be fully effected on the first day of the implementation period. However, where a Member currently has less than [60] per cent of its bound tariffs in simple ad valorem terms, it shall ensure that:

(a) at least [75] per cent of all bound tariffs are expressed as simple ad valorem tariffs on the first day of implementation;

(b) at least [80] per cent of all bound tariffs are expressed as simple ad valorem tariffs no later than twelve months later; and

\footnotetext{
${ }^{9}$ Asakura op. cit., p.48
} 
(c) [90] per cent of all bound tariffs are expressed as simple ad valorem tariffs no later than the end of the second year of the implementation period. ${ }^{10}$

The objective of the agricultural tariff negotiations in the context of the Doha Round that "no less than 90 percent of bound tariffs on products in a developed country Member's Schedule be expressed as simple ad valorem tariffs" is a confirmation of the importance that is attached to tariff simplification and reduction for trade liberalization.

As briefly mentioned before, the GATT justification for tariff simplification is fundamentally the need to negotiate and to bind tariffs. ${ }^{11}$ Under the argument of binding tariffs, the GATT ignored that each tariff type was created to fulfil a different function. The point of view that tariff simplification might be prejudicial for certain countries to meet their government's revenue targets and domestic producers' protection needs is not addressed in the negotiation documents.

Another point to address is the WTO members' focus on tariff simplification for trade liberalization without consideration of the need for revenue predictability, which in turn might lead to political distrust in relation to trade liberalization. The fact is that many countries are unprepared to cope with revenue volatility and the shifting of taxes, and hence they cannot compensate losses in one area by increasing revenue in another area.

The dissertation suggests that the approach of simplification to suppress all different NAV might be prejudicial for many countries. Each tariff type, be it AV, specific, compound, mixed or technical, has its best use depending on several variables such as the country fiscal circumstances, the class of goods, and the overall objectives regarding trade and fiscal policy.

Given the fact that AV tariffs are levied based on a percentage of the value of the goods, the rules governing the value of the goods is of great relevance. The value of traded goods for the purposes of AV tariffs is known as the customs value. The rules for establishing a customs value have been regulated by the WTO. AV tariffs oblige countries to adopt the WTO rules and, therefore, it is imperative to study the WTO valuation rules.

Concerning the importance of determining customs valuation rules, Levett wrote: "Let me write the Administrative Act, and I care not who fixes the rates of duty." 12 By the Administrative Act, Levett was referring to the dutiable value, which is the customs value. Thus, according to Levett, establishing the customs valuation rules is more

\footnotetext{
${ }^{10}$ WTO, 2008, p. 17

${ }^{11}$ Tariff binding is the commitment not to increase a rate of duty beyond an agreed level. Once a rate of duty is bound, it may not be raised without compensating the affected parties.

${ }^{12}$ Levett, Benjamin Arthur (1923).
} 
important than the tariff rates. Adapting to the WTO context, the effect of tariff bindings depends on the rules governing how the value of goods is assessed.

A customs valuation is a valuation that is carried out by a customs officer or by a person entitled by the government to act as a customs officer, such as a Pre-shipment Inspection (PSI) company. ${ }^{13}$ In other words, customs valuation is thus named because it serves mainly customs purposes. However, the purpose of customs valuation goes beyond the determination of the customs duties to be collected, as in many cases the value can be zero or suspended. Customs valuation also serves to calculate guarantees, penalties and statistics, among others. When setting the value of goods, the customs authority is the third party in the process. The buyer and seller are the direct parties.

Customs valuation gives the basis on which tariffs are calculated using the AV rate. The WTO Annual Report for 2017 explains the importance of customs valuation as follows:

The customs value of a good plays a critical role in the calculation of import duties on an ad valorem basis. An ad valorem duty rate is one that is expressed as a percentage of the value of the imported goods, and it is the most common duty rate used in international trade. The Agreement on Customs Valuation seeks to establish a fair system for the valuation of goods for customs purposes. The Committee on Customs Valuation oversees this agreement and the Agreement on Pre-shipment Inspection. ${ }^{14}$

Nowadays, IT systems, as a starting point, automatically take the prices declared in the invoice and make adjustments to arrive at a customs value figure in line with national legislation. ${ }^{15}$ The numbers declared in the import declaration for customs valuation, such as the price for the goods, cost of freight and cost of insurance, are also the source from which national and international organizations obtain the data to produce trade statistics, make decisions and take actions implementing economic policies. As a rule, the customs authority is the agency responsible for sending international trade data to other agencies or ministries. Once the data is received, it is sent to international

\footnotetext{
${ }^{13}$ Pre-shipment inspection (PSI) is the practice of employing specialized companies (normally private contractors) to check shipment cargo details such as price, quantity, and quality of goods ordered overseas. Countries that operate with PSI agencies argue this is needed to safeguard national financial interests (preventing capital flight, commercial fraud, and customs duty evasion, for instance) and to compensate for inadequacies in administrative infrastructures. The WTO PSI Agreement recognizes that GATT principles and obligations apply to the activities of pre-shipment inspection agencies mandated by governments.

${ }^{14}$ WTO Annual Report for 2017, p.64

15 Some examples of IT systems are: ASYCUDA World, ASYCUDA ++, TIMS (Trade Information Management System), Sistema Informático MALVINA (SIM), SIGAD (Système d'Information et de Gestion Automatisée des Douanes), VAIS (Unitque Automated Management System), CAS (Customs Automated System), National Automatic System of Customs Declaration (NASCD), SISCOMEX (Foreign Trade Integrated System) and many others.
} 
organizations, such as the UN and the WTO. Almost every country repeats this data flow process, supported by customs clearance systems. ${ }^{16}$

For this dissertation, an analogy for the AV tariff assessment process, which is based on the invoice and import declaration data, is reflected in Oscar Wilde's definitions of a cynic and a sentimentalist:

\section{Cecil Graham: What is a cynic? \\ Lord Darlington: A man who knows the price of everything, and the value of nothing.}

Cecil Graham: And a sentimentalist, my dear Darlington, is a man who sees an absurd value in everything and doesn't know the market price of any single thing. ${ }^{17}$

In other words, the customs authority that is performing customs valuations might act as a cynic, knowing the price of everything and the value of nothing, or as a sentimentalist seeing absurd values in everything, while not knowing the price of anything. To put it another way, unverified data or data verified by a cynic or a sentimentalist, collected from traders' invoices, can be harmful to the entire trading system. ${ }^{18}$

Commonly, traders and governments are subject to conflicting tax incentives, depending on the goods traded, the markets and overall strategy. In some cases, it is beneficial to have high export values and low import values. In other cases, the strategy is to have low export values and high import values.

On this matter, it is important to remember that the WTO rules on customs valuation are restricted to import AV customs duties. Although export appears in the GATT Art. VII, it was excluded from the GATT valuation code, later the WTO Customs Valuation Agreement. In that sense, export prices are only subject to national regulations, if they are in place for export duties.

\footnotetext{
${ }^{16}$ Access to real-time Customs data can be advantageous when making decisions in financial markets. For instance, changes in China's Customs data on iron-ore can cause spikes in the commodity and related companies' market prices. Other examples of the impact of real-time Customs data can be found in the markets for energy (oil, gas), metals (aluminum, copper, gold) and agriculture (meat, coffee, corn, sugar, soya).

17 Oscar Wilde. Lady Windermere's Fan. Act III.

${ }^{18}$ In many countries, for risk management purposes, customs procedures on goods are separated into green, yellow (orange) and red channels. In the green channel the goods are automatically cleared to enter the market. In the yellow (orange) channel, only the documentation is verified as some information might need clarification. In the red channel the goods are physically inspected, and the documentation is also verified. The criteria used to select goods to the green, yellow (orange) and red channels varies from country to country. When deciding what documents or goods to verify, customs usually takes the tariffs and customs valuation into consideration. Thus, if goods have low tariffs there is a higher chance for the system to select to the green channel, as it would be of less interest to customs.
} 
Because of the lack of regulation, it is possible to conclude that export prices are easy to manipulate. For instance, MNE can export commodities to their subsidiaries in tax havens at lower prices and later sell these commodities for the market price in futures exchanges, shipping the commodities directly from the country of origin to the market buyer.

The acceptance of the invoice information on price and quantity is a question that is up for debate. In the 1960s, while some countries started the customs valuation process with the invoice data, others opted to initiate the process considering domestic prices of identical or similar goods. The use of different methods for customs valuation also affected tariff negotiations. A bound tariff was easily circumvented by manipulating the parameters for customs valuation. For instance, countries using domestic price parameters were accused of increasing the customs value and using it as an obstacle to imported goods.

The fact is that, depending on the price reference, international invoice prices or domestic prices, the customs valuation of goods resulted in different outcomes, thus affecting the calculation of AV tariffs causing higher or lower amounts applied.

Therefore, tariff negotiations could not proceed, because the customs value in different importing countries for identical exported goods varied significantly. As a result, during the 1960s and 1970s, the international trade community undertook the task to create rules for customs valuation. Hence, beginning in the GATT Kennedy Round (1964 - 1967) and finishing in the Tokyo Round (1974-1979) the US, the European Community (EC) and other countries negotiated a Customs Valuation Code ${ }^{19}$ that established the so-called "transaction value", which is reflected in the invoice price', as the primary source of information. ${ }^{20}$ The CV Code already explicitly banned the use of domestic prices in the determination of customs value. Later, the GATT CV Code became the WTO CVA and all WTO members were obliged to use it. ${ }^{21}$

Despite decades of experience with the application of GATT/WTO customs valuation rules, their implementation remains difficult. Adrien Goorman and Luc De Wulf, from the World Bank, referred to the implementation challenges as follows:

\footnotetext{
${ }^{19}$ General Agreement on Tariffs and Trade (GATT). Agreement on Implementation of Article VII of the General Agreement on Tariffs and Trade. MTN/NTM/W/206. 14 December 1978.

20 The US and the EEC were the leading negotiators. On 13 January 1981, at the first meeting of the GATT Committee on Customs Valuation (CCV), a total of seventeen delegations (the EEC counting as one) had signed the Agreement. The list of delegations which had signed the Agreement and the Protocol is contained in document L/4914/Rev.4, namely: Argentina, Austria, Canada, EEC, Finland, Hungary, India, Japan, Republic of Korea, Norway, Romania, Spain, Sweden, Switzerland, United Kingdom Turkey, United States, and Yugoslavia.

${ }^{21}$ Marrakesh Declaration of 15 April 1994 - Final Act, Agreement Establishing the World Trade Organization, Annex 1 - Annex 1A Multilateral Agreements on Trade in Goods, Agreement on Implementation of Article VII of the General Agreement on Tariffs and Trade 1994.
} 
Despite receiving substantial technical assistance (TA), many developing countries have not succeeded in adequately implementing the WTO valuation standard. $^{22}$

\begin{abstract}
Although valuable technical assistance was given and continues to be provided to countries for the implementation of WTO customs valuation rules, this dissertation considers that the implementation problems are neither due to the economic status of countries nor due to a lack of technical understanding of the standards. For this dissertation, the problem lies in the disconnection between the set of rules and revenue predictability and necessity in tax systems.
\end{abstract}

Tariffs and customs valuation continue to be the building blocks for trade liberalization or protection. Governments, companies, and individuals are motivated by prices, which in turn affect customs valuation and tariffs. Nevertheless, many believe that AV tariffs will one day reduce to zero, and therefore the topic might be considered of less importance in developed countries. Contrary to this belief, this dissertation argues that tariff rates, whether for imports or exports, is still a relevant topic, meaning that the conversion of NAV tariffs into AV should be studied on a case-by-case basis. Therefore, the subject is more important than ever, and it is far from being exhausted.

This dissertation is about the limitations of tariff simplification, the complexity of the WTO customs valuation rules, and the weaknesses of tax systems in general. It shows that there is a wide gap between the needs of countries in reality and the WTO arguments supporting tariff simplification, valuation rules and the functioning of tax systems. In this regard, it suggests that there is a need to question whether AV fulfil their function, whether customs valuation reflects market reality, whether multilateral cooperation is functioning, and whether countries' tax systems are able to replace tariffs with other good sources of revenue.

There are situations where NAV tariffs can function better than the AV tariffs. For instance, there are commodity imports in monopolistic markets where information about related parties' transactions influencing the price is unavailable and systems have no records of identical or similar goods. Many countries are unprepared to apply the residual methods and NAV tariffs relying on metrics such as weight and volume are more efficient. In addition, there are tax systems that lack basic tools, such as the identification of taxpayers (Tax Identification Numbers - TIN), making it impossible to collect valuation records between different traders for the same goods. There are even occasions where customs valuation is subject to large fluctuations associated with tax planning strategies between related parties.

\footnotetext{
${ }^{22}$ Goorman, Adrien and Luc De Wulf. (2005) p.156.
} 
From these considerations, this dissertation will discuss tariffs and customs valuation in international trade. The dissertation questions WTO assumptions on these topics and suggests the need to connect trade liberalization with revenue security. 


\section{Globalization and Taxation}

The purpose of this chapter is to present a concise overview of economic globalization and discuss the taxation challenges associated with it. Also, and more importantly, this chapter intends to present the institutional weaknesses of domestic tax systems to guide the discussions that will follow. It begins with a brief reflection on economic globalization and global value chains (GVC) particularly in relation to aspects of international trade and taxation.

The chapter further discusses the importance of commodities in international trade and the efforts of the UNCTAD commodities agreements to stabilize commodity prices. It also discusses trade reforms, trade revenue and initiatives of international organizations to mobilize domestic revenue. Finally, the chapter presents the UN Addis Ababa Action Agenda (AAAA) supporting the mobilization of domestic resources to achieve the Sustainable Development Goals (SDGs).

\subsection{Economic Globalization and Global Value Chains}

First, it is important to establish the link between economic globalization, the Global Value Chains (GVC) business model and trade tariffs. In addition to the general importance of economic globalization and GVC in trade, economic globalization emerged because firms understood that it was more profitable to outsource some sequences of production activity than to produce everything by themselves. The decision to outsource production is also based on tax strategies allowing firms to design strategies to benefit from low corporate taxes, shifting international trade profits with the use of intangibles and services to low tax jurisdictions.

Economic integration associated with removing borders and free trade started long ago. For instance, Alexander the Great (356 BC - 323 BC) pushed for the integration of economic areas in the Hellenic expansion process. In the words of Asakua:

As a result of the transformation from a city state to a territorial state brought about by Alexander's eastern expedition, a number of frontiers had disappeared. The Hellenistic world was a borderless one and there was a remarkable increase in the demand for eastern products in the west and western products in the east. ${ }^{23}$

As the centuries went by, local or regional economic integration expanded to global levels. As a result, the term economic globalization began to be used in the 1980s to express the increasing global movement of goods, services, and capital. The term relates to innovation, technological progress and a borderless society.

\footnotetext{
${ }^{23}$ Asakura op. cit., p.44.
} 
Joseph Stiglitz, winner of the Nobel Prize for Economics, emphasizes the impact of the reduction of the costs of transportation and communication on economic globalization as follows:

(...) the closer integration of the countries and peoples of the world which has been brought about by the enormous reduction of costs of transportation and communication, and the breaking down of artificial barriers to the flow of goods, services, capital, knowledge, and (to a lesser extent) people across borders. ${ }^{24}$

With lower costs of transportation, shipping goods internationally became comparable to shipping goods domestically. For example, the costs of shipping a container from China to the United States are similar to the shipping costs from the West coast to the East coast of the United States. The same can be said to shipping costs in continental countries such as Australia, Brazil, Canada, India, and Russia. Lower costs in transportation made international goods competitive in domestic markets.

The progress in communication systems and the cost reductions in global transportation gave birth to Global Value Chains (GVCs) also known as "trade in value-added," "production sharing", or "outsourcing". The GVC production system plays a central role in economic globalization.

As Deborah Elms and Patrick Low teach:

Any discussion today of international trade and investment policy that fails to acknowledge the centrality of global value chains (GVCs) would be considered outmoded and of questionable relevance. ${ }^{25}$

GVCs emerged as the paradigm for the international organization of production, where most production activities are vertically fragmented. For instance, items are produced in separate stages in various geographic spaces and assembled in steps either along the supply chain or in a final establishment. ${ }^{26}$

The new business model first applied in the manufacturing industry, allowed companies to save on capital investments that were otherwise difficult to achieve, to benefit from the complementary capabilities of suppliers, and to become highly flexible in supply chain management. ${ }^{27}$

Accordingly, to support growth and, at the same time, reduce costs, MNEs need to continuously monitor their supply chains, which mainly involves product engineering,

\footnotetext{
${ }^{24}$ Stiglitz, Joseph E. (2002), p. 9.

${ }^{25}$ Elms, Deborah K. and Low, Patrick. (2013). p. xv.

${ }^{26}$ European Central Bank, 2014.

${ }^{27}$ Ravenhill (2014)
} 
sourcing, manufacturing, and logistics. Activities are outsourced, centralized, and streamlined to gain efficiencies and maximize resources. Corporate structures and functions are constantly transforming. Victor Fung, Chairman of the Fung Global Institute, emphasizes the process impact as follows:

The proliferation of internationally joined-up production arrangements - that is, global supply chains - has changed our economic and political landscape in fundamental ways. ${ }^{28}$

Over the past decade, valuable interdisciplinary studies on GVCs highlighted how organizationally fragmented and geographically dispersed sequences of production have represented a significant characteristic of economic globalization.

In the mid-1990s, Gereffi and Korzeniewicz (1994) created a framework that was described as a global commodity chain (GCC), which linked the construct of valueadded chain directly to the global organization of industrial sectors. The authors stressed the role of coordination across company boundaries and also the rising importance of new worldwide buyers (retailers and brand marketers) as critical drivers in the formation of globally dispersed and organizationally fragmented production and distribution channels. Gereffi (1994) mentioned the term "buyer-driven global commodity chain" to explain how global acquirers turned to precise coordination to establish a highly competent supply base to support the global-scale production and distributions systems without direct ownership.

The increasing sophistication of GVCs connected with the expansion of international trade, for parts and components, and foreign direct investments, create a global corporate arena. The production of goods is internationally interdependent and GVCs are integrated networks of production operations with implications in multiple policy areas. These include trade policy concerns, investment policy, and a broad range of tax policies affecting both goods and services.

For the purposes of this dissertation, GVCs force worldwide tax systems to be redesigned, as none of the existing systems are robust enough to operate with these sophisticated relationships.

Interlinkages within GVCs have resulted in some suppliers significantly improving their capabilities and achieving exponential growth (Yeung, 2014). The rationale of the GVC business model is that leading market participants reserve sequences of the value chain for themselves that are characterized by higher entry barriers and substantial profits. These substantial profits are allocated to low tax jurisdictions.

\footnotetext{
${ }^{28}$ Fung, Victor K. (2013), p. xix
} 
It is argued here that in international trade the most important issue in relation to GVCs is customs valuation. GVCs is a main topic for customs valuation because of, inter alia, the lack of controls in relation to intangibles and double counting goods in the statistics.

Customs valuation rules require intangibles to be calculated into the price as long as they are related to the goods. ${ }^{29}$ However, countries' trade tariff systems lack control systems concerning intangibles. The major lack of control is due to the absence of specific data information in trade systems for intangibles. This can be verified when analysing the fields available on customs' systems, such as the Automated System for Customs Data (ASYCUDA), used by more than 90 countries globally. The ASYCUDA system provides a single general field for adjustment, which compromises the data quality, making it almost impossible to interlink the information with other administrative systems such as the ones used by central banks or IP authorities. ${ }^{30}$ Therefore, for countries using the ASYCUDA system, almost half of the globe, royalties, licenses, and services connected to imported goods are likely to evade being subject to tariffs. As such, one strong recommendation to address intangibles for the trade of goods should be the adoption of IP standards and development of tools for the exchange of electronic information between border management authorities and IP organizations.

Concerning the double-counting issue, the GVC business model requires goods to cross borders several times. Given the fact that each time the gross value of goods is registered, research says that these gross values distort the statistics on trade balances. In brief, statisticians say that the use of the gross value of exports and imports of goods results in the double-counting of trade flows, attribution of production to incorrect geographical locations, the incorrect specification of the technological content of exports at the national level, and a misunderstanding about the actual relationship between imports and exports. ${ }^{31}$

Therefore, to solve the problems created by gross values computed in international trade databases, GVC experts propose to create mechanisms that allow the measurement of added value in each transaction. As a result, the proposal requires enormous changes in procedures and IT systems. In other words, the data requirements to measure the added value of international trade transactions are complex.

\footnotetext{
29 The WTO CVA lists "royalties" and "licence fees" for what the payment which relate to the manufacture, sale, use or resale of imported goods, need to be adjusted to the customs value, Article 8.1(c).

${ }^{30}$ The adjustment field is generic, and prepared to accommodate any type of monetary adjustment. For instance, for detailed information about the system, please see: Barbados Customs \& Excise Department. Brokers and Broker Clerks User ASYCUDA Manual, ASYCUDA World Project Unit. Pdf file Available at https://asycuda.customs.gov.bb/files/BROKER\%20MANUAL.docx.pdf. On the manual please refer to Box no 45 “Adjustment”. [accessed 16 July 2020]

${ }^{31}$ Elms op. cit., p. Xv
} 
In addition to the technological challenge, it is relevant to reflect the value-added methodology impact on the WTO CVA. Once the technological solution is available, will trade tariffs focus on the value added, as is the case in the domestic markets of many countries in the imposition of value-added tax (VAT) ${ }^{32}$

In relation to customs valuation based on invoice prices, and statistics in GVCs, the dissertation also considers the problem of misinvoicing in the context of Illicit Financial Flows (IFFs). This problem was registered as a concern in the G20 Leaders Communique of Hangzhou, 2016:

36. We will continue our work on addressing cross-border financial flows derived from illicit activities, including deliberate trade misinvoicing, which hampers the mobilization of domestic resources for development, and welcome the communication and coordination with the World Customs Organization for a study report in this regard following the Hangzhou Summit. ${ }^{33}$

IFFs connected with trade misinvoicing is a problem that concerns governments. The phenomenon has been assessed using statistical tools, such as mirror data analysis. For instance, the International Tropical Timber Organization (ITTO) reports significant trade gaps when analysing export and import statistics in bilateral trade for different types of wood. The case of sawnwood serves as example:

In sawnwood the following trade flows were reviewed:

- From Côte d'Ivoire to Mali and Nigeria

- From Ghana to Burkina Faso, Côte d'Ivoire and Nigeria

- From Cameroon to Nigeria

The results are provided in Table 2.16, indicating that three flows have been recorded: (i) from Côte d'Ivoire to Nigeria (reported as USD 26000 only by importer), (ii) from Côte d'Ivoire to Mali (reported as USD 1307000 only by exporter), and from Ghana to Burkina Faso (reported as USD 42000 by the exporter, and as USD 1642000 by the importer). The second case may be due to misclassification in Mali statistics, as the economic incentive to avoid the payment of tariffs is low in Mali (tariff is 3.33\%). The third case is possibly due to Burkina Faso reporting Ghanaian sawnwood imports from other countries

\footnotetext{
${ }^{32}$ A value-added tax (VAT), known in some countries as a goods and services tax (GST), is a type of tax that is collected incrementally, based on the value added to the price by the work at each stage of production, which is usually implemented as a destination-based tax, where the tax rate is based on the location of the customer.

${ }^{33}$ G20 China. (2016). Leaders' Communique, Hangzhou Summit, 4-5 September 2016. Available at: https://www.g20.org/Content/DE/_Anlagen/G7_G20/2016-09-04-g20-kommuniqueen.html;jsessionid=29EF225E4A19ABD291972F80BD904D64.s1t1?nn=2068780). [accessed 22 June 2017].
} 
as coming from Ghana (which could have been a transit country for deliveries originating from elsewhere). ${ }^{34}$

Nevertheless, on the matter of misinvoicing and IFFs, the Swiss Academy of Sciences explains:

Illicit financial flows linked to commodity trading are a major challenge that demands greater analysis with a view to prevention and policy coherence. There is no agreement on the estimated scale of the problem. Of prime concern are possible commodity-related practices of trade mispricing. This involves transactions in which two parties - e.g. a Europe-based multinational and an African subsidiary or a state-owned firm-trade a commodity but manipulate its price (in collusion or one-sidedly). (...); Global Financial Integrity has estimated that it costs developing countries as much as USD 106 billion annually in lost tax revenues. ${ }^{35}$

In summary, it is argued in this dissertation that data fragility affects trade statistics in a serious way. Therefore, trade statistics reports are not as trustworthy as assumed. ${ }^{36}$ This is a serious problem, particularly for those countries where effective trade policies are needed to support economic development.

Taken together, there are several tax issues to be considered when discussing economic globalization and GVCs. For customs valuation and tariffs, it is worth highlighting the increased use of intangibles in GVCs, the double-counting pricedistorting trade statistics, the VAT tax system rationale for international trade and the misinvoicing associated to the IFFs.

\subsection{Volatility of Commodity Prices}

Commodities are intermediate products traded globally and used in most GVC business models. Commodity prices affect the economic performance both of resource-rich countries and of import-dependent countries. How commodities affect both sides is a subject of long debate, and it is not a topic for this dissertation.

\footnotetext{
${ }^{34}$ International Tropical Timber Organization (ITTO) (2016), p. 52

${ }^{35}$ Swiss Academy of Sciences. (2016). Switzerland and the Commodities Trade Taking Stock and Looking Ahead. Vol. 11, No 1, 2016. Pdf available at: https://www.wti.org/media/filer_public/56/50/5650e771-d6f0-4e8c-95a0e9526fd9b85c/a_factsheet_rohstoffe_eng_web.pdf. [accessed 22 June 2017].

${ }^{36}$ A reference to question the trustworthiness of trade statistics can be found in the Research Paper by Thomas Cantens where he discusses revenue fraud by mirror analysis calculation, that is cofronting export data with import data for Cameroon and Ecuador. CANTENS, Thomas. Mirror Analysis and Revenue Fraud. WCO Research Paper No. 35. April 2015. Available at http://www.wcoomd.org/en/topics/research/activities-andprogrammes/ /media/9F730547EF794600ADB7B2012BB5EE63.ashx. [accessed 16 July 2020].
} 
What matters here is the consideration that the booms and busts commodity prices are important to AV tariffs and customs valuation. The volatility in commodity prices affects not only trade revenue based on AV tariffs, but also tax revenue from corporate profits. $^{37}$

GVCs use commodities in different markets, such as agriculture, metals, minerals, and energy. In relation to the importance of commodities to international trade, Buchan explains:

The story of the modern commodities trading industry is part of the history of our time. The vast expansion of international trading in fuels, minerals and food in recent decades is one of the vital building blocks and enablers of globalisation. ${ }^{38}$

The literature provides rich analyses focused on the determinants of the recent price evolution of various commodities. Often, studies investigate the changes in supply/demand factors. From the perspective of demand, specialists emphasize the rapid economic development of Asian countries during the last decades. From the standpoint of supply, essential factors include limited investments in agriculture, complemented by low commodity inventory amounts over the past few years. ${ }^{39}$

Commodity dependency is also referred to as a "resource curse", as many resourcerich countries are likely to remain poor and indebted. Researchers from the Swiss Academy of Sciences summarized the situation as follows:
For years, researchers have highlighted the worrisome tendency of many commodity-producing countries to remain poor and indebted-victims of a posited "resource curse". Some have stressed the need for studies on systemic causes, including insufficient global rules and rich-country policies (e.g. on taxation of multinationals) that help to shift commodity revenues away from developing countries. ${ }^{40}$

Given the fact that most of the least developed and low-income economies depend on commodity exports to guarantee foreign exchange earnings, the price level of commodities is extremely relevant. Commodity price performance can have a significant impact on a country's balance of payments. Therefore, for certain

\footnotetext{
${ }^{37}$ Commodities are goods used in commerce that are interchangeable with other goods of the same type. Commodities are often used as inputs in the production of other goods or services. Commodities usually meet specified minimum standards, also known as a basis grade. For instance, in the case of the automotive industry, several metals, such as aluminum and steel, plastics, glass, and other materials, are considered commodities traded through different countries before being used in a car, the final product.

38 Buchan (2017), p.4

${ }^{39}$ Abbott and Borot de Battisti (2009); Gilbert (2010); Gilbert and Morgan (2010)

${ }^{40}$ Swiss Academy of Sciences. (2016), p.1
} 
economies, the value of commodity exports needs to be balanced with the value of goods imported to achieve equilibrium in the balance of payments. Concerning the price volatility in agriculture commodities Meerhaeghe notes:

Experience has shown that a disequilibrium between supply and demand on the commodity markets may give rise to considerable price fluctuations. This holds true particularly for agricultural commodities, production of which is influenced by changing weather conditions and cannot be adapted to changes in demand immediately. Efforts have been made to achieve greater stability in the commodity markets. ${ }^{41}$

Price fluctuations, also referred to as price volatility, are a constant in commodities markets and, as such, have also had an impact on customs valuation, tariffs and tax revenue. AV tariffs are unfit to provide tax revenue stability in countries that depend on the export and/or import of commodities. For instance, countries whose share of tariff revenue is significantly linked to the import of oil commodities are more exposed to revenue risks and to price fluctuations of this energy commodity. In such a situation, specific or other types of tariffs are best suited to ensure a significant share of the revenue.

Commodity volatility became worse at the end of the gold standard in 1971. Lately, with the financial crisis that started in 2008, public and private sectors are concerned about the start of a descending phase in the commodities supercycles. ${ }^{42}$ The descending trend in prices, or even a moderate price growth, has serious implications for revenue in many economies.

Energy, non-energy, minerals, metals, and other commodities had low market prices during the 1980s and 1990s. In the late 1990s, considering the rising demand from emerging markets, in particular China, commodity prices began to rise steadily, reaching a possible maximum around 2008-2009. The IMF's Primary Commodities Price System indicates the increase in commodity prices in the period from mid-2008 to around 2011. From 2011 to 2014, the prices were flat. At the end of 2014, there was a sharp decline in commodity prices towards the levels of 2005. The decline led investors away from investing in many countries that are commodity-dependent and therefore seen as riskier investments. ${ }^{43}$

The decline in commodity prices is important to understand the fiscal crisis that many governments must deal with daily. As an example, it is worth mentioning the case of oil, which is the most globalized commodity. Ebrahim indicated that, due to its unique

\footnotetext{
${ }^{41}$ Meerhaeghe, M. A. G. van. (1992). p. 147

42 The commodities supercycles refer to long periods of ascending or descending prices.

${ }^{43}$ IMF Primary Commodity Prices (2017)
} 
importance, price movements in the crude oil market increase faster and are more volatile than in other commodities sectors. ${ }^{44}$

The uncertainty caused by fluctuating oil prices has adverse and destabilizing fiscal implications. The extreme volatility in the oil market over the past decades is a major obstacle to stability and long-term planning.

Looking beyond the oil market to the more recent scenario, the financial crisis that started in 2008 continues to affect global trade growth negatively. Economies seem to be slowly recovering. The G20 expressed the situation as follows:

2. We met at a time when the global economic recovery is progressing, resilience is improved in some economies, and new sources for growth are emerging. But growth is still weaker than desirable. ${ }^{45}$

Clearly, the G20 recognizes that growth is weak and that volatility in financial markets represents a risk. The global scenario remains unstable and, because of such a slow recovery, countries suffer severe fiscal problems. In simple terms, the question about commodities in international trade is important for government revenue, AV tariffs and WTO customs valuation rules. The volatility in commodity prices leads to fluctuations in revenue for commodity-exporting countries and to fluctuations in trade revenue for commodity-importing countries, threatening both export and import countries fiscal stability.

\subsection{Commodities Agreements and GATT Art XX(h)}

Commodity agreements to regulate the markets are part of economic history. For instance, the International Wheat Agreement in 1933 and the International Sugar Agreement in 1937 attempted to deal with commodity price fluctuations. ${ }^{46,47}$

In 1947, the UN Economic and Social Council (ECOSOC) adopted a resolution that created the Interim Coordinating Committee for International Commodity Arrangements (ICCICA). In relation to this issue, it is relevant to mention that in 1947 the ECOSOC formulated principles that are in the Charter of the International Trade Organization (ITO). According to Meerhaeghe, these principals were:

\footnotetext{
${ }^{44}$ Ebrahim, Z., Inderwildi, O., Kimg, A., (2014).

${ }^{45}$ G20 China. op. cit.

46 The International Wheat Agreement was signed at the Conference of Wheat Exporting and Importing countries in London, 25 August 1933.

${ }^{47}$ The International Agreement regarding the Regulation of Production and Marketing of Sugar was signed in London, 6 May 1937.
} 
1. any government may call for and participate in discussions on matters in which it claims to have a major stake;

2. adequate representation of importing (consumer) countries has to be guaranteed;

3. full publicity must be given to the terms of the agreements proposed or concluded;

4. "control agreements" (regulation of production or foreign trade) may only be introduced in the event of considerable surpluses, general unemployment or inadequate employment opportunities;

5. in the case of a control agreement there has always to be a sufficient supply available and, as a general rule, increasing use must be made of the most efficient production sources; no serious disturbance must be caused to the economic and social organization of any country. ${ }^{48}$

Principles existed for "commodity agreements" under the ITO, however, the ITO failed. GATT 1947 existed before the ITO Charter failed to enter into force and it brings a reference to the "commodity agreements" in Art XX(h).

GATT 1947

Article XX

(...)

(h) undertaken in pursuance of obligations under any intergovernmental commodity agreement which conforms to criteria submitted to the

CONTRACTING PARTIES and not disapproved by them or which is itself so submitted and not so disapproved; *

Interpretative Note Ad Article XX from Annex I

Sub-paragraph $(h)$

The exception provided for in this sub-paragraph extends to any commodity agreement which conforms to the principles approved by

the Economic and Social Council in its resolution 30 (IV) of 28 March 1947.

Art XX(h) of the GATT is an exception for the GATT Contracting Parties to adopt trade measures, such as export or import quotas, that are in conformity with intergovernmental commodity agreements. Khan explains as follows:

The GATT recognises international commodity agreements as an exception to MFN and other principles. The ICAs are validated by reference to the abovenoted resolution of the ECOSOC. In the original paragraph $(h)$ of article XX of

\footnotetext{
${ }^{48}$ Meerhaeghe, M. A. G. van. Op. cit., p. 158
} 
the GATT, intergovernmental commodity agreements qualifying for exemption were those which conformed "to the principles approved by the Economic and Social Council...in its Resolution of March 28, 1947”. The 1955 amendment of GATT omitted a reference to the 1947 resolution. This however not altered the legal position, as it is accepted that those principles still apply. ${ }^{49}$

In 1964, the UNCTAD succeeded in doing the job of the ICCICA, created in 1947.

In 1966, George Ball, US Under Secretary of State, mentioned the challenge to improve the trade position of less-developed countries and the link between trade and their foreign exchange earnings with commodities as follows:

This problem of improving the trading position of the less-developed countries is a complicated one. It involves many factors, not merely improving their access to markets so far as tariffs are concerned, but also providing some stability for the price structure of the primary commodities upon which so many of these countries depend almost exclusively, for their foreign exchange earnings and, in fact, for their entire well-being. ${ }^{50}$

Thus, for a long-time, national and international institutions have been aware that a considerable number of countries depend on commodity exports to guarantee foreign exchange earnings.

In the 1960s and 1970s, to deal with commodity prices and foreign exchange, lessdeveloped countries proposed the negotiation of other international commodities agreements at UNCTAD, such as the 1962 International Coffee Agreement. At that time, there were discussions about the need for other agreements on essential commodities. Associated with the agreements, there was also a demand for supplementary and compensatory financing when the prices for commodity exports fell below certain levels. UNCTAD cooperation between producers and consumers of commodities takes place in the form of International Commodity Agreements (ICAs) and International Study Groups (ISGs).

The idea of strengthening and establishing new ICAs was a core element of the Integrated Program for Commodities (IPC), adopted at UNCTAD IV in 1976. It was envisaged that ICAs would have mechanisms within themselves for the regulation of production, supply and demand, and prices at the world commodity markets. UN Commodities Conferences held by UNCTAD resulted in the following ICAs and ISGs:

- International Sugar Agreement (1968);

\footnotetext{
${ }^{49}$ Khan, K. R. (1982), p.67

${ }^{50}$ United States House of Representatives (1966), p.9.
} 
- International Cocoa Agreement (1972);

- International Natural Rubber Agreement (1980);

- International Jute Agreement (1982);

- International Tropical Timber Agreement (1983);

- International Nickel Study Group (1990);

- International Copper Study Group (1992).

However, historically, only three ICAs, on coffee, on cocoa, and, on natural rubber, were reasonably successful over limited periods of time. According to Brandt, former Director of the Food Research Institute of Stanford University, some of the reasons for the failure of the ICAs are the lack of geographical location production mobility and the surpluses that exceed demand as a result of subsidized production. As such, the government has to both finance and store commodity stockpiles at the taxpayers' expense. The falsely set fixed price still governs producers, processors, everybody in the trade chain, and consumers. And, since there is excess supply at the public's expense, the government has socialized stock carrying, resulting in the most effective commodity price and supply stabilizing institution, the commodity exchange with its trading in future delivery contracts, is made idle. ${ }^{51}$

In the first two cases of coffee and cocoa, international prices were maintained at "an adequate level" through retention schemes, while in the third one, natural rubber, a buffer stock was put in place. In October 1999, the International Natural Rubber Agreement, the last remaining ICA with the price-regulating mechanism, terminated its activities.

The cause for the failure of the ICAs was that, without any intent to do so, the government would be responsible for determining and managing the levels of stock maintained. By doing so, governments had to pay for the commodity inventory and manage market entries and exits. Furthermore, there were many side effects, such as the vested interests of logistics groups and real estate land prices.

After the failure of the price-regulating systems, the existing ICAs (on cocoa, coffee, cotton, grains, olive oil and table olives, sugar, and tropical timber) do not include economic provisions, i.e. they do not attempt to regulate markets with supply or price management mechanisms. ICAs became administrative in nature, serving as a forum for producer-consumer cooperation and consultations, market transparency, development projects, and sources of statistics.

The UN experience in commodity price stabilization has not proven successful. Commodity prices fluctuate and therefore there is always uncertainty in relation to the revenue linked to this class of goods. This dissertation criticizes all types of price controls. However, it recognizes that price volatility is detrimental to fiscal systems,

\footnotetext{
${ }^{51}$ Brandt, Karl. (1964)
} 
causing revenue fragility and hinders adequate long-term planning. Therefore, the dissertation assumes that AV tariffs and customs valuation rules aggravate the fiscal instability associated with the volatility of commodity prices.

From a tax perspective, at some point, the topic of commodity price volatility needs to be addressed by the WTO and other international organizations. In that sense, this dissertation considers that the WTO simplification process to convert NAV tariffs into $\mathrm{AV}$ equivalent tariffs is inappropriate for major commodity classes, as it leaves countries more exposed to fluctuation risks.

\subsection{From Trade Revenue to Domestic Revenue}

Trade revenue has played an important role since ancient times. For instance, in classical Greece, indirect taxes, particularly those obtained from international trade, were preferred to direct taxes. Asakura highlights some possible reasons for the preference:

\section{(...) the preference for indirect taxes, stemmed from the unpopularity of direct taxes. (...)Consequently, the relative incidence of indirect taxes such as sales tax on city markets, monopoly tax on sales of salt and sales tax on wine, increased and both import and export duty, in particular, became very important taxes in classical Greece. ${ }^{52}$}

Nowadays, direct taxes are still difficult to collect in several economies. As such, indirect taxes, including tariffs, continue to be of importance for many economies.

Regarding the contribution of Customs to total tax revenue, the WCO in its 2017-2018 Annual report brings the following data for different regions of the world: South America, North America, Central America and the Caribbean (27.9\%); West and Central Africa (40.5\%); East and Southern Africa (33.3\%); North of Africa, Near and Middle East (36.2\%); Europe (24.6\%); and the Far East, South and South-East Asia, Australasia and the Pacific Islands $(29.9 \%) .{ }^{53,54}$

Many of the taxes administered by Customs authorities are in the category of other duties and charges (ODC) or are domestic taxes such as VAT. However, all these taxes relate to importation and exportation. Thus, the high percentage of the contribution of

\footnotetext{
52 Asakura op. cit., p.35

${ }^{53}$ WCO (2017-2018) Annual Report, p.26

54 The contribution of Customs to total tax revenue takes into account the following taxes: a) customs duties; b) general consumption taxes; c) special consumption taxes; d) taxes on exporting goods; e) other taxes collected by Customs authorities.
} 
Customs to tax revenue is a strong indication of the importance of revenue derived from trade. $^{55}$

The adoption of AV tariffs and the use of the customs valuation rules presents a real risk for the loss of trade revenue. In addition, the risk of shifting from customs duties or other ODC collected at the border to internal taxes, simply because several national and subnational tax agencies lack the necessary tools to collect internal taxes, is also worth mentioning.

According to the IMF, a structured tax administration would have the following nine functional areas: I) Integrity of the Registered Taxpayer Base; II) Effective Risk Management; III) Supporting Voluntary Compliance; IV) Timely Filing of Tax Declarations; V) Timely Payment of Taxes; VI) Accurate Reporting in Declarations; VII) Effective Tax Dispute Resolution; VIII) Efficient Revenue Management; and IX) Accountability and Transparency. ${ }^{56}$

Each of these areas requires trained HR, adequate IT systems and processes to function. To illustrate the situation, the integrity of the registered taxpayer base is necessary and, as such, the country needs to register and maintain a complete and accurate taxpayer database. However, several economies lack reliable IT systems with complete, accurate, and up-to-date registers of businesses, individuals, and other entities.

A tax administration assessment of the Hashemite Kingdom of Jordan, undertaken in 2016 by IMF and USAID, reports the problem as follows:

Table 1. Jordan: Summary of TADAT Performance Assessment P1-1. Accurate and reliable taxpayer information Score $C$

The registration procedures and database capture the minimum information required to support effective interaction with taxpayers. However, legal and regulatory impediments to removing inactive taxpayers from the register undermine effective compliance management. ${ }^{57}$

Another similar tax administration assessment in Liberia reports a worse situation regarding the taxpayer registration database:

Table 1. Liberia: Summary of TADAT Performance Assessment P1-1. Accurate and reliable taxpayer information

\footnotetext{
${ }^{55}$ Note that this is a question of shifting from customs duties to other border taxes. It is quite misleading to make a lot of publicity about the negotiations to reduce customs duties without mentioning the increase in the other national border taxes to compensate for the losses.

56 TADAT (2015), p. 4

57 TADAT (2016). Hashemite Kingdom of Jordan. p. 7
} 
Taxpayer registration is not computerized outside of Monrovia. The design of the registration database and the information held is generally inadequate. The registration process itself is weak resulting in numerous inaccuracies in the information. ${ }^{58}$

The list of tax administrations lacking the capacity to monitor taxpayers is significant. For transitions from trade revenue to internal revenue based, for instance, on companies' profits, requires, as a basic strategy, that national Taxpayer Identification Number (TIN) is connected to international trade systems. Unfortunately, several national tax administrations have significant weaknesses in terms of taxpayer information and are not prepared to receive trader's registers or other relevant information regarding risk.

To make things worse, national or subnational tax administrations can be politically driven to exempt certain groups. In summary, trade liberalization based on tariff reductions, eliminations or simplification policies to convert from NAV to AV have consequences for revenue.

Regarding the link between revenue mobilization and trade facilitation, Duran and Sokol, from the World Bank, write about their work to implement trade reforms to enhance revenue:

The challenge faced by all case study countries has been to achieve the trade facilitation objective without undermining the revenue mobilization function of customs services, which is the most important motive for undertaking the customs reforms. As there were indications that trade liberalization measures would tend to reduce revenues from international trade transactions, a special effort was made to enhance the revenue-generating capabilities of customs. ${ }^{59}$

It is essential to reflect on whether countries can risk losing revenue while trade reforms mature and bring economic growth, and this is central to international trade. The hard reality is that, despite countries' tariff reduction commitments, revenue losses represent a challenge for governments worldwide. Therefore, trade liberalization reforms need to consider fiscal equilibrium.

In addition to governments' incapacity to undergo losses, there is, in fact, no guarantee that revenue will increase with trade liberalization. Ebrill and others from the IMF, writing about the revenue implications of trade liberalization, put the challenge as follows:

\footnotetext{
${ }^{58}$ Idem. Liberia (2016) p. 5

${ }^{59}$ Duran, P. and Sokol, José B. (2005), p. 118
} 
The revenue implications of trade liberalization are, in general, uncertain. Blejer and Cheasty (1990) and Tanzi (1989) conclude that ultimately the net impact of trade reform on revenue is an empirical matter. Similarly, in a case study analysis of the revenue implications of World Bank - supported Structural Adjustment Loans, Greenway and Milner (1991) conclude that a range of outcomes is possible, depending on the country's initial conditions and the components of the reform package. ${ }^{60}$

Considering the uncertainty of tariff reduction policies, it is certain that the implications are dependent on the country's initial conditions and the components of the trade reform package. Naturally, the ideal scenario would be for countries to prepare for trade reforms assuming certain trade revenue losses and implement adequate fiscal policies to maintain revenue equilibrium. For trade reforms to be economically and politically sustainable, domestic revenue must compensate for losses in trade revenue. In the words of Ebrill:

A recent IMF study of trade liberalization in general in countries undergoing IMF-supported programs (IMF, 1998) also finds a range of fiscal outcomes from liberalization. The study concludes that some programs could have targeted more extensive trade reform if greater attention had been given to supporting fiscal policies and to revenue-neutral trade measures. ${ }^{61}$

For trade reforms to be successful, it is important to have an adequate fiscal structure. Nowadays, most of the fiscal policies try to compensate for tariff reductions or their elimination by increasing VAT rates.

Writing for the World Bank, Wulf and Sokol make this explicit:

Tariff reductions made in conjunction with customs reform positively affected trade, but initially had an adverse impact on customs duties in the countries reviewed. The reform often replaced sales taxes by the VAT. Higher VAT rates accompanied the cuts in import tariffs and raised import revenues other than customs duties for a given level of imports. ${ }^{62}$

Besides VAT, other direct or indirect taxes, such as excises, can also be used to compensate for losses in trade revenue.

Referring to the GATT, there are two options to compensate for the loss in trade revenue:

a) impose a charge on imports that is equivalent to an internal tax (Article II:2); or

\footnotetext{
${ }^{60}$ Ebrill, Liam P. and others (1999), p.1

${ }^{61}$ Idem, p.2

${ }^{62}$ Wulf and Sokol (2004), p.119
} 


\section{Article II: Schedules of Concessions}

2. Nothing in this Article shall prevent any contracting party from imposing at any time on the importation of any product:

(a) a charge equivalent to an internal tax imposed consistently with the provisions of paragraph 2 of Article III* in respect of the like domestic product or in respect of an article from which the imported product has been manufactured or produced in whole or in part; ${ }^{63}$

b) increase internal taxes such as the VAT rate (Article III:2).

\section{Article III*: National Treatment on Internal Taxation and Regulation}

2. The products of the territory of any contracting party imported into the territory of any other contracting party shall not be subject, directly or indirectly, to internal taxes or other internal charges of any kind in excess of those applied, directly or indirectly, to like domestic products. Moreover, no contracting party shall otherwise apply internal taxes or other internal charges to imported or domestic products in a manner contrary to the principles set forth in paragraph $1 . *$

Logically, members can adopt both actions to compensate for revenue losses in tariffs. The point to remember is that imported goods must be subject to equal or more favourable tax treatment than domestic products. ${ }^{64}$ Thus, for instance, if a contracting party decides to increase the VAT rate to compensate for tariff losses, it must affect only the domestic goods or both equally. ${ }^{65}$

For the purposes of this dissertation, there is a lack of fiscal studies that address the negotiation of tariff policies by WTO members, while tariff negotiations have serious consequences for revenue.

This section aimed at presenting the revenue implications of the adoption or reduction of AV tariffs. As such, the negotiations to reduce tariffs have an unpredictable result that affects other key areas that are relevant in maintaining fiscal stability in affected countries.

\footnotetext{
${ }^{63}$ WTO (1999)

${ }^{64}$ Note that there is no violation if domestic products are treated less favorably than imported goods in taxation. The requirement only mentions that imports must not be taxed in excess of like domestic products (under the first sentence of GATT 1994, Art III:2).

${ }^{65}$ It is relevant to mention that several tax administration systems lack the means to collect VAT properly. Also, in countries with poorer consumers, a VAT increase can have a negative effect on the economy.
} 
Governments aim to compensate possible losses by imposing charges on imports that are equivalent to internal taxes (GATT Article II:2) or increasing internal taxes such as the VAT rate (GATT Article III:2). The dissertation assumes that such measures are not always successful as they expose countries to revenue risks.

\title{
1.5 WCO Revenue Package
}

In 2009, the World Customs Organization (WCO) launched the Revenue Package (RP) initiative to support countries in managing trade revenue better. The initiative reflected the governments' concerns on the downturn in international trade that has an impact on trade revenue.

\begin{abstract}
The Revenue Package was initiated as a response to Members' concerns over declining revenue returns in the context of the global financial crisis of 2008 and falling duty rates in general.

Collection of revenue has historically been the cornerstone of a Customs administration's responsibilities. ${ }^{66}$
\end{abstract}

On the link between imports and tax revenue, in an IMF Working paper, Li and Pablo found that "the link between tax revenue downturns and import contractions is stronger in the case of emerging and developing economies." ${ }^{67}$ In other words, emerging and developing economies are more penalized regarding tax revenue during times of trade contractions than advanced economies. The explanation for this is that advanced economies rely more on income taxes while emerging and developing economies rely more on expenditure taxes in which imports play a major role.

The RP intention is to make international materials and tools more readily available for countries to utilize and improve trade revenue collection. Such tools apply to customs valuation controls, post-clearance audits, preferential origin verification and tariff classification.

More specifically with respect to customs valuation, the RP collection of materials recommends practices regarding the development and use of a valuation database as a risk assessment tool and the best practices to deal with the informal trade sector, secondhand goods and the use of PSI companies. The RP also recommends the development of Post-Clearance Audit (PCA) programmes as a tool to migrate controls from the border inland. ${ }^{68}$

\footnotetext{
${ }^{66} \mathrm{WCO}(2012), \mathrm{p} .2$

${ }^{67} \mathrm{Li}$ and Pablo (2010), p.14

${ }^{68} \mathrm{WCO}(2012)$, p. 3
} 
This section was aimed at presenting the WCO RP initiative. For the purposes of this dissertation, the WCO RP initiative does not address relevant tax discussions related to tariffs reductions, elimination, or simplification. The initiative also fails to address the WTO mechanisms to compensate for trade revenue losses by imposing charges on imports that are equivalent to internal taxes (GATT Article II:2) or increasing internal taxes such as the VAT rate (GATT Article III:2).

\subsection{OECD BEPS Package - A Response to Tax Evasion}

Tax evasion is a pressing cause for concern on the agenda of most governments. Profitshifting undertaken mainly by multinational enterprises or corporations (MNEs) ${ }^{69}$ to avoid taxes takes the form of transfer pricing operations in international trade. ${ }^{70}$ Transfer pricing diminishes taxable profits and hence, domestic tax revenue. ${ }^{71}$ For the purposes of this dissertation, transfer pricing affects the reliability of prices used as the basis for customs valuation and AV tariffs. As noted by Marsilla the two tax worlds are connected.

The relevance of corporate income tax as a tool to ensure compliance in customs valuation rests on the assumption that there is a relationship or connection between the valuation rules in both taxes. ${ }^{72}$

The transfer pricing strategies of MNEs raise concerns. Writing particularly about under-invoicing relating to transfer pricing, Sawyer and Sprinkle explain:

Under-invoicing also may occur when a multinational corporation ships intermediate products from one of its plants located in one country to one of its plants in another country. (...) In the case of under-invoicing, customs officials must be extremely knowledgeable about the market prices for all imported goods. As a result, ad valorem tariffs are more difficult for a country to administer than specific tariffs. ${ }^{73}$

MNEs with entities in low-tax jurisdictions tend to use transfer pricing to shift incomes to higher-tax jurisdictions and to reduce the overall tax burden at the group level. Both

\footnotetext{
${ }^{69}$ Multinational Corporation is a corporation that has production facilities or other fixed assets in at least one foreign country and makes its major management decisions in a global context. Downes, J. and Goodman, J. E. (1985), p.240

70 Transfer Price is the price charged by individual entities in a multi-entity corporation on transactions among themselves; it is also called the transfer cost. This concept is used where each entity is managed as a profit center - that is, held responsible for its own return on invested capital - and must therefore deal with the other internal parts of the corporation on an arm's length (or market) basis. Downes, J. and Goodman, J. E. (1985), p.442

${ }^{71}$ Brandstetter (2014)

${ }^{72}$ Marsilla, Santiago Ibáñez (2011). Towards customs valuation compliance through corporate income tax. World Customs Journal, Volume 5, Number 1. p. 73.

${ }^{73}$ Sawyer and Sprinkle (2015), Ch.8
} 
transfer pricing and misinvoicing are deliberate strategies to move money from one jurisdiction to another through international trade, however, the former is often legal while the latter is illegal. ${ }^{74}$

Fuest's and others comment on the fragility of developing economies when faced with such tax planning strategies by MNEs.

\begin{abstract}
Recent studies however suggest that multinational firms engage in tax planning activities to avoid taxation in high-tax economies by shifting income from hightax to low-tax countries. While this happens in both developing and developed countries, there is a common perception that developing economies are especially prone to multinational profit shifting. This is because their tax authorities often lack the resources to implement effective anti tax avoidance policies. ${ }^{75}$
\end{abstract}

As a response to the negative impact of transfer pricing on tax revenue, many states decrease corporate taxes to narrow the tax rate differential compared to fiscal havens and, thus, offer incentives for MNEs' entities to retain profits in their jurisdiction. The process of reducing corporate taxes to attract MNEs to certain jurisdictions is also referred to as the "race to the bottom". ${ }^{76}$

Separate Accounting (SA) systems are currently used for the corporate taxation of MNEs at the global level. Given that SA implies that profits should be taxed in the state where they accrue, MNEs choose to relocate income from high-tax to low-tax jurisdictions.

As a rule, MNEs can shift profits in two ways. First, MNEs can distort transfer prices for products and services traded within the corporation. Second, they may turn to the distortion of the corporate debt-equity structure, for instance through intra-firm capital lending. If the low-tax subsidiary offered a loan to the mother company, it would receive interest payments that diminish pre-tax profits at the company headquarters and reallocate them to the subsidiary in the fiscal haven.

\footnotetext{
${ }^{74}$ In the case of transfer pricing, the tax strategy is transparent and the inter-company prices must obey the arm's length principle. Although some of the schemes used are illegal, most are not. As for misinvoicing, the strategy where the company deliberately misreports the price of goods on an invoice is always illegal.

${ }^{75}$ Fuest, C., Hebous, S., Riedel, N. (2011), p 2.

${ }^{76}$ The race to the bottom results from competition where companies, states or nations attempt to undercut the prices of their competitors by sacrificing standards, safety, regulations, wages, and so on. A race to the bottom can also occur between nations and regions. In an attempt to attract investment, such as a new factory or corporate office, a jurisdiction may lessen regulation, reduce oversight, or otherwise compromise the public good in order to convince a company to commit. (Read more: Race to the Bottom Definition | Investopedia https://www.investopedia.com/terms/r/race-

bottom.asp\#ixzz58zoVzgix).
} 
While the practical outcomes of income relocation are significant and straightforward, there is still little knowledge on the relative impact of the two techniques that facilitate the shifting of profits from high to low-tax countries. The reality is that well-known companies such as Google, Apple, Starbucks, and other global giants have the means to limit their tax burden substantially by shifting profits from high-tax to low-tax jurisdictions.

National tax authorities establish transfer pricing rules, allowing the tax authorities to adjust transfer prices when they do not comply with the arm's length principle. However, this involves administrative expenses and may be difficult to execute depending on the tax system structure of HR and IT systems. It may be almost impossible to monitor MNEs transfer pricing strategies when the goods are traded using unique arrangements, and MNEs use services or "intangible" costs that are unknown to the authorities. ${ }^{77}$

Researching the use of intangibles for transfer pricing, Dischinger and Riedel revealed that MNEs' income relocation practices are connected to the location of intangible assets and service units within the corporate group. These authors showed that profitshifting behaviour is more pronounced if the affiliates are in a low-tax jurisdiction compared to other group entities. Also, Dischinger and Riedel stressed that multinationals distort the location of their intangible assets towards low-tax jurisdictions. ${ }^{78}$

Answering governments' concerns on the extensive use of transfer pricing strategies to reduce corporate taxes, the $\mathrm{OECD},{ }^{79}$ at the request of the $\mathrm{G} 20,{ }^{80}$ launched the base erosion profit shifting (BEPS) package. ${ }^{81}$ The OECD defines the BEPS package as follows:

BEPS refers to tax planning strategies that exploit gaps and mismatches in tax rules to artificially shift profits to low or no-tax locations where there is little or no economic activity. ${ }^{82}$

\footnotetext{
${ }^{77}$ Chapter VI - Special Consideration of Intangibles" of the OECD Transfer Pricing Guidelines for Multinational Enterprises and Tax Administrations (2017).

${ }^{78}$ M. Dischinger and N. Riedel (2007)

${ }^{79}$ The OECD's origins date back to 1960, when 18 European countries plus the United States and Canada joined forces to create an organization dedicated to economic development.

${ }^{80}$ The G20 is a forum for international cooperation on financial and economic issues. According to the G20 Germany 2017 website (G20, 2017), the group account for more than four-fifths of gross world product and three-quarters of global trade. Therefore, "Its decisions are influential and help to bring about reform at national and multinational levels." The G20 comprises 19 countries plus the EU. These countries are Argentina, Australia, Brazil, Canada, China, France, Germany, India, Indonesia, Italy, Japan, Mexico, Russia, Saudi Arabia, South Africa, South Korea, Turkey, the United Kingdom (UK), and the United States of America (US).

${ }^{81}$ In Antalya in 2015, the G20 agreed on the BEPS Action Plan.

82 OECD BEPS webpage at http://www.oecd.org/tax/beps/beps-about.htm
} 
As an international response to profit shifting practices, the OECD BEPS package has 15 actions that are intended to support countries in reinforcing their taxation systems. These actions are:

\section{OECD BEPS Actions}

Action 1 Addressing the Tax Challenges of the Digital Economy

Action 2 Neutralizing the Effects of Hybrid Mismatch Arrangements

Action 3 Designing Effective Controlled Foreign Company Rules

Action 4 Limiting Base Erosion Involving Interest Deductions and Other

Financial Payments

Action 5 Countering Harmful Tax Practices More Effectively, Taking into Account Transparency and Substance

Action 6 Preventing the Granting of Treaty Benefits in Inappropriate Circumstances

Action 7 Preventing the Artificial Avoidance of Permanent Establishment Status Actions 8-10 Aligning Transfer Pricing Outcomes with Value Creation

Action 11 Measuring and Monitoring BEPS

Action 12 Mandatory Disclosure Rules

Action 13 Transfer Pricing Documentation and Country-by-Country Reporting

Action 14 Making Dispute Resolution Mechanisms More Effective

Action 15 Developing a Multilateral Instrument to Modify Bilateral Tax Treaties $^{83}$

The BEPS package actions intend to equip governments with instruments to address profit shifting and to improve tax predictability. It aims to close international tax gaps that create incentives for companies to shift profits from high to low tax jurisdictions legally.

Although the OECD BEPS package measures are coherent, there are innumerous tax gaps around the world and, for the purposes of this dissertation, it is still early to draw conclusions on the results of the package. However, it is important to understand that MNEs' profit shifting practices have an impact on prices affecting WTO customs valuation rules.

This dissertation argues that the success of the BEPS package actions depends upon cooperation, and cooperation is overestimated. That said, it is important to differentiate multilateral cooperation from bilateral cooperation. The former is more desirable, but it is difficult to achieve, while the latter is less effective, but easier to achieve.

\footnotetext{
${ }^{83}$ OECD (2015b)
} 
Another possible obstacle for the BEPS package is the fact that most of the world's countries are not OECD members. ${ }^{84}$ The OECD has only 35-member countries. ${ }^{85}$ Although the 35 OECD member countries represent most of the world's economy, the majority of countries are outside the OECD. Furthermore, the OECD does not have a tax dispute settlement system to enforce global cooperation or to punish low tax jurisdictions that favour profit shifting practices.

The OECD BEPS package can be applauded, following public opinion that finds it outrageous that global firms pay such low taxes. In England, BBC journalists publicize tax evasion by MNEs to "expose" corporations such as Starbucks, Google, and Amazon that use such strategies to avoid paying taxes. ${ }^{86}$

For the purposes of this dissertation, it is relevant to approach the OECD BEPS package from a customs valuation, AV tariffs perspective. Regardless of the BEPS package, the WTO customs valuation rules remain unchanged, meaning that the rules are static and fail to evolve and adapt to new realities. Thus, although the WTO customs valuation rules have provisions addressing transactions between related parties, they are static and not adjustable to new scenarios. For instance, the WTO CVA Art. 15.4 provisions that define which persons are related parties are exhaustive, even though they continue to encounter new types of relationships for doing business.

On related parties, Marsilla observes that some jurisdictions consider not only the legal, but also the economic relationship.

As for the concept of related parties, both customs valuation rules and the income tax share basically the same definition. The only substantial difference in this regard is that it seems that, in some jurisdictions, such as the US, relationship may be held to exist not only on the basis of legal relationship (that is, formal, legal ties between the parties) but also in terms of economic relationship (on what is called 'economic control'). ${ }^{87}$

This dissertation assumes that, due to the OECD BEPS package actions for cooperation, including information exchange, more transparency from companies is expected and, consequently, customs valuations might benefit from more information about the prices of goods and intangibles. For instance, the OECD "Global Standard for Automatic

\footnotetext{
${ }^{84}$ As of June 2017, there are 195 United Nations member countries in the world today. This total comprises 193 countries that are member states and 2 countries that are non-member observer states: the Holy See and the State of Palestine.

${ }^{85}$ As of June 2017, the OECD Member countries are: Australia, Austria, Belgium, Canada, Chile, Czech Republic, Denmark, Estonia, Finland, France, Germany, Greece, Hungary, Iceland, Ireland, Israel, Italy, Japan, Korea, Latvia, Luxembourg, Mexico, Netherlands, New Zealand, Norway, Poland, Portugal, Slovak Republic, Slovenia, Spain, Sweden, Switzerland, Turkey, United Kingdom, United States.

${ }^{86}$ Barford (2013)

${ }^{87}$ Marsilla, Santiago Ibáñez (2011). Towards customs valuation compliance through corporate income tax. World Customs Journal, Volume 5, Number 1. p. 74.
} 
Exchange of Financial Account Information in Tax Matters" is expected to bring more financial and tax transparency. ${ }^{88}$ As of November 2019, a total of 94 jurisdictions had exchanged information amounting to around 6,100 bilateral exchanges. ${ }^{89}$

At this point, it is worth mentioning that, according to the GATT/WTO rules, the primary basis for a customs value is the "transaction value" together with adjustments of services and intangibles related to the goods being imported. ${ }^{90}$ It is also important to explain that one of the main challenges for customs administrations is to discuss cases in which the relationship might have influenced the price. When the importer declares or customs suspects that the exporter is a related party, customs authorities should be able to examine whether the relationship influenced the price. Therefore, when there is a related party transaction case:

the customs administrations should be prepared to examine relevant aspects of the transaction, including the way in which the buyer and the seller organize their commercial relations and the way in which the price in question was arrived at, in order to determine whether the relationship influenced the price. ${ }^{91}$

The issue of sales between related parties for the purposes of customs valuation was addressed by the WTO panel in Thailand - Cigarettes (Philippines) (2010), pending appeal. ${ }^{92}$ The $\mathrm{AB}$ stated that, in a related-party situation, both customs authorities and importers have obligations regarding the acceptability of the price. ${ }^{93}$ These mutual

\footnotetext{
${ }^{88}$ OECD (2014). The Standard for Automatic Exchange of Financial Account Information, developed by the OECD with G20 countries, represents the international consensus on automatic exchange of financial account information for tax purposes, on a reciprocal basis. Over 60 jurisdictions have committed to implementing the Standard.

${ }^{89}$ OECD (2019). Global Forum on Transparency and Exchange of Information for Tax Purposes. The AEOI Implementation Report. p.2

${ }^{90}$ WTO, CVA, General Introductory Commentary

1. The primary basis for Customs value under this Agreement is "transaction value" as defined in Article 1. Article 1 is to be read together with Article 8 which provides, inter alia, for adjustments to the price actually paid or payable in cases where certain specific elements which are considered to form a part of the value for Customs purposes are incurred by the buyer but are not included in the price actually paid or payable for the imported goods. Article 8 also provides for the inclusion in the transaction value of certain considerations which may pass from the buyer to the seller in the form of specified goods or services rather than in the form of money. Articles 2 through 7 provide methods of determining the Customs value whenever it cannot be determined under the provisions of Article 1.

${ }^{91}$ WTO CVA Interpretative Note to Article 1.2

${ }^{92}$ Second Recourse to Art 21.5 DSU Panel report circulated 12 July 2019. Not adopted report.

${ }^{93}$ WTO DS371, WT/DS371/R

Para. 7.155. Overall, therefore, the determination of whether to accept the transaction value as the customs value in a related-party situation under Article 1.2(a) entails the following procedural steps: - The importer declares a transaction value for the goods imported;

- The customs authority is required to examine the circumstances of the sale only if it has doubts about the validity of the transaction value of the imported goods, because the fact that the buyer and seller are related should not in itself be grounds for regarding the transaction value as unacceptable; - The customs authority shall examine the circumstances of the sale in the light of the information provided by the importer or otherwise and communicate to the importer the grounds for preliminarily considering that the relationship influenced the price;
} 
obligations are complex and can last several days. More recently, transfer pricing documentation is considered to assist in the examination of the relationship. To this date, the Thailand - Customs and Fiscal Measures on Cigarettes from the Philippines (2011) is an ongoing dispute and provides a vivid example of the difficulties encountered in assessing customs values for products that are subject to high tariffs.

This dissertation assumes that most countries' customs authorities lack the information to perform complex examinations on the "circumstances surrounding the sale", to determine whether the relationship influenced the price. The assumption takes into consideration two main points: a) the set of data available for the ASYCUDA system, used on almost half the countries in the globe is the main customs-trade system to control imports and exports, lacking structured, harmonized data fields for connectivity with other internal tax systems to monitor values in cross-border trade; and, b) the lack of transfer pricing expertise within customs and tax administrations for most countries. ${ }^{94}$

Thus, an increase in transparency resulting from the OECD BEPS package might help customs authorities to perform many of the related parties' examinations and the services and intangibles adjustments existent in the WTO CVA. The GATT/WTO adjustments include royalties, intellectual property, and services related to the goods being imported.

However, for OECD BEPS package information to reach customs authorities, it is necessary to have good cooperation between customs and tax authorities. In this aspect, it is worth observing that in many countries customs and tax authorities operate as separate agencies, and they are sometimes connected to different administrative

\footnotetext{
- The customs authority gives the importer a reasonable opportunity to respond. Given the opportunity, the importer submits further information; and

- The customs authority makes a final decision on whether to accept the transaction value.

Para. 7.171. In sum, we consider that the customs authorities and importers have respective responsibilities under Article 1.2(a). The customs authorities must ensure that importers be given a reasonable opportunity to provide information that would indicate that the relationship did not influence the price. Importers are responsible for providing information that would enable the customs authority to examine and assess the circumstances of sale so as to determine the acceptability of the transaction value. Provided with such information, the customs authorities must conduct an "examination" of the circumstance of sale, which would require an active, critical review and consideration of the information before them.

94 The Addis Agenda stresses the need for assistance to developing countries to improve their capacity to collect tax and other revenues and contains commitments to provide international support to developing countries in reaching targets for enhanced domestic revenue. See https://www.addistaxinitiative.net/
}

Reinforcing the need to build tax capacity in developing countries, please see the publication: IMF et al., Enhancing the Effectiveness of External Support in Building Tax Capacity in Developing Countries, 2016. Available at http://www.oecd.org/tax/enhancing-the-effectiveness-of-external-support-inbuilding-tax-capacity-in-developing-countries.pdf . [accessed 18 July 2020] 
structures. ${ }^{95}$ Regarding the cooperation between customs and tax authorities, the WCO observes:

There is a clear need for greater synergy between Customs and Tax authorities. Some Customs and Tax authorities (in particular where they are two separate administrations or within federal states where the central state as well as its member states both have fiscal competences) have already developed formal arrangements for cooperation and information exchange, such as Guidelines/Instructions and/or a Memorandum of Understanding/Agreement (MOU/MOA) on cooperation and data exchange, establishing detailed technical and functional specifications and collaboration protocols. ${ }^{96}$

The OECD BEPS package actions to increase tax transparency might be limited to corporate taxation. In other words, sharing OECD BEPS documentation, such as local files with the transactional detail and financial data and country-by-country reports, needs to be strategically managed to produce effects for customs valuation.

This section was aimed at presenting the challenges of corporate tax evasion by MNEs using transfer pricing. It also presented the OECD BEPS package which was an international response to engage and support tax administrations in addressing revenue risks. This section considered the availability of essential information resulting from the OECD BEPS package to examine the customs valuation of related parties' transactions and to perform services and adjustments to intangibles. Furthermore, it discussed the different administrative structures for customs and tax authorities when dealing with the challenges in relation to cooperation. It concluded by reflecting on the impact of the OECD BEPS package for customs valuation.

\subsection{UN - Addis Ababa Action Agenda (AAAA) and Tobacco}

In 2015, the UN held the Third International Conference on Financing for Development in Addis Ababa, Ethiopia. ${ }^{97}$ The final document of the Conference became known as the Addis Ababa Action Agenda (AAAA) and it recognizes the central role played by public policies and the mobilization of domestic resources for sustainable development, including achieving the Sustainable Development Goals (SDGs). ${ }^{98}$

\footnotetext{
${ }^{95}$ Many different institutional frameworks exist around the world, and no single model can be identified as superior. Sometimes customs are under the framework of the Ministry of Finance together with the revenue administrations. In other systems, customs might be within the framework of Ministry of Security or Defense. There are still cases where customs is within the framework of the Ministry of Industry.

96 WCO (2016), p.4

97 The final text of the UN Addis Ababa Conference was endorsed by the General Assembly in its resolution 69/313 of 27 July 2015.

98 The Sustainable Development Goals (SDGs), otherwise known as the Global Goals, are a universal call to action to end poverty, protect the planet and ensure that all people enjoy peace and prosperity.
} 
While all 17 SDGs are important, for the purposes of this dissertation, it is essential to highlight Goal 17 and its Article 17.1 urging states to strengthen tax and revenue collection:

\section{Sustainable Development Goals}

Goal 17. Strengthen the means of implementation and revitalize the Global Partnership for Sustainable Development ${ }^{99}$

17.1 Strengthen domestic resource mobilization, including through international support to developing countries, to improve domestic capacity for tax and other revenue collection ${ }^{100}$

SDG Goal 17 with Article 17.1 envisions that domestic capacity for tax and revenue is essential for development. In this regard, the AAAA reinforces the need for internal revenue resiliency.

The insufficiency of countries' resources to meet UN goals has long been recognized. For instance, the problem was identified as an obstacle when trying to achieve the Millennium Development Goals (MDGs) adopted during the UN Millennium Summit in September 2000. In a 2010 synthesis on the MDGs status, the UN Development Program (UNDP) reported inadequate revenue resources as follows:

Inadequate resources: Lack of finances has also hindered countries as they work toward meeting MDGs. Particularly in the wake of the global food and financial crises, many national budgets are straining to maintain the status quo and to avoid reversing progress already achieved toward reaching the Millennium targets. ${ }^{101}$

Considering that revenue resources continue to be a challenge in many countries, the AAAA commits to supporting revenue administrations in securing domestic tax resources:

22. (...). We commit to enhancing revenue administration through modernized, progressive tax systems, improved tax policy and more efficient tax collection. We will work to improve the fairness, transparency, efficiency and effectiveness of our tax systems, including by broadening the tax base and continuing efforts to integrate the informal sector into the formal economy in line with country circumstances. ${ }^{102}$

\footnotetext{
${ }^{99}$ UN Resolution A/RES/70/1 of 25 September 2015, p.14

100 UN (2015), September.

101 UNDP (2010)

102 UN (2015), par.22
} 
Thus, according to the AAAA, tax systems need to be modernized to improve tax collection. Fairness, transparency, efficiency, and effectiveness are recognized as necessary for UN countries to sustain their governments. The AAAA also highlights the need to reduce opportunities for tax avoidance:

23. (...). We will enhance disclosure practices and transparency in both source and destination countries, including by seeking to ensure transparency in all financial transactions between Governments and companies to relevant tax authorities. We will make sure that all companies, including multinationals, pay taxes to the Governments of countries where economic activity occurs and value is created, in accordance with national and international laws and policies. ${ }^{103}$

As expected, the AAAA aligns with the OECD BEPS package that also seeks transparency between tax jurisdictions to address the problem of tax avoidance. The AAAA agenda recognizes the need to increase tax cooperation and encourage countries to make the issue a priority.

For the purposes of this dissertation, it is relevant to highlight that the AAAA recognizes tobacco and tobacco prices as important in preventive policies and for tax purposes. As such, AAAA states:

We recognize, in particular, that, as part of a comprehensive strategy of prevention and control, price and tax measures on tobacco can be an effective and important means to reduce tobacco consumption and health-care costs, and represent a revenue stream for financing for development in many countries. ${ }^{104}$

Thus, tobacco prices and tariffs are linked to preventive health policies and also provide a revenue stream for funding development. Notice that the AAAA tobacco tax agenda aligns with Article 6 of the obligations of countries that are parties to the World Health Organization (WHO) Framework Convention on Tobacco Control (FCTC).

\section{Article 6}

Price and tax measures to reduce the demand for tobacco

1. The Parties recognize that price and tax measures are an effective and important means of reducing tobacco consumption by various segments of the population, in particular young persons. ${ }^{105}$

\footnotetext{
${ }^{103}$ Idem par. 23

${ }^{104}$ Idem par.32

${ }^{105}$ WHO Framework Convention on Tobacco Control. Available at: http://www.who.int/fctc/en. [accessed 10 January 2020]
} 
Regarding tariffs on tobacco goods, a World Health Organization report stated the following about AV taxes for tobacco:

Parties should implement the simplest and most efficient system that meets their public health and fiscal needs, taking into account their national circumstances. Parties should consider implementing specific or mixed excise systems with a minimum specific tax floor, as these systems have considerable advantages over purely ad valorem systems. ${ }^{106}$

Some of the reasons against AV taxes for tobacco are: a) the difficulty of implementation; b) the weak impact of tax policy, because companies can manufacture low price brands; and c) uncertainty regarding the revenue stream.

Switzerland provides a concrete example of avoiding AV customs duties and customs valuation rules for tobacco products. The Switzerland and Liechtenstein 2017 Trade Policy Review (TPR) explain tobacco tariffs as follows:

\subsection{The tobacco tax is levied on imported and domestically produced cigarettes, cigars, and other tobacco products. The tax may be a compound rate or ad valorem. For cigarettes, the compound rate amounts to SwF 118.32 per 1,000 cigarettes plus $25 \%$ ad valorem of the retail selling price. In addition, each cigarette sold is subject to a tax of $S w F 0.0013$ for the domestic tobacco financing fund (SOTA) and SwF 0.0013 for the Tobacco Control Fund. ${ }^{107}$}

For the purposes of this dissertation, the WHO conclusions on avoiding AV taxes for tobacco are worth publicizing and further discussions about their extension to other types of commodities are merited. Thus, it is argued in this dissertation that, depending on countries and types of commodities, AV tariffs should not be implemented. Instead of AV tariffs, NAV tariffs might have considerable advantages over purely ad valorem systems. ${ }^{108}$ The dissertation also argues that neo-tariff constructions could also be used.

Alcoholic beverages, commodities and public goods in general that are imported in great amounts that the country cannot produce itself call for NAV tariffs. These NAV tariffs however must also take the eventuality of smuggling into account, when rates are high. Rates should be sufficiently low to encourage the legal importation of goods.

This section addressed the AAAA Goal 17 and Article 17.1 to strengthen tax and revenue collection to achieve the SDGs. It discussed the alignment of the AAAA tax agenda with the OECD BEPS package and addressed the price and tax measures on

\footnotetext{
106 WHO Report on the Global Tobacco Epidemic (2015), p.23

${ }^{107}$ WTO (2017), WT/TPR/S/355, p. 64

${ }^{108}$ WHO Report on the Global Tobacco Epidemic (2015), p.23
} 
tobacco. This section presented the World Bank findings against AV tariffs and in favour of NAV tariffs for tobacco. Finally, the section briefly considered using NAV tariffs for alcoholic beverages and commodities imported in large amounts.

\subsection{Concluding Remarks}

A central point in this chapter was the link between GVCs and revenue. In that sense, the use of GVCs outsourcing the production of goods, making use of high-value intangibles and worldwide services impacted the ability of countries' tax systems to further tax corporate profits to replace the trade revenue from tariffs. In addition to corporate profit shifting, countries also face challenges in the area of GVCs statistics double-counting, accurate price data, volatility of ERs and commodity price cycles.

The chapter explained that the domestic capacity to compensate losses from tariff reductions by, for example, an increase in VAT is also no longer functional.

The chapter addressed the deficiencies of tax administrations, such as inaccurate and unreliable taxpayer registration databases, weak compliance risk management, weak data analysis and poor audit capacity. These deficiencies reinforce the conclusion that countries lack the capacity to compensate for trade tariff resources with domestic revenue.

The lack of proper revenue resources jeopardizes long-term planning for international trade growth, which is expected to bring economic development.

Commodity price fluctuations, also referred to as price volatility, was a main topic of the chapter, as it directly affects the revenue that is collected using AV tariffs. On this matter, the chapter recalled the work done by the UNCTAD in the 1960s and 1970s to deal with commodity prices and foreign exchange. The attempts to control prices did not work.

In this regard, the chapter argued that the combination of AV tariffs with WTO customs valuation rules exposes countries to unnecessary trade revenue risks. High or low AV tariffs are precarious in a scenario where traded goods are volatile or where the value is disappearing with the use of intangibles and services. The chapter submitted that the WTO rules for tariffs and customs valuation did not envisage such a scenario. As such, taking that revenue is at risk, trade liberalization is consequently at a crossroads.

The chapter reviewed some initiatives from international organizations, such as the WCO revenue package and the OECD BEPS package. The WCO revenue package resulted mainly in customs valuation, origin and harmonized system materials 
intended to serve as a "...the pathway towards fair and efficient revenue collection." 109 The OECD BEPS package provides guidelines to address MNEs transfer pricing strategies that contribute to avoid taxes by shifting profits from high to low tax jurisdictions.

The chapter mentioned that international organizations are active in producing new packages and proposing "innovative" taxation, but they are reluctant to revisit past recommendations and admit backward steps. None of these initiatives, or others, address the problem of AV tariffs and WTO customs valuation rules.

To highlight the concern regarding domestic revenue mobilization, the chapter discussed the UN AAAA, which addresses the importance of preventing tax avoidance to secure resources for achieving the SDGs. Proposals, such as the use of price/tax measures for tobacco, including the unsuitability of AV tariffs as identified by the World Bank, were presented. NAV tariffs were also considered for alcoholic beverages and commodities imported in large amounts.

This introductory chapter provided the background upon which the following chapters will be developed to answer the research questions.

${ }^{109}$ WCO. Revenue Package Phase II folder. Available at: http://www.wcoesarocb.org/wpcontent/uploads/2017/03/BROCHURE_EN-WEB.pdf. 


\section{Import Tariffs}

This chapter deals with the main aspects of import tariffs. It presents a concise overview of the preference in GATT/WTO law for tariffs over non-tariff trade barriers and discusses the legitimacy and importance of tariffs in generating revenue.

Further, it presents the different types of tariffs, including AV tariffs, specific, compounded, mixed, technical tariffs, and tariffs based on quotas. It considers the pros and cons for each of the tariff types and introduces the idea of neo-tariffs.

The chapter presents arguments in favour and against tariff simplification in favour of the AV type. It highlights the points against the choice for simplification and presents the tariff outcomes of several GATT multilateral negotiation rounds.

Subsequently, the chapter presents the conversion processes from NAV to AV tariffs. It argues that GATT contracting parties overlooked the importance of trade revenue when using tariff conversion formulae and that the lack of capacity for domestic mobilization debilitated countries' fiscal structures. ${ }^{110}$

Finally, the chapter introduces national tariff lists and GATT/WTO schedules as tools that provide transparency, security and predictability in trade. It discusses the origin and importance of tariff lists and the relevant information contained in these documents. It argues that the importance of national tariff schedules and the WTO schedules of concessions is directly related to the variety of trade exceptions and a wide range of tariff rates.

\subsection{Tariff and Non-Tariff Barriers}

Trade barriers are divided into two groups: (1) tariff barriers; and (2) non-tariff barriers. For the purposes of this dissertation, the differentiation matters, because the investigation is restricted to tariff barriers.

A tariff barrier is, very simply, a tax imposed on goods traded between different jurisdictions. The tariff is typically collected when the traded goods enter or depart a country territory. From an economic standpoint, a tariff represents a barrier, as it

\footnotetext{
${ }^{110}$ As the GATT 1947 was intended to be a treaty on the reduction of tariffs and other trade barriers, not a treaty establishing an international organization, multilateral decisions were taken by the Contracting Parties, acting jointly, rather than by any organ or body. The designation 'Contracting Parties' is therefore, according to Article XXV of the GATT, a reference to the Contracting Parties acting jointly, and, in other words, the collective decision-making forum under the GATT 1947. Later, a large number of subordinate bodies, such as committees, working parties and panels, were established to carry out the tasks under the GATT, and the meetings of the Contracting Parties were reduced to yearly sessions of a few days each. John H. Jackson. (1997), pages 38 and 63.
} 
increases the domestic price of the imported good. The WTO explains that a tariff produces a negative welfare effect:

The imposition of import tariffs increases the domestic price of the imported good. This usually brings gains for domestic producers of the good as well as the government, but also losses for consumers (who will buy less of the product since the price is higher) and for other domestic producers who use that good as an input. In economic theory, this is called the welfare effect of a tariff. ${ }^{111}$

According to the WTO: "the net welfare effect of the tariff is negative for the importing country because the losses incurred by consumers cannot be fully offset by the gains of the domestic producers and the government."112

The economic effects of a tariff are undeniable, and, from a tariff revenue perspective, one must be in favour of tariff elimination as long as the gains of consumers and producers are taxed domestically.

However, if developing countries fail to develop their exports, domestic taxation fails to capture a share of the gains from consumers or producers, and if over the years MNE companies transfer profits to low tax jurisdictions, is the theory still valid? Flat exports, fewer import tariffs, more imports, less taxable profits, and less revenue mobilization to keep public services all point to a negative vicious circle.

The other types of trade barriers are non-tariff barriers, which include quotas, lack of transparency, red tape, burdensome procedures, technical barriers, and sanitary and phytosanitary measures, among others. For instance, quantitative restrictions (QRs) are non-tariff barriers that impose limits to trade in goods over a certain period.

A QR is one of the best-known NTBs. Quantitative restrictions impose specific limits on the quantity or value of goods that can be imported (or exported) during a given period. Whereas tariffs are allowed as long as they do not exceed the scheduled bound levels and are applied on an MFN basis, Members are in general prohibited to apply QRs. ${ }^{113}$

Several WTO provisions are intended to address non-tariff barriers. The Agreement on the Application of Sanitary and Phytosanitary Measures (SPS), which restricts the use of SPS measures for trade protection, and the Agreement on Technical Barriers to Trade (TBT) which recognizes the rights to adopt technical regulations and standards,

\footnotetext{
${ }^{111}$ WTO E-learning 12. Introduction to Market Access in Trade in Goods in the WTO, p.10. Available at: https://ecampus.wto.org/admin/files/Course_385/Module_1578/ModuleDocuments/MA-L1-R1E.pdf. [accessed 17 August 2018]

${ }_{112}$ Idem

${ }^{113}$ Idem, p. 4.
} 
as long as these do not constitute unnecessary barriers to trade, provide important provisions.

As for tariffs and non-tariff barriers, WTO law clearly prefers tariffs over non-tariff barriers. The main reason is that tariffs are more transparent and predictable, while the non-tariff barriers can be disguised in many ways and difficult to evaluate. Another reason for the preference is that tariffs are relative barriers to trade, whereas quotas and many other types of NTBs are absolute barriers to trade. In addition, tariffs offer flexibility in negotiations, while NTBs are more rigid.

Love and Lattimore sum up the discussion on the preference of tariff barriers over non-tariff barriers considering the transparency aspect.

The reasons for imposing barriers to trade can be economic, environmental, social, political, or a combination of these. ( '.). Tariffs, even complex schemes, are relatively visible; many non-tariff barriers are much more complex, seldom very transparent, and their impact unclear. ${ }^{114}$

In conclusion, tariffs, even complex ones, are more transparent than non-tariff trade barriers. $^{115}$

Furthermore, regular tariffs, other duties and charges may be levied at the border, such as border tax adjustments, e.g. VAT, anti-dumping or countervailing duties. ${ }^{116}$ The WTO Secretariat excludes these charges from the concept of tariffs:

It is important to note the difference between tariffs and other charges that may be levied at the border on imports:

- A tariff is not an "internal tax" (e.g. value added tax). The latter is mainly regulated by Article III:2 of the GATT 1994 on National Treatment;

\footnotetext{
${ }^{114}$ Love and Lattimore (2009), p.73

115 An example of a complex tariff is the EU technical duty rate for cocoa with sugar (chocolate) (HS 18069050 - Sugar confectionery and substitutes therefor made from sugar substitution products, containing cocoa) applied on third country origin goods. The import duty is calculated with the formula: 8,3\% + EA MAX 18.7 + ADSZ which should be "translated" as $8.3 \%$ import tariff + agricultural component (EA), limited to a maximum of $18.7 \%$ + additional duty on sugar contents (ADSZ). To calculate the complete rate of duty, it is necessary to determine the amount of agricultural component (EA) and additional duty on sugar contents (ADSZ). This means that, to calculate the complete rate of the duty, one must know the composition of the product in milk fat, milk proteins starch/glucose sucrose/invert sugar/isoglucose.

${ }^{116}$ Many WTO Members utilize a border adjustable VAT on imported goods. GATT Article II:2(a) allows a government to impose at the time a product crosses its border "a charge equivalent to an internal tax imposed... on a like domestic product," as long as the internal charge is imposed consistently with the "national treatment" principle of GATT Article III.
} 
- a tariff is not a "fee" or "charge" associated with an import service. The latter are mainly regulated by Article VIII of the GATT 1994 on Fees and Formalities connected with Importation and Exportation;

- a tariff is not an "other duty and charge" in the sense of the second sentence of Article II(1)(b) of the GATT 1994, which includes those taxes levied on imports in addition to the customs duties; and,

- a tariff is not an "antidumping" or "countervailing duty"117

The WTO Secretariat explains each of these categories of other charges that may be levied at the border.

Other duties or charges (ODCs) include all taxes levied on imports in addition to the customs duties (sometimes called "para-tariffs") and can only be charged if they were recorded in the Member's WTO Schedule of concessions.

"Fees" or "charges" connected with importation or exportation include all fees and charges of whatever character imposed by the Members on or in connection with importation or exportation. These include licence fees, inspection fees, etc.

Internal taxes (e.g. value-added tax or sales tax) shall be applied to imported products and domestic like products in a non-discriminatory manner.

Anti-dumping or countervailing duties are normally applied in the form of additional customs duties, which may exceed the bound tariff rate (the maximum level of customs duty to be levied on products imported into a Member). ${ }^{118}$

On the matter of trade taxation, the WTO Panel in US - FSC (Article 21.5 - EC) clarified that the "national treatment" principle of GATT Article III also applies to "direct taxes" like corporate income taxes.

8.144 (...). On the basis of the text and context of Article III:4 in light of the object and purpose of the GATT and the WTO Agreement, we therefore consider that Article III:4 of the GATT 1994 applies to measures conditioning access to income tax advantages in respect of certain products. ${ }^{119}$

\footnotetext{
117 WTO E-learning 12. Introduction to Market Access in Trade in Goods in the WTO, p.9-10. Available at: https://ecampus.wto.org/admin/files/Course_385/Module_1578/ModuleDocuments/MAL1-R1-E.pdf. [accessed 17 August 2018]

${ }_{118}$ WTO E-learning (n.a.). Detailed Presentation of Tariffs and Tariff Negotiations. p. 5. Available at: https://ecampus.wto.org/admin/files/Course 385/Module 1579/ModuleDocuments/MA Tariff-L2-R1E.pdf. [accessed 17 August 2018]

${ }^{119}$ WTO Panel Report, US - FSC (Article 21.5 - EC), WT/DS108/RW, para 8.144.
} 
Although this dissertation is restricted to the examination of the role played by regular tariffs, it acknowledges that other charges levied at the border, such as those mentioned earlier, also play a role in generating revenue for government institutions.

In conclusion, there are tariff barriers and non-tariff barriers, and the WTO prefers tariff barriers over non-tariff barriers. Regular tariffs exclude other charges that may be levied at the border. In this sense, the scope of this dissertation is limited to regular tariffs in international trade. Taking this into account, the mentioning of tariffs should be understood as limited to regular tariffs only.

\subsection{Focus on Ordinary Customs Duties, Regular Tariffs}

This section deals with the use of tariffs. It presents the tariff functions of revenue and protection as being dynamic rather than static and the need to have broader considerations of concrete examples. Finally, this section points out the lack of fiscal considerations in WTO discussions.

Tariffs are legitimate instruments to generate fiscal revenue. The role of tariffs to generate fiscal revenue was made clear when the GATT 1947 was reviewed in 19541955 to allow for additional flexibility in the GATT disciplines for developing countries. An important revision was on Article XXVIII bis, Paragraph 3(b) stating the importance of tariffs for revenue purposes: ${ }^{120}$

GATT 1947 - Review 1954-1955

Article XXVIII bis: Tariff Negotiations

$(\cdots)$

3. Negotiations shall be conducted on a basis which affords adequate opportunity to take into account:

(b) the needs of less-developed countries for a more flexible use of tariff protection to assist their economic development and the special needs of these countries to maintain tariffs for revenue purposes; and

Sawyer and Sprinkle explain the rationale of revenue tariffs:

\footnotetext{
120 The GATT 1947 was reviewed in 1954-1955 and on the insistence of developing country Contracting Parties, this Review Session recognized for the first time the need for additional flexibility in GATT disciplines for developing countries, thus introducing the concept of differential treatment of developing countries in the GATT. This 'differential treatment' took the form of exempting developing countries from certain GATT disciplines. Prévost, Denise (2009), p. 34.
} 
Some tariffs imposed by governments are designed as revenue tariffs. A revenue tariff is an import tariff levied on a good that is not domestically produced. ${ }^{121}$

However, according to Haberler, the distinction between revenue raising and protective tariffs is not clear. Revenue and protective tariff functions can intertwine and be difficult to distinguish. ${ }^{122}$

\begin{abstract}
But this distinction is by no means clear cut. ( '.) The majority of protective duties bring in something to the national Exchequer and on that account are welcomed by the Treasury, while many revenue duties indirectly provide some protection for certain home-produced products. For example, if a country which itself produces no wines raises its duty upon imported wine, part of the various demand for wine will be diverted towards beer.
\end{abstract}

The tariff that has a protective function can also serve to generate revenue. Both tariff functions are connected, making it difficult to draw a line to distinguish between them. In addition, it is also possible to observe tariff functions change from protective to revenue, and conversely, depending on the time, country, and type of good. Thus, tariffs have a dynamic function and not a static function, and, consequently, it is wrong to assume that tariffs always serve as trade barriers.

However, when discussing international trade liberalization, there is less focus on the tariff revenue purpose. Trade liberalization negotiators are more inclined to monitor the use of tariffs as trade barriers.

It is a fact that several countries are in debt and, more recently, in a dispute about additional import duties, the WTO Appellate Body reinforced the legitimacy of tariffs to generate fiscal revenue.

Tariffs are legitimate instruments to accomplish certain trade policy or other objectives such as to generate fiscal revenue. Indeed, under the GATT 1994, they are the preferred trade policy instrument, whereas quantitative restrictions are in principle prohibited. Irrespective of the underlying objective, tariffs are permissible. ${ }^{123}$

In 2005, the International Monetary Fund (IMF) and the International Development Association (IDA) introduced the Debt Sustainability Framework (DSF), which is a tool to conduct public and external debt sustainability analyses in low-income countries.

\footnotetext{
${ }^{121}$ Sawyer and Sprinkle. Op. cit., p.165

122 Haberler (1936), p. 238

123 WTO, Appellate Body, India - Additional Import Duties (2008), paragraph 159.
} 
The primary aim of the DSF is to guide borrowing decisions of low-income countries in a way that matches their need for funds with their current and prospective ability to service debt, tailored to their specific circumstances. ${ }^{124}$

It is argued in this dissertation that the GATT/WTO push for the conversion of tariffs from NAV to AV types and their reduction or elimination, which damaged the fiscal revenue of various countries. As such, trade liberalization based on AV tariff rates negotiations makes countries blind to several tariffs issues, such as: a) the appropriate tariffs for different classes of goods; $b$ ) the process and results of shifting the revenue lost to other border taxes or direct taxes; c) the adequate level of tariffs per country; and d) the possibility of developing neo-tariffs in international trade. In other words, tariffs still need to be properly addressed by countries, WTO Members and scholars. ${ }^{125}$

Sawyer and Sprinkle explain why tariffs are a suitable instrument of taxation for developing countries:

For a developing country, tariffs can be an attractive form of taxation for several reasons. First, imports legally must pass through customs. In effect, this is a choke point where the government can easily collect revenue. The goods cannot pass into the country until the tariff is paid. The administrative costs of such a tax are also small relative to income or sales taxes. Second, in a developing country GDP per capita frequently is low. (...) $)^{126}$

In conclusion, the ease of collecting tariffs, the low cost of a taxation system based on tariffs, and the challenge of targeting the people who can pay taxes in LDCs and developing countries, are some of the factors that contribute to using trade tariffs as an important revenue source.

\subsection{GATT Tariff Negotiations}

The GATT tariff negotiations mandate is set out in Article XXVIII bis of the GATT. ${ }^{127}$ Article XXVIII addresses important aspects of the tariff negotiations

\footnotetext{
${ }^{124}$ IMF, The Debt Sustainability Framework for Low-Income Countries. Available at: https://www.imf.org/external/pubs/ft/dsa/lic.htm. [accessed 17 August 2018]

${ }^{125}$ For LDCs and developing countries, the perspective of converting from non-ad valorem to ad valorem types, reducing tariffs, or replacing them for GST or VAT should be examined carefully and linked to the trade liberalization agenda. This dissertation assumes that GST or VAT are AV valueadded taxes with similar problems to AV tariffs. In addition, many countries have deficient administrative structures to administer GST or VAT systems internally.

${ }^{126}$ Sawyer and Sprinkle. Op. cit. p. 165

${ }^{127}$ The insertion of Article XXVIII bis was affected by the 1955 Protocol Amending the Preamble and Parts II and III, which entered into force on 7 October 1957. This Article would have become Article XXIX if the 1955 Protocol Amending Part I and Articles XXIX and XXX had entered into force.
} 
including: (a) the importance of tariff negotiations; (b) the mandate; (c) the principle of tariff negotiations; (d) the use of tariff negotiating techniques; and (e) the objective of tariff negotiations among other aspects. ${ }^{128}$

Article XXVIIIbis: Tariff Negotiations

1. The Contracting Parties recognize that customs duties often constitute serious obstacles to trade; thus negotiations on a reciprocal and mutually advantageous basis, directed to the substantial reduction of the general level of tariffs and other charges on imports and exports and in particular to the reduction of such high tariffs as discourage the importation even of minimum quantities, and conducted with due regard to the objectives of this Agreement and the varying needs of individual contracting parties, are of great importance to the expansion of international trade. (...)

For this study, a relevant point about Article XXVIII bis is the concern expressed in Paragraph 3 on the need to take the Contracting Parties fiscal circumstances into account.

Article XXVIIIbis: Tariff Negotiations

(...)

3. Negotiations shall be conducted on a basis which affords adequate opportunity to take into account:

(a) the needs of individual Contracting Parties and individual industries;

(b) the needs of less-developed countries for a more flexible use of tariff protection to assist their economic development and the special needs of these countries to maintain tariffs for revenue purposes; and

(c) all other relevant circumstances, including the fiscal, * developmental, strategic and other needs of the Contracting Parties concerned.

(*) See Ad note to Article XXVIIIbis Paragraph 3

The Ad note to Article XXVIII bis Paragraph 3 stresses the revenue aspect of tariffs.

Interpretative Note Ad Article XXVIII bis from Annex I, Paragraph 3

${ }^{128}$ GATT 1994 was GATT 1947. 
It is understood that the reference to fiscal needs would include the revenue aspect of duties and particularly duties imposed primarily for revenue purposes, or duties imposed on products which can be substituted for products subject to revenue duties to prevent the avoidance of such duties.

From 1947 to 1994, the GATT tariff negotiations were conducted in eight multilateral trade negotiation rounds. The negotiating rounds, the tariff reduction modality, the outcome, and the number of countries are in the table below.

Table 1 - GATT from 1947 to 1994 - Tariff Negotiations

\begin{tabular}{|c|c|c|c|}
\hline Negotiating Rounds & $\begin{array}{c}\text { Modality used to reduce } \\
\text { tariffs }\end{array}$ & Outcome & $\begin{array}{c}\text { Number of } \\
\text { Countries }\end{array}$ \\
\hline Geneva Round 1947 & $\begin{array}{c}\text { Product-by-product } \\
\text { negotiations; }\end{array}$ & 15,000 tariff concessions & 23 \\
\hline Annecy Round 1949 & $\begin{array}{c}\text { Product-by-product } \\
\text { negotiations; }\end{array}$ & 5,000 tariff concessions & 13 \\
\hline $\begin{array}{l}\text { Torquay Round 1950- } \\
1951\end{array}$ & $\begin{array}{l}\text { Product-by-product } \\
\text { negotiations; }\end{array}$ & 8,700 tariff concessions & 38 \\
\hline Geneva Round 1956 & $\begin{array}{c}\text { Product-by-product } \\
\text { negotiations; }\end{array}$ & Modest reductions & 26 \\
\hline Dillon Round 1960-1961 & $\begin{array}{l}\text { Product-by-product } \\
\text { negotiations; }\end{array}$ & $\begin{array}{l}\text { 4,400 concessions } \\
\text { exchanged }\end{array}$ & 26 \\
\hline $\begin{array}{l}\text { Geneva - Kennedy } \\
\text { Round 1963-1967 }\end{array}$ & $\begin{array}{l}\text { Tariffs: formula approach } \\
\text { (linear cut formula) with } \\
\text { exceptions; Product-by- } \\
\text { product negotiations; }\end{array}$ & $\begin{array}{c}\text { Average tariffs reduced } \\
\text { by } 35 \% \text {; some } 33,000 \\
\text { tariff lines bound }\end{array}$ & 62 \\
\hline $\begin{array}{c}\text { Geneva - Tokyo Round } \\
1973-1979\end{array}$ & $\begin{array}{l}\text { Tariffs: formula approach } \\
\text { ("Swiss Formula") with } \\
\text { exceptions; Product-by- } \\
\text { product negotiations; }\end{array}$ & $\begin{array}{l}\text { Average tariffs reduced } \\
\text { by one-third to } 6 \% \text { for } \\
\text { OECD manufactured } \\
\text { imports }\end{array}$ & 102 \\
\hline $\begin{array}{l}\text { Uruguay Round 1986- } \\
\qquad 1994\end{array}$ & $\begin{array}{c}\text { Tariffs: formula approach } \\
\text { (simple average reduction } \\
\text { + sectoral approach); } \\
\text { Product-by-product } \\
\text { negotiations; }\end{array}$ & $\begin{array}{l}\text { Average tariffs again } \\
\text { reduced by one-third on } \\
\text { average }\end{array}$ & 123 \\
\hline
\end{tabular}

Source: WTO E-Learning, N.A., p. 24 (Based on World Trade Report 2007, page 198)

The GATT rounds of Geneva 1947, Annecy 1949, Torquay 1950-1951, Geneva 1956 and Dillon 1960-61 were exclusively intended for tariff reduction negotiations. Only from the Kennedy round 1964-67, the GATT started to enlarge the trade topic discussions to include matters such as anti-dumping and development. Later, the 
Tokyo Round 1973-79 represented the first round to agree on issues other than tariffs. $^{129}$

Tariffs were negotiated in all GATT rounds, and the level of reduction is generally accepted as a metric to measure the round performance. Writing about the GATT negotiations, Peter Van den Bossche stresses the success of tariff reductions.

Under the GATT 1947, negotiations on the reduction of customs duties, commonly and in short referred to as tariff negotiations, took place primarily in the context of eight successive 'Rounds`of trade negotiations. ${ }^{130}$

A relevant aspect of GATT tariff negotiations for this study is the modality referred to as the negotiation "technique" used for tariff reduction. There are different modalities and each leads to different negotiation outcomes. The choice of modality is influenced by economic, political and practical considerations, among others. Stressing the importance of the choice of modality, Low and Santana explain:

One of the first and most important issues that has to be agreed in a multilateral tariff negotiation is the methodology or "modality" that will be used to negotiate. And since tariff negotiations inevitably involve sectors which are sensitive for some of the participants, but are of export interest to others, the modalities have to balance competing interests. ${ }^{131}$

The common modalities used are a) product-by-product, b) formula and c) sectoral.

a) The product-by-product modality, also known as request-offer, is the oldest negotiating modality, which implies that the submission of the request list (products of interest to one party) is followed by the offer list (description of items on which another member offers concessions).

This modality was the basis for the negotiations in Annecy 1949, Torquay 19501951, Geneva 1956 and Dillon 1960-61. The rules for the Dillon round were as follows:

For example, the request-offer process in the Dillon Round of 1960-1961 proceeded as follows: in the first stage delegations presented request lists to the countries with which they wished to negotiate, and in the second stage delegations submitted consolidated offer lists. In the next stage

\footnotetext{
129 The WTO derestricted an important number of documents relating to earlier GATT Rounds of negotiations. The documents are accessible at: https://www.wto.org/english/docs_e/gattbilaterals_e/indexbyround_e.htm [Accessed on 18 August 2018]

${ }^{130}$ Van den Bossche, Peter and Zdouc, Werner (2013), p. 427

${ }^{131}$ Low and Santana, (2008) p.7-8
} 
countries gradually defined their positions in a series of bilateral meetings and finally struck a bilateral balance with each of their negotiating partners. "'132

Currently, the product-by-product modality is mostly used in the process of the accession of new WTO members.

This negotiating methodology requires that participants request tariff concessions in products where they are likely to be the "principal supplier" to the country from which the concession is being requested. The process is mostly bilateral in nature. ${ }^{133}$

b) The formula modality is based on tariff reductions compounded mathematically, in contrast to an individually negotiated manner. It has been debated since the early years of the GATT, and the formula modality gained force during the Dillon Round.

The Ministers agreed that the reduction of tariff barriers on a mostfavoured-nation basis in accordance with the terms of the General Agreement should be continued. They recognized, however, that while the traditional GATT techniques for tariff negotiations on a commodityby-commodity and country-by-country basis had produced substantial results, both in the past and during the present tariff conference, they were no longer adequate to meet the changing conditions of world trade. ${ }^{134}$

The formula modality allows for simplified negotiations among numerous participants.

A large number of mathematical expressions exist that could be used to negotiate tariff reductions and the advantages and limitations of the approach are intrinsically linked to the type of formula used. ${ }^{135}$

Although it was generally accepted in the Tokyo and Uruguay GATT Rounds, for the purposes of this study, the formula approach presents the most serious risk for the fiscal needs of individual countries, as it may not give proper weight to the revenue aspect of tariffs.

\footnotetext{
${ }^{132}$ MTN/W/8, Note on "Rules and Procedures for the Dillon and Kennedy Rounds", p. 3-5, citing Dillon Round rules at $8 \mathrm{~S} / 118$, para. VII(e).

${ }^{133}$ Low and Santana, (2008) p. 8

${ }^{134}$ WTO (2012). Analytical Index of the GATT. Article XXVIII bis Tariff Negotiations. P. 922. Reference to $10 \mathrm{~S} / 25,26$. Available at: https://www.wto.org/english/res_e/publications_e/ai17_e/gatt1994_art28 bis_gatt47.pdf. [accessed 22 June 2019]

${ }^{135}$ Low and Santana, (2008) p. 9
} 
c) The sectoral modality is intended for participants to decrease or eliminate tariffs on some items within a sector. This technique comprises the harmonization of sectors where members agree to diminish their bound tariffs to a standard level in each sector to provide similar market access parameters.

Low and Santana teach the following about the history of the sectoral modality:

This methodology has been used mostly in the context of plurilateral negotiations (i.e. where only a sub-set of WTO Members participate), with the results extending to all WTO Members through their inclusion in the Schedules of concessions. ${ }^{136}$

Regardless of the modality, product-by-product, formula or sectoral, the simplification from NAV into AV tariffs is seen as preparatory work for a successful tariff negotiation.

The critique in this study is related to the lack of attention of GATT Contracting Parties in relation to both the modality of negotiation and the AV simplification conversion with respect to revenue. The initial fiscal and revenue concerns of Article XXVIIIbis, Paragraph 3 disappeared with the advance of GATT Rounds. As a result, once the negotiations were completed, tariff revenue was foregone for LDCs and developing countries.

In summary, this dissertation argues that the eight GATT rounds may have overlooked the capacity of LDCs and developing member countries to compensate for revenue losses. The tariff revenue problem, particularly for developing countries, was detected by other scholars, such as Prévost.

As tariffs form a significant source of revenue for many developing countries, this has meant a reduction in the resources available for their development needs. ${ }^{137}$

The situation has not changed with the advent of the WTO. The WTO Marrakesh Agreement recognizes the benefits of tariff reduction with a view to raising global standards of living and ensuring full employment.

Marrakesh Agreement Establishing the World Trade Organization

The Parties to this Agreement,

$$
(\cdots)
$$

\footnotetext{
${ }^{136}$ Idem. p. 9

${ }^{137}$ Prévost, Denise (2009), p. 52
} 
Being desirous of contributing to these objectives by entering into reciprocal and mutually advantageous arrangements directed to the substantial reduction of tariffs and other barriers to trade and to the elimination of discriminatory treatment in international trade relations, ${ }^{138}$

From the WTO angle, tariff negotiations are still on the radar to boost trade. However, it is argued here that tariff revenue is important for LDCs and developing countries. Thus, the WTO Members' general assumption about the need to reduce tariffs can have adverse consequences for many LDCs and developing countries.

Using tariff reductions as the target to measure the success of multilateral negotiations creates difficulties for LDC and developing countries to evaluate whether the revenue tariff function can be effectively shifted to domestic taxes such as GST, VAT or other forms of taxation.

That said, this dissertation argues that WTO Members should be cautious about revenue tariffs, needing to evaluate whether tariff negotiations contribute to fostering trade and/or dismantling fiscal revenue. One of the main points here is that revenue tariffs are essential for the sustainability of LDCs and developing countries with large informal sectors and poor administrative tax structures.

LDCs and developing countries should be careful about reducing their revenue tariffs, knowing that countries with a far better fiscal infrastructure face an array of challenges when shifting to GST, VAT and other types of domestic taxes. ${ }^{139}$

With these considerations in mind, this dissertation argues that it was a mistake to implement GATT tariff reductions considering the fiscal and revenue concerns of LDCs and developing countries. Simply put, many LDCs and developing countries could not, during the GATT times, and cannot, during the WTO, afford tariff reductions or tariff simplifications without putting their revenue equilibrium at risk.

From the perspective of GATT Article XXVIIIbis, Paragraph 3, the dissertation questions the success of the eight GATT Rounds of negotiations. It questions whether tariff reduction is the right yardstick for measuring trade success. Consequently, lower tariffs have supported international trade growth, but this is only sustainable if countries can mobilize tax domestic resources to replace tariff revenue loss.

\footnotetext{
${ }^{138}$ World Trade Organization (WTO). (1999). The Legal Texts: The Results of the Uruguay Round of Multilateral Trade Negotiations. Cambridge University Press.

${ }^{139}$ I refer here to challenges such as the Missing Trader Fraud (MTF) and the related carousel fraud that results in the theft of the VAT within multiple domestic jurisdictions and the MNEs transfer pricing strategies to shift profit to low tax jurisdictions.
} 
In the next sections, when explaining about tariff types, the dissertation discusses the tariff policy of AV simplification as detrimental to the multilateral trade system. It argues that the improper use of WTO customs valuation rules for all sorts of goods is diminishing the capacity of tariffs to generate revenue for numerous WTO Members.

\subsection{Tariff Types}

This section presents the international trade tariff types which are classified into five categories: a) AV; b) specific; c) compound; d) mixed; e) technical; and f) based on quotas. The following paragraphs explain each of these types.

\section{a) Ad Valorem Tariffs}

Ad valorem tariffs are imposed based on the monetary value of the good to be taxed. Ad valorem means "according to value" and it means that the tariff is calculated as a percentage of the monetary value of the product (e.g. $5 \%, 10 \%$, or $15 \%){ }^{140}$

Nowadays, most goods are subject to AV tariffs. The overall preference for these tariffs emerged as the world became more industrialized. According to Carbaugh, AV tariffs are more satisfactory for manufactured goods.

\section{Ad valorem tariffs usually lend themselves more satisfactorily to manufactured goods, because they can be applied to products with a wide range of grade variations. ${ }^{141}$}

Ad valorem tariffs are calculated according to the price of goods. However, if the price is fixed, the AV tariff becomes a specific type of tariff. In other words, an AV rate applied to a fixed value results in a specific duty. For instance, a 5\% AV rate applied to a fixed price of 100 units of currency per kilo, always results in five units of currency per kilo. In the past, some governments used minimum prices that were applied as fixed prices to calculate AV tariffs.

Economists defend that, when using AV tariffs, the level of protection remains constant. Price increases or decreases do not affect the tariff protection capacity. Such an assumption is based on an open market situation.

However, when market prices are controlled, AV tariffs function as specific tariffs and the level of protection depends on the government policy in relation to the controlled

\footnotetext{
${ }^{140}$ Ad valorem tariffs date back to the Romans and history suggests that, at that time, assessments regarding the value of the goods tended to be unpredictable and arbitrary.

${ }^{141}$ Carbaugh (2008), p.111
} 
price. Also, if export prices are artificial, the AV level of protection in the import country is false.

For this dissertation, it is important to observe that the main challenge for AV tariffs is the customs value, as AV tariffs imply the application of the WTO customs valuation rules. As such, it is reasonable to state that several countries lack the administrative and fiscal capacity to handle AV tariffs in international trade. Therefore, countries wishing to escape the WTO customs valuation rules should opt to use other types of tariffs.

\section{b) Specific Tariffs}

Specific tariffs are those calculated based on a unit of measurement such as weight, volume, surface, or another quantifiable measure for goods. The specific tariff stipulates how many units of currency are to be levied per measurable unit (e.g. of quantifiers: litres, gallons, $\mathrm{Kg}$, tons., $\mathrm{m}^{3}$ ). For instance, Australia applies a specific tariff of $\$ 1.22 / \mathrm{kg}$ on particular types of cheeses.

Table 2 - Tariff Schedule of Australia ${ }^{142}$

\begin{tabular}{|l|l|l|l|l|}
\hline $\begin{array}{l}\text { Product } \\
\text { Grouping }\end{array}$ & $\begin{array}{l}\text { Tariff } \\
\text { Reference }\end{array}$ & Description & $\begin{array}{l}\text { Base } \\
\text { Rate }\end{array}$ & $\begin{array}{l}\text { Specific } \\
\text { Duty }\end{array}$ \\
\hline AG & 0406 & CHEESE AND CURD: & & \\
\hline & 0406.10 .00 & $\begin{array}{l}\text {-Fresh (unripened or uncured) cheese, } \\
\text { including whey } \\
\text { cheese, and curd }\end{array}$ & $\$ 1.220 / \mathrm{Kg}$ \\
\hline
\end{tabular}

Sometimes, the quantifiable unit for the calculation of the specific tariff may be expressed in ways that are difficult to determine without laboratory equipment. As an example, the European Union (EU) charges specific tariffs on certain dairy products based on the weight of lactic matter in the product, which requires a laboratory test to check.

On the one hand, the advantages of specific tariffs are that it is normally easy to apply and no customs valuation is necessary. Therefore, when dealing with specific tariffs, the WTO CV rules do not apply. Regarding the advantages of specific tariffs, Carbaugh explains:

\footnotetext{
${ }^{142}$ Australian Government, Department of Home Affairs. Available at: https://www.homeaffairs.gov.au/busi/cargo-support-trade-and-goods/importing-goods/tariffclassification-of-goods/current-tariff-classification/schedule-3/section-i/chapter-4\#fres [accessed 15 September 2018]
} 
As a fixed monetary duty per unit of the imported product, a specific tariff is relatively easy to apply and administer, particularly to standardized commodities and staple products where the value of the dutiable goods cannot be easily observed. ${ }^{143}$

On the other hand, Carbaugh also acknowledges the disadvantages of specific tariffs:

A main disadvantage of a specific tariff is that the degree of protection it affords domestic producers varies inversely with changes in import prices. For example, a specific tariff of $\$ 1,000$ on autos will discourage imports priced at $\$ 20,000$ per auto to a greater degree than those priced at $\$ 25.000 .^{144}$

This example takes into consideration a manufactured good, such as a vehicle, to show that specific tariffs provide different levels of protection to the same category of good. The level of protection decreases as the price of the goods increases. It is an inverse relationship. However, it is appropriate to recognize that specific tariffs operate better with commodities than for manufactured goods that have a wide grade of variation.

A further complementary consideration to specific tariffs is that they need to keep being adjusted to take inflation into account.

\section{c) Compound or Hybrid Tariffs}

Compound or hybrid tariffs are those that comprise an AV tariff to which a specific tariff (e.g. $10 \%$ plus $\$ 2.00 / \mathrm{kg}$ ) is added or subtracted. For example, Pakistan charges a specific tariff of Rs. 0.88 per litre for some petroleum products plus a $25 \%$ AV tariff.

Explaining the use of compound tariffs, Carbaugh elaborates that the AV portion grants protection to the finished-goods industry, while the specific portion compensates the raw material producers.

Compound tariffs are often applied to manufactured products embodying raw materials that are subject to tariffs. In this case, the specific portion of the duty neutralizes the cost disadvantage of domestic manufactures that results from tariffs protection granted to domestic suppliers of raw materials, and the ad valorem portion of the duty grants protection to the finished-goods industry. ${ }^{145}$

Therefore, the use of a compound tariff has a dual purpose, to grant protection and to neutralize cost disadvantages. For the purposes of this dissertation, compound tariffs minimize both protection and revenue risks by using a diversification approach.

\section{d) Mixed Tariffs}

\footnotetext{
143 Idem

${ }^{144}$ Idem

${ }^{145}$ Idem, p. 112
} 
A mixed tariff can be considered a variation of the compound tariff. Note that mixed tariffs have both AV and specific elements but apply only one. The mixed tariff aim is to ensure a minimum or maximum level of protection through a choice between an AV and a specific tariff (e.g. $10 \%$ or $\$ 2.00 / \mathrm{kg}$; whichever is less). Using mixed tariffs, countries generally choose the one form that generates the most protection or revenue. For example, Indian tariffs on certain rayon fabrics are either $15 \%$ or Rs. 87 per square meter, whichever results in a higher tax outcome.

\section{e) Technical Tariffs}

A technical tariff can be AV, specific, compound, or mixed. The tariff is determined by technical factors such as alcohol content, sugar content, or the value of the imported product. For example, the technical tariff for a laptop is US\$ 3 each unit + US\$ 2 per $\mathrm{kg}$ of the battery. Thus, a laptop with a battery of $1.5 \mathrm{~kg}$ in weight would be subject to US\$ 6 (US\$ $3+\mathrm{US} \$ 2 * 1.5 \mathrm{~kg}$ ) as customs duty.

The use of technical tariffs can be complicated. An example of a quirky technical tariff comes from the EU with its technical tariff rules for chocolate - cocoa with sugar (HS 18069050 - Sugar confectionery and substitutes therefore made from sugar substitution products, containing cocoa (third country origin)). The EU cocoa with sugar import duty is calculated using the formula: $8.3 \%+$ EA MAX $18.7 \%+$ AD S/Z which should be "translated" as $8.3 \%$ AV import tariff + agricultural component (EA), ${ }^{146}$ limited to a maximum of $18.7 \%$ + additional duty on sugar contents (in Euro per 100 kilograms net) (AD S/Z). ${ }^{147148}$

To calculate the total rate of duties, it is necessary to determine the amount of agricultural component (EA) and additional duty on sugar contents (AD S/Z). In other words, it means that, in order to calculate the total rate of tariff, the customs authority in the import country needs to have specialized officers and equipment. ${ }^{149}$

\section{f) Neo Tariffs}

\footnotetext{
146 The agricultural component (EA) depends on the average content in milk fats, milk proteins, sucrose, isoglucose, glucose, and starch of the assortment.

${ }^{147}$ Reference TARIC, available at:

http://ec.europa.eu/taxation_customs/dds2/taric/measures.jsp?Lang=en \&SimDate=20180916\&Area=\& MeasType $=\&$ StartPub $=\&$ EndPub $=\&$ MeasText $=\&$ GoodsText $=\& o p=\&$ Taric $=18069050 \&$ search text $=g$ oods\&textSearch=\&LangDescr=en $\&$ OrderNum $=\&$ Regulation=\&measStartDat $=\&$ measEndDat $=$ [accessed 15 September 2018]

${ }^{148}$ Reference EU Regulation $n^{\circ}$ R2204/99, Journal no L278. Available at Eurolex: https://eurlex.europa.eu/legal-content/EN/TXT/PDF/?uri=uriserv:OJ.L_.1999.278.01.0001.01.ENG. [accessed 15 September 2018]

${ }^{149}$ Due to the complexity of technical tariffs, several Customs Administrations have partnerships with external laboratories or have their own laboratories.
} 
The tariff types that are available are those that are used in international trade.

However, this dissertation argues that neo tariffs can be implemented in international trade using other tariff structures as models. In this way, tariffs are open to innovation.

For instance, the electricity market is remarkable at designing pricing structures. As a way of comparison, consider the pricing structure for electricity, where to promote the efficient use of electricity it is necessary to consider peak and off-peak periods.

Filippini explains how it works in Switzerland:

The majority of electricity utilities in Switzerland, however, use a combination of time-of-use tariffs and two-part tariffs. Two-part time-of-day tariff is a twopart tariff containing a fixed monthly charge and a constant price per $k$ Wh of electricity consumed that varies according to time (day/night). ${ }^{150}$

Thus, while trade tariffs are generally fixed, ignoring seasons or economic cycles, electricity pricing is dynamic regarding market peaks. For the sake of argument, trade tariffs could have automatic triggers to vary depending on the demand or quality of the good in the country of importation.

As big data advances to analyse structured and unstructured data it is possible to foresee a future where the price and quantity of physical energy commodities negotiated in over the counter (OTC) markets with physical deliveries can merge with customs systems. Following this logic, it will be possible to assess the electricity, natural gas or most known physical energy goods markets to optimize the tariff structure with parameters other than price. An optimal trade tariff would be able to differentiate the tariff for peak and off-peak imports regardless if declared prices are the same.

Unfortunately, with the negotiated tariff schedules, the process of "engineering" tariffs and experimenting with them to find the best type is almost impossible.

Internationally, even with the WTO taking into consideration the provision for negotiations under GATT Article XXVIII and their relationship to the ensuing modification or rectification of schedules, tariff schedules are quite rigid. Furthermore, this dissertation argues in favour of optimal "engineering" using NAV tariff types, which is not the intention of Article XXVIII. Nationally, governments fear change, and passivity is the rule.

The fact that most countries have converted all their tariffs into AV tariffs has substantially narrowed the use of tariffs. For various reasons, tariffs are being reduced in type and sometimes negatively wrongly judged instead of positively seen as a tool that can be optimized to achieve an end. As a consequence, the next trade generation risks seeing only the negative aspect side lacking the knowledge to optimize a tariff.

${ }^{150}$ Filippini (2012), p.13 


\subsection{Algorithms for Tariff Optimization}

This section briefly covers the functioning of algorithms and the possible challenges when using them to design neo tariffs and benefit from tariff optimization. It aims to give the reader an overview of the possibilities that exist when working with value and tariff types, while simultaneously satisfying several necessary conditions (or constraints), such as using the WTO schedules to find an optimal tariff.

An algorithm is a "systematic procedure that produces - in a finite number of stepsthe answer to a question or the solution of a problem."151 According to Erickson, the idea of using algorithms has been around since the dawn of civilization.

\section{Descriptions of step-by-step arithmetic computation are among the earliest examples of written human language, long predating the expositions by Fibonacci and al-Khwarizmi, or even the place-value notation they popularized. ${ }^{152}$}

Illustrations of the use of algorithms are evident in different areas such as: a) finance; b) manufacturing, and c) logistics.

a) Finance: algorithms are used to decide how much cash to allocate to different purposes, across multiple time periods, to maximize interest earnings, and to create "efficient investment portfolios".

b) Manufacturing: algorithms are used to decide how to assign work orders to different types of production equipment, to minimize delivery time or maximize equipment utilization. They are also useful to determine the combination of raw materials of different types and grades, to meet demand while minimizing costs.

c) Logistics: algorithms are used to decide which paths transport vehicles should take to arrive at various destinations, to minimize costs or maximize the delivery of goods. They are also used when loading cargo into a ship to decide how items of different sizes should be placed to minimize unused space.

As the examples show, the use of algorithms in different areas is a powerful tool to solve problems using logic concepts and expressing solutions that can be run multiple times on a computer. The process begins with having a problem to solve, such as trade tariffs that are suboptimal for revenue in national schedules, breaking the problem into parts, finding the necessary data, and developing a step-by-step solution. For this

\footnotetext{
${ }^{151}$ Encyclopædia Britannica (2006), Article Title: Algorithm. Book at http://jeffe.cs.illinois.edu/teaching/algorithms/.

${ }^{152}$ Erickson, Jeff (2019). Algorithms.
} 
dissertation, national tariffs need to be revised according to their performance in government trade revenue. Applying a structured logic approach to such a problem, that considers combining different tariff types to obtain an optimal rate structure can have positive results for long-term sustainable trade.

Although this dissertation defends the use of algorithms to perfect tariffs for revenue purposes in national schedules, there are several challenges in the process. The use of algorithms is by no means a straightforward issue.

The first group of challenges envisaged are related to the technicalities of algorithms, such as the complexity involved in the design of trade revenue solutions and the growth rates as data increases. ${ }^{153}$ In this regard, the number of elements (input data) and steps for the operation of the algorithm needs to be considered carefully. As such, it might be best to begin to revise a national schedule by selecting only a few representative goods that are most importance for trade revenue. For instance, a good way to start the revision could be balancing ad valorem and specific rates to construct an optimal mixed rate for a particular type of good, using constraints such as the WTO schedule, and limiting the application of this new rate to that good over a short time frame

A further consideration related to the technical aspect of algorithms is the scale of the complexity of the algorithm.

Table 3 - A Possible Qualitative Scale of Algorithmic Complexity

\begin{tabular}{|l|l|l|}
\hline Algorithm Type & Nickname & Description \\
\hline Type 0 & "White Box" & $\begin{array}{l}\text { Algorithm is entirely deterministic (i.e., the } \\
\text { algorithm is merely a pre-determined set of } \\
\text { instructions). }\end{array}$ \\
\hline Type 1 & "Grey Box" & $\begin{array}{l}\text { Algorithm is non-deterministic, but its non- } \\
\text { deterministic characteristics are easily predicted } \\
\text { and explained. }\end{array}$ \\
\hline Type 2 & "Black Box" & $\begin{array}{l}\text { Algorithm exhibits emergent proprieties making } \\
\text { it difficult or impossible to predict or explain its } \\
\text { characteristics. }\end{array}$ \\
\hline Type 3 & "Sentient" & $\begin{array}{l}\text { Algorithm can pass a Turing Test (i.e., has } \\
\text { reached or exceeded human intelligence). }\end{array}$ \\
\hline Type 4 & "Singularity" & $\begin{array}{l}\text { Algorithm is capable of recursive self- } \\
\text { improvement (i.e., the algorithm has reached } \\
\text { "singularity"). }\end{array}$ \\
\hline
\end{tabular}

${ }^{153}$ Algorithms growth rates is the analysis of the algorithm functioning in relation to the quantity of data. As data gets bigger algorithm processing can grow in different ways such as linear, logarithm, quadratic, cubic, exponential and others. 
Source: Tutt A (2016) p. 107.

The scale ends with the implementation of learning, "self-improvement" algorithms, which are often considered the future of algorithms. Tuff refers to this class of algorithms as follows:

The future of algorithms is algorithms that learn. Such algorithms go by many names, but the most common are "Machine Learning," "Predictive Analytics," and "Artificial Intelligence," although the use of "intelligent" and its variants can be misleading because it is more important to distinguish between algorithms that learn and algorithms that do not, than it is to distinguish between algorithms that appear intelligent and those that do not. ${ }^{154}$

The more the learning algorithms perform the task, the better they can become at predicting which type of tariff combination is best for the country. Futurists refer to the moment at which learning algorithms can improve themselves beyond the human capacity of understanding as the "singularity" (Type 4). ${ }^{155}$

These sophisticated algorithms could automatically revise entire national schedules or several countries' national schedules to optimize tariffs. The future use of deep reinforcement learning algorithms could far exceed the performance of all the GATT Rounds that have negotiated tariff schedules until now.

The second group of challenges in promoting the use of algorithms to perfect national tariffs is associated with ethics, including different aspects of algorithm transparency and data privacy. On this matter, Mittelstadt, B. D. and others observe that: "The uncertainty and opacity of the work being done by algorithms and its impact is also increasingly problematic." 156

It is clear that the level of sophistication and the decision about what parameters and available data to use will always prioritize some values and interests over others and result in difficulties. According to Tuff, predictability and explainability are main problems to be concerned about.

Determining that an algorithm is sufficiently predictable and explainable to be "safe" is difficult, both from a technical perspective and a public policy perspective. If an algorithm is insufficiently predictable, it could be more

\footnotetext{
${ }^{154}$ Idem. p. 94

155 Singularity results from the development of an algorithm that can engage in "recursive selfimprovement." See Kurzweil, Ray. The Singularity Is Near: When Humans Transcend Biology. New York: Penguin, 2006.

${ }^{156}$ Mittelstadt, B. D., and others (2016). p. 3.
} 
dangerous than we know. If an algorithm is insufficiently explainable, it might be difficult to know how to correct its problematic outputs. ${ }^{157}$

In terms of predictability and explainability, a primary action is to decide on a standard pseudocode language to describe the multitude of algorithm solutions that could be developed by countries. ${ }^{158}$ Regarding the importance of well-written pseudocode Erick writes:

\section{Well-written pseudocode reveals the internal structure of the algorithm but hides irrelevant implementation details, making the algorithm easier to understand, analyze, debug, and implement. ${ }^{159}$}

At present, there is no official pseudocode syntax. A standard pseudocode language for international trade is necessary to address concerns about ethics and transparency. Ethics around the use of algorithms can raise several discussions, such as about the reproducibility and verifiability of the algorithms. What we know, and what can be known, about how fundamental an algorithm function is in determining whether it is discriminatory and produces unintended consequences is limited at this moment. For instance, countries might be tempted to develop algorithms using data that is not publicly accessible to perfect algorithms. ${ }^{160}$

In this regard, the WTO and other international organizations have a key role to play in developing the principles to ensure the predictability and explainability of algorithms. Algorithms should not operate in a non-transparent manner, as nations' trade secrets. Transparency in such a public policy matter, such as international trade, would require the immediate, thorough disclosure of how the algorithms operate to the general public.

At a basic level, the WTO could act as a standard-setting organization for the design of and best practices in relation to national tariff algorithms. This would result in carrying out functions related to the classification, performance evaluation, and design standards of tariffs algorithms. The WTO and other international organizations could establish guidance for developing algorithms that meet specific standards. The goal is to ensure that algorithms are fair and effective. As such, algorithmic regulation will require expert judgment, political independence, and constant review to prevent

\footnotetext{
157 Idem p. 103.

${ }^{158}$ Pseudocode is an informal high-level description of the operating principle of an algorithm intended to be read by humans rather than machines. No standard for pseudocode syntax exists. Flowcharts, drakon-charts and Unified Modeling Language (UML) charts can be thought of as a graphical alternative to pseudocode but are more spacious on paper.

${ }^{159}$ Erickson, Jeff (2019). Algorithms. p.13.

${ }^{160}$ Much of the present international trade data is collected by private companies (Maersk, Alibaba, Amazon, and others), which are not readily available for use by countries. Trade data for tax and business decisions are sold by providers such as Refinitiv. Some countries might have a limited capacity for collecting trade data to perfect their national schedules.
} 
unintended consequences. Given the pace of algorithmic progress, it is already time to address this topic.

It is certain that trade policy would need to adapt to this new phase of automated decision making. The interplay between countries' interests and the public interest for trade growth would continue to require multilateral negotiations. As Kroll and others noted, working with algorithms would still also require the input of courts and reviewers.
Although lawmakers and policymakers can offer clarifications or other changes to guide the work done by developers,204 drafters may be unable to remove certain ambiguities for political reasons or be unwilling to resolve details to meet flexibility objectives. As such, computer scientists must account for the lack of precision--and the corresponding need for after-the-fact oversight by courts or other reviewers-when designing decision making algorithms. ${ }^{161}$

Clearly, there is also a place for the WTO DSU to interpret and deliver decisions in emerging disputes dealing with specific issues related to the application of algorithms to national schedules.

To conclude the section, it is clear that many questions remain regarding the use of algorithms and big data that need to be addressed in international trade. Algorithms have a role to play in perfecting national schedules for revenue purposes and providing support for long-term sustainable trade. The basic idea is that an effective tariff is better than a lower or higher inefficient tariff. The pros and cons need to be adequately balanced by countries and international organizations.

\subsection{Ad Valorem and Excise Reflections}

This section reflects and questions the fact that AV tariffs became the international standard for trade. Smith puts it as follows:

In today's global economy, the ad valorem tariff is the prominent form. Countries have moved to this common form in an effort to standardize the liberalization of policies through trade agreements. ${ }^{162}$

The WTO Secretariat refers to three main reasons to justify a preference for AV tariffs: (1) transparency; (2) penalization of cheaper products, and (3) the fact that other tariffs change the level of protection when prices change:

\footnotetext{
161. Kroll, Joshua and others. (2016). p. 57

${ }^{162}$ Smith (2013) Chapter 5
} 
There is widespread agreement among trade economists that ad valorem tariffs are preferable to specific or compound tariffs for at least three reasons. First, specific tariffs are less transparent than ad valorem tariffs. In particular, the protective impact of a given specific tariff is difficult to assess as it depends on the unit value of the imported product. This lack of transparency makes it easier for special interest groups to obtain governmental support for high levels of protection. Second, specific tariffs have a greater impact on cheap products than on expensive products falling under the same tariff line. Third, when prices change, the protective effect of specific tariffs also changes. ${ }^{163}$

For the purposes of this dissertation, the WTO Secretariat reasons are questionable.

The first reason put forward by the Secretariat is transparency. The transparency reason is questionable because, although the AV rate is known, the fact that it needs a customs value creates transparency problems. The most transparent method is to work with units of measurement such as weight, volume, or surface. The simplicity and transparency of the specific tariff type is undeniable. The WTO transparency argument is biased towards transparency in negotiations but not transparency in trade.

Also, trade economists cannot measure the lack of transparency associated with MNEs transfer pricing policies or misinvoicing practices affecting customs valuation. The obligatory adjustments of intangibles and services related to the goods being imported are also factors that cause uncertainty. In addition, most countries add facultative adjustments, freight and insurance to the customs valuation and such adjustments create minor delays. Economists do not consider the non-transparency factor of adjustments. As a result, traders face a lack of transparency, which requires a longer time to clear the goods with naturally higher costs. Therefore, the transparency argument does not hold in practice.

The second reason stated by the WTO Secretariat is that specific tariffs have a greater impact on cheap products than on expensive products falling under the same tariff line. The argument is correct but it is mostly valid for manufactured goods and not so much for commodities or raw materials. To explain this differently, the penalization of cheaper products occurs in reality if there is a broad range of differently priced products within the same tariff line. However, in the case of commodities or standard manufactured goods, this is of less importance.

Furthermore, even if there are cheap and expensive goods within the same tariff line, there are other technical solutions that can be used to differentiate between tariffs. To

${ }^{163}$ WTO (2001), p.9 
accommodate different rates for the same tariff line, some countries adopt national, regional, or statistical nomenclatures to complement the HS system. ${ }^{164}$

Although the regional nomenclature cannot directly distinguish products based on price, the distinction is determined indirectly based on the materials, components or processes used to make the good under the 6-digit code. For instance, HS code 6207.21 is for “Men's Or Boys' singlets and other vests, underpants, briefs, nightshirts, pyjamas, bathrobes, dressing gowns and similar articles" made of cotton, and it is possible to add regional codes to differentiate the goods with a single cotton colour from those with more colours. Another possibility is to distinguish knitted products from not knitted but made in another way. The logic behind this is that the goods available in multiple colours and knitted goods are more expensive than those available only in a single colour and that are not knitted. In this way, it is possible to distinguish by price or other criteria and therefore use different rates and controls for the different products.

Thus, having in mind the common practice of national, regional, or statistical complementary nomenclatures, it is questionable whether AV tariff conversion can be justified by reason of the disproportionate impact of specific tariffs on cheaper compared to more expensive goods. ${ }^{165}$

The third reason refers to price changes. The constant level of protection argument is valid if prices are negotiated in free market conditions. However, for major commodities with anti-competitive structures formed by a few MNE or state-owned companies, the prices are not set in free market conditions, and thus prices change according to the related party's interests, exchange rates policies, or other external factors and not so much because of markets. ${ }^{166}$

Over the years, a number of disputes have addressed the use of other types of tariffs in conjunction with or as a replacement for the existent AV tariffs. For instance, in Argentina - Textiles and Apparel (1998), the issue was about the imposition of specific duties affecting imports of footwear, textiles, apparel, and other items that amounted to more than the bound rate. At the end, the AB found that other types of tariffs could be applied as long as they were not in excess of the country schedule.

87. For the reasons set out in this Report, the Appellate Body:

\footnotetext{
${ }^{164}$ Contracting Parties to the HS Convention usually subdivide the HS nomenclature beyond 6-digits and add their legal needs based on their own tariffs and statistical requirements. Parties often set their tariffs at the 8-digit "tariff code" level. Hence, adding two digits to the 6-digits of the HS nomenclature. Statistical suffixes can be also added to the 8-digit tariff code for a 10-digit code. There are no limits to the number of extra digits that can be added to the HS code.

${ }^{165}$ Codification systems such as the HS system have to be supplemented by other nomenclatures and these can be used to distinguish between the value of goods to have different tariffs.

${ }^{166}$ An example is the food and agribusiness commodities markets dominated by a few companies, such as ADM, Bunge Limited, Cargill, COFCO International, and Louis Dreyfus Company (LDC).
} 
(a) modifies the Panel's findings in paragraphs 6.31 and 6.32 of the Panel Report by concluding that the application of a type of duty different from the type provided for in a Member's Schedule is inconsistent with Article II:1(b), first sentence, of the GATT 1994 to the extent that it results in ordinary customs duties being levied in excess of those provided for in that Member's Schedule. In this case, Argentina has acted inconsistently with its obligations under Article II:1(b), first sentence, of the GATT 1994, because the DIEM regime, by its structure and design, results, with respect to a certain range of import prices in any relevant tariff category to which it applies, in the levying of customs duties in excess of the bound rate of 35 per cent ad valorem in Argentina's Schedule; ${ }^{167}$

A dispute that caused the evolution of the use of tariffs to fulfil its functions is Peru Agricultural Products (2015) which discusses the imposition of an "additional duty" on imports of certain agricultural products. This dispute is relevant as it discusses the possibility of using PRS/PBS mechanisms as long as the total rate remains lower than the bound rate. Russia - Tariff Treatment (2016) also refers to the use of a combined duty rate system and is discussed further in this dissertation.

For the purposes of this dissertation, one of the major problems regarding AV tariffs is the lack of consideration for the domestic revenue mobilization of LDCs and developing countries. In other words, economists' reasoning is biased for developed countries where tariffs serve mainly as trade barriers and not for revenue.

Consequently, for LDCs and developing countries, the WTO Secretariat reasons favouring AV tariffs are more theoretical than practical.

Writing about the argument that trade openness brings gains, the UN and WTO recognize that the argument is awkward because it is essentially static:

The textbook argument is that openness to trade brings gains from pure exchange and from specialization (Ricardo's wine-and-[grape] demonstration). This argument, however, is awkward because it is essentially static. $^{168}$

When negotiating tariffs, it is necessary to remember that some countries remain commodity exporters and import almost everything else, from raw materials to manufactured goods. For such countries, there is no significant trade policy going on, and tariffs serve mainly as revenue tools.

\footnotetext{
${ }^{167}$ AB Report, Argentina - Measures Affecting Imports of Footwear, Textiles, Apparel and Other Items, WT/DS56/AB/R, p. 32, adopted 11 March 1998.

${ }^{168}$ UN/WTO (2012), p. 64. David Ricardo refers to Portugal grapes and wine comparative advantages to England. In the UN/WTO publication it is wrongly written "wine-and-drape" while the correct is "wine-and-grape".
} 
A study from DeJong and Ripoll concluded that the impact of tariffs on growth differs according to a country's level of economic development. Thus, high tariffs are detrimental to growth in rich economies, but they are favourable in poor countries.

We have examined the relationship between tariff and growth rates from 1975 to 2000, paying particular attention to its potential contingency on the level of economic development. Our analysis has revealed the presence of a significant interaction effect under which the marginal impact of tariffs on growth is declining in initial income. In particular, the relationship between tariffs and growth is negative and significant among the world's rich countries, while positive (with significance exhibiting sensitivity to the particular estimator being employed) among the world's poor countries. ${ }^{169}$

As such, the study contradicts the general belief in favour of reducing or eliminating tariffs. It opens the argument up for further research and discussions. In addition to the use of tariffs, it is relevant to take into consideration the lack of administrative structure to collect domestic taxes. Putting it differently, the AV tariff debate is incapable of measuring a country's political capacity to shift revenue from tariffs to other taxes such as GST or VAT.

This section questioned some of the arguments favouring the adoption of AV tariffs. The economic reality of developed economies differs from that in LDCs and developing countries, and thus revenue tariffs need to be considered properly. Considering the WTO Secretariat's reasons for favouring AV tariffs, many countries converted full tariff schedules to AV. By doing so, these countries renounced their preference for caution and to minimizing fiscal risks. In brief, tariffs offer a vast field of possibilities to assist LDCs and developing countries in building resilient economies and this should be revisited by WTO Members.

\subsection{Non-Ad Valorem Conversion for Ad Valorem Equivalents}

AV tariffs are the dominant type of tariffs in international trade. All other tariff types, such as specific, mixed, compound, and technical are often grouped and referred to as NAV. In relation to NAV tariffs, the WTO explains:

All tariffs other than ad valorem tariffs are considered non-ad valorem (NAV) tariffs. Although ad valorem duties are the most commonly used form of tariffs

${ }^{169}$ DeJong and Ripoll (2003), p. 23 
among WTO Members in respect of non-agricultural products, there are some Members that apply non-ad valorem duties on some products. ${ }^{170}$

As such, NAV are less frequent but, despite efforts to convert NAV tariffs into AV equivalent tariffs, many NAV continue to exist. The proportion of tariff lines and NAV rates varies across countries. In 2003, the overall share of NAV tariff lines to total tariff lines for WTO members that reported NAV tariffs was calculated at $6.6 \%$. NAV rates are more frequently used for agricultural goods.

A higher incidence of NAV duties appear in agricultural products such as meat products (chapter 02), dairy produce (chapter 04), sugars (chapter 17), cocoa (chapter 18), preparations of cereals, flour, starch or milk (chapter 19) and beverages (chapter 22). For industrial products, most of the NAV lines are concentrated in textile products. ${ }^{171}$

In the agriculture sector, developed countries are the greatest users of NAV tariffs: Switzerland (approximately 83\%), Norway (63\%), European Communities (45\%), United States (43\%), Canada (26\%), and Iceland (25\%). Several economies in transition also have relatively high NAV tariff shares: Belarus (33\%), the Russian Federation (33\%), Poland (25\%), and Bulgaria (15\%). Among the developing country members, Thailand (56\%) and Cyprus (50\%) have the highest incidence. ${ }^{172}$

In the industrial sector, the greatest users of NAV are Switzerland (82.2\%), South Africa (26.1\%), Thailand (16.3\%), Kenya (11.6\%), Israel (11.3\%), Belarus (9.5\%), the Russian Federation (9.4\%), and Japan $(4.1 \%) .{ }^{173}$

Therefore, countries are using NAV tariffs in the agriculture and industrial sectors. These countries are delaying or refusing to convert NAV to AV tariffs. One of the countries that deserves more attention is Switzerland, which maintains a large portion of NAV tariffs both for agricultural and industrial products. According to the WTO, $83 \%$ of Switzerland's tariff lines consist of NAV tariffs. ${ }^{174}$ The Switzerland and Liechtenstein 2017 Trade Policy Review (TPR) states:

15. All of Switzerland-Liechtenstein's applied tariffs continue to be expressed as specific rates. ${ }^{175}$

The conversion from NAV to AV equivalent tariffs is based on the argument that any tariff can be estimated as being ad valorem. Accordingly, any tariff can be expressed as

\footnotetext{
${ }^{170}$ WTO E-Learning (n.a.), p. 5

${ }^{171}$ WTO, TN/MA/S/10 (2003)

${ }^{172}$ Idem

${ }^{173}$ Idem

${ }^{174}$ Idem

${ }^{175}$ WTO, WT/TPR/S/355 (2017), p.10
} 
a percentage of the price, which is known as an AV equivalent. The European Union (EU) defines AV equivalent as follows:

The ad valorem equivalent or AVE, is the equivalent in an "ad valorem" form of a tariff originally expressed as a "specific" or mixed duty. ${ }^{176}$

Hence, AV equivalents are obtained by converting NAV to AV tariffs. ${ }^{177}$ The conversion is designed to make it easier to negotiate the reduction in tariff barriers. Commenting about the need for conversion, Kerr and Gaisford explain:

The conversion of non-ad valorem tariffs into ad valorem tariffs is essential so that we can better depict the actual level of protection of a tariff structure. But while there is a broad recognition of the importance of the so called "ad valorem equivalent ( $A V E$ ), there is no consensus on how to calculate it. ${ }^{178}$

Concerning the effort to convert NAV to the AV equivalent, WTO members agreed on the conversion in the Negotiating Group on Non-Agricultural Market Access (NAMA) negotiations: ${ }^{179}$

WTO Members have broadly agreed to convert non-ad valorem tariffs for nonagricultural products to ad valorem equivalents and to bind them in ad valorem terms in the context of the on-going NAMA negotiations. ${ }^{180}$

In fact, the General Council decision of 1 August 2004 (commonly referred to as the "NAMA Framework") indicated that all NAV duties of non-agricultural products shall be converted to AV equivalents. An important point about the General Council decision is the question of the methodology for conversion which remains open for discussion. ${ }^{181}$

Regarding the different countries' proposals submitted to the NAMA, the WTO Secretariat commented:

The overview of proposals submitted to the Negotiating Group on Market Access (TN/MA/6/Rev.1) notes that several of these proposals are related to issue of NAV tariffs. Whereas some submissions speak more generally of the need to maximize the use of ad valorem rates, others state that Members should consider

\footnotetext{
${ }^{176}$ EC (2005)

${ }^{177}$ It is important to register that there are two types of conversions to AV tariffs. The first is from NAV tariffs to AV resulting in an AVE. The second is from NTBs to AV called tariffication.

${ }^{178}$ Kerr and Gaisford (2007), p. 224

179 NAMA refers to all products not covered by the Agreement on Agriculture. In other words, in practice, it includes manufacturing products, fuels and mining products, fish and fish products, and forestry products. They are sometimes referred to as industrial products or manufactured goods. 180 WTO, TN/MA/S/10 (2003)

${ }^{181}$ WTO, WT/L/579 - 2 August 2004
} 
converting all NAV duties to ad valorem rates. One proposal calls for a common methodology to calculate these rates. ${ }^{182}$

Avoiding going into detail about the countries' proposals, the discussion about full conversion from NAV to AV is related to the method to be applied. In 2011, the WTO Negotiating Group on Market Access stated that:

All duties shall be bound on an ad valorem basis. Existing bindings on a non-ad valorem basis shall be converted to ad valorem equivalents on the basis of the methodology outlined in document TN/MA/20. ${ }^{183}$

The WTO presents the methodology underlying the conversion in the document entitled "Draft Guidelines for the Conversion of Non-Ad Valorem Duties of Non-Agricultural Products into Ad Valorem Equivalents". The Draft Guidelines propose a standard methodology for converting the various types of NAV tariffs to AV equivalents, which are then to be used in a nonlinear tariff cutting formula and bound in AV terms.

\section{CONVERSION METHODOLOGY}

4. The principal method for converting the non-ad valorem duties into their ad valorem equivalents will be the unit value method based on the WTO Integrated Data Base (IDB) import data. This method will be applied in accordance with the modalities outlined in Section A below.

(...). ${ }^{184}$

In the paper "Ad valorem, Specific and Other Tariffs", The WTO Secretariat presented two primary methods for AV equivalents conversion: (1) the use of revenue collected divided by the value of imports and (2) the use of unit values of traded products. ${ }^{185}$

For the first method, AV equivalents are estimated as a ratio of the customs revenue collected on a product (at the tariff line level) to the value of imports of the same product. Analysing this method, the WTO Secretariat said it had a few shortcomings.

\section{B. REVENUE METHOD}

While for certain purposes this method can technically be accurate, it has a number of shortcomings:

\footnotetext{
${ }^{182}$ WTO, TN/MA/S/10, 20 May 2003

${ }^{183}$ WTO, TN/MA/W/103/Rev.3/Add.1, 2011, p. 27

${ }^{184}$ WTO, TN/MA/20, 2007

${ }^{185}$ WTO AIE/S5, 6 February 1998
} 
- data on revenue collection by tariff line are often unavailable publicly, or even to statistical agencies (though customs authorities normally collect information at this level).

- $\quad$ where data are available, a major problem with this method of estimation is that it can measure only the AVEs of applied tariffs but not those of bound tariffs, except when applied duties are equal to bound duties.

- $\quad$ AVEs may understate the applied MFN tariff rate if any trade within the product category concerned flows under a preferential trading arrangement, such as a GSP scheme, a special regime for least-developed countries, or a free trade area.

- $\quad$ other duties and charges, duty drawbacks, safeguard measures, antidumping duties, tariffs waived for re-export, and so on may affect the estimations as well. Adjustments for all these factors designed to identify the actual MFN rate may be a cumbersome exercise. ${ }^{186}$

In conclusion, the WTO view on the shortcomings of the revenue method conversion is based on a lack of available data on revenue and the fact that applied tariffs are frequently different from bound tariffs. Although the deficiencies are relevant, this is probably the best method of conversion. For revenue tariffs, there is revenue data and, in many cases, particularly in times of crisis, the tariffs are equivalent to the bound tariffs. In conclusion, the revenue conversion method should remain an option for conversion.

For the second method, NAV are converted into AV equivalents based on the use of unit values of traded products. The monetary values of the duty per unit of imports is divided by the import unit value. All values are sourced from the WTO Integrated Data Base (IDB) import data. ${ }^{187}$

Many see this second method as the most appropriate one. This is probably due to the availability of data in the WTO IDB system. This dissertation argues against such a method. It is important to notice that the parameters of calculation consider average monetary values, which are subject to price negotiations, ERs volatility, transfer pricing practices, misinvoicing and other prejudicial factors. The WTO Secretariat notes some of the limitations of the method:

16. In all cases the limits of AVEs must be kept in mind. AVEs are only a snap-shot of the actual effect of a specific duty in the reference period used for the calculation. Even though the specific duties used are fixed, their impact may change over time and in relation to each shipment. Moreover, AVEs are usually calculated in terms of annual averages and, in this case, they can only be assessed at the end of the period, when all relevant trade data have been

186 WTO, TN/MA/S/10 (2003)

${ }^{187}$ WTO, TN/MA/20, (2007) 
collected. The annual averages also mask a potentially wide variation of AVEs. ${ }^{188}$

Also, almost all of the data in the WTO IDB system comes from Customs systems based on HS codes. Many trade values available in the Customs systems are from related parties' transactions. Although it is unfair to say that the relationship influenced the price in all such transactions, this dissertation believes the price influence is considerable and values declared by traders are not always trustworthy. In other words, the level of trust in the WTO IDB data is questionable.

Switzerland expresses its doubts about the conversion to AVEs in the following way:

The Swiss authorities expressed reservations about the methodology and noted that any estimate of AVEs has limitations as they are affected by many factors, including the base period, unit prices, exchange rates, and cases where only limited volumes were imported. 189

Surely, the simplification process is useful for tariff multilateral negotiations. ${ }^{190}$ However, this is the easy path and there is not enough consideration given to the role played by NAV tariffs in the countries' revenue systems. NAV tariffs have a reason to exist and a purpose to fulfil both for trade and revenue. In this regard, full AV conversion might not be desirable. ${ }^{191}$

For the purposes of this dissertation, it is important to understand that tariff diversity, as most diversity in life, is positive, offering a relevant option for countries to address international trade advantages and disadvantages. Converting NAV into AV tariffs for all classes of goods is inadequate, particularly, from a revenue perspective.

\subsection{Converting NTBs to AV - Tariffication}

In addition to converting NAV into AV tariffs, there are current negotiations to convert non-tariff barriers (NTBs) into AV equivalents. In other words, there are efforts to quantify NTBs, such as quotas, technical barriers, and sanitary and phytosanitary measures, among others, to obtain AVEs. The efforts to convert NTBs into AV equivalents are known as tariffication. ${ }^{192}$

\footnotetext{
188 WTO, TN/MA/S/10, 2003

189 WTO, TN/MA/S/10, 2003

190 Tariffication is an effort to convert all existing agricultural Non-tariff barriers to trade (NTBs) into bound tariffs and to reduce these tariffs over time. A bound tariff is one which has a "ceiling" beyond which it cannot be increased.

${ }^{191}$ Switzerland NAV tariffs, for example, should be more observed and studied than combated.

192 The tariffication goal is to make it possible bound NTBs tariffs and to reduce these tariffs over time. A bound tariff is one which has a "ceiling" beyond which it cannot be increased.
} 
According to Shaffer and Winters, the US aimed to eliminate agricultural protection and at the Uruguay Round, but it faced a difficult time "tariffying" their trade barriers:

In the Uruguay Round, the U.S. aimed to eliminate agricultural protection, and from an early date pressed the case for 'tariffying' all trade barriers other than ordinary customs duties - i.e. converting them into tariffs of the same protective effect - and then gradually reducing those tariffs to zero. The Round nearly came to grief several times over agriculture, but at the last moment agreement was reached, including to tariffy nontariff barriers and then reduce (but not eliminate) the tariff rates. ${ }^{193}$

After the Uruguay Round, the "tariffying" process continued in many countries. For instance, the WTO Annual Report of 2017 recorded Thailand's complaint about the Korean delay in concluding the conversion of non-tariff measures into tariffs:

Thailand expressed concern that Korea has not finished converting non-tariff measures into tariffs (so-called tariffication) and introducing a tariff rate quota for rice. ${ }^{194}$

Obviously, the conversion of NTBs into AV equivalents is complex. It deals with the quantification of NTBs, such as quotas, technical barriers, and sanitary and phytosanitary measures, among others. In relation to the quantification difficulty, the OECD explains:

Not only do these measures take often non-transparent forms, analysis also has to take into account whether and how they are linked to non-trade policy objectives. Some NTBs serve important regulatory purposes and are legitimate under WTO rules under clearly defined conditions even though they restrict trade. ${ }^{195}$

From the OECD document, it is important to retain that the objective is not to eliminate NTBs but to make sure they are legitimate and under reasonable terms.

This section presented the WTO efforts to convert NTBs into AV equivalents. Such efforts are complex and intended to bind tariffs to further reductions.

\subsection{Tariff Principles Before the GATT}

\footnotetext{
193 Shaffer and Winters (2016), p.2

${ }^{194}$ WTO Annual Report 2017, p.51

195 OECD (2005), p. 13
} 
This section presents and comments on some tariff principles from the XVII century. This is relevant to understand the historical views about tariff rates, tariff types, trade volumes, and different classes of goods.

In this aspect, the GATT and its effort to standardize, reduce, or eliminate tariffs had a detrimental influence on the study of tariffs. The truth being that the standardization of tariffs contributes to less research and discussions about the instrument.

The American State Papers ${ }^{196}$ addresses tariff principles, showing some of the variables that need to be taken into consideration when deciding about the use of tariffs for protection or revenue:

The principles involved in the proposition for a new tariff, in relation to the protection of domestic manufactures, being thus presented for consideration, the more general principles of the system remain to be briefly stated, in relation to the production of revenue. Thus:

1. Articles intended as the source of revenue should never be heavily charged with duties as to prevent importation or much to diminish it.

2. Articles should never be so heavily charged with duties as to create a temptation to smuggling.

3. Articles of great size and weight, of comparatively small value, are difficult to be smuggled; and, other things being equal, they may be charged with higher duties.

4. Articles of small size and great value are easily smuggled and must be charged with low duties, to destroy the otherwise fatal temptation to evade the law.

5. Articles imported to a great amount should rather be charged with specific duties upon their weight and measure, in order to guard against evasions and frauds, than with ad valorem duties on their value. ${ }^{197}$

Item 1 refers to the use of tariffs for revenue purposes. In such a case, tariffs should not contribute to diminishing the number of goods being imported. In other words, the flow of imported goods for tax purposes should not be stopped by the tariff. It is argued here that rates testing is the only appropriate method to find the combination of maximum rates with constant trade volumes.

\footnotetext{
196 The United Sates American State Papers, originally republished in the second quarter of the $19^{\text {th }}$ century, is a retrospective collection of largely United States Congressional, but also Executive materials originating from 1789 through 1838.

${ }^{197}$ United States (US). American State Papers (1834), p. 91
} 
Item 2 recommends caution when applying tariffs not to charge the goods very heavily creating a temptation to smuggle.

Items 3 and 5 address goods that have large volumes or a heavy weight with comparable low values. According to the principle, these goods should be taxed with high tariffs. Large quantities and heavy weights are common with commodities. For instance, minerals or agricultural commodities are perfect examples. Also, specific tariffs suit commodities better. Commodity markets are extremely concentrated and value is subject to manipulation. As such, commodities traded in enormous amounts present a high risk for tax evasion and fraud.

Item 4 refers to goods of small sizes and high value, also known as high-value goods. This class of goods should be subject to low tariffs. This comes from the fact that a high duty is an incentive for smuggling. Smuggling becomes more rampant when countries impose high tariffs on goods that have a high value, such as electronics, thus giving strong incentives to circumvent the system and create enforcement challenges. This dissertation puts forward the view that the use of AV tariffs offers incentives to engage in fraud when declaring the value of these goods.

These XVII century tariff principles are relevant since they are connected with the type of goods, which is essential for the type of tariff choice. Naturally, the selection of tariff types depends on many factors, such as: if it is for export or import, if it is for trade barrier or revenue purposes, and the administrative structure of the country to collect the tariff.

For this section, it is important to understand that each tariff should be adequate to fulfil its intent. Size, weight, volume, value, and whether the purpose is for trade protection or revenue are all relevant when deciding about the type and level of a tariff.

\subsection{National Tariff and WTO Member Schedules}

A national tariff is a record of all tariffs applied to all goods when imported into the country. A national tariff provides transparency, security, and predictability for trade. ${ }^{198,199}$ Concerning the structure and format, a national tariff typically shows: the

\footnotetext{
${ }^{198}$ A database containing information regarding Members' tariffs is available in the Tariff Analysis Online facility provided by WTO at: https://tao.wto.org/welcome.aspx?ReturnUrl=/Default.aspx. Data on WTO members' tariffs are of two types: a) Bound rates (the ceiling rates as listed in members' "schedules" or lists of commitments); and b) Applied rates (the rates members currently charge, which can be lower than the bound rates).

${ }^{199}$ It is important to register that a National Tariff normally set tariffs at 8-digit or 10-digit "tariff code" level. The HS system 6-digit "tariff code" is complemented by national, regional coding or statistical suffixes. The GATT Schedule is limited to the HS system 6-digit "tariff code".
} 
Harmonized System (HS) code, the product description, the tariff rate for each product, the other duties and charges, and the special qualifications.

National tariffs have existed since classical Greece, where tariffs were charged at a flat rate of around $2 \% \mathrm{AV}$. Asakura mentions that this rate was increased to $5 \%$ or even $20 \%$ AV during the Peloponnesian war.

For example, in Athens, the rate of Customs duty during the Peloponnesian war, the war between Athens and Sparta that lasted for 27 years from 431 B.C., was increased to $5 \%$ or even $20 \%$ ad valorem. ${ }^{200}$

A unique type of tariff with a flat rate is indeed the simplest possible structure for a national tariff, and one could then say that the list becomes unnecessary. In other words, with a single type of tariff using a single duty, there is no need for any list, because all goods are taxed equally. Thus, the national tariff becomes dispensable.

National tariff rates cannot be higher than those negotiated during the GATT rounds. Article II of the GATT 1994 is the core provision dealing with the WTO schedules of concessions for trade in goods. It requires Members to limit tariffs along with other duties and charges (ODCs) to no more than what is set out in the schedule. Therefore, countries are precluded from imposing tariffs and ODCs in excess of what was negotiated. In relation to the hierarchy of schedules, it is important to note that, in EC - Computer Equipment (1998), the Appellate Body said that the schedules constitute an integral part of the GATT 1994.

A Schedule is made an integral part of the GATT 1994 by Article II:7 of the GATT 1994. Therefore, the concessions provided for in that Schedule are part of the terms of the treaty. ${ }^{201}$

Thus, the schedules bind the WTO Members and form part of the GATT 1994. Although nowadays tariff schedules have different duty rates depending on the good, once the tariffs are set, the schedules remain mostly static. In relation to the permanent structure and possibilities for re-negotiation, the WTO Secretariat explains:

Once bound, a tariff rate becomes permanent and a Member can only increase its level after negotiating with its trading partners and compensating them for possible losses of trade. ${ }^{202}$

It is true that according to GATT 1994, Article XXVIII tariffs can be renegotiated, but the requirements and bureaucracy make it challenging and time-consuming. In 2012, Ukraine requested the renegotiation of its tariff bindings on 371 tariff lines and the

\footnotetext{
${ }^{200}$ Asakura op. cit., p. 37

${ }^{201}$ WTO Appellate Body Report, WT/DS62/AB/R, par.84.

${ }^{202}$ WTO Secretariat, E-Learning. (N.A.), p. 8
} 
request faced opposition by WTO Members. The opposition to the tariff's renegotiation was clear in the words of EU Ambassador Angelos Pangratis and was backed by several other members:

\section{The EU is of the firm opinion that the procedure set out in Article XXVIII GATT is not meant for renegotiating a significant part of the accession commitments of WTO members ${ }^{203}$}

Thus, WTO Members expect negotiated tariff schedules to remain static while waiting for future rounds of new reductions. ${ }^{204}$ Changes to schedules happen more often as a result of the establishment of customs unions or the enlargement/shrinking of existing ones. As such, the path of tariffs for most WTO Members is only viewed as a downward spiral. The lack of flexibility is a negative aspect for tariff schedules in a constantly changing trade scenario.

In this regard, tariff schedules, rather than being an instrument to eliminate import tariffs should be regarded as a tax tool to secure revenue in certain economies. For certain types of goods, the negotiation of tariff bindings is disconnected from the impact in the tax policy.

The schedules commitments supposedly the backbone of the multilateral trading can also become a relevant weakness for tax revenue. The argument here is about the rigidity of tariffs schedules and that GATT Art XXVIII is too limited and rarely used. Renegotiations of tariff concessions are rare, and a Member seeking renegotiation is expected to give compensatory concession on other products.

Unfortunately, GATT Art. XXVIII provisions did not foresee the need for tariff schedules to be used as live, adaptive instruments in terms of tariff type which can evolve over time. ${ }^{205}$ Art. XXVIII was designed to negotiate or renegotiate AV bindings, while this work questions the validity the AV type of tariff and consequentially also the binding.

The work believes in the need for a tariff schedule to promote the adaptive use of different tariff types, engineering and perfecting such tools to strengthen revenue according to the country's economy. If that is not possible at the WTO level than it is the case to implement such an adaptive mindset in the national tariff.

\footnotetext{
${ }^{203}$ Pangratis, Angelos. Ukraine Renegotiation Request Fuels Concern Among Trading Partners at WTO Ctte. Bridges Weekly Trade News, Volume 16 - Number 35, 17 October 2012.

${ }^{204}$ Tariff rounds of negotiations have been unsuccessful since the establishment of the WTO in 1995. An exception is the plurilateral tariffs negotiations in the Information Technology Agreement (ITA). ${ }^{205}$ For the purposes of this work, tariff negotiations allowing both upwards and downwards movements is the key to predictability. Security and predictability suffer when WTO Members, knowing that the WTO inhibits the upward movements of tariffs, attempt to circumvent the system or act unilaterally taking the risk of a dispute.
} 
As for the WTO AV bindings, the work questions the existence of free market assumptions to support the nature of value. It argues that goods prices are an imperfect representation of value.

On the matter of type convertibility to use a different tariff type rather than the AV type, the AB in Argentina - Textiles and Apparel (1998) was clear about the possibility of applying a type of duty different from the type provided for in a Member's Schedule, as long as the duty is not in excess of the bound rate.

GATT Art. II (schedules of concessions): The Appellate Body found Argentina's measure was, in fact, inconsistent with Art. II:1(b). It held that "the application of a type of duty different from the type provided for in a Member's Schedule is inconsistent with GATT Art. II:1(b), first sentence, to the extent that it results in ordinary customs duties being levied in excess of those provided for in that Member's Schedule." In this case, the Appellate Body concluded that "the structure and design of the Argentine system is such that for any DIEM ... the possibility remains that there is a 'break-even' price below which the ad valorem equivalent of the customs duty collected is in excess of the bound ad valorem rate of 35 per cent." 206

As such, as long as it is not in excess of the bound rate, any type of tariff can be used, and countries should have the option to use existent convertibility or propose new tariff types when necessary.

The possibility of adaptation goes beyond the tariff type. A general idea of how to adapt tariffs to a changing scenario can be found in the national tariff of Switzerland and Liechtenstein.

Switzerland's MFN customs tariff features tariff escalation, adjustable tariffs, seasonal tariffs, and in-quota tariffs.

a. Tariff escalation is found in the customs duties on certain processed agricultural products (...)

b. Switzerland maintains a complex scheme of adjustable MFN tariffs based on target import prices, in order to protect its farmers or producers offeedstuffs, oilseeds, and feed mixtures. The basic structure of the schemes remains unchanged, as described in previous TPRs.

- Tariffs are reviewed monthly and adjusted if necessary, so that the duty-inclusive prices, including guarantee fund contributions, are raised to the level of target import prices, called "threshold prices".

(...)

${ }^{206}$ WTO Dispute Settlement: One-Page Case Summaries 1995-2016, p. 28 
- Imports of cereals of bread-making quality (e.g. wheat) are subject to a separate tariff mechanism with the statutory target import price called the "reference price". The levied tariffs are based on the tariffs of the grain, the standard flour yield, and an extra fixed tariff (industrial protection). The scheme works in combination with a tariff quota of 70,000 tonnes (TQ No. 27); the adjustable tariffs may not exceed the bound in-quota tariffs of the products concerned.

- A similar tariff mechanism exists for MFN sugar imports. Switzerland is aiming at approximate price parity with $E U$ sugar prices in order not to hamper the competitiveness of the Swiss food industry. MFN tariffs are examined, normally every month, and adjusted if necessary, so that duty-inclusive reference prices are aligned with EU sugar market prices (with a tolerance band of +/- SwF 30/tonne).

(...)

c. Switzerland levies seasonal tariffs on 95 agricultural products, all of which are fresh fruit, vegetables, or cut flowers. The seasonal tariffs are applied in combination with tariff quotas for most domestically produced fruit and vegetables. ${ }^{207}$ )

Switzerland is one of the few countries that continues to express all applied tariffs as specific rates, continues to monitor minimum prices, and manages other practices that might be seen as contrary to WTO rules, but that in fact are not.

The fact that Switzerland's entire tariff schedule and national tariff are expressed in specific rates means only that the country does not trust value to calculate tariffs. It uses specific rates for tariffs and AV rates for VAT. As such, by applying both types it minimizes the taxation risk of applying a single type of tariff.

\subsection{All tariffs in Switzerland and Liechtenstein are specific duties and do not need a customs valuation as the gross weight (weight of goods plus packaging) is used to calculate the duty. For VAT and some other taxes, such as the automobile duty, which are collected at the border and are based on value, the invoice value is used. ${ }^{208}$ )}

A national tariff should be tailor-made to each country's unique requirements, which would allow it to be more responsive to changes in the markets. Countries should

\footnotetext{
${ }^{207}$ WTO (2017). Trade Policy Review - Report by The Secretariat - Switzerland And Liechtenstein. WT/TPR/S/355, 2017, para 4.7, p. 96. Available at: https://www.wto.org/english/tratop_e/tpr_e/tp455_e.htm [accessed 15 September 2018]

${ }^{208}$ WTO (2017). Trade Policy Review - Report by The Secretariat - Switzerland And Liechtenstein. WT/TPR/S/355, 2017, para 3.1.2, p. 43. Available at:

https://www.wto.org/english/tratop_e/tpr_e/tp455_e.htm [accessed 15 September 2018]
} 
refrain from using the AV type in their entire national tariff, as there are better types of tariffs to be used according to the period and class of goods.

Both a national tariff and a WTO Member schedule could be perfectioned having rules for tariff features, such as convertibility between types, the recommendation of using the appropriate type for the class of goods, the suggestion to use multiple types to minimize risk, different rates aligned with seasonality, and even threshold rates for certain types of goods and/or countries to protect their national revenue. In such a scenario, rates could vary in many ways, such as according to prices, quantities, and market conditions. It is a change from most current national tariff and WTO Member schedules that consider only the bound rate. The main point here is against the standard AV reductionist approach that limits the use of tariffs as a revenue tool.

\subsection{Tariff Assessment: Classification, Value and Origin}

Tariff assessment means the determination of the amount of a tariff to be payable. For the purposes of this dissertation, it is relevant to understand the main elements to calculate a tariff. This section provides an overview of these elements.

A tariff assessment is based on the following criteria: a) customs classification; $b$ ) customs valuation; and c) country of origin, where liability depends upon all three of these criteria. Peter Van den Bossche summarizes the need for these three criteria:

The need for these determinations follows from the fact that customs duties differ from good to good (customs classification); are usually ad valorem duties and thus calculated on the basis of the value of the products concerned (customs valuation); and may differ depending on the exporting country (determination of origin). ${ }^{209}$

These criteria are assessed through a Customs declaration before the imported goods enter the customs territory. Customs declarations have existed since time immemorial, and a good example comes from the port of Piraeus:

When a ship entered the port of Piraeus and moved to a berth in the front of an emporium, the importer had to make a declaration to the so-called "pentecostologue", the Customs officer in charge of collecting the one-fiftieth duty, and pay him the duty before the merchandise could be released from the emporium or sold to someone else. ${ }^{210}$

\footnotetext{
${ }^{209}$ Bossche (2013), p.453

${ }^{210}$ Asakura op. cit., p. 39
} 
Nowadays, with the advancement of ICT systems, a pre-arrival import declaration is used in many countries. Such pre-arrival documents allow for the tariff assessment to be done before the goods arrive. Typically, after the assessment, a payment happens, and the goods are cleared to enter the territory. Reinforcing the obligation to pay customs duties, the AB held in EC - Poultry (1998):

it is upon entry of a product into a customs territory, but before the product enters the domestic market, that the obligation to pay customs duties... accrues. ${ }^{211}$

Thus, as briefly described, after the assessment and payment, the imported goods are released to enter the customs territory. In more detail, the three assessment criteria are as follows:

\section{Customs classification}

A customs classification for each good is necessary to find the tariffs, internal taxes, and other obligations to be satisfied before the good can enter a customs territory. Under the same classification, the goods have a range of different tariffs and obligations depending on each national customs tariff.

The goods classification is self-assessed by the importer or exporter and eventually audited by Customs. Naturally, a wrong classification can lead to misleading tariffs and obligations and thus when audits typically result in penalties.

In international trade, it is vital to have a standard system of customs classification. Hence, without a standard classification, it is virtually impossible to achieve transparency, to negotiate reductions, to formulate global statistics, and to implement world policies, among other things.

Nowadays, the standard classification system for international trade is the Harmonized Commodity Description and Coding System referred to as "Harmonized System" or simply "HS", developed by the Customs Cooperation Council (CCC), best known as the World Customs Organization (WCO). ${ }^{212}$

As of July 2018, the HS Convention had 157 Contracting Parties (156 countries and the European Union). However, according to the WCO, the system is used "by more than 200 countries and economies as a basis for their Customs tariffs and for the collection of international trade statistics". 213

\footnotetext{
${ }^{211}$ WTO, WT/DS69/AB/R, 13 July 1998, paragraph 145

${ }^{212}$ The Harmonized System Convention was approved in June 1983, during the $61^{\mathrm{st}} / 62^{\text {nd }}$ Sessions of the CCC and entered into force on 1 January 1988.

${ }^{213}$ WCO (2017)
} 
About the importance of the HS System the WCO writes:

It is a multipurpose goods nomenclature used, as of September 2006, by more than 200 countries and Customs or Economic Unions, 124 of which are the basis for Customs tariffs and for the compilation of international trade statistics. ${ }^{214}$

The HS groups goods in a logical structure of four-digit headings, which are later subdivided into five- and six-digit subheadings. Finally, the goods are identified by a sixdigit code. ${ }^{215}$ In relation to the HS structure the WCO explains:

Indeed, this structure reflects the manner in which the System was developed: first by the deliberate creation of 4-digit headings to accommodate particular groupings of related products, and second, by the subdivision of these headings to provide separate treatment for the more important trade products included in the headings. ${ }^{216}$

To illustrate the HS classification of goods, it is useful to give some examples:

- The HS code for vanilla is 0905.00, which indicates that heading 09.05 (Vanilla) has not been subdivided (fifth and sixth digits $=0$ ).

- The HS code for buckwheat is 1008.10 , which means that buckwheat is included in the first subheading (fifth digit $=1$ ) or heading 10.08 and that this subheading has not been further subdivided ( sixth digit $=0$ ).

At the WCO, the HS Committee, representing the Contracting Parties to the HS Convention, is responsible for maintaining the HS. Every five years the Committee prepares amendments. The latest amendment entered into force on 1 January 2017. It included 233 sets of amendments, divided as follows: agricultural sector 85 ; chemical sector 45 ; wood sector 13 ; textile sector 15 ; base metal sector 6 ; machinery sector 25 ; transport sector 18 ; and other sectors $26 .^{217}$

Therefore, the HS is the standard system used for the classification of goods and contributes to the harmonization of international trade. Consequently, the system is used by governments, international organizations and the private sector for matters of taxation, transport, statistics and research, among others. ${ }^{218}$

\footnotetext{
${ }^{214}$ WCO (2006a), p.5

215 The Harmonized System comprises 96 chapters (two-digit level), 1,241 headings (four-digit level), and around 5,000 subheadings (six-digit level).

${ }^{216}$ WCO (2006a) p.12

217 The next set of amendments is being discussions and will most likely enter into force on 1 January 2022.

218 The official interpretation of the HS is given in the Explanatory Notes published by the WCO.
} 
For the WTO, the importance of the HS System is evident in at least two disputes: EC - Computer Equipment (1998) and EC - Chicken Cuts (2006). ${ }^{219}$ In EC - Chicken Cuts (2006), the AB explained:

199. The above circumstances confirm that, prior to, during, as well as after the Uruguay Round negotiations, there was broad consensus among the GATT Contracting Parties to use the Harmonized System as the basis for their WTO Schedules, notably with respect to agricultural products. In our view, this consensus constitutes an "agreement" between WTO Members "relating to" the WTO Agreement that was "made in connection with the conclusion of" that Agreement, within the meaning of Article 31(2)(a) of the Vienna Convention. ${ }^{220}$

Thus, the AB made it clear that the HS System is the basis for tariff schedules and that it is applicable for the purposes of interpreting tariff commitments in the WTO Members' Schedules.

\section{Customs Valuation}

Once the good is classified according to its HS code and the correct tariff is found, it is necessary to determine the amount payable. Nowadays, most tariffs are AV tariffs and hence a percentage rate is applied to the value, also known as the customs value.

The assessment of the customs value is called customs valuation and is based on a set of GATT/WTO rules. Due to the complexity and length of the discussion about the applicability of such rules, this dissertation addresses this topic in specific chapters. ${ }^{221}$

\section{Rules of Origin}

Rules of origin enable the use of different tariff rates, depending on the country of origin of a good. In simple terms, the origin of the goods is like a person's nationality and therefore, depending on the determination of the nationality, the requirements may vary from one country to another.

The International Convention on the Simplification and Harmonization of Customs Procedures (the so-called Kyoto Convention, which entered into force in 1974) defines rules of origin as follows:

The specific provisions developed from principles established by national legislation or international agreements applied by a country to determine the origin of goods. (Annex K to the Revised Kyoto Convention)

\footnotetext{
${ }^{219}$ WTO DS62 and DS269

${ }^{220}$ WTO, WT/DS269/AB/R, p.199

221 The WTO customs valuation rules are dealt with extensively in Chapters 5, 6 and 7.
} 
Addressing the determination of the rules of origin, Wulf and Sokol explain:

\begin{abstract}
Determining the country of origin, or the "nationality, " of imported products is necessary for the application of basic trade policy measures such as tariffs, quantitative restrictions, antidumping and countervailing duties, and safeguard measures, as well as for requirements relating to origin marking and public procurement, and for statistical purposes. ${ }^{222}$
\end{abstract}

In international trade, there are two classes of rules of origin: a) preferential rules of origin and b) non-preferential rules of origin.

On the one hand, preferential rules of origin are those negotiated in various regional trade agreements to enable preferential tariffs to be implemented among the Contracting Parties of the preferential agreement. ${ }^{223}$ The preferential tariff rate is lower than the WTO Most-Favored Nation Tariff (MFN). ${ }^{24}$

\title{
Preferential Rules of Origin \\ Preferential rules of origin determine whether goods qualify for a preferential treatment under a given free trade agreement. They respond to specific trade interests linked to a preferential trade agreement and they clearly reflect those specific interests. Preferential rules of origin are therefore patterned after the economic interests of the parties involved with the result that preferential rules of origin are unavoidably individualistic and differ from agreement to agreement. ${ }^{225}$
}

In relation to preferential rules of origin, it is important to state that there are also preferential rules of origin used for the General System of Preference (GSP). ${ }^{226}$ The preferential rules of origin are rarely the same from one agreement to another. Therefore, there is a diversity of preferential rules of origin in today's trade system.

Nowadays, the number of Preferential Trade Agreements (PTA) is increasing the obligation of countries to determine the origin of the goods. Such a determination is often time-consuming and results in longer customs clearance times. The risk associated with the origin is the acceptance of a false origin declaration, which incorrectly permits the goods to benefit from preferential treatment.

\footnotetext{
${ }^{222}$ Wulf and Sokol (2004), p.xxi

223 In today's trading system, various regional trade agreements are being negotiated across the globe.

${ }^{224}$ MFN tariffs are what countries promise to impose on imports from other members of the WTO, unless the country is part of a preferential trade agreement.

225 WCO (2017). Origin Compendium. P. 13

226 Under the Generalized System of Preferences (GSP), developed countries offer non-reciprocal preferential treatment (such as zero or low duties on imports) to products originating in developing countries. Preference-giving countries unilaterally determine which countries and which products are included in their schemes. The basis for such preferential treatment derives from the "Enabling Clause" officially called the "Decision on Differential and More Favourable Treatment, Reciprocity and Fuller Participation of Developing Countries", adopted under GATT in 1979.
} 
As already mentioned, the rules for the determination of origin vary significantly depending on the FTA. However, in simple terms, there are two types of origin criteria: a) wholly obtained or b) substantial transformation.

Therefore, while there are direct criteria for 'wholly obtained', including among others: goods that naturally occur; live animals born and raised in a given country; and minerals extracted or taken from a single country, the criteria for substantial transformation is quite complex.

According to the WCO, the three major criteria that result in a substantial transformation are: a) a criterion of a change in tariff classification; b) a criterion of value added (AV percentages); and c) a criterion of manufacturing or processing operations (technical requirement).

a. A criterion of a change in tariff classification

A good is considered substantially transformed when the good is classified in a heading or subheading (depending on the exact rule) different from all nonoriginating materials used.

(...)

b. A criterion of value added (ad valorem percentages)

Regardless a change in its classification, a good is considered substantially transformed when the value added of a good increases up to a specified level expressed by ad valorem percentage. (...)

\section{c. A criterion of manufacturing or processing operations (technical} requirement)

Regardless a change in its classification, a good is considered substantially transformed when the good has undergone specified manufacturing or processing operations. ${ }^{227}$

The choice of the criteria to determine whether there is a substantial transformation often varies according to the PTA. In this regard, the WTO describes the rules of origin variation to determine substantial transformation as follows:

There is wide variation in the practice of governments with regard to the rules of origin. While the requirement of substantial transformation is universally recognized, some governments apply the criterion of change of tariff classification, others the ad valorem percentage criterion and yet others the criterion of manufacturing or processing operation. ${ }^{228}$

\footnotetext{
${ }^{227}$ WCO (2012), Rules of Origin - Handbook.

${ }^{228}$ WTO (2017). Technical Information on Rules of Origin.
} 
Therefore, depending on the FTA, the rules of origin vary from a) a change in tariff classification; b) a value-added determination; and c) a technical requirement).

In conclusion, the preferential rules for origin are determined on a case-by-case basis depending on the negotiated FTAs or GSP.

In contrast, non-preferential rules of origin are used in the application of nonpreferential measures, such as antidumping and countervailing duties. ${ }^{229}$

\section{Non-Preferential Rules of Origin}

$$
\text { (...) }
$$

The non-preferential rules of origin are used for the implementation of an array of trade policy measures which are listed under paragraph 2 of Article 1 of the WTO Agreement on Rules of Origin:

- Application of Most-Favoured Nation-Treatment;

- Anti-Dumping and Countervailing Duties;

- Safeguard Measures;

- Origin Marking Requirements;

- Quantitative Restrictions or Tariff Quotas;

- Government Procurement; and

- Trade Statistics. ${ }^{230}$

Thus, while the preferential origin results in benefits, such as a lower tariff rate, the non-preferential origin implies a more restrictive and costly procedure for the goods to enter a customs territory.

At the GATT Uruguay Round (UR) the negotiators started to negotiate an Agreement on Rules of Origin (ARO) for non-preferential rules of origin. The intention of the $\mathrm{ARO}$ is to harmonize the non-preferential rules of origin. So far, the non-preferential harmonization working programme has proved unsuccessful and, after many years there has been no conclusion to the negotiations.

Despite the absence of harmonization, it is worth mentioning that the WTO ARO provides the following four basic principles:

(1) Non-discrimination: RoO must apply equally for all purposes of nonpreferential treatment;

\footnotetext{
${ }^{229}$ One of the annexes to the Marrakech Agreement is the WTO Agreement on Rules of Origin (part of the Annex 1A: Multilateral Agreements on Trade in Goods). The Agreement on Rules of Origin aims at harmonizing the non-preferential rules of origin.

${ }^{230}$ WCO (2017). Origin Compendium. P. 13
} 
(2) Predictability: RoO must be objective, understandable and predictable;

(3) Transparency: RoO must not be used directly or indirectly as instruments to pursue trade policy objectives; and

(4) Neutrality: RoO must not, in and of themselves, have a restrictive, distorting or disruptive influence on international trade.

Finally, it is worth mentioning that a draft consolidated text on non-preferential rules of origin was developed reflecting discussions held by the WTO Committee on Rules of Origin. ${ }^{231}$

\subsection{Concluding Remarks}

The GATT/WTO law prefers tariff over non-tariff trade barriers, as the former is more transparent and easier to eliminate. However, in some LDCs and developing countries, if domestic taxation fails to capture a share of the gains from consumers and/or producers, the GATT/WTO assumption about the benefits of the elimination of tariffs might be wrong. In other words, tariff elimination might put revenue mobilization to pay for public services at risk.

There are different types of tariffs, including AV, specific, compounded, mixed, and technical. There are also neotypes of tariffs used in other market pricing structures, such as electricity. The GATT/WTO preference for AV tariffs to the exclusion of other tariff types is questioned in this chapter. There are several reasons why AV tariffs might not be appropriate from the perspective of LDCs and developing countries.

Tariffs are legitimate instruments that can be used to generate fiscal revenue. However, it is necessary that their purpose is to generate revenue. Some of the tariff issues are: a) the appropriate tariffs for different classes of goods; b) the adequate level of tariffs per country; and c) the possibility of developing neo-tariffs in international trade.

In summary, the chapter argued that, in the GATT/WTO move for the conversion of tariffs from NAV to AV duties, and their reduction or elimination, more attention must be paid to the unintended fiscal consequences for various countries. In this vein, this chapter takes a critical approach to the modality of negotiations and AV simplification.

Following on from this, the chapter presented customs tariff schedules. It argued that national tariff schedules should be dynamic, with both the possibility of downward

\footnotetext{
${ }^{231}$ WTO (2010). Draft Consolidated Text of Non-Preferential Rules of Origin Harmonization Work Programme. G/RO/W/111/Rev.6. 11 November 2010
} 
and upward adjustments, serving as relevant tools to assist countries in dealing with tariff revenue.

Finally, the chapter introduced the three main elements necessary to calculate a tariff, namely: a) customs classification; b) customs valuation; and c) country of origin, where liability depends upon all three of these criteria. From these elements, for the purposes of this dissertation, the most important is customs valuation, which will be set out in the next chapters. 


\section{Theory of Value and Customs Valuation}

The conversion of different tariff types to AV tariffs makes it necessary for WTO Members to determine the value of imported goods in accordance with the CVA. Therefore, the discussion in this chapter is necessary to answer the research question, as it examines the basis of the theory of value and its impact on customs valuation. It provides a theoretical background to understand the complexity of attempting to value goods according to the WTO CVA set of rules. The history of customs valuation is essential for the debate about the WTO set of rules. It is important to understand that WTO rules can be changed in the future for other valuation attempts. The quest for finding proper methods to valuing goods is key to international trade.

The research question addressed in this dissertation is whether AV tariffs are the best type of tariffs for the entire spectrum of traded goods and for all WTO Member countries as well as the trade revenue that comes from the determination of value of goods. For the purposes of this investigation, it is questioned whether the conversion of different types of tariffs into AV may create undesired fiscal consequences such as restricting the ability to generate revenue using tariffs. Considering that AV tariffs need a customs value, the examination of value and its derived customs valuation is essential to understand the problem.

In this sense, the chapter reveals the evolution in the thinking related to the theory of value, addressing its different approaches. As society, manufacturing and technology advance, so does the scholarly thinking about how to value the goods. Thus, how value was considered in the past and how it is considered now serves to give information to the reader to be in a position to analyse the WTO CVA set of rules critically.

In summary, the purpose of this chapter is threefold. First, it will present the main economic ideas about the theory of value. Second, it will explain valuation for international trade and the customs valuation negotiations of the League of Nations in the 1920s to the GATT 1947. Third, it will examine different types of customs valuation systems, including the American Selling Price (ASP) and the Brussels Definition of Value (BDV).

\subsection{Brief Introduction to the Theory of Value}

According to the Oxford English Dictionary, valuation is: "An estimation of the worth of something, especially one carried out by a professional valuer." 232 In my view, the definition brings up at least two points that need to be considered: (1) the nature of worth; and (2) the importance of the valuer in the estimation of worth. Many scholars

${ }^{232}$ OED, 2016 
have addressed these two questions. This chapter briefly introduces the studies of several scholars about the theory of value.

Already in Ancient Greece, the theory of value was an important area of study.

Aristotle (384-322 B.C.), the Greek philosopher, was the first known scholar to write extensively about value. His theory of value is formulated in Politics, Book I, Chapter IX where, for the first time, he differentiates between the two types of value: use value and exchange value:

The uses of every possession are two, both dependent upon the thing itself, but not in the same manner, the one supposing an inseparable connection with it, the other not; as a shoe, for instance, which may be either worn, or exchanged for something else, both these are the use of the shoe; for he who exchanges a shoe with some man who wants one, for money or provisions, uses the shoe as a shoe, but not according to the original intention, for shoes were not at first made to be exchanged. ${ }^{233}$

Aristotle's shoe example illustrates two different types of value: use value and exchange value. These two types of values are understandable. Goods that are acquired to be used according to their original intention, such as owning a pair of shoes to wear them, would be valued according to use value. On the other hand, goods that are acquired to be used in exchange for other goods would be valued according to their exchange value.

It is interesting that a good might have a high use value and a low exchange value and vice-versa. For example, consider a good that, regardless of its value, evokes emotions and memories. That good might have a high use value and, at the same time, a low exchange value. Examples of use and exchange value discrepancy can be found in artistic goods, such as paintings, sculptures and handicraft items.

Aristotle knew how difficult, subjective, and sometimes impossible it is to determine the use-value of an object. His focus was therefore on the exchange value. For him, the exchange value had to be determined on an objective basis. Therefore, one fundamental question formulated by Aristotle was, how can the exchange value be determined objectively?

Another fundamental question related to Aristotle's teachings is whether it is possible to separate the subjective from the objective. Is it feasible to develop a methodology to calculate the fair value that is not affected by the subjective value?

These questions are rather philosophical, but they have practical implications for any valuation method, including customs valuation.

${ }^{233}$ Aristotle \& Ellis (2006), p.22 
Thomas Aquinas (1225-1274), the Italian Dominican friar, whose best-known work is the Summa Theologica, written between 1265 and 1274, was another distinguished contributor to the theory of value.

In the Summa Theologica, Thomas Aquinas developed the theory of the just price, among other things. This theory deals with ethics in economics and is an attempt to set standards of fairness in transactions. Thomas Aquinas argues against usury, saying that a Christian should "do unto others as you would have them do unto you," meaning that one should trade value for value and nothing else.

Aquinas believed that it was immoral to raise prices based on the buyer's urgent need and that the seller should not profit from this situation. In his Summa Theologica, Second Section of Part II, he deals with Humanity and Morals and on question 77, he writes about trade, buying, selling, and his primary concern about just price:

\section{Question 77 - (D) BY SINS COMMITTED IN BUYING AND SELLING}

$$
\text { (...) }
$$

On the contrary, It is written (Mat. 7:12): "All things . . whatsoever you would that men should do to you, do you also to them." But no man wishes to buy a thing for more than its worth. Therefore no man should sell a thing to another man for more than its worth. I answer that; It is altogether sinful to have recourse to deceit in order to sell a thing for more than its just price because this is to deceive one's neighbor so as to injure him. Hence Tully says (De Offic. iii, 15): "Contracts should be entirely free from double-dealing: the seller must not impose upon the bidder, nor the buyer upon one that bids against him."234

Notice the emphasis that Saint Thomas Aquinas put on equality and justice. According to him, money was invented to measure the quality of things and thus make things comparable. He would be surprised how normal it has become to accept usury instead of the fair and reasonable "just price."

This dissertation assumes that Saint Thomas Aquinas' interpretation of a fair price and reasonable "price" is alive in the concept of "actual value" found in GATT 1947, Article VII, where it says:

Article VII: Valuation for Customs Purposes

$$
\text { (...) }
$$

\footnotetext{
${ }^{234}$ Aquinas (2013), p.1507
} 
2. (a) The value for customs purposes of imported merchandise should be based on the actual value of the imported merchandise on which duty is assessed, or of like merchandise, and should not be based on the value of merchandise of national origin or on arbitrary or fictitious values. *

According to this, the actual value is seen as the just price referred to by Saint Thomas Aquinas. It is an amount assessed in the ordinary course of trade under fully competitive conditions.

Adam Smith $^{235}$ (1723-1790) is another scholar that discussed the theory of value. He is the father of the labour theory of value (LTV) and thus argues that, in a primitive society, the amount of labour put into producing a good determines its exchange value. In this case, exchange value refers to the amount of labour necessary to acquire a good. Labour would be the first and original price by which all wealth can be acquired.

The value of any commodity, therefore, to the person who possesses it, and who means not to use or consume it himself, but to exchange it for other commodities, is equal to the quantity of labor which it enables him to purchase or command. Labor, therefore, is the real measure of the exchangeable value of all commodities. 236

According to Adam Smith, it is not by the abstract notion of labour that the exchangeable value is commonly estimated. He refers to the fact that commodities are compared to other commodities and not directly to labour. Exchange value is estimated using comparison. "It is more natural, therefore, to estimate its exchangeable value by the quantity of some other commodity, than by that of the labor which it can produce". ${ }^{237}$

Adam Smith's teachings about estimation by comparability are essential to understanding valuation methods. In fact, there seems to be no other way to undertake valuation. The use of comparison goods is an essential process to determine value. Later, he teaches that estimation and comparability can be carried out by using money:

Hence, it comes to pass, that the exchangeable value of every commodity is more frequently estimated by the quantity of money, than by the quantity either of labor or other commodity which can be had in exchange for it. ${ }^{238}$

Adam Smith also wrote about the ambiguity of the two types of value identified by Aristotle: use and exchange value. According to Smith, a paradox could be found, since things that have the greatest value in use often have little value in exchange and vice

\footnotetext{
${ }^{235}$ In 1777, Adam Smith was appointed Scottish Commissioner of Customs and the Salt Duties, which was a position that was vacant after the death of Mr. Archibald Menzies.

${ }^{236}$ Smith, A. (2005), p.31

${ }^{237}$ Smith, A. (2005), p.32

${ }^{238}$ Idem, p.33
} 
versa; that is, things that have the greatest value in exchange, such as a diamond, often have little value in use.

A major critic of Adam Smith's theory of value is that, in a more advanced society, the price of goods is no longer proportional to the labour required to produce them alone, since the value of the good now includes compensation for the owner of the means of production and many other services related to the production of the good. In current society, the value of the input technology and intangibles exceed the manufacturing costs, meaning that the value can no longer be calculated by only taking the goods into consideration.

David Ricardo (1772-1823) also wrote extensively about the theory of value, dealing with the relationship between the value of a commodity and the relative quantity of labour necessary for its production.

For goods to have a price and a respective value, David Ricardo argued that they must be useful. For Ricardo, utility is essential for a good to have an exchangeable value:

1.3 - Utility then is not the measure of exchangeable value, although it is absolutely essential to it. If a commodity were in no way useful, - in other words, if it could in no way contribute to our gratification, - it would be destitute of exchangeable value, however scarce it might be, or whatever quantity of labor might be necessary to procure it. ${ }^{239}$

However, David Ricardo also said that there were other essential factors for a good to obtain a value, such as scarcity and the quantity of labour required to acquire the good. According to David Ricardo, due to the relationship between the supply and demand of commodities in the market, their prices continuously oscillate around a nucleus. This core nucleus is its value.

David Ricardo continued to explore the labour theory of value (LTV) by focusing on new, more complex issues, and thus he managed to address many of Smith's inconsistencies and ambiguities. Ricardo, for example, discredited Adam Smith's narrow vision that the value of a commodity is solely based on the direct labour needed to produce it. Instead, he said that the value of a good is proportional to the labour employed to produce it. The view of proportional labour to produce a good and determine its exchange value, however, was altered by the introduction of the use of machinery and other fixed and sustainable capital.

John Stuart Mill (1806-1873) dedicated a large part of his writings on political economy to the discussion of value. He dedicated book III of Principles of Political

${ }^{239}$ Ricardo (1821), p.1.3 
Economy to exchange and the questions related to value. John Stuart Mill considered the theory of value to be fundamental in society's economic interests:

III.1.2 - In a state of society, however, in which the industrial system is entirely founded on purchase and sale, each individual, for the most part, living not on things in the production of which he himself bears a part, but on things obtained by a double exchange, a sale followed by a purchase-the question of Value is fundamental. (... $)^{240}$

John Stuart Mill continued to analyse this topic and stated that the laws of value were complete. According to him, it was now a question of understanding the complexities of the matter:

III.1.2 - (...) Happily, there is nothing in the laws of value which remains [1848] for the present or any future writer to clear up; the theory of the subject is complete: the only difficulty to be overcome is that of so stating it as to solve by anticipation the chief perplexities which occur in applying it: and to do this, some minuteness of exposition, and considerable demands on the patience of the reader, are unavoidable. $(. . .)^{241}$

For John Stuart Mill, political economy should only study the exchange value. One of the most significant contributions from Mill is the distinction between exchange value and price. He argued that price is not value; rather, it is just an expression of value about money. In its complete sense, value comprehends the general power of purchase in relation to all other commodities.

III.1.5 - Exchange value requires to be distinguished from Price. The words Value and Price were used as synonymous by the early political economists, and are not always discriminated even by Ricardo. (...) By the price of a thing, therefore, we shall henceforth understand its value in money; by the value, or exchange value of a thing, its general power of purchasing; the command which its possession gives over purchasable commodities in general". ${ }^{242}$

Depending on the circumstances, the value of a good can increase in comparison to some factors and decrease in relation to others. Mill illustrated the need to differentiate value from price by pointing out a common error in believing that all goods could rise or fall in value at the same time. That would be a contradiction, since it is evident that, for something to rise in value, something else needs to fall in value:

III.1.8 - (...). All commodities may rise in their money price. But there cannot be a general rise of values. It is a contradiction in terms. A can only rise in value

\footnotetext{
${ }^{240}$ Mill (1870), III.1.2

${ }^{241}$ Idem

${ }^{242}$ Idem, III.1.5
} 
by exchanging for a greater quantity of $B$ and $C$; in which case these must exchange for a smaller quantity of $A$. All things cannot rise relatively to one another. (...). ${ }^{243}$

Hence, Mill pointed out that a general rise or fall in prices is just a consequence of the change in the value of money and not in the value of goods. For John Stuart Mill, the laws of value and price can only be applied when competition is in place. As David Ricardo, he relates value with utility and connects value with supply and demand.

Considering supply and demand, John Stuart Mill formulates the "Law of Value" as follows:

III.2.14 - Demand and supply, the quantity demanded and the quantity supplied, will be made equal. If unequal at any moment, competition equalizes them, and the manner in which this is done is by an adjustment of the value. If the demand increases, the value rises; if the demand diminishes, the value falls: again, if the supply falls off, the value rises; and falls if the supply is increased. ${ }^{244}$

He further introduces the concept of "minimum value" as an essential value of labour and expenditure that sets a condition to produce a good. It is important to note that Adam Smith and David Ricardo also talk about a "natural value," which is a core value or, in the words of John Stuart Mill, a "minimum value" from which value may fluctuate but which is always returned to ultimately.

Karl Marx (1818-1883) considered the theory of value as a pillar for his entire economic system. Marx recognized value as an expression of the quantity of the social labour contained in a product, a perspective that overestimated the manual labour of the proletarians.

Marx's labour theory of value (LTV) leverages the contributions of classical economists. Marx saw beyond the commodities of human labour and saw the relationships between workers and the connections between classes as also relevant. Hence, what is exchanged between people is crystallized labour embodied in various commodities. Marx also made a distinction between the exchange value and the concept of utility.

Karl Marx did not base his LTV on an individual perspective of labour, but on a more complex concept of "socially necessary abstract labor-time." Whereas most economists start with the individual's perspective, Marx begins with the view of society as a whole. "Social production" involves a complicated and interconnected division of labour of a wide variety of people who depend on each other for survival and prosperity. ${ }^{245}$

\footnotetext{
243 Idem, III.1.8

${ }^{244}$ Idem, III. 2.14

${ }^{245}$ Marx \& Engels (2007)
} 
This complicated division of labour implies that the fact that two goods have an equivalent amount of labour does not mean that they have a similar exchange value; rather, the two goods must have the same amount of "socially necessary" labour.

Max explains the transformation of a use-value good into a commodity or exchange value good as the process of commodification in a scenario where trade must exist and where it is possible to transfer ownership.

John Maynard Keynes (1883-1946) writes about market valuation in financial markets and reflects on these questions and the theory of value:

We are assuming, in effect, that the existing market valuation, however, arrived at, is uniquely correct in relation to our existing knowledge of the facts which will influence the yield of the investment, and that it will only change in proportion to changes in this knowledge; though, philosophically speaking it cannot be uniquely correct, since our existing knowledge does not provide a sufficient basis for a calculated mathematical expectation. ${ }^{246}$

John Maynard Keynes emphasizes that our existing knowledge of the facts is insufficient to calculate mathematical expectations about the market. In other words, market valuations rely on imperfect knowledge. Later, John Maynard Keynes refers to the influence of mass psychology on market valuations:

(3) A conventional valuation which is established as the outcome of the mass psychology of a large number of ignorant individuals is liable to change violently as the result of a sudden fluctuation of opinion due to factors which do not really make much difference to the prospective yield; since there will be no strong roots of conviction to hold it steady. ${ }^{247}$

John Maynard Keynes says that even though there are no firm roots for market valuations to change, they may change according to optimistic and pessimistic sentiments. In other words, feelings play a major role in valuation.

Gérard Debreu (1921-2004) contributed to the development of the general equilibrium theory. Debreu's masterpiece is the Theory of Value, published in 1959 and dedicated to presenting the general equilibrium theory resulting from the interaction via markets in a purely axiomatic form.

The theory of value is treated here with the standards of rigor of the contemporary formalist school of mathematics. The efforts towards rigor

\footnotetext{
${ }^{246}$ Keynes, J. M., (1936). Chapter 12, IV

${ }^{247}$ Idem
} 
substitutes correct reasoning and results for incorrect ones, but it offers other rewards too...Allegiance to rigor dictates the axiomatic form of the analysis where the theory, in the strict sense, is logically entirely disconnected from its interpretations. ${ }^{248}$

In sum, Debreu's explanation is that the value of goods and services results from the interaction via markets, between economic agents and private ownership, and the exploration of the role of prices in the optimal state of a given economy. The analysis is organized around the price system or the value function defined in the commodities market.

In my view, the critical point in Debreu's explanation is the commodities market approach to the value function. Thus, if the good can be classified as a commodity, it is possible to use the value function. On the other hand, if it cannot be classified as a commodity then the value function might not be applicable. The question then returns to whether goods can be classified as commodities or not.

Jean Baudrillard (1929-2007) was a social theorist who claimed that commodities are not merely to be characterized by use-value and exchange value, but by sign value, the expression and mark of style, prestige, luxury, power, and so on, which becomes an increasingly important part of the commodity and consumption. ${ }^{249}$

Jean Baudrillard claimed that commodities are bought and displayed as much for their sign value as their use value and that the phenomenon of sign value has become an essential constituent of the commodity and consumption in a consumer society.

For Baudrillard, society is organized around consumption and the display of commodities through which individuals gain prestige, identity, and standing. In this system, the more prestigious one's commodities (houses, cars, clothes, etc.) are the higher one's standing in the realm of sign value.

The car epitomizes the object, perfectly illustrating every trait we have described: the rendering abstract of any practical goal in the interests of speed and prestige, formal connotation, technical connotation, forced differentiation, emotional cathexis, and protection in phantasy. ${ }^{250}$

Thus, just as words take on meaning according to their position in a language system, sign values also take on meaning according to their place in a differential system of prestige and status.

\footnotetext{
248 Debreu (1959), p. 80

${ }^{249}$ Baudrillard (1994)

${ }^{250}$ Baudrillard (1996) p., 69
} 
In conclusion, Aristotle, Thomas Aquinas, Adam Smith, David Ricardo, John Stuart Mill, Karl Marx, John Maynard Keynes, Gérard Debreu, Jean Baudrillard and many others show the importance of the theory of value for a better understanding of the complexities of valuation. Use, exchange, and sign value are examples of elements that have been associated with value. In my opinion, the discussion about the elements that form value is constantly changing.

None of these scholars provides definitive answers about the nature of value or how to conduct a valuation process. Most modern scholars agree, however, that a valuation process is subjective, which therefore depends on who is performing the valuation and his/her knowledge.

More recently, some scholars said that a valuation process and consequently value could be interpreted as a symbol that is linked to beliefs. The conclusion is that valuation is thus an abstract process that depends on people's opinions. In other words, inner beliefs or, what John Maynard Keynes referred to in his works as sentiments, play a role in the valuation outcomes.

The importance of the conclusion about the theory of value is to critically question the extreme importance of the supply and demand theory in the WTO CVA. As such, this dissertation asserts that the prices of internationally traded goods suffer, among other things, from the effects of psychological conditions that cannot be clearly understood or quantified. This results in the possibility that price volatility results in trade distrust, as it makes it impossible to plan or predict any revenue or control based on AV tariffs calculated as a fixed percentage of the unknown customs value of the goods.

Considering that the WTO CVA set of rules is based on the belief that a transaction value is negotiated in free market circumstances, the idea that there are unforeseen psychological factors in the equation, makes it almost impossible, for example, to use Adam Smith's teachings about estimation by comparability. In such a volatile trade system, the use of comparison goods is useless to audit the customs valuation.

Consequently, customs valuation as a derivative of the theory of value is directly influenced by the trader's subjectivity and beliefs. Thus, revenue coming from AV tariffs is also affected, and countries that rely on such trade revenue to provide public services are in danger.

\subsection{History of Customs Valuation}

The "Monument of Ephesus" shows that the Roman empire had customs valuation measures in place for the Roman province of Asia from 75 B.C. to A.D. 62. The 
inscription is written in Greek, and it is mainly about a self-declaratory value for customs valuation.

[87] Whatever anyone registers under the terms of this law, he shall pay the tax on it to the tax-collector according to the valuation of the item; if he does not do this, he shall give double the amount [of tax], and for this matter the tax-collector is permitted to confiscate or take a surety. ${ }^{251}$

According to the "Monument of Ephesus," the trader seemed to be responsible for the customs valuation register, and the tax-collector was responsible to audit that value. If the trader did not disclose the correct value, the tax-collector had the authority to double the tax and even confiscate or get a surety bond on the good. Customs valuation was, therefore, self-declaratory and subject to penalties.

Kautilya's Arthashastra includes registers about the customs systems on the Indian sub-continent during the Maurya Dynasty (317 - 180 B.C.). ${ }^{252}$ In the Arthasastra, the customs valuation system seems to be similar to an auction. ${ }^{253}$

\section{Book II, "The Duties of Government Superintendents"}

Chapter XXI. The Superintendent of Tolls.

\section{(...)}

The merchandise being placed near the flag of the toll-house, the merchants shall declare its quantity and price, cry out thrice "who will purchase this quantity of merchandise for this amount of price, " and hand over the same to those who demand it (for that price). When purchasers happen to bid for it, the enhanced amount of the price together with the toll on the merchandise shall be paid into the king's treasury. When under the fear of having to pay a heavy toll, the quantity or the price of merchandise is lowered, the excess shall be taken by the king or the merchants shall be made to pay eight times the toll. The same punishment shall be imposed when the price of the merchandise packed in bags is lowered by showing an inferior sort as its sample or when valuable merchandise is covered over with a layer of an inferior one. ${ }^{254}$

Thus, according to the Arthasastra, imported goods were subject to an auction to verify the importers' declared price. The king would benefit from a price enhancement and would punish under-invoicing. It was a self-declaratory system audited by auction.

\footnotetext{
${ }^{251}$ Cottier et al. (2008)

252 The Arthashastra is an ancient Indian treatise on statecraft, economic policy and military strategy, written in Sanskrit between the $2^{\text {nd }}$ and $3^{\text {rd }}$ century B.C.. The first English translation was published in 1915 .

${ }^{253}$ Kautilya's Arthashastra (1915), p. 155

${ }^{254}$ Kautilya's Arthashastra (1915). Book II, "The Duties of Government Superintendents". Chapter XXI. The Superintendent of Tolls.
} 
In more recent times, the Tudor Book of Rates from around 1303 further illustrates the question of customs valuation. The Book of Rates had a list of imports and exports with their respective values for tariffs collection.

However, to avoid complicated valuation procedures and disputes between the Customs and merchants, a list of imports and exports merchandise with their values per unit quantity was drawn up and with this list the Customs was able to assess the $5 \%$ ad valorem duty without difficulty. ${ }^{255}$

Thus, values were determined alongside the goods. It is a type of black book with a list of goods and minimum prices for each one. It seems that the biggest problem with such a fixed list was the inflation which, at that time, was difficult to measure.

The First International Conference of American States (1889-90), which established the International Union of American Republics (later called the Pan-American Union), registered its concerns related to classification and customs valuation. ${ }^{256}$ During the 1890 Conference, the U.S. Secretary of State James G. Blaine declared:

The act of Congress authorizing the International American Conference, recently in session in this capital, provided that, among other subjects, it should-consider the establishment of a uniform system of customs regulations in each of the independent American States, to govern the made of importation and exportation of merchandise, and port dues and charges, a uniform method of determining the classification and valuation of such merchandise in the ports of each country, and a uniform system of invoices. ${ }^{257}$

For the purposes of this dissertation, it is relevant to mention that the committee on customs regulations declared the importance of customs duties for the national revenue of countries at the 1890 International Conference of American States.

2. The committee has given due weight to the fact that each of the countries represented depends upon customs duties as the chief source of national revenue, and that the productiveness as security of revenue must not be threatened nor impaired under the guise of simplification or improvement of regulations or its collection. ${ }^{258}$

It is a clear message about the importance of trade revenue and the danger of simplification to the collection of revenue. This is an important message that was and

\footnotetext{
255 Asakura op. cit. p.173

${ }^{256}$ The countries in the 1890 International American Conference were: Haiti, Nicaragua, Peru,

Guatemala, Uruguay, Colombia, Argentina, Costa Rica, Paraguay, and Brazil.

${ }^{257}$ International American Conference (1890). President Message.

${ }^{258}$ Idem. Reports of the Committee on Customs Regulations.
} 
is still overlooked by the GATT/WTO members when using formulas and converting tariffs into $\mathrm{AV}$.

The historical examples provided here present the background to understand the importance of customs valuation better. The main idea is to have a fair and accepted customs valuation system. A misregister or an arbitrary audit could lead to tax avoidance or protectionist measures. Therefore, rules for customs valuation have been in place since ancient times.

\subsection{The Roaring 1920s - Trade Tariffs}

The history of tariffs is full of ups and downs. The more recent history of tariffs begins in the period immediately after World War I. This period is known as the "Roaring Twenties", "Années Folles", or the "Crazy Years," all of which describe a booming time for Western society and culture in the 1920s. It was a period of economic prosperity and cultural transformations in the United States, Canada, and Western Europe. The 1920s represented the large-scale use of automobiles, telephones, motion pictures, radio, and electricity; commercial, passenger, and freight aviation; as well as unprecedented industrial growth, and accelerated consumer demand.

However, the 1920s was a time of significant protectionism. After World War I and during the years of the Great Depression in the 1930s, many countries tried to protect their economies by implementing different barriers such as customs duties, quantitative restrictions, and exchange controls.

As background, it is important to mention that the 1920s election in the U.S. put the Republican Warren G. Harding in control of the White House. The Republicans were also in control of the Congress. The same configuration occurred in 2017 with Republicans controlling both the executive branch (with President Donald Trump) and the legislative branch.

During the 1920s, the United States, for example, published the Fordney-McCumber Tariff Act (1922) and the Smoot-Hawley Tariff Act (1930). Both tariff laws are extremely important in understanding the customs duties roller coaster. The FordneyMcCumber Act was a law made to raise American tariffs on many imported goods, allegedly to protect factories and farms. The US Congress passed the tariff bill to increase import tariffs and promoted American exports backed up by loans made to Europe. To give some more context to these times, Northrup explains:

Prior to World War I, President Woodrow Wilson persuaded Congress to pass the Underwood-Simmons Tariff Act, reducing duty rates from an average of 41 to 27 percent and placing over a hundred items on the free list. (...) Before the 
net effect of the tariff reductions could be realized, World War I disrupted the normal international patterns. At the end of the war, the U.S. economy

underwent a period of recession. Congress responded by passing the Emergency Tariff Act of 1921 as well as the Fordney-McCumber Tariff of $1922 .{ }^{259}$

In the Fordney-McCumber Tariff of 1922, the U.S. Congress worked with at least two important new tools for protection. The first was called the "scientific tariff", the purpose of which was to equalize production costs among countries. The Tariff Commission was responsible for calculating the difference in production costs between third countries and the U.S. to set the scientific tariff. The second protection tool and even more relevant to this dissertation was the American Selling Price (ASP) system of customs valuation. The ASP system allowed the president to calculate the duty based on the American price of a good, not the price of the imported product. ${ }^{260}$

In the end, the tariff law of 1922 raised the American AV tariff rate which should be determined by the cost of production and market value of the products produced nationally.

\subsection{League of Nations - Customs Valuation 1927 - 1930}

After World War I, many countries tried to protect their economies by implementing different barriers such as tariffs, quantitative restrictions, and exchange controls. During these years, the US published the Fordney-McCumber Tariff Act (1922) and the Smoot-Hawley Tariff Act (1930). These laws are relevant in understanding tariff policies in recent history.

Considering the overall use of tariffs, the need for international rules on customs valuation was on the agenda of the League of Nations Economic Conferences in 1927 and 1930.

In the early 1920's, the need for international standards of customs valuation was voiced by some countries. The subject was on the agenda of the League of Nations Economic Conferences held in Geneva in 1927 and 1930; though the participating countries agreed on the need for action, none resulted. ${ }^{261}$

\footnotetext{
${ }^{259}$ Northrup (2003), p.146

${ }^{260}$ United States (1922), p.218

${ }^{261}$ US United States Tariff Commission \& United States Congress Senate Committee on Finance Subcommittee on International Trade, (1972), p.10
} 
Thus, the records of the League of Nations Economic Conferences held in Geneva from 1927 to 1930 shows that the discussions about international customs valuation rules pre-date the GATT. ${ }^{262}$

Unfortunately, the League of Nations stopped the examination of customs valuation and other trade-related issues due to world instability and the beginning of World War II. After the war, the UN replaced the League, and the topic was taken up in the GATT and the Havana Charter for the ITO creation signed in 1948.

Regarding this matter, the GATT Analytical index on Article VII - Valuation for Customs Purposes states the following:

\section{Provisions corresponding to Article VII of the GATT - Valuation for Customs Purposes, appear in Chapter III-4 of the US-UK Proposals, in Article 12 of the US Draft Charter, in Article 18 of the New York Draft Charter, and in Article 34 of the Geneva Draft Charter. ${ }^{263}$}

By the end of World War II, leaders of the major countries concluded that to promote peace and avoid another war, a system of international organizations to solve global political, economic, and trade problems was necessary. In response to such needs, delegates from forty-four countries gathered in July 1944 at the UN Monetary and Financial Conference in Bretton Woods, New Hampshire. The Conference became known as the Bretton Woods Conference. Its outcome was an Agreement containing a system of rules, institutions, and procedures to regulate the international monetary system.

The Breton Woods Agreement established the International Monetary Fund (IMF) and the IBRD (International Bank for Reconstruction and Development), which is part of the World Bank Group today. The Conference is relevant for the multilateral trade system because delegates at Bretton Woods also considered the establishment of an institution designed to regulate trade: the International Trade Organization (ITO).

\subsection{ITO and GATT - Background 1947 - 1948}

The ITO would complete the structure of the economic post-war Bretton Woods triad of international agencies responsible for creating a new economic order. Regarding the Bretton Woods system and the role of the ITO, Fulton and Buterbaugh teach:

\footnotetext{
${ }^{262}$ Many international organizations, including the WCO, can trace their origins to the different committees from the League of Nations in Geneva.

${ }^{263}$ WTO (2012). GATT Analytical index, p. 266
} 
The result of the conference was the Bretton Woods System. It "was based upon three pillars: economic development, monetary stability, and trade." The World Bank supported the first pillar, the International Monetary Fund the second, and an International Trade Organization (ITO) was to be formed to support the third. ${ }^{264}$

Thus, the ITO was the organization that would support the trade pillar. Following the discussions at Bretton Woods, the US and Great Britain continued to exchange views about the future institution. Fulton and Buterbaugh register the past discussions:

In September of 1945, America sent a proposal to Great Britain based on a State Department publication entitled "Proposals for the Expansion of the World Trade and Employment," closely following a 1937 secret memo written by Leo Pasvolsky of the Hull State Department group. It outlined three basics of American policy: (1) use tariffs as the major trade regulator (thus minimizing nontrade barriers), (2) lower tariff rates, (3) establish an unconditional most favored nation (MFN) principle. ${ }^{265}$

The US-Great Britain discussions included the fundamental principles of the tariffication policy, tariff reductions, and MFN. These discussions became the basis for the 1946 UN Economic and Social Council (ECOSOC) conference held in London 1946 to establish a Preparatory Committee to draft a Charter for the ITO.

The draft ITO Charter included rules on employment, commodity agreements, restrictive business practices, international investment and services (Love and Lattimore, 2009, p.79). The Charter was presented during the UN Conference on Trade and Employment held in Havana from November 21, 1947, to March 24, 1948. As a result, fifty-three countries signed the Havana Charter (formally the "Final Act of the United Nations Conference on Trade and Employment") to establish the ITO.

The Havana Charter for an ITO is a comprehensive set of rules to regulate international trade. Studying the Charter, it is possible to understand the level of the discussions held at the time and why the Charter is the precursor of the GATT/WTO. The main chapters of the Charter are: Chapter I - Purpose and Objectives; Chapter II Employment and Economic Activity; Chapter III - Economic Development and Reconstruction; Chapter IV - Commercial Policy; Chapter V - Restrictive Business Practices; Chapter VI - Inter-Governmental Commodity Agreements; Chapter VII The International Trade Organization; Chapter VIII - Settlement of Differences; and Chapter IX - General Provisions. Commenting about the Charter's broad powers, Fulton and Buterbaugh write:

\footnotetext{
${ }^{264}$ Fulton and Buterbaugh (2007), p. 20

265 Idem
} 
On the whole, the charter gave the ITO "broad powers to regulate tariffs, quotas, labor standards, investments, monopolistic practices, and commodity prices. ${ }^{266}$

Thus, many of the GATT/WTO current discussions existed in the 1948 ITO Charter. In fact, in some respects, it is possible to affirm that the Charter is more advanced than the GATT 1994. For instance, from the beginning, the Charter has a clear hierarchical and structured set of rules, while the GATT/WTO 1994 is made up of different parts and pieces of Agreements negotiated over the years. That by itself makes the Charter more coherent. Also, the Charter has provisions to deal with inter-governmental commodity agreements, competition, and labour, and thus is ahead of many GATT/WTO discussions.

The conditions for the entry into force of the Havana Charter, outlined in its Article 103, were not fulfilled within the prescribed time-limit of 30 September 1949. The UN registers that no instrument of acceptance was deposited with the Secretary-General. ${ }^{267}$

Among the explanations for the Havana Charter failure is the failure of the US Congress to obtain the necessary two-thirds of the votes to approve the instrument. The Charter was submitted to the US Congress but never approved. As a result, on 6 December 1950, President Truman withdrew the Charter from the US Congress.

Congress did not actually reject the ITO proposal, but the beginning of the Cold War and the US domestic political changes with which it was associated made it clear to Truman administration officials that Congress would not approve the Charter. Realizing this, President Truman simply withdrew the ITO agreement from consideration by Congress on December 6, 1950, allowing the grand plan to die. ${ }^{268}$

Thus, for political reasons, captained by the US Congress, the ITO failed and, in its place, as a sort of consolation prize, the world had to live with the GATT 1947. ${ }^{269}$

The Havana Charter text benefited from previous discussions about the customs valuation that took place during the League of Nations Economic Conferences in Geneva from 1927 to 1930. Subsequently, as an outcome of past debates and new necessities, the Havana Charter 1948 regulated customs valuation in Article 35.

\section{Havana Charter 1948}

\footnotetext{
${ }^{266}$ Idem, p. 21

${ }^{267}$ UN Treaty Collection. Information available at: https://treaties.un.org/pages/ViewDetails.aspx?src=TREATY\&mtdsg_no=X-1b\&chapter=10\&clang= en.

${ }^{268}$ Gerber (2012), p. 48

269 The secretariat of the Interim Commission for the ITO served as the ad hoc secretariat of GATT.
} 
1. The Members shall work toward the standardization, as far as practicable, of definitions of value and of procedures for determining the value of products subject to customs duties or other charges or restrictions based upon or regulated in any manner by value. With a view to furthering co-operation to this end, the Organization may study and recommend to Members such bases and methods for determining value for customs purposes as would appear best suited to the needs of commerce and most capable of general adoption.

2. The Members recognize the validity of the general principles of valuation set forth in paragraphs 3, 4 and 5, and they undertake to give effect, at the earliest practicable date, to these principles in respect of all products subject to duties or other charges or restrictions on importation based upon or regulated in any manner by value. Moreover, they shall, upon a request by another Member directly affected, review in the light of these principles the operation of any of their laws or regulations relating to value for customs purposes. The Organization may request from Members reports on steps taken by them in pursuance of the provisions of this Article.

3. (a) The value for customs purposes of imported merchandise should be based on the actual value of the imported merchandise on which duty is assessed, or of like merchandise, and should not be based on the value of merchandise of national origin or on arbitrary or fictitious values.

$$
\text { (...). }{ }^{270}
$$

Article 35 text of the Havana Charter is almost identical to the wording used in GATT Article VII. To put it in another way, the GATT 1947 includes elements of the Havana Charter text, but it does not include the entire Charter. Regarding customs valuation, both are almost identical, putting forward the concept of "actual value" to serve as the basis for duties on imported goods.

After the failure to establish the ITO, the GATT that would initially serve as a stepping-stone for the ITO became the only multilateral instrument for international trade.

Historically, GATT negotiations started in December 1945 when fifteen countries began negotiations to reduce customs tariffs. By 1947, the negotiating group of

${ }^{270}$ Annex A for the Havana Charter 
countries had expanded to twenty-three. ${ }^{271}$ The GATT was signed on 30 October 1947 and came into effect on 1 January 1948, serving as the basis for eight rounds of international negotiations on the liberalization of international trade.

Regarding the history of the GATT negotiations, Love and Lattimore explain:

Meanwhile, separate talks involving 15 countries began in December 1945, aimed at reducing and binding customs tariffs. This first round of negotiations resulted in a package of trade rules and 45000 tariff concessions affecting one-fifth of all world trade at the time. The core negotiating group had expanded to 23 by the time the deal was signed on 30 October 1947. The tariff concessions went into effect by 30 June 1948, through a "Protocol of Provisional Application ". ${ }^{272}$

The primary purpose of the establishment of the GATT was the creation of international trade rules and negotiation mechanisms to discuss the most pressing issues related to the escalation of trade disputes, with their potential transition to "trade wars" and then to actual armed conflict. ${ }^{273}$ Thus, the GATT was envisioned to put tariff reductions into place quickly and to serve as a provisional agreement until the ITO entered into force. Instead of being a treaty like the ITO, the GATT was a tariff negotiation agreement and therefore had to be applied directly by the Contracting Parties.

Detailing the legitimation process between the ITO and the GATT in the US, Fulton and Buterbaugh explain:

The GATT was to emerge as the fundamental document guiding international trade relations for most of the rest of the century. It was signed as a temporary measure on October 27, 1947, to go into effect on January 1, 1948. Such a measure could not become immediately operational if it were in a treaty form, of course. This meant that the document had to be worded in such a way that it would not require the approval of the U.S. Congress. The mechanism for its legitimization for the United States was the Trade Agreement Act of 1934. This act, you will remember, allowed the president to unilaterally make agreements on the lowering of tariffs as long as they contained reciprocity for American $\operatorname{goods}{ }^{274}$

\footnotetext{
${ }^{271}$ The 23 founding members were Australia, Belgium, Brazil, Burma, Canada, Ceylon, Chile, China, Cuba, Czechoslovakia, France, India, Lebanon, Luxembourg, Netherlands, New Zealand, Norway, Pakistan, Southern Rhodesia, Syria, South Africa, United Kingdom, and the United States.

${ }^{272}$ Love and Lattimore, op cit., p.79

${ }^{273}$ The GATT was signed on 30 October 1947 at the Palais des Nations in Geneva.

${ }^{274}$ Fulton and Buterbaugh, op. cit., p. 21
} 
Bearing in mind that GATT tariff negotiations are reciprocal, several countries successfully approved the Agreement in their internal order. Compared to the Havana Charter, the GATT tariff negotiations were simpler.

\subsection{GATT Article VII Customs Valuation}

Customs valuation was regulated by Article VII of the GATT. In comparison with Article 35 of the Havana Charter, Article VII of the GATT 1947 is shorter and has fewer rules. Not surprisingly, much of the text is similar in both instruments.

According to Article VII of the GATT 1947, the customs valuation principles were intended to value all products subject to duties or other charges or restrictions on importation and exportation based upon or regulated in any manner by value.

\section{GATT 1947}

\section{Article VII: Valuation for Customs Purposes}

1. The contracting parties recognize the validity of the general principles of valuation set forth in the following paragraphs of this Article, and they undertake to give effect to such principles, in respect of all products subject to duties or other charges or restrictions on importation and exportation based upon or regulated in any manner by value. (...)

One should realize that GATT Article VII implicitly recognizes that not all products are regulated by value, but that some products could be regulated by means other than value.

GATT Article VII principles that address valuation for customs purposes state that they: a) should be based on the actual value of the imported goods or of similar goods; b) should not be arbitrary, fictitious or based on the value of indigenous goods; c) should be the price at which such or like goods are sold in the ordinary course of trade under fully competitive conditions; and d) when the actual value is not ascertainable, the value should be based on the nearest ascertainable equivalent of such a value.

The GATT 1947 principles are valid for importation and exportation, and not only for importation, as many scholars are led to believe. It is a coherent approach to use the same principles for both sides of trade.

The basis for customs valuation used in the GATT system is the actual value, which is regulated in paragraph 2. (a) of Article VII of the GATT:

GATT 1947 
2. (a) (...)

(b) "Actual value" should be the price at which, at a time and place determined by the legislation of the country of importation, such or like merchandise is sold or offered for sale in the ordinary course of trade under fully competitive conditions. (...)

The actual value or the "just price" is the central principle on which the valuation system is intended to operate. One of the most important things to consider about the GATT 1947 actual value or "just price" concept is the discretion of the importing country to determine the time and place when establishing what is a comparable product for valuation purposes. Time and place are the essential elements in determining the GATT "just price".

Interpretative notes 2 and 3 to paragraph 2 of Article VII of the GATT permitted Contracting Parties to exclude related parties' transactions and special discount operations that were limited to exclusive agents.

Interpretative notes, Ad Article VII from Annex I

2. It would be in conformity with Article VII, paragraph 2 (b), for a contracting party to construe the phrase "in the ordinary course of trade ... under fully competitive conditions", as excluding any transaction wherein the buyer and seller are not independent of each other and price is not the sole consideration.

3. The standard of "fully competitive conditions" permits a contracting party to exclude from consideration prices involving special discounts limited to exclusive agents.

In other words, at that time both related parties and exclusive agents' transactions were already identified as raising problems for customs valuation. ${ }^{275}$

Article VII, paragraph 3, states that the value for customs purposes should not include the amount of any internal tax.

GATT 1947

Article VII: Valuation for Customs Purposes

\footnotetext{
${ }^{275}$ While many scholars see related parties' discussions as a novelty, the reality is different, as they have been on the trade agenda already for a long time.
} 
3. The value for customs purposes of any imported product should not include the amount of any internal tax, applicable within the country of origin or export, from which the imported product has been exempted or has been or will be relieved by means of refund.

By referring to the internal tax within the country of origin or export, Article VII only excludes the internal taxes which are levied directly on the exported goods (or directly on the materials used in the manufacture of such goods).

Article VII, paragraph 4, addresses the conversion rates of exchange. This provision is connected to Article IV of the original Agreement of the International Monetary Fund (IMF).

GATT 1947

Article VII: Valuation for Customs Purposes

4. (a) Except as otherwise provided for in this paragraph, where it is necessary for the purposes of paragraph 2 of this Article for a contracting party to convert into its own currency a price expressed in the currency of another country, the conversion rate of exchange to be used shall be based, for each currency involved, on the par value as established pursuant to the Articles of Agreement of the International Monetary Fund or on the rate of exchange recognized by the Fund, or on the par value established in accordance with a special exchange agreement entered into pursuant to Article XV of this Agreement.

(...)

(c) The CONTRACTING PARTIES, in agreement with the International Monetary Fund, shall formulate rules governing the conversion by contracting parties of any foreign currency in respect of which multiple rates of exchange are maintained consistently with the Articles of Agreement of the International Monetary Fund.

\section{(...)}

In the beginning, the IMF required each country member to provide a par value for its currency, either in terms of the gold value or the US dollar equivalent of a fixed gold value. Later, in 1978, the IMF revised Article IV and replaced the par value requirements in relation to its members' currencies with a requirement to collaborate to promote a stable system of exchange rates. Thus, Article VII, paragraph 4 became obsolete in light of the changes to the IMF's requirements. 
Finally, Article VII, paragraph 5, refers to the need for the system to be stable and for there to be publicity of information on the system, which is in line with GATT Article $\mathrm{X}$.

\begin{abstract}
5. The bases and methods for determining the value of products subject to duties or other charges or restrictions based upon or regulated in any manner by value should be stable and should be given sufficient publicity to enable traders to estimate, with a reasonable degree of certainty, the value for customs purposes.
\end{abstract}

The application of GATT Article VII was monitored and, during the ninth review session in 1954-55, a GATT Technical Working Party examined the laws and regulations of Contracting Parties concerning customs valuation. Its Report, "Comparative Study of Methods of Valuation for Customs Purposes" describes the systems of customs valuation at the time in the perspective of the criteria in Article VII. The GATT Study identified three main valuation criteria used by countries to audit the actual value or "just price":

4. Valuation criteria. It emerges from the replies that three main criteria are used:

(1) the price at which goods comparable with the exported goods are sold in the internal markets of the exporting country ("current domestic value");

(2) the price at which the imported goods are sold from the exporting country to the importing country ("transaction value");

(3) the price at which goods comparable with the imported goods are sold in the markets of the importing country ("import market value"). ${ }^{276}$

In other words, countries were applying the GATT Article VII actual value or "just price" concept using three different systems: a) prices on the domestic market of the exporting country; b) prices negotiated by the parties; and c) prices on the domestic import market. In summary, GATT Article VII was leading to different customs valuation results depending on the price methodology used by the country of importation to obtain the "just price".

For countries using the prices on the domestic export market, the customs value for AV tariffs was based on the price at which goods comparable with those imported were sold under fully competitive conditions on the export national markets. However, when the price at which the goods were sold to the importer was higher than the current domestic value, most countries using this system usually required that the

\footnotetext{
${ }^{276}$ GATT Document, G/88, 2 March 1955. Available at https://docs.wto.org/gattdocs/q/g.htm. [access 8 March 2018].
} 
actual sale price had to be taken as the basis of value for duty purposes. Therefore, it was a dual methodology with a preference for the higher price.

For countries using the transaction value, the customs value for tariffs was based on the price at which the goods were sold to the importing country, under fully competitive conditions. Normally, the invoice price at which the goods were sold to the importer was acceptable to provide the value. However, when the price of the invoice was not acceptable, it was necessary to establish alternative methods of valuation and, in some cases, this was done by increasing the invoice price and, in other cases, by basing the value on the price at which the goods were sold after importation, with various deductions.

Finally, for countries using the buyer's import market value, the legislation required the tariffs to be based on the price (generally at the wholesale level) at which goods comparable with the goods in question were sold in the internal markets of the importing country.

Considering that the GATT Article VII text set out general principles for customs valuation that allowed for the use of different customs valuation methods and that these possibilities allowed for a range of valuation criteria, it is understandable that such flexibility created problems.

\subsection{European Customs Union Study Group (ECUSG) - 1949 - BDV Convention}

History played a key role in the origins of the GATT Tokyo Round CV code. In that sense, it is relevant that the $\mathrm{CV}$ discussions trying to result in a uniform application to GATT Article VII date back to the Committee of European Economic Co-operation (CEEC) / European Customs Study Group (ECSG).

The CEEC was created on 12 July 1947 and was composed of thirteen European Governments. The CEEC work was to determine the priorities for the recovery of the European economy after World War II and to assist in the administration of the Marshall Plan. ${ }^{277}$

On 12 September 1947, the CEEC agreed to set up a European Customs Union Study Group (ECUSG). The ECUSG had a series of tasks based on international cooperation in the area of customs and examined the possibility of establishing one or more interEuropean Customs Unions based on the principles of the GATT 1947. Thus, in 1948, the ECUSG set up two committees: 1) the Economic Committee, and 2) the Customs

\footnotetext{
277 The CEEC was superseded on 30 September 1961 by the now Organisation for Economic Cooperation and Development (OECD) based in Paris.
} 
Committee. A summary of these events was reported in 1972 by the United States Tariff Commission:

After World War II, international efforts toward the establishment of common valuation standards focused on two major approaches. On the one hand, the Contracting Parties to the (sic) General Agreement on Tariffs and Trade (GATT) agreed in 1947 to certain valuation principles to be observed by all member countries, leaving each country rather broad discretion in the formulation of its national valuation standards. On the other hand, by mid1949 the European Customs Union Study Group developed a comprehensive customs valuation standard, which participating countries agreed to incorporate into their customs laws. This standard, which is set forth in the Convention on the Valuation of Goods for Customs Purposes and is known familiarly as the Brussels Definition, represents the first successful effort to create an international valuation standard. ${ }^{278}$

Later on, the ECUSG Customs Committee became the Customs Co-operation Council (CCC) based in Brussels. ${ }^{279}$

The studies of the ECUSG Valuation Sub-Committee were based on the principles set by the GATT 1947 and established the "Brussels Principles" presented in 1949. The work of the ECUSG was incorporated into the Convention on the Valuation of Goods for Customs Purposes, also known as the Brussels Definition of Value Convention (BDV), by the CCC and was signed in Brussels on 15 December 1950 and entered into force on 28 July $1953 .^{280}$

Historically, the BDV Convention was first a European system. Considering the CCC membership growth, the BDV Convention later became international. ${ }^{281}$ It became the first official interpretation of the general principles from Article VII of the GATT 1947. The BDV principles are:

Principle I: Dutiable value should be based on equitable and simple principles which do not cut across commercial practice.

\footnotetext{
${ }^{278}$ United States Tariff Commission (1972). US Congress Senate Committee on Finance Subcommittee on International Trade, p. 10.

${ }^{279}$ In 1952, the Convention that formally established the CCC came into force. The inaugural Session of the CCC took place in Brussels on 26 January 1953. Representatives from 17 European countries attended the first Council Session of the CCC. After years of membership growth, in 1994, the Council adopted the working name, World Customs Organization, to reflect its transition to a truly global intergovernmental institution more clearly. Now, it is the voice of 183 Customs administrations that operate on all continents and represent all stages of economic development.

${ }^{280} 15$ December 1950, 171 U.N.T.S. 307 (entered into force on 28 July 1953)

${ }^{281}$ The maximum number of Contracting Parties to the BDV Convention was thirty-three. However, it is estimated that more than seventy used elements of the BDV in their customs legislation.
} 
Principle II: The concept of dutiable value should be readily comprehensible to the importer as well as the Customs.

Principle III: The system of valuation should not prevent the quick clearance of goods.

Principle IV: The system of valuation should enable traders to estimate, in advance, with a reasonable degree of certainty, the value of customs purposes.

Principle V: The system of valuation should protect the honest importer against unfair competition arising from undervaluation, fraudulent or otherwise.

Principle VI: When the Customs consider that the declared value may be incorrect, the verification of essential facts for the determination and enforcement of dutiable value should be speedy and accurate.

Principle VII: Valuation should be based to the greatest possible degree on commercial documents.

Principle VIII: The system of valuation should reduce formalities to a minimum.

Principle IX: The procedures for dealing with lawsuits between importers and the Customs should be simple, speedy, equitable and impartial. ${ }^{282}$

The BDV is based on a notional concept of "normal price", which is the price that the goods would obtain under open market conditions between an unrelated buyer and seller at a specific time and place. Annex 1, Article 1 defines customs value as:

BDV - Definition of Value

\section{Article 1}

(1) For the purposes of levying ad valorem duties of customs, the value of any goods imported for home use shall be taken to be the normal price, that is to say, the price which they would fetch at the time when the duty becomes payable on a sale in the open market between a buyer and a seller independent of each other."

\section{$(\ldots)^{283}$}

28215 December 1950, 171 U.N.T.S. 307 (entered into force on 28 July 1953)

${ }^{283}$ Idem 
Thus, "normal price" can be compared to a price at perfect market conditions (open market) between unrelated parties. ${ }^{284}$ The key is to understand the specific time and place determined by the governments to verify the "normal price."

The BDV recommended that the invoice price should be used as the normal price, however, if the invoice price did not align with the open market price, customs could construct the normal price. In practice, customs could construct the normal price taking the domestic price in the importing country of identical or similar goods into consideration. Thus, at that time, some customs administrations had a catalogue of goods "database" commonly referred to as "black book," with comparable reference prices to check against the declared prices.

The BDV had a maximum of thirty-three Contracting Parties. To discuss technical matters and ensure the uniformity of interpretation, the BDV established a Valuation Committee under the auspices of the CCC. The Committee was composed of delegates from the Contracting Parties to the Convention and observers from other CCC Members and international organizations. The BDV Valuation Committee issued instruments, such as Recommendations, Explanatory Notes, and Opinions based on specific problems encountered by Members. ${ }^{285}$

In the beginning, the BDV was prepared only for CIF countries and therefore had to be amended in 1974 to include FOB countries. ${ }^{286}$ The BDV Convention was intended to grow and last as the only valid interpretation of GATT Article VII, but that did not happen.

In addition to the the BDV, it is important to also recognize the other valuation systems in place in countries such as the US, Australia, Canada, South Africa, and New Zealand.

The United States, Australia, Canada, South Africa and New Zealand did not use the BDV and used varying systems of valuation. Even among those countries applying the $B D V$, there was considerable variety in its application and interpretation. The BDV method was based on the CIF value while the United States, Australia, and Canada had systems based on the FOB value. Although both groups used invoice values in most cases, in situations where no invoices could be produced or where the invoice price appeared to be

\footnotetext{
${ }^{284}$ Also known in transfer pricing language as “arm's length".

285 These instruments issued by the BDV Valuation Committee incorporated were incorporated later on, sometimes with minor modifications, as the GATT Valuation Code Technical Committee instruments.

${ }^{286} \mathrm{CIF}$ countries are those that include expenses with international freight and insurance in the value of imported goods. FOB countries are those that do not consider the expenses of freight, insurance or others in the value of imported goods
} 
unacceptable, the value for customs purposes was established by the two groups according to widely differing methods. ${ }^{287}$

The difference between the systems was referred to as the difference between the "notional" concept and the "positive" concept.

The BDV was based on a "notional" concept of valuation (i.e. a price at which goods ought to be sold under a specified set of circumstances) which specified a set of procedures for arriving at the price at which the goods should be valued. The US and Canadian systems were based on a "positive" concept (i.e. the price at which imported goods or like good are in fact sold under specified conditions.). ${ }^{288}$

It should be clear, however, that the BDV was the dominant CV methodology from the 1950s to the 1970s. Up until today, the BDV Convention continues to exist as a regular Convention of the CCC/WCO. ${ }^{289}$

As written in the BDV Convention, everything related to the BDV Convention must pass through the Belgian Ministry of Foreign Affairs. In 2015, according to the Belgian Ministry of Foreign Affairs, there were still eight Contracting Parties to the BDV Convention, namely: Algeria, Haiti, Israel, Kenya, Pakistan, Rwanda, Senegal, and Tanzania. Notice that seven of these countries: Haiti, Israel, Kenya, Pakistan, Rwanda, Senegal, and Tanzania are WTO member countries and therefore also adopted the Customs Valuation Agreement. As such, all of these seven countries should one day withdraw from the BDV Convention. ${ }^{290}$ Notice that only Algeria is the exception, as it is not yet a WTO member. The country is in the process of accession to the WTO. ${ }^{291}$

In summary, from the remaining eight countries in the BDV Convention, only Algeria could legally apply the Convention. All of the other seven countries that are still signatories to the BDV Convention cannot apply the Convention as it conflicts with the WTO Customs Valuation Agreement.

Soon after the approval of the GATT Customs Valuation Code in the Tokyo Round, the CCC suspended the BDV Valuation Committee meetings. They were suspended, expecting that one day the BDV Convention would cease to exist. For that to happen,

\footnotetext{
${ }^{287}$ GATT Document, G/VAL/W/95. Available at: https://docs.wto.org.

${ }^{288}$ GATT Document, G/VAL/W/95. p.2 Available at: https://docs.wto.org.

${ }^{289}$ WCO Document SG0214Ea (July 2020). Conventions: Summary of Position. Available at: http://www.wcoomd.org/-/media/wco/public/global/pdf/about-us/legal-instruments/conventions-andagreements/revised-kyoto/sg0214ea.pdf?la=en.

${ }^{290}$ It is worth mentioning that every year the CCC/WCO TCCV sends instructions to these countries on how to withdraw from the BDV Convention.

${ }^{291}$ Algeria's working party to the WTO accession process was established on 17 June 1987 . To this date the conclusion of the accession is still pending.
} 
all remaining countries need to withdraw from the BDV Convention by sending correspondence to the Belgian Ministry of Foreign Affairs.

(a) The present Convention is of unlimited duration, but at any time after the expiry of five years from its entry into force under paragraph (a) of Article $X I V$, any Contracting Party may withdraw therefrom. Withdrawal shall take effect one year after the date of receipt by the Belgium Ministry of Foreign Affairs of a notification of withdrawal. The Belgian Ministry of Foreign Affairs shall notify each withdrawal to all signatory and acceding Governments and to the Secretary General. ${ }^{292}$

A suggested letter to withdraw from the BDV Convention is presented in Annex D. Observe that withdrawal only takes effect after one year from the arrival of the letter at the Belgian Ministry of Foreign Affairs.

In theory, once countries have acceded to the GATT CV Code or the WTO CVA, they should immediately send the letter requesting to withdraw from the BDV Convention. In practice, however, there are still a few countries that never withdrew from the BDV Convention and thus the mentioned international instrument continues to exist.

\subsection{Concluding Remarks}

The adoption of AV tariffs made it compulsory for the GATT Contracting Parties, and later on for all WTO Members, to use the CVA set of rules.

$\mathrm{CV}$ is a derivative of value. Therefore, before entering into the technical details of $\mathrm{CV}$, the chapter discussed the work of several authors about the theory of value. Scholars such as Aristotle, Adam Smith, John Maynard Keynes, and Jean Baudrillard produced relevant work in the field of value. To this day, there are complex considerations related to the theory of value, including the cost of labour, machinery, technology, and service.

More recently, some scholars have said that a valuation process, and consequently value, could be interpreted as an image linked to beliefs. The conclusion from this is that valuation is thus an abstract process, that depends on people's opinions and sentiments. In other words, inner beliefs, or what John Maynard Keynes referred to in his works as sentiments, play a role in the value outcome.

The importance of studying the theory of value in this chapter is to critically question the excessive importance of "competitive conditions" assumptions coming from the CVA. Considering the role played by sentiments in different countries and cultures, it

${ }^{292}$ BDV. Article XVI addresses the withdrawal process. 
must be asked whether is it possible to assess "competitive conditions" associated with the value of traded goods?

As such, the chapter argued that several factors related to beliefs and sentiments cannot be clearly understood or quantified when dealing with valuation. The conclusion is that the price volatility stemming from "sentiments" makes it difficult to find comparable market prices. The lack of comparables for appraisal contributes to trade distrust, as it makes it impossible to plan or predict any revenue, or control based on AV tariffs calculated as a fixed percentage of the customs value of the goods. Consequently, countries that rely on trade revenue from AV tariffs to provide public services are at risk.

The history of customs valuation is rich in examples from the past. In 1890, the International American Conference expressed its concerns on customs valuation and its risk for revenue. More recently, during the 1920s, due to economic circumstances, tariffs gained importance and major countries such as the US adopted a number of Tariff Acts. Tariffs are thus an outcome of the particular state of political and economic times at that time. It is for this reason that CV appeared on the agenda of the League of Nations (1927 - 1930).

The work of the League of Nations, together with the work done for the unsuccessful ITO in the Havana Charter, paved the way for the GATT Article VII CV principles. However, countries came up with different interpretations of the customs value when applying the principles of GATT Article VII. Depending on the country, the "actual value" was influenced by comparable goods from the market in the export or import country.

Hence, in an attempt to provide a uniform interpretation of the GATT Article VII principles, the ECUSG, created under the CEEC, developed studies that caused the development of the "Brussels Principles". Such work was incorporated into the Convention on the Valuation of Goods for Customs Purposes, also known as the Brussels Definition of Value (BDV), by the CCC/WCO as of 1950.

For a couple of decades, the BDV CV system became the standard system in use. To this date, the system continues to exist with the participation of eight Contracting Parties. 


\section{The GATT Valuation Code and the WTO CVA}

Considering the teachings on the theory of value and the history of CV that were presented in the previous chapter, it is now time to discuss the GATT/WTO CV system. The discussion is necessary to understand the results of the work carried out to create a uniform interpretation of the GATT Article VII principles.

It is critical to understand the customs valuation history when considering taxing the value of goods. Value and valuation methods are products of their times. There is no correct value or fair value between nations. The decision about a value methodology derives from a certain period in time among with some nations. This decision affects how tariffs are calculated and the amount of trade revenue collected. Most of the literature portrays very little about the past before delving into the WTO rules. However, the WTO rules are a mere product of their history. As such, one can only understand the WTO rules by first understanding the history associated with them.

The research question gives weight to the possibility that tariff conversion and multilateral reductions were undertaken without proper consideration for trade revenue. A key element in this issue is valuation. The GATT/WTO valuation set of rules opted for a methodology that emphasises "transaction value" under "competitive conditions", which makes it difficult to find market comparables.

In order to discuss the GATT/WTO CVA, the chapter starts with an analysis of the 1960s main customs valuation systems, mainly the Brussels Definition of Value (BDV) and the American Selling Price (ASP). It also discusses the reasons for the decision to negotiate another valuation system during the GATT Tokyo Round.

The chapter continues by presenting the developments on customs valuation during the GATT Uruguay Round and later on the consequences from the creation of the WTO.

Finally, the chapter shows the complexities associated with valuation systems and the difficulty in sustaining such systems indefinitely. The fact that value creation is constantly evolving puts pressure on trade valuation systems.

\subsection{GATT Kennedy Round and the ASP: 1964 - 1967}

The US mandate to negotiate the Kennedy Round came from the Trade Expansion Act of 1962. US President John F. Kennedy's decision to spearhead the negotiations makes it easier to understand why the Round bears his name, instead of purely the name of the city, Geneva, where negotiations started. In 1962, he referred to the need for the US to negotiate as follows: 
The success of our foreign policy depends in large measure upon the success of our foreign trade, and our maintenance of Western political unity depends in equally large measure upon the degree of Western economic unity. An integrated Western Europe joined in trading partnership with the United States, will further shift the world balance of power to the side of freedom. ${ }^{293}$

Thus, Kennedy believed that a successful US foreign policy depended significantly upon the success in foreign trade. In those times, the US was working with the North Atlantic Treaty Organization (NATO) for its military objectives and with the OECD for its economic objectives. President Kennedy believed in strengthening the Atlantic community based on the partnership of North America and Western Europe. US President Kennedy wanted to negotiate trade tariffs that benefited American exports:

Unless we have this authority to negotiate and have it this year-if we are separated from the Common Market by high tariff barriers on either side of the Atlantic - then we cannot hope to play an effective part in those basic questions. ${ }^{294}$

After years of investment, Europe's post-war economy was showing signs of recovery and Europeans were anxious to sell their products on other markets, such as in the US. In addition, there was a threat that the European Common Market (ECM) and the European Free Trade Association (EFTA) could fix common external tariffs at levels that would disadvantage American goods exported to Europe. The relationship between the US and Europe, but also between Europe and the rest of the world, was changing, and there was a need to negotiate trade policies.

US and Europe had 80-85\% of the world's industrial capacity. Thus, any negotiation first had to focus on these two players, and later on the others. In a statement from the Subcommittee on Foreign Economic Policy made in 1966, the chairman stated:

In this complex of nations, the Western European nations and North America, there is perhaps as much as 80 to 85 percent of the industrial capacity of the free world. $^{295}$

The US-Europe views mattered most because it is from this bilateral negotiation that the valuation code was going to be negotiated. The US and Europe held negotiations

\footnotetext{
${ }^{293}$ Kennedy, John F. (1962). Special Message to the Congress on Foreign Trade Policy. January 25, 1962. Available at: http://www.presidency.ucsb.edu/ws/?pid=8688. [accessed 22 June 2017]

${ }^{294}$ Kennedy, John F. (1962). Special Message to the Congress on Foreign Trade Policy. January 25, 1962. Available at: http://www.presidency.ucsb.edu/ws/?pid=8688. [accessed 22 June 2017]

${ }^{295}$ US House of Representatives, Committee on Foreign Affairs, Subcommittee on Foreign Economic Policy, August 9, 1966
} 
mainly on agricultural and industrial items. By 1966, countries' trade offers were on the table, and the US needed to improve its offers to close the Round on time.

The US Trade Expansion Act expired in July 1967 and, under President Lyndon Johnson, there was little chance of success for Congress to reauthorize the Act. Thus, July 1967 became the deadline for the GATT Kennedy Round. George Ball, US Under Secretary of State in 1966, explained:

We want to see a substantial completion of the bargaining process by the end of the year so that all technical problems can be met in time to conclude the definitive agreements before the expiration of the authority which the President was given under the Trade Expansion Act. ${ }^{296}$

The US Trade Expansion Act was the main engine pushing the GATT Kennedy Round. Thus, the fact that the Act would expire in 1967 made it urgent for countries to conclude the negotiations. With this background, it is interesting to examine what happened in the Kennedy Round negotiations in connection with the valuation code.

The Kennedy Round included 52 participants, but it was mainly a tariff-reducing negotiation between the US and the ECC countries. The Round pioneered a system of linear across-the-board cuts of a certain percentage on all tariffs of participating countries. The tariff negotiating participants were divided between those leading the linear negotiations and those that negotiated in a non-linear style that were not seen as leaders. ${ }^{297}$

Referring to the history of the GATT valuation code, some authors mention that negotiations for this code started during the Kennedy Round (1964 - 1967). Rosenow and O'Shea explain this part of the historical background as follows:

The last major GATT initiative on valuation in these early years came in the Kennedy Round of 1964-1967. In that round, for the first time, non-tariff barriers were included in negotiations. One such non-tariff nominated for negotiation by a number of countries was "customs valuation including use of arbitrary or excessive values. ${ }^{298}$

\footnotetext{
${ }^{296}$ US House of Representatives, Committee on Foreign Affairs, Subcommittee on Foreign Economic Policy, 9 August 1966

${ }^{297}$ List of Kennedy Round participants (52).

Linear (16): Austria, Belgium, Denmark, Finland, France, Germany (Fed. Rep. of), Italy, Iceland, Japan, Luxembourg, Netherlands, Norway, Sweden, Switzerland, United Kingdom, and the United States.

Non Linear (36): Argentina, Australia, Brazil, Canada, Ceylon, Chile, Cyprus, Czechoslovakia (not negotiating with the US), Dominican Republic, Ghana, Greece, India, Indonesia, Ireland (not a member of the GATT), Israel, Ivory Coast, Jamaica, Korea, Malta, New Zealand, Nicaragua, Niger, Nigeria, Pakistan, Peru, Portugal, Poland, South Africa, Spain, Togo, Trinidad and Tobago, Turkey, Uganda, United Arab Republic, Uruguay, and Yugoslavia.

${ }^{298}$ Rosenow and O'Shea (2010), p.9
} 
In fact, the Kennedy Round is where most of the discussions started and followed up in the years before the Tokyo Round. Later, in the Tokyo Round (1973 - 1979) delegates approved the text that had been prepared from 1972 to1973 with minor changes. To put it another way, to understand the valuation code, it is necessary to study the Kennedy round $(1964-1967)^{299}$ and to recognize that it was at that time that it was decided that there was a need for a valuation code. In this regard, it is important to understand that, for certain imported types of goods such as certain chemicals, the US used a system of valuation called the American Selling Price (ASP).

Under the ASP valuation system, the customs duty value is not based on the invoice price, nor on the import of identical or similar products, but it is based on the price of the competing domestic product. In other words, the domestic manufacturer price is the customs valuation applied to the competing imported products. ${ }^{300}$

\footnotetext{
299 The records to support a deeper study of the discussions during the Kennedy round (1964 - 1967) are not easy to obtain. Most books, including Rosenow and O'Shea, refer only to GATT documents, while relevant information is recorded in the US congressional documents, in particular in the house of representatives committee on foreign policy. I am grateful to Georgetown Law University for the visiting researcher position in January 2017, which made it possible to find such historical documents. 300 Phil Knight, the founder of Nike, tells about his battle against US Customs over the American Selling Price (ASP) valuation system used in the 1930s. Extract from Phil Knight's 2014 address to the Graduating Class at the Diploma Award Ceremony for the Stanford Graduate School of Business in the Frost Amphitheater.
}

\section{(...)}

But I found in the morning mail a letterhead that says, "United States Customs." The announcement that this is an important letter. It turned out to be so. Attached was an invoice for past due customs duties of $\$ 25$ million - the exact same number as our total sales for the year. I had no idea what they were talking about.

So what we find out is that there is a little-used part of the customs code, dated back to the 1930s. Duty in three categories: benzedine chemicals, cherry stone clams, and athletic footwear with synthetic uppers could be assessed not the factory cost of the goods but the American wholesale selling price of those goods. "Goods that were like or similar," if you like that language, "to American manufactured goods."

So here comes this invoice. And despite the fact we'd been charged and paid the amount at invoice that had been enforced previously, our prices based on that had long ago been sold. The \$25 million was on top of that.

While things were fuzzy and unclear one thing was absolutely certain: No way were we going to be able to pay that amount of money.

So we go to Washington, D.C., reaching as high up in the political ladder as I can. When first contemplating nylon upper running shoes, we had asked customs for a ruling on what the duty would be. We showed the letter that had been signed by the assistant director of customs saying our duty would be 20 percent of factory costs, now to double that, the response of John B. Simpson, deputy secretary of the Treasury was, "Well, that letter is not binding on U.S. Customs."

In other words, we lied to you. You screwed up. You trusted us. 
Export countries, from Europe, complained that the ASP was protectionist and demanded the abolition of the system. To abolish the ASP, the US wanted counterconcessions and Congress had to approve the conversion from the ASP valuation system to any other type of valuation system. Mr. Christian A. Herter, who served as US Special Representative for Trade Negotiations, in his statement on 10 August 1966 at the Subcommittee on Foreign Economic Policy, describes as follows:

\author{
In chemicals, abolition of the American Selling Price system of valuation, as \\ applied to certain chemicals is demanded. ${ }^{301}$
}

From a European perspective, the ASP valuation system was a non-tariff barrier that needed to be abolished. The US, on the other hand, wanted counter-concessions to abolish this system of valuation used for chemicals and a few other goods. From 1921 to 1979, the US used the ASP customs valuation method for certain products.

Rosenow and O'Shea write about the American Selling Price (ASP):

Gradually, we began to figure it out. This obscure rule had been on the books for nearly half a century, and now U.S. shoe manufacturers - Converse and others - banded together to lobby the government and apply the additional duty on exports in general and us in particular.

They had to make something that met the test of a customs officer who'd never worked in a shoe factory, like or similar, and they then had to sell only a few of those shoes to hugely increase the cost of our shoes going forward if, in fact, the retroactive part didn't put us out of business, which it nearly did.

Thus began the great ASP (American Selling Price) fight. The fight for our very lives. It lasted three years. This is the sneaker business and I've got to have a Washington, D.C., lobbyist. Most lobbying firms on K Street were more than willing to take our case - for a fee of $\$ 1,000$ an hour. We hired Jay Edwards, Stanford '68. He had just opened an office representing Portland General Electric, the Oregon public utility, the Nez Perce Indians, and now, for a retainer of \$300 a month, us.

(...)

And in perhaps our best maneuver we came up with this one.

We had a factory in Exeter, NH, making 15,000 pair a month. What if we created a second line?

Knocked off ourselves, selling to discount retailers at a very low but marginally profitable price. No one could copy us closer than we could copy ourselves. When this first came up in a brainstorming session, everybody laughed at its absurdity. Then we looked at each other. The whole law was absurd. And it evolved into, eventually, "Let's try it."

Thus was born the One Line, which for a couple years sold a couple thousand pairs and reduced the increase in our duties by two-thirds.

And after three years of fighting, we settled the great ASP customs battle for $\$ 9$ million or

approximately one-third of the former demand. In those three years our sales had grown to $\$ 440$ million and we could actually pay the bill. One year after the settlement, we got ASP eliminated from the entire U.S. Customs coding for benzedene chemicals, cherrystone clams as well as athletic footwear with synthetic uppers.

When we'd reached the critical mass to go public, throughout the ASP years we could not go public because we could not report earnings -- which were very materially affected by the ultimate ASP resolution. With the resolution of ASP, a public offering was opened to us.

And in December 1980, we did just that. From that point, the only thing standing in the way of real success, with having our dreams come true, was ourselves.

Extract from Phil Knight's 2014 delivered address to the Graduating Class at the Diploma Award Ceremony for the Stanford Graduate School of Business in the Frost Amphitheater. The complete speech can be found at http://www.oregonlive.com/playbooks-profits/index.ssf/2014/06/post 40.html

${ }^{301}$ US House of Representatives (1966), p.24 
The ASP, explicitly protectionist in design, required certain imports benzenoid chemical products, rubber footwear, canned clams and knitted woolen gloves - to be valued on the basis of the price at which similar USorigin products were sold in the US market, rather than the actual invoice price for the goods. ${ }^{302}$

For the US, there was the normal valuation system and the ASP valuation system. The US never applied the BDV. The ASP protected industry sectors that produced products in areas such as benzenoid chemical products, rubber footwear, canned clams, and knitted woollen gloves, and it could not be easily changed. Regarding the legal status of the ASP, Mr. Christian A. Herter, who served as US Special Representative for Trade Negotiations, in his statement on 10 August 1966 at the Subcommittee on Foreign Economic Policy, explains:

We determined some time ago from a legal point of view that we couldn't change the American selling price, that that was not part of our authority under the Trade Expansion Act. If any change were to come in the American selling price, it would have to be done as a separate agreement entirely from the overall Kennedy Round agreement. ${ }^{303}$

In other words, negotiations to abolish the US ASP valuation system needed to consider special authority from Congress. In other words, the ASP could not be negotiated within the realms of the Trade Expansion Act. Nevertheless, there was an agreement to eliminate the ASP valuation system at the Kennedy Round. This consensus is addressed in the Agreement Relating Principally to Chemicals, Supplementary to the Geneva (1967) Protocol to the GATT:

Agreement Relating Principally to Chemicals, Supplementary to the Geneva (1967) Protocol to the GATT

PART I - GENERAL

Article 1 - Conditions of Entry into Force

(a) Elimination of American Selling Price system. In order that the United States may obtain the benefits of the tariff concessions on chemicals and other articles and the concessions on non-tariff barriers, provided for in Parts III, IV and V of this Agreement, additional to the concessions it will obtain under the Protocol, the President of the United States undertakes to use his best efforts to obtain promptly such legislation as is necessary to enable the United States to eliminate the American Selling Price system of valuation, as provided in Part II of this Agreement, and to give effect to the

\footnotetext{
302 Rosenow and O'Shea (2010), p.9

${ }^{303}$ US House of Representatives (1966), p.34
} 
other provisions of that Part. ${ }^{304}$

The elimination of the ASP valuation system was a priority for the negotiating parties of the chemicals' agreements, namely: Belgium, France, Italy, Switzerland, the United Kingdom, the US, and the European Economic Community. How the ASP was to be eliminated is detailed in Article 2 of the Agreement Relating Principally to Chemicals, Supplementary to the Geneva (1967) Protocol to the GATT:

\section{PART II - UNITED STATES}

\section{Sub-Part A - Chemicals}

Article 2 - Elimination of American Selling Price System

(a) Explanation. This Article provides for the elimination of the American Selling Price system of valuation (see Sections $402(\mathrm{e})$ and $402 \mathrm{a}(\mathrm{g})$ of the Tariff Act of 1930 (19 U.S.C. (1964), 1401a (e) and $1402(\mathrm{~g}))$ as the basis for determining dutiable value in the case of certain chemicals, provided for in Schedule XX (United States), Part I, annexed to the Protocol (hereinafter referred to as Schedule XX), Section 4, Chapter 1.

$$
(\ldots)^{305}
$$

However, the Agreement Relating Principally to Chemicals, Supplementary to the Geneva (1967) Protocol to the GATT was not implemented. Thus, after the conclusion of the Kennedy Round in 1967, the negotiations to abolish the US ASP continued. These negotiations took place mainly around 1972 to1973 outside of the GATT.

\subsection{Introduction to the GATT Tokyo Round: 1972-1973}

After the conclusion of the Kennedy Round (1964-1967), it was clear that the ASP valuation system would be abolished. The US wanted more access to the European market and Europe wanted to sell chemicals to the US without having to deal with the price controls from the ASP valuation system.

In 1971, the GATT Committee on Trade in Industrial Products explored the opportunities to make progress towards the further liberalization of trade and made the following suggestions in relation to customs valuation harmonization:

\footnotetext{
${ }^{304}$ WTO (1968). Agreement Relating Principally to Chemicals, Supplementary to The Geneva (1967) Protocol to The General Agreement on Tariffs and Trade. Available at: https://www.wto.org/english/docs_e/legal_e/kennedy_e.pdf. [accessed 22 June 2017]

${ }^{305}$ WTO (1968). Agreement Relating Principally to Chemicals, Supplementary to The Geneva (1967) Protocol to The General Agreement on Tariffs and Trade. Available at: https://www.wto.org/english/docs_e/legal_e/kennedy_e.pdf. [accessed 22 June 2017]
} 
2. An overall solution along the following lines (paragraphs 15,20):

(a) valuation systems to be harmonized so that each contracting party uses one single concept of valuation based on economic and commercial realities, on the principles of Article VII and on specific interpretative rules to that Article;

(b) these interpretative rules to be based on the Brussels Definition, but the f.o.b. system to continue to exist side by side with c.i.f. by the f.o.b. countries accepting the interpretations outlined above and reducing the resulting valuation by the amount of freight and insurance up to the point of importation (to avoid lengthy renegotiations);

(c) countries applying the Brussels Convention on Valuation but not yet signatories to it, to accede to the Convention;

(d) countries using valuation methods requiring determination of export values on the internal market of the exporting country to use invoice prices for like products for export to the major market or invoice prices generally obtained for like products. ${ }^{306}$

As can be seen from the 1971 text, the GATT suggestion to its Contracting Parties was to harmonize the customs valuation methodology with the adoption of the BDV Convention.

On the matter of the GATT proposal, the US Tariff Commission held hearings in 1972 to 1973 . These US hearings are essential to understand the arrival of new actors to discuss the GATT proposal that would later be reformed.

In late 1972 and early 1973 the then Tariff Commission held hearings on a proposal by its staff for a possible new Valuation System which could be adopted as a uniform international standard. This Tariff Commission staff proposed would have put the United States on a slightly modified version of the Brussels Definition of Value. ${ }^{307}$

In short, the US hearings in late 1972 and 1973 were to consider the adoption by the US of a new Valuation System that was aligned with the BDV valuation system. During the hearings, the American Importers Association (AIA) produced a paper that made a new proposal that seems to be the precursor to the valuation code..$^{308}$

\footnotetext{
306 GATT, L/3496, 10 February 1971

${ }^{307}$ US House of Representatives, Subcommittee on International Trade of the Committee on Finance, 1979 , p.45

308 The American Importers Association (AIA) was a nonprofit organization formed in 1921 to foster and protect the importing business in the United States. In 1979 it had nearly 1,300 firms directly or indirectly involved and thus had a relevant voice in the US.
} 
The American Importers Association responded with a paper which in many ways was the father if the MTN Valuation Code. Its basic premise was that both the U.S. and the Brussels valuation system should be discarded and replaced by a new system based on "transaction value". 309

The AIA valuation code proposal abolished the ASP, discarded the BDV and set the transaction value as the main valuation method. That is exactly what was negotiated and approved later on at the GATT Tokyo Round (1974-1979).

\subsection{GATT Tokyo Round: 1973 - 1979}

The GATT multilateral trade negotiations, known as the Tokyo Round, took place in Geneva from 1973 to 1979 . The primary objective of the Tokyo Round was "to achieve the expansion and ever-greater liberalization of world trade, inter alia, through the progressive dismantling of obstacles to trade."

One perceived way to achieve this goal was the adoption of a common international customs valuation system that would be more widely accepted and result in a more uniform and positive valuation basis. At that time, the BDV system was the predominant international valuation system. Despite the fact that the GATT was recommending that its Contracting Parties adopt the BDV, another valuation system was negotiated. This deserves attention, as it has a direct impact on the AV tariff calculations.

The shift from the BDV to the GATT Code came after the AIA produced a paper with a preference for the so-called "transaction value". In other words, the GATT Tokyo Round negotiations did not produce the most widely accepted CV set of rules, but instead produced the valuation set of rules proposed by the US.

One of the authors of the US proposal for the valuation code, hence one of the fathers of the GATT valuation code, was Saul L. Sherman, a partner at the law firm Sherman, Rivkin \& Levy, who testified at the US Congress in 1979 on behalf of the Joint Industry Group. ${ }^{310} \mathrm{He}$ explains the world situation in terms of valuation systems as follows:

\footnotetext{
${ }^{309}$ US House of Representatives, Subcommittee on International Trade of the Committee on Finance, 1979, p.45

${ }^{310}$ Saul L. Sherman $(1927$ - 2011) was a graduate of Harvard Law School and served in the US Foreign Service during the occupation of Germany. He was a partner at Rivkin, Sherman and Levy, specializing in trade law. He co-authored the definitive guide to the GATT and served on NAFTA panels as an international arbitrator. He also served as a member of the executive committee of the international section of the New York State Bar Association for many years and was one of the founding members of NYSBA International.
} 
Prior to this time and up through the present, the United States has had a unique valuation system for its customs operation. Most of the rest of the world is on the so-called Brussels Definition of Value, which is basically a European system, but it has been adopted widely in Far East, South American, and around the world generally. ${ }^{311}$

The US opposed the idea of adopting the BDV, and therefore set a proposal for a new uniformity valuation system based on the "transaction value" concept. In the words of Mr. Sherman:

"On that subject, the code that has emerged from Geneva has adopted the concept of transaction value which is, very simply, that duty value, customs value, should be based upon the invoice price agreed upon between the parties to that transaction unless there is a very strong reason to depart from that approach." 312

The idea was that every GATT country would apply the same method of valuation to all goods, based on the invoice, to arrive at the dutiable value for AV tariffs.

According to Sherman, there were easy cases and difficult cases in relation to customs valuation. The easy cases should be handled as quickly as possible, just by looking at the value on the invoice, while the difficult cases, for example, involving related parties, could take more time.

The more difficult cases derived from the question, in the case of related parties, so-called. There in the transaction, for example, between a parent and a subsidiary, serious questions can sometimes be raised as to whether the price is a realistic market price or one set for the convenience of the related parties. $^{313}$

Notice that the statement reveals that the debate about the so-called "related parties" trade transactions, nowadays commonly referred to as transfer pricing among tax professionals, was already seen as difficult for customs valuation.

The US opposition to the BDV is clear. During the Tokyo Round, they had to negotiate against the adoption of the BDV preferred methodology. The US explains its opposition to the BDV, saying that it leaves too much room for administrative regulation and discretion. The US preferred a system in which the value could be different depending on the time and place.

\footnotetext{
${ }^{311}$ United States Senate. Ninety-Sixth Congress. First Session. Hearings before the Subcommittee on International Trade of the Committee on Finance, February 21 and 22, 1979, p.92

${ }^{312}$ Idem. p.93

${ }^{313}$ Idem, p.93
} 
There is no one right value for an article, even at a given time and place, nor is there one right way to arrive at a value. The valuation problem is thus inherently complex and difficult. ${ }^{314}$

The preference for a valuation system in which prices can fluctuate according to the markets might seem like a contradiction to the quest for arriving at uniformity in valuation. However, this is exactly how the preference should be understood: arriving at uniformity by the adoption of a volatile valuation system.

In summary, the Agreement on Implementation of Article VII of the GATT, known as the GATT Valuation Code, was adopted in the Tokyo Round, aligned with the US objectives, and established a so-called "positive" system of customs valuation based on the "price actually paid or payable" for imported goods.

Admittedly, it was a victory for the US delegation who convinced the other members, particularly the Europeans, to use the new valuation system instead of the BDV.

Europe's acceptance was compensated for by the US that agreed on the elimination of the ASP valuation system. Sherman details it as follows:

The Kennedy Round side-agreement designed to eliminate ASP was not presented to the Congress and so did not take effect. In the Tokyo Round the elimination of ASP has been accepted in principle by our negotiators, and by the American chemical industry, for whose benefit it was originally enacted in 1921; the controversy has centered around the alternatives and the compensation to be received in return by way of duty rate increases and otherwise. $^{315}$

The US victory, however, was not without opposition. At that time, the differences between developed and developing countries in relation to fraud, related parties' transactions, royalties, and all other types of complex adjustments stemmed from the "transaction value".

Differences between developed and developing countries were apparent during the negotiations. For example, there was reportedly "strong opposition" from developing countries to the treatment of transactions between related companies under the proposed GATT Valuation Code which, they argued, favored firms and enterprises from the developed countries. ${ }^{316}$

\footnotetext{
${ }^{314}$ United States Senate. Ninety-Sixth Congress. First Session. Hearings before the Subcommittee on International Trade of the Committee on Finance, February 21 and 22, 1979, p.96

${ }^{315}$ United States Senate. Ninety-Sixth Congress. First Session. Hearings before the Subcommittee on International Trade of the Committee on Finance, February 21 and 22, 1979, p.96.

${ }^{316}$ Rosenow \& O'Shea (2010), p.15
} 
In the end, the US proposals prevailed and, not surprisingly, the GATT Tokyo Round Valuation Code has significant similarities with section 402 of the US Tariff Act of 1930, which governed the valuation of many US imports, except those subject to the controls of the ASP system.

Accordingly, the Agreement on the Implementation of Article VII of the General Agreement, negotiated during the Tokyo Round of multilateral trade negotiations, was signed on 12 April 1979 and entered into force on 1 January 1981. The Protocol to the Agreement on the Implementation of Article VII ("Customs Valuation Protocol”), adopted on 1 November 1979, provided that, upon the entry into force of the Agreement, the provisions of the Protocol would be deemed to be part of the Agreement.

On 13 January 1981, at the first meeting of the GATT Committee on Customs Valuation (CCV), a total of seventeen delegations (the EEC counting as one) had signed the Agreement.

\section{In opening the meeting, the representative of the Director-General welcomed the signatories to the first meeting. He said that as of this day, a total of seventeen delegations (the EEC counting as one) had signed the Agreement and the Protocol and had thus become members of the Committee. (...). ${ }^{317}$}

By 1994, the number increased to thirty-five Contracting Parties. ${ }^{318}$ The number of parties agreeing to the GATT CV code cannot be seen as an impressive number, especially considering that the BDV had achieved thirty-three in the 1960s. It is worth observing that, from the beginning, the GATT Valuation Code was prepared for adoption by both FOB and CIF countries. ${ }^{319}$

In conclusion, the foundation of the GATT Valuation Code was to provide a fair, uniform, and neutral system for the valuation of imported goods for customs purposes, conforming to the commercial reality and outlawing the use of arbitrary and fictitious customs values. The reduction or elimination of restrictions on international trade was also a basis of this valuation discipline. It is said that the system established an open and transparent foundation for customs value based on competitive "actual value" rather than on arbitrary and fictitious values.

\footnotetext{
317 GATT, VAL/M/1, 27 February 1981

${ }^{318}$ Argentina, Australia, Austria, Bolivia, Botswana, Brazil, Canada, Colombia, Cyprus, Czech Republic, EC, Finland, Hong Kong, Hungary, India, Japan, Republic of Korea, Lesotho, Malawi, Mexico, Morocco, New Zealand, Norway, Peru, Poland, Romania, Slovak Republic, Slovenia, South Africa, Sweden, Switzerland, Turkey, United States, Yugoslavia, and Zimbabwe. Source: Rosenow \& O'Shea (2010), p.17.

319 The BDV, in its first introduction in 1953, accommodated only CIF countries. In 1974 the BDV was amended to accommodate FOB countries.
} 


\subsection{GATT Uruguay Round: 1986- 1994}

The Uruguay Round commenced in September 1986 in Punta del Este and negotiations were substantially concluded in December 1993. The agenda included several topics: tariffs, non-tariff barriers, natural resource products, textiles and clothing, agriculture, tropical products, GATT articles, Tokyo Round codes, antidumping, subsidies, intellectual property, investment measures, dispute settlement, the GATT system, and services. According to the WTO, it was a long and comprehensive negotiation round:

It took seven and a half years, almost twice the original schedule. By the end, 123 countries were taking part. It covered almost all trade, from toothbrushes to pleasure boats, from banking to telecommunications, from the genes of wild rice to AIDS treatments. ${ }^{320}$

For customs valuation, the purpose of the Uruguay Round was to improve, clarify, or expand the Agreements negotiated in the Tokyo Round of Multilateral Negotiations. The Agreement on Implementation of Article VII of the GATT was included in the Uruguay Round. ${ }^{321}$

The final objective was to convince countries to accept the Tokyo Round CV Code since it was not a popular code. According to the GATT Report of the Committee on Customs Valuation, only twenty-six countries were parties to the Valuation Code until November 1986. In other words, the Tokyo Valuation Code was unpopular, and countries continued to use the BDV valuation system.

At the time that the Uruguay Round was formally launched, less than one-third of the GATT contracting parties had signed the GATT Valuation Agreement.

The limited participation in the valuation and other Tokyo Round Codes, particularly by developing countries, had been a concern to GATT contracting parties and became an important focus of GATT activity in the years leading to the Uruguay Round. ${ }^{322}$

In 1985, just before the beginning of the round, after several meetings held at the GATT Valuation Committee and at the CCC Technical Committee, the following obstacles were identified:

23.

\footnotetext{
${ }^{320}$ WTO site, https://www.wto.org/english/thewto_e/whatis_e/tif_e/fact5_e.htm. [accessed 3 Feb 2017]

${ }^{321}$ GATT Multilateral Trade Negotiations, The Uruguay Round. Ministerial Declaration on the Uruguay Round, NIN.DEC (September 20, 1986).

${ }^{322}$ Rosenow \& O'Shea (2010), p.16
} 
- The need to take the decision collectively or in a coordinated fashion in the framework of a regional grouping.

- The concern that the Agreement might not give customs adequate possibilities to deal with false invoicing and to maintain government revenue.

- The legal and administrative requirements to be fulfilled by signatories, for example, the need to adapt national legislation and procedures and to train staff. $^{323}$

From these three obstacles, it was clear that the most serious one was related to false invoicing and government revenue. Countries' concerns were that, by signing the agreement, they would lose their ability to fight fraud and revenue would fall. It was identified that, in order to answer these concerns, there was a need to reinforce the powers of Article 17 of the Agreement, which was to reaffirm the legal powers of customs administrations to question the importer's declared value.

24. (...) As to this latter question, it was stated that Article 17 of the Agreement and paragraph 7 of the Protocol to the Agreement reaffirmed the rights of customs administrations. (...) As regards implications for revenue, it was recognized that the taxable base may be subject to some reduction compared to some other systems because of the exclusion of certain uplifts, but it was pointed out that some parties had endeavoured to quantify this and had found that the shrinkage was very small. ${ }^{324}$

The discussions surrounding Article 17 were driven mainly by India's concern about the burden of proof. India requested that the burden of proof should be shifted to the importer to provide elements to support the declared price.

\section{(ii) AGREEMENT ON IMPLEMENTATION OF ARTICLE VII}

Burden of proof regarding transaction value.

Article 1 of the above Agreement mandates the acceptance of the transaction value as the customs value of the imported goods except under certain circumstances enumerated in the Article. Article 17 clarifies that the Customs Administration have the authority to satisfy themselves as to the truth or accuracy of any statement, document or declaration presented for customs valuation purposes. The burden of proof for establishing the inaccuracy of the declared price is placed on the Customs Administration. This gives rise to

\footnotetext{
${ }^{323}$ GATT, Working Group on MTN Agreements, Adequacy and Effectiveness of the MTN Agreements and Arrangements and Obstacles to their Acceptance: Consolidation of the Observations Made and Conclusions Reached in the Committees and Councils, MDF/12, p.8, 11 June 1985.

${ }^{324}$ GATT, Working Group on MTN Agreements, Adequacy and Effectiveness of the MTN Agreements and Arrangements and Obstacles to their Acceptance: Consolidation of the Observations Made and Conclusions Reached in the Committees and Councils, MDF/12, p.9, 11 June 1985.
} 
difficulties mainly in the following circumstances: (i) when the declared price is less than that noticed in a series of transactions immediately preceding the relevant one; (ii) when the declared price is less than that noticed for transactions involving identical goods imported directly from the country of manufacture. Adequate flexibility needs, therefore, to be provided to enable the Customs Administration to shift the burden of proof to the importer at least in the cases of the type described above. ${ }^{325}$

In the end, the GATT Contracting Parties' solution in relation to the burden of proof discussion was to issue a Ministerial Decision to clarify the issue. Rosenow puts it as follows:

In short, however, while India's proposal did not result in any alteration of the terms of the Agreement itself, it did produce the important WTO Ministerial Decision clarifying the burden of proof issue, namely the Decision Regarding Cases Where Customs Administrations Have Reasons to Doubt the Truth or Accuracy of the Declared Value. ${ }^{326}$

The Decision Regarding Cases Where Customs Administrations Have Reasons to Doubt the Truth or Accuracy of the Declared Value is considered by Customs administrations as one of the most important Decisions about the CVA. The Decision was used in Thailand - Cigarettes (Philippines) (2010) and will be covered in great detail in further chapters. ${ }^{327}$

However, although the Decision contributed to reinforcing Article 17, it appears that the lack of customs authority in cases of fraud for "double-invoicing" was not the real problem. A good customs valuation system is easy to enforce and achieve a high level of compliance. Thus, it seems that the true problem lay in the subjectivity and lack of comparables to appraise the declared value, resulting in a feeling of distrust of the declared trade values.

Other issues related to the Tokyo Round CV Code were raised during the Uruguay Round, and several requests were submitted by Kenya on behalf of the members of the Preferential Trade Area of Eastern African States (PTA). ${ }^{328}$

\section{PART I}

\footnotetext{
325 GATT. Group of Negotiations on Goods. Negotiating Group on MTN Agreements and Arrangements, Communication from India, MTN.GNG/NG8/W/9 (30 September 1987). p.2 ${ }^{326}$ Rosenow \& O'Shea (2010), p.16

${ }^{327}$ Panel Report, Thailand - Cigarettes (Philippines) (2010), para 7.155 to 7.171. Second Recourse to Art 21.5 DSU Panel report circulated 12 July 2019. Not adopted report.

${ }^{328}$ At the time, the Member States of the PTA participants in the Uruguay Round were Burundi, Kenya, Malawi, Mauritius, Lesotho, Rwanda, Tanzania, Uganda, Zambia and Zimbabwe. The other members of PTA were Comoros, Djibouti, Ethiopia, Mozambique, Somalia, and Swaziland.
} 
Proposal to amend/modify the Agreement on Implementation of Article VII of GATT

The following proposals are submitted to amend/modify the Agreement in order to take into account some of the serious difficulties and concerns of the PTA Member States in acceding to and in applying the Agreement.

(a) In accordance with the requirement in Article VII of GATT which states that the customs value should be the price at which the merchandise is sold or offered for sale in the ordinary course of trade under fully competitive conditions, the customs value should, in the case of developing countries, normally include discounts allowed to sole agents, distributors and concessionaires and to other parties which have entered into special trading agreements.

(b) Article I of the Agreement should be amended to place on the importer the burden of proving that the declared value is the full amount paid or payable for the goods when it is, in the opinion of the Customs Administration, lower than the price at which such or like merchandise is offered for sale in the ordinary course of trade under fully competitive conditions.

(c) The derogation in paragraph 3 of the Protocol to the Agreement which allows developing countries to retain officially established minimum values on a transitional basis should not be limited in scope nor subject to the imposition of restrictive terms and conditions by the Parties to the Agreement.

(d) Developing countries which currently use uplifting value can make a reservation to enable them to retain the system.

(e) Developing countries should be given assistance by the CCC and developed countries to strengthen their customs administrations in order to handle the complexities of the Agreement. ${ }^{329}$

For the purposes of this dissertation, Kenya's requests main points for consideration are: (a) to maintain in the customs valuation the discounts allowed to sole agents, distributors and concessionaires, as it could put at risk the customs value and jeopardize revenue; (b) to continue applying minimum values to assess the customs valuation of a few commodities; and (c) to apply an increase of values in cases where the importer and exporter were associated in business, and under-declaration was detected and eventually confirmed by investigation.

\footnotetext{
${ }^{329}$ GATT (1990). Group of Negotiations on Goods. Negotiating Group on MTN Agreements and Arrangements, Communication from India, MTN.GNG/NG8/W/73. p.1-2
} 
As with the concern of India regarding burden of proof, the GATT Uruguay Round negotiators' response was to issue a Ministerial Decision. Therefore, the Decision on Texts Relating to Minimum Values and Imports by Sole Agents, Sole Distributors and Sole Concessionaires states that (a) sympathetic consideration should be given by the Committee on Customs Valuation to the use of minimum prices by developing countries; and (b) the CCC/WCO is asked to assist developing countries in formulating studies to identify concerns relating to importations by sole agents, sole distributors and sole concessionaires.

This Decision is also covered in great detail in chapter 5 of this dissertation.

Besides the discussions that resulted in these two Ministerial Decisions, the structure and text of the GATT CV Code suffered some minor modifications and was renamed to be the "Agreement on Implementation of Article VII of GATT 1994". Majumder gave a detailed account of the minor changes between the GATT Tokyo Round CV Code and the GATT Uruguay Round CV Code:

The WTO Valuation Code retained the General Introductory Commentary and the contents of the erstwhile Preamble without however mentioning the word "Preamble". Part-I comprising 17 Articles dealing with Rules on Customs Valuation and Annex-I containing the Interpretative Notes were left untouched. The nomenclature of Part-II was changed to "Administration, Consultation and Dispute Settlement", and it contained only two Articles (Articles 18 \& 19) in place of erstwhile three Articles. Part-III dealing with Special and Differential Treatment and containing Article 20 was largely unchanged. The Final Provisions dealt with in Part-IV were substantially reduced and it now contained only 4 Articles (Articles 21 to 24) in place of 10 Articles in previous "Final Provisions". As mentioned, Annex-I was retained as such, while AnnexII was changed slightly inasmuch as additional responsibility of the Technical Committee was included in clause ( $f$ ) as follows:

"(f) to carry out an examination of a matter referred to it by a panel under Article 19 of this Agreement; and"

Another significant change was that Annex-III dealing with the Constitution and Responsibilities of Ad Hoc panels, and the Protocol to the Agreement of 1980 signed in recognition of particular problems of the developing countries were deleted in the new agreement. However, the substantive clauses of the protocol dealt with in clauses 2 to 8 were retained in a different from as Paras 1 to 7 of Annex-III. ${ }^{330}$

A few minor modifications were made to the text during the Uruguay Round, namely: a) Reduction of Articles (regarding technical assistance delivery by developed countries to developing countries); b) Additional responsibilities for the CCC/WCO

${ }^{330}$ Majumder (2001), p. 81. 
TCCV; c) Presentation of the Valuation Code into Parts I, II, III, and IV with three Annexes; d) Responsibilities in Ad Hoc panels; e) Changing the title to GATT Uruguay Valuation Agreement Code and later to WTO Customs Valuation Agreement.

Finally, the big change came in Marrakesh in April 1994, when all the documents of the Uruguay Round, including those referring to customs valuation, were incorporated into the Marrakesh Agreement, to which WTO members became signatories. From this moment on, after the creation of the WTO, the Agreement on Implementation of Article VII of the General Agreement on Tariffs and Trade 1994 became binding on all WTO Members.

\subsection{The World Trade Organization: 1995 and onwards}

The WTO was created in 1994, at the end of the Uruguay Round (1986-1994), when GATT members decided to establish an organization to succeed the GATT.

It is worth remembering that the International Trade Organization (ITO) failed in the 1940s and the creation of the WTO represented a new attempt to have an international organization for international trade. Thus, at the Marrakesh meeting in 1994, the most important act, which is expressed in the Marrakesh Agreement, Article I, is the establishment of the WTO:

\section{Article I}

Establishment of the Organization

The World Trade Organization (hereinafter referred to as "the WTO") is hereby established. ${ }^{331}$

Among the reasons that justify the creation of the WTO are the following:

a) The WTO would provide for a permanent address, with the presence of permanent staff, instead of conducting meetings in various places on the initiative of its members. GATT Contracting Parties increased, and the work needed to be organized.

b) The WTO would provide a platform to expand trade discussions into new areas.

c) The WTO would transform the GATT codes into compulsory Agreements. The fact is that the GATT codes were voluntary, binding only on those Contracting Parties that had signed them. This led to different levels of acceptance and uniformity in GATT codes.

\footnotetext{
${ }^{331}$ GATT, Marrakesh Agreement, 1994
} 
A main point being that the GATT instruments that were binding only on their signatories turned into multilateral agreements binding on all WTO Members. Thus, for instance, the GATT Valuation Code, that was binding on only 36 Contracting Parties, suddenly became binding on all 123 WTO Members.

At its heart are the WTO agreements, negotiated and signed by the bulk of the world's trading nations. These documents provide the rules for international commerce. They are essentially contracts, binding governments to keep their trade policies within agreed limits. ${ }^{332}$

Therefore, with the establishment of the WTO, all Members must respect the binding trade contracts and keep their trade policies in accordance with what was negotiated.

The WTO became operational on 1 January 1995. All previous international instruments negotiated during the GATT were incorporated into the Marrakesh Agreement.

The "Final Act" signed in Marrakesh in 1994 is like a cover note. Everything else is attached to this. (...) The schedules of commitments also form part of the Uruguay Round agreements. ${ }^{333}$

The Marrakesh Agreement includes about sixty agreements and many Decisions are attached to it. The Customs Valuation Agreement is in Annex 1A of the Marrakesh Agreement, together with other Multilateral Agreements on Trade in Goods (MATGs), such as the Agreement on Agriculture, the SPS Agreement, and the TBT Agreement.

The WTO is an organization dedicated to international trade. The WTO Annual Report 2017 describes itself as follows:

There are a number of ways of looking at the World Trade Organization. It is an organization for trade opening. It is a forum for governments to negotiate trade agreements. It is a place for them to settle trade disputes. It operates the global system of trade rules. It helps developing countries build their trade capacity. ${ }^{334}$

Thus, the WTO is an organization to: a) negotiate trade agreements, which fulfils a legislative function; b) settle trade disputes, which fulfils a judiciary function, and c) operate trade rules and assist developing and LDCs countries to build trade capacity, which fulfils an executive function. In summary, the WTO is an organization that performs legislative, judiciary and executive functions for international trade. It is a

\footnotetext{
${ }^{332}$ WTO Annual Report (2017), p.4

${ }^{333}$ WTO site https://www.wto.org/english/docs_e/legal_e/legal_e.htm. [accessed 14 Feb 2017]

${ }^{334}$ WTO Annual Report (2017), p.4
} 
unique experiment to have the three branches of power in an international organization for international trade.

\subsection{Concluding Remarks}

Having presented the discussions that arose during the GATT Kennedy Round (1964 1967), the chapter showed that tariffs and customs valuation were at the centre of the negotiations between the US and EEC countries. In fact, customs valuation was one of the main non-tariff issues on the table, with much criticism of the US ASP customs valuation system, especially on the part of the European chemical industry. The limited time for concluding the Round and the lack of US Congress authority were reasons to leave the topic of customs valuation pending for the next GATT Round.

While waiting for the next GATT Round, the discussions to abolish the ASP in favour of new customs valuation rules continued to make progress. During the 1960s and 1970s, the BDV Convention from the CCC was the most used customs valuation standard. In 1971, the GATT Committee on Trade in Industrial Products suggested the harmonization of valuation systems with the adoption of the BDV rules. In short, for a moment in time, it seemed that the BDV set of rules interpreting GATT Article VII would prevail as the customs valuation global standard.

However, US Congressional hearings in late 1972 and 1973 unveiled opposition to the country's alignment with the BDV system. The private sector, represented by the AIA, presented a proposal for a new valuation system based on "transaction value". In conclusion, this chapter revealed that much of the negotiations and discussions related to the harmonization of customs valuation happened before the GATT Tokyo Round. For many scholars, this is an unknown fact about CV history and it certainly gives a better perspective from which to understand the topic.

The matter of customs valuation returned to the negotiating table during the GATT Tokyo Round (1973 - 1979). The US opposition to the BDV resulted in a proposal for a new code that had to be negotiated with other GATT Contracting Parties. At the end of the Tokyo Round, the US proposal prevailed with the adoption of a so-called "positive" system of customs valuation based on the "price actually paid or payable", as the main method for the imported goods subject to AV tariffs. The Agreement on Implementation of Article VII of the General Agreement, negotiated during the Tokyo Round of multilateral trade negotiations, was signed on 12 April 1979 and entered into force on 1 January 1981.

The Tokyo Round CV code cannot be considered a success. By the end of 1994, the code had only thirty-five Contracting Parties. Therefore, during the Uruguay Round (1986 - 1994), the GATT Contracting Parties aimed to improve, clarify, or expand the 
Agreements negotiated in the Tokyo Round of Multilateral Negotiations. The Agreement on Implementation of Article VII of the GATT was included in the Uruguay Round.

The negotiations at the GATT Uruguay Round attempted to address the concerns of countries, spearheaded by India and Kenya (PTA group). Such discussions resulted in the issue of two Ministerial Decisions: (a) Decision Regarding Cases Where Customs Administrations Have Reasons to Doubt the Truth or Accuracy of the Declared Value; and (b) Decision on Texts Relating to Minimum Values and Imports by Sole Agents, Sole Distributors and Sole Concessionaires.

In addition to the Ministerial Decisions, the GATT CV code went through a few minor modifications, such as (a) A reduction of Articles (regarding technical assistance delivery by developed countries to developing countries); (b) Additional responsibilities for the $\mathrm{CCC} / \mathrm{WCO} \mathrm{TCCV}$; (c) Better presentation structure of the Valuation Code into Parts I, II, III, and IV with three Annexes; (d) Attribution of responsibilities in Ad Hoc panels; e) Changing the title to GATT Uruguay Valuation Agreement Code and later to the WTO Customs Valuation Agreement.

Finally, the biggest transformation in the customs valuation landscape came with the creation of the WTO. The new international trade organization turned the GATT instruments that were binding only for their signatories, into multilateral agreements that were binding on all WTO Members. Thus, for instance, the GATT Valuation Code, that was only binding on thirty-six Contracting Parties at the time of the creation of the WTO, suddenly became binding on all 123 WTO Members. 


\section{WTO Customs Valuation Agreement (CVA)}

With the creation of the WTO, the agreements and associated legal instruments that were negotiated during the GATT times were included in the annexes of the Marrakesh Agreement. In that regard, the GATT CV Code became the WTO CV Agreement, part of Annex 1A Multilateral Agreements on Trade in Goods. In contrast to the GATT CV Code, the WTO CV is binding on all Members.

To address the research question about the lack of proper consideration for trade revenue in customs valuation and AV tariffs, it is necessary to study the methodology of the WTO CVA. The principles and interpretation that support the so-called "positive" system of customs valuation, based on the "price actually paid or payable" for imported goods, are essential elements to investigate.

Along these lines, the chapter provides a thorough examination of the WTO CVA. It presents the main aspects of the CVA, using the interpretative notes from Annex I, the WTO Disputes interpretation, the WCO TCCV instruments, and scholars' materials. The chapter is rich in references on how to interpret key provisions of the CVA. Therefore, the chapter comments on the WTO CVA rules as addressed in Part I. The other Parts of the WTO CVA are discussed in the following chapters.

\subsection{GATT Article VII and WTO Agreement - Hierarchy}

Before commenting on the WTO CVA, it is important to clarify that the hierarchy between GATT Article VII and the WTO Agreement is solved by an interpretative note to the 1994 Agreement Establishing the WTO.

ANNEX 1
ANNEX IA
MULTILATERAL AGREEMENTS ON TRADE IN GOODS
General interpretative note to Annex 1A:
In the event of conflict between a provision of the General Agreement on
Tariffs and Trade 1994 and a provision of another agreement in Annex 1 A to
the Agreement Establishing the World Trade Organization (referred to in the
agreements in Annex 1 a as the "WTO Agreement"), the provision of the other
agreement shall prevail to the extent of the conflict.


As the interpretative note shows, the WTO Agreement prevails over GATT Article VII. However, as Rosenow and O'Shea point out, the conflict has never been examined by a WTO panel or the Appellate Body in a dispute. ${ }^{335}$

\subsection{WTO CVA Interpretation - Vienna Convention on the Law of Treaties}

The WTO agreements are interpreted in accordance with Article 31 of the Vienna Convention on the Law of Treaties. Therefore, provisions of the WTO CVA must also be interpreted in accordance with the general rules of treaty interpretation as set out in Article 31 of the Vienna Convention on the Law of Treaties. The sentences in the Agreement must be read in its context and considering the object and purpose of the GATT 1994.

\section{Vienna Convention}

Article 31

\section{General rule of interpretation}

1. A treaty shall be interpreted in good faith in accordance with the ordinary meaning to be given to the terms of the treaty in their context and in the light of its object and purpose. ${ }^{336}$

The Vienna Convention on the Law of Treaties does not prioritize any of the elements to be examined in the interpretation over the others. In brief, the WTO agreements should be interpreted considering three main aspects: (1) the ordinary meaning of the terms of the treaty; (2) their context; and (3) the treaty's object and purpose.

An important point in Article 31 of the Vienna Convention on the Law of Treaties for the subject matter of this dissertation, specifically the WTO CVA and the WCO TCCV instruments, is whether the term "the parties" in Article 31.3(c) VCLT means that the rule should be applied in the relations between all WTO Members or only to the States that accepted the rule.

This point regarding the interpretation of "the parties" was addressed by the Panel in EC - Approval and Marketing of Biotech Products (2006). The Panel addressed the issue under the topic of "Other applicable rules of international law as an interpretative element to be taken into account together with the 'context' (Article 31(3)(c) of the Vienna Convention on the Law of Treaties)".

\footnotetext{
${ }^{335}$ Rosenow, Sheri and O'Shea, Brian J. (2010), p.25

${ }^{336}$ UN (1969)
} 
7.70 Taking account of the fact that Article 31(3)(c) mandates consideration of other applicable rules of international law, and that such consideration may prompt a treaty interpreter to adopt one interpretation rather than another, we think it makes sense to interpret Article 31(3)(c) as requiring consideration of those rules of international law which are applicable in the relations between all parties to the treaty which is being interpreted. ${ }^{337}$

The Panel stated that Article 31(3)(c) VCLT should be interpreted to mandate consideration of rules of international law that are applicable in the relations between all parties to the treaty which is being interpreted. It then concluded that "if a rule of international law is not applicable to one of the four WTO Members which are parties to the present dispute, the rule is not applicable in the relations between all WTO Members." 338

The Harmonized System, a Convention from the WCO, is a good example of a rule in international law that is likely to be used in the context of Article 31(3)(c) VCLT and to compare it with the WCO TCCV instruments.

In addition to the general rule of interpretation from Article 31, the VCLT also considers supplementary means of interpretation in Article 32.

The supplementary means of interpretation takes into consideration the preparatory works of the treaty or, in other words, the historical documents produced in the time leading up to the conclusion of the treaty. Going further, Prévost (2009) explains that arguments based on the negotiating history are not dispositive and subject to an evolutive interpretation.

Of course, arguments based on the negotiating history of the SPS Agreement are not dispositive. They could be countered by a call for an evolutive interpretation of the Agreement to take account of the current reality where the difference between public and private standards for exporters has blurred. ${ }^{339}$

In summary, Articles 31 and 32 of the VCLT are meant to assist in the interpretation of a treaty to identify the ordinary meaning of terms and find the common intention of the parties.

\subsection{WCO TCCV Instruments legal status}

\footnotetext{
337 WTO, Panel, WT/DS291/R, WT/DS292/R, WT/DS293/R, para. 7.70

${ }^{338}$ WTO, Panel, WT/DS291/R, WT/DS292/R, WT/DS293/R, para. 7.71

${ }^{339}$ Prévost, D. (2009), p. 548
} 
In consideration of the legal status of the texts of the Technical Committee(Advisory Opinions, Commentaries, Explanatory Notes, Case Studies and Studies), in Annex II, it is recognized that it is the intention of the Agreement that the Technical Committee will prepare instruments as a guide towards achieving uniformity in the interpretation and application of the Agreement at the technical level. Advisory opinions, commentaries, explanatory notes, studies or reports would all be instruments of this nature.

In theory, these texts, however, do not constitute international law. As distinct from the Interpretative Notes on the Agreement contained in Annex I, there is nothing in the Agreement to imply that any of the Technical Committee's decisions would have the force of law within the Member countries to the extent that they are not incorporated into the national legislation of the Member.

The question of whether the WCO texts are or are not considered international law is important because it determines whether these instruments can or cannot be used in WTO disputes. To interpret terms at issue in disputes, the interpreter refers to Articles 31 and 32 of the VCLT, which are recognized as the fundamental rules of treaty interpretation. Article 31(3) of the Vienna Convention on the Law of Treaties provides:

However, even if the WCO instruments are not international law within the meaning of Article 31(3)(c), they may still be useful for interpretation pursuant to Article 31(1) of the VCLT.

In the present case, an important observation relates to the fact that not all WTO members are WCO members. However, the situation is slightly different from the HS Convention, because the TCCV was established by the CVA, Part II Article 18 Paragraph 2, under the auspices of the Customs Co-operation Council (CCC), in practice, the WCO. Both the WTO CVC and the WCO TCCV work in coordination. The WTO CVC, for example, sought the assistance of the TCCV relating to the development of some decisions. In addition, Paragraph 23 of Annex II of the CVA requires the Chair of the TCCV to report to the CVC on its meetings and outcomes. In practice, the WTO Secretariat also reports to the WCO TCCV on valuation activities and outcomes of the Committee and the WTO Secretariat.

Thus, the question here regarding "the parties" of the TCCV becomes difficult to distinguish from the WTO Members, as "the parties", with rare exceptions, participate in discussions of both committees.

Nevertheless, until now the WCO TCCV have never been mentioned in the WTO disputes. For instance, in Thailand - Cigarettes (Philippines) (2010), it would have been reasonable to expect a reference to the WCO Case Study 13.1 Application of Decision 6.1 of the Committee on Customs Valuation (Declared value of imported 
goods lower than identical goods) or WCO Case Study 13.2 Application of Decision 6.1 of the Committee on Customs Valuation (Declared value of imported goods lower than raw materials.)

Therefore, whether the WCO instruments could one day be used in WTO disputes for the purposes of interpretation remains a possibility.

It is useful to refer to the language used in Annex II of the CVA where it states that it is expected that the decisions of the Technical Committee are to play a vital role in achieving uniformity in the interpretation and application of the Agreement. It follows that this can be best attained by the establishment of a reporting procedure whereby there is recognition of the Committee's work by both the Council and the Committee on Customs Valuation, each within its respective mandate: the Council under its Convention and the Committee on Customs Valuation under the Agreement. Therefore, if the WCO instruments are meant to achieve uniformity and obey a reporting procedure that requires approval by the highest bodies of the $\mathrm{WCO}$ and the WTO, how can it be that the WCO instruments have not been referred to in any disputes?

A main topic here is for example the question of which sale is the sale for customs valuation? The first sale or the last sale? Ruessman and Willems translate the importance of the question as follows:

If the customs value of imported goods is determined on the basis of this first sale price, that is, the price of the transaction between the manufacturer and a middleman, the value added in subsequent sales is effectively ignored. Thus, an importing company may achieve considerable savings on duties by using the first sale as the basis for the customs value. ${ }^{340}$

On this matter, Commentary 22.1 shows how far the WCO TCCV is in "achieving uniformity in the interpretation and application of the Agreement" in terms of the acceptance of such WCO instruments in domestic law. The adoption of this instrument required a lengthy discussion and was finally adopted by consensus. However, after returning home, the US delegates discovered that there was opposition to the adoption of such an instrument and decided to reject the instrument. Hence the US continues to adopt its common practice of accepting the first sale in some circumstances. A more detailed account of this case is provided in the box below.

WCO TCCV Commentary 22.1 - "Sold for export to the country of importation" in a series of sales

\footnotetext{
${ }^{340}$ Ruessmann, Laurent and Willems, Arnoud (2009). Revisiting the First Sale for Export Rule: an Attempt to Remove Fairness in the Interests of Raising Revenues, Without Improving Legal Certainty, in World Customs Journal, Volume 3, Number 1, p. 1.
} 
The First Sale - Last Sale case - Uniformity in interpretation and application of the Agreement

On the matter of sale, one of the most emblematic instruments produced by the WCO TCCV in the last years is Commentary 22.1 about the meaning of the expression "sold for export to the country of importation" in a series of sales.

The WCO TCCV noted that there were various indications in the General Introductory Commentary, Article 1 and other provisions of the Agreement that it was envisaged that Article 1 would normally be based on sales to buyers in the country of importation. It concluded that the last sale would reflect better the entire transaction.

"20. In sum, a transaction value based on the first sale may not fully reflect the substance of the inputs resulting from, or forming part of the entire commercial chain as envisioned by the General Introductory Commentary, and Articles 1 and 8. In contrast, a transaction value based on the last sale will more fully reflect the substance of the entire transaction as envisioned."

The WCO TCCV reached a consensus that:

“(...) in a series of sales situation, the price actually paid or payable for the imported goods when sold for export to the country of importation is the price paid in the last sale occurring prior to the introduction of the goods into the country of importation, instead of the first (or earlier) sale. This is consistent with the purpose and overall text of the Agreement.

About the discussions, it is important to mention that the US is one of the few countries at the CCC/WCO TCCV who has always been represented in all the TCCV sessions. As such, the US actively participated in every session where Commentary 22.1 was discussed and later approved by consensus.

Though approved by consensus, this commentary and all other instruments produced by the TCCV are not binding in any way. To became binding, such instruments need to be internalized by each country according to its legislation.

So for that matter, the US decided to follow the interpretation of the last sale obtained in CCC/WCO TCCV Commentary 22.1 with a notice published in the Federal Register [73 FR 4254] on January 24, 2008, which proposed a new interpretation of the phrase 'sold for exportation to the United States' for purposes of applying the transaction value method of valuation in a series of sales importation scenario. 
Under this new interpretation, in a transaction involving a series of sales, the price actually paid or payable for the imported goods when sold for exportation to the United States would be the price paid in the last sale occurring prior to the introduction of the goods into the United States, instead of the first (also referred as earlier) sale. Accordingly, the transaction value would typically be determined on the basis of the price paid by the buyer in the United States.

According to the US, after the US Customs and Border Protection (CBP) published its proposed interpretation document, the US Congress enacted the Food, Conservation and Energy Act of June 18, 2008 in which section 15422 required the CBP Commissioner to collect information from importers for a one-year period as to whether the declared value was based on a 'first sale' in a series of sales transactions. CBP was required to report the data to the International Trade Commission (ITC).

The US Congress also stated that, prior to January 1, 2011, CBP should not implement any change to its existing interpretation of the expression 'sold for exportation to the United States' for purposes of applying the transaction value method of valuation in a series of sales importation scenario. (US Federal Register, Vol. 75, nr.188, Wednesday, September 29, 2010, Notices)

On this matter, Ruessman and Willems concluded:

What is clear, though, is that the potential impact on international trade of the abolition of the first sale rule in the EU and/or the US would be profound. (...)

The first sale rule has been in place in the EU and the US for more than 20 years and reflects a commonsense recognition that, in international trade, the first buyer for export may be located anywhere and a resale of the product before importation is not uncommon. In the absence of more compelling reasons than those cited by the Commentary, the first sale customs valuation rule should not be discarded.. ${ }^{341}$

A recent development in the acceptance of the last sale as the appropriate sale to achieve uniformity in the interpretation and application of the CVA comes from the EU. The application of the UCC on 1 May 2016 led to the implementation of the "last sale for export rule" as opposed to the earlier "first sale for export rule". Under the previous Community Customs Code, it was possible to use an earlier sale in the chain of transactions if it could be evidenced that this sale was already aimed at being an export to the EU. Under the new UCC, this is no longer possible. Although WCO TCCV Commentary 22.1 instrument is not mentioned, it is known in the customs community that it influenced the change of interpretation in the UCC.

\footnotetext{
${ }^{341}$ Ruessmann, Laurent and Willems, Arnoud (2009). 'Revisiting the First Sale for Export Rule: an Attempt to Remove Fairness in the Interests of Raising Revenues, Without Improving Legal Certainty', in World Customs Journal, Volume 3, Number 1, p. 7.
} 
A key point here is about the legal status and interpretation implications of the WCO TCCV instruments. The WCO TCCV provide guidance in achieving uniformity in the interpretation and application of the CVA. These instruments influence national legislation, assist in solving domestic disputes and are used as a reference by the customs community. Nevertheless, these instruments are not considered as international law and have never been used by the WTO dispute settlement system. To this date, neither the panels nor the Appellate Body has ever referred to an instrument of the TCCV.

This discussion is relevant, as it shows a lack of legal coordination between the WTO and the WCO technical body when interpreting the provisions of the CVA. The creation of a body that produces technical instruments lacking legal status is also something to reflect upon since it limits the possibilities of solving customs valuation disputes outside the WTO.

\subsection{WTO CVA Part I - Rules on Customs Valuation}

The WTO CVA, officially named "Agreement on Implementation of Article VII of the General Agreement on Tariffs and Trade 1994" is made up of a General Introductory Commentary, 24 Articles, and three Annexes. ${ }^{342}$

The structure of the Agreement is divided into four parts and three annexes as shown in the table below.

Table 4 - WTO Customs Valuation Agreement - Structure

\begin{tabular}{|c|c|}
\hline General In & oductory Commentary \\
\hline Part I - Ru & on Customs Valuation \\
\hline Article 1 - & Transaction Value \\
\hline Article 2 - & Identical goods \\
\hline Article 3 - & Similar goods \\
\hline Article 4 - & Reversal Provision \\
\hline Article 5 - & Deductive \\
\hline Article 6 - & Computed \\
\hline Article 7 - & Fall Back \\
\hline Article 8 - & Adjustments \\
\hline Article 9 - & Conversion of currency \\
\hline Article 10 & Confidentiality \\
\hline
\end{tabular}

${ }^{342}$ Note that it is interesting that the CVA includes a commentary before the preamble, which is
unusual. 
Article 11 - Right of appeal

Article 12 - Publication and Administration of Trade Regulations

Article 13 - Withdraw goods under guarantee

Article 14 - Legal force of Annexes

Article 15 - Definitions

Article 16 - Right for a written explanation for customs administration

Article 17 - Customs right to question

Part II - Administration, Consultations and Dispute Settlement comprehends

Article 18 - Institutions: WTO CCV and CCC TCCV

Article 19 - Consultations and Dispute Settlement

\section{Part III - Special and Differential Treatment comprehends}

Article 20 - Developing country rights to delay

Part IV - Final Provisions

Article 21 - Reservations

Article 22 - National Legislation

Article 23 - Review

Article 24 - Secretariat

Annexes

Annex I - Interpretative Notes

Annex II - Technical Committee on Customs Valuation

Annex III - Reservations and concessions for developing countries

The CVA, in fact, is a package formed by different parts and annexes which are essential in the correct application and maintenance of the text. This chapter analyses the various parts, its Articles and the annexes. The technical nature of the discussion not only guides the reader through the complexity of the rules in this agreement, but also serves to illustrate the enormous difficulties both customs officials and traders have when applying the set of rules from the Agreement. ${ }^{343}$

\subsubsection{General Introductory Commentary}

The WTO CVA begins with a General Introductory Commentary (GIC) before the preamble, which is unusual when compared to other WTO Agreements. Sherman and Glashoff explain the section as follow:

\footnotetext{
${ }^{343}$ The work tried to achieve balance showing important points, illustrating complexities, but avoiding long and complex discussions.
} 


\begin{abstract}
Although it is not part of the body of the Code, the official General Introductory Commentary (GIC) which precedes Article 1 is an authoritative text which may be resorted to as an aid to interpreting and understanding the Code. ${ }^{344}$
\end{abstract}

Paragraph 1 of the general introductory commentary explains that transaction value is the primary basis for customs value. In addition, it explains that transaction value is determined based on Article 1 together with Article 8. Transaction value is the primary method of valuation, and most of the imported goods are valued using this method. As such, it is by far the most important method of valuation.

The Agreement has a total of six methods, but, in fact, the first method is what matters most. The alternate methods are rarely used, and many scholars say they represent less than ten per cent of the cases of determining the value of goods.

Paragraph 2 explains that the alternate methods are in Articles 2 to 7. It explains that, where it is not possible to use Article 1 or, in other words, to find the price, a consultation process must be initiated between customs and the importer, with a view to using the other methods. Such a case occurs, for example, with leased goods and gifts when no sale occurs. ${ }^{345}$ Thus, Customs authority must find identical or similar imported goods to compare with the imported good. The lack of identical or similar goods affects many customs administrations and forces customs to move on to the other alternate methods.

Paragraph 3 refers to Articles 5 and 6 which provide for alternate methods, known as deductive and computed methods. The deductive method takes the value of identical or similar imported goods in the importer's domestic market as a basis. The computed method starts with the value of the imported goods produced in the country of exportation.

Finally, paragraph 4 mentions Article 7, which is the last resource and also known as the fallback method, which, in brief, starts the process all over again with a more flexible approach.

The AB in Colombia - Ports of Entry (2009) commented on the importance of the transaction value and the sequential nature of the valuation methods.

Para. 7.138. The Panel therefore understands that the Customs Valuation Agreement imposes an obligation on national authorities to determine the

\footnotetext{
${ }^{344}$ Sherman Saul L. and Glashoff H. (1988), p.59

${ }^{345}$ Note that this is a friendly consultation and not, as some might think, an adversarial consultation. In real life, these friendly consultations are rare, as customs tends to skip the consultation and move on direct into the other methods. That happens in part because the importer rarely has any additional information to provide.
} 
customs value of imported goods based on the "transaction value" and, whenever that is not possible, to sequentially apply the customs valuation methods provided for in Articles 1, 2, 3, 5, 6 and 7.1 of the Agreement. ${ }^{346}$

Thus, in summary, the GIC to the Agreement introduces the predominance of the transaction value and presents the five alternate methods that must be used in a sequential manner: (Article 2) the transaction value of identical goods; (Article 3) the transaction value of similar goods; (Article 5) the deductive value method; (Article 6) the computed value method; and (Article 7) the fallback option.

Table 5 - WTO Customs Valuation Methods

\section{WTO Customs Valuation - Methods}

\section{Transactional methods}

First method - Transaction Value

Second method - $\quad$ Transaction Value of identical goods

Third method - $\quad$ Transaction Value of similar goods

\section{Other methods}

Fourth method - Deductive value

Fifth method - $\quad$ Computed value

Sixth method - $\quad$ Fall back

It is important to note that the first three methods of valuation under the Agreement are based on the determination of a transaction value. Therefore, in other words, the first three methods are transactional methods. Only when a transaction cannot be found, it is possible to move on to methods that require a calculation to deduct or add values.

In conclusion, the Agreement requires the methods of valuation to be considered in strict hierarchical order. Therefore, only if one method cannot be applied, it is possible to move onto the next method. For example, only if it is not feasible to find identical goods, it is possible then to look for similar goods.

\subsubsection{Preamble}

Before moving onto the Articles, it is worth noting that the preamble gives guidance to interpreting and understanding the WTO CVA. Some key elements of the preamble are:

${ }^{346}$ WTO DS366, WT/DS366/R, paras. 7.137-7.138 
a) to further the objectives of the GATT 1994: among other objectives, this sentence refers to the promotion of peace and prosperity through international trade. From a customs valuation perspective that means to guarantee that the exports from developing and LDCs would receive fair valuation treatment when entering the territory of import markets.

b) to provide greater uniformity and certainty in their implementation: a reference to the different interpretations of GATT Article VII and the need for a uniform interpretation that could provide certainty in the transactions.

c) the need for a fair, uniform, and neutral system: a reference against arbitrary systems that could use higher prices and be harmful to international trade.

d) the basis for the valuation of goods for customs purposes should, to the greatest extent possible, be the transaction value: a reminder that the transaction value is the desirable method of customs valuation. The system is based on a self-declared value by the parties.

e) it should be based on simple and equitable criteria: the alternative valuation criteria should be simple and equitable when arriving at a customs value.

f) without distinction between sources of supply: the customs valuation rules should not be used in a discriminatory way.

g) valuation procedures should not be used to combat dumping: a dumping investigation and procedure is different than a customs valuation procedure to collect AV tariffs. Therefore, customs valuation should not be increased to calculate tariffs in cases of dumping. An alert that the antidumping "normal value" definition is different from the "transaction value" customs valuation definition.

\subsubsection{Article 1 - Transaction Value}

Article 1 is the most important Article of the Agreement. It describes the transaction value concept.

Paragraph 1 explains that the transaction value is the price actually paid or payable for the goods when sold for export to the country of importation adjusted in accordance with the provisions of Article 8. By using the terms "paid" or "payable", paragraph 1 highlights that payments before, during, and also after the importation, but linked to the goods, need to be considered. 
A key point is the concept of sale for export. Thus, domestic sales are excluded. The sale for export must be to the country of importation. Sales to intermediate countries are excluded. Some fundamental points about Article 1 are explained in the interpretative note to Article 1.

Annex I: Interpretative Notes
Note to Article 1
Price Actually Paid or Payable
1. The price actually paid or payable is the total payment made or to be made
by the buyer to or for the benefit of the seller for the imported goods. The
payment need not necessarily take the form of a transfer of money. Payment
may be made by way of letters of credit or negotiable instruments. Payment
may be made directly or indirectly. An example of an indirect payment would
be the settlement by the buyer, whether in whole or in part, of a debt owed by
the seller.
2. Activities undertaken by the buyer on the buyer's own account, other than
those for which an adjustment is provided in Article 8 , are not considered to be
an indirect payment to the seller, even though they might be regarded as of
benefit to the seller.
(...)

In general, restrictions on the sale of goods are not allowed.

If the imported goods are not sold, there can be no transaction value and, therefore, Article 1 of the agreement cannot be used. The Agreement lists situations where a sale should not be considered a sale, such as when there are restrictions, when the price is subject to conditions that cannot be quantified, when proceeds from the resale are linked to the seller, and finally when there is a relationship between the buyer and the seller that cannot be quantified.

There is no international definition of "sale", and every country is free to establish its own definition of sale in its national law. However, the lack of a clear international definition has led to lengthy discussions and to the production of instruments from the WCO TCCV. One example is WCO TCCV Advisory Opinion 1.1, which states that the term "sale" should be interpreted as widely as possible and lists situations not to be considered as a sale. 


WCO TCCV - Advisory Opinion 1.1 - The concept of "sale" in the
Agreement. ${ }^{347}$
(...)
The Technical Committee on Customs Valuation expressed the opinion that:
(a) The Agreement on implementation of Article VII of the General Agreement
on Tariffs and Trade 1994, hereinafter called the "Agreement", contains no
definition of "sale". Article 1, paragraph 1, merely stipulates a specific
commercial operation satisfying certain requirements and conditions.
(...)
List of situations in which imported goods would not be deemed to have been
the subject of a sale under the Agreement
I. Free consignments
(...)
II. Goods imported on consignment
(...)
III. Goods imported by intermediaries, who do not purchase the goods and
who sell them after importation
(...)
IV. Goods imported by branches which are not separate legal entities
(...)
V. Goods imported under a hire or leasing contract
(...)
VI. Goods supplied on loan, which remain the property of the sender
(...)
VII. Goods (waste or scrap) imported for destruction in the country of
importation, with the sender paying the importer for his services
(...)

Advisory Opinion 1.1 is thus rich in examples where there is no sale and therefore the transaction value cannot be applied.

It can happen that there are goods where a sale has occurred and other goods where there has been no sale in the same shipment. This is the case, for example, where certain gifts, samples, prototypes, and promotional items are shipped together with goods for which payment is required. Hence, for the goods free of charge, an alternate method of valuation must be used.

${ }^{347}$ WCO (2014). Customs Valuation Compendium. 
An illustration of the difficulties to identify the international sale is when goods are dispatched to a country of importation not as the result of a sale, but with the intention that they would be sold on account of the supplier, at the best price obtainable. These goods are typically stored at customs warehouses awaiting the final international sale to happen before they can enter the importer's territory.

Another example of how difficult it is to find out if there was a sale or not is when goods are imported by branches that are not separate legal entities. As a sale necessarily involves a transaction between two distinct persons, the delivery of goods to a branch office, which does not have a separate legal status, is merely a transfer of goods from one office to another of the same legal entity. Hence, the customs value of goods imported by a branch office that does not have a separate legal status can only be based on the transaction value if the importation follows a sale by the exporting company to a person distinct from the branch; namely, the end customer.

Other situations where a sale is excluded are: goods imported under a leasing contract, goods supplied on loan, which remains the property of the exporter, and goods which are the subject of barter or compensation.

Another interesting question under Article 1 that captures the spirit of volatility in the WTO CVA is when prices for identical goods are different from each other, and in some cases below the usual market prices. This question was the subject of discussion in the WCO TCCV Advisory Opinion 2.1.

WCO TCCV - Advisory Opinion 2.1 - Acceptability of a price below prevailing market prices for identical goods. ${ }^{348}$

(...)

2. The Committee considered this question and concluded that the mere fact that a price is lower than prevailing market prices for identical goods should not cause it to be rejected for the purposes of Article 1, subject of course to the provisions of Article 17 of the Agreement.

The answer shows how open the set of rules of the WTO CVA are in terms of price market references. In fact, it is a statement that there are no comparables for trade valuation purposes. Identical goods imported with equal conditions, at the same moment in time, can thus have, according to the CVA, different prices and that is normal. It all depends on the ability of the parties to negotiate the price.

${ }^{348}$ WCO (2014). Customs Valuation Compendium. 
There are several WTO disputes addressing the use of other prices rather than the price determined by the transaction value.

A first example is Argentina - Textiles and Apparel (1998). The complainant United States noted that Argentina was using an adjusted "average import price" instead of the actual transaction values when setting the specific duties.

3.109 (...) Argentina's use of an adjusted "average import price" instead of actual transaction values in setting its specific duties was contrary to Articles II:3 GATT 1994, as well as Article VII GATT 1994 as clarified by Articles 1 to 8 of the Customs Valuation Agreement. ${ }^{349}$

Thus, the Panel found that suspicions of under-pricing could not be used as an argument to justify an Article II violation.

6.44 (...) However, neither the Customs Valuation Agreement nor any other provision of the WTO Agreement allows the breach of tariff bindings made under Article II of GATT on the grounds of a general suspicion that declared customs values are sometimes understated. ${ }^{350}$

It is important to highlight the dispute conclusion that if the declared customs value is under-priced, then Argentine authorities should audit the customs value on a case-bycase basis. Argentina appealed, but the AB upheld the Panel's findings and conclusions for customs valuation.

A second example is Brazil - Minimum Import Prices (1999) regarding the use of minimum import prices instead of the transaction value price. The complainant EC claimed that Brazil's measures violated, among others, Articles 1 through 7 of the Agreement on Implementation of Article VII of the GATT 1994.

In other cases, the Brazilian customs authorities ignore the transaction price on which the customs duties should be applied but instead apply a minimum price to calculate the duties. ${ }^{351}$

Thus, the EC argued that Brazil ignored the transaction value and instead applied a minimum price as customs value. The case had successful consultations, and the dispute ended.

A third example is Mexico - Pricing Measures (2005). The complainant Guatemala requested consultations with Mexico concerning certain Mexican customs rules, procedures and administrative practices that impose officially established prices for

\footnotetext{
$349 \mathrm{WT} / \mathrm{DS} 56 / \mathrm{R}$

$350 \mathrm{WT} / \mathrm{DS} 56 / \mathrm{R}$

${ }^{351}$ WTO, WT/DS183/1
} 
customs valuation and other purposes. Guatemala also contested the Mexican authorities' practice of requiring a deposit or bond to guarantee the observance of these officially established prices.

In Guatemala's view, these measures are inconsistent with Mexico's obligations under the WTO Agreements, because they fix and/or apply minimum prices, minimum values or estimated prices officially established for more than 300 imported products, while also requiring the provision of a deposit or surety in order to ensure application of this mechanism, (...). ${ }^{352}$

In Guatemala's view, Mexican customs rules, procedures, and administrative practices at issue were inconsistent with Mexico's obligations under the following WTO CVA provisions: Art. 1, 2, 3, 4, 5, 6, 7, 8, 12, 13, 15, 16 and 22. On 29 August 2005, Guatemala informed the DSB that, because of the consultations, Guatemala and Mexico reached a mutually satisfactory solution concerning footwear and brushes, two areas that were severely affected by the measures imposed by Mexico, and that the request for consultations should be withdrawn.

The dispute cases are indicative examples of attempts to avoid using the transaction value price. For the purposes of this dissertation, this is a central question, as transaction value has no comparability parameters. According to the CVA, one should always believe that parties have negotiated in good faith. However, this jeopardizes any attempt at value predictability.

Paragraph 2 of Article 1 is about international sales between related parties. This is a topic of great relevance for multinational companies, with links to direct taxation and transfer pricing.

The interpretative note to Article 1, Paragraph 2 explains:

\begin{tabular}{|l|}
\hline Annex I: Interpretative Notes \\
Note to Article 1 \\
Paragraph 2 \\
(...) \\
2. Paragraph $2($ a) provides that where the buyer and the seller are related, the \\
circumstances surrounding the sale shall be examined and the transaction \\
value shall be accepted as the customs value provided that the relationship did \\
not influence the price. It is not intended that there should be an examination \\
of the circumstances in all cases where the buyer and the seller are related.
\end{tabular}

${ }^{352}$ WTO, WT/DS298/1 
Such examination will only be required where there are doubts about the
acceptability of the price. (...)
3. Where the customs administration is unable to accept the transaction
value without further inquiry, it should give the importer an opportunity to
supply such further detailed information as may be necessary to enable it to
examine the circumstances surrounding the sale.
(...)

The main question is whether the relationship influenced the price. The paragraph explains the need to examine the circumstances surrounding the sale.

The Appellate Body in Thailand - Cigarettes (Philippines) (2010) $)^{353}$ commented about related parties' transactions and the examination of the circumstances surrounding the sale:

Para. 7.150. Therefore, paragraph 2 sets out that in a related-party situation, an examination of the circumstances surrounding the sale is not required in all cases, but only when there are doubts about the acceptability of the price. Article 1.2(a), taken together with paragraph 2 of the Interpretative Notes to Article 1.2, indicates that only when customs authorities have doubts about the transaction value in a related-party transaction, they will need to inquire into the acceptability of the transaction value. ${ }^{354}$

Therefore, in the case of doubts during such an examination, customs administrations should hold dialogues with the importers to address the doubts. The Appellate Body in Thailand - Cigarettes (Philippines) (2010) explains the procedures for the examination and the respective responsibilities of both customs authorities and importers:

Para. 7.155. Overall, therefore, the determination of whether to accept the transaction value as the customs value in a related-party situation under Article 1.2(a) entails the following procedural steps:

- The importer declares a transaction value for the goods imported;

- The customs authority is required to examine the circumstances of the sale only if it has doubts about the validity of the transaction value of the imported

\footnotetext{
${ }^{353}$ It is worth mentioning that the Philippines initiated under Article 21.5 of the Understanding on Rules and Procedures Governing the Settlement of Disputes (DSU), due to concerns about the alleged failure by Thailand to comply with the Dispute Settlement Body's (DSB) recommendations and rulings in the original proceeding in Thailand - Customs and Fiscal Measures on Cigarettes from the Philippines. The Panel Report for Art 21.5 DSU was circulated on 12 November 2018. A second recourse to Art 21.5 DSU Panel Report circulated on 12 July 2019. Not adopted report.

${ }^{354}$ WTO DS371, WT/DS371/R
} 
goods, because the fact that the buyer and seller are related should not in itself be grounds for regarding the transaction value as unacceptable;

- The customs authority shall examine the circumstances of the sale in the light of the information provided by the importer or otherwise and communicate to the importer the grounds for preliminarily considering that the relationship influenced the price;

- The customs authority gives the importer a reasonable opportunity to respond. Given the opportunity, the importer submits further information; and - The customs authority makes a final decision on whether to accept the transaction value. ${ }^{355}$

Therefore, the importer must demonstrate that: i) the transaction value is of unrelated buyers of identical or similar goods; or ii) the value of identical or similar goods is as determined under the provisions of Article 5, or iii) the customs value of identical or similar goods is as determined under the provisions of Article $6 .{ }^{356}$

In this line of work, there are rich discussions in the WCO TCCV about the use of transfer pricing documentation to examine whether the relationship has influenced the price. An example is WCO TCCV Commentary 23.1.

WCO TCCV-Commentary 23.1 - Examination of The Expression
"Circumstances Surrounding the Sale" Under Article 1.2 (A) in Relation to
The Use of Transfer Pricing Studies. 357
1. This Commentary seeks to provide guidance on the use of a transfer pricing
study, prepared in accordance with the OECD Transfer Pricing Guidelines,
and provided by importers as a basis for examining "the circumstances
surrounding the sale" under Article $1.2($ a) of the Agreement.
(...)
. Accordingly, the use of a transfer pricing study as a possible basis for
examining the circumstances of the sale should be considered on a case by
case basis. As a conclusion, any relevant information and documents provided
by an importer may be utilized for examining the circumstances of the sale. A
transfer pricing study could be one source of such information.

\footnotetext{
${ }^{355} \mathrm{WTO}, \mathrm{AB}, \mathrm{WT} / \mathrm{DS} 371 / \mathrm{R}$.

356 A real problem might be the lack of dialogue between customs administrations and importers to clarify doubts in related parties' transactions. In addition, related importers might lack the means or desire to demonstrate that the value closely approximates unrelated traded values. Thus, paragraph 2 seems more theoretical than practical. Therefore, in many audit cases, customs administrations might assume that the relationship influenced the price, have scarce or no communication with importers and immediately file penalties and let related parties defend themselves in administrative or judicial courts.
}

${ }^{357}$ WCO (2014). Customs Valuation Compendium. 
According to TCCV Commentary 23.1, it is possible to use transfer pricing studies when examining whether the relationship has influenced the price.

For the purposes of this dissertation, it should be observed how fundamental concepts, such as which sale should be used "first sale" or "last sale" have not been harmonized to this date. Furthermore, concerning related parties' transactions, the difficulties to harmonize concepts increase exponentially, leaving both customs authorities and importers in an open dialogue that can last several days or weeks. For instance, the challenges in implementing transaction value and the CVA in general are reported in Nigeria's WTO trade policy review.

\subsection{There are on-going efforts by the authorities to ensure Nigeria fulfil its WTO obligations. Nigeria has made notifications on SPS and TBT measures up to 2015 but is still lagging behind in other WTO areas such as (...) Customs Valuation (Table A2.2).}

\subsection{In some cases, Nigerian Customs finds it difficult to assess the valuation for a certain product. For example, it notes that it is difficult to confirm invoice value with transaction value. For social reasons, the government may maintain a minimum value on certain products, such as staple foods, second-hand goods and tyres, in which case the government sets a benchmark. ${ }^{358}$}

Malaysia's WTO trade policy review body also reveals the difficulties in adopting transactions' value to certain types of goods and passenger cars.

4.82. On customs valuation, we note Malaysia's update that it is reviewing the gazette price system with a view to adopting the transaction value method for passenger cars. The adoption of the transaction value method would be a positive step in improving the transparency and openness of Malaysia's trade regime. ${ }^{359}$

Finally, it is worth mentioning that everything in Article 1 is subject to discussion, doubt, and interpretation.

\subsubsection{Articles 2 and 3 - Identical and Similar}

Article 2 addresses identical goods. The method described in Article 2 requires the transaction value of identical, comparable goods to be used as the customs value. The Agreement provides criteria for defining identical goods, covering the goods

\footnotetext{
${ }^{358}$ WTO (2017). Trade Policy Review - Nigeria. WT/TPR/S/356. p. 28.

${ }^{359}$ WTO (2018). Trade Policy Review - Malaysia. WT/TPR/W/144. p. 20.
} 
themselves, time of importation, the commercial level of the transaction, and other criteria.

Per Article 2, identical goods are those produced in the same country as the goods being valued and, "are the same in all respects, including physical characteristics, quality, and reputation. Minor differences in appearance (in color, size or labeling, etc.,) do not preclude goods otherwise conforming to the definition from being regarded as identical".

Discussing the criteria required to be considered identical goods, Wolffgang highlights that even que reputation of the goods need to be taken into consideration.

Reputation in this context refers to the views which are generally held about a given product. To judge whether the goods under consideration are of the same reputation it is helpful to consider their brand(s), quality and the general impression the public has about such goods. ${ }^{360}$

So the criteria to be considered indentical are likely difficult to be fullfilled.

Article 3 is about similar goods. The criteria for similar goods are less restrictive than for identical goods, allowing a broader range of comparable goods to be considered. As with identical goods, similar goods found in customs records or systems databases, need to be registered with transaction values.

In Article 3, similar goods are goods produced in the same country as the goods being valued "which, although not alike in all respects, have like characteristics and like component materials, which enable them to perform the same function and be commercially interchangeable".

Here Wolffgang teaches: "What is most important is that they perform the same functions and that they are commercially interchangeable with the goods being valued." 361

When determining whether goods are similar, consideration is to be given, among other factors, to "the quality of the goods, their reputation and the existence of a trademark."

Commenting on the existence of a trade mark, Wolffgang observes that "whereas it would be unthinkable to regard goods produced under different trade marks as

\footnotetext{
${ }^{360}$ Wolffgang (2010). "Agreement on Customs Valuation” in WTO - Trade in Goods: Max Planck. Commentaries on World Trade Law: Volume 5. Wolfrum, Stoll, Hestermeyer (Editors). Martinus Nijhoff Publishers, p. 906

${ }^{361}$ Idem, p. 912
} 
identical, it is possible to consider goods produced under different trade mark as similar" 362

The method might require commercial level adjustments. Interpretative Notes to Articles 2 and 3 contain relevant points in relation to the adjustments.

Annex I: Interpretative Notes
Note to Article 2
5. A condition for adjustment because of different commercial levels or
different quantities is that such adjustment, whether it leads to an increase or a
decrease in the value, be made only on the basis of demonstrated evidence that
clearly establishes the reasonableness and accuracy of the adjustments, e.g.
valid price lists containing prices referring to different levels or different
quantities.
(...)

On the use of the transaction value of identical or similar goods, Sherman and Glashoff give the following explanation:

74. Where Customs does depart from Transaction Value (TV), the next recourse is to the Transaction Value previously accepted by Customs as the dutiable value of Identical or Similar Imported Goods (TVI or TVS). The comparison goods must have been exported at or about the same time and be the product of the same country as the goods being valued $(C 88) .{ }^{363}$

When questioned about identical and similar goods, the WCO TCCV issued Commentary 1.1 which refers to consultations between Customs and the importer and the requirements of Article 15.

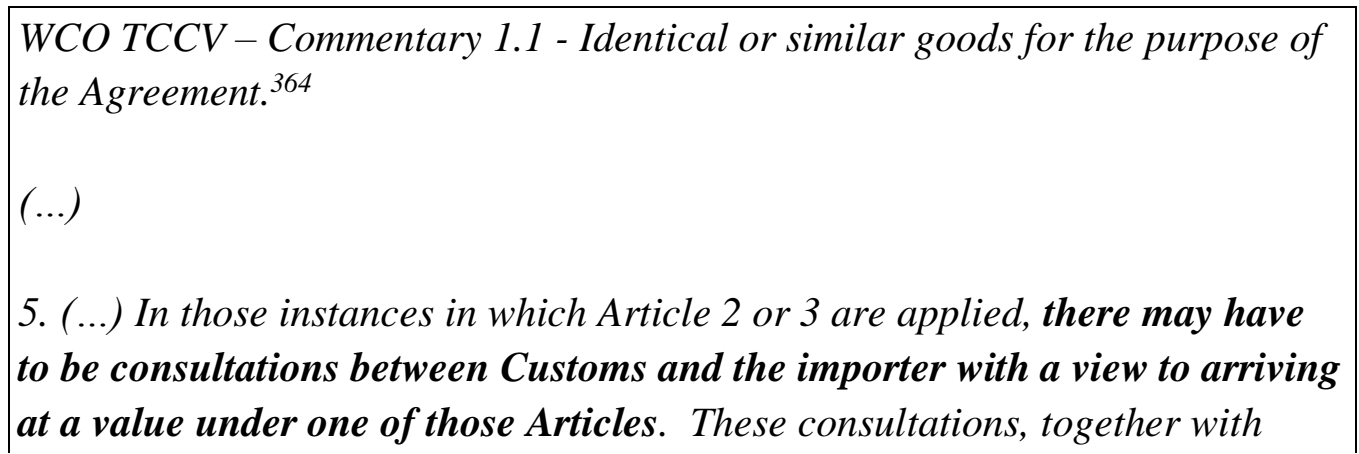

\footnotetext{
362 Idem p. 912.

${ }^{363}$ Sherman Saul L. and Glashoff H. op. cit., p.59

${ }^{364}$ WCO (2014). Customs Valuation Compendium.
} 


information from other sources, should enable Customs to determine what, if
any, goods might be considered identical or similar for purposes of the
Agreement. Obviously, there will be many instances where the answer is self-
evident and no market enquiries or consultations with importers are necessary.
6. The principles in Article 15 must be applied on the basis of the particular
facts in the market in question with respect to the goods being compared. The
questions that might arise in making such determinations will vary because of
the nature of the goods being compared and because of differences in market
conditions. A careful analysis of the facts in each case, in the light of the
principles set out in Article 15, will be necessary to arrive at sound decisions.
(...)

The Appellate Body in Thailand - Cigarettes (Philippines) (2010) explains the overall importance of the consultation process between customs authorities and importers to all alternative methods of the CVA:

Para. 7.327. Although the first sentence of paragraph 2 refers to "value under the provisions of Article 2 or 3", we consider that the spirit of the Customs Valuation Agreement envisaged under this paragraph, namely the determination of customs value through a process of consultation between the customs administration and importer, equally applies to other valuation methods. ${ }^{365}$

When the customs value cannot be determined under Article 1 "transaction value", it is necessary to start a consultation process to consider a transaction value for identical or similar goods, sold for export at about the same time, at the same commercial level, and in the same quantity as the goods being valued. Here again, the consultation process might be time-consuming and uncertain in relation to the ability of the parties to reach an agreement.

Therefore, some points worth keeping in mind in respect of identical and similar goods are: a) both have to be produced in the same country as the goods being valued, thus the same origin; b) goods have to be imported at about the same time and several countries use ninety days as the time period to search the records/database and double this up to one hundred and eighty days when using the fallback method; c) both have to be adjusted to suit the commercial level and quantity of the goods being valued; d) if there are several suitable values for identical or similar goods, customs valuation will be based on the lowest value shipment.

\footnotetext{
${ }^{365}$ WTO DS371, WT/DS371/R. Second Recourse to Art 21.5 DSU Panel report circulated 12 July 2019. Not adopted report.
} 
For the purposes of this dissertation, one should notice that the search for identical or similar goods might require detailed databases that go beyond the existent systems normally used by Customs administrations. Importers might also lack the capacity to provide information about identical or similar goods, as these might be imported by competitors whose information is not available. The lack of practical means to verify the declared value was identified under paragraph 8.3 of the Doha Decision in $2001 .{ }^{366}$

The discussions under paragraph 8.3 resulted in the document "Guidelines on the Development and Use of a National Valuation Database as a Risk Assessment Tool". ${ }^{367}$ The WCO guidelines are an example of the challenge faced by customs and traders to discuss the declared values.

Concerning customs systems, the system of reference is the Automated System for Customs Data (ASYCUDA) which is used by more than ninety countries globally. ${ }^{368,369}$ However, although it is quite detailed and based on international standards, the database of transactions provided by ASYCUDA does not fulfil all the requirements for a search of identical and similar goods that take into consideration criteria such as: (a) like characteristics, and (b) like component materials which enable the identical or similar goods to: perform the same function, and be commercially interchangeable.

Considering the level of complexity of searching for identical and similar goods in a dynamic environment, such as in ports, airports and borders, the methods are more theoretical than in the real world. International trade cargo moves fast with high costs for importers, and it is fair to say that there is no time to search manually for identical or similar goods. When time allows, there is no guarantee that identical or similar goods do exist in the database and if they do exist, but the consultation process with the importer comes up with negative results, the entire effort can be a waste of time.

Therefore, for the purposes of this dissertation, the identical and similar methods of the WTO CVA are complex and are of minimal use in the real world. Furthermore, these methods are not concerned with the import costs related to waiting for a valuation, nor for trade revenue.

\footnotetext{
366 WTO WT/MIN(01)/17. Doha WTO Ministerial 2001.

${ }^{367}$ WCO (2004). Guidelines on the development and use of a national database as a risk assessment tool. Available at: http://www.wcoomd.org/en/topics/valuation/instruments-and-tools/guidelines.aspx

368 The Automated System for Customs Data (ASYCUDA) is a computerized customs management system developed and maintained by the United Nations Conference on Trade and Development (UNCTAD) which covers most foreign trade procedures. The system handles manifests and customs declarations, accounting procedures, transit and suspense procedures. The system generates trade data that is sent to many international organizations and is used for statistical economic analysis.

${ }^{369}$ An updated list of countries where ASYCUDA has been installed or is being implemented is available at the ASYCUDA official site: http://www.asycuda.org
} 


\subsubsection{Article 4 - Reversal deductive and computed}

Article 4 of the Agreement is not a valuation method, but rather it provides an option to reverse the order of application of Article 5, deductive method, and Article 6, computed method, at the request of the importer. If the importer elects to reverse the order, meaning that the computed method is going to be used instead of the deductive method, then he/she has the right to do so.

Regarding developing countries, however, Annex III, paragraph 3 of the Agreement gives those countries the right to require the agreement of the Customs administration.

Consequently, if a developing country reserves this right, an importer's request to reverse Articles 5 and 6, may be rejected by the Customs administration. According to the WTO $24^{\text {th }}$ annual review of the CVA, there are fifty-three country members that have reserved this right. ${ }^{370}$

For the purposes of this dissertation, one of the few cases that justify the use of such Article is when the importer has a relationship with the exporter that makes it possible to calculate production costs in the country of exportation. Such a hypothesis is logical for related parties where the importer is a business partner, or a subsidiary and hence has access to production costs in the country of origin.

\subsubsection{Article 5 - Deductive}

Article 5 presents the deductive method. The deductive customs value is based on the price at which the imported goods are sold in the country of importation. The sales to be considered must be between unrelated parties, and they must occur at or about the time of the importation of the goods being valued. This establishes a unit price from which costs pertaining to post-importation activities and elements are to be deducted, such as post-import transportation, storage costs, profits, and general expenses.

Interpretative Note to Articles 5 contains relevant information about the definition of unit price.

Annex I: Interpretative Notes

\footnotetext{
${ }^{370}$ November 2018, G/VAL/W/311. Countries that made the reservation on Annex III, paragraph 3 (reservation concerning reversal of sequential order of Articles 5 and 6) (53): Argentina, Kingdom of Bahrain, Bangladesh, Benin, Brazil, Brunei Darussalam, Burkina Faso, Cameroon, Chile, Colombia, Costa Rica, Côte d'Ivoire, Djibouti, Dominican Republic, Ecuador, Egypt, El Salvador, Gabon, Guatemala, Guyana, Haiti, Honduras, India, Indonesia, Israel, Jamaica, Kenya, Madagascar, Malawi, Malaysia, Maldives, Mali, Mexico, Morocco, Myanmar, Nicaragua, Niger, Pakistan, Panama, Peru, Philippines, Senegal, Sri Lanka, Thailand, Togo, Tunisia, Turkey, Uganda, United Arab Emirates, Uruguay, Bol. Rep. of Venezuela, Zambia, and Zimbabwe.
} 
Note to Article 5
1. The term "unit price at which ... goods are sold in the greatest aggregate
quantity" means the price at which the greatest number of units is sold in sales
to persons who are not related to the persons from whom they buy such goods
at the first commercial level after importation at which such sales take place.
(...)

For the purposes of Article 5, the deductions are: (a) either commissions or profit and general expenses; (b) the cost of post-importation transport and insurance; (c) costs and charges of Article 8.2 as appropriate; and (d) customs duties and taxes payable in the country of importation.

Sherman and Glashoff explain the deductive method as follows:

It will be recalled that the general approach of DDV is that (a) valuation begins with the resale price in the country of importation, and (b) appropriate deductions are then made to arrive at a value at the point of importation (CIF countries) or exportation (FOB countries).

While DDV was known in one form or another under both the BDV and the old US Section 402, there are many new features to DDV under the Code, and it should not be assumed that the old rules apply. ${ }^{371}$

The main point to notice from Sherman and Glashoff's explanation is that the deductive method existed in both the BDV and in US Section 402.

The customs value based on Article 5 is hence based on the price after such deductions are made. In the absence of previously imported goods, the procedure can be carried out with identical or similar goods that are sold in the domestic market of the country of importation. In other words, customs need to find, in the local market, identical or similar goods and proceed to make the deductions to find a customs value.

A consideration in selecting the goods to use as a basis for the deductions is that the sale must take place in the domestic marketplace, at or about the time of the importation of the goods being valued (Article 5.1(a) refers). The goods must also have been sold "in the condition as imported" (Article 5.1(a)). Thus, the two further elements to consider when applying the deductive method are: a) the time; and b) the condition.

${ }^{371}$ Sherman Saul L. and Glashoff H. op. cit., p.209 
The Agreement provides flexibility for goods that have been further processed after importation, to be used as the basis for the deductive method. Article 5.2 provides for the valuation treatment of "goods processed after import" while still using the deductive method of valuation. Article 5.2 states that "... if the importer so requests, the customs value shall be based on the unit price at which the imported goods, after further processing, are sold ... due allowance being made for the value added by such processing ...". This is known as the "super deductive" method.

According to the WTO $24^{\text {th }}$ annual review of the CVA, there are 51 country members that have reserved the right to apply Article 5.2, the "super deductive" method, regardless of whether or not the importer requests this. ${ }^{372}$

A possible application of Article 5 is given in WCO TCCV Study 1.1 about motor vehicles.

WCO TCCV - Study $1.1^{373}$
(...)
Article 5
12. Failing Article 2 or 3 , if the imported used vehicles or identical or similar
imported used vehicles are sold in the country of importation in the condition
as imported, the provisions of Article 5, paragraph 1, should be applied
whenever the requirements of that Article can be met.

Regarding the deductive method, Rosenow and Brian describe:

As a practical matter, however, it may most often be based upon the importer's resale price of the goods that are under valuation or, possibly, the importer's second shipment will be valued on the basis of his resale price of this first shipment. Information concerning imports and resales of identical or similar goods by other importers may not be as readily available. ${ }^{374}$

\footnotetext{
372 November 2018, G/VAL/W/311. Countries that made the reservation on Annex III, paragraph 4 (reservation to apply Article 5.2 whether or not the importer so requests) (51): Argentina, Kingdom of Bahrain, Bangladesh, Benin, Brazil, Brunei Darussalam, Burkina Faso, Cameroon, Chile, Colombia, Costa Rica, Côte d'Ivoire, Djibouti, Dominican Republic, Ecuador, Egypt, El Salvador, Gabon, Guatemala, Guyana, Haiti, Honduras, India, Indonesia, Israel, Jamaica, Kenya, Madagascar, Malawi, Malaysia, Maldives, Mali, Mexico, Morocco, Myanmar, Nicaragua, Niger, Nigeria, Pakistan, Peru, Philippines, Senegal, Sri Lanka, Thailand, Togo, Tunisia, Turkey, Uruguay, Bol. Rep. of Venezuela, Zambia, and Zimbabwe.

${ }^{373}$ WCO (2014). Customs Valuation Compendium.

${ }^{374}$ Rosenow, Sheri and O'Shea, Brian J. (2010), p.109
} 
The authors assume customs waits for the resale price of the imported goods or that the same importer has an acceptable first shipment that can be used to value the second shipment. None of the assumptions seems reasonable. Firstly, customs almost always must value the goods in a few hours/days and cannot keep waiting to conclude the import process based on the resale price. Secondly, it is unlikely that there exists a first shipment with identical or similar goods by the same importer with acceptable prices. If that exists, the problem falls into the identical or similar method.

Finally, the authors reach the core of the problem admitting the difficulties countries face to find other importers identical or similar goods importations. It must be emphasized that these other importations need to have happened "at or about the time" and also have been based on the transaction value. That seems to be the practical challenge for the use of the deductive method. Did other importers bring identical or similar goods using the transaction value into the market "at or about the time"? Based on such reflections, it is possible to assume that the use of the deductive method is rare.

\subsubsection{Article 6 - Computed}

Article 6 of the Agreement covers the computed method. The computed customs value is based on a price which is built up from the various elements which contribute to the manufactured goods. This includes the cost of materials, components, etc., manufacturing costs, profit, and general expenses and transport. This method is rarely applied, as it requires financial data that may be confidential to the manufacturer and will not be willingly made available to the importer or Customs in the importing country.

Whereas the deductive method works backward from the domestic sale price of the imported goods (or identical or similar) in the country of importation, the computed method is based on the cost of production and the price is built up to determine a customs value.

Interpretative Note to Article 6 contains information about the computed method.

\begin{tabular}{|l|}
\hline Annex I: Interpretative Notes \\
Note to Article 6 \\
1. As a general rule, customs value is determined under this Agreement on the \\
basis of information readily available in the country of importation. In order to \\
determine a computed value, however, it may be necessary to examine the costs \\
of producing the goods being valued and other information which has to be \\
obtained from outside the country of importation. Furthermore, in most cases
\end{tabular}


the producer of the goods will be outside the jurisdiction of the authorities of
the country of importation. The use of the computed value method will
generally be limited to those cases where the buyer and seller are related, and
the producer is prepared to supply to the authorities of the country of
importation the necessary costings and to provide facilities for any subsequent
verification which may be necessary.
(...)

The information required to substantiate production costs is usually at the manufacturer's premises and, therefore, is unlikely to be available to the buyer in the country of importation immediately. Also, it is unlikely that the importer will be able to obtain this information unless it is related to the seller or has a long-term trusting association. An independent seller is usually very reluctant to provide details of the manufacture and cost structure of the goods, which would also reveal the profit margin. If the importer cannot obtain such production cost information and no other evidence is available to determine a value using the computed method, then it is impossible to apply Article 6.

The WCO TCCV has no instruments for this method, meaning that WCO/WTO Members have in decades never raised questions about the application of the method.

For the purposes of this dissertation, the computed method is a champion in complexity and probably the most complex rule in the entire WTO set of rules. Such conclusion is supported by Rosenow and O'Shea: "Computed value may be the least frequently used and most challenging method of valuation for customs administrations." 375

Sherman and Glashoff took it lightly in the 1980s by stating: "Computed Value (CPV), the last basis of customs valuation specified in the Code, is in some ways the simplest basis of valuation; in other ways it is the most complex and controversial." 376

The fact is that decades later, there is no record in the available literature that the method has been used, as it requires a considerable amount of commercial information from the country of exportation. Export countries are not compelled to provide such information. The origins of this method are in the constructed value method that existed in the US Customs valuation statutes and were imported to the WTO CVA.

The method raises no concerns in terms of costs for importers or for Customs authorities. It also does not show any signs of affecting trade revenue.

\footnotetext{
375 Rosenow, Sheri and O'Shea, Brian J. (2010), p.117

376 Sherman Saul L. and Glashoff H. op. cit. p. 227
} 


\subsubsection{Article 7 - Fallback}

Article 7 deals with the "fallback" method or "fallbacks". It is not a specified 'method' as such, but rather it describes the possible means of establishing the customs value when the previous methods cannot be applied. It also lists approaches which are expressly forbidden by the Agreement, such as arbitrary or fictitious values to be used.

The fallback method is applicable when none of the previous methods mentioned can be used to determine the customs value of the imported goods. This happens, for example, in cases where there has not been a sale; where there have been no importations of identical or similar goods; when the goods are not resold in the country of importation, and when no data is available on their production costs. In such instances, the Agreement provides that the fallback method of valuation shall be used.

In short, the fallback is a set of principles to be adhered to when determining the customs value of goods. Article 7 principles for the valuation of imported goods using the fallback method are: a) the customs value must be determined using reasonable means; b) these means must be consistent with the principles and general provisions of the Agreement and of Article VII of GATT; and c) the customs value must be determined based on data available in the country of importation.

Interpretative Note to Article 7 contains relevant information about the definition of unit price.

Annex I: Interpretative Notes
Note to Article 7
1. Customs values determined under the provisions of Article 7 should, to the
greatest extent possible, be based on previously determined customs values.
2. The methods of valuation to be employed under Article 7 should be those
laid down in Articles 1 through 6 but a reasonable flexibility in the application
of such methods would be in conformity with the aims and provisions of Article
7.

Article 7 does not define what constitutes "reasonable means" precisely, but the Interpretative Note to the Article states that "customs values determined under the 
provisions of Article 7 should, to the greatest extent possible, be based on previously determined customs values".

Moreover, to depart as little as possible from the text and the spirit of the Agreement, the Note recommends that the value arrived at should be the result of a more flexible application of Articles 1 to 6, and that, as far as possible, this flexible application should be achieved by respecting the sequential order of those methods.

For example, a fallback flexible application would be to extend the requirement of "at or about the same time as the goods being valued" when applying Articles 2 and 3 to identical or similar goods. Another fallback flexible application would be to look for identical or similar goods produced in a different country of origin that has a comparable economic development to the country of origin of the imported goods.

The flexibility of Article 7 has limitations that are set out in paragraph 2, which prohibits the determination of a customs value based on (a) the selling price in the country of importation of goods produced in that country; (b) a system which provides for the acceptance of the higher of two alternative values for customs purposes; (c) the price of goods on the domestic market of the country of exportation; (d) the cost of production other than computed values which have been determined for identical or similar goods in accordance with the provisions of Article 6; (e) the price of the goods for export to a country other than the country of importation; (f) minimum customs values; or (g) arbitrary or fictitious values.

The prohibition against determining the customs value using (g) arbitrary or fictitious values was addressed in several dispute settlement procedures. Canada addressed this issue in EC - Cereals (1995). According to the complainants, Canada, United States and Thailand, the respondent, the European Community, the EC imposed a duty on wheat imports based on reference prices rather than on Article 1, the transaction value of the Agreement on Implementation of Article VII of the GATT 1994.

\section{The regulations cited above impose a duty on wheat imports based on reference prices rather than transaction values. As a result, the duty-paid import price for Canadian wheat will be greater than the effective intervention price increased by 55\% whenever the transaction value is greater than the representative price. ${ }^{377}$}

On 18 April 1997, the European Community adopted regulations to implement the provisions that seemed to satisfy the complaints in these cases. Considering these EU regulations, the dispute appeared to have been solved.

\footnotetext{
${ }^{377}$ WTO, WT/DS9/1, European Communities - Duties on Imports of Cereals - Request for Consultations by Canada.
} 
More recently, the use of (g) arbitrary or fictitious values was the subject of the analysis by the Appellate Body in Colombia — Ports of Entry (2009).

Para. 7.147. (...) In relation to Article 7.2(f) of the Customs Valuation Agreement, Panama claims that the indicative prices are minimum customs values because importation of products subject to indicative prices will not be permitted unless this minimum value is declared by the importer. ${ }^{378}$

The rationale behind the restrictions of Article 7 is explained by Sherman and Glashoff as necessary to close the door for other prior valuation systems that were consistent with the GATT, such as the BDV.

Intentionally, this provision is extremely broad and vague, so as to give a maximum of flexibility, while the principal guidelines which should apply within these broad limits are laid down in the Notes.

The reference to Article VII of the GATT, standing alone, is of little or no practical significance; but Article 7 of the Code requires compliance with both the Code and Article VII of the GATT. Otherwise, the back door would be opened to the return of $B D V$ and other prior systems consistent with the GATT but not with the Code. ${ }^{379}$

The prohibition in Article 7.2(c) against using the value of goods in the domestic market of the country of exportation as a reference is important to address. It had a direct effect on Canada.

\section{c) THE PRICE OF GOODS ON THE DOMESTIC MARKET OF THE COUNTRY OF EXPORTATION}

This was a basic Canadian approach to valuation for many years. Its unacceptability under the Code was a major reason for Canada's delay in adoption of the Code until 1985.(...) ${ }^{380}$

In the WTO system, domestic values in the export country are used to calculate the normal value for anti-dumping purposes. Anti-dumping methodology requires countries to find the "normal value" before applying anti-dumping measures. The normal value concept considers the prices or production costs in the export country.

\footnotetext{
378 WTO, WT/DS366/R

${ }^{379}$ Sherman Saul L. and Glashoff H. op. cit., p.236

${ }^{380}$ Idem p.239
} 
The only exception to Article 7 prohibitions is the that which is provided to developing countries in Ministerial Decision 7.1 - Minimum values and imports by sole agents, sole distributors, and sole concessionaires. ${ }^{381}$

Decision 7.1 is discussed in chapter 7 which deals with the WTO CVA Part III Special and Different treatment.

Finally, Article 7, paragraph 3 states that "If the importer so requests, the importer shall be informed in writing of the customs value determined under the provisions of this Article and the method used to determine such value."

This provision is needed because Article 7 is not a precise method of valuation. In these circumstances, an importer may be unaware of how Customs authorities valued the imported goods.

For the purposes of this dissertation, it is assumed that, once the transaction value cannot be used, many cases will have their customs value determined using the fallback flexibilities.

\subsubsection{Article 8 - Adjustments}

Article 8 is about the adjustments to the transaction value in Article 1. Together with Article 1, Article 8 forms the core of the WTO CVA. The primary basis for determining the customs value of goods is the transaction value, adjusted where necessary with the elements of Article 8 . Article 8 establishes two groups of adjustments to the transaction value: compulsory and optional. The compulsory adjustments are obligatory for all member countries, while the optional adjustments depend on the national legislation of each country.

\section{Compulsory adjustments}

Article 8 compulsory adjustments are complicated and include exceptions. In other words, they are difficult adjustments that lead to different interpretations and discussions both nationally and internationally.

Compulsory adjustments are found in Article 8.1(a)(i); 8.1(a)(ii) and 8.1(a)(iii); 8.1(b); 8.1(c); and, 8.1(d).

For example, Article 8.1(a)(i) addresses the commissions and brokerage adjustments and buying commissions are excluded. Hence, Customs authorities must be capable of

${ }^{381}$ Adopted, $1^{\text {st }}$ meeting of WTO Valuation Committee, 12 May 1995 
distinguishing whether commissions are the seller's or the buyer's responsibility. The price should only be adjusted if they are the sellers' responsibility.

The Interpretative Note to Article 8 defines buying commissions as follows:

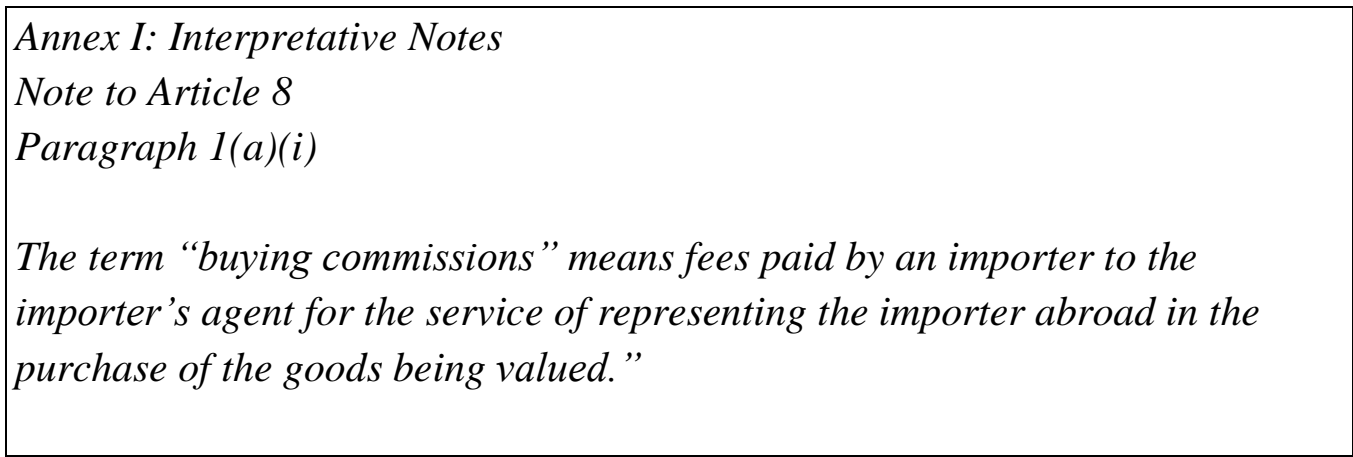

Thus, only the commissions paid for the seller's agent services should be included as part of the customs value. The seller's agent is related to the seller or the factory and thus acts on its behalf promoting the export. The note exempts the commissions paid for the services undertaken by the buyer's agents. The functions undertaken by a buying agent include, but are not restricted to: a) finding suppliers of the goods wanted by the buyer; b) helping to negotiate the best prices; c) informing the seller of the buyer's requirements; d) obtaining samples for the buyer's inspection; e) inspecting the goods; f) assisting in arranging insurance, transport, storage, and delivery; g) consolidating shipments from different sources; and h) preparation of invoices.

Article 8.1(a)(ii) concerns the cost of containers and there are different considerations regarding who produced them and the cost of production. It seems unrealistic in international trade to keep track of such elements in order to carry out the adjustment. The adjustment seems to be related to internal taxes.

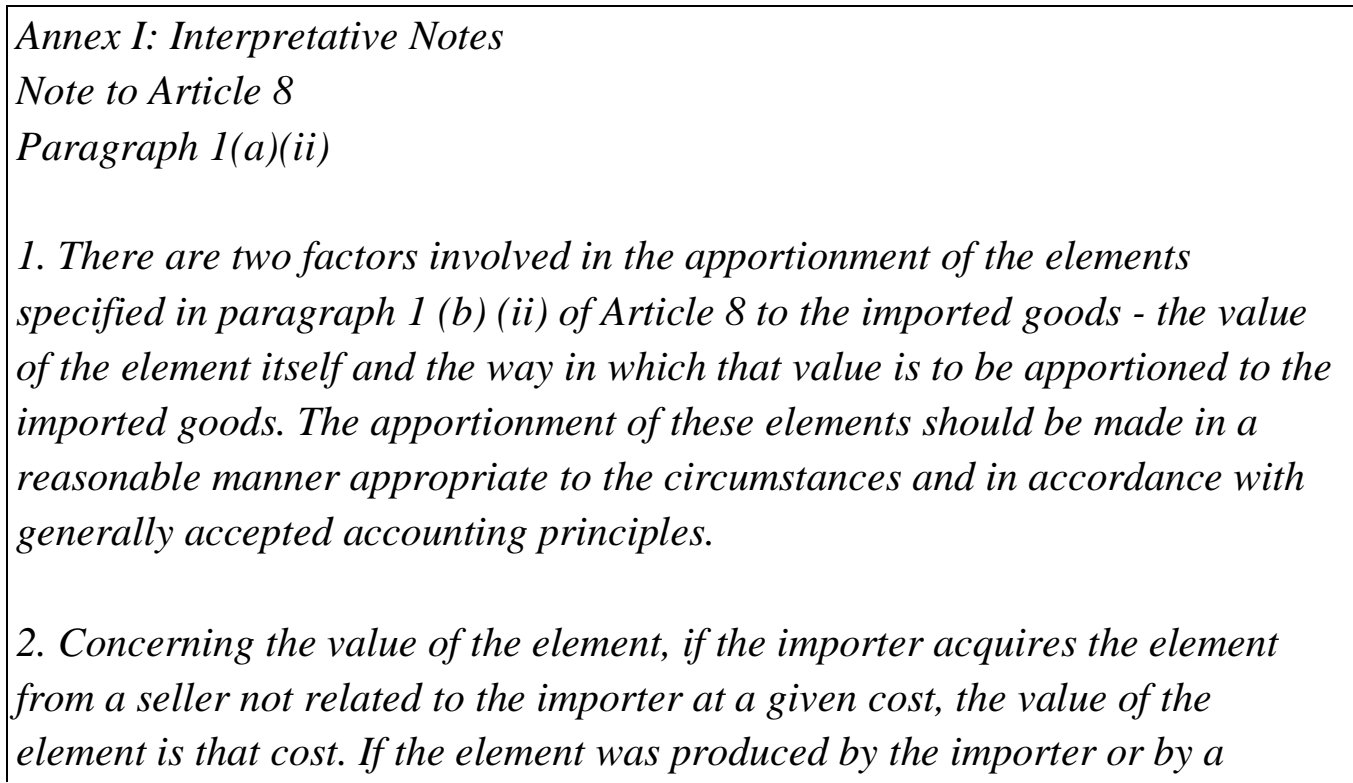


person related to the importer, its value would be the cost of producing it. If the element had been previously used by the importer, regardless of whether it had been acquired or produced by such importer, the original cost of acquisition or production would have to be adjusted downward to reflect its use in order to arrive at the value of the element.

3. Once a value has been determined for the element, it is necessary to apportion that value to the imported goods. Various possibilities exist. For example, the value might be apportioned to the first shipment if the importer wishes to pay duty on the entire value at one time. As another example, the importer may request that the value be apportioned over the number of units produced up to the time of the first shipment. As a further example, the importer may request that the value be apportioned over the entire anticipated production where contracts or firm commitments exist for that production. The method of apportionment used will depend upon the documentation provided by the importer.

(...)

Probably the most relevant example about the complexity of WTO CVA compulsory adjustments is in Article 8.1(c) that refers to the adjustments for "royalties and licence fees related to the goods being valued...".

Royalties and licence fees are difficult to identify in an international trade transaction, and they are also difficult to calculate in relation to the goods being valued. The payments for such services are usually separated from the invoice and it is necessary for Customs authorities to have the capacity to cross-check the information from different government agencies, including Central Banks and Intellectual Property agencies, to find out whether companies with imported goods pay royalties or licence fees. Once these companies are identified, it is necessary to carry out audits on a caseby-case basis to check whether the royalties and licence fees are or are not related to the imported goods. The whole process seems extremely time consuming and requires a high level of trained professionals.

\begin{tabular}{|l|}
$\begin{array}{l}\text { Annex I: Interpretative Notes } \\
\text { Note to Article } 8 \\
\text { Paragraph } 1(c)\end{array}$ \\
$\begin{array}{l}\text { 1. The royalties and licence fees referred to in paragraph } 1(\mathrm{c}) \text { of Article } 8 \text { may } \\
\text { include, among other things, payments in respect to patents, trade marks and } \\
\text { copyrights. However, the charges for the right to reproduce the imported } \\
\text { goods in the country of importation shall not be added to the price actually } \\
\text { paid or payable for the imported goods in determining the customs value. }\end{array}$
\end{tabular}


2. Payments made by the buyer for the right to distribute or resell the imported
goods shall not be added to the price actually paid or payable for the imported
goods if such payments are not a condition of the sale for export to the country
of importation of the imported goods.

Commenting on royalties and licence fees in the WTO CVA, Rosenow and O'Shea explain:

Royalties or licence fees may also be paid for rights to other intangible assets, such as franchise or exclusive marketing rights. Often, the amount of a royalty or license fee is calculated on the basis of the number of patented (or trademarked or copyrighted) units that the licensee manufactures, sells or uses, or on the percentage of the profits the license realizes in the sales. These fees might also be calculated as fixed payments per unit of time. ${ }^{382}$

Note that the costs of royalties are only included in the customs value if they are a condition of sale for the goods. In other words, if the royalties can be excluded when buying the goods, they are also excluded from the customs value.

Commenting on the terms of sales and licensing agreements, Rosenow and O'Shea illustrate how the condition can be identified:

The terms of sales and licencing agreements may answer this question directly by, for example, explicitly providing that the failure to pay the royalty shall terminate the seller's obligation to deliver the goods. More likely, however, the contract terms will not be dispositive, and an examination of all the facts and circumstances surrounding the transaction will be required to determine whether the sale of goods in dependent on payment of the royalty. ${ }^{383}$

An important point on including these elements in the customs value is the need for objective and quantifiable data. If data related to intangibles or services is not available, the WTO CVA requires tax and customs authorities to use other customs valuation methods. Thus, regarding identifiable and non-identifiable values, the Note to paragraph 3 of Article 8 explains:

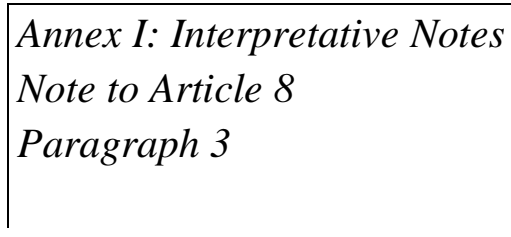

\footnotetext{
${ }^{382}$ Rosenow, Sheri and O'Shea, Brian J. (2010), p.54

${ }^{383}$ Idem. p. 57
} 


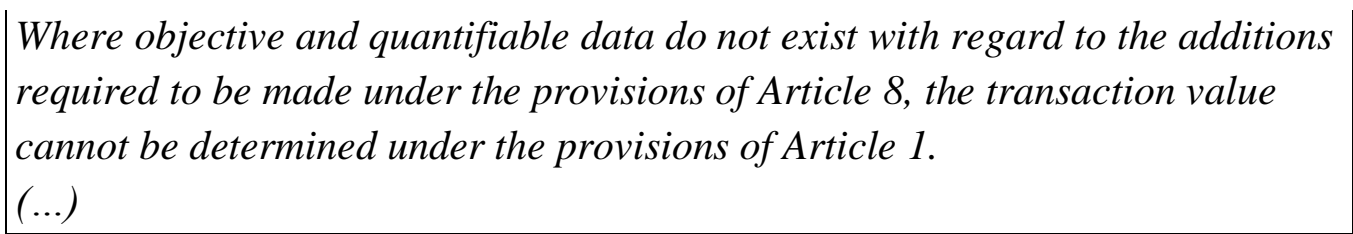

The example illustrates a case where the royalty payment is indistinguishable from other financial arrangements between the buyer and seller. In this scenario, it is impossible to make the correct adjustment for the royalty and, consequently, the transaction value method cannot be used. In other words, the importer should clarify his/her accounting and have the necessary knowledge to submit the import declaration in such a way that permits the quantification of the royalties that are included in the customs value to be subject to import tariffs. As a general rule, it is harmful when Customs authorities discard the transaction value from Article 1 and use other customs valuation methods because of a lack of information.

Hence, if the importer does not provide the intangibles or services information, he/she risks that an audit will be carried out and penalties will be imposed by Customs authorities. Thus, companies that rely heavily on cross-border transactions associated with GVCs need to be aware of their Customs obligations and Customs authorities must have trained personnel to deal with royalties.

Considering the growing importance of intangibles and/or services in international trade, royalties and licence fees play a major role and continue to raise doubts in the world of Customs valuation. They have a direct effect on trade revenue, and they are one of the most important topics in customs valuation.

Since 1995, the WCO TCCV has produced several instruments guiding countries on how to consider royalties and licence fees for the purposes of customs valuation. ${ }^{384} \mathrm{~A}$ list containing the WCO TCCV instruments and a brief summary is below. ${ }^{385}$

Table 6 - CCC/WCO Instruments on Royalties ${ }^{386}$

\begin{tabular}{|l|l|}
\hline Title & Brief summary \\
\hline Advisory Opinion 4.1 & $\begin{array}{l}\text { The royalty that the seller requires the importer to pay to a third party (the } \\
\text { patent holder) should be added to the price in accordance with the } \\
\text { provisions of Article 8.1(c) of the WTO CVA, since the payment of the }\end{array}$ \\
\hline
\end{tabular}

\footnotetext{
${ }^{384}$ In consideration of the legal status of the CCC/WCO TCCV's instruments, it is recognized that it is the intention of the Agreement that the TCCV prepare instruments as a guide towards achieving uniformity in the interpretation and application of the Agreement at the technical level. Advisory opinions, commentaries, explanatory notes, studies, or reports would all be instruments of this nature. However, as distinct from the Agreement's Interpretative Notes, it is said that these texts do not constitute international law. Nevertheless, the CCC/WCO TCCV instruments have can have legal or administrative force within the Member countries to the extent that they are incorporated into the national legislation of the Member.

${ }^{385}$ For a detailed description of each of the instruments, check the WCO library for the Customs Valuation Compendium.

386 WCO (2014). Customs Valuation Compendium.
} 


\begin{tabular}{|c|c|}
\hline & $\begin{array}{l}\text { royalty by the buyer is related to the goods being valued and is a condition } \\
\text { of sale of those goods. }\end{array}$ \\
\hline Advisory Opinion 4.2 & $\begin{array}{l}\text { The royalty that the laws of the country of importation require the importer } \\
\text { to pay to a third party (the copyright holder) when he resells the imported } \\
\text { records in accordance with the WTO CVA should not be added to the price } \\
\text { in determining the Customs value. }\end{array}$ \\
\hline Advisory Opinion 4.3 & $\begin{array}{l}\text { The royalty that the importer is required to pay to a third party (the patent } \\
\text { holder), under a separate contract, for the right to use a patented process for } \\
\text { the manufacture of certain products in accordance with the WTO CVA is } \\
\text { not part of the customs value since its payment is not a condition of the sale } \\
\text { of the machine for export to the importing country. }\end{array}$ \\
\hline Advisory Opinion 4.4 & $\begin{array}{l}\text { The royalty that the importer is required to pay to a seller (the patent } \\
\text { holder), as a condition of sale, for the right to incorporate or use the } \\
\text { patented concentrate in products intended for resale in accordance with } \\
\text { Article 8.1(c) of the WTO CVA should be added to the price. }\end{array}$ \\
\hline Advisory Opinion 4.5 & $\begin{array}{l}\text { The royalty that the importer is required to pay to a trademark holder for } \\
\text { making and selling under that trademark six types of cosmetics irrespective } \\
\text { of whether he uses the ingredients imported from the trademark holder or } \\
\text { not, is not a condition of sale of the goods, and for customs valuation } \\
\text { purposes in accordance with the WTO CVA Article 8.1(c) cannot be added } \\
\text { to the price. }\end{array}$ \\
\hline Advisory Opinion 4.6 & $\begin{array}{l}\text { The royalty that the importer is required to pay to a seller (the trademark } \\
\text { holder), as a condition of sale, when he resells the imported goods (the } \\
\text { concentrate) with the trademark must be added in accordance with the WTO } \\
\text { CVA to the price for the imported goods. }\end{array}$ \\
\hline Advisory Opinion 4.7 & $\begin{array}{l}\text { The royalty that the importer is required to pay to a seller, who has been } \\
\text { assigned world-wide reproduction, marketing and distribution rights by a } \\
\text { rights holder, for the marketing and distribution rights in the country of } \\
\text { importation should in accordance with the WTO CVA be added to the price. }\end{array}$ \\
\hline Advisory Opinion 4.8 & $\begin{array}{l}\text { The royalty that the importer is required to pay to a third party (the licence } \\
\text { holder), for the right to use the trademark, is not to be added to the price. }\end{array}$ \\
\hline Advisory Opinion 4.9 & $\begin{array}{l}\text { The royalty that the importer is required to pay to a seller (the trademark } \\
\text { holder) for the right to manufacture, use and sell the "licensed preparation" } \\
\text { in the country of importation, and for the right and licence to use the } \\
\text { trademark in connection with the manufacture and sale of licensed } \\
\text { preparations in the country of importation, is not a condition of the sale for } \\
\text { export of the imported goods, but a condition for manufacture and therefore } \\
\text { should not form part of the price. }\end{array}$ \\
\hline Advisory Opinion 4.10 & $\begin{array}{l}\text { The licence fee that the importer is required to pay to a seller (the trademark } \\
\text { holder) for the right to resell the imported garments containing trademarked } \\
\text { material) should be added to the price actually paid or payable. }\end{array}$ \\
\hline Advisory Opinion 4.11 & $\begin{array}{l}\text { The royalty that the importer is required to pay to a related party the } \\
\text { trademark holder), who is also related to a seller (manufacturer), for the } \\
\text { right to use the trademark, which is affixed to the imported goods, should be } \\
\text { added to the price. }\end{array}$ \\
\hline Advisory Opinion 4.12 & $\begin{array}{l}\text { The licence fee that the importer is required to pay to a seller for the right to } \\
\text { use the patented process, which is performed through a technology } \\
\text { (incorporated in the imported goods) is a condition of the sale, and should } \\
\text { be added to the price for the imported equipment. }\end{array}$ \\
\hline Advisory Opinion 4.13 & $\begin{array}{l}\text { The royalty that the importer is required to pay to a related party (the } \\
\text { trademark holder) for the right to use the trademark should not be added to } \\
\text { the price actually paid or payable as an adjustment under Article } 8.1(\mathrm{c}) \text {. }\end{array}$ \\
\hline
\end{tabular}




\begin{tabular}{|l|l|}
\hline Advisory Opinion 4.14 & $\begin{array}{l}\text { The royalty or licence fees that are paid to the licensor in the country of } \\
\text { importation) should be added to the price. }\end{array}$ \\
\hline Advisory Opinion 4.15 & The royalty paid to a third-party licensor should be added to the price. \\
\hline
\end{tabular}

It is possible to conclude that Article 8.1(c) royalties adjustments result in a neverending complexity. The WCO TCCV Members constantly request guidance and the complexity is also evident in national administrative customs-tax courts. As royalties and services gain importance in international trade, it has an important impact on trade revenue. It must be added that developing countries and LDCs have limited capacity to deal with royalties and licence fees adjustments.

One of the latest CCC/WCO TCCV instruments on royalties or licence fees is Commentary 25.1 which, after almost a decade of debates, provided factors that could be considered in determining whether the payment of the royalty or licence fee is a condition of sale as follows:

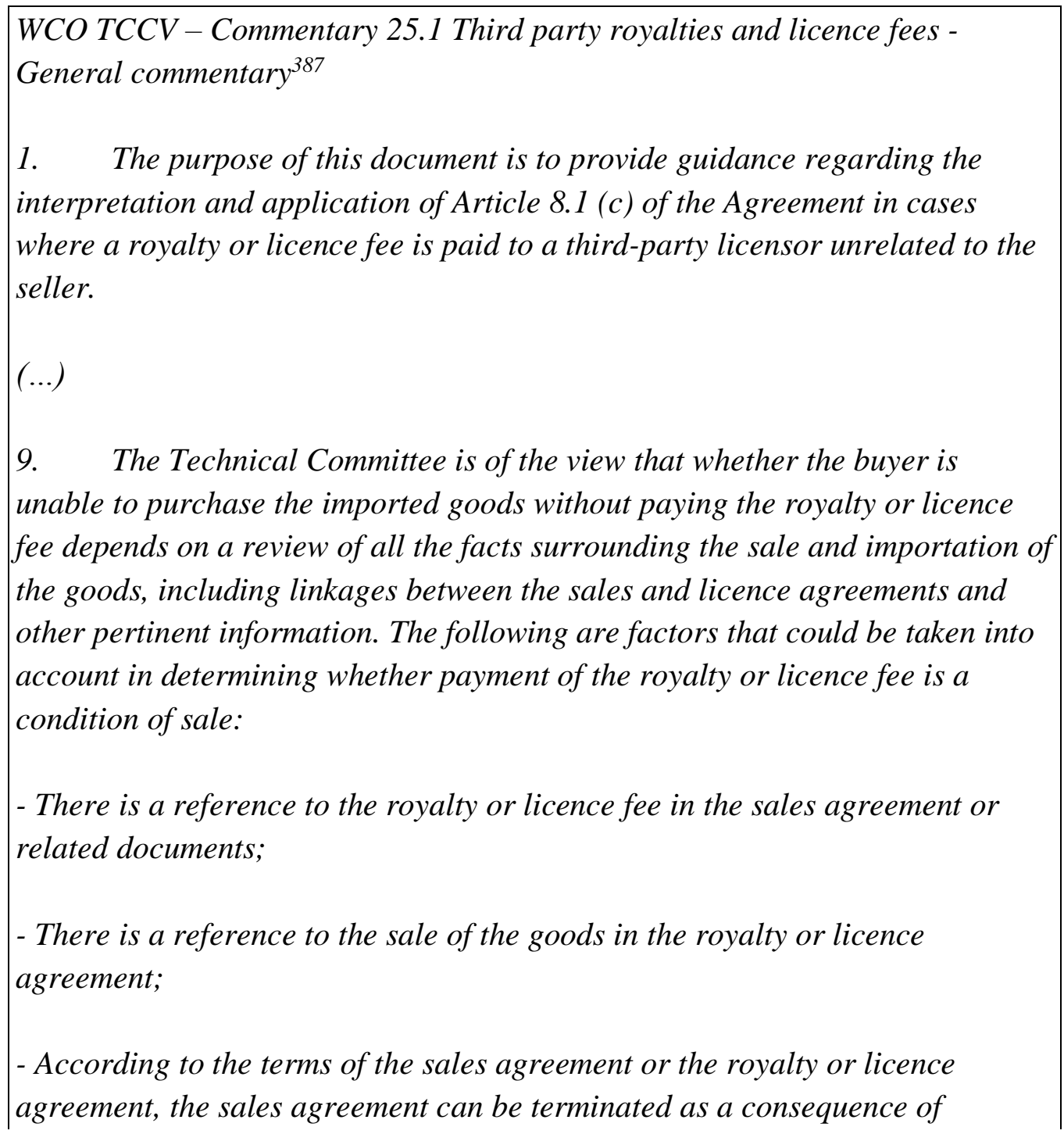

${ }^{387}$ WCO (2014). Customs Valuation Compendium. 
breaching the royalty or licence agreement because the buyer does not pay the
royalty or licence fee to the licensor. This would indicate a linkage between the
royalty or licence fee payment and the sale of the goods being valued;
- There is a term in the royalty or licence agreement that indicates if the
royalties or licence fees are not paid, the manufacturer is forbidden to
manufacture and sell the goods incorporating the licensor's intellectual
property to the importer;
- The royalty or licence agreement contains terms that permit the licensor to
manage the production or sale between the manufacturer and importer (sale
for export to the country of importation) that go beyond quality control.
Each case must be considered individually having regard to the
relevant circumstances

However, as Sherman and Glashoff put it, the number of situations regarding royalties and/or licence fees is infinite.

Imported goods often are involved with intangible rights of various kinds, including rights to use ideas or names. (...) The types of rights and the various possible payment arrangements are so numerous that the number of situations which may be presented is infinite. (...). ${ }^{388}$

On the matter of royalties and licence fees, Liu presents a practical problem that Customs has to distinguish these payments from other proprietary rights.

In practice, it is often the case that, in a contract, fees are paid for several proprietary rights and not just for royalties and/or licences. Since only royalties and licences fees are to be added to the price actually paid or payable under Art. 8.1 lit. $c$, in considering the valuation treatment of such fees it is therefore necessary to distinguish royalties and licence fees from fees paid for other rights. ${ }^{389}$

Another main challenge is to prove that the royalties and licence fees are paid as "condition of sale". Liu expresses this point: "Major differences exist at the national level regarding the interpretation of this term, and international opinion is still evolving." 390

\footnotetext{
388 Sherman Saul L. and Glashoff H. op. cit. p.120

${ }^{389}$ Liu, Ping (2010). "Agreement on Customs Valuation” in WTO - Trade in Goods : Max Planck Commentaries on World Trade Law: Volume 5. Wolfrum, Stoll, Hestermeyer (Editors). Martinus Nijhoff Publishers, p. 947.

${ }^{390}$ Idem. p. 948.
} 
The need to distinguish such intangibles together with the difficulties in interpreting the "condition of sale" requirement, makes it challenging for countries to control royalties and/or licence fees.

The conclusion seems to be that most countries are not prepared to perform the compulsory adjustments in the Agreement. These adjustments require a level of economic and accounting sophistication that is far from the trade reality. The implications of this situation for the research question are that they expose the fragility of trade revenue under the WTO CVA set of rules. Trade revenue depends more and more on intangibles and the WTO CVA might not be the appropriate instrument to deal with it. In short, the WTO CVA methodology is inappropriate and puts both trade revenue and companies facing audits at risk.

A final remark that seems to affect several Customs administrations refers to the domestic rules that provide for limitations to adjust import declarations when the intangibles or services information is not available at the time of importation. Acknowledging that such information might only be available later, Customs authorities need to evolve to solve such limitations and reach mutual agreement procedures.

\section{Optional adjustments}

Article 8.2 lists several cost elements that Members may choose, in whole, or in part, to include in, or exclude from the customs value. These are optional adjustments and a matter of national legislation. Many countries have adopted all the optional adjustments into their national legislation. In other words, invoice prices must be adjusted with all the elements of Article 8.2 to arrive at the customs value.

Article 8.2 optional adjustments reflect the questions related to transport, logistics, and insurance that are essential to identify the commercial terms, Incoterms, for the delivery of goods. Incoterms are widely used to identify the terms of trade, like FOB (Free on Board), FCA (Free Carrier), CIP (Carriage and Insurance Paid To), CIF (Cost, Insurance \& Freight), DES (Delivered Ex Ship), which all have very precise meanings for the sale of goods in international trade. ${ }^{391}$

Considering that the adjustments in Article 8.2 are optional, if a country decides on an FOB price as its customs value, it only considers the negotiated FOB price without adding freight or insurance. At the other end of the spectrum, if a country decides on a

\footnotetext{
${ }^{391}$ Incoterms is an acronym for International Commercial Terms representing a series of pre-defined commercial terms published by the International Chamber of Commerce (ICC) relating to international commercial law. They are widely used in international trade.
} 
CIF price, it must make sure to add the costs of freight and insurance when calculating the customs value. ${ }^{392}$

Countries are free to exclude or include these adjustments. The WCO TCCV produced Advisory Opinion 20.1 addressing this issue.

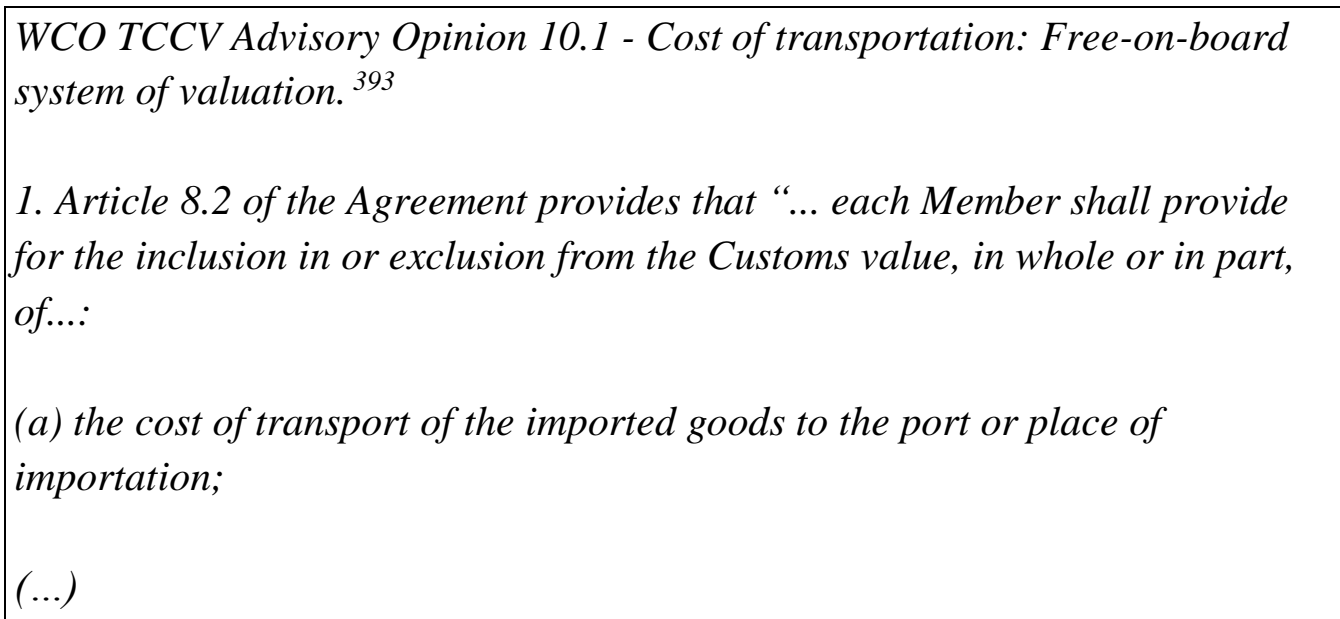

Sherman and Glashoff comment on the division of the opinion between FOB and CIF rules:
1. (...) if two imports have different transport costs, the one is regarded as more expensive than the other. If one comes from a nearby country and another from a distant country, the differences can be very meaningful economically. Thus, there is a logic in CIF valuation. There is also much to recommend $F O B$ valuation. It avoids stresses between different means of transportation (e.g., air versus sea) and different ports of importation (a factor which can be especially important where the customs territory is large). ${ }^{394}$

Concerning the expenses related to the international freight of the goods, it is important to mention that such costs can represent more than the tariff costs.

High transport costs added to the price represent a higher customs value for the AV tariff. Transport costs are usually declared directly by the importer. However, when in doubt, the Customs authority can also use indirect measures such as indexes to calculate the freight costs. ${ }^{395}$

\footnotetext{
392 CIF countries are those that include expenses with international freight and insurance in the value of imported goods while FOB countries are those that do not consider the expenses of freight, insurance or others in the value of imported goods

${ }^{393}$ WCO (2014), Customs Valuation Compendium.

${ }^{394}$ Sherman Saul L. and Glashoff H. op. cit., p.160

${ }^{395}$ For example, indexes of ad valorem shipping liner rates have been collected by the Royal Netherlands Shipowners Association (reported in the Review of Maritime Transport) since 1961, but they are limited only to a certain number of commodities and routes.
} 
A situation that deserves attention is when the imported goods are not covered by insurance, but the country's national legislation requires insurance to be included in the customs value. In such cases, the tax and customs authorities estimate the insurance value and add this estimation to the price. Therefore, an arbitrary value is added to the price for the customs value.

Until now, the WTO DSB has never had a case discussing the indirect methodology developed by several countries to calculate the amount of freight and/or insurance that should be added to the price to arrive at the customs value.

Regarding the definition of insurance, the WCO TCCV produced Advisory Opinion 13.1.

WCO TCCV Advisory Opinion 13.1 - Scope of the word "insurance" under
Article 8.2 (c) of the Agreement. 396
1. What interpretation should be given to the word "insurance" in Article 8.2
(c) of the Agreement?
$\begin{aligned} & \text { (...) Hence the word "insurance" used in subparagraph (c) should be } \\ & \text { interpreted as referring solely to insurance costs incurred for the goods during } \\ & \text { the operations specified in Article } 8.2(a) \text { and }(b) \text { of the Agreement. }\end{aligned}$

In addition to freight insurance, Article 8.2 also provides for the inclusion in or exclusion from the customs value of the costs of loading, unloading, and handling charges associated with the transport. These costs are normally the additional costs, on top of freight, charged by shipping companies or terminals related to loading and unloading the cargo, like Terminal Handling Charges (THC) and Container Service Charges (CSC).

Note that all adjustments can only be made if they are not yet included in the price actually paid or payable for the imported goods. If the adjustment is already part of that price, then it is not possible to add it again. Adjustments can also be deducted from the price. This happens when the national legislation does not include any of the expenses of Article 8.2, and they are included on the invoice. In this case, it is necessary to separate such expenditures and exclude them from the customs value.

Adjustments are made for costs supported by the buyer, and they should be based on objective and quantifiable data. Articles 8.3 and 8.4 state the need for quantifiable data and that no further additions are to be made to the price.

\footnotetext{
${ }^{396}$ WCO (2014). Customs Valuation Compendium.
} 
It is worth mentioning that these optional adjustments create additional problems for the standardization of the customs value. A number of complex issues arise, such as the different methodologies applied for the arbitration of international freight, the insurance arbitration based on the goods valuation which creates incentives to declare lower values or includes false insurance values, the challenges to segregate the costs related to loading and unloading the cargo, and many others. ${ }^{397}$

The importance of optional adjustments in this dissertation is the lack of uniformity in national legislations dealing with the calculations of the customs value.

\subsubsection{Articles 9 to 17 - - Currency conversion, confidentiality, and other issues}

Article 9 of the CVA explains the conversion from another currency to the importing country's national currency (where necessary) and the publication of approved rates of exchange. This Article states that "where the conversion of currency is necessary for the determination of the customs value, the rate of exchange to be used shall be that duly published by the competent authorities of the country of importation."

The Agreement allows for the importing country to decide whether it wants to use the ER at the date of exportation or the ER at the date of importation. The Note to Article 9 explains:

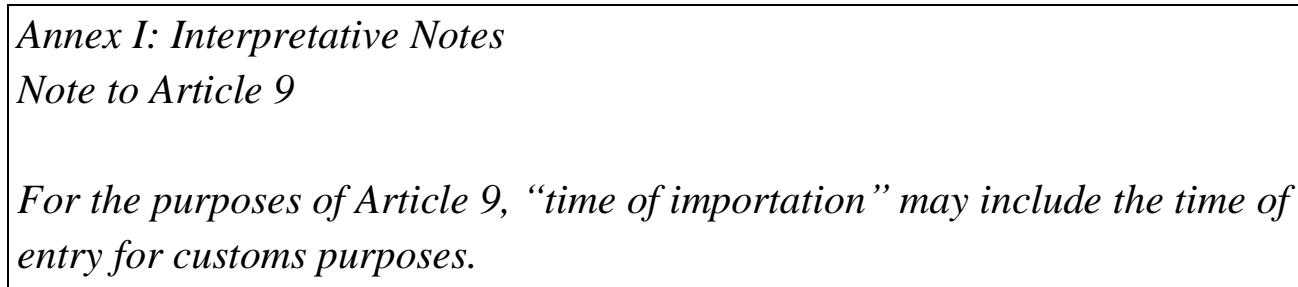

On the matter of the rate of exchange, the WCO TCCV produced Advisory Opinion 20.1 .

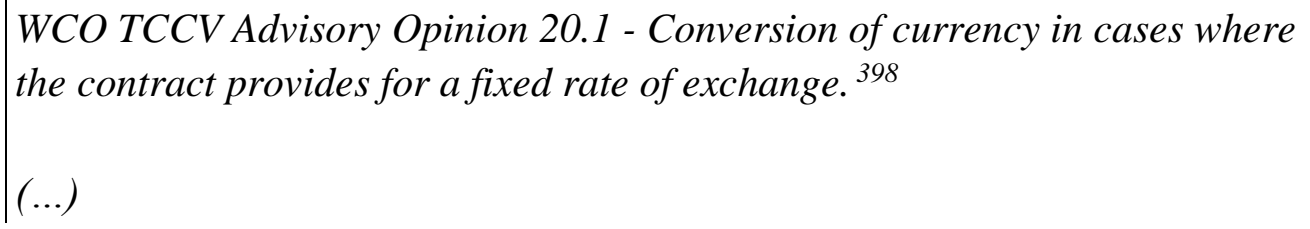

\footnotetext{
${ }^{397}$ For instance, in the calculation of air transport freight, some countries calculate the costs based on several zones from which the goods have been shipped, while others calculate the distance on $\mathrm{Km}$ and apply to a formula. HM Revenue \& Customs (2018). "Air transport costs to be included in the customs value", available at https://www.gov.uk/government/publications/air-transport-costs-to-be-included-inthe-customs-value [accessed 14 January 2020].

${ }^{398}$ WCO (2014). Customs Valuation Compendium.
} 
Therefore, what is important in this matter is the currency in which the price is settled and the amount of the payment.

(...)

For the research question, ER issues are relevant as they affect the prices of goods traded internationally.

ER volatility was not foreseen as a major problem during the negotiations for the GATT CV Code. Under the Bretton-Woods Agreement (1944), there was relative stability of the ERs. However, after decades, the volatility that started in the early 1970s, with the adoption of floating ER regimes, created uncertainty for developing countries and LDCs economies.

National monetary policies to evaluate or devaluate their ERs, also referred to as "currency wars", became standard practice. The G20 express the situation of ER volatility as follows:

We reiterate that excess volatility and disorderly movements in exchange rates can have adverse implications for economic and financial stability. (...) $)^{399}$

Enlarged cross-border flows driven by the liberalization trends of the capital account, technological innovations, and speculative activities on currencies contributed to an increase in ER volatility. ${ }^{400}$ Consequently, the customs values of goods fluctuate affecting trade revenue based on AV tariffs.

The connections between ER volatility and global trade have resulted in extensive theoretical and empirical explorations. In a paper about ER volatility and trade, Ilhan Ozturk describes ER volatility as a source of risk, and this leads to higher costs for riskaverse traders and consequently to less foreign trade:

Theoretical analyses of the relationship between higher exchange-rate volatility and international trade transactions have been conducted by Hooper and Kohlhagen (1978) and some other economists. The argument is as follows: Higher exchange-rate volatility leads to higher cost for risk averse traders and to less foreign trade. 401

It is believed that higher ER volatility inhibits the growth of international trade. ER volatility produces a negative effect on economies that depend on the export of

\footnotetext{
${ }^{399}$ G20 China. op. cit.

${ }^{400}$ Hook and Boon (2000)

${ }^{401}$ Ozturk (2006), p.86
} 
commodities to guarantee foreign exchange earnings. For instance, some LDCs and developing countries' economies that are dependent on commodities have experienced episodes of currency stress.

For this dissertation it is particularly important to note that exchange rates volatility can have a tremendous impact on customs valuation and therefore tariffs. For instance, ad valorem tariffs can be minimized or even cancelled by exchange rates policies. Economists refer to this problem as a misalignment in the fundamental equilibrium exchange rate (FEER). ${ }^{402}$

About the FEER, Cline, W. and Williamson, J. from the Peterson Institute for International Economics noted in 2017:

Whereas global imbalances and exchange rate misalignments have moderated since the end of the Great Recession, political tolerance of imbalances has declined in at least the United States. The Trump administration's rhetoric of outrage about US trade deficits far exceeds any comparable critiques in 200508, even though the US current account deficit has fallen by about half since then. The dislocation caused by the Great Recession, and the growing attention to geographically concentrated adjustment problems from the impact of rising trade with China, have no doubt contributed to this decline in political tolerance of trade imbalances The hedging of royalty revenues using futures and options markets is costly, cannot remove all volatility or uncertainty, and, given the experience of other jurisdictions, may have significant political risk. ${ }^{403}$

More recently the trade war between the United States and China has gotten worse. In addition, the COVID-19 pandemic has led several major economies to implement monetary policies that aggravate the currency equilibrium among nations. As such, it is reasonable to expect further problems in this area that naturally will affect trade tariffs.

To counterbalance ER volatility, financial markets use hedge mechanisms. Over the past decades, the use of hedging tools has helped countries to decrease their vulnerability to ER risks. ${ }^{404}$

Unfortunately, financial tools such as hedging are not widely available in LDCs and developing economies. Governments of LDCs and some developing countries'

\footnotetext{
402 The FEER is defined as that real effective exchange rate value which is compatible with the macroeconomic equilibrium. It is the real exchange rate which produces an external balance which is accurately matched with equilibrium medium-term capital flows.

${ }^{403}$ Cline, W. (2017). Estimates of Fundamental Equilibrium Exchange Rates. Peterson Institute for International Economics, Washington, DC. p. 8.

${ }^{404} \mathrm{~A}$ hedge is an investment to reduce the risk of adverse price movements in an asset. Normally, a hedge consists of taking an offsetting position in a related security, such as a futures contract. Investors can hedge against ERs risks by paying a premium.
} 
economies would benefit from using hedge mechanisms against ER risks. Financial instruments can be also directly used to hedge revenue volatility. Landon and Constance address the experience of hedging revenue, mentioning the significant political risk.

The hedging of royalty revenues using futures and options markets is costly, cannot remove all volatility or uncertainty, and, given the experience of other jurisdictions, may have significant political risk. ${ }^{405}$

However, considering the absence of hedging mechanisms in many countries to counterbalance ER volatility, precarious countries' economies are exposed to ER risks.

ER volatility results in adverse effects for the WTO CVA set of rules. For example, since prices fluctuate according to ERs, it renders it difficult to apply the transactional method and to have a comparable database of transactions to be used when applying the identical or similar customs valuation methods.

Article 10 of the CVA deals with issues of confidentiality. All information which is by nature confidential, or which is provided on a confidential basis for the purposes of customs valuation, shall be treated as strictly confidential by the authorities concerned. They must not disclose it without the specific permission of the person or government providing such information, except to the extent that it may be required to be disclosed in the context of judicial proceedings.

The AB discussed the confidentiality issue in Thailand - Cigarettes (Philippines) (2010).

Para. 7.405. The Philippines claims that Thailand breached Article 10 of the Customs Valuation Agreement when Thai government officials disclosed the c.i.f. price, transaction values of PM Thailand for the year 2006, and PM Thailand's import volumes for the year 2005 to the press. The Philippines argues that this information is confidential by nature within the meaning of Article 10 of the Customs Valuation Agreement.

\section{(...)}

Para. 7.411. Therefore, the Panel concludes that Thailand acted inconsistently with Article 10 of the Customs Valuation Agreement by disclosing confidential customs valuation information provided by PM Thailand to Thai Customs in the Thai media. ${ }^{406}$

\footnotetext{
${ }^{405}$ Landon, Stuart and Constance, Smith (2013). Government Revenue Volatility in Alberta in Boom and Bust Again: Policy Challenges for a Commodity-Based Economy, University of Alberta.

${ }^{406}$ WTO DS371, WT/DS371/R
} 
The issue of confidentiality is a serious one for the verification of transaction value. Often, customs authorities have difficulty to obtain export values from the export country due to the confidentiality requirement. Even when countries have so-called Mutual Assistance Agreements, it takes time to verify exports and the information may be incomplete.

Article 11 of the CVA explains the obligations of Members to provide importers with the right to appeal a customs value decision without penalty.

The Note to Article 11 explains:

Annex I: Interpretative Notes
Note to Article 11
1. Article 11 provides the importer with the right to appeal against a valuation
determination made by the customs administration for the goods being valued.
Appeal may first be to a higher level in the customs administration, but the
importer shall have the right in the final instance to appeal to the judiciary.
(...)

Appeals against customs valuation decisions are judged by the national authorities in administrative or judicial tribunals. Regarding the right of recourse, Rosenow and O'Shea write:

WTO Members can require that importers take an initial appeal to customs (for example, to customs headquarters against a decision by a local office) or another independent body, such as an administrative tribunal. ${ }^{407}$

A considerable number of customs valuation appeals and rulings are available on national websites. For instance, Canada and the USA make such material available on their websites. ${ }^{408,409}$

Normally, national legislation requires a guarantee to release the goods before the appeal. Therefore, when using Article 11, the importer must wait for the goods to be

\footnotetext{
${ }^{407}$ Rosenow, Sheri and O'Shea, Brian J. (2010), p.137

${ }^{408}$ Decisions rendered by the Canadian International Trade Tribunal (CITT) and the Federal Court of Canada: Canadian Customs legislation provides for quasi-judicial and judicial redress for importers beyond the administrative redress mechanisms in the Customs Act. The first level is a quasijudicial panel, the Canadian International Trade Tribunal (CITT). Decisions of the CITT may be appealed, by either Customs or the importer, to the Federal Court of Canada.

409 The USA publishes the Customs Valuation Encyclopedia, which is a publication that includes a synopsis of all valuation rulings issued by the Valuation and Special Programs Branch, Office of International Trade: Regulations and Rulings, U.S. Customs and Border Protection, Headquarters.
} 
released, or he/she will have to provide a guarantee to obtain the goods before the appeal is decided. In any case, the importer incurs all extra costs when appealing, and hence many prefer to accept the demands of the Customs authorities.

The issue of the appeals provision in Article 11 is associated with the Ministerial Decision on "Cases where Customs administrations have reasons to doubt the truth or accuracy of the declared value". ${ }^{410}$ It should be noted that, when analysing the application of such a Decision, the WCO TCCV produced Case Study 13.1.

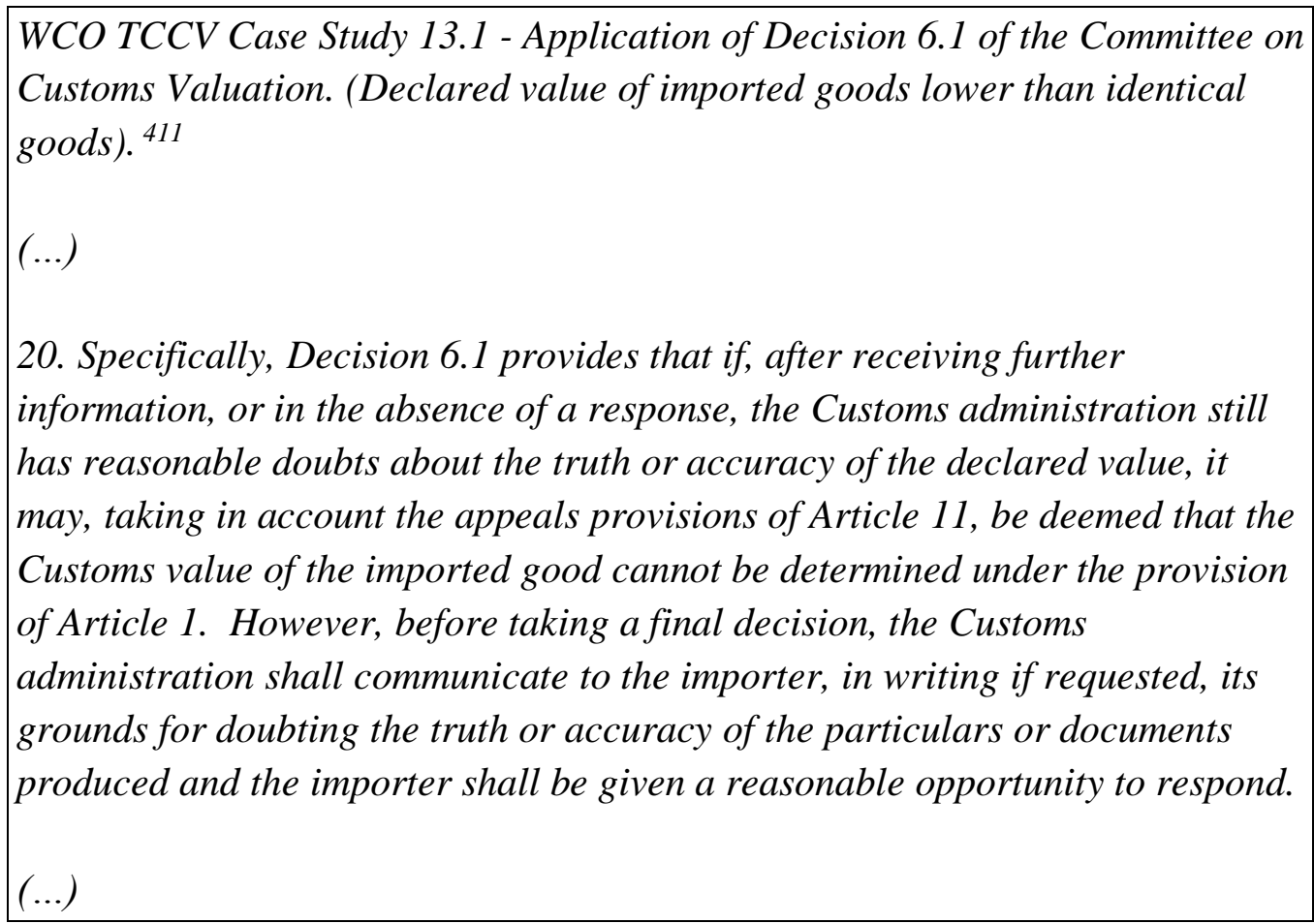

Article 12 of the CVA explains the obligations of Members to publish laws in conformity with Article X: Publication and Administration of Trade Regulations, of the GATT 1994. Notice that customs valuation is mentioned at the beginning of Article X:

Article X: Publication and Administration of Trade Regulations

1. Laws, regulations, judicial decisions and administrative rulings of general application, made effective by any contracting party, pertaining to the classification or the valuation of products for customs purposes, or to rates of duty, taxes or other charges, or to requirements (...)

Article 12 requires that each Member must publish all texts relating to the application of the CVA. On this point, it is worth mentioning that some Members have

\footnotetext{
${ }^{410}$ The Customs Community refers to the Decision as Decision 6.1

${ }^{411}$ WCO (2014), Customs Valuation Compendium.
} 
consolidated customs legislation, while other Members regulate customs in more than one piece of legislation.

Members applying the Agreement should also inform other countries of their national legislation and the decisions or conclusions they have adopted in terms of valuation. Moreover, countries applying the Agreement must submit their national legislation to the WTO Committee on Customs Valuation for examination. ${ }^{412}$

Article 13 of the CVA explains the obligations of Members to provide a guarantee system for the release of imported goods where there is a delay in determining the customs value "if, in the course of determining the customs value of imported goods, it becomes necessary to delay the final determination of such customs value", the importer shall nevertheless, on request, be able to withdraw them subject to providing a guarantee or surety to Customs covering the Customs duties the goods may be subject to.

Article 13 is used in cases where the goods are released, but there are doubts about the value and a post-clearance audit is initiated. The Panel in US - Certain EC Products (2000) explains the use of Article 13. ${ }^{413}$

Para. 6.77. In the present dispute the United States is not claiming that, as of 3 March, it required additional guarantees because the customs value of the EC listed imports had increased or changed on 3 March 1999. In the present dispute, there is no disagreement between the parties on the customs value of the EC listed imports. Article 13 of the Customs Valuation Agreement allows for a guarantee system when there is uncertainty regarding the customs value of the imported products, but is not concerned with the level of tariff obligations as such. (...). ${ }^{414}$

Note that Article 13 is employed when there is uncertainty regarding the customs value. An example of the use of Article 13 is given in WCO TCCV Advisory Opinion 11.1:

WCO TCCV Advisory Opinion 11.1 Treatment of inadvertent errors and of incomplete documentation. ${ }^{415}$

\footnotetext{
${ }^{412}$ The WCO Valuation Compendium contains an index classified by subject and administration comprising a number of brief summaries of judicial decisions with the full texts being available from the administration having issued the decisions or conclusions in question. The WCO's Index of Reference Materials also contains information relating to the laws, procedures and decisions of the national Customs administration, which are also of assistance. Both WCO references to countries' judicial decisions and legislation depend on the country's information to be updated, which might not always be the case.

${ }^{413}$ WTO, WT/DS165/R

${ }^{414}$ WTO, WT/DS165/R, 17 July 2000

${ }^{415}$ WCO (2014), Customs Valuation Compendium.
} 
Recourse could be taken to provisional clearance as provided by Article 13 of the Agreement pending importer or his agent furnishing complete information or causing the error in the document to be rectified

There are instances where Article 13 can be used incorrectly as a form of pressure for importers to accept minimum price values. When that happens, the government may hold the guarantee for long periods creating financial problems for the importer.

In Colombia - Ports of Entry (2009), it was argued that Article 13 guarantees cannot function based on indicative prices.

The Panel's analysis in the previous sections demonstrates that payments made by importers in the situation described by Article 128.5 e) of Decree No. 2685 and Article 172.7 of Resolution No. 4240 are payments strictu sensu and not "guarantees in the form of a cash deposit". ${ }^{416}$

In conclusion, the Article 13 guarantee is to be used on a case-by-case basis where the uncertainty will be verified.

The diversity and lack of uniformity in national legislation dealing with the calculations and procedures of guarantees to release the goods are important in this dissertation. Importers and Customs authorities face difficulties in calculating such guarantees, since there is no clear guideline on the formula to be used. The worst-case scenario is when there is a lack of national regulation, when Customs authorities refuse to apply Article 13 and goods are retained for long periods in Customs bonded warehouses. The costs can add up quickly, and the importer might prefer to abandon the goods. In conclusion, Article 13 dealing with guarantees might not be used by some Members.

Article 14 of the CVA states that the Notes in Annex I have an on an equal footing in the hierarchy as the text of the Agreement itself. In fact, the Agreement relies on the notes in Annex I for its interpretation. Other texts, such as the Decisions produced by the WTO CCV and the instruments generated by the WCO TCCV are not part of the Agreement.

Article 15 of the CVA defines certain words and terms used in the Agreement. The definitions are used to clarify the meaning of words in the Agreement. For instance, the definition of "related persons" in 15.4, including legal entities, is relevant for the

\footnotetext{
${ }^{416}$ WTO, Panel WT/DS366/R, 27 April 2009, VII.129.
} 
application of Article 1.2 to determine whether the sale occurred between related parties.

Article 15.4 restricts the related hypothesis to a few cases. In other words, Article 15.4 limits the interpretation of a sale between related parties to the following cases: (a) they are officers or directors of one another's businesses; (b) they are legally recognized partners in business; (c) they are employer and employee; (d) any person directly or indirectly owns, controls or holds five per cent or more of the outstanding voting stock or shares of both of them; (e) one of them directly or indirectly controls the other; (f) both of them are directly or indirectly controlled by a third person; (g) together they directly or indirectly control a third person; or (h) they are members of the same family.

The Note to Article 15.4 explains:

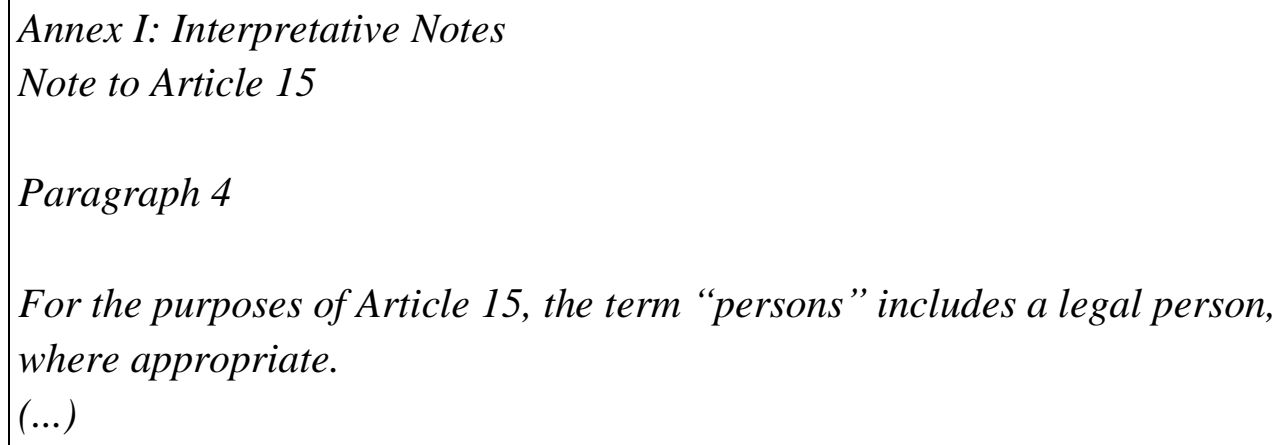

Sherman and Glashoff explain the origins of Article 15.4:

One preliminary observation: Relationship is not simply a yes-or-no question. It is, rather, a matter of degree. Where there is a relationship, the nature and extent of the relationship between the parties may have an important bearing on the further question of whether, in respect of a transaction between them, $T V$ should be rejected. Thus a sale to a third cousin is less likely to be influenced by the relationship than a sale to a brother, and a sale to a 5 per cent stockholder is less likely to be influenced than a sale to a 100 per cent stockholder ${ }^{417}$

The main criticism of Article 15.4 relates to the conditions to define related parties. The limitation of such a static definition is evident when compared to transfer pricing legislation that evolves according to a dynamic scenario in economic relationships.

\footnotetext{
${ }^{417}$ Sherman Saul L. and Glashoff H. op. cit., p.160
} 
A significant portion of international trade occurs between related parties in an infinite number of commercial situations. For instance, it makes no sense to limit the controlling situation to five per cent or more of the outstanding voting stock. A situation of control can occur with less than five per cent, depending on a number of other factors such as the importance of the import market to the export company.

In summary, the limited number of scenarios covered by the WTO CVA represents a risk to AV tariffs trade revenue. A number of transactions happen between related parties, but, for the WTO CVA, they are considered to take place within open market conditions.

Article 16 of the CVA explains the right of importers to a written explanation on how the customs value was determined.

The obligation of customs authorities to provide an explanation on how the value was determined was the subject of Thailand - Cigarettes (Philippines) (2010).

Para. 7.393. We observe that the obligation to inform the customs value determined under the provisions of Article 7.3 and the method used to determine such value can be compared to the obligation under Article 16 to provide an explanation as to how the customs value was determined. We clarified above that the explanation to be provided under Article 16 must be sufficient to make clear and give details of how the customs value of the importer's goods was determined, including the basis for rejecting the transaction value, the identification of the method used and the illustration of how the method was applied in reaching the final customs value. (...). ${ }^{418}$

Article 17 of the CVA explains the rights of Customs administrations to satisfy themselves regarding the truth and accuracy of any statement, document, or declaration provided to customs authorities. ${ }^{419}$

Regarding Article 17, it is important to comment on Ministerial Decision 6.1 - Cases Where Customs Administrations Have Reasons to Doubt the Truth or Accuracy of the Declared Value, as it provides guidelines regarding the interpretation and application of Article $17 .{ }^{420}$

\footnotetext{
${ }^{418}$ Panel, WT/DS371/R, Para. 7.235 to 7.393

${ }^{419}$ In the Uruguay Round, Article 17 on the rights of Customs originated the Ministerial Decision Regarding Cases Where Customs Administrations Have Reasons to Doubt the Truth or Accuracy of the Declared Value. This Decision is considered by Customs administrations as one of the most important Decisions about the CVA. This Decision has been used in a Thailand - Cigarettes (Philippines) (2011) and will be covered in great detail in chapter 6.

420 This Decision is referred in the Customs community simply as Decision 6.1. It forms the basis of a Ministerial Decision in the Legal Texts of the Results of the Uruguay Round of Multilateral Trade Negotiations and was adopted at the $1^{\text {st }}$ meeting of WTO Valuation Committee, 12 May 1995.
} 
In line with Article 17 of the Agreement, customs authorities have the right to "satisfy themselves as to the truth or accuracy of any statement, document or declaration." As a first step, customs authorities may ask the importer to provide a further explanation that the declared value represents the total amount actually paid or payable for the imported goods. If reasonable doubt still exists after receiving further information (or in the absence of a response), customs authorities may decide that the value cannot be determined according to the transaction value method. Before a final decision is taken, customs authorities must communicate its reasoning to the importer, who, in turn, must be given reasonable time to respond. In addition, the reasoning of the final decision must be communicated to the importer in writing.

In Thailand - Cigarettes (Philippines) (2011) the Appellate Body provided an interpretation of the need to strike a balance between customs authorities and importers' rights.

\subsection{2 (...)As indicated in the Ministerial "Decision Regarding Cases Where Customs Administrations Have Reasons to Doubt the Truth or Accuracy of the Declared Value”, the Customs Valuation Agreement aims at striking the balance between respecting the customs authorities' need to address cases where it has reason to doubt the truth or accuracy of the particulars or of documents produced by traders in support of a declared value and protecting the legitimate commercial interests of traders. ${ }^{421}$}

Finally, it is relevant to mention that, based on Decision 6.1, the TCCV produced two WCO TCCV instruments: Case Study 13.1 Application of Decision 6.1 of the Committee on Customs Valuation (Declared value of imported goods lower than identical goods) and Case Study 13.2 Application of Decision 6.1 of the Committee on Customs Valuation (Declared value of imported goods lower than raw materials).

\subsection{Concluding Remarks}

The chapter provided a thorough analysis of the WTO CVA Part I. It presented the main aspects of the CVA using the interpretative notes from Annex I, the WTO panel and Appellate Body interpretations, the WCO TCCV instruments and scholars' materials.

From the beginning, it was clear that the provisions of the WTO CVA prevail over the GATT 1994 provisions. In addition, the WTO CVA is interpreted in accordance with the general rules of treaty interpretation set out in Article 31 of the Vienna Convention on the Law of Treaties. A relevant point regarding the interpretation, when using

\footnotetext{
${ }^{421}$ Appellate Body, WT/DS371/R.
} 
relevant rules from other organizations, is the fact that WTO Members may not be represented in such organizations.

The discussion of the WTO CVA interpretation is important in relation to the legal status of the WCO TCCV instruments. Although the WCO TCCV instruments can be used in the context of Article 31.1 of the Vienna Convention on the Law of Treaties, for the interpretation in accordance with the ordinary meaning of its terms, they have never been used by the WTO DSB.

Therefore, until now the WCO instruments have only been used domestically in each country to the extent that they have been incorporated into national law. This deserves attention, as it contradicts the intention to achieve uniformity in interpretation. For instance, the chapter described the situation of the discussions about "first sale" and "last sale" that have not yet been harmonized among WTO Members.

The chapter proceeded to examine the WTO CVA Part I - Rules on Customs Valuation, showing in several articles how complex, dubious, and time consuming the determination of the customs value can be.

The WTO CVA works mainly with the transaction value (Article 1) and presents five alternate methods that must be used in a sequential manner: (Article 2) the transaction value of identical goods; (Article 3) the transaction value of similar goods; (Article 5) the deductive value method; (Article 6) the computed value method; and (Article 7) the fallback option.

For Article 1, the transaction value method, the question surrounding the sale for export is still, after decades, subject to debate. There is no international definition of "sale", and every country is free to establish its own definition of sale in its national law.

The transaction value method is, by nature, volatile and possibly results in arriving at different values for every shipment without any regard for certainty, predictability, or security. Every trade transaction, occurring sometimes at the same time and with the same parties, can be considered a new transaction. The system is supposed to work without any market price references or comparables. In conclusion, it jeopardizes any predictability in relation to trade revenue.

It can be said that cases in which there is a relationship between the importer and the exporter are worst-case scenarios in terms of complexity. The main question is whether the relationship influenced the price. The Appellate Body in Thailand Cigarettes (Philippines) (2011) commented about related parties' transactions and the examination of the circumstances surrounding the sale, which is supposed to involve length and costly dialogues with the importer. 
A new aspect in the discussions about related-party transactions is the use of transfer pricing documentation to examine whether the relationship influenced the price. This was the outcome of WCO TCCV Commentary 23.1.

For Articles 2 and 3, identical and similar goods, the methodology continues to be complex and difficult to apply. The methodologies have a series of limitations, including the subjectivity elements, such as the quality and reputation of the goods.

A main aspect of looking for identical and similar goods is the consultation process. However, neither customs authorities' databases nor importers trade systems are equipped to provide adequate data to support the consultation phase and the exchange of views can be quite complicated. Therefore, the methodology can be both time consuming and uncertain in relation to ability of the parties to reach an agreement.

Article 4 allows for the possibility of reversing the order of using the deductive and computed methods, which also seem to be used rarely.

Article 5 addresses the deductive method based on the price at which the imported goods are sold on the domestic market, considering previous importations of goods between unrelated parties. It is, nevertheless, a complex methodology, as it establishes a unit price from which costs pertaining to post-importation activities and elements, such as post-import transportation, storage costs, profits and general expenses, are to be deducted.

Article 6 concerns the computed method. The computed customs value is based on a price that is built up from the various elements which contribute to the manufactured goods. It is possibly the most complex of all methodologies, as it requires data from the manufacturer of the goods in the export country, which may be subject to confidentiality issues and may never be available to the importer or customs authorities.

Article 7 is known as a fallback and is not a specified method as such, but it rather describes the possible means of establishing the customs value when the previous methods cannot be applied. It also lists approaches which are expressly forbidden by the Agreement, such as arbitrary or fictitious values that are to be used.

The main intention of Article 7 is to make the previous valuation methods more flexible, such as broadening the origin of the identical/similar goods and extending the time period for the possibility to find database comparables.

The rationale behind the limitations in Article 7 is to block the use of other valuation systems that may be consistent with the GATT, but that are not desirable for the WTO CVA. This has happened in the past with the BDV and the Canadian customs 
valuation methodology. Article 7 is also used to block the use of CV rules for antidumping purposes.

Article 8 is about the adjustments to the transaction value in Article 1. Together with Article 1, Article 8 forms the core of the WTO CVA. The main complexities revealed in the chapter when applying Article 8 refer to the compulsory adjustments, in particular to intangibles and services.

Article 8.1(c), referring to the "royalties and licence fees related to the goods being valued..." adjustments, results in a significant number of discussions in the WCO TCCV. As the importance of intangibles increases for trade revenue, customs authorities lack the human and technical capacity to check for such adjustments. This results in a major risk for trade tariff revenue in countries with unstable trade and tax infrastructures.

As for Article 8 optional adjustments, the chapter called attention to WTO Members using CIF customs values when adding arbitrary values for insurance.

Articles 9 to 17 relate to challenges that refer to exchange rate calculations, confidentiality issues, appeals against customs decisions, transparency, guarantees systems, and definitions. Each of these Articles present difficulties to the application of the WTO CV set of rules.

The chapter called attention to the issue of Article 13 guarantees that can be used incorrectly as a form of pressure for importers to accept minimum price values. It also highlights the limitations of the Article 15 definition of related parties. A significant portion of international trade occurs between related parties in an infinite number of commercial situations. The limited number of scenarios covered in Article 15.4 represents a risk for trade revenue.

In conclusion, the chapter analysed and provided examples of the complexities, uncertainty and fragilities of the WTO CVA. Several aspects of the system result in risks for trade tariff revenue. 


\section{WTO CVA Part II - Administration, Consultations and Dispute Settlement}

The purpose of this chapter is to continue to comment on the WTO CVA, specifically Part II. It addresses the administration, consultations, and dispute settlement provisions of the agreement of the WTO CVA.

The administrative bodies, namely the WTO CCV and the WCO TCCV, are established in Article 18. This chapter presents the instruments produced by both of these administrative bodies, addressing their legal force and referencing trade revenue concerns. The chapter also considers the WTO Decisions, the origins of BDV and some of the critical issues caused by these instruments.

The procedures for consultations and dispute settlement are described in Article 19. This chapter focuses on the WTO dispute settlement mechanism, presenting the rules and all the disputes related to customs valuation in chronological order. The key issues of each dispute are highlighted with an emphasis on trade revenue issues.

This chapter addresses the research question as it examines the administration, consultations, and dispute settlement from a trade revenue perspective, pointing out possible inconsistencies and making suggestions.

\subsection{Article 18 - Institutions}

\subsubsection{WTO CCV}

The WTO CCV was established on 1 January 1995 and replaced the previous GATT Tokyo Round CV Code CCV. ${ }^{422}$ The Committee's existence is regulated in Part II, Article 18.1 of the WTO CVA.

The WTO CCV meets at the WTO headquarters in Geneva. Its purpose is to provide Members with the opportunity to consult on matters relating to the administration of the WTO Valuation Agreement. It also furthers its objectives by carrying out other responsibilities as may be assigned to it by the Members. The Committee elects its own Chair and is assisted by the WTO Secretariat.

Among other things, the Committee monitors: 1) the status of notifications; 2) the examination of national legislation; 3 ) notification of the checklist of issues; 4)

\footnotetext{
${ }^{422}$ Alt there is a clear division in the reports from the CCV and TCCV in terms of time, in fact they are exactly the same Committees that functioned during the GATT Tokyo Round CV Code.
} 
Information on the application of the Committee Decisions; 5) Technical assistance; and 6) Pre-shipment Inspection.

Note that none of the WTO CCV monitoring attributions is related to revenue. In fact, looking at the attributions of the $\mathrm{CCV}$, one could forget that the purpose of customs valuation is mainly to serve as the basis for AV tariff calculations. The discussions are focused on the administrative aspects of the CVA.

A typical CCV discusses, among other things: (a) the status of the implementation and administration of the Agreement; (b) information on the application of Decisions of the Committee on Customs Valuation; and (c) technical assistance matters. As such, many topics on the agenda are formalities related to legislation information and technical assistance.

However, revenue issues revealed in the topic of the use of minimum prices and/or database price systems often appear to serve as a reminder that the revenue issue is present.

In the October 2016 meeting, the topic appeared on the agenda twice.

- United States - Armenia's Reference Price System in Connection with the Valuation of Goods;

- Ukraine - Abolition of the Resolution of the Cabinet of Ministers of Ukraine "On the Use of Benchmarks for Customs Valuation of Goods in the System of Risk Management” No. 724 Dated 16 September $2015 .^{423}$

In May 2017, it appeared again:

- United States - Armenia's Reference Price System in Connection with the Valuation of Goods;

- Thailand - Pakistan's Determination of Customs Values of Paper. ${ }^{424}$

Thailand complained about the use of Article 7.2 (f) of the WTO CVA.

6.3. (...) Since the customs value should have been determined on the basis of the transaction value, Thailand sought clarification on the following aspects: could Pakistan provide a justification on the use of minimum customs values in light of the commitments pursuant to Article 7.2(f) of the customs valuation

\footnotetext{
${ }^{423} \mathrm{WTO}, \mathrm{G} / \mathrm{VAL} / \mathrm{M} / 63$
}

${ }^{424}$ WTO, G/VAL/M/64 
agreement; and, could Pakistan explain why the transaction values could not be used to determine the customs values of paper products from Thailand. ${ }^{425}$

In November 2017, both questions from May 2017 remained on the agenda. ${ }^{426}$

In April 2018, Switzerland was of the view that Oman had violated Article 7.2 of the CVA.

7.2. (...) As a result, Switzerland was of the view that, instead of using the declared transaction value as the basis for assessing the value of the goods in question, Omani Customs had corrected the value on the basis of a calculation or methodology that was unclear to them. Switzerland considered such a practice to be in breach of Article 7.2 of the CVA, which explicitly prohibited national customs authorities from using "minimum customs values" and "arbitrary or fictitious values". 427

Switzerland declared that the Swiss authorities were satisfied with Oman's explanation in the November 2018 meetings.

\subsection{The representative of Switzerland said that Switzerland and Oman had} held successful discussions on this issue and that her authorities were satisfied with Oman's explanation. ${ }^{428}$

All of these examples address the constant discussions regarding possible violations of the WTO CVA. For the purposes of this dissertation, the discussions relating to the WTO CCV are a sample of a bigger problem involving AV tariffs, customs valuation, and trade revenue.

The WTO CCV may issue Decisions to guide the interpretation, administration, and working procedures of the WTO CVA. The WTO CCV Decisions can be divided into two groups: a) Decisions concerning the interpretation of the Agreement; and b) Decisions concerning the administration and working procedures of the Agreement.

At its first meeting on 12 May 1995, the WTO CCV adopted Decisions which had been previously adopted by the GATT Tokyo Round CCV. ${ }^{429}$

Writing about the WTO CCV Decisions, Rosenow and O'Shea explain:

\footnotetext{
425 WTO, G/VAL/M/64

426 WTO, G/VAL/M/65

427 WTO, G/VAL/M/66

${ }^{428}$ WTO, G/VAL/M/67

429 The GATT/WTO Decisions are reproduced in document G/VAL/5, dated 13 October 1995. The $\mathrm{CCV}$ also adopted Decisions that were referred by the Ministers at Marrakesh to the Committee. The texts of the Decisions are contained in document G/VAL/1, dated 27 April 1995.
} 
Over the years, the Committee has adopted important decisions interpreting the terms of the Agreement - such as those on treatment of interest charges and software - as well as decisions on administration of the Agreement and working procedures of the Committee. $(\cdots)^{430}$

Since its existence, the CCV has issued seven Decisions for interpretation and four Decisions concerning the administration and working procedures. The text of all of these interpretative and administrative decisions can be found in the Committee on Customs Valuation document G/VAL/5 (October 13, 1995)

Table 7 - WTO Decisions concerning the CVA

\begin{tabular}{|c|c|}
\hline A. Decisions concerning the interpretation of the Agreement & Doc \\
\hline $\begin{array}{l}\text { Decision } 1.1 \text { - French translation of the term "copyrights" in the Interpretative } \\
\text { Note to Article } 8.1 \text { (c) of the Agreement (Adopted by the GATT Tokyo Round } \\
\text { Committee, 1st meeting, } 13 \text { January 1981) }\end{array}$ & G/VAL/5 \\
\hline $\begin{array}{l}\text { Decision } 2.1 \text { - Meaning of the word "undertaken" used in Article } 8.1 \text { (b) (iv) of } \\
\text { the Agreement (Adopted by the GATT Tokyo Round Committee, } 6^{\text {th }} \text { meeting, } \\
3 \text { March 1983) }\end{array}$ & G/VAL/5 \\
\hline $\begin{array}{l}\text { Decision } 3.1 \text { - Treatment of interest charges in the Customs value of imported } \\
\text { goods (Adopted by the GATT Tokyo Round Committee, } 9^{\text {th }} \text { meeting, } 26 \text { April } \\
\text { 1984) }\end{array}$ & G/VAL/5 \\
\hline $\begin{array}{l}\text { Decision } 4.1 \text { - Valuation of carrier media bearing software for data processing } \\
\text { equipment is about the customs valuation of software (Adopted by the GATT } \\
\text { Tokyo Round Committee, } 10^{\text {th }} \text { meeting, } 24 \text { September 1984) }\end{array}$ & G/VAL/5 \\
\hline $\begin{array}{l}\text { Decision } 5.1 \text { - Terms in Article } 8.1 \text { (b) (iv): Development (Adopted by the } \\
\text { GATT Tokyo Round Committee, } 12^{\text {th }} \text { Meeting, } 9-10 \text { May 1985) }\end{array}$ & G/VAL/5 \\
\hline $\begin{array}{l}\text { Decision } 6.1 \text { - Cases where Customs administrations have reasons to doubt the } \\
\text { truth or accuracy of the declared value (Adopted by the WTO Valuation } \\
\text { Committee, } 1^{\text {st }} \text { meeting, } 12 \text { May 1995) }\end{array}$ & G/VAL/1 \\
\hline $\begin{array}{l}\text { Decision } 7.1 \text { - Minimum values and imports by sole agents, sole distributors, } \\
\text { and sole concessionaires (Adopted by the WTO Valuation Committee, 1st } \\
\text { meeting, } 12 \text { May 1995) }\end{array}$ & G/VAL/1 \\
\hline $\begin{array}{l}\text { B. Decisions concerning the administration of the Agreement and working } \\
\text { procedures of the Committee }\end{array}$ & Doc. \\
\hline $\begin{array}{l}\text { Decision } 1 \text { - Reservations under the Agreement (Adopted by the GATT Tokyo } \\
\text { Round Committee on } 13 \text { January } 1981 \text { (VAL/M/1, paragraph } 36 \text { and Annex 2) }\end{array}$ & G/VAL/5 \\
\hline $\begin{array}{l}\text { Decision } 2 \text { - Notification and circulation of national legislation in accordance } \\
\text { with Article } 22 \text { of the Agreement (Adopted by the GATT Tokyo Round } \\
\text { Committee on } 13 \text { January } 1981 \text { (VAL/M/1, paragraph 37) }\end{array}$ & G/VAL/5 \\
\hline $\begin{array}{l}\text { Decision } 3 \text { - Checklist of issues (Adopted by the GATT Tokyo Round } \\
\text { Committee on } 5 \text { May } 1981 \text { (VAL/M/2, paragraph 52) }\end{array}$ & G/VAL/5 \\
\hline
\end{tabular}

${ }^{430}$ Rosenow and O'Shea (2010), p. 159 
While each of these Decisions is essential to the interpretation and administration of the Agreement, some are more important than others.

In the interpretation group, Decisions 1.1,2.1, and 5.1 refer to translation and meaning. Therefore, these Decisions are intended for linguistic clarification and are therefore less important. Decisions 3.1, 4.1, 6.1, and 7.1 that deal with the application of the Agreement are considered by many to be the important Decisions in the group.

In addition, it is important to consider the legal status of the Decisions. On this matter, Decisions 6.1 and 7.1 were referred to by the Ministers at Marrakesh to the Committee and might have a higher legal status than the Decisions originally adopted by the Tokyo Round Committee on Customs and later adopted by the WTO. About this point, Liu makes the following remark:

However, the legal force of these two Ministerial Decisions, which form part of the Final Act, vis-à-vis the Agreement and other Decisions of the Committee on Customs Valuation, is not clear. In certain countries they are regarded as having less binding force than the text of the Agreement. ${ }^{431}$

All the Decisions are reproduced in Annex $\mathrm{J}$ of this dissertation. For the purposes of the research question, and dealing with trade revenue, the main Decisions are 3.1, 4.1, 6.1, and 7.1. Considering that Decisions 6.1 and 7.1 were discussed in previous chapters, in this chapter the discussion will only address Decisions 3.1 and 4.1.

\section{Decision 3.1 - Treatment of interest charges in the Customs value of imported goods (Adopted, $9^{\text {th }}$ meeting, 26 April 1984)}

The origins of Decision 3.1 are the GATT CCV fourth meeting discussions that started to amend the Agreement on the treatment of interest for deferred payment. The proposal came from the European Economic Community (EEC) that believed interest charges should not form part of the customs value.

1. In view of the likelihood of disparity in the treatment accorded to interest charges by some of the Parties applying the Customs Valuation Agreement in the determination of the customs value of imported goods, it would seem desirable for the Committee on Customs Valuation to consider the adoption of a common solution in order to achieve the uniformity referred to in the Preamble to the Agreement.

\footnotetext{
${ }^{431}$ Liu, Ping (2010). "Agreement on Customs Valuation” in WTO - Trade in Goods : Max Planck Commentaries on World Trade Law: Volume 5. Wolfrum, Stoll, Hestermeyer (Editors). Martinus Nijhoff Publishers, p. 866.
} 


$$
(\ldots)^{432}
$$

Thus, according to the EEC, interest charges for the purchase of goods from loans in the country of importation, from the country of exportation or in any other country, should not be included in the customs value. The EEC's initial proposal was to amend the Interpretative Note to Article 1, on the price actually paid or payable, to exclude "interest payable under a financing arrangement relating to the purchase of the imported goods."

Subsequent discussions showed that most Parties believed that it would be more appropriate to deal with the matter with a Committee Decision interpreting the Agreement (GATT, VAL/W/13/Rev.2). The final text of Decision 3.1 is below:

Decision 3.1 - Treatment of interest charges in the Customs value of imported goods (Adopted, $9^{\text {th }}$ meeting, 26 April 1984).

During its Ninth Meeting held on 26 April 1984, the Committee on Customs Valuation adopted the following decision:

The Parties to the Agreement on Implementation of Article VII of the GATT agree as follows:

Charges for interest under a financing arrangement entered into by the buyer and relating to the purchase of imported goods shall not be regarded as part of the Customs value provided that:

(a) the charges are distinguished from the price actually paid or payable for the goods;

(b) the financing arrangement was made in writing;

(c) where required, the buyer can demonstrate that:

- such goods are actually sold at the price declared as the price actually paid or payable, and

- the claimed rate of interest does not exceed the level for such transactions prevailing in the country where, and at the time when the finance was provided.

This Decision shall apply regardless of whether the finance is provided by the seller, a bank or another natural or legal person. It shall also apply, if appropriate, where goods are valued under a method other than the transaction value.

432 GATT VAL/W/8, 4 May 1982 
Each Party shall notify the Committee on the date from which it will apply the Decision.

This topic is important for the research question in this dissertation, since the payment of interest charges for deferred payments, financing and excessive interest deductions in international trade is a concern for trade revenue.

MNEs make extensive use of corporate debt-equity structures, and it would be necessary to evaluate such corporation using debt to equity ratios and other finance indicators.

This dissertation submits that several customs authorities in developing countries and LDCs are not equipped to address corporate finance topics making the connection with indirect taxation. ${ }^{433} \mathrm{An}$ indicator of the weak institutional capacity is measured by the World Bank's Country Policy and Institutional Assessment (CPIA) score. Using the CPIA methodology, the IMF classified 39 countries that can be considered as Fragile and Conflict-Affected States (FCS). When referring to the revenue capacity of such group of countries that are in a conflict, disaster, post-conflict, or post-disaster situations, the IMF writes: "The inability of FCS to raise sufficient tax revenue is strongly associated with the constraints they face in building resilience ${ }^{\circledR 34}$

The WTO Decision is for CV to disregard the costs of interest charges under a financing arrangement entered into by the buyer and relating to the purchase of imported goods as long as the listed provisions are met. This dissertation submits that the implementation of the Decision leads to challenges both for importers and customs authorities, contributing negatively to a lack of uniform application of rules for interest charges in international trade. To name a few of the challenges, most interest charges cannot be distinguished from the price of the goods, the financing arrangements do not make their way to the port and several border authorities lack the means to audit the level of interest rate charges.

Putting it another way, it is difficult to distinguish the net price for the goods without interest charges. Therefore, major finance contracts, for instance, involving oil and mining operations assembling on-site industrial plants to operate, can exist with interest charges for decades without being noticed by customs authorities.

The Decision requires the parties to notify the WTO CCV and the updated list of required notifications is summarized by the WTO. So far, only 46 out of 164 WTO

\footnotetext{
${ }^{433}$ The debt-to-equity ratio is a measure of a corporation's financial leverage and a subject related to corporate finance. It is a topic addressed in direct taxation rather than in indirect taxation. The ratio average changes according the type of industry and country. For moreOECD (2020), Financial corporations debt to equity ratio (indicator). doi: 10.1787/a3108a99-en (Accessed on 27 July 2020). ${ }^{434}$ IMF (2020). Tax Revenues in Fragile and Conflicted-Affected States - Why Are They Low and How Can We Raise Them?. Prepared by Bernardin Akitoby, Jiro Honda, and Keyra Primus.
} 
members have reported the adoption of the treatment of interest charges for the customs value of imported goods decisions. ${ }^{435}$ Therefore, the procedures related to interest charges on imported goods of the other 118 WTO members can differ from those of the Decision rules.

Notice that the GATT/WTO Decision concerning interest charges is only applicable to imported goods. Exports have no regulatory rules for customs valuation nor for interest charges in international trade. Export prices are a matter for domestic legislation. Regulations on how to deal with the payment of interest charges associated with the goods being exported are rare.

In conclusion, financial transactions, such as intra-group loans that impact trade revenue, are not properly addressed by the CVA.

\section{Decision 4.1 - Valuation of carrier media bearing software for data processing equipment (Adopted, 10 ${ }^{\text {th }}$ meeting, 24 September 1984)}

The origin of Decision 4.1 is the GATT CCV fourth meeting when the US delegation explained a possible problem related to the customs valuation of computer software derived from the implementation of the new code:
36. (...) Since the Agreement had entered into force, some countries had felt that the concept of transaction value required that the value of the programme or software be included in the dutiable value. (...) Therefore, the United States proposed, in document VAL/W/7, to deal with this matter by an amendment to the Agreement. The proposal was limited to valuation aspects and was not intended to cover intellectual property issues for which the Committee was not the proper forum. ${ }^{436}$

Thus, at the GATT CCV in 1982, according to the US delegation, under the new GATT Tokyo Round Code using the "transaction value" concept, some countries felt that it was necessary at that time to include the value of the software itself in the customs value of the software. Notice that, under the Brussels Definition of Value (BDV), the procedure was to consider only the value of the carrier medium and the cost of putting such information onto the medium in the customs value. The US favoured the BDV practice and thus opposed the inclusion of the software value for customs valuation.

\footnotetext{
${ }^{435}$ WTO document G/VAL/W/5/Rev.26 shows that forty-six countries have notified the adoption of the decision: Albania, Argentina, Australia, Brazil, Brunei Darussalam, Canada, Chile, China, Colombia, Costa Rica, Cuba, Ecuador, European Union, Hong Kong, China, Indonesia, Israel, Japan, Jordan, Kazakhstan, Kenya, Korea, Rep. of, Kyrgyz Republic, Lesotho, Mexico, Moldova, Rep. of, Montenegro, New Zealand, Norway, Oman, Panama, Peru, Russian Federation, Saudi Arabia Kingdom of, Singapore, South Africa, Sri Lanka, Chinese Taipei, Tanzania, Thailand, Turkey, The Former Yugoslav Republic of Macedonia, Ukraine, Uruguay, United States of America, and Zimbabwe. ${ }^{436}$ GATT, Committee on Customs Valuation, VAL/Spec/4, 17 June 1982
} 
The BDV guidance is documented in the Text of Study III, available in the Compendium of the BDV CCV texts. This dissertation submits that the BDV study is superior to the GATT Decision, because it gives a better explanation of the idea behind the differentiation between hardware-related software, usually called operating system software, and user application programs. According to the BDV study, hardware-related software is included in the customs value, while user application programmes are excluded. The full text of the BDV CCV is reproduced in Annex F.

In summary, considering the BDV practice to exclude the software value from the customs valuation, in 1982 the US proposed VAL/W/14, a draft text for a GATT Decision, to exclude the software from the customs value.

\section{$V A L / W / 14$}

DECISION

The Parties to the Agreement on Implementation of Article VII of the General Agreement on Tariffs and Trade agree as follows:

In determining the customs value of imported carrier media (except integrated circuits, other semi-conductor devices and articles incorporating such devices) with data or instructions recorded thereon (other than sound, visual or video recording), only the price actually paid or payable for the carrier medium itself shall be taken into account. The customs value shall not, therefore, include the value of the data or instructions, provided that this is distinguished from the price actually paid or payable.

(...)

The initial proposal from the US was to exclude the value of the data or instructions, provided that this is distinguished from the price paid or payable from the customs value. However, in subsequent GATT CCV meetings, the US proposal faced opposition. At the $\mathrm{CCV}$, some countries viewed it as a trade liberalization measure that was not contemplated in the GATT.

21. (...) The aim of the proposal was to reduce the taxable basis of the goods in question to a very large extent. The proposal thus would not just entail a change in customs valuation procedures, but also a liberalization of trade in this sector. While not being against trade liberalization as such, his authorities doubted that the method in the proposal was the appropriate way to achieve this objective. It was not a method for trade liberalization contemplated in the GATT. Since the proposal was innovative in this respect, it was bound to create a precedent however much the Committee wished to deny it. ${ }^{437}$

${ }^{437}$ GATT, Committee on Customs Valuation, VAL/M/6, 19 April 1983. 
Countries such as Brazil, India, and Canada opposed the US proposal to exclude the value of the software from the customs value completely. Hence, in the end, the US initial proposal was modified to accommodate different views. The final result was the possibility of applying the Agreement in a variety of ways and allowing each Party to choose which way it considered to be in its interest. This ambiguity only shows how difficult it is for countries to find common ground and to reach an agreement.

While Decision 4.1, paragraph 1 provides for the customs value of goods to be based on the cost of the carrier medium plus the cost/value of the software, paragraph 2 allows for Customs administrations to value the goods using only the cost of the carrier medium as the basis of the customs value. ${ }^{438}$

Decision 4.1 is complemented by a separate statement that is appended to the Decision. The attachment is the "Statement Made by the Chairman at the Meeting of the Committee on Customs Valuation of 24 September 1984 prior to the Adoption of the Decision on the Valuation of Carrier Media Bearing Software for Data Processing Equipment".

Decision 4.1 and the supporting statement confirm that both valuation approaches are in line with the Agreement. It is a matter for each Member how they will apply Decision 4.1. To publicize its practice, each country should adopt or should not adopt paragraph 2 of the Decision.

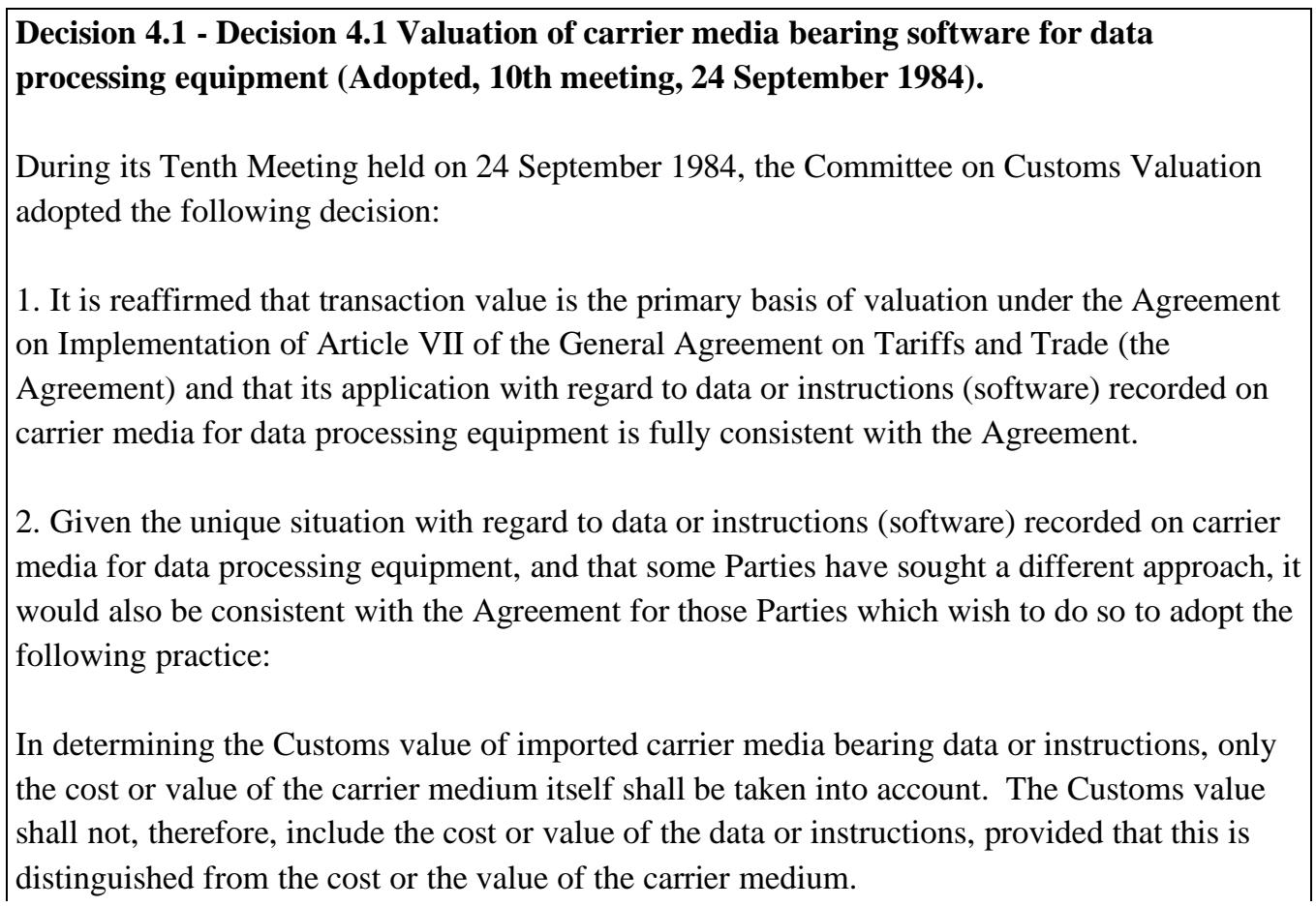

\footnotetext{
${ }^{438}$ Notice that when a country decides to base the customs value on the carrier medium only, the cost or value of the data/software must be distinguished from the cost of the carrier medium. If not, the total cost will form the basis of the customs value, i.e., the carrier medium plus the data/software.
} 
For the purpose of the Decision, the expression "carrier medium" shall not be taken to include integrated circuits, semiconductors and similar devices or articles incorporating such circuits or devices; the expression "data or instructions" shall not be taken to include sound, cinematic or video recordings.

3. Those Parties adopting the practice referred to in paragraph 2 of this Decision shall notify the Committee of the date of its application.

4. Those Parties adopting the practice in paragraph 2 of this Decision will do so on a mostfavoured-nation (m.f.n.) basis, without prejudice to the continued use by any Party of the transaction value practice.

\section{Statement Made by the Chairman at the Meeting of the Committee on Customs Valuation of 24 September 1984 Prior to the Adoption of the Decision on the Valuation of Carrier Media Bearing Software for Data Processing Equipment}

"In the case of imported carrier media bearing data or instructions for use in data processing equipment (software), it is essentially the carrier media itself, e.g. the tape or the magnetic disc, which is liable to duty under the Customs tariff. However, the importer is, in fact, interested in using the instructions or data; the carrier medium is incidental. Indeed, if the technical facilities are available to the Parties to the transaction, the software can be transmitted by wire or satellite, in which case the question of Customs duties does not arise. In addition, the carrier medium is usually a temporary means of storing the instructions or data; in order to use it, the buyer has to transfer or reproduce the data or instructions into the memory or data-base of his own system.

Under the international Customs valuation practices which were superseded by the Agreement on Implementation of Article VII of the General Agreement on Tariffs and Trade (the Agreement), the value of the software was not, as a general rule, included when valuing the carrier medium. Following their adoption of the Agreement, those countries which followed the previous international practice have either changed their rules for valuing carrier media bearing computer software or have maintained their previous practice.

The proposed decision of the Committee on Customs Valuation on the valuation of carrier media bearing software for data processing equipment indicates that transaction value is the primary basis of valuation under the Agreement and that its application with regard to software recorded on carrier media for data processing equipment is fully consistent with the

Agreement. It also would provide that given the "unique situation" regarding software just described and the fact that some Parties sought a different approach, it would also be consistent with the Agreement for those Parties which wish to do so to only take account of the cost or value of the carrier medium itself in determining the Customs value of imported carrier media bearing data or instructions.

In taking this decision on the valuation of carrier media bearing software for data processing equipment, it is understood that should any difficulties arise in the implementation and application of the decision, it would be useful for those difficulties to be considered by the Parties to the Agreement."

Operationally, Decision 4.1 seems essentially straightforward. That is, a Customs administration will either determine a customs value of the carrier medium and software or the carrier medium only. However, the reality is different in practice. 
As an example, since 2014, the World Trade Organization (WTO) Committee on Customs Valuation (CCV) has discussions on a proposal by Uruguay to update Decision 4.1. ${ }^{439}$ Uruguay's proposal is to include "USB flash drives or similar devices" as acceptable carriers media for software, and thus allows Members applying paragraph 2 of Decision 4.1 to take into account only the value of the flash drives or similar devices to calculate the customs value. In other words, the proposal gives security to exclude the value of the software when it is imported in flash drives or similar devices. It is a trade liberalization proposal intended to broaden the concept of carrier media for software.

The problem is due to the definition of a carrier media set out in the third subparagraph of paragraph 2 of Decision 4.1:

The expression 'carrier medium' shall not be taken to include integrated circuits, semiconductors and similar devices or articles incorporating such circuits or devices;

The fact is that some governments, interpreting Decision 4.1, consider "USB flash drives or similar devices" as having integrated circuits and/or semiconductors and, because of this, exclude them from being considered carrier media. As a result, the customs value of software imported on "USB flash drives or similar devices" might end up being the value of the software added to the value of the device.

To avoid the legal problem of interpretation, Uruguay proposes to amend Decision 4.1. At the time of this writing, the definition of carrier media in Decision 4.1, if adopted by the WTO, as amended by Uruguay and Switzerland, would read: ${ }^{440}$
the expression "carrier medium" shall not be taken to include integrated circuits, semiconductors and similar devices or articles incorporating such circuits or devices, with the exception of those which are presented to Customs solely as a means of storage for transfer of data or instructions (software) to data processing equipment in order to be used;

This case illustrates the need for amendments to the Decision to broaden the definition of carrier media and by extension avoid obstacles for software traded physically. Naturally, all software can be imported electronically, and it is necessary to remove barriers for software that is still imported on physical media. Trade obstacles to software affect economic productivity and development. After all, how can countries increase productivity without software?

\footnotetext{
${ }^{439}$ WTO, G/VAL/W/241/Rev.1

${ }^{440} \mathrm{G} / \mathrm{VAL} / \mathrm{W} / 254$
} 
During all these years, Decision 4.1 created problems for border procedures. For instance, the exclusion of sound, cinematic, or video recordings within the concept of data or instructions became more difficult to differentiate from data.

\section{the expression "data instructions" shall not be taken to include sound, cinematic or video recordings. ${ }^{441}$}

The original idea was to exclude all entertainment from the concept of software. However, with the convergence of media, it has become difficult to differentiate entertainment such as movies and games from software. Despite the difficulties, government authorities feel obliged, in some instances, to apply such a differentiation, and thus customs valuation procedures may take longer and vary from country to country.

In conclusion, discussions related to Decision 4.1 have a bigger impact than many imagine. It goes beyond trade revenue aspects and enters the field of trade and development. As software becomes increasingly important for development, and Internet of Things (IoT) devices gain importance, it becomes clear that the Decision needs revision.

\section{Notifications}

Another function of the CCV is to deal with the notifications of national legislation. The "Decision on Notification and circulation of national legislation in accordance with Article 22 of the Agreement" requires Members to submit the complete texts of their national legislation (laws, regulations, etc.) on customs valuation in one of the three official WTO languages. ${ }^{442}$ This is a Decision that reinforces GATT 1994 Article $\mathrm{X}$ Publication and Administration of Trade Regulations. Article X contains two central principles for the international trading system: transparency of existing trade regulations and the uniform application of these regulations. ${ }^{443}$

On the point of notifications, it is worth noting that neither WTO CVA Article 22 nor the Decision on Notification have succeeded in achieving full compliance with notifications. After many years since the adoption of the GATT CV Code from the Tokyo Round, some countries never notified their customs valuation legislation to the GATT/WTO and many that did give notifications had difficulties to update the notification to comply with the latest legislation.

\footnotetext{
${ }^{441}$ The exclusion of sound, cinematic, or video recordings is in the third subparagraph of paragraph 2 of Decision 4.1.

${ }^{442}$ Decision B.2 - Notification and circulation of national legislation in accordance with Article 22 of the Agreement (Adopted by the GATT Tokyo Round Committee on 13 January 1981 (VAL/M/1, paragraph 37).

${ }^{443}$ GATT Article $\mathrm{X}$ is very relevant, as it addresses uncertainty about legislation and its application. Article $\mathrm{X}$ is one of the pillars of the WTO TFA.
} 
In the context of efforts to "modernize" the WTO, the EU proposes several measures to remedy the long-standing problem regarding the notifications, such as: a) more effective committee-level monitoring; b) incentives for improving notification compliance; c) sanctions for wilful and repeated non-compliance; d) counternotifications; and e) strengthening the Trade Policy Review Mechanism (TPRM). ${ }^{444}$

From the list of EU proposals to remedy the notifications and/or outdated legislation mentioned, the most useful would probably be the one that seeks to strengthen the TPRM. For example, in the case of Angola, a country that has not made notifications, the TPR explains that:

\subsection{The tax base for customs duty is the c.i.f. value of the goods at the point of entry. In principle, the provisions in the WTO Customs Valuation Agreement have been in force in Angola since 2006. Angola has not made any notification to the WTO in this regard. ${ }^{445}$}

From the example, it is clear that relevant information about the application of the WTO CVA is often available in TPR documents. As such, it is useful to look for information in various WTO documents. In short, the conclusion is that non-compliant countries are faced with limited resources to allow them to improve their compliance with Article 22 of the CVA.

Another point worth mentioning in the work of the WTO CCV is the update of the responses to the checklist of issues that was established in Decision B.3 - Checklist of issues. ${ }^{446}$ The checklist is embedded in a Decision that contains a questionnaire focusing on sales between related persons, the price of lost or damaged goods, provisions for the reverse order of Articles 5 and 6, implementation of Articles 5.2 (super deductive method), and 6.2 (verifications in the export country) among other things.

According to the latest version of the document on Decision B.3 notifications, a significant number of members have not yet replied to the checklist of issues. ${ }^{447}$ In addition, many of the compliant Members did so several years ago without updating their answers thereafter. Thus, it is evident that Decision B.3 is taken lightly by Members and that after so many years many Members must still reply and notify their answers to the checklist of issues. A possible reason for the failure of Members to provide notifications might be connected to problems of internal coordination between a country's representatives at the WTO and that country's national authorities.

\footnotetext{
${ }^{444}$ European Union (EU) (2018).

445 Angola 2015 TPR 2015 is in document WTO WT/TPR/S/321, from 18 August 2015.

${ }_{446}$ Decision adopted by the GATT Tokyo Round Committee on 5 May 1981 (VAL/M/2, paragraph 52)

${ }^{447}$ The latest status of Decision B.3 notifications is contained in document G/VAL/W/232/Rev.5 from October 2016.
} 


\subsubsection{WCO TCCV}

The TCCV was established on 1 January 1995 and replaced the previous GATT Tokyo Round TCCV. The TCCV is regulated in Part II, Article 18.2 of the WTO CVA. It operates under the auspices of the CCC/WCO.

Annex II of the WTO CVA sets out the responsibilities of the TCCV.

ANNEX II

TECHNICAL COMMITTEE ON CUSTOMS VALUATION

1. In accordance with Article 18 of this Agreement, the Technical Committee shall be established under the auspices of the CCC with a view to ensuring, at the technical level, uniformity in interpretation and application of this Agreement.

2. The responsibilities of the Technical Committee shall include the following:

(a) to examine specific technical problems arising in the day-to-day administration of the customs valuation system of Members and to give advisory opinions on appropriate solutions based upon the facts presented;

(b) to study, as requested, valuation laws, procedures, and practices as they relate to this Agreement and to prepare reports on the results of such studies;

(c) to prepare and circulate annual reports on the technical aspects of the operation and status of this Agreement;

(d) to furnish such information and advice on any matters concerning the valuation of imported goods for customs purposes as may be requested by any Member or the Committee. Such information and advice may take the form of advisory opinions, commentaries or explanatory notes;

(e) to facilitate, as requested, technical assistance to Members with a view to furthering the international acceptance of this Agreement;

(f) to carry out an examination of a matter referred to it by a panel under Article 19 of this Agreement; and 
(g) to exercise such other responsibilities as the Committee may assign to it.

The terms of reference of the work of the TCCV provide, inter alia:

(...) examine specific technical problems arising in the day-to-day

administration of the customs valuation systems of Parties and to give advisory opinions on appropriate solutions based upon the facts presented; to study, as requested, valuation laws, procedures and practices as they relate to this Agreement and to prepare reports on the results of such studies; (...) $)^{448}$

The WCO TCCV normally meets twice per year, in spring and autumn, at the WCO headquarters in Brussels. In cases of urgency, such as when it was responding to the WTO CCV consultation on the Doha paragraph 8.3, the TCCV also met at other times during the year.

As a practical matter, the provisions of paragraph 23 of Annex II are sufficient with respect to the presentation of the reports of the TCCV to the CCV and the CCC/WCO, with it being understood that either body may request a reconsideration or further consideration of any matter covered in each report.

It has been considered that some of the work of the TCCV will be formalized. To formalize its work, the TCCV publishes instruments in the form of Advisory Opinions, Commentaries, Explanatory Notes, Case Studies, and Studies. However, these published instruments are not binding on tax and customs administrations and therefore they do not represent international valuation law.

A key consideration regarding the TCCV instruments is that some of the first instruments originated in BDV times. In other words, some texts of the TCCV were produced during the time of the BDV and were later adapted and incorporated into the GATT framework. It is clear that many of the concepts, doubts, and clarifications are the same for both international agreements.

All TCCV instruments can be found in the WCO publication "Customs Valuation Compendium". The WCO Compendium is a complete publication on customs valuation. This is the only publication in which it is possible to find the full set of texts issued by the WCO TCCV. Due to copyright legislation, it is not possible to reproduce the totality of such texts. ${ }^{449}$ However, a list of the titles of all texts is provided in Annex K to this dissertation.

${ }^{448}$ WCO (2014). Customs Valuation Compendium.

${ }^{449}$ WCO (2014), Customs Valuation Compendium. 
Another publication of the WCO TCCV is the Conspectus of Technical Valuation Questions. The Conspectus is a record of items raised within the TCCV and consists of three parts: Part I contains the instruments, or other questions and studies adopted, or concluded by the Technical Committee; Part II includes work currently being considered, and Part III contains questions previously raised that have not yet been considered, or have been put aside for later recall, both of which may then form part of the Technical Committee's future work.

The Conspectus is divided into three parts:

PART I: Questions concluded (unless a new aspect arises).

Work of the Technical Committee established under the Agreement on implementation of Article VII of the GATT 1947 (From March 1981 to September 1995).

Work of the Technical Committee established under the Agreement on implementation of Article VII of the GATT 1994 (Since October 1995).

PART II: Questions on the Technical Committee's program of work.

PART III: Questions raised pending future work.

In accordance with established procedure, the Secretariat has updated the Conspectus, which is reproduced in Annex L of this dissertation.

\subsection{Article 19 - Consultation and Dispute Settlement}

Article 19 of the WTO CVA describes the procedure to be followed for consultations and disputes.

The WTO agreements are agreements binding governments to keep their trade policies within the negotiated limits. Although governments are aware of these limits, sometimes for different reasons, it is necessary to enforce the provisions of these agreements. Thus, to enforce the agreements, the WTO resolves disputes, according to the Dispute Settlement Understanding (DSU). In the 2017 Annual Report, the WTO Secretariat refers to dispute settlement as follows:

\section{Dispute settlement}

The WTO's procedure for resolving trade disputes under the Dispute Settlement Understanding is vital for enforcing the rules and therefore for ensuring that trade flows smoothly. ${ }^{450}$

${ }^{450}$ WTO, 2017, p.5 
WTO member governments, when in disagreement with each other on a matter related to the "covered agreements", can seek a solution within the WTO using the WTO DSU. ${ }^{451}$ Provisions on consultations and dispute settlement in Articles XXII and XXIII of the GATT 1994 are elaborated on in the WTO DSU.

The settlement of disputes is set out expressly in the list of functions of the WTO Agreement. ${ }^{452}$ As a result, the WTO dispute settlement system works in a quasi-judicial fashion and is the main resource for interpreting the WTO agreements. ${ }^{453}$ On the importance of the WTO dispute settlement system to resolve conflicts, Bhatia, the 20172018 Chairman of the Appellate Body, explains:

In this connection, it is pertinent to recall that the demonstrated success of the dispute settlement system in effectively, predictably and expeditiously resolving disputes is why it is often called the crown jewel of the WTO. ${ }^{454}$

Along the same lines of GATT 1994 Articles XXII and XXIII, each individual agreement tends to incorporate such provisions into their body. For instance, the WTO CVA incorporates consultations and dispute settlement in Article 19.1 and 2.

\section{WTO CVA - Article 19: Consultations and Dispute Settlement}

1. Except as otherwise provided herein, the Dispute Settlement Understanding

is applicable to consultations and the settlement of disputes under this Agreement.

$$
(\cdots)
$$

The provisions in Article 19 of the WTO CVA make the rights of the parties to apply the DSU mechanism clear.

In the WTO structure, the DSB is responsible for settling disputes. The DSB establishes the panels of experts to consider each case, appoints the members of the Appellate Body, adopts the reports of the panels and the Appellate Body, monitors the implementation

\footnotetext{
${ }^{451}$ The DSU applies to all disputes brought under the WTO agreements listed in Appendix 1 of the DSU (Article 1.1 of the DSU). In the DSU, these agreements are referred to as the "covered agreements".

${ }^{452}$ Agreement Establishing the World Trade Organization, Article III, Functions of the WTO: 3. The WTO shall administer the Understanding on Rules and Procedures Governing the Settlement of Disputes (hereinafter referred to as the "Dispute Settlement Understanding" or "DSU") in Annex 2 to this Agreement.

${ }^{453}$ The operation of the (WTO) dispute settlement process involves the parties and third parties to a case, the DSB panels, the Appellate Body, the WTO Secretariat, arbitrators, independent experts, and several specialized institutions.

${ }^{454}$ Bhatia (2017)
} 
of the rulings and recommendations of the panels, and finally has the power to authorize retaliation when a country does not comply with a ruling. ${ }^{455}$

The procedure set out in the DSU is a structured process with defined stages. The entire procedure can be summarized as follows:

Table 8 - WTO DSU Stages

\begin{tabular}{|l|l|}
\hline 60 days & Consultations, mediation, etc \\
\hline $\begin{array}{l}\text { 45 days } \\
\text { months }\end{array}$ & Panel established and panelists appointed \\
\hline 3 weeks & Final panel report to parties \\
\hline 60 days & Final panel report to WTO members \\
\hline Total = 1 year & (without appeal) \\
\hline $\begin{array}{l}\text { Shall not exceed } \\
\text { 90 days }\end{array}$ & Appellate Body report \\
\hline $\begin{array}{l}\text { 30 days } \\
\text { Total should } \\
\text { not exceed 1y } \\
\text { 3m }\end{array}$ & $\begin{array}{l}\text { Dispute Settlement Body adopts Appellate Body } \\
\text { report }\end{array}$ \\
\hline
\end{tabular}

Source: WTO

The entire procedure has several stages, which should take a total time of approximately one year in the cases where there is no appeal, and one year and three months in cases where there is an appeal to the Appellate Body. However, as time goes by, the disputes are increasing in complexity, with an increasing number of appeals and longer times are expected. The WTO Annual Report for 2017 confirms the trend for growing appeals and longer submissions in the disputes:

The then chair of the Appellate Body, Thomas Graham, delivered a lecture on the state of the Appellate Body at an event in November. He highlighted that the number of appeals, the number of issues appealed and the number of pages of submissions have all grown significantly in recent years. ${ }^{456}$

Since its establishment in 1995, 593 trade disputes have been brought in the system. ${ }^{457}$ In the WTO 2018 Annual Report, Roberto Azevedo, Director General, addressed the

\footnotetext{
455 The Appellate Body is composed of seven Members who are appointed by the Dispute Settlement Body (DSB) to serve for four-year terms. Each person may be reappointed for another four-year term. 456 WTO Annual Report (2017), p.15

${ }^{457}$ WTO website, Chronological list of disputes cases. Available at:

https://www.wto.org/english/tratop_e/dispu_e/dispu_status_e.htm [accessed 11 January 2019].
} 
growing demand on the system and expressed concerns regarding the appointment of Appellate Body members.

A properly functioning system requires full capacity in all areas, including the Appellate Body. However, there is currently an impasse in the process of appointing new Appellate Body members. Finding a solution here is a systemic priority. 458

The growing number of disputes pose a challenge to the WTO dispute system. It is a negative indicator regarding the members voluntary compliance in relation to the "covered agreements". In addition, the growing complexity of cases needs consideration, as more time is necessary to conclude disputes. Finally, the political impasse created by the US when appointing new $\mathrm{AB}$ members clearly points to the fragility of the dispute settlement system for the long term. ${ }^{459}$ On this matter, the US accused the Appellate Body of "judicial activism".

At the present date, the WTO multilateral trading system is in deep crisis with the blocking of the $\mathrm{AB}$. The dispute settlement system is falling into paralysis.

For the purposes of this dissertation, it is relevant to link the US "judicial activism" accusation to cases referring to the price of the goods exported to the US. For this dissertation, this can be narrowed down to the cases in which the US complained about the normal value which serves as the basis for the application of specific anti-dumping duties on imports from a particular source. In the rationale of this dissertation the lowering of tariffs caused countries that were accustomed to using tariffs as a protectionist instrument to apply anti-dumping duties more often. In cases where antidumping duties are not sufficient to offer the desired protection, the remaining alternative in an AV world is to raise rates and/or create minimum price controls. For countries where the tariffs serve as a revenue instrument, the alternative is to raise domestic taxes, such as corporate taxes or VAT.

To date, the 133 anti-dumping disputes from a total of 593, account for $22.5 \%$ of all disputes. This provides a strong argument, showing that the protectionist function of tariffs shifted to anti-dumping duties, with the US as one the most active Members. ${ }^{460}$ That said, it is not the objective of this dissertation to go into detail about the US reasons for blocking the AB. In any case, the Appellate Body is not to blame and it is envisaged that the protectionist function of anti-dumping duties, as well as of tariffs, needs to be reformed.

\footnotetext{
${ }^{458}$ WTO Annual Report (2018), p.9

459 The US blocked the re-appointment of members and the nomination of candidates to replace retiring Appellate Body members. On 11 December 2019 the Appellate Body stopped functioning given that it could not meet the minimum requirement of three Appellate Body members.

${ }^{460}$ Updated until 14 January 142020.
} 
In the period from 1995 to 2019, there were eighteen disputes related to the WTO Customs Valuation Agreement. The oldest dispute is European Communities - Duties on Imports of Cereals (1995), and the most recent is Colombia - Anti-Dumping Duties on Frozen Fries (2019).

Table 9 - WTO DS Cases Art. VII - Number and Short Title

\begin{tabular}{|l|}
\hline EC - Cereals (1995) \\
\hline EC - Grains (1995) \\
\hline EC - Rice (1995) \\
\hline Argentina - Textiles and Apparel (1998) \\
\hline EC - Rice (1998) \\
\hline Brazil - Minimum Import Prices (1999) \\
\hline Brazil - Minimum Import Prices (2000) \\
\hline Romania - Minimum Import Prices (2001) \\
\hline Belgium - Rice (2001) \\
\hline Argentina - Poultry Anti-Dumping Duties (2003) \\
\hline Mexico - Customs Valuation and Other Purposes (2005) \\
\hline Colombia - Customs Measures (2006) \\
\hline Colombia - Ports of Entry (2009) \\
\hline Thailand - Cigarettes (Philippines) (2011) \\
\hline Peru - Agricultural Products (2015) \\
\hline Russia - Tariff Treatment (2016) \\
\hline $\begin{array}{l}\text { Colombia - Anti-Dumping Duties on Frozen Fries from Belgium, Germany and } \\
\text { the Netherlands (2019) }\end{array}$ \\
\hline
\end{tabular}

A key issue underlying all of these disputes is the use of minimum/reference prices/indicative prices for CV, including for applying anti-dumping duties DS241, instead of the transaction value price.

Another noticeable point is that the earlier disputes were resolved in consultations (DS9, DS13, DS17, DS134, DS183, DS197, DS198, DS134, and DS298), while more recent disputes required panels (DS348, DS366, DS370, DS371, DS457).

Most of these disputes were presented in previous chapters together with the provisions they interpret. However, there are a few cases that deserve a closer examination due to their importance for the research question. These are (a) Colombia — Ports of Entry (2009); (b) Thailand - Cigarettes (Philippines) (2011); (c) Peru Agricultural Products (2015), and (d) Russia - Tariff Treatment (2019).

\subsection{WTO CVA Selected Disputes}


In Colombia - Ports of Entry, initiated on 12 July 2007, Panama requested consultations with Colombia on (i) indicative prices applicable to specific goods and (ii) restrictions on ports of entry for certain goods. Panama's request concerning indicative prices relates to a series of resolutions promulgated in June 2007 by Colombia, which established a mechanism of indicative prices. ${ }^{461}$

Colombia requires that importers of specific goods pay customs duties and other duties or charges and taxes based on the indicative prices, rather than on the valuation methods set out in Article VII of the GATT 1994 and the Agreement on Customs Valuation. Panama is challenging the indicative price measures on an "as such" and "as applied" basis. ${ }^{462}$

Thus, more specifically, Panama noted that Colombia required the importers of specific goods from Panama to pay customs duties and other duties or charges and taxes based on the indicative prices, rather than on the valuation methods set out in Article VII of the GATT 1994 and the CVA.

The panel upheld Panama's claims that the various resolutions establishing indicative prices were inconsistent "as such" with the obligation established in the Customs Valuation Agreement to apply, in a sequential manner, the methods of valuation provided in Articles 1, 2, 3, 5, and 6 of the Customs Valuation Agreement and with Article 7.2(b) and (f) of the Customs Valuation Agreement.

\section{CONCLUSIONS AND RECOMMENDATIONS}

VIII.1 In light of the above findings, the Panel upholds Panama's claims that that Articles 128.5 e) of Decree No. 2685 and 172.7 of Resolution No. 4240, as well as the various resolutions establishing indicative prices, are inconsistent "as such" with the obligation established in the Customs Valuation Agreement to apply, in a sequential manner, the methods of valuation provided in Articles 1, 2, 3, 5 and 6 of the Customs Valuation Agreement. ${ }^{463}$

On 20 May 2009, the DSB adopted the panel report. At the DSB meeting on 19 June 2009, Colombia informed the DSB of its intention to comply and that it needed a reasonable period to comply with the DSB recommendations. On 23 February 2010, Panama and Colombia notified the DSB of Agreed Procedures under Articles 21 and 22 of the DSU.

\footnotetext{
${ }^{461}$ Panel Report, Colombia - Indicative Prices and Restrictions on Ports of Entry, WT/DS366/R and Corr.1, adopted 20 May 2009, DSR 2009:VI, p. 2535.

${ }^{462}$ WTO, WT/DS366/1

${ }^{463}$ WTO, WT/DS366/R
} 


\section{Thailand — Cigarettes (Philippines) (2011)}

In Thailand - Cigarettes (Philippines), initiated on 7 February 2008, the Philippines requested consultations with Thailand concerning many Thai fiscal and customs measures affecting cigarettes from the Philippines. Such measures included Thailand's customs valuation practices, excise tax, health tax, TV tax, VAT regime, retail licensing requirements, and import guarantees imposed upon cigarette importers. ${ }^{464}$

In relation to customs valuation, the Philippines claimed that Thailand acted inconsistently with various provisions of the Agreement and the interpretative notes to these provisions, as well as paragraphs 1 and 2 of the General Introductory Commentary and various provisions of Articles II and VII of the GATT 1994. According to the Philippines, Thailand did not use transaction value as the primary basis for customs valuation as required and failed to conform to the sequence of valuation methods mandated by the Customs Valuation Agreement. Rather, it used a valuation method with no basis on the Agreement.

The Philippines claimed that Thai customs questioned the declared transaction value, and that it failed to follow the procedural rules set out in the Customs Valuation Agreement in examining the circumstances of the transaction between the importer and the exporter, and also it did not respect the sequential order of valuation methods in using another method to establish the valuation.

The DSB adopted the Appellate Body Report, and the Panel Report, as modified by the Appellate Body Report. In these reports, Thai measures were found to be inconsistent with provisions of the CVA, as follows: ${ }^{465}$

(i) Thailand acted inconsistently with Articles 1.1 and 1.2 of the CVA by rejecting the declared transaction values for entries of cigarettes imported by the Thailand branch office of Philip Morris (Thailand) Limited ("PM Thailand");

(ii) Thailand acted inconsistently with Article 1.2(a) of the CVA by failing to communicate its "grounds" for considering that the relationship between PM Thailand and Philip Morris Philippines Manufacturing Inc. ("PM Philippines") influenced the price paid by PM Thailand;

(iii) Thailand acted inconsistently with Article 16 of the CVA by failing to provide an adequate explanation as to how the Thai Customs Department ("Thai Customs") determined the customs values for the imported cigarettes;

\footnotetext{
${ }^{464}$ Panel Report, Thailand - Customs and Fiscal Measures on Cigarettes from the Philippines, WT/DS371/R, adopted 15 July 2011, as modified by Appellate Body Report WT/DS371/AB/R, DSR 2011: IV, p. 2299.

46515 July 2011 (WT/DSB/M/299)
} 
(iv) Thailand acted inconsistently with Article 7.1 of the CVA by improperly assessing the customs values of the imported cigarettes using a deductive method;

(v) Thailand acted inconsistently with Article 7.3 of the CVA by failing to inform PM Thailand properly in writing of the customs values determined under Article 7 and the method used to determine these values;

(vi) Thailand acted inconsistently with Article 10 of the CVA by disclosing to the Thai media confidential customs valuation information provided by PM Thailand to Thai Customs authorities.

Furthermore, Thailand said that it took a series of measures to comply with the DSB's recommendations and rulings. Later, Thailand in its Trade Policy Review (TPR) for 2015, explained that, since June 2014, the Philippines and Thailand disagreed on the extent of the implementation of the DSB's recommendations and rulings.

3.19. (...) During the review period the WTO dispute settlement case raised by the Philippines against Thailand's customs valuation practices, excise tax, health tax, TV tax, VAT regime, retail licensing requirements, and import guarantees imposed upon cigarette importers was seemingly concluded; in June 2014, both countries disagreed on the extent of implementation of the Dispute Settlement Body's recommendations and rulings. ${ }^{466}$

Thus, since June 2014, Thailand and the Philippines have disagreed on the implementation of the DSB recommendations and rulings.

The Philippines questioned several measures adopted by Thailand. According to the Philippines, such measures are not in compliance with the DSB's recommendations and rulings. The complaints from the Philippines regarding customs valuation are: 1) the Thailand BoA Ruling rejected the declared value for several entries and Thai Customs authorities issued revised notices; 2) the criminal investigation against PM Thailand for cigarettes imported from the Philippines, and 3) the disclosure to the media of business confidential information. ${ }^{467}$

To date, the Thailand - Customs and Fiscal Measures on Cigarettes from the Philippines (2011) is still an ongoing dispute that offers an opportunity for learning. The dispute is in the phase of the Philippines's second recourse to Article 21.5 of the Understanding on Rules and Procedures Governing the Settlement of Disputes (DSU) concerning the alleged failure by Thailand to comply with the Dispute Settlement Body's (DSB) recommendations and rulings in the original proceeding. The latest conclusion was that Thailand failed to implement the DSB rulings for the WTO CVA.

\footnotetext{
${ }^{466}$ WTO, WT/TPR/S/326 (20 October 2015)

${ }^{467}$ WTO, WT/DS371/17 (12 May 2016)
} 
8.4. The Panel therefore concludes that Thailand has failed to implement the recommendations and rulings of the DSB to bring its measures into conformity with its obligations under the Customs Valuation Agreement. ${ }^{468}$

For the purposes of this dissertation, this is the richest case in this subject matter that addresses several questions of the CVA. It advances into examining related parties' transactions, the sequential order of methods, the procedures of Decision 6.1, and transfer pricing. In addition to several CV issues, it also brings the trade on cigarettes, which are sensitive goods in international trade, into the limelight.

In relation to the research question, cigarettes are a typical example of goods that should not be subject to AV tariffs. The main reasons are that the industry concentration that menaces free market prices, the recognition by the WHO that minimum specific tax floor systems have considerable advantage over purely ad valorem systems for tobacco (health policy) ${ }^{469}$, and the importance of tariffs on such goods for governments' trade revenue (fiscal policy). As such, WTO Members should consider the use of NAV tariffs which guarantee some form of protection against price volatility. The use of NAV tariffs might present better results for international trade in tobacco goods. That said, Thailand - Cigarettes (Philippines) (2011) is an example of the difficulties in assessing customs values for products that are subject to ad valorem tariffs in non-competitive markets.

\section{Peru - Agricultural Products (2015)}

Peru - Agricultural Products (2015), initiated on 12 April 2013, concerns the imposition by Peru of an "additional duty" on imports of certain agricultural products, such as rice, sugar, maize, milk, and certain dairy products.

The Peruvian additional duty on imports of certain agricultural products was seen by Guatemala as inconsistent with Articles 1, 2, 3, 5, 6, and 7 of the CVA. Unfortunately, the panel report did not address Guatemala's CV claims, because these allegations were only put forward as arguments in the alternative in the dispute.

For the research question, it is important to register that DS457 is a reference case on the autonomy of Free Trade Agreements (FTAs) in relation to WTO Agreements. In other words, to what extent does WTO law interact with FTA rules. The fact is that Peru and Guatemala had a bilateral FTA with provisions that "in the event of any inconsistency" between WTO rules and FTA rules, the FTA rules "shall prevail". Because of the Peru-Guatemala FTA, Peru argued that it could maintain a "Price Range System" (PRS) or "Price Band System" (PBS) mechanism that would normally not be allowed under WTO rules.

\footnotetext{
${ }^{468}$ WT/DS371/RW2 (12 July 2019)

${ }^{469}$ WHO Report on the Global Tobacco Epidemic (2015), p.23
} 
7.25. Peru maintains that its PRS is consistent with WTO rules, but even if the Panel were to find that it is not, there would be an inconsistency between the FTA and the WTO agreements. (...) In the presence of such inconsistency, by virtue of the provisions of its Article 1.3.2, the FTA would prevail. ${ }^{470}$

The Peru argument that the Peru-Guatemala FTA would prevail over WTO rules is important for all WTO members. If the argument prevailed, all countries could institute different rules under FTAs. On the question of whether, by means of the FTA, Peru could modify its WTO rights, the Panel stated that it would not rule since the FTA had not entered into force.

f. in as much as the Free Trade Agreement signed by Peru and Guatemala in December 2011 has not entered into force, it is not necessary for this Panel to rule on whether the parties may, by means of the FTA, modify as between themselves their rights and obligations under the covered agreements. ${ }^{471}$

In conclusion, the question whether it is possible to modify the WTO rules using FTAs remains open for debate. Shaffer and Winters noted that, after the Appellate Body report, Peru maintained its PRS with prices published monthly.

Peru maintained its PRS, but with reference prices that will now by published monthly. In this way, Peru aims to advance an argument that the PRS is no longer a "variable import levy" (since it only changes monthly), and thus an ordinary customs duty with an applied rate that is less than Peru's tariff binding. ${ }^{472}$

Thus, if Peru succeeds in proving that the PRS is supported by an increase or decrease in ordinary customs duties, it can continue to use the mechanism. Putting it differently, specific duties that support PRS should stay within the WTO negotiated tariff bindings to be considered compliant with WTO rules.

Finally, it is worth remembering that the use of price band systems was also the subject of discussions in Chile — Price Band System. ${ }^{473}$ According to Chile's TPR 2015, the country continues to use the PRS for wheat, wheat flour, and sugar (forty-one eightdigit lines in the HS 2012).

\footnotetext{
${ }^{470}$ Idem

${ }^{471}$ Idem

472 Shaffer and Winters., Op. cit., p10

${ }^{473}$ DS207 Chile - Price Band System and Safeguard Measures Relating to Certain Agricultural Products.
} 
10. (...). Chile still applies a price band system based on international reference prices for imports of wheat, wheat flour and sugar. ${ }^{474}$

Under Chile's PRS system, a specific duty is added to the AV tariff when the reference price for the product concerned falls below a lower threshold ("floor") of the price band. An AV tariff reduction is applied when the reference price exceeds the upper threshold ("ceiling") of the band.

Chile's applied tariff is always lower than its AV bound tariff. This is the justification it gives to continue applying the band system. In my view, based on Chile's justification, other countries may be tempted to use a price band system in the future.

This dispute is relevant in the context of the research question addressed in this dissertation, as it discusses the possibility of using PRS/PBS mechanisms. As an analogy it might also suggest the use of Advance Price Agreements (APA) or Double Taxation Agreements to circumvent the WTO CVA set of rules. For tax revenue purposes, this case shows that, as long as the number of duties collected for the imported goods stays within the WTO negotiated tariff bindings, it is considered compliant with WTO rules.

\section{Russia - Tariff Treatment (2016)}

Russia - Tariff Treatment (2016), initiated on 31 October 2014, is about the tariff treatment that Russia accords to certain goods in both agricultural and manufacturing sectors. In relation to $\mathrm{CV}$, the EU complains that Russia's authorities use other values, rather than the actual value, for certain goods originating in the EU.

In addition, it appears that, in relation to certain goods originating in the European Union, Russia's authorities do not base their valuation for customs purposes on the actual value of imported merchandise on which duty is assessed. ${ }^{475}$

The EU claimed that the measures appeared to be inconsistent with Article VII of the GATT 1994 and the CVA, Articles 1 through 7 and Annex I.

Unfortunately, the Panel Report did not address the CV issue. Instead, the Panel Report focused on Article II related to the combined duty system applied by Russia. Russia applied a system of combined duty rates of AV and specific duties for certain goods. For instance, if one kilogram of palm oil was imported under tariff line 1511901902 , it would consider the customs value and apply an AV rate, or it would consider the weight and apply a specific rate depending on the customs value. If the customs value

\footnotetext{
${ }^{474}$ WTO (2015). Trade Policy Review Report by the Secretariat, Chile, p. 8

475 WTO, WT/DS485/1 (4 November 2014), Request for consultations by the European Union.
} 
resulted in a rate lower than $0.09 \mathrm{EUR} / \mathrm{kg}$, it would apply the specific rate. In summary, the combined duty system between AV rates and specific rates resulted in the specific rate acting as a "floor" for the duty rate.

Thus, the dispute is centred on whether the application of Russia's specific duty is consistent with the AV equivalent that was negotiated to serve as a bound tariff. The Panel examined EU examples of when the application of the specific tariff results in a higher AV than the bound rate. Finally, the panel concluded that, for certain situations, the resulting specific duties were higher than the AV bound levels.

7.230. We have found above that, in relation to the seventh and eighth measures as they existed at the time the Panel was established, the duties required to be applied by Russia were higher than bound levels for imports at or below specified break-even prices (customs values). ${ }^{476}$

This case was a victory for Russia, as it allowed for the possibility for Russia to continue to apply the combined duty rate system as long as it uses a ceiling or cap to prevent that the specific duties from going above the bound AV equivalents. In other words, the Appellate Body decided once more that a tariff system is WTO compatible as long as it does not exceed the AV bound rates. This is important for the research question in this dissertation, as it shows that there are ways to develop tariff systems that go beyond the simple AV systems and that can be more efficient in terms of revenue.

\subsection{Concluding Remarks}

The WTO CCV and the WCO TCCV are the institutions responsible for administering the CVA. Both institutions are established in Part II, Article 18 of the CVA.

The WTO CCV functions at the WTO headquarters and monitors several administrative issues of the CVA. Discussions related to the use of minimum prices/reference databases, commonly associated with revenue, constantly appear in the agenda of the CCV. These issues are possible violations of the CVA, but this dissertation submits that these issues are an indication of a bigger problem involving the functioning of AV tariffs.

The WTO CCV adopts Decisions to guide the interpretation, administration and working procedures of the CVA. The WTO Decisions can be divided into two groups: a) Decisions concerning the interpretation of the Agreement; and b) Decisions concerning the administration and working procedures of the Agreement. Since its existence, the CCV has issued only seven Decisions for interpretation and four Decisions concerning the administration and working procedures. While each of these

476 WTO, WT/DS485/R (12 August 2016) 
Decisions is essential for the interpretation and administration of the Agreement; some are more important than others. Customs professionals consider Decisions 3.1, 4.1, 6.1, and 7.1 dealing with the application of the Agreement as the most important Decisions. This chapter discussed Decisions 3.1 and 4.1 because of their strong connection with trade revenue.

WTO Decision 3.1 - "Treatment of interest charges in the Customs value of imported goods" deals with interest rates charges. The Decision is important because the payment of interest charges for deferred payment, financing, and other financial transactions is a concern for trade revenue.

Related parties' companies might use interest charges and debt strategies incorporated into international trade prices as a mechanism to send and receive values using international trade. According to Decision 3.1, interest charges that cannot be distinguished from the price actually paid or payable for the imported goods are included as part of the customs value. Although few are aware, interest charges for the use of money are mostly within the customs value and therefore considered for tariff collection and trade statistics.

The application of Decision 3.1 seems to be limited to only a part of the Members. In that sense, other Members might be adopting different procedures for interest rates or, most likely, having no regulated procedures. In conclusion, financial transactions, such as intra-group loans, that impact trade revenue are not addressed properly by the CVA.

WTO Decision 4.1 - Valuation of carrier media bearing software for data processing equipment offers the possibility for the inclusion or exclusion of the value of the software in the customs value. While Decision 4.1, paragraph 1 provides for the customs value of goods to be based on the cost of the carrier medium plus the cost/value of the software, paragraph 2 provides for customs administrations to value the goods using only the cost of the carrier medium as the basis of the customs value.

In summary, GATT/WTO CCV Decision 4.1 provides for both types of policies: the customs value of the imported carrier media bearing data or instructions (software) may be either the carrier medium and the software or only the carrier medium. For the purposes of this dissertation, the dual procedure created by the Decision contributes to the lack of uniformity and increases uncertainty for traders and customs authorities. The previous BDV guidance is regarded as being superior in providing guidance.

Other identified deficiencies in Decision 4.1 are the restrictive definition of carrier media, excluding devices such as USB flash drives, and the exclusion of sound, cinematic, or video recordings for the concept of data or instructions. All these limitations create uncertainty for traders when paying AV tariffs. 
Concerning the CCV notifications that form Article 22 of the CVA, this dissertation identifies a high level of non-compliance. To address this question, this dissertation suggests an analysis of the TPR to identify an updated evaluation of the situation regarding the legislation of non-compliant countries that face limited resources.

The WCO TCCV works under the auspices of the WCO. The TCCV has complementary tasks to the $\mathrm{CCV}$. One of its main responsibilities is to examine specific technical problems and to formalize instruments that provide appropriate solutions based upon the facts presented. As mentioned previously, the TCCV is nonbinding, depending on how Members adopt the instruments in their national legislation. The "Customs Valuation Compendium" is a complete publication on customs valuation.

Article 19 of the CVA describes the procedure to be followed for consultations and disputes. In that regard, to enforce the agreements, the WTO DSU is applicable.

The settlement of disputes is set out expressly in the list of functions of the WTO Agreement. ${ }^{477}$ As a result, the WTO dispute system works in a quasi-judicial fashion and is the main resource for interpreting the WTO Agreements. ${ }^{478}$

Since its establishment in 1995, 596 trade disputes have been brought before the dispute settlement system. Of these, eighteen disputes concerned the WTO CVA. Most of those disputes refer to the use of minimum/reference/indicative prices for $\mathrm{CV}$ (including for applying Anti-dumping duties DS241) instead of the transaction value price. Though the number of customs valuation disputes might indicate that the topic is not problematic, that is not true. What this author believes is that WTO Members understand that the CVA is a complex Agreement, poorly equipped to face undervaluation and other valuation problems. In this respect, it is important to highlight that WTO Members seek price protection on the Anti-Dumping Agreement, where it is easier to disqualify the normal value. So, in terms of disputes dealing with prices, the Anti-dumping Agreement is the most used Agreement from all WTO Agreements, 134 trade dispute cases to date.

A way to understand Member countries' behaviour is that instead of fighting the import value, WTO Members opted for an easier way to impose anti-dumping duties on the export value. The decision to fight the export value rather than the import value is a practical strategy for faster results.

\footnotetext{
${ }^{477}$ Agreement Establishing the World Trade Organization, Article III, Functions of the WTO: 3. The WTO shall administer the Understanding on Rules and Procedures Governing the Settlement of Disputes (hereinafter referred to as the "Dispute Settlement Understanding" or "DSU") in Annex 2 to this Agreement.

${ }^{478}$ The operation of the (WTO) dispute settlement process involves the parties and third parties to a case, the DSB panels, the Appellate Body, the WTO Secretariat, arbitrators, independent experts, and several specialized institutions.
} 
As for the CVA, to this date, the most relevant disputes that are associated with trade revenue are: (a) Colombia — Ports of Entry (2009); (b) Thailand — Cigarettes (Philippines) (2011); (c) Peru - Agricultural Products (2015); and (d) Russia - Tariff Treatment (2016).

Colombia - Ports of Entry (2009) is partly about the use of indicative prices applicable to specific goods. More specifically, Colombia required importers of specific goods from Panama to pay customs duties and other duties or charges and taxes based on the indicative prices, rather than on the valuation methods set out in the CVA. The panel upheld Panama's claims that the various resolutions establishing indicative prices, were inconsistent "as such" with the obligation established in the CVA to apply, the methods of valuation in a sequential manner as provided in Articles 1, 2, 3, 5, and 6 of the CVA and with Article 7.2(b) and (f) of the CVA. Colombia Ports of Entry (2009) is relevant for the research question as it shows that Member countries continue to seek ways to avoid accepting declared transaction value prices.

Until now, Thailand - Cigarettes (Philippines) (2011) is the richest case for CV issues. Among other tax issues, it advances to address several key CV questions, such as related parties' transactions, the sequential order of methods, the procedures of Decision 6.1, and the connection with transfer pricing. In addition to several CV issues, it also brings trade on cigarettes, which are sensitive goods in international trade, into focus. For the research question, cigarettes are a typical example of goods that should not be the object of AV tariffs. Considering the relationship scenario in the industry, the number of tariffs for trade revenue and the question involving health policies, WTO Members should use other types of tariffs, such as specific tariffs, for international trade in tobacco goods.

Peru - Agricultural Products (2015) discusses the imposition of an "additional duty" on imports of certain agricultural products. DS457 refers to "Price Range Systems" (PRS) or "Price Band Systems" (PBS) negotiated in an FTA. The dispute is relevant as it discusses the possibility of using PRS/PBS mechanisms under FTAs to circumvent WTO CVA rules. As an analogy, it might also suggest the use of Advance Price Agreements (APA) and other tax agreements to circumvent the WTO CVA set of rules.

Russia - Tariff Treatment (2019) refers to the use of a combined duty rate system, specific or AV, as long as it uses a ceiling or cap to prevent the specific duties from exceeding the bound AV equivalents. This dispute is important for the research question, as it shows that there are ways to develop tariff systems that go beyond the simple AV calculation and hence they can be more efficient in achieving government's protective or revenue goals. 


\section{WTO CVA Part III - Special and Different Treatment}

Before discussing the issues of special and different treatment, it is worth recalling that, until the GATT Uruguay Round, a country could be a Contracting Party of GATT, but it was not obliged to use the then Valuation Code. However, after the creation of the WTO in 1995, all countries became obliged to accept all the WTO multilateral agreements, including the CVA. In recognition of this, special arrangements were introduced for developing country members who may face difficulties implementing the CVA.

This chapter is therefore dedicated to the WTO CVA Part III, Article 20, that deals with the special and different treatment provisions. The study of Article 20 should be combined with Annex III of the CVA that describes the special dispensation available on request to developing countries when they become Members.

Article 20 is made up of three paragraphs that explain the derogations from the general rules available to developing country members who were not a party to the Agreement when it was first drawn up in 1979, as well as the obligations placed on developed countries to provide technical assistance to developing countries.

Commenting on the special and differential treatment, Rosenow and Brian explain:

Like other WTO Agreements, the WTO Customs Valuation Agreement allows developing-country Members certain concessions or "special and differential treatment" which is intended to mitigate the difficulty and cost of implementation. ${ }^{479}$

One must notice that trade revenue is one of the main concerns for the implementation of the CVA. As such, with the derogation prerogative, there is a recognition of the difficulty and possible cost of implementing the CVA.

\section{Article 20}

Article 20, paragraph 1 states that WTO developing country members who were not party to the Agreement when it was first drawn up in 1979 may delay the application of the provisions of the Agreement for a period not exceeding five years from the date of entry into force of the Agreement in those particular countries. ${ }^{480}$

\footnotetext{
${ }^{479}$ Rosenow, Sheri and O'Shea, Brian J. (2010), p.152-153

${ }^{480}$ For example, if a developing country becomes a signatory to the Agreement on 1 March 2015, the five-year delay reservation option can be applied for, and, if granted, the implementation date for that country would be 1 March 2020. Developing countries who wish to delay must notify the WTO.
} 
It is worth noting that Annex III of the Agreement allows for the possibility of a further extension to the initial five-year period. ${ }^{481}$ For the research question in this dissertation, however, the delay option is useful and should be used when possible, as it delays the onset of uncertainty and lack of predictability regarding customs valuation.

Article 20, paragraph 2 states that WTO developing country Members who were not a party to the Agreement when it was drawn up in 1979 may seek the delayed application of Article 6 (the computed value method) for a period not exceeding three years. It also allows for the delayed application of Article 1.2 (b) (iii), which covers the use of the computed value as a test value. ${ }^{482}$

As mentioned previously, due to its complexity, the computed value method is rarely, if ever, used in practice. Thus, the provision for delayed application is of no real use. The applicability of the computed value, to be used as a test value in related party transactions, is also unrealistic due to the difficulties of applying such a method.

Article 20, paragraph 3 places the obligation on developed countries to provide technical assistance for the implementation of the CVA. In this regard, both the WTO and the WCO Secretariats have been providing technical assistance. According to the WTO Secretariat:

\begin{abstract}
The WTO Secretariat has been providing technical assistance based on biennial plans. Individual Members may submit a request for technical assistance at any time and it will be met by a national activity designed according to the needs of the recipient. ${ }^{483}$
\end{abstract}

Although plenty of technical assistance has been provided over the years ${ }^{484}$, challenges continue to exist, and technical assistance requests remain a relevant item on the agenda of the WTO CCV.

\footnotetext{
${ }^{481}$ According to the WTO $24^{\text {th }}$ annual review of the CVA, no members delayed applications of this provision of the Agreement. G/VAL/W/311, November 2018.

${ }^{482}$ According to the WTO $24^{\text {th }}$ annual review of the CVA, no members delayed applications of this provision of the Agreement. G/VAL/W/311, November 2018.

${ }^{483}$ WTO (2012). Analytical Index. Customs Valuation Agreement - Article 20/Annex III (Practice). Available at: https://www.wto.org/english/res_e/publications_e/ai17_e/cusval_anniii_oth.pdf [13/01/2019].

${ }^{484}$ The WTO Biennial Technical Assistance Plan 2018-19 contained in document WT/COMTD/W/227 declares that:

15. In 2016, the Secretariat carried out 274 TA activities, in Geneva and elsewhere, and participated in 40 TA-related activities mainly organized by partner institutions. Counting eLearning and face-to-face activities, around 18,600 participants were trained during the year. LDCs continued to be a priority for the WTO TA offer. Data for both e-Learning and face-toface activities show that participants from LDCs accounted for one third of WTO TA beneficiaries in 2016. In addition, four of the 27 global activities held in Geneva were
} 


\subsection{At the meetings of 23 April and 19 November, the Committee had discussions on how best to respond to a request for technical assistance by some LDCs that were experiencing implementation challenges. ${ }^{485}$}

It is important to note that the WTO technical assistance programme started in 1997, but the WCO have been providing technical assistance to the GATT Valuation Code since the 1980s. Over the decades, the WCO has organized numerous training programmes and workshops. ${ }^{486}$

The continuous need for customs valuation technical assistance is a clear symptom of the difficulties faced by several WTO Member governments when accepting the price declared in the transaction value. The lack of parameters for accepting a multitude of low and high transaction value prices affects trade revenue and statistics, with serious repercussions for trade policies.

Annex III, paragraph 1, allows for a further extension to the initial five-year delay allowable under Article 20, paragraph 1.

Annex III, paragraph 2 addresses the reservation concerning the use of minimum values. It allows developing country members that currently use officially established minimum values for $\mathrm{CV}$ to make a limited and transitional reservation to allow themselves to continue to do so (subject to agreed terms and conditions). This reservation was reinforced by Decision 7.1 - Minimum values and imports by sole agents, sole distributors, and sole concessionaires. ${ }^{487}$

Decision 7.1 concerns the developing country reservation to retain officially established minimum values within the terms of paragraph 2 of Annex III. Where a reservation is consented to, the terms and conditions referred to in paragraph 2 of Annex III shall take full account of the development, financial, and trade needs of the developing country concerned. ${ }^{488}$

The lack of reservations concerning minimum values at the CCV is contradicted by WTO disputes. All WTO CVA disputes mention the use of minimum/reference

specifically designed for LDCs, 3 and LDC nationals represented $56 \%$ of total participants in the long-term internship programmes in Geneva.

While WCO TCCV recent technical assistance is available in documents G/VAL/8/Add.36 and G/VAL/8/Add.37.

${ }^{485}$ WTO $24^{\text {th }}$ annual review of the CVA. G/VAL/W/311, November 2018.

${ }^{486}$ Customs Administrations worldwide have benefited from customs valuation training since the 1980s, and in 2018 WCO e-learning customs valuation courses became available also for the general public through the WCO Academy: https://academy.wcoomd.org

${ }^{487}$ Adopted, $1^{\text {st }}$ meeting of WTO Valuation Committee, 12 May 1995

${ }^{488}$ According to the WTO $24^{\text {th }}$ annual review of the CVA, the are no members that made reservations to concerning minimum values, G/VAL/W/311, November 2018. 
prices/indicative prices instead of the transaction value price. ${ }^{489}$ Confronting the notifications with the disputes, it is possible to assume that there is a clear mismatch between the two. While in practice countries continue to use minimum/reference prices/indicative prices, these policies are not notified to the CCV. This dissertation submits that the disputes are only a hint of a much more complex issue in the field of valuation regarding the distrust in relation to the declared transaction value prices.

Annex III, paragraph 3 is the reversal of the sequential order of Articles 5 (deductive) and 6 (computed) methods. This paragraph allows developing countries the right to seek a reservation enabling them to refuse an importer's request to reverse the order of Articles 5 and 6 . This is on the basis that it "... may give rise to real difficulties for them." 490

Annex III, paragraph 4 of the Agreement provides developing countries with a variation (known in the customs community as super deductive) of Article 5.2 in accordance with the provisions of whether or not the importer makes such a request. The so-called super deductive method provides the flexibility to use goods that have been further processed after importation to be used as the basis for the deductive method. ${ }^{491}$

Annex III, paragraph 5 refers to the valuation management of sole agents, sole distributors, and sole concessionaires. The paragraph refers to the concern of some countries that these groups of importers negotiate and receive disproportionately low prices for the goods. It is relevant to remember that these groups are not considered to be related parties and therefore the transaction value prices should prevail in normal trade conditions. The CVA mentions a study to find appropriate solutions for the transaction value problems of these groups. However, to this date, there is no indication of any study to address the problem. This issue is also the subject of Decision 7.1.

\footnotetext{
${ }^{489}$ WTO seventeen disputes mentioning CV: DS9, DS13, DS17, DS56, DS134, DS183, DS197, DS198, DS210, DS241, DS298, DS348, DS366, DS370, DS371, DS457, and DS485.

${ }^{490}$ According to the WTO $24^{\text {th }}$ annual review of the CVA, fifty-three countries made a reservation concerning the reversal of sequential order of Articles 5 and 6, namely: Argentina, Kingdom of Bahrain, Bangladesh, Benin, Brazil, Brunei Darussalam, Burkina Faso, Cameroon, Chile, Colombia, Costa Rica, Côte d'Ivoire, Djibouti, Dominican Republic, Ecuador, Egypt, El Salvador, Gabon, Guatemala, Guyana, Haiti, Honduras, India, Indonesia, Israel, Jamaica, Kenya, Madagascar, Malawi, Malaysia, Maldives, Mali, Mexico, Morocco, Myanmar, Nicaragua, Niger, Pakistan, Panama, Peru, Philippines, Senegal, Sri Lanka, Thailand, Togo, Tunisia, Turkey, Uganda, United Arab Emirates, Uruguay, Venezuela, Zambia, and Zimbabwe. G/VAL/W/311, November 2018.

${ }^{491}$ According to the WTO $24^{\text {th }}$ annual review of the CVA, there are fifty-one country members that reserved the right to apply Article 5.2, the "super deductive", whether or not the importer requests, namely: Argentina, Kingdom of Bahrain, Bangladesh, Benin, Brazil, Brunei Darussalam, Burkina Faso, Cameroon, Chile, Colombia, Costa Rica, Côte d'Ivoire, Djibouti, Dominican Republic, Ecuador, Egypt, El Salvador, Gabon, Guatemala, Guyana, Haiti, Honduras, India, Indonesia, Israel, Jamaica, Kenya, Madagascar, Malawi, Malaysia, Maldives, Mali, Mexico, Morocco, Myanmar, Nicaragua, Niger, Nigeria, Pakistan, Panama, Peru, Philippines, Senegal, Sri Lanka, Thailand, Togo, Tunisia, Turkey, Uruguay, Venezuela, Zambia, and Zimbabwe. G/VAL/W/311, November 2018.
} 
Annex III, paragraph 6 refers to Article 17 of the CVA, which was dealt with in connection with Decision 6.1 in previous chapters of this dissertation.

Annex III, paragraph 7 is an alert that all payments made by the buyer to the seller in connection with the sale of the imported goods are included as part of the customs value. The most important part in this paragraph is that the payments made to a "third party to satisfy an obligation to the seller" should also be considered in the customs value.

\subsection{Concluding Remarks}

The CVA is binding on all WTO Members. To accommodate difficulties in implementing the CVA, developing countries have special and different treatment provisions in the Agreement. Such provisions are in Article 20 and Annex III of the CVA. The main element of Article 20 is the possibility of delaying the application of the CVA for a maximum period of five years from the date of entry into force of the Agreement. ${ }^{492}$ Other special and different provisions in Article 20 relate to the delayed application of methods to calculate the customs value and to technical assistance.

The main provision of Annex III is the possibility for countries to continue to use minimum values. ${ }^{493}$ Other provisions relate to the delayed application of Article 6 (the computed value method) for a period not exceeding three years and the delayed application of Article 1.2 (b) (iii), which covers the use of the computed value as a test value. Perhaps the most relevant point in Annex III is the inclusion of payments made to a "third party to satisfy an obligation to the seller" as part of the customs value.

Although useful, the delays and provisions on certain methods do not solve the real valuation problems of the lack of comparables, mutual trust, uncertainty in the setting of rules, lack of application uniformity, and others that put at risk any planning for trade revenue purposes.

\footnotetext{
${ }^{492}$ For example, if a developing country becomes a signatory to the Agreement on 1 March 2020, the five-year delay reservation option can be requested and, if granted, the implementation date for that country would be 1 March 2025.

${ }^{493}$ Developing countries that currently value goods on the basis of officially established minimum values may seek a further reservation to retain such values on a specific limited and transitional basis.
} 


\section{Customs Valuation Issues: Doha and the TFA}

At the Doha WTO Ministerial Conference in 2001, WTO Members decided to raise several concerns about the implementation of several WTO Agreements. ${ }^{494}$ The objective of this chapter is to present and discuss these concerns.

\subsection{Doha Implementation Decision Paragraph 8 - Exchange of Information}

The CV concerns raised by the Doha implementation decision are in paragraphs 8.1, 8.2, and 8.3.

One group of concerns, expressed in paragraphs 8.1 and 8.2, refers to the five-year transitional period provided in Article 20.1 of the CVA and to waive obligations imposed on Members in accordance with Article IX.3 of the WTO Agreement. Some members require additional time to shift from domestic price valuation controls to the transaction method control. The reason for such a request mainly concerns trade revenue.

However, this dissertation submits that, although the request is necessary, regardless of the extra time, some countries will continue to face difficulties in getting away from domestic price controls. This is mainly because of the numerous challenges when considering declared transaction value prices.

Commenting on the challenges to implement the CVA, Rosenow and Brian register:

Thus, in the absence of this kind of customs modernization, a country may nominally adopt the WTO valuation rules, but to protect revenue collections, apply practices that are inconsistent with the terms or purposes of the Agreement, such as aggressive use of price lists and valuation databases, frequent rejection of importer 's declared values and resort to the fall back method of valuation, etc. ${ }^{495}$

It is submitted that, over the years, the implementation challenges for customs valuation will continue to exist, as these challenges are inherent to assessing the value of goods and are not simple customs modernization challenges. Customs modernization reforms mitigate the problem, but the evolving nature of economic value, currently shifting towards intangibles, and services; the psycho-emotional aspect of value, which influences the perception of value; and the growing influence of

\footnotetext{
${ }^{494}$ The Fourth WTO Ministerial Conference was held in Doha, Qatar from 9 to 14 November 2001. The concerns related to the CVA are in paragraph 8 of the WTO document WT/MIN (01)/17.

${ }^{495}$ Rosenow, Sheri and O'Shea, Brian J. (2010), p.152-153
} 
related parties' transactions are not technicalities. The main challenges that customs valuation faces are part of the economical and psychological elements of valuation, which are not addressed by special and different treatment provisions for delay or for technical assistance. In addition, these core challenges are not restricted or limited to particular countries, but they affect all countries that apply the WTO CVA rules.

Another Doha Implementation Decision concern, expressed in paragraph 8.3, is about the need for export countries to provide collaboration and assistance for importing countries that have doubts about the declared values by importers. In other words, several importing countries have complained about the lack of collaboration from exporting countries on providing export valuation information.

It is a basic question of cooperation in the exchange of information about the declared export value and the trader's legitimacy in the export country. In this regard, WTO member countries are basically expressing their concerns about tax evasion and fraud. However, after years of discussions about paragraph 8.3, almost no progress has been made in the exchange of information. ${ }^{496}$

The conclusion is that it is difficult to achieve cooperation between WTO Members to exchange export values to cross check with the declared values of imports and to minimize gaps in statistics, to combat fraud, and to provide more certainty in terms of trade revenue. The refusal, based on several arguments from secrecy to technical incapacity, make the WTO CVA set of rules based on the transaction value result in unreliable data.

There are rare exceptions to collaborative transparency in export values, but they are the result of bilateral or regional alliances and not a result of any WTO obligation. There is no multilateral willingness to increase transparency in the field of declared values for export, which puts trade revenue, statistics and policies that are based on goods and services valuation numbers at risk.

\subsection{WTO TFA - Customs Valuation Issues}

The WTO Trade Facilitation Agreement (TFA) is the main outcome from the Doha Round. ${ }^{497}$ The TFA was agreed at the Bali Ministerial Conference in December 2013

\footnotetext{
496 At a request made by the WTO CCV, the WCO TCCV conducted discussions and produced a Guide to the Exchange of Customs Valuation Information and Guidelines on the development and use of a national database as a risk assessment tool. Unfortunately, for the purposes of this work, the guide that came was produced did not provide any innovative solution to speed the exchange of information. 497 The Doha Round is the latest round of trade negotiations among the WTO membership. It was officially launched at the WTO's Fourth Ministerial Conference in Doha, Qatar, in November 2001. The Doha Ministerial Declaration provided the mandate for the negotiations, including on agriculture, services and an intellectual property topic, which began earlier. The Round is also known semi-
} 
and entered into force on 22 February 2017, when two-thirds of the 164 WTO members ratified it. ${ }^{498}$

Customs valuation was among the topics included in the WTO TFA. It appears in three TFA Articles: a) Article 1 which refers to publication and availability of information; b) Article 3 which deals with advance rulings; and c) Article 10 which is about formalities connected with importation, exportation, and transit. ${ }^{499}$

WTO TFA, Article 1, states that Members should publish the rules for customs valuation in a non-discriminatory and easily accessible manner to enable governments, traders, and other interested parties to become acquainted with them.

Article 1.1(d) reinforces Article X (Publication and Administration of Trade Regulations) of GATT 1994 and does not innovate from what should normally be done by Members. Publishing information is a general obligation.

Article 3 is about advance rulings which are written decisions provided by the authorities of the country of importation prior to the importation to clarify procedures and provide predictability to the importer.

According to the TFA, Article 3.9(a)(i)(ii), countries are obliged to provide advance rulings for classification and origin. However, according to Article 3.9(b)(i) for customs valuation, the provision is only encouraged. Thus, members are not obliged to provide customs valuation advance rulings.

In addition, TFA Article 3.9(b)(i) explains that the scope of advance rulings for customs valuation is about the method or criteria. Thus, logically, the ruling does not address the value per se. Regarding this matter, it is important to consider that advance rulings in the context of the TFA are rather different from those from the BDV.

While in the BDV, the advance ruling was directed to determine the value, in the WTO TFA the ruling is related to the methodology to be used to assess the value. Under the BDV valuation rules, advance rulings for importers were binding for extended periods of time and the practice was to focus on the value and have rulings that might say "uplift invoice price by $4 \%, 10 \%$ or accept invoice price of USD1,00 per Kg". The BDV rulings are considered to infringe the WTO CVA set of rules for fixing a value. Under the WTO CVA set of rules, particularly the transaction value

officially as the Doha Development Agenda as a fundamental objective is to improve the trading prospects of developing countries.

498 To date, 140 WTO Members have domestically ratified a Protocol of Amendment and notified the WTO of their acceptance of this Protocol. The TFA forms now part of the WTO Agreement. Trade Facilitation Agreement Facility available at: https://www.tfafacility.org [accessed 13 January 2019]. 499 The WTO TFA is in document WT/L/931, 15 July 2014. Available at:

https://www.tfafacility.org/trade-facilitation-agreement-facility [accessed 13 January 2019] 
methodology, values cannot be fixed nor determined in advance, as they may vary for each transaction.

For this dissertation the TFA outcome on advance rulings for customs valuation represents a weak incentive for WTO members to provide methodological information. As such, it does not increase certainty in international trade.

Article 10 deals with formalities connected with importation, exportation, and transit. It prohibits members from requiring valuation information in pre-shipment inspections. ${ }^{500}$ Notice that this is a provision that only affects the group of WTO members that use PSI. ${ }^{501}$

The TFA provision prohibits the valuation checks in the exporting country, but it continues to allow PSI to provide their services in other jurisdictions. Therefore, for instance, PSI relocate their valuation checks to post-shipment or destination. In other words, PSI companies can perform post-shipment or destination valuation checks. However, PSI companies should no longer check invoices and prices in the export country. The customs valuation provisions that entered into force with the TFA are disappointing, as they do not address relevant aspects of the CVA.

A final comment about customs valuation in the WTO TFA is about the lack of willingness to exchange valuation information. Here, it is worth registering that, during the negotiations, there was much discussion about automatic provisions for the exchange of customs valuation information in Article 12. Useful bulk data exchange and not individual, time consuming, case-by-case, exchange. However, the final text of Article of 12 continued to rule the exchange under the 1994 provisions.

Article $12-$ Customs Cooperation
$2 \quad$ Exchange of Information
$2.1 \quad$ Upon request and subject to the provisions of this Article, Members
shall exchange the information set out in subparagraphs $6.1(b)$ and/or $(c)$ for
the purpose of verifying an import or export declaration in identified cases
where there are reasonable grounds to doubt the truth or accuracy of the
declaration.

\footnotetext{
${ }^{500}$ Since 1999, the PSI Agreement has been monitored by the Committee on Customs Valuation, which has remained as a standing agenda item on PSI.

501 The WTO Secretariat noted that six countries were reported as having PSI programmes for revenue protection, namely: Central African Rep. (BIVAC), Chad (BIVAC), Dem. Rep. Congo (BIVAC), Iran (BIVAC, Cotecna, OMIC, SGS), Somalia (Intertek, BIVAC) and Uzbekistan(CUI, Intertek, OMIC, SGS), and nine others as having customs support services including destination inspection and/or selective PSI, namely Burkina Faso (Cotecna); Cameroon(SGS); Congo(Cotecna), Haiti(SGS), Liberia(BIVAC), Mali(BIVAC), Mozambique(Intertek), Senegal(Cotecna), and Togo(Cotecna). November 2017, G/VAL/W/63/Rev.21 [accessed 14 January 2019]
} 
The restrictiveness of Article 12 of the TFA has been the norm for customs valuation since the GATT Tokyo Round Code. It was always on a case-by-case basis and based on reasonable grounds. Article 12 of the WTO TFA repeats the language of WTO CCV Decision 6.1 "where there are reasonable grounds" and does not innovate or improve the cooperation that is expected from the Doha Ministerial Decision according to paragraph 8.3. In summary, it is an antiquated response in view of technological advances and integration, database analytics and distributed ledgers technological developments in trade systems. This is one more example of the same antiquated refusal of WTO members to exchange valuation trade data.

In conclusion, the final text of the WTO TFA kept customs valuation measures for transparency, provided encouragement for advance rulings, and prohibited valuation checks in export countries by PSI companies. As the TFA negotiations concluded, exchange of information was cut out from the text.

\subsection{Concluding Remarks}

At the WTO Ministerial Conference in Doha 2001, WTO Members raised concerns about the application of the CVA. Developing-country Members requested further extension periods and underlined the importance of strengthening cooperation between the customs administrations of Members in the prevention of customs fraud.

A main point coming from the 2001 Doha Ministerial Conference was the request for the exporting Member to offer better cooperation and assistance, including furnishing information on the export value of the good, according to Paragraph 8.3 of the Doha Implementation Decision. After years of discussions on Paragraph 8.3, almost no practical progress can be accounted for in relation to the exchange of information.

The WTO TFA brought to light relevant issues for customs valuation, namely: (a) Article 1 reinforces the obligation for the publication and availability of information, including customs valuation; (b) Article 3 encourages countries to adopt advance rulings procedures for customs valuation; and (c) Article 10 prohibits countries from requiring pre-shipment customs valuation information.

During the TFA negotiations, there were discussions on Article 12 about the automatic exchange of valuation information. However, the final outcome of the discussions was disappointing as it merely repeated the wording of Decision 6.1 from 1994. The exchange of information remained upon request, on a case-by-case basis and only where there are reasonable grounds to doubt the truth or accuracy of the declaration. The conclusion was that cooperation between WTO Members to exchange information, and in particular export valuation information, is difficult to achieve. 
This chapter discussed not only special and different treatment provisions, but also several implementation challenges to the CVA, including those coming from the Doha Implementation Decision and others from the WTO TFA.

A final thought to be addressed here is to consider the possibility that the challenges to implement the CVA are more of social-economic nature and that they cannot be solved by merely providing technical assistance and delaying the implementation of procedures. The evolving nature of value, currently shifting towards intangibles and services; the psychological aspect of value; and the growing influence of related parties' transactions are representative of situations that are not mere technicalities. These challenges are part of the transformative economic order. 


\section{Final Conclusions}

Globalization progress over the past decades has been impressive. International trade expanded with the support of the GATT and WTO rules-based multilateral system that seeks to provide transparency, stability and predictability in terms of market access and other trading issues. At the heart of globalization are customs tariff and WTO agreements, negotiated and signed by nations.

One of the main goals of the global trading system is to reduce and create ceilings for customs tariff. To make the process easier, the GATT and the WTO promote the conversion of NAV tariff types, such as specific, compound, mixed, and technical, into a unique type, the AV format. The fundamental argument in favour of the AV tariff is the resulting simplification in monitoring and negotiating tariff preferences for goods.

Trade plays a crucial role in achieving the United Nations 2030 Sustainable Development Goals (SDGs), bringing development in areas such as poverty reduction, health, education and the environment. Indicators of social and human development improve with trade performance.

Nevertheless, significant challenges remain to be addressed in the multilateral trade system to put several economies on a more reliable and sustainable path to diminishing economic and social inequalities. The adoption of AV tariffs with the consequently use of the WTO CV rules neglects relevant aspects of the export and import market reality faced by many economies. For instance, in countries where import revenue is still heavily reliant on trade tariffs, commodity price volatility, such as the existent on energy, agricultural, metals and minerals markets, makes governments more vulnerable, with significant implications for trade stability. More recently, due to the trade war between the United States and China and the COVID-19 pandemic, countries have implemented several monetary policies that might affect the fundamental equilibrium exchange rates (FEER) and have consequences for customs valuation calculation in international trade. As such, the amount of ad valorem tariffs related to revenue will also be impacted.

Another challenging scenario to secure revenue and protect society occurs for sin goods, such as tobacco and alcohol, subject to high customs duties and expensive enforcement programs. ${ }^{502}$

\footnotetext{
502 There are 195 countries in the world today. This total comprises 193 countries that are member states of the United Nations and 2 countries that are non-member observer states: the Holy See and the State of Palestine. From the 193 countries, 39 were classified by the IMF as Fragile and Conflict-Affected States (FCS) which represents approximately $20 \%$ of the number of countries. The FCS classification indicates a weak institutional capacity to raise sufficient tax revenue.
} 
Manufactured goods, produced in GVCs, also brings challenges to AV tariffs and customs valuation. Production fragmentation, the intensive use of intangibles and producer's relationship affect prices. In a scenario in which goods are losing their inherent value to intangibles, the AV tariff type might be compromised to fulfil its function. WTO rules to assess values on individual goods transactions to apply rates in percentages in an interconnected economy is questionable.

The dissertation defends that the reality for trade and tariffs regarding revenue is not properly addressed by the theory supporting AV tariff as well as formula reductions. All these still needs to stand the test of time.

Unfortunately, the WTO does not directly address revenue-raising problems that can afflict countries. Internal fiscal policies often address these. Nevertheless, revenue mobilization, including the revenue originated from trade, is critical to secure resources to achieving trade growth and the 2030 SDGs. As such, considering the revenue aspect of tariffs, the author criticizes the GATT and WTO formulas for AV conversion that do not take revenue into consideration in a serious way. The AV use, promoted by the WTO and adopted extensively by the large majority of countries, inhibits the process of tariff "engineering" to optimize its revenue function and explore new possibilities. In times of digital economies and GVCs, trade stability and predictability is connected with revenue security. The optimal tariff is the one that supports countries.

In search for the optimal tariff it is clear that to meet fiscal needs in several countries it needs to have a minimum specific tax floor. Once defined the specific floor it is then up to consideration markets concentration, peak and off-peak periods, seasonality, liquidity, volatility and public interest among other factors.

Neo tariffs, envisaged by the author, would be diversified using NAV and AV and work in a range that could vary from a negative terrain to a positive ceiling. These neo tariffs are to be developed and tested using algorithms and serve as tools for trade and revenue policies. The use of a structured logic approach to the problem of suboptimal revenue tariffs would imply in combining different tariff types to obtain an optimal rate. Optimized national tariffs could bring positive results to long term sustainable trade.

The use of algorithms in trade tariffs optimization present considerable challenges. The first group of challenges are of a technical nature associated with the number of elements, steps and constraints. In a scale of complexity, the use of learning algorithms would represent the last phase, referred as singularity. The second group of challenges is associated with transparency, namely the predictability and explainability of the algorithms. 
To address the issue of transparency it is necessary a standard for pseudocode language, regulation and review. In this regard, the WTO could act as a standardssetting organization for national tariffs algorithms design and best practices.

Trade tariffs can and should evolve considering a combination of different tariff types like in the case of Peru - Agricultural Products (2015) or even mimic more dynamic structures from other markets, such as electricity and stock markets. These markets normally use fixed, transaction and volume factors to calculate the fees.

All these factors have their importance to construct the final rate and should be promoted by the WTO and other international organizations to assist countries in designing their optimal tariffs. The more experimentation on developing tariffs, the more likely algorithms would be able to provide better tariff solutions.

The author criticizes the current WTO CVA set of rules that must be used for the application of AV tariffs. In respect to $\mathrm{CV}$, the dissertation discusses the theory of value, seeking to explain the evolution over time of the understanding of how value is created. In that sense, the dissertation discussed the ideas of authors such as Aristotle, Adam Smith, John Maynard Keynes, and Jean Baudrillard on the theory of value, showing how problematic it can be to determine the source of value creation. Value is the cornerstone of any valuation system and is constantly evolving. As manufacturing and technology advances, so do the considerations about the value of goods and services.

Reviewing the theory of value through history, it is possible to understand that the creation of value derives, among others, from labour, innovation, and sentiments. It is impossible to determine the amount of value contributed by each of these factors when assessing the price of a final product. Note that international trade is profoundly affected by the questions surrounding the nature of value, as trade challenges domestic production in many ways.

The WTO CVA works mainly with the transaction value (Article 1) and provides for five alternate methods that must be used in a sequential manner: (Article 2) the transaction value of identical goods; (Article 3) the transaction value of similar goods; (Article 5) the deductive value method; (Article 6) the computed value method; and (Article 7) the fallback option. This dissertation considered that several rules for the application of these methods are complex, dubious, and time consuming. After decades, even supposedly relative basic concepts, such as sale for export, have not yet been harmonized.

The WTO CVA's set of rules is based on free market assumptions that value creation is reflected in transaction prices. However, value for the purposes of international trade may be determined by taking into consideration a series of elements other than 
free market assumptions. As such, the transaction value method originated in domestic assumptions represents a risk when transposed to different international scenarios. Countries are exposed to unfair competition arising from imperfect market structures, undervaluation, fraud or otherwise.

The transaction value method is, by nature, volatile, resulting in possibly arriving at different values for every shipment without any regard for revenue certainty, predictability, or security. Every trade transaction, occurring sometimes at the same time and with the same parties, is to be considered a new transaction. The system is supposed to work without any market price references or comparables. Such volatility jeopardizes the minimum requirements for valuation planning or predictability.

Trade transactions where there is a relationship between the importer and the exporter are the worst scenarios in terms of complexity, as they sometimes require the examination of whether the relationship influenced the price.

Article 8 on adjustments to the transaction value reveals great complexity as it demands the control of intangibles and services. Royalties, in particular, pose many infinite situations. Other Articles also pose challenges to the valuation of goods, such as Article 13, dealing with guarantees, and Article 15, limiting the definition of related parties. There is not much room to modernize the Articles and the system is rigid.

The WTO CCV and the WCO TCCV are the institutions responsible for administering the CVA. The WTO CCV issues Decisions to guide the interpretation, administration, and working procedures of the CVA. Although the WCO TCCV produce international instruments giving guidance towards achieving uniformity in the interpretation and application of the CVA, they are not considered international law and have never been used by the WTO dispute settlement system. To date, no panel or Appellate Body has ever referred to an instrument of the TCCV.

Several WTO Members do not follow the obligations on notification and transparency from Article 22, which creates difficulties in following the obligations for the customs valuation in different jurisdictions.

Resolving trade disputes is one of the core activities of the WTO, and the organization has a dispute settlement mechanism. Since its establishment in 1995, 593 trade disputes have been brought for settlement to the dispute settlement system. Of these, there are eighteen disputes regarding the WTO CVA. ${ }^{503}$

\footnotetext{
${ }^{503}$ From these, it is worth mentioning Thailand - Cigarettes (Philippines) (2011) and Peru Agricultural Products (2015). The first (2011) examines several aspects of the CVA, showing how difficult it can be to apply AV tariffs and customs valuation rules for sensitive high taxed goods, such as cigarettes. The second Peru - Agricultural Products (2015) is relevant as it opens the possibility of using Price Range Systems (PRS) or Price Band Systems (PBS) mechanisms, as long as the total tariff remains lower than the bound AV tariff.
} 
Most of these disputes refer to the use of minimum/reference/indicative prices for $\mathrm{CV}$, instead of the transaction value price. The number of disputes dealing with minimum/reference prices/indicative prices reveals the practice of WTO Member countries to resist accepting the transaction value. The dissertation argues that one of the main reasons for using minimum/reference prices/indicative prices is to keep the revenue tariff function. Without the mechanism, this tariff function would be at risk.

After 10 December 2019, the WTO Appellate Body ceased to function as the US administration blocked the replacement of judges and the body is no longer able to have the minimum quorum to decide on appeals in trade disputes between WTO Members. To date, it is uncertain when the Appellate Body will resume its functions again.

Regarding the analysis of the WTO CVA special and different treatment provisions for developing countries, the dissertation showed that most of these provisions are related to delaying the application of certain provisions in the text and to provide technical assistance. Although useful, the dissertation argues that delays do not solve the real questions such as the lack of comparables, mutual trust, uncertainty in the setting of rules, and lack of uniformity.

The WTO TFA agreed at the Bali Ministerial Conference in December 2013, and that entered into force on 22 February 2017, addresses customs valuation issues. Customs valuation appears in three TFA Articles: a) Article 1 which refers to publication and availability of information; b) Article 3 which deals with advance rulings; and c) Article 10 which is about formalities connected with importation, exportation, and transit.

Although it is relevant to address customs valuation in the TFA, none of the new Articles solve fundamental questions. In short, the TFA basically reinforces the publication of information, encourages customs valuation advance rulings, and phases out PSI. Summing up, there is no solution for old problems.

A final comment about customs valuation in the WTO TFA addresses the lack of willingness to exchange multilateral information on $\mathrm{CV}$. It is worth registering that during the negotiations there was much discussion about automatic provisions for the exchange of CV information in Article 12, specifically, useful bulk data exchange and not individual, time-consuming, case-by-case, exchange. However, in the final text of Article 12, case-by-case exchange prevailed under the 1994 provisions.

A main conclusion from the dissertation is that the AV tariff advocacy, together with the WTO CVA set of rules, is complex and jeopardizes countries' trade revenue. The use of AV tariffs and application of CV set of rules are resisted daily in international 
trade and neither enforcement nor technical assistance are solutions to these challenges.

As a result, the dissertation contends that it is time to revisit the tariff theory and open Pandora box to find appropriate solutions to retain its functions. AV tariffs and the WTO CVA set of rules need to be challenged in the current economy. WTO tariff schedules and particularly national tariff lists need an adaptive structure to a changing world. The use of different tariff types minimizes revenue risks and helps to strengthen the tool's effectiveness.

In conclusion, tariffs should be kept open for algorithm engineering and CV rules need to adjust for bulk transactions and multilateral information exchange. Excessive tariff regulation and oversimplification are detrimental to the multilateral system. The free market assumptions and complexity of WTO CV are prejudicial to the trade system. Trade evolution is not linear; there is no right or wrong and it will continue to thrive as a human necessity. 


\section{Summary}

\section{Introduction: Why Study Ad Valorem Tariffs and Customs Valuation?}

Revenue is essential to providing public goods and services, increasing equity and helping manage macroeconomic stability. It is a central component of financing sustainable development goals (SDGs) among the United Nations (UN). In this context, there is a strengthened awareness of the link between taxation and international trade.

Assuming a scenario of global fiscal debt, low inflation and slow economic growth, this dissertation investigates the adoption of AV tariffs in association with the WTO rules on customs valuation for countries' revenue needs. It questions beliefs about sustainable international trade liberalization based on the perspective of converting all types of tariffs into AV tarriffs, to be applied in combination with customs valuation rules. In this regard, the dissertation takes a critical view of the WTO policies relevant for converting NAV into AV tariffs and setting customs valuation rules based on free market assumptions.

Goods with high import tariffs, countries lacking the capacity to check declared import prices, unknown export prices, regulated markets, and an increasing importance of services in the value of traded goods are some elements that must be considered when debating the pros and cons of AV tariffs.

The social and economic relevance of the revenue function of tariffs is thus the understanding that AV tariffs can result in risks for countries in need of the revenue resources from tariffs. Revenue instability and uncertainty result in undesired outcomes for sustainable economic and social policies, as well as for trade liberalization.

\section{Globalization and Taxation}

Chapter 1 presented a concise overview of economic globalization and discussed the taxation challenges associated with it.

Section 1.1 it showed the link between economic globalization, the Global Value Chains (GVC) business model and trade tariffs. Decisions to outsource production are also based on tax strategies. GVCs force worldwide tax systems to be redesigned, as none of the existing systems are robust enough to operate within these sophisticated relationships. 
The volatility of commodity prices used in most GVCs business models is presented in Section 1.2. The booms and busts of commodity prices compromise the capacity governments have for long term planning in relation to trade revenue. The uncertainty caused by fluctuations in commodities such as oil has adverse and destabilizing fiscal implications.

The UN experience with commodity agreements and the GATT Article $\mathrm{XX}(\mathrm{h})$ was discussed in Section 1.3. Commodity agreements were negotiated in UNCTAD. Although a few were successful during a certain period, they all failed in the end. Price controls do not work, and price volatility is detrimental to fiscal systems, causing revenue fragility. The dissertation assumes that AV tariffs and customs valuation rules aggravate the fiscal instability associated with the volatility of commodity prices.

The attempt to replace trade revenue with domestic revenue was discussed in Section 1.4. There is a risk of shifting from customs duties or other ODC collected at the border to internal taxes, simply because several national and subnational tax agencies lack the necessary tools to collect internal taxes. Unfortunately, several national tax administrations have significant weaknesses in terms of taxpayer information and are not prepared to receive trader's registers or other relevant information regarding risk.

The hard reality is that, despite countries' tariff reduction commitments, revenue losses represent a challenge for governments worldwide. Therefore, trade liberalization reforms need to consider fiscal equilibrium.

Section 1.5 presents a case analysis for the WCO Revenue Package showing the link between imports and tax revenue. The WCO RP intention is to make international materials and tools more readily available for countries to utilize and improve trade revenue collection.

Another example of a cause for concern regarding fiscal revenue is presented in Section 1.6 with the OECD BEPS Package. Tax evasion is a pressing issue on the agenda of most governments. The text addressed several of the BEPS limitations related to customs valuation because of the different institutions, systems and methodology.

Lastly, Section 1.7 discussed the importance of the UN Addis Ababa Action Agenda (AAAA) for the mobilization of domestic resources for sustainable development, including achieving the Sustainable Development Goals (SDGs). Considering that revenue resources continue to be a challenge in many countries, the work defends the importance of trade tariffs for the AAAA in securing revenue resources.

\section{Import Tariffs}


Chapter 2 provided the background necessary for a full understanding of the main aspects of import tariffs.

Section 2.1 examined the preference in GATT and WTO law for tariffs over non-tariff trade barriers. The main reason is that tariffs are more transparent and predictable, while the non-tariff barriers can be disguised in many ways and are difficult to evaluate.

Section 2.2 focused on ordinary customs duties. It presented the tariff functions of revenue and protection as being dynamic rather than static and the need to have broader considerations of concrete examples. Tariffs are legitimate instruments to generate fiscal revenue. The ease of collecting tariffs, the low cost of a taxation system based on tariffs and the challenge of targeting the people who can pay taxes in LDCs and developing countries are some of the factors that contribute to using trade tariffs as an important revenue source.

The GATT tariff negotiations were discussed in Section 2.3 where special consideration was given to the lack of consideration for fiscal matters during the negotiation rounds. It presented the different modalities and "techniques" for tariff reduction, offering a critique of the lack of attention of GATT Contracting Parties with respect to revenue. GATT rounds may have overlooked the capacity of LDCs and developing member countries to compensate for revenue losses. Caution should be employed in WTO tariff negotiations with regard to revenue tariffs, as it is necessary to evaluate whether tariff negotiations contribute to fostering trade and/or dismantling fiscal revenue. LDCs and developing countries should be aware that countries with a far better fiscal infrastructure face an array of challenges when shifting tariff revenue away from GST, VAT and other types of domestic taxes.

The different tariff types, namely: a) AV; b) specific; c) compound; d) mixed; e) technical; and f) based on quotas was presented in Section 2.4. Each of these types has advantages and disadvantages. The combination of different types minimizes risks by using a diversification approach. The Section introduced the need for neo tariffs which can be implemented in international trade using other tariff structures as models, such as in the electricity market. Big data and new data analytical technologies make it possible for tariff design, using structured and unstructured data to "engineer" the optimal tariff.

Section 2.5 discusses the use of algorithms in trade tariffs optimization. The use of algorithms in trade tariffs optimization present considerable challenges. The first group of challenges are of a technical nature associated with the number of elements, steps and constraints. In a scale of complexity, the use of learning algorithms would represent the last phase, referred as singularity. The second group of challenges is associated with transparency, namely the predictability and explainability of the algorithms. All these factors have their importance to construct the final rate and should be promoted by the WTO and other international organizations to assist 
countries in designing their optimal tariffs. Optimized national tariffs could bring positive results to long term sustainable trade.

Section 2.6 questions the main reasons stated by the WTO Secretariat for the conversion of different tariff types into AV: (1) transparency; (2) penalization of cheaper products, and (3) the fact that other tariffs change the level of protection when prices change. The transparency assumption is questionable since it requires a customs value. Customs values are not transparent. The argument on penalization is minimized for standard commodities and raw materials. Lastly the argument of the level of protection assumes free market conditions, which are not always a reality.

The conversion of NAV for AV was detailed in Section 2.7. Although AV tariffs are the dominant type of tariffs in international trade, some countries continue to use NAV. In the agriculture sector, developed countries are the greatest users of NAV tariffs: Switzerland (approximately 83\%), Norway (63\%), European Communities (45\%), United States (43\%), Canada (26\%), and Iceland (25\%). Concerning the effort to convert NAV to the AV equivalent, WTO members agreed on the conversion in the Negotiating Group on Non-Agricultural Market Access (NAMA) negotiations.

Although one of the WTO conversion methods considered the customs revenue, this was not applied mainly because of the lack of available data on revenue. The preferred method is based on monetary values of duty per unit of imports divided by the import unit value. The dissertation argues against using such a method.

Section 2.8 discussed the efforts and risks of converting non-tariff barriers (NTBs) into AV equivalents. The so-called tariffication process. Some tariff principles that were in existence before the GATT were explored in Section 2.9. The use of tariff for revenue purposes, and the necessity to keep revenue at reasonable levels, implied the need to combine rates with volumes.

Section 2.10 analysed the national tariff and WTO Member schedules. National tariff rates cannot be higher than those negotiated during the GATT rounds. Article II of the GATT 1994 is the core provision dealing with the WTO schedules of concessions for trade in goods. It requires Members to limit tariffs along with other duties and charges (ODCs) to no more than what is set out in the schedule. Therefore, countries are precluded from imposing tariffs and ODCs more than what was negotiated. Although, according to GATT 1994, Article XXVIII tariffs can be renegotiated, once the tariffs are set, the schedules remain mostly static. The opposition to the renegotiation of tariffs is clear in WTO documents. The argument for this addresses the rigidity of tariff schedules and that GATT Art XXVIII is too limited and rarely used. This dissertation defended the point that, if it is not more than the bound rate, any type of tariff can be used, and countries should develop frameworks to optimize tariffs by using different types when necessary. A national tariff should be tailor made to each country's unique requirements, which would allow it to be more responsive to changes in the markets. 
Tariff assessment was dealt with in Section 2.11. A tariff assessment is based on the following criteria: a) customs classification; b) customs valuation; and c) country of origin, where liability depends upon all three of these criteria.

\section{Theory of Value and Customs Valuation}

Chapter 3 addressed the theory of value and customs valuation. The conversion of different tariff types to AV tariffs makes it necessary for WTO Members to determine the value of imported goods in accordance with the CVA. The chapter provided a theoretical background to understand the complexity of attempting to value goods according to the WTO CVA set of rules.

Section 3.1 introduced the studies of several scholars. Aristotle, Thomas Aquinas, Adam Smith, David Ricardo, John Stuart Mill, Karl Marx, John Maynard Keynes, Gérard Debreu, Jean Baudrillard, and many others show the importance of the theory of value for a better understanding of the complexities of valuation. The discussion on the elements that form value is constantly changing. Valuation can be an abstract process that depends on people's opinions. The dissertation asserted that the prices of internationally traded goods suffer, among other things, from the effects of psychological conditions that cannot be clearly understood or quantified. Consequently, customs valuation, as a derivative of the theory of value, is directly influenced by the trader's subjectivity and beliefs.

The history of customs valuation was discussed in detail in Section 3.2. From the Roman Empire to nowadays, customs valuation has always been a challenging topic.

The roaring 1920s for trade tariffs was studied in Section 3.3. After World War I and during the years of the Great Depression in the 1930s, many countries tried to protect their economies by implementing different barriers such as customs duties, quantitative restrictions and exchange controls.

Considering the overall use of tariffs, the need for international rules on customs valuation was on the agenda of the League of Nations Economic Conferences in 1927 and 1930. Unfortunately, the League of Nations stopped the examination of customs valuation and other trade related issues due to international instability and the beginning of World War II. After the war, the UN replaced the League, and the topic was taken up in the GATT and the Havana Charter for the ITO creation signed in 1948.This was explored in Section 3.4.

Section 3.5 discussed the ITO and GATT. Article 35 text of the Havana Charter is almost identical to the wording used in GATT Article VII. To put it in another way, the GATT 1947 includes elements of the Havana Charter text, but it does not include the entire Charter. Regarding customs valuation, both are almost identical, putting 
forward the concept of "actual value" to serve as the basis for duties on imported goods. In some respects, the Charter is more advanced than the GATT.

GATT Article VII, that regulates customs valuation, is the subject of Section 3.6. According to Article VII of the GATT 1947, the customs valuation principles were intended to value all products subject to duties or other charges or restrictions on importation and exportation based upon or regulated in any manner by value. The actual value or the "just price" is the central principle on which the valuation system is intended to operate. Countries applied the GATT Article VII actual value or "just price" concept using three different systems: a) prices on the domestic market of the exporting country; b) prices negotiated by the parties; and c) prices on the domestic import market.

The discussions held by the Committee of European Economic Co-operation (CEEC), European Customs Study Group (ECSG) on GATT Article VII was the subject of discussion in Section 3.7. The work of the ECUSG was incorporated into the Convention on the Valuation of Goods for Customs Purposes, also known as the Brussels Definition of Value Convention (BDV).

\section{The GATT Valuation Code and the WTO CVA}

Chapter 4 discussed the GATT and later WTO CV system in detail. The custom valuation set of rules opted for a methodology that emphasizes "transaction value" under "competitive conditions", which makes it difficult to find market comparables.

The GATT Kennedy Round and the ASP valuation method was examined in Section 4.1. The Round pioneered a system of linear across-the-board cuts of a certain percentage on all tariffs of participating countries. The Kennedy Round is where the discussions for a customs valuation agreement started. At the time, the US used the ASP valuation system which was causing difficulties for European exporters of chemical products. The assassination of President Kennedy contributed to the round being terminated without concluding the discussions on this topic.

Section 4.2 explained how the discussions on customs valuation evolved during 1972 1973. The US wanted more access to the European market and Europe wanted to sell chemicals to the US without having to deal with the price controls from the ASP valuation system. In 1971 the GATT Secretariat suggested to its Contracting Parties to harmonize the customs valuation methodology with the adoption of the BDV Convention. However, the US opposed such path and preferred the adoption of a new valuation system based on "transaction value". 
The GATT Tokyo round from 1973 to 1979 marked the adoption of a common international customs valuation system that would be more widely accepted and result in a more uniform and positive valuation basis, discussed in Section 4.3. In summary, the Agreement on the Implementation of Article VII of the GATT, known as the GATT Valuation Code, was adopted in the Tokyo Round. It aligned with the US objectives and established a so-called "positive" system of customs valuation based on the "price actually paid or payable" for imported goods.

The GATT Uruguay round from 1986 to 1994 was the subject of Section 4.4. For customs valuation, the purpose of the Uruguay Round was to improve, clarify or expand the acceptance of the Valuation Code. Countries were concerned about false invoicing and government revenue. The response from the negotiations led to reinforce the powers of Article 17, reaffirming the legal powers of customs administrations to question the importer's declared value. WTO Decision Regarding Cases Where Customs Administrations Have Reasons to Doubt the Truth or Accuracy of the Declared Value is the document that supports such a reinforcement of customs legal powers.

Section 4.5 discusses the creation of the WTO and its consequences for customs valuation. The WTO was created in 1994, at the end of the Uruguay Round from 1986 to 1994 , forcing all Members to respect the binding trade contracts and keep their trade policies in accordance with what was negotiated, including the customs valuation set of rules.

\section{WTO Customs Valuation Agreement (CVA)}

Chapter 5 provided a thorough analysis of the WTO CVA Part I, arguing a lack of proper consideration for trade revenue in customs valuation and AV tariffs. It presented the main aspects of the CVA, using the interpretative notes from Annex I, the WTO panel and Appellate Body interpretations, the WCO TCCV instruments, and scholars' materials.

Section 5.1 explained that the WTO CVA prevails over GATT Article VII.

The interpretation in accordance with the general rules of treaty interpretation set out in Article 31 of the Vienna Convention on the Law of Treaties was discussed in Section 5.2.

Section 5.3 discussed the WTO CVA interpretation and legal status of the WCO TCCV instruments. These international instruments are meant to achieve uniformity in the interpretation and application of the CVA; however, they have never been used by 
the WTO DSB and their national force depends on the way they are internalized. Therefore, the goal of uniformity in the interpretation is not achieved.

In Section 5.4 the dissertation proceeded to examine the WTO CVA Part I - Rules on Customs Valuation, showing in several articles how complex, dubious and time consuming the determination of the customs value can be. The WTO CVA works mainly with the transaction value (Article 1) and presents five alternate methods that must be used in a sequential manner: (Article 2) the transaction value of identical goods; (Article 3) the transaction value of similar goods; (Article 5) the deductive value method; (Article 6) the computed value method; and (Article 7) the fallback option. The transaction value method is, by nature, volatile and possibly results in arriving at different values for every shipment without any regard for certainty, predictability or security. The other methods are used less and present implementation challenges to customs administrations. The Section provided examples of the complexities, uncertainty and fragilities of the WTO CVA.

\section{WTO CVA Part II - Administration, Consultations and Dispute Settlement}

Chapter 6 commented on the WTO CVA, specifically Part II. It addressed the administration, consultations and dispute settlement provisions of the agreement of the WTO CVA. The administrative bodies, namely the WTO CCV and the WCO TCCV, are established in Article 18. The procedures for consultations and dispute settlement are described in Article 19. This chapter focused on the WTO dispute settlement mechanism, presenting the rules and all the disputes related to customs valuation in chronological order. The key issues of each dispute were highlighted with emphasis on trade revenue issues.

\section{WTO CVA Part III - Special and Different Treatment}

Chapter 7 was dedicated to the WTO CVA Part III, Article 20, that deals with the special and different treatment provisions. The study of Article 20 was combined with Annex III of the CVA that describes the special dispensation available on request to developing countries when they become Members. The implementation delays and provisions on certain methods do not solve the real valuation problems of the lack of comparables, mutual trust, uncertainty in the setting of rules, lack of application uniformity, and others that put any planning for trade revenue purposes at risk.

\section{Customs Valuation Issues: Doha and the TFA}

Chapter 8 discussed the main concerns raised by WTO Members with respect to the CVA during the Doha WTO Ministerial Conference in 2001. The chapter also presented the CV outcomes expressed in the TFA. 
Section 8.1 pointed out that paragraphs 8.1 and 8.2 of Doha Implementation Decision express concerns regarding the five-year transitional period provided in Article 20.1 of the CVA and obligations imposed on Members in accordance with Article IX.3 of the WTO Agreement. Another Doha Implementation Decision concern, expressed in paragraph 8.3, is about the need for export countries to provide collaboration and assistance for importing countries that have doubts about the declared values by importers.

The results for CV in the TFA agreed at the Bali Ministerial Conference in December 2013 were presented in Section 8.2. CV appears in three TFA Articles: a) Article 1 which refers to publication and availability of information; b) Article 3 which deals with advance rulings; and c) Article 10 which is about formalities connected with importation, exportation and transit. The final text of the WTO TFA kept CV measures for transparency, provided encouragement for advance rulings and prohibited valuation checks in export countries by PSI companies. When the TFA negotiations were concluded, exchange of information was cut out from the text.

\section{Conclusion}

The progress in globalization over the past decades has been impressive. One of the main goals of the global trading system is to reduce and create ceilings for tariffs. To make the process easier, the GATT and the WTO promote the conversion of NAV tariff types, such as specific, compound, mixed, and technical, into a unique type, the AV tariff format. The fundamental argument in favour of AV tariffs is the resulting simplification in monitoring and negotiating tariff preferences for goods.

Trade plays a crucial role in achieving the United Nations 2030 Sustainable Development Goals (SDGs), bringing development in areas such as poverty reduction, health, education, and the environment. Indicators of social and human development improve with trade performance.

Nevertheless, significant challenges remain to be addressed in the multilateral trade system to put several economies on a more reliable and sustainable path in relation to diminishing economic and social inequalities.

Unfortunately, the WTO does not directly address revenue-raising problems that can afflict countries. Internal fiscal policies often address this. Nevertheless, revenue mobilization, including revenue originating from trade, is critical to secure resources to achieve trade growth and the 2030 SDGs. As such, considering the revenue aspect of tariffs, the author criticizes the GATT and WTO formulas for AV conversion that do not take revenue into consideration in a serious way. The AV use, promoted by the WTO and adopted extensively by a large majority of countries, inhibits the process of tariff "engineering" to optimize its revenue function and explore new possibilities. In times of digital economies and GVCs, trade stability and predictability are connected with revenue security. The optimal tariff is the one that supports countries. 
Globalized trade requires tariff types that take market concentration, peak and off-peak periods, seasonality, volatility, and public interest into consideration, among other factors. Neo tariffs, envisaged by the author, would be diversified using NAV and AV and work within a range that could vary from a negative terrain to a positive ceiling. These neo tariffs are to be developed and tested using algorithms and could serve as tools for trade and revenue policies.

The author also criticizes the current WTO CVA set of rules that must be used for the application of AV tariffs. The WTO CVA works mainly with the transaction value (Article 1) and provides for five alternate methods that must be used in a sequential manner: (Article 2) the transaction value of identical goods; (Article 3) the transaction value of similar goods; (Article 5) the deductive value method; (Article 6) the computed value method; and (Article 7) the fallback option. This dissertation considered that several rules for the application of these methods are complex, dubious and time consuming.

The WTO CVA set of rules is based on free market assumptions that value creation is reflected in transaction prices. However, value for the purposes of international trade may be determined by taking into consideration a series of elements other than free market assumptions. As such, the transaction value method originating in domestic assumptions represents a risk when transposed to different international scenarios. Countries are exposed to unfair competition arising from undervaluation, fraud or otherwise.

Most of the WTO CV disputes refer to the use of minimum/reference/indicative prices for $\mathrm{CV}$, instead of the transaction value price. The number of disputes dealing with minimum/reference prices/indicative prices reveals the practice of WTO Member countries to resist accepting the transaction value. The dissertation argues that one of the main reasons for using minimum/reference prices/indicative prices is to keep the revenue tariff function.

As a result, the dissertation contends that it is time to revisit the tariff theory and open Pandora's box to find appropriate solutions to retain its functions. AV tariffs and the WTO CVA set of rules need to be challenged in the current economy. WTO tariff schedules and particularly national tariff lists need an adaptive structure in a changing world. The use of different tariff types minimizes revenue risks and helps to strengthen the tool effectiveness.

In conclusion, tariffs should be kept open for algorithm engineering and CV rules need to adjust for bulk transactions and multilateral information exchange. Excessive tariff regulation and oversimplification are detrimental to the multilateral system. The free market assumptions and complexity of WTO CV are prejudicial to the trade system. Trade evolution is not linear; there is no right or wrong and it will continue to thrive as a human necessity. 


\title{
Annexes
}

Annex A:

\section{Havana Charter for an ITO - Customs Valuation and Commodities}

\author{
I N D E X
}

Section E. General Commercial Provisions

Article 33 Freedom of Transit 49

Article $34 \quad$ Anti-dumping and Countervailing Duties 50

Article $35 \quad$ Valuation for Customs Purposes

Article 36 Formalities connected with Importation and Exportation 53

$\begin{array}{lll}\text { Article } 37 \quad \text { Marks of Origin } & 54\end{array}$

Article $38 \quad$ Publication and Administration of Trade Regulations 55

Article 39 Information, Statistics and Trade-Terminology 56

Section F. Special Provisions

Article 40 Emergency Action on Imports of Particular Products 57

Article $41 \quad$ Consultation 58

Article 42 Territorial Application of Chapter IV 58

Article $43 \quad$ Frontier Traffic 59

Article 44 Customs Unions and Free-Trade Areas 59

Article 45 General Exceptions to Chapter IV 61

\section{CHAPTER V - RESTRICTIVE BUSINESS PRACTICES}

Article 46 General Policy Towards Restrictive Business Practices 63

Article 47

Consultation Procedure 64

Article $48 \quad$ Investigation Procedure 64

Article 49 Studies relating to Restrictive Business Practices 65

Article 50 Obligations of Members 66

Article 51 Co-operation Remedial Arrangements 66

Article 52 Domestic Measures Against Restrictive Business

Practices 67

Article 53 Special Procedures with respect to Services 67

Article 54 Interpretation and Definition 67 
Section A. Introductory Considerations

Article 55 Difficulties Relating to Primary Commodities 69

Article 56 Primary and Related Commodities 69

Article 57 Objectives of Inter-governmental Commodity

Agreements

Section B. Inter-governmental Commodity Agreements in General

$\begin{array}{lll}\text { Article } 58 & \text { Commodity Studies } & 70\end{array}$

Article 59 Commodity Conferences 71

Article 60 General Principles Governing Commodity Agreements 71

$\begin{array}{lll}\text { Article } 61 & \text { Types of Agreements }\end{array}$

Section C. Inter-governmental Commodity Control Agreements

Article 62 Circumstances Governing the use of Commodity

Control Agreements 73

Article 63 Additional Principles Governing Commodity Control

Agreements 74

Article 64 Administration of Commodity Control Agreements 74

Article 65 Initial Term, Renewal and Review of Commodity

Control Agreements $\quad 75$

$\begin{array}{lll}\text { Article } 66 & \text { Settlement of Disputes } & 75\end{array}$

Section D. Miscellaneous Provisions

Article 67 Relations with Inter-governmental Organizations 76

Article 68 Obligations of Members Regarding Existing and Proposed Commodity Agreements 76

Article 69 Territorial Application $\quad 76$

$\begin{array}{lll}\text { Article } 70 \quad \text { Exceptions to Chapter VI } & 77\end{array}$

$(\ldots)$ 


\title{
Annex B:
}

\section{Havana Charter - Article 35 Valuation for Customs Purposes}

\author{
HAVANA CHARTER \\ FOR AN INTERNATIONAL TRADE ORGANIZATION
}

Article 35

Valuation for Customs Purposes

1. The Members shall work toward the standardization, as far as practicable, of definitions of value and of procedures for determining the value of products subject to customs duties or other charges or restrictions based upon or regulated in any manner by value. With a view to furthering cooperation to this end, the Organization may study and recommend to Members such bases and methods for determining value for customs purposes as would appear best suited to the needs of commerce and most capable of general adoption.

2. The Members recognize the validity of the general principles of valuation set forth in paragraphs 3, 4 and 5, and they undertake to give effect, at the earliest practicable date, to these principles in respect of all products subject to duties or other charges or restrictions on importation based upon or regulated in any manner by value. Moreover, they shall, upon a request by another Member directly affected, review in the light of these principles the operation of any of their laws or regulations relating to value for customs purposes. The Organization may request from Members reports on steps taken by them in pursuance of the provisions of this Article.

3. (a) The value for customs purposes of imported merchandise should be based on the actual value of the imported merchandise on which duty is assessed, or of like merchandise, and should not be based on the value of merchandise of national origin or on arbitrary or fictitious values.

(b) "Actual value" should be the price at which, at a time and place determined by the legislation of the country of importation, and in the ordinary course of trade, such or like merchandise is sold or offered for sale under fully competitive conditions. To the extent to which the price of such or like merchandise is governed by the quantity in a particular transaction, the price to be considered should uniformly be related to either (i) comparable quantities, or (ii) quantities not less favourable to importers than those in which the greater volume of the merchandise is sold in the trade between the countries of exportation and importation.

(c) When the actual value is not ascertainable in accordance with sub-paragraph (b), the value for customs purposes should be based on the nearest ascertainable equivalent of such value.

4. The value for customs purposes of any imported product should not include the amount of any internal tax, applicable within the country of origin or export, from which the imported product has been exempted or has been or will be relieved by means of refund. 
5. (a) Except as otherwise provided in this paragraph, where it is necessary for the purposes of paragraph 3 for a Member to convert into its own currency a price expressed in the currency of another country, the conversion rate of exchange to be used shall be based on the par values of the currencies involved, as established pursuant to the Articles of Agreement of the international Monetary Fund or by special exchange agreements entered into pursuant to Article 24 of this Charter.

(b) Where no such par value has been established, the conversion rate shall reflect effectively the current value of such currency in commercial transactions.

(c) The Organization, in agreement with the International Monetary Fund, shall formulate rules governing the conversion by Members of any foreign currency in respect of which multiple rates of exchange are maintained consistently with the Articles of Agreement of the International Monetary Fund. Any Member may apply such rules in respect of such foreign currencies for the purposes of paragraph 3 of this Article as an alternative to the use of par values. Until such rules are adopted by the Organization, any Member may employ, in respect of any such foreign currency, rules of conversion for the purposes of paragraph 3 of this Article which are designed to reflect effectively the value of such foreign currency in commercial transactions.

6. Nothing in this Article shall be construed to require any Member to alter the method of converting currencies for customs purposes which is applicable in its territory on the date of this Charter, if such alteration would have the effect of increasing generally the amounts of duty payable.

7. The bases and methods for determining the value of products subject to duties or other charges or restrictions based upon or regulated in any manner by value should be stable and should be given sufficient publicity to enable traders to estimate, with a reasonable degree of certainty, the value for customs purposes. 


\section{Annex C: \\ BDV - Convention on the Valuation of Goods for Customs Purposes}

Done at: Brussels

Date enacted: $15^{\text {th }}$ December 1950

In force: $28^{\text {th }}$ July 1953

Amended by the Council Recommendation of $7^{\text {th }}$ June 1967 concerning the amendment of the Convention, which came into force on $18^{\text {th }}$ April 1972.

The Governments signatory to the present Convention,

Desiring to facilitate international trade,

Desiring to simplify international customs tariff negotiations and the comparison of foreign trade statistics inasmuch as such comparisons are more exact if based upon a uniform valuation of goods,

Being convinced that the maximum uniformity in defining the value of goods for customs purposes will constitute an important step towards the attainment of these objects,

Having taken into consideration the work already accomplished in Brussels in this sphere by the European Customs Union Study Group, and Considering that the best way of achieving results in this respect is to conclude an international Convention,

Have agreed as follows:

\section{Article I}

For the purpose of the present Convention,

a. $\quad$ "the Convention establishing the Council" means the Convention establishing the Customs Cooperation Council opened for signature in Brussels on the 15th December, 1950;

b. $\quad$ "the Council" means the Customs Co-operation Council referred to in paragraph (a) of this Article;

c. "the Secretary General" means the Secretary General of the Council.

\section{Article II}

Subject to the provisions of Article IV, each Contracting Party shall introduce into its domestic law and apply, as from the date on which the present Convention comes into force in respect of it, the Definition of Value (hereinafter referred to as the "Definition") set out in Annex I of the Convention. 
Each Contracting Party shall, in applying the Definition, conform to the provisions of the Interpretative Notes (hereinafter referred to as the "Notes") set out in Annex II to the present Convention.

\section{Article IV}

Each Contracting Party may adapt the text of the Definition

a. by inserting therein such provisions of the Notes as it may consider necessary,

b. by giving the text such legal form as may be essential to render it operative in its domestic law, if necessary by adding complementary provisions clarifying the purport of the Definition.

\section{Article V}

a. The Council shall supervise the operation of the present Convention with a view to securing uniformity in its interpretation and application.

b. To this end, the Council shall establish a Valuation Committee on which each Member of the Council to which the present Convention applies shall have the right to be represented.

\section{Article VI}

The Valuation Committee shall have the following functions which shall be exercised under the authority of the Council and in accordance with any directions which the Council may give:

a. to collate and circulate to the Contracting Parties information concerning the valuation of goods by the Contracting Parties for customs purposes;

b. to study, the domestic laws, procedures and practices of the Contracting Parties in relation to the Definition and Notes, and, accordingly, to make recommendations to the Council or the Contracting Parties to secure uniformity; in the interpretation and application of the Definition and Notes and the adoption of standard procedures and practices;

c. $\quad$ to prepare explanatory notes as a guide to the application of the Definition;

d. on its own initiative or on request, to furnish to Contracting Parties information or advice on any-matters concerning the valuation of goods for customs purposes;

e. to submit to the Council proposals for any amendment of the present Convention which it may consider desirable;

f. to exercise such other powers and functions of the Council in relation to the valuation of goods for customs purposes as the Council may delegate to it.

\section{Article VII}


a. The Valuation Committee shall meet at least three times a year.

b. It shall elect its own Chairman and one or more Vice-Chairmen.

c. It shall draw up its own Rules of Procedure by decision taken by not less than two-thirds of its members. The Rules of Procedure so drawn up shall be subject to the approval of the Council.

\section{Article VIII}

The Annexes to the present Convention shall form an integral part thereof and any reference to the Convention shall be deemed to include a reference to the Annexes.

\section{Article IX}

The Contracting Parties accept the provisions of the Protocol attached to the present Convention concerning special methods of taxing goods falling within Chapter 30 and Heading 33.06 of the Nomenclature annexed to the Convention on Nomenclature for the Classification of Goods in Customs Tariffs opened for signature in Brussels on the same date as the present Convention.

\section{Article X}

a. The present Convention shall abrogate as between the Contracting Parties all obligations under other international agreements in so far as they are inconsistent with the present Convention.

b. The present Convention shall not derogate from the obligations, under any other international agreement, incurred by any, Contracting Party before the coming into force of the present Convention in respect of it towards any Government not a party to the present Convention. However, the Contracting Parties shall, as soon as circumstances permit and in any case on the renewal of such prior agreements, arrange to make any necessary amendments thereto in order to bring them into conformity with the provisions of the present Convention.

\section{Article XI}

a. Any dispute between two or more Contracting Parties concerning the interpretation or application of the present Convention shall so far as possible be settled by negotiation between them.

b. Any dispute which is not settled by negotiation shall be referred by the Contracting Parties in dispute to the Valuation Committee which shall thereupon consider the dispute, and make recommendations for its settlement.

c. If the Valuation Committee is unable to settle the dispute, it shall refer the matter to the Council which shall make recommendations in conformity with Article III (e) of the Convention establishing the Council. 
d. The Contracting Parties in dispute may agree in advance to accept the recommendations of the Committee or Council as binding.

\section{Article XII}

The present Convention shall be open for signature until 31st March 1951, by any Government which has signed the Convention establishing the Council.

\section{Article XIII}

a. The present Convention shall be subject to ratification.

b. Instruments of ratification shall be deposited with the Belgian Ministry of Foreign Affairs, which shall notify all signatory and acceding Governments and the Secretary General of each such deposit. However, no Government may deposit its instrument of ratification of the present Convention until it has deposited its instrument of ratification of the Convention establishing the Council.

\section{Article XIV}

a. Three months after the date on which the Belgian Ministry of Foreign Affairs has received the instruments of ratification of seven Governments, the present Convention shall come into force in respect of those Governments.

b. For each signatory Government ratifying after that date, the Convention shall come into force three months after the date of the deposit of its instrument of ratification with the Belgian Ministry of Foreign Affairs.

\section{Article XV}

a. The Government of any State which is not a signatory to the present Convention, but which has ratified or acceded to the Convention establishing the Council, may accede to the present Convention as from 1st April, 1951.

b. Instruments of accession shall be deposited with the Belgian Ministry of Foreign Affairs, which shall notify all signatory and acceding Governments and the Secretary General of each such deposit.

c. The present Convention shall come into force for any acceding Government three months after the date of the deposit of its instrument of accession but not before it comes into force in accordance with paragraph (a) of Article XIV.

\section{Article XVI}

a. The present Convention is of unlimited duration, but at any time after the expiry of five years from its entry into force under paragraph (a) of Article XIV, any Contracting Party may withdraw therefrom. Withdrawal shall take effect one year after the date of receipt by the Belgian Ministry of 
Foreign Affairs of a notification of withdrawal. The Belgian Ministry of Foreign Affairs shall notify each withdrawal to all signatory and acceding Governments and to the Secretary-General.

b. Any Contracting Party which ceases to be a party to the Convention establishing the Council shall thereupon cease to be a party to the present Convention.

\section{Article XVII}

a. Any Government may at the time of its ratification or accession or at any time thereafter, declare by, notification given to the Belgian Ministry of Foreign Affairs that the present Convention shall extend to any of the territories for whose international relations it is responsible, and the Convention shall extend to the territories named in the notification three months after the date of the receipt thereof by the Belgian Ministry of Foreign Affairs but not before the Convention has come into force for the Government concerned.

b. Any Government which has made a declaration under paragraph (a) above extending the present Convention to any territory for whose international relations it is responsible, may by notification given to the Belgian Ministry of Foreign Affairs withdraw in respect of that territory in accordance with the provisions of Article XVI.

c. The Belgian Ministry of Foreign Affairs shall inform all signatory and acceding Governments and the Secretary General of any notification received by it under this Article.

\section{Article XVIII}

a. The Council may recommend amendments to the present Convention to the Contracting Parties.

b. Any Contracting Party accepting an amendment shall notify the Belgian Ministry of Foreign Affairs in writing of its acceptance and the Belgian Ministry of Foreign Affairs shall notify all signatory and acceding Governments and the Secretary General of the receipt of the notice of acceptance.

c. An amendment shall come into force three months after receipt by the Belgian Ministry of Foreign Affairs of notice of acceptance by all the Contracting Parties. When any amendment has been accepted by all the Contracting Parties the Belgian Ministry of Foreign Affairs shall notify all signatory and acceding Governments and the Secretary General of such acceptance and of the date on which the amendment will come into force.

d. After an amendment has come into force, no Government may ratify or accede to the present Convention unless it also accepts the amendment.

In witness whereof the undersigned, having been duly authorized thereto by their respective Governments, have signed the present Convention. 
Done at Brussels on the fifteenth day of December, nineteen hundred and fifty (December 15th, 1950) in the English and French languages, both texts being equally authentic, in a single original, which shall be deposited in the archives of the Government of Belgium which shall transmit certified copies thereof to each signatory and acceding Government.

\section{Annex I}

\section{Definition of value}

\section{Article I}

1. For the purposes of levying duties of customs, the value of any goods imported for home consumption shall be taken to be the normal price, that is to say, the price which they would fetch at the time when the duty becomes payable on a sale in the open market between buyer and seller independent of each other.

2. The normal price of any imported goods shall be determined on the following assumptions:

(a) that the goods are treated as having been delivered to the buyer at the port or place of introduction into the country of importation; and

(b) that the seller will bear all costs, charges and expenses incidental to the sale and to the delivery of the goods at that port or place; but

(c) that the buyer will bear any duties or taxes applicable in the country of importation.

\section{Article II}

1. A sale in the open market between buyer and seller independent of each other pre-supposes:

(a) that the price is the sole consideration; and

(b) that the price made is not influenced by any commercial, financial or other relationship, whether by contract or otherwise, between the seller or any person associated in business with him and the buyer or any person associated in business with him (other than the relationship created by the sale of the goods in question); and

(c) that no part of the proceeds of the subsequent re-sale, use or disposal of the goods will accrue either directly or indirectly to the seller or any person associated in business with him.

2. Two persons shall be deemed to be associated in business with one another if, whether directly or indirectly, either of them has any interest in the business or property of the other or both have a common interest in any business or property or some third person has an interest in the business or property of both of them. 


\section{Article III}

When the goods to be valued

a. are manufactured in accordance with any patented invention or are goods to which any registered design has been applied; or

b. are imported under a foreign trade mark or are imported for sale under a foreign trade mark, the normal price shall be determined on the assumption that the value of the right to use the patent, design or trade mark in respect of the goods is covered by the price.

Annex II

Interpretative notes to the definition of value

Addendum to Article I

Note 1

"The time when the duty becomes payable" referred to in paragraph (1) of Article I may, in accordance with the legislation of each country, be either the time at which the entry is presented or registered, the time of payment of customs duty or the time of clearance.

Note 2

The "costs, charges and expenses" mentioned in Article I, paragraph (2) (b) include, inter alia, any of the following:

- $\quad$ carriage and freight;

- $\quad$ insurance;

- $\quad$ commission;

- $\quad$ brokerage;

- $\quad$ costs, charges and expenses of drawing up outside the country of importation documents incidental to the introduction of the goods into the country of importation, including consular fees; - $\quad$ the net amount (after allowing for re-payments made or to be made) of duties and taxes applicable outside the country of importation;

- $\quad$ cost of containers excluding those which are treated as separate articles for the purpose of levying duties of customs; cost of packing (whether for labour, materials or otherwise);

- $\quad$ loading charges.

Note 3

Where the normal price would depend upon the quantity in the sale, it shall be determined on the assumption that the sale is a sale of the quantity to be valued.

Note 4 
Where the determination of the value or of the price paid or payable depends upon factors which are expressed in a currency other than that of the country of importation, the foreign currency shall be converted into the currency of the importing country at the official rate of exchange of that country.

\section{Note 5}

The object of the definition of value is to make it possible in all cases to calculate the duties payable on the basis of the price at which imported goods are freely available to any buyer in the open market at the port or place of introduction into the country of importation. It is a concept for general use and is applicable whether or not the goods are in fact imported under a contract of sale, and whatever the terms of that contract.

But the application of the Definition implies an enquiry into current prices at the time of valuation. In practice, therefore, when imported goods are the subject of a bona fide sale, the price paid or payable on that sale can generally be considered as a valid indication of the normal price mentioned in the Definition. This being so, the price paid or payable can reasonably be used as basis for valuation, and Customs authorities are recommended to accept this price as the value of the goods in question subject:

a. to proper safeguards aimed at preventing evasion of duty by means of fictitious or colourable contracts or prices; and

b. to such adjustment of the contract price as may be considered necessary on account of circumstances differentiating the contract from the notional concept embodied in the Definition of Value.

Adjustments under paragraph (b) above may in particular be required with reference to freight and other expenses dealt with in paragraph (2) of Article I and Note 2 of the Addendum to Article 1, or with reference to discounts or other reductions in price granted in favour of sole agents or sole concessionaires, or to any abnormal discount or any reduction from the ordinary competitive price.

\section{Addendum to Article III}

\section{Note 1}

The provisions of Article III (b) may also be applied to goods imported for sale, after further manufacture, under a foreign trade mark.

\section{Note 2}

Sub-paragraph (b) of Article III, or that sub-paragraph amended in accordance with Note 1 above, may be extended so that it shall not apply to a trade mark registered within the country of importation, unless it is a mark used for the purpose of indicating that goods in relation to which it is used are those of: 
a. any person by whom the goods to be valued have been grown, produced, manufactured, selected, offered for sale or otherwise dealt with outside the country of importation; or b. a person associated in business with any such person as is referred to in (a) above; or c. a person to whom any such person as is referred to in (a) or (b) above has assigned the goodwill of the business in connection with which the trade mark is used.

General Addendum

It is recommended that the concept of value expressed by the Definition and these Interpretative Notes be employed for the valuing of all goods subject to customs declaration, including duty-free goods and goods liable to specific customs duties.

\section{Annex III}

Protocol concerning special methods of taxing goods falling within chapter 30 and heading 33.06 of the nomenclature for the classification of goods in customs tariffs

At the time of signing the Convention on the Valuation of Goods for Customs Purposes (hereinafter referred to as "the Convention") the Governments signatory to that Convention have agreed as follows:

1. Any Government signatory to the Convention which, at the time when the Convention comes into force in respect of it, is applying, in respect of the following goods imported put up for retail sale: (a) pharmaceutical products falling within Chapter 30 of the Annex to the Convention on Nomenclature for the Classification of Goods in Customs Tariffs, or

(b) perfumes, cosmetics and toilet preparations falling within heading 33.06 of that Annex,

(c) a system of taxation based upon the internal retail resale price of the goods, instead of upon the normal price as defined in the Convention, may continue this system.

(d) Nevertheless, the Governments concerned recognize the importance of bringing the system of taxation of these products within the framework of the Convention and will do so as soon as possible. (e) The present Protocol shall enter into force on the date on which the Convention enters into force.

2. In witness whereof the undersigned, having been duly authorized thereto by their respective Governments, have signed the present Protocol.

3. Done at Brussels on the fifteenth day of December, nineteen hundred and fifty (December 15th, 1950) in the English and French languages, both texts being equally authentic, in a simple original, which shall be deposited in the archives of the Government of Belgium which shall transmit certified copies thereof to each signatory Government and to each other Government which signs or accedes to the Convention.

The Brussels Principles of Valuation

"Principle I: Dutiable value should be based on equitable and simple principles which do not cut across commercial practice. 
Principle II: The concept of dutiable value should be readily comprehensible to the importer as well as the Customs.

Principle III: The system of valuation should not prevent the quick clearance of goods.

Principle IV: The system of valuation should enable traders to estimate, in advance, with a reasonable degree of certainty, the value of customs purposes.

Principle V: The system of valuation should protect the honest importer against unfair competition arising from undervaluation, fraudulent or otherwise.

Principle VI: When the Customs consider that the declared value may be incorrect, the verification of essential facts for the determination and enforcement of dutiable value should be speedy and accurate.

Principle VII: Valuation should be based to the greatest possible degree on commercial documents.

Principle VIII:The system of valuation should reduce formalities to a minimum.

Principle IX: The procedures for dealing with lawsuits between importers and the Customs should be simple, speedy, equitable and impartial." 
Annex D

CCC/WCO BDV Convention Current Membership - 2017

\begin{tabular}{|l|l|}
\hline CCC/WCO MEMBERS & $\begin{array}{l}\text { CONVENTION ON THE VALUATION OF GOODS } \\
\text { FOR CUSTOMS PURPOSES (BDV) }\end{array}$ \\
\hline Algeria & $1977-08-18$ \\
\hline Haiti & $1958-01-31$ \\
\hline Israel & $1981-02-26$ \\
\hline Kenya & $1967-03-13$ \\
\hline Pakistan & $1957-10-14$ \\
\hline Rwanda & $1964-06-01$ \\
\hline Senegal & $1978-10-16$ \\
\hline Tanzania & $1977-12-09$ \\
\hline $\begin{array}{l}\text { Number of BDV Convention Contracting } \\
\text { Parties }\end{array}$ & $\mathbf{8}$ \\
\hline
\end{tabular}




\section{Annex E:}

\section{CCC/WCO BDV Convention - Model Withdraw Letter}

A suggested letter to withdraw from the BDV Convention that is registered in the Ministry of Foreign Affairs in the Kingdom of Belgium

\section{MINISTRY OF FOREIGN AFFAIRS}

COUNTRY X

The Ministry of Foreign Affairs of the Republic of CONTRY X presents its compliments to the Ministry of Foreign Affairs of the Kingdom of Belgium and has the honour to inform it that, by law No. ... of .... the COUNTRY X has acceded to Agreement Establishing the World Trade Organization (WTO).

Given that with this accession COUNTRY X has undertaken to apply the Agreement on Implementation of Article VII of the General Agreement on Tariffs and Trade 1994 (Customs Valuation Agreement), with effect from DATE the COUNTRY X withdraws from the Convention on the Valuation of Goods for Customs Purposes, signed in Brussels on 15 December 1950, and from the related Recommendations.

Thus, the Customs value of goods imported into COUNTRY X will be determined, with effect from DATE in accordance with the provisions of the Agreement on Implementation of Article V11 of the General Agreement on Tariffs and Trade 1994.

The Ministry of Foreign Affairs of COUNTRY X thanks the Ministry of Foreign Affairs of the Kingdom of Belgium for its kind cooperation and avails itself of this opportunity to renew the assurance of its high consideration.

TO THE MINISTRY OF FOREIGN AFFAIRS IN THE KINGDOM OF BELGIUM BRUSSELS 


\title{
Annex F \\ BDV - CCV - Dutiable Value of Computers and Carrier Media
}

\author{
Text of Study III
}

\section{Introduction}

1. In the course of its work on the valuation of computers and their associated equipment, the Valuation Committee found that the complexity and wide variety of these goods and the complications of the commercial practices of the computer industry have given rise to special problems in Customs valuation. Accordingly, the Committee has issued this Study for guidance in this matter.

\section{Elements of a computer system}

2. A computer system usually comprises:

- A processor unit (there may be several processor units working together);

- Several "peripheral" units (for the purpose of transmitting input and output data, providing various other operations for the processor unit); they may occasionally be combined with the processor unit in a self-contained unit;

- Programs.

3. The relationship between the programs (commonly called "software") and the hardware has a bearing on the valuation of the hardware.

4. Programs are the instructions provided for the operation of the computer. They may be supplied on media suitable for immediate use with the computer (e.g. on punched cards, punched or magnetic tape, magnetic disks and diskettes) or in the form of diagrams, manuscript or printed matter.

5. There are two main types of programs, hardware-related software, usually called operating system software, and user application programs. Hardware-related programs are necessary for the operation of the computer itself, regardless of the use for which it is required. Application programs, e.g., user programs and testing/maintenance programs provide the computer with instructions as to the specific tasks to be processed.

6. The processor unit as peripheral units (commonly known as "hardware") are treated together for valuation purposes.

\section{Valuation}

7. For the purposes of Customs valuation, a distinction has to be made between the hardwarerelated software which is necessary for the operation of the hardware and all other types of programs. The value of the hardware-related software cannot be excluded from the dutiable value of the hardware. Other types of software may be supplied by either the manufacturer of the computer system or an independent software supplier or may be developed by the computer 
user; on importation, media bearing these programs should be treated separately along the lines set out in paragraph 30 below.

\section{Hardware}

8. When a computer system is sold to the user at an overall price which includes an amount for programs other than those necessary for the operation of the hardware, that amount does not form part of the dutiable value of the hardware. In determining this value it is necessary to distinguish two cases:

a. The computer system is invoiced by the seller at a price which varies according to the type of program supplied. In this case, the dutiable value of the hardware is the price that a buyer not purchasing programs from the seller (other than those necessary for the operation of the hardware) would have to pay;

b. The seller includes in the overall price invoiced for the system a flat rate sum to cover whatever program may be supplied with it. If one knows the flat rate sum in respect of programs other than those necessary for the operation of the hardware, it must be deducted from the overall price in order to determine the dutiable value of the hardware; otherwise, the case must be treated on its own merits.

\section{Provision of services in relation to the imported hardware}

9. In general, and whatever the status of the importer (user, intermediary, buyer-reseller), an invoice for imported hardware may also include the provision of services necessary for the use of the hardware itself or of its software.

10. These services, when included in the invoice price (which is used as the basis for valuation) or specified in a rental contract, may be deducted from the dutiable value. This would apply, in particular, to the following elements:

- Pre-sale expenditures representing either technical costs such as specification of the buyer's requirements, the definition, preparation, running and post-facto analysis of trial programs, or commercial sales costs;

- Expenditures relating to installation planning;

- Costs of installing and assembling the hardware;

- Post-importation delivery and insurance costs;

- Training of the seller's staff;

- Training of the user's technical staff (programmers, operators, etc.);

- General overheads (e.g, general administrative services), only insofar as they relate to the items listed above.

11. Where these elements are separately invoiced, their costs are not to be added for valuation purposes. 
12. The same treatment would apply to the value of various services, such as:

- Access to a program library;

- Advice on the organization of the commercial operator;

- Maintenance costs;

- Advertising costs;

Which are generally the subject of a separate contract.

13. Nevertheless, care must be taken to include the value of any "services", however described, which are effectively selling expenses, and which the price would normally cover whether the so-called services are rendered or not.

14. These include, for example, brokerage and commission; tooling-up, mould-making and development costs; discounts and rebates not in accordance with the definition of the normal price, such as discounts on demonstration models or retrospective discounts; licensing fees and rights and, in particular, the right to use and resell the goods.

15. It has been thought advisable to consider separately importations of computer hardware by the following classes of importers:

(a) Users;

(b) Importers performing the functions of agents of the foreign suppliers;

(c) Buyers-resellers;

\section{Where the importer is the user}

16. If a computer system is imported on direct purchase by a user independent of the foreign supplier, the selling price to the user should be an acceptable basis for valuation. Subject to any necessary adjustments for other reasons, it should be reduced by any amounts which may be included on account of programs other than those necessary for the operation of the hardware (see paragraphs 7 and 8).

\section{Where the importer is an agent of distribution}

17. If the importer performs the functions of an agent for distribution acting for the account and risk of the foreign supplier, valuation should proceed on the same basis as for an importation by a user (see paragraphs 9 to 16 above).

18. However, as agents for distribution are generally related to the supplier, it is necessary to check that the price has not been influenced by the relationship, particularly in the area of discounts and rebates. Moreover, to the extent that various services may be rendered within a multinational group, and that these may be invoiced as a whole, expenditures relating to such services should not be deducted from the dutiable value unless they genuinely correspond to an actual service rendered for the benefit of the importer or the user, which would normally be paid for in transaction between independent companies. 
19. If the importer performs the functions of a buyer-reseller, the invoice price to the importer may provide a satisfactory basis for valuation. This is true even where the buyer and seller are related, if the relationship has not influenced the price. In this connection the fact that the computer has been designed to meet the user's requirement does not in itself indicate that the importer cannot be treated as a buyer-reseller. If the invoice price cannot be accepted as a satisfactory basis, valuation should proceed on the basis of the price paid or payable by the user, subject to the deduction of the gross margin.

20. This margin will include the cost of the services referred to in paragraph 9 , provided that this cost, uplifted by a reasonable profit, is included in the price to the user.

21. However, the profit margin must be analyzed carefully.

22. In some cases the buyer-reseller performs only minimum functions and assumes very few risks in the operation concerned; in these circumstances, the profit is more akin to commission or fees than to a margin.

23. In general, the profit margin itself depends on the functions performed and the risks run.

24. Thus, a buyer-reseller who merely resells the goods without taking delivery of them or assuming the commercial risks cannot expect a high profit of margin.

25. On the other hand, where the reseller assumes responsibility for packing, advertising, commercializing and storing the goods and for after-sales services, etc., and bears the corresponding financial and commercial risks, the profit margin may be significant.

26. Moreover, the existence of an exclusive sale contract may influence the profit margin. In the case of related companies, a contract of this kind may not be written but may arise out of the general sales conditions, thus accounting for a higher profit margin.

\section{Special case of rented systems}

27. Computer systems are sometimes supplied on a rental basis but, since sales are frequent, selling prices to independent users may furnish a reliable guide for establishing the value of rented systems. If the selling prices do not correspond with the list prices, this does not necessarily mean that the selling prices should be rejected as a basis for valuation, because to meet a market situation, sellers may be obliged to offer discounts which can be accepted for valuation purposes. For the sale reason, list prices might not be a reliable guide if no sales are known to have taken place at such prices. In the absence of other evidence a suitable indication of dutiable value may be derived from an analysis of rental charges. This would proceed on the usual basis as described in the Explanatory Notes (pages 80,81 and 82), by taking the total rental payments for the normal life of the system and excluding interest and any maintenance charges. 
28. There may, of course, be further elements covered by the rental which are not includible in the dutiable value and which must therefore be deducted. Additionally, practical guidance is given by the CCC "Examples illustrating the Explanatory Notes", Section "Importation of goods on hire".

\section{The OEM (Original Equipment Manufacturers) market}

29. The expression "OEM market" refers to transactions between one manufacturer and another who needs to supplement or build up his range of hardware. Such transactions may also be concluded through an agent acting for the account and risk of a foreign supplier. Substantial discounts may be granted by a manufacturer selling to independent OEM buyers, and may be accepted for valuation purposes if they are in line with trade practice.

\section{Carrier media}

30. In most cases the dutiable value of carrier media is either known or is likely to be ascertainable. Where it is not available, it may be determined by estimation using reasonable means.

\section{Used computers}

31. The foregoing paragraphs deal only with new goods. Used computers which may be imported fall broadly into three categories, as follows:

a. "Old for new". These are machines which have been completely overhauled and updated by the original manufacturer. If they are sold as new machines, under the same conditions, they should be treated as new machines for valuation purposes.

b. Computers which may have been overhauled or reconditioned, but not updated, computers which are imported for the purpose of reconditioning and computers which are imported for resale without overhaul. In some countries there are price lists for such machines which may furnish indications for establishment of dutiable value. However the list prices for different types of unit develop differently, with rapid falls for some units as a consequence of the development of new machines. Consequently no general guidance is practicable, and each case has to be dealt with on its merits.

c. Computers which are imported for cannibalization, i.e. as a source of spare parts, etc. The invoice prices, frequently representing a small fraction of the new value of the computer, can generally be accepted for duty purposes.

\section{Final observation}

32. Since the situation in the computer industry is developing constantly, in regard to both computer design and marketing, these developments may necessitate changes in the conclusions of this paper from time to time. 


\title{
Annex G
}

\section{GATT Article VII and Interpretative Note Ad Article VII}

\author{
Article VII
}

Valuation for Customs Purposes

1. The contracting parties recognize the validity of the general principles of valuation set forth in the following paragraphs of this Article, and they undertake to give effect to such principles, in respect of all products subject to duties or other charges* or restrictions on importation and exportation based upon or regulated in any manner by value. Moreover, they shall, upon a request by another contracting party review the operation of any of their laws or regulations relating to value for customs purposes in the light of these principles. The CONTRACTING PARTIES may request from contracting parties reports on steps taken by them in pursuance of the provisions of this Article.

2. (a) The value for customs purposes of imported merchandise should be based on the actual value of the imported merchandise on which duty is assessed, or of like merchandise, and should not be based on the value of merchandise of national origin or on arbitrary or fictitious values.*

(b) "Actual value" should be the price at which, at a time and place determined by the legislation of the country of importation, such or like merchandise is sold or offered for sale in the ordinary course of trade under fully competitive conditions. To the extent to which the price of such or like merchandise is governed by the quantity in a particular transaction, the price to be considered should uniformly be related to either (i) comparable quantities, or (ii) quantities not less favourable to importers than those in which the greater volume of the merchandise is sold in the trade between the countries of exportation and importation.*

(c) When the actual value is not ascertainable in accordance with sub-paragraph (b) of this paragraph, the value for customs purposes should be based on the nearest ascertainable equivalent of such

value.*

3. The value for customs purposes of any imported product should not include the amount of any internal tax, applicable within the country of origin or export, from which the imported product has been exempted or has been or will be relieved by means of refund.

4. (a) Except as otherwise provided for in this paragraph, where it is necessary for the purposes of paragraph 2 of this Article for a contracting party to convert into its own currency a price expressed in the currency of another country, the conversion rate of exchange to be used shall be based, for each currency involved, on the par value as established pursuant to the Articles of Agreement of the International Monetary Fund or on the rate of exchange recognized by the Fund, or on the par value established in accordance with a special exchange agreement entered into pursuant to Article XV of this Agreement. 
(b) Where no such established par value and no such recognized rate of exchange exist, the conversion rate shall reflect effectively the current value of such currency in commercial transactions.

(c) The CONTRACTING PARTIES, in agreement with the International Monetary Fund, shall formulate rules governing the conversion by contracting parties of any foreign currency in respect of which multiple rates of exchange are maintained consistently with the Articles of Agreement of the International Monetary Fund. Any contracting party may apply such rules in respect of such foreign currencies for the purposes of paragraph 2 of this Article as an alternative to the use of par values. Until such rules are adopted by the CONTRACTING PARTIES, any contracting party may employ, in respect of any such foreign currency, rules of conversion for the purposes of paragraph 2 of this Article which are designed to reflect effectively the value of such foreign currency in commercial transactions.

(d) Nothing in this paragraph shall be construed to require any contracting party to alter the method of converting currencies for customs purposes which is applicable in its territory on the date of this Agreement, if such alteration would have the effect of increasing generally the amounts of duty payable.

5. The bases and methods for determining the value of products subject to duties or other charges or restrictions based upon or regulated in any manner by value should be stable and should be given sufficient publicity to enable traders to estimate, with a reasonable degree of certainty, the value for customs purposes.

\section{Interpretative Note Ad Article VII from Annex I}

\section{Paragraph 1}

The expression "or other charges" is not to be regarded as including internal taxes or equivalent charges imposed on or in connexion with imported products.

\section{Paragraph 2}

1. It would be in conformity with Article VII to presume that "actual value" may be represented by the invoice price, plus any non-included charges for legitimate costs which are proper elements of "actual value" and plus any abnormal discount or other reduction from the ordinary competitive price.

2. It would be in conformity with Article VII, paragraph 2 (b), for a contracting party to construe the phrase "in the ordinary course of trade $\cdots$ under fully competitive conditions", as excluding any transaction wherein the buyer and seller are not independent of each other and price is not the sole consideration.

3. The standard of "fully competitive conditions" permits a contracting party to exclude from consideration prices involving special discounts limited to exclusive agents. 
4. The wording of sub-paragraphs (a) and (b) permits a contracting party to determine the value for customs purposes uniformly either (1) on the basis of a particular exporter's prices of the imported merchandise, or (2) on the basis of the general price level of like merchandise. 


\title{
Annex H:
}

\section{WTO Agreement on Implementation of Article VII of the General Agreement on Tariffs and Trade 1994}

\author{
General Introductory Commentary
}

1. The primary basis for customs value under this Agreement is "transaction value" as defined in $\underline{\text { Article } 1}$. Article 1 is to be read together with Article 8 which provides, inter alia, for adjustments to the price actually paid or payable in cases where certain specific elements which are considered to form a part of the value for customs purposes are incurred by the buyer but are not included in the price actually paid or payable for the imported goods. Article 8 also provides for the inclusion in the transaction value of certain considerations which may pass from the buyer to the seller in the form of specified goods or services rather than in the form of money. Articles 2 through $\underline{7}$ provide methods of determining the customs value whenever it cannot be determined under the provisions of Article 1.

2. Where the customs value cannot be determined under the provisions of Article 1 there should normally be a process of consultation between the customs administration and importer with a view to arriving at a basis of value under the provisions of Article 2 or $\underline{3}$. It may occur, for example, that the importer has information about the customs value of identical or similar imported goods which is not immediately available to the customs administration in the port of importation. On the other hand, the customs administration may have information about the customs value of identical or similar imported goods which is not readily available to the importer. A process of consultation between the two parties will enable information to be exchanged, subject to the requirements of commercial confidentiality, with a view to determining a proper basis of value for customs purposes.

3. Articles 5 and $\underline{6}$ provide two bases for determining the customs value where it cannot be determined on the basis of the transaction value of the imported goods or of identical or similar imported goods. Under paragraph 1 of $\underline{\text { Article } 5}$ the customs value is determined on the basis of the price at which the goods are sold in the condition as imported to an unrelated buyer in the country of importation. The importer also has the right to have goods which are further processed after importation valued under the provisions of Article 5 if the importer so requests. Under Article 6 the customs value is determined on the basis of the computed value. Both these methods present certain difficulties and because of this the importer is given the right, under the provisions of Article 4, to choose the order of application of the two methods.

4. Article 7 sets out how to determine the customs value in cases where it cannot be determined under the provisions of any of the preceding Articles.

Members,

Having regard to the Multilateral Trade Negotiations;

Desiring to further the objectives of GATT 1994 and to secure additional benefits for the international trade of developing countries;

Recognizing the importance of the provisions of Article VII of GATT 1994 and desiring to elaborate rules for their application in order to provide greater uniformity and certainty in their implementation;

Recognizing the need for a fair, uniform and neutral system for the valuation of goods for customs purposes that precludes the use of arbitrary or fictitious customs values;

Recognizing that the basis for valuation of goods for customs purposes should, to the greatest extent possible, be the transaction value of the goods being valued;

Recognizing that customs value should be based on simple and equitable criteria consistent with commercial practices and that valuation procedures should be of general application without distinction between sources of supply;

Recognizing that valuation procedures should not be used to combat dumping;

Hereby agree as follows:

PART I

RULES ON CUSTOMS VALUATION 


\section{Article 1}

1. The customs value of imported goods shall be the transaction value, that is the price actually paid or payable for the goods when sold for export to the country of importation adjusted in accordance with the provisions of $\underline{\text { Article } 8}$, provided:

(a) that there are no restrictions as to the disposition or use of the goods by the buyer other than restrictions which:

(i) are imposed or required by law or by the public authorities in the country of importation;

(ii) limit the geographical area in which the goods may be resold; or

(iii) do not substantially affect the value of the goods;

(b) that the sale or price is not subject to some condition or consideration for which a value cannot be determined with respect to the goods being valued;

(c) that no part of the proceeds of any subsequent resale, disposal or use of the goods by the buyer will accrue directly or indirectly to the seller, unless an appropriate adjustment can be made in accordance with the provisions of $\underline{\text { Article }}$ $\underline{8}$; and

(d) that the buyer and seller are not related, or where the buyer and seller are related, that the transaction value is acceptable for customs purposes under the provisions of paragraph 2.

2. (a) In determining whether the transaction value is acceptable for the purposes of paragraph 1 , the fact that the buyer and the seller are related within the meaning of Article 15 shall not in itself be grounds for regarding the transaction value as unacceptable. In such case the circumstances surrounding the sale shall be examined and the transaction value shall be accepted provided that the relationship did not influence the price. If, in the light of information provided by the importer or otherwise, the customs administration has grounds for considering that the relationship influenced the price, it shall communicate its grounds to the importer and the importer shall be given a reasonable opportunity to respond. If the importer so requests, the communication of the grounds shall be in writing.

(b) In a sale between related persons, the transaction value shall be accepted and the goods valued in accordance with the provisions of paragraph 1 whenever the importer demonstrates that such value closely approximates to one of the following occurring at or about the same time:

(i) the transaction value in sales to unrelated buyers of identical or similar goods for export to the same country of importation;

(ii) the customs value of identical or similar goods as determined under the provisions of Article 5;

(iii) the customs value of identical or similar goods as determined under the provisions of Article 6;

In applying the foregoing tests, due account shall be taken of demonstrated differences in commercial levels, quantity levels, the elements enumerated in Article 8 and costs incurred by the seller in sales in which the seller and the buyer are not related that are not incurred by the seller in sales in which the seller and the buyer are related.

(c) The tests set forth in paragraph 2 (b) are to be used at the initiative of the importer and only for comparison purposes. Substitute values may not be established under the provisions of paragraph 2 (b).

\section{Article 2}

1. (a) If the customs value of the imported goods cannot be determined under the provisions of Article 1 , the customs value shall be the transaction value of identical goods sold for export to the same country of importation and exported at or about the same time as the goods being valued.

(b) In applying this Article, the transaction value of identical goods in a sale at the same commercial level and in substantially the same quantity as the goods being valued shall be used to determine the customs value. Where no such sale is found, the transaction value of identical goods sold at a different commercial level and/or in different quantities, adjusted to take account of differences attributable to commercial level and/or to quantity, shall be used, provided that such adjustments can be made 
on the basis of demonstrated evidence which clearly establishes the reasonableness and accuracy of the adjustment, whether the adjustment leads to an increase or a decrease in the value.

2. Where the costs and charges referred to in paragraph 2 of Article 8 are included in the transaction value, an adjustment shall be made to take account of significant differences in such costs and charges between the imported goods and the identical goods in question arising from differences in distances and modes of transport.

3. If, in applying this Article, more than one transaction value of identical goods is found, the lowest such value shall be used to determine the customs value of the imported goods.

\section{Article 3}

1. (a) If the customs value of the imported goods cannot be determined under the provisions of Articles 1 and $\underline{2}$, the customs value shall be the transaction value of similar goods sold for export to the same country of importation and exported at or about the same time as the goods being valued.

(b) In applying this Article, the transaction value of similar goods in a sale at the same commercial level and in substantially the same quantity as the goods being valued shall be used to determine the customs value. Where no such sale is found, the transaction value of similar goods sold at a different commercial level and/or in different quantities, adjusted to take account of differences attributable to commercial level and/or to quantity, shall be used, provided that such adjustments can be made on the basis of demonstrated evidence which clearly establishes the reasonableness and accuracy of the adjustment, whether the adjustment leads to an increase or a decrease in the value.

2. Where the costs and charges referred to in paragraph 2 of Article 8 are included in the transaction value, an adjustment shall be made to take account of significant differences in such costs and charges between the imported goods and the similar goods in question arising from differences in distances and modes of transport.

3. If, in applying this Article, more than one transaction value of similar goods is found, the lowest such value shall be used to determine the customs value of the imported goods.

\section{Article 4}

If the customs value of the imported goods cannot be determined under the provisions of $\underline{\text { Articles } 1}, \underline{2}$ and $\underline{3}$, the customs value shall be determined under the provisions of Article $\mathbf{5}$ or, when the customs value cannot be determined under that Article, under the provisions of Article 6 except that, at the request of the importer, the order of application of Articles 5 and $\underline{6}$ shall be reversed.

\section{Article 5}

1. (a) If the imported goods or identical or similar imported goods are sold in the country of importation in the condition as imported, the customs value of the imported goods under the provisions of this Article shall be based on the unit price at which the imported goods or identical or similar imported goods are so sold in the greatest aggregate quantity, at or about the time of the importation of the goods being valued, to persons who are not related to the persons from whom they buy such goods, subject to deductions for the following:

(i) either the commissions usually paid or agreed to be paid or the additions usually made for profit and general expenses in connection with sales in such country of imported goods of the same class or kind;

(ii) the usual costs of transport and insurance and associated costs incurred within the country of importation;

(iii) where appropriate, the costs and charges referred to in paragraph 2 of Article 8; and

(iv) the customs duties and other national taxes payable in the country of importation by reason of the importation or sale of the goods.

(b) If neither the imported goods nor identical nor similar imported goods are sold at or about the time of importation of the goods being valued, the customs value shall, subject otherwise to the provisions of paragraph 1 (a), be based on the unit price at which the imported goods or identical or similar imported goods are sold in the country of importation in the condition as imported at the earliest date after the importation of the goods being valued but before the expiration of 90 days after such importation. 
2. If neither the imported goods nor identical nor similar imported goods are sold in the country of importation in the condition as imported, then, if the importer so requests, the customs value shall be based on the unit price at which the imported goods, after further processing, are sold in the greatest aggregate quantity to persons in the country of importation who are not related to the persons from whom they buy such goods, due allowance being made for the value added by such processing and the $\begin{array}{llllll}\text { deductions } & \text { provided } & \text { for } & \text { in } & \text { paragraph } & 1\end{array}$

\section{Article 6}

1. The customs value of imported goods under the provisions of this Article shall be based on a computed value. Computed value shall consist of the sum of:

(a) the cost or value of materials and fabrication or other processing employed in producing the imported goods;

(b) an amount for profit and general expenses equal to that usually reflected in sales of goods of the same class or kind as the goods being valued which are made by producers in the country of exportation for export to the country of importation;

(c) the cost or value of all other expenses necessary to reflect the valuation option chosen by the Member under paragraph 2 of Article 8 .

2. No Member may require or compel any person not resident in its own territory to produce for examination, or to allow access to, any account or other record for the purposes of determining a computed value. However, information supplied by the producer of the goods for the purposes of determining the customs value under the provisions of this Article may be verified in another country by the authorities of the country of importation with the agreement of the producer and provided they give sufficient advance notice to the government of the country in question and the latter does not object to the investigation.

\section{Article 7}

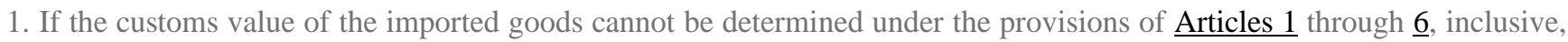
the customs value shall be determined using reasonable means consistent with the principles and general provisions of this Agreement and of Article VII of GATT 1994 and on the basis of data available in the country of importation.

2. No customs value shall be determined under the provisions of this Article on the basis of:

(a) the selling price in the country of importation of goods produced in such country;

(b) a system which provides for the acceptance for customs purposes of the higher of two alternative values;

(c) the price of goods on the domestic market of the country of exportation;

(d) the cost of production other than computed values which have been determined for identical or similar goods in accordance with the provisions of Article 6;

(e) the price of the goods for export to a country other than the country of importation;(f) minimum customs values; or (g) arbitrary or fictitious values.

3. If the importer so requests, the importer shall be informed in writing of the customs value determined under the provisions of this Article and the method used to determine such value.

\section{Article 8}

1.In determining the customs value under the provisions of Article 1, there shall be added to the price actually paid or payable for the imported goods:

(a) the following, to the extent that they are incurred by the buyer but are not included in the price actually paid or payable for the goods:

(i) commissions and brokerage, except buying commissions;

(ii) the cost of containers which are treated as being one for customs purposes with the goods in question;

(iii) the cost of packing whether for labour or materials; 
(b) the value, apportioned as appropriate, of the following goods and services where supplied directly or indirectly by the buyer free of charge or at reduced cost for use in connection with the production and sale for export of the imported goods, to the extent that such value has not been included in the price actually paid or payable:

(i) materials, components, parts and similar items incorporated in the imported goods;

(ii) tools, dies, moulds and similar items used in the production of the imported goods;

(iii) materials consumed in the production of the imported goods;

(iv) engineering, development, artwork, design work, and plans and sketches undertaken elsewhere than in the country of importation and necessary for the production of the imported goods;

(c) royalties and licence fees related to the goods being valued that the buyer must pay, either directly or indirectly, as a condition of sale of the goods being valued, to the extent that such royalties and fees are not included in the price actually paid or payable;

(d) the value of any part of the proceeds of any subsequent resale, disposal or use of the imported goods that accrues directly or indirectly to the seller.

2. In framing its legislation, each Member shall provide for the inclusion in or the exclusion from the customs value, in whole or in part, of the following:

(a) the cost of transport of the imported goods to the port or place of importation;

(b) loading, unloading and handling charges associated with the transport of the imported goods to the port or place of importation; and (c) the cost of insurance.

3. Additions to the price actually paid or payable shall be made under this Article only on the basis of objective and quantifiable data.

4. No additions shall be made to the price actually paid or payable in determining the customs value except as provided in this Article.

Article 9

1. Where the conversion of currency is necessary for the determination of the customs value, the rate of exchange to be used shall be that duly published by the competent authorities of the country of importation concerned and shall reflect as effectively as possible, in respect of the period covered by each such document of publication, the current value of such currency in commercial transactions in terms of the currency of the country of importation.

2. The conversion rate to be used shall be that in effect at the time of exportation or the time of importation, as provided by each Member.

Article 10

All information which is by nature confidential or which is provided on a confidential basis for the purposes of customs valuation shall be treated as strictly confidential by the authorities concerned who shall not disclose it without the specific permission of the person or government providing such information, except to the extent that it may be required to be disclosed in the context of judicial proceedings.

Article 11

1. The legislation of each Member shall provide in regard to a determination of customs value for the right of appeal, without penalty, by the importer or any other person liable for the payment of the duty.

2. An initial right of appeal without penalty may be to an authority within the customs administration or to an independent body, but the legislation of each Member shall provide for the right of appeal without penalty to a judicial authority.

3. Notice of the decision on appeal shall be given to the appellant and the reasons for such decision shall be provided in writing. The appellant shall also be informed of any rights of further appeal. 
Laws, regulations, judicial decisions and administrative rulings of general application giving effect to this Agreement shall be published in conformity with Article X of GATT 1994 by the country of importation concerned.

\section{Article 13}

If, in the course of determining the customs value of imported goods, it becomes necessary to delay the final determination of such customs value, the importer of the goods shall nevertheless be able to withdraw them from customs if, where so required, the importer provides sufficient guarantee in the form of a surety, a deposit or some other appropriate instrument, covering the ultimate payment of customs duties for which the goods may be liable. The legislation of each Member shall make provisions for such circumstances.

\section{Article 14}

The notes at Annex I to this Agreement form an integral part of this Agreement and the Articles of this Agreement are to be read and applied in conjunction with their respective notes. Annexes II and III also form an integral part of this Agreement.

\section{Article 15}

\section{In this Agreement:}

(a) "customs value of imported goods" means the value of goods for the purposes of levying ad valorem duties of customs on imported goods;

(b) "country of importation" means country or customs territory of importation; and

(c) "produced" includes grown, manufactured and mined.

2. In this Agreement:

(a) "identical goods" means goods which are the same in all respects, including physical characteristics, quality and reputation. Minor differences in appearance would not preclude goods otherwise conforming to the definition from being regarded as identical;

(b) "similar goods" means goods which, although not alike in all respects, have like characteristics and like component materials which enable them to perform the same functions and to be commercially interchangeable. The quality of the goods, their reputation and the existence of a trademark are among the factors to be considered in determining whether goods are similar;

(c) the terms "identical goods" and "similar goods" do not include, as the case may be, goods which incorporate or reflect engineering, development, artwork, design work, and plans and sketches for which no adjustment has been made under paragraph 1 (b) (iv) of Article 8 because such elements were undertaken in the country of importation;

(d) goods shall not be regarded as "identical goods" or "similar goods" unless they were produced in the same country as the goods being valued;

(e) goods produced by a different person shall be taken into account only when there are no identical goods or similar goods, as the case may be, produced by the same person as the goods being valued.

3. In this Agreement "goods of the same class or kind" means goods which fall within a group or range of goods produced by a particular industry or industry sector, and includes identical or similar goods.

4. For the purposes of this Agreement, persons shall be deemed to be related only if:

(a) they are officers or directors of one another's businesses;

(b) they are legally recognized partners in business;

(c) they are employer and employee;

(d) any person directly or indirectly owns, controls or holds 5 per cent or more of the outstanding voting stock or shares of both of them; 
(e) one of them directly or indirectly controls the other;

(f) both of them are directly or indirectly controlled by a third person;

(g) together they directly or indirectly control a third person; or

(h) they are members of the same family.

5. Persons who are associated in business with one another in that one is the sole agent, sole distributor or sole concessionaire, however described, of the other shall be deemed to be related for the purposes of this Agreement if they fall within the criteria of paragraph 4.

\title{
Article 16
}

Upon written request, the importer shall have the right to an explanation in writing from the customs administration of the country of importation as to how the customs value of the importer's goods was determined.

\section{Article 17}

Nothing in this Agreement shall be construed as restricting or calling into question the rights of customs administrations to satisfy themselves as to the truth or accuracy of any statement, document or declaration presented for customs valuation purposes.

\section{PART II}

\section{ADMINISTRATION, CONSULTATIONS AND DISPUTE SETTLEMENT}

\author{
Article 18
}

Institutions

1. There is hereby established a Committee on Customs Valuation (referred to in this Agreement as "the Committee") composed of representatives from each of the Members. The Committee shall elect its own Chairman and shall normally meet once a year, or as is otherwise envisaged by the relevant provisions of this Agreement, for the purpose of affording Members the opportunity to consult on matters relating to the administration of the customs valuation system by any Member as it might affect the operation of this Agreement or the furtherance of its objectives and carrying out such other responsibilities as may be assigned to it by the Members. The WTO Secretariat shall act as the secretariat to the Committee.

2. There shall be established a Technical Committee on Customs Valuation (referred to in this Agreement as "the Technical Committee") under the auspices of the Customs Co-operation Council (referred to in this Agreement as "the CCC"), which shall carry out the responsibilities described in Annex II to this Agreement and shall operate in accordance with the rules of procedure contained therein.

Article 19

Consultations and Dispute Settlement

1. Except as otherwise provided herein, the Dispute Settlement Understanding is applicable to consultations and the settlement of disputes under this Agreement.

2. If any Member considers that any benefit accruing to it, directly or indirectly, under this Agreement is being nullified or impaired, or that the achievement of any objective of this Agreement is being impeded, as a result of the actions of another Member or of other Members, it may, with a view to reaching a mutually satisfactory solution of this matter, request consultations with the Member or Members in question. Each Member shall afford sympathetic consideration to any request from another Member for consultations. 
3. The Technical Committee shall provide, upon request, advice and assistance to Members engaged in consultations.

4. At the request of a party to the dispute, or on its own initiative, a panel established to examine a dispute relating to the provisions of this Agreement may request the Technical Committee to carry out an examination of any questions requiring technical consideration. The panel shall determine the terms of reference of the Technical Committee for the particular dispute and set a time period for receipt of the report of the Technical Committee. The panel shall take into consideration the report of the Technical Committee. In the event that the Technical Committee is unable to reach consensus on a matter referred to it pursuant to this paragraph, the panel should afford the parties to the dispute an opportunity to present their views on the matter to the panel.

5. Confidential information provided to the panel shall not be disclosed without formal authorization from the person, body or authority providing such information. Where such information is requested from the panel but release of such information by the panel is not authorized, a non-confidential summary of this information, authorized by the person, body or authority providing the information, shall be provided.

\section{PART III}

\section{SPECIAL AND DIFFERENTIAL TREATMENT}

\section{Article 20}

1. Developing country Members not party to the Agreement on Implementation of Article VII of the General Agreement on Tariffs and Trade done on 12 April 1979 may delay application of the provisions of this Agreement for a period not exceeding five years from the date of entry into force of the WTO Agreement for such Members. Developing country Members who choose to delay application of this Agreement shall notify the Director-General of the WTO accordingly.

2. In addition to paragraph 1, developing country Members not party to the Agreement on Implementation of Article VII of the General Agreement on Tariffs and Trade done on 12 April 1979 may delay application of paragraph 2 (b) (iii) of $\underline{\text { Article } 1}$ and Article 6 for a period not exceeding three years following their application of all other provisions of this Agreement. Developing country Members that choose to delay application of the provisions specified in this paragraph shall notify the Director-General of the WTO accordingly.

3. Developed country Members shall furnish, on mutually agreed terms, technical assistance to developing country Members that so request. On this basis developed country Members shall draw up programmes of technical assistance which may include, inter alia, training of personnel, assistance in preparing implementation measures, access to sources of information regarding customs valuation methodology, and advice on the application of the provisions of this Agreement.

\section{PART IV}

\section{FINAL PROVISIONS}

\section{Article 21}

\section{Reservations}

Reservations may not be entered in respect of any of the provisions of this Agreement without the consent of the other Members.

Article 22

\section{National Legislation}

1. Each Member shall ensure, not later than the date of application of the provisions of this Agreement for it, the conformity of its laws, regulations and administrative procedures with the provisions of this Agreement.

2. Each Member shall inform the Committee of any changes in its laws and regulations relevant to this Agreement and in the administration of such laws and regulations. 


\section{Article 23}

\section{Review}

The Committee shall review annually the implementation and operation of this Agreement taking into account the objectives thereof. The Committee shall annually inform the Council for Trade in Goods of developments during the period covered by such reviews.

\section{Article 24}

\section{Secretariat}

This Agreement shall be serviced by the WTO Secretariat except in regard to those responsibilities specifically assigned to the Technical Committee, which will be serviced by the CCC Secretariat.

\section{Annex I: Interpretative Notes}

\section{General Note}

\section{Sequential Application of Valuation Methods}

1. Articles 1 through $\underline{7}$ define how the customs value of imported goods is to be determined under the provisions of this Agreement. The methods of valuation are set out in a sequential order of application. The primary method for customs valuation is defined in Article 1 and imported goods are to be valued in accordance with the provisions of this Article whenever the conditions prescribed therein are fulfilled.

2. Where the customs value cannot be determined under the provisions of Article 1 , it is to be determined by proceeding sequentially through the succeeding Articles to the first such Article under which the customs value can be determined. Except as provided in Article 4, it is only when the customs value cannot be determined under the provisions of a particular Article that the provisions of the next Article in the sequence can be used.

3. If the importer does not request that the order of Articles 5 and $\underline{6}$ be reversed, the normal order of the sequence is to be followed. If the importer does so request but it then proves impossible to determine the customs value under the provisions of $\underline{\text { Article } 6}$, the customs value is to be determined under the provisions of $\underline{\text { Article } 5}$, if it can be so determined.

4. Where the customs value cannot be determined under the provisions of $\underline{\text { Articles } 1}$ through $\underline{6}$ it is to be determined under the provisions of Article 7.

\section{Use of Generally Accepted Accounting Principles}

1. "Generally accepted accounting principles" refers to the recognized consensus or substantial authoritative support within a country at a particular time as to which economic resources and obligations should be recorded as assets and liabilities, which changes in assets and liabilities should be recorded, how the assets and liabilities and changes in them should be measured, what information should be disclosed and how it should be disclosed, and which financial statements should be prepared. These standards may be broad guidelines of general application as well as detailed practices and procedures.

2. For the purposes of this Agreement, the customs administration of each Member shall utilize information prepared in a manner consistent with generally accepted accounting principles in the country which is appropriate for the Article in question. For example, the determination of usual profit and general expenses under the provisions of $\underline{\text { Article } 5}$ would be carried out utilizing information prepared in a manner consistent with generally accepted accounting principles of the country of importation. On the other hand, the determination of usual profit and general expenses under the provisions of Article 6 would be carried out utilizing information prepared in a manner consistent with generally accepted accounting principles of the country of production. As a further example, the determination of an element provided for in paragraph 1 
(b) (ii) of Article 8 undertaken in the country of importation would be carried out utilizing information in a manner consistent with the generally accepted accounting principles of that country.

\section{Note to Article 1}

\section{Price Actually Paid or Payable}

1. The price actually paid or payable is the total payment made or to be made by the buyer to or for the benefit of the seller for the imported goods. The payment need not necessarily take the form of a transfer of money. Payment may be made by way of letters of credit or negotiable instruments. Payment may be made directly or indirectly. An example of an indirect payment would be the settlement by the buyer, whether in whole or in part, of a debt owed by the seller.

2. Activities undertaken by the buyer on the buyer's own account, other than those for which an adjustment is provided in $\underline{\text { Article } 8}$, are not considered to be an indirect payment to the seller, even though they might be regarded as of benefit to the seller. The costs of such activities shall not, therefore, be added to the price actually paid or payable in determining the customs value.

3. The customs value shall not include the following charges or costs, provided that they are distinguished from the price actually paid or payable for the imported goods:

(a) charges for construction, erection, assembly, maintenance or technical assistance, undertaken after importation on imported goods such as industrial plant, machinery or equipment;

(b) the cost of transport after importation;

(c) duties and taxes of the country of importation.

4. The price actually paid or payable refers to the price for the imported goods. Thus the flow of dividends or other payments from the buyer to the seller that do not relate to the imported goods are not part of the customs value.

\section{Paragraph 1 (a) (iii)}

Among restrictions which would not render a price actually paid or payable unacceptable are restrictions which do not substantially affect the value of the goods. An example of such restrictions would be the case where a seller requires a buyer of automobiles not to sell or exhibit them prior to a fixed date which represents the beginning of a model year.

Paragraph $1(b)$

1. If the sale or price is subject to some condition or consideration for which a value cannot be determined with respect to the goods being valued, the transaction value shall not be acceptable for customs purposes. Some examples of this include:

(a) the seller establishes the price of the imported goods on condition that the buyer will also buy other goods in specified quantities;

(b) the price of the imported goods is dependent upon the price or prices at which the buyer of the imported goods sells other goods to the seller of the imported goods;

(c) the price is established on the basis of a form of payment extraneous to the imported goods, such as where the imported goods are semi-finished goods which have been provided by the seller on condition that the seller will receive a specified quantity of the finished goods.

2. However, conditions or considerations relating to the production or marketing of the imported goods shall not result in rejection of the transaction value. For example, the fact that the buyer furnishes the seller with engineering and plans undertaken in the country of importation shall not result in rejection of the transaction value for the purposes of Article 1 . Likewise, if the buyer undertakes on the buyer's own account, even though by agreement with the seller, activities relating to the marketing of the imported goods, the value of these activities is not part of the customs value nor shall such activities result in rejection of the transaction value.

\section{Paragraph 2}

1. Paragraphs 2 (a) and 2 (b) provide different means of establishing the acceptability of a transaction value. 
2. Paragraph 2 (a) provides that where the buyer and the seller are related, the circumstances surrounding the sale shall be examined and the transaction value shall be accepted as the customs value provided that the relationship did not influence the price. It is not intended that there should be an examination of the circumstances in all cases where the buyer and the seller are related. Such examination will only be required where there are doubts about the acceptability of the price. Where the customs administration have no doubts about the acceptability of the price, it should be accepted without requesting further information from the importer. For example, the customs administration may have previously examined the relationship, or it may already have detailed information concerning the buyer and the seller, and may already be satisfied from such examination or information that the relationship did not influence the price.

3. Where the customs administration is unable to accept the transaction value without further inquiry, it should give the importer an opportunity to supply such further detailed information as may be necessary to enable it to examine the circumstances surrounding the sale. In this context, the customs administration should be prepared to examine relevant aspects of the transaction, including the way in which the buyer and seller organize their commercial relations and the way in which the price in question was arrived at, in order to determine whether the relationship influenced the price. Where it can be shown that the buyer and seller, although related under the provisions of Article 15, buy from and sell to each other as if they were not related, this would demonstrate that the price had not been influenced by the relationship. As an example of this, if the price had been settled in a manner consistent with the normal pricing practices of the industry in question or with the way the seller settles prices for sales to buyers who are not related to the seller, this would demonstrate that the price had not been influenced by the relationship. As a further example, where it is shown that the price is adequate to ensure recovery of all costs plus a profit which is representative of the firm's overall profit realized over a representative period of time (e.g. on an annual basis) in sales of goods of the same class or kind, this would demonstrate that the price had not been influenced.

4. Paragraph 2 (b) provides an opportunity for the importer to demonstrate that the transaction value closely approximates to a "test" value previously accepted by the customs administration and is therefore acceptable under the provisions of $\underline{\text { Article }}$ 1. Where a test under paragraph 2 (b) is met, it is not necessary to examine the question of influence under paragraph 2 (a). If the customs administration has already sufficient information to be satisfied, without further detailed inquiries, that one of the tests provided in paragraph 2 (b) has been met, there is no reason for it to require the importer to demonstrate that the test can be met. In paragraph 2 (b) the term "unrelated buyers" means buyers who are not related to the seller in any particular case.

\section{Paragraph $2(b)$}

A number of factors must be taken into consideration in determining whether one value "closely approximates" to another value. These factors include the nature of the imported goods, the nature of the industry itself, the season in which the goods are imported, and, whether the difference in values is commercially significant. Since these factors may vary from case to case, it would be impossible to apply a uniform standard such as a fixed percentage, in each case. For example, a small difference in value in a case involving one type of goods could be unacceptable while a large difference in a case involving another type of goods might be acceptable in determining whether the transaction value closely approximates to the "test" values set forth in paragraph 2 (b) of Article 1.

\section{Note to Article 2}

1. In applying Article 2, the customs administration shall, wherever possible, use a sale of identical goods at the same commercial level and in substantially the same quantities as the goods being valued. Where no such sale is found, a sale of identical goods that takes place under any one of the following three conditions may be used:

(a) a sale at the same commercial level but in different quantities;

(b) a sale at a different commercial level but in substantially the same quantities; or

(c) a sale at a different commercial level and in different quantities.

2. Having found a sale under any one of these three conditions adjustments will then be made, as the case may be, for :

(a) quantity factors only; 
(b) commercial level factors only; or

(c) both commercial level and quantity factors.

3. The expression "and/or" allows the flexibility to use the sales and make the necessary adjustments in any one of the three conditions described above.

4. For the purposes of Article 2, the transaction value of identical imported goods means a customs value, adjusted as provided for in paragraphs 1 (b) and 2, which has already been accepted under Article 1.

5. A condition for adjustment because of different commercial levels or different quantities is that such adjustment, whether it leads to an increase or a decrease in the value, be made only on the basis of demonstrated evidence that clearly establishes the reasonableness and accuracy of the adjustments, e.g. valid price lists containing prices referring to different levels or different quantities. As an example of this, if the imported goods being valued consist of a shipment of 10 units and the only identical imported goods for which a transaction value exists involved a sale of 500 units, and it is recognized that the seller grants quantity discounts, the required adjustment may be accomplished by resorting to the seller's price list and using that price applicable to a sale of 10 units. This does not require that a sale had to have been made in quantities of 10 as long as the price list has been established as being bona fide through sales at other quantities. In the absence of such an objective measure, however, the determination of a customs value under the provisions of Article 2 is not appropriate.

\section{Note to Article 3}

1. In applying Article 3, the customs administration shall, wherever possible, use a sale of similar goods at the same commercial level and in substantially the same quantities as the goods being valued. Where no such sale is found, a sale of similar goods that takes place under any one of the following three conditions may be used:

(a) a sale at the same commercial level but in different quantities;

(b) a sale at a different commercial level but in substantially the same quantities; or

(c) a sale at a different commercial level and in different quantities.

2. Having found a sale under any one of these three conditions adjustments will then be made, as the case may be, for:

(a) quantity factors only;

(b) commercial level factors only; or

(c) both commercial level and quantity factors.

3. The expression "and/or" allows the flexibility to use the sales and make the necessary adjustments in any one of the three conditions described above.

4. For the purpose of Article 3 , the transaction value of similar imported goods means a customs value, adjusted as provided for in paragraphs 1 (b) and 2, which has already been accepted under Article 1.

5. A condition for adjustment because of different commercial levels or different quantities is that such adjustment, whether it leads to an increase or a decrease in the value, be made only on the basis of demonstrated evidence that clearly establishes the reasonableness and accuracy of the adjustment, e.g. valid price lists containing prices referring to different levels or different quantities. As an example of this, if the imported goods being valued consist of a shipment of 10 units and the only similar imported goods for which a transaction value exists involved a sale of 500 units, and it is recognized that the seller grants quantity discounts, the required adjustment may be accomplished by resorting to the seller's price list and using that price applicable to a sale of 10 units. This does not require that a sale had to have been made in quantities of 10 as long as the price list has been established as being bona fide through sales at other quantities. In the absence of such an objective measure, however, the determination of a customs value under the provisions of Article 3 is not appropriate.

\section{Note to Article 5}

1. The term "unit price at which ... goods are sold in the greatest aggregate quantity" means the price at which the greatest number of units is sold in sales to persons who are not related to the persons from whom they buy such goods at the first commercial level after importation at which such sales take place. 
2. As an example of this, goods are sold from a price list which grants favourable unit prices for purchases made in larger quantities.

\begin{tabular}{|r|c|l|c|}
\hline Sale quantity & Unit price & Number of sales & Total quantity sold at each price \\
\hline $1-10$ units & 100 & $\begin{array}{l}\text { 10 sales of 5 units } \\
5 \text { sales of 3 units }\end{array}$ & 65 \\
\hline $11-25$ units & 95 & 5 sales of 11 units & 80 \\
\hline over 25 units & 90 & $\begin{array}{l}1 \text { sale of } 30 \text { units } \\
1 \text { sale of 50 units }\end{array}$ & \\
\hline
\end{tabular}

The greatest number of units sold at a price is 80 ; therefore, the unit price in the greatest aggregate quantity is 90 .

3. As another example of this, two sales occur. In the first sale 500 units are sold at a price of 95 currency units each. In the second sale 400 units are sold at a price of 90 currency units each. In this example, the greatest number of units sold at a particular price is 500; therefore, the unit price in the greatest aggregate quantity is 95 .

4. A third example would be the following situation where various quantities are sold at various prices.

\begin{tabular}{|c|c|}
\hline $\begin{array}{c}\text { a) Sales } \\
\text { Sale quantity }\end{array}$ & Unit price \\
\hline 40 units & 100 \\
30 units & 90 \\
15 units & 100 \\
50 units & 95 \\
25 units & 105 \\
35 units & 90 \\
5 units & 100 \\
\hline b) Totals & Unit price \\
Total quantity sold & \\
\hline 65 & 90 \\
50 & 95 \\
60 & 100 \\
25 & 105 \\
\hline
\end{tabular}

In this example, the greatest number of units sold at a particular price is 65 ; therefore, the unit price in the greatest aggregate quantity is 90 .

5. Any sale in the importing country, as described in paragraph 1 above, to a person who supplies directly or indirectly free of charge or at reduced cost for use in connection with the production and sale for export of the imported goods any of the elements specified in paragraph 1 (b) of Article 8, should not be taken into account in establishing the unit price for the purposes of Article 5.

6. It should be noted that "profit and general expenses" referred to in paragraph 1 of Article 5 should be taken as a whole. The figure for the purposes of this deduction should be determined on the basis of information supplied by or on behalf of the importer unless the importer's figures are inconsistent with those obtained in sales in the country of importation of imported goods of the same class or kind. Where the importer's figures are inconsistent with such figures, the amount for profit and general expenses may be based upon relevant information other than that supplied by or on behalf of the importer. 
7. The "general expenses" include the direct and indirect costs of marketing the goods in question.

8. Local taxes payable by reason of the sale of the goods for which a deduction is not made under the provisions of paragraph 1 (a) (iv) of Article 5 shall be deducted under the provisions of paragraph 1 (a) (i) of Article 5.

9. In determining either the commissions or the usual profits and general expenses under the provisions of paragraph 1 of

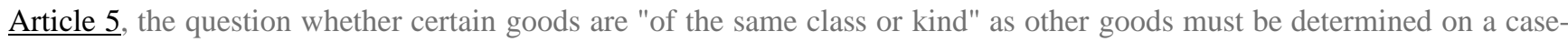
by-case basis by reference to the circumstances involved. Sales in the country of importation of the narrowest group or range of imported goods of the same class or kind, which includes the goods being valued, for which the necessary information can be provided, should be examined. For the purposes of Article 5, "goods of the same class or kind" includes goods imported from the same country as the goods being valued as well as goods imported from other countries.

10. For the purposes of paragraph 1 (b) of Article 5, the "earliest date" shall be the date by which sales of the imported goods or of identical or similar imported goods are made in sufficient quantity to establish the unit price.

11. Where the method in paragraph 2 of Article 5 is used, deductions made for the value added by further processing shall be based on objective and quantifiable data relating to the cost of such work. Accepted industry formulas, recipes, methods of construction, and other industry practices would form the basis of the calculations.

12. It is recognized that the method of valuation provided for in paragraph 2 of Article 5 would normally not be applicable when, as a result of the further processing, the imported goods lose their identity. However, there can be instances where, although the identity of the imported goods is lost, the value added by the processing can be determined accurately without unreasonable difficulty. On the other hand, there can also be instances where the imported goods maintain their identity but form such a minor element in the goods sold in the country of importation that the use of this valuation method would be unjustified. In view of the above, each situation of this type must be considered on a case-by-case basis.

\section{Note to Article 6}

1. As a general rule, customs value is determined under this Agreement on the basis of information readily available in the country of importation. In order to determine a computed value, however, it may be necessary to examine the costs of producing the goods being valued and other information which has to be obtained from outside the country of importation. Furthermore, in most cases the producer of the goods will be outside the jurisdiction of the authorities of the country of importation. The use of the computed value method will generally be limited to those cases where the buyer and seller are related, and the producer is prepared to supply to the authorities of the country of importation the necessary costings and to provide facilities for any subsequent verification which may be necessary.

2. The "cost or value" referred to in paragraph 1 (a) of Article 6 is to be determined on the basis of information relating to the production of the goods being valued supplied by or on behalf of the producer. It is to be based upon the commercial accounts of the producer, provided that such accounts are consistent with the generally accepted accounting principles applied in the country where the goods are produced.

3. The "cost or value" shall include the cost of elements specified in paragraphs 1 (a) (ii) and (iii) of $\underline{\text { Article } 8}$. It shall also include the value, apportioned as appropriate under the provisions of the relevant note to $\underline{\text { Article } 8}$, of any element specified in paragraph 1 (b) of Article 8 which has been supplied directly or indirectly by the buyer for use in connection with the production of the imported goods. The value of the elements specified in paragraph 1 (b) (iv) of Article 8 which are undertaken in the country of importation shall be included only to the extent that such elements are charged to the producer. It is to be understood that no cost or value of the elements referred to in this paragraph shall be counted twice in determining the computed value.

4. The "amount for profit and general expenses" referred to in paragraph 1 (b) of Article 6 is to be determined on the basis of information supplied by or on behalf of the producer unless the producer's figures are inconsistent with those usually reflected in sales of goods of the same class or kind as the goods being valued which are made by producers in the country of exportation for export to the country of importation. 
5. It should be noted in this context that the "amount for profit and general expenses" has to be taken as a whole. It follows that if, in any particular case, the producer's profit figure is low and the producer's general expenses are high, the producer's profit and general expenses taken together may nevertheless be consistent with that usually reflected in sales of goods of the same class or kind. Such a situation might occur, for example, if a product were being launched in the country of importation and the producer accepted a nil or low profit to offset high general expenses associated with the launch. Where the producer can demonstrate a low profit on sales of the imported goods because of particular commercial circumstances, the producer's actual profit figures should be taken into account provided that the producer has valid commercial reasons to justify them and the producer's pricing policy reflects usual pricing policies in the branch of industry concerned. Such a situation might occur, for example, where producers have been forced to lower prices temporarily because of an unforeseeable drop in demand, or where they sell goods to complement a range of goods being produced in the country of importation and accept a low profit to maintain competitivity. Where the producer's own figures for profit and general expenses are not consistent with those usually reflected in sales of goods of the same class or kind as the goods being valued which are made by producers in the country of exportation for export to the country of importation, the amount for profit and general expenses may be based upon relevant information other than that supplied by or on behalf of the producer of the goods.

6. Where information other than that supplied by or on behalf of the producer is used for the purposes of determining a computed value, the authorities of the importing country shall inform the importer, if the latter so requests, of the source of such information, the data used and the calculations based upon such data, subject to the provisions of $\underline{\text { Article } 10}$.

7. The "general expenses" referred to in paragraph 1 (b) of Article 6 covers the direct and indirect costs of producing and selling the goods for export which are not included under paragraph 1 (a) of Article 6.

8. Whether certain goods are "of the same class or kind" as other goods must be determined on a case-by-case basis with reference to the circumstances involved. In determining the usual profits and general expenses under the provisions of $\underline{\text { Article }}$ $\underline{6}$, sales for export to the country of importation of the narrowest group or range of goods, which includes the goods being valued, for which the necessary information can be provided, should be examined. For the purposes of $\underline{\text { Article } 6}$, "goods of the same class or kind" must be from the same country as the goods being valued.

\section{Note to Article 7}

1. Customs values determined under the provisions of Article 7 should, to the greatest extent possible, be based on previously determined customs values.

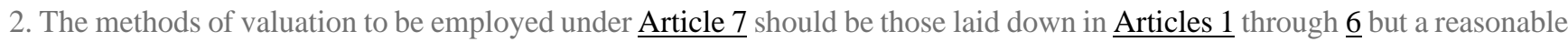
flexibility in the application of such methods would be in conformity with the aims and provisions of Article 7.

3. Some examples of reasonable flexibility are as follows:

(a) Identical goods - the requirement that the identical goods should be exported at or about the same time as the goods being valued could be flexibly interpreted; identical imported goods produced in a country other than the country of exportation of the goods being valued could be the basis for customs valuation; customs values of identical imported goods already determined under the provisions of $\underline{\text { Articles } 5}$ and $\underline{6}$ could be used.

(b) Similar goods - the requirement that the similar goods should be exported at or about the same time as the goods being valued could be flexibly interpreted; similar imported goods produced in a country other than the country of exportation of the goods being valued could be the basis for customs valuation; customs values of similar imported goods already determined under the provisions of $\underline{\text { Articles } 5}$ and $\underline{6}$ could be used.

(c) Deductive method - the requirement that the goods shall have been sold in the "condition as imported" in paragraph 1 (a) of Article 5 could be flexibly interpreted; the "90 days" requirement could be administered flexibly. 


\title{
Note to Article 8
}

\author{
Paragraph 1 (a) (i)
}

The term "buying commissions" means fees paid by an importer to the importer's agent for the service of representing the importer abroad in the purchase of the goods being valued.

\section{Paragraph 1 (b) (ii)}

1. There are two factors involved in the apportionment of the elements specified in paragraph 1 (b) (ii) of $\underline{\text { Article } 8}$ to the imported goods - the value of the element itself and the way in which that value is to be apportioned to the imported goods. The apportionment of these elements should be made in a reasonable manner appropriate to the circumstances and in accordance with generally accepted accounting principles.

2. Concerning the value of the element, if the importer acquires the element from a seller not related to the importer at a given cost, the value of the element is that cost. If the element was produced by the importer or by a person related to the importer, its value would be the cost of producing it. If the element had been previously used by the importer, regardless of whether it had been acquired or produced by such importer, the original cost of acquisition or production would have to be adjusted downward to reflect its use in order to arrive at the value of the element.

3. Once a value has been determined for the element, it is necessary to apportion that value to the imported goods. Various possibilities exist. For example, the value might be apportioned to the first shipment if the importer wishes to pay duty on the entire value at one time. As another example, the importer may request that the value be apportioned over the number of units produced up to the time of the first shipment. As a further example, the importer may request that the value be apportioned over the entire anticipated production where contracts or firm commitments exist for that production. The method of apportionment used will depend upon the documentation provided by the importer.

4. As an illustration of the above, an importer provides the producer with a mould to be used in the production of the imported goods and contracts with the producer to buy 10,000 units. By the time of arrival of the first shipment of 1,000 units, the producer has already produced 4,000 units. The importer may request the customs administration to apportion the value of the mould over 1,000 units, 4,000 units or 10,000 units.

$$
\text { Paragraph } 1 \text { (b) (iv) }
$$

1. Additions for the elements specified in paragraph 1 (b) (iv) of Article 8 should be based on objective and quantifiable data. In order to minimize the burden for both the importer and customs administration in determining the values to be added, data readily available in the buyer's commercial record system should be used in so far as possible.

2. For those elements supplied by the buyer which were purchased or leased by the buyer, the addition would be the cost of the purchase or the lease. No addition shall be made for those elements available in the public domain, other than the cost of obtaining copies of them.

3. The ease with which it may be possible to calculate the values to be added will depend on a particular firm's structure and management practice, as well as its accounting methods.

4. For example, it is possible that a firm which imports a variety of products from several countries maintains the records of its design centre outside the country of importation in such a way as to show accurately the costs attributable to a given product. In such cases, a direct adjustment may appropriately be made under the provisions of Article 8 .

5. In another case, a firm may carry the cost of the design centre outside the country of importation as a general overhead expense without allocation to specific products. In this instance, an appropriate adjustment could be made under the provisions of Article 8 with respect to the imported goods by apportioning total design centre costs over total production benefiting from the design centre and adding such apportioned cost on a unit basis to imports.

6. Variations in the above circumstances will, of course, require different factors to be considered in determining the proper method of allocation.

7. In cases where the production of the element in question involves a number of countries and over a period of time, the adjustment should be limited to the value actually added to that element outside the country of importation. 
1. The royalties and licence fees referred to in paragraph 1 (c) of Article 8 may include, among other things, payments in respect to patents, trade marks and copyrights. However, the charges for the right to reproduce the imported goods in the country of importation shall not be added to the price actually paid or payable for the imported goods in determining the customs value.

2. Payments made by the buyer for the right to distribute or resell the imported goods shall not be added to the price actually paid or payable for the imported goods if such payments are not a condition of the sale for export to the country of importation of the imported goods.

\section{Paragraph 3}

Where objective and quantifiable data do not exist with regard to the additions required to be made under the provisions of $\underline{\text { Article } 8}$, the transaction value cannot be determined under the provisions of Article 1 . As an illustration of this, a royalty is paid on the basis of the price in a sale in the importing country of a litre of a particular product that was imported by the kilogram and made up into a solution after importation. If the royalty is based partially on the imported goods and partially on other factors which have nothing to do with the imported goods (such as when the imported goods are mixed with domestic ingredients and are no longer separately identifiable, or when the royalty cannot be distinguished from special financial arrangements between the buyer and the seller), it would be inappropriate to attempt to make an addition for the royalty. However, if the amount of this royalty is based only on the imported goods and can be readily quantified, an addition to the price actually paid or payable can be made.

\section{Note to Article 9}

For the purposes of Article 9, "time of importation" may include the time of entry for customs purposes.

\section{Note to Article 11}

1. Article 11 provides the importer with the right to appeal against a valuation determination made by the customs administration for the goods being valued. Appeal may first be to a higher level in the customs administration, but the importer shall have the right in the final instance to appeal to the judiciary.

2. "Without penalty" means that the importer shall not be subject to a fine or threat of fine merely because the importer chose to exercise the right of appeal. Payment of normal court costs and lawyers' fees shall not be considered to be a fine.

3. However, nothing in $\underline{\text { Article } 11}$ shall prevent a Member from requiring full payment of assessed customs duties prior to an appeal.

\section{Note to Article 15}

\section{Paragraph 4}

For the purposes of Article 15, the term "persons" includes a legal person, where appropriate.

$$
\text { Paragraph } 4(e)
$$

For the purposes of this Agreement, one person shall be deemed to control another when the former is legally or operationally in a position to exercise restraint or direction over the latter.

\section{Annex II: Technical Committee on Customs Valuation}

1. In accordance with $\underline{\text { Article } 18}$ of this Agreement, the Technical Committee shall be established under the auspices of the CCC with a view to ensuring, at the technical level, uniformity in interpretation and application of this Agreement.

2. The responsibilities of the Technical Committee shall include the following: 
(a) to examine specific technical problems arising in the day-to-day administration of the customs valuation system of Members and to give advisory opinions on appropriate solutions based upon the facts presented;

(b) to study, as requested, valuation laws, procedures and practices as they relate to this Agreement and to prepare reports on the results of such studies;

(c) to prepare and circulate annual reports on the technical aspects of the operation and status of this Agreement;

(d) to furnish such information and advice on any matters concerning the valuation of imported goods for customs purposes as may be requested by any Member or the Committee. Such information and advice may take the form of advisory opinions, commentaries or explanatory notes;

(e) to facilitate, as requested, technical assistance to Members with a view to furthering the international acceptance of this Agreement;

(f) to carry out an examination of a matter referred to it by a panel under Article 19 of this Agreement; and

(g) to exercise such other responsibilities as the Committee may assign to it.

\section{General}

3. The Technical Committee shall attempt to conclude its work on specific matters, especially those referred to it by Members, the Committee or a panel, in a reasonably short period of time. As provided in paragraph 4 of Article 19, a panel shall set a specific time period for receipt of a report of the Technical Committee and the Technical Committee shall provide its report within that period.

4. The Technical Committee shall be assisted as appropriate in its activities by the CCC Secretariat.

\section{Representation}

5. Each Member shall have the right to be represented on the Technical Committee. Each Member may nominate one delegate and one or more alternates to be its representatives on the Technical Committee. Such a Member so represented on the Technical Committee is referred to in this Annex as a "member of the Technical Committee". Representatives of members of the Technical Committee may be assisted by advisers. The WTO Secretariat may also attend such meetings with observer status.

6. Members of the CCC which are not Members of the WTO may be represented at meetings of the Technical Committee by one delegate and one or more alternates. Such representatives shall attend meetings of the Technical Committee as observers.

7. Subject to the approval of the Chairman of the Technical Committee, the Secretary General of the CCC (referred to in this Annex as "the Secretary General") may invite representatives of governments which are neither Members of the WTO nor members of the CCC and representatives of international governmental and trade organizations to attend meetings of the Technical Committee as observers.

8. Nominations of delegates, alternates and advisers to meetings of the Technical Committee shall be made to the Secretary General.

\section{Technical Committee Meetings}

9. The Technical Committee shall meet as necessary but at least two times a year. The date of each meeting shall be fixed by the Technical Committee at its preceding session. The date of the meeting may be varied either at the request of any member of the Technical Committee concurred in by a simple majority of the members of the Technical Committee or, in cases requiring urgent attention, at the request of the Chairman. Notwithstanding the provisions in sentence 1 of this paragraph, the Technical Committee shall meet as necessary to consider matters referred to it by a panel under the provisions of $\underline{\text { Article } 19}$ of this Agreement. 
10. The meetings of the Technical Committee shall be held at the headquarters of the CCC unless otherwise decided.

11. The Secretary General shall inform all members of the Technical Committee and those included under paragraphs 6 and 7 at least 30 days in advance, except in urgent cases, of the opening date of each session of the Technical Committee.

\section{Agenda}

12. A provisional agenda for each session shall be drawn up by the Secretary General and circulated to the members of the Technical Committee and to those included under paragraphs 6 and 7 at least 30 days in advance of the session, except in urgent cases. This agenda shall comprise all items whose inclusion has been approved by the Technical Committee during its preceding session, all items included by the Chairman on the Chairman's own initiative, and all items whose inclusion has been requested by the Secretary General, by the Committee or by any member of the Technical Committee.

13. The Technical Committee shall determine its agenda at the opening of each session. During the session the agenda may be altered at any time by the Technical Committee.

\section{Officers and Conduct of Business}

14. The Technical Committee shall elect from among the delegates of its members a Chairman and one or more ViceChairmen. The Chairman and Vice-Chairmen shall each hold office for a period of one year. The retiring Chairman and ViceChairmen are eligible for re-election. The mandate of a Chairman or Vice-Chairman who no longer represents a member of the Technical Committee shall terminate automatically.

15. If the Chairman is absent from any meeting or part thereof, a Vice-Chairman shall preside. In that event, the latter shall have the same powers and duties as the Chairman.

16. The Chairman of the meeting shall participate in the proceedings of the Technical Committee as such and not as the representative of a member of the Technical Committee.

17. In addition to exercising the other powers conferred upon the Chairman by these rules, the Chairman shall declare the opening and closing of each meeting, direct the discussion, accord the right to speak, and, pursuant to these rules, have control of the proceedings. The Chairman may also call a speaker to order if the speaker's remarks are not relevant.

18. During discussion of any matter a delegation may raise a point of order. In this event, the Chairman shall immediately state a ruling. If this ruling is challenged, the Chairman shall submit it to the meeting for decision and it shall stand unless overruled.

19. The Secretary General, or officers of the CCC Secretariat designated by the Secretary General, shall perform the secretarial work of meetings of the Technical Committee.

\section{Quorum and Voting}

20. Representatives of a simple majority of the members of the Technical Committee shall constitute a quorum.

21. Each member of the Technical Committee shall have one vote. A decision of the Technical Committee shall be taken by a majority comprising at least two thirds of the members present. Regardless of the outcome of the vote on a particular matter, the Technical Committee shall be free to make a full report to the Committee and to the CCC on that matter indicating the different views expressed in the relevant discussions. Notwithstanding the above provisions of this paragraph, on matters referred to it by a panel, the Technical Committee shall take decisions by consensus. Where no agreement is reached in the Technical Committee on the question referred to it by a panel, the Technical Committee shall provide a report detailing the facts of the matter and indicating the views of the members.

\section{Languages and Records}

22. The official languages of the Technical Committee shall be English, French and Spanish. Speeches or statements made in any of these three languages shall be immediately translated into the other official languages unless all delegations agree to dispense with translation. Speeches or statements made in any other language shall be translated into English, French and Spanish, subject to the same conditions, but in that event the delegation concerned shall provide the translation into English, 
French or Spanish. Only English, French and Spanish shall be used for the official documents of the Technical Committee. Memoranda and correspondence for the consideration of the Technical Committee must be presented in one of the official languages.

23. The Technical Committee shall draw up a report of all its sessions and, if the Chairman considers it necessary, minutes or summary records of its meetings. The Chairman or a designee of the Chairman shall report on the work of the Technical Committee at each meeting of the Committee and at each meeting of the CCC.

\section{Annex III}

1. The five-year delay in the application of the provisions of the Agreement by developing country Members provided for in paragraph 1 of Article 20 may, in practice, be insufficient for certain developing country Members. In such cases a developing country Member may request before the end of the period referred to in paragraph 1 of Article 20 an extension of such period, it being understood that the Members will give sympathetic consideration to such a request in cases where the developing country Member in question can show good cause.

2. Developing countries which currently value goods on the basis of officially established minimum values may wish to make a reservation to enable them to retain such values on a limited and transitional basis under such terms and conditions as may be agreed to by the Members.

3. Developing countries which consider that the reversal of the sequential order at the request of the importer provided for in Article 4 of the Agreement may give rise to real difficulties for them may wish to make a reservation to Article 4 in the following terms :

"The Government of ... reserves the right to provide that the relevant provision of Article 4 of the Agreement shall apply only when the customs authorities agree to the request to reverse the order of $\underline{\operatorname{Articles}} \mathbf{5}$ and $\underline{\mathbf{6}}$.

If developing countries make such a reservation, the Members shall consent to it under Article 21 of the Agreement.

4. Developing countries may wish to make a reservation with respect to paragraph 2 of Article 5 of the Agreement in the following terms:

"The Government of ... reserves the right to provide that paragraph 2 of Article 5 of the Agreement shall be applied in accordance with the provisions of the relevant note thereto whether or not the importer so requests."

If developing countries make such a reservation, the Members shall consent to it under Article 21 of the Agreement.

5. Certain developing countries may have problems in the implementation of Article 1 of the Agreement insofar as it relates to importations into their countries by sole agents, sole distributors and sole concessionaires. If such problems arise in practice in developing country Members applying the Agreement, a study of this question shall be made, at the request of such Members, with a view to finding appropriate solutions.

6. Article 17 recognizes that in applying the Agreement, customs administrations may need to make enquiries concerning the truth or accuracy of any statement, document or declaration presented to them for customs valuation purposes. The Article thus acknowledges that enquiries may be made which are, for example, aimed at verifying that the elements of value declared or presented to customs in connection with a determination of customs value are complete and correct. Members, subject to their national laws and procedures, have the right to expect the full co-operation of importers in these enquiries.

7. The price actually paid or payable includes all payments actually made or to be made as a condition of sale of the imported goods, by the buyer to the seller, or by the buyer to a third party to satisfy an obligation of the seller. 


\section{Annex I \\ WTO Uruguay Round Ministerial Decisions}

World Trade Organization

G/VAL/1

27 April 1995

Committee on Customs Valuation

MARRAKESH MINISTERIAL DECISIONS AND TEXTS

RELATING TO CUSTOMS VALUATION

In accordance with the recommendation made by Ministers at Marrakesh, the following Decision and texts are being put forward to the Committee for adoption.

\section{DECISION REGARDING CASES WHERE CUSTOMS ADMINISTRATIONS HAVE REASONS TO DOUBT THE TRUTH OR ACCURACY}

\section{OF THE DECLARED VALUE}

The Committee on Customs Valuation,

Reaffirming that the transaction value is the primary basis of valuation under the Agreement on Implementation of Article VII of GATT 1994 (hereinafter referred to as the "Agreement");

Recognizing that the customs administration may have to address cases where it has reason to doubt the truth or accuracy of the particulars or of documents produced by traders in support of a declared value;

Emphasizing that in so doing the customs administration should not prejudice the legitimate commercial interests of traders;

Taking into account Article 17 of the Agreement, paragraph 6 of Annex III to the Agreement, and the relevant decisions of the Technical Committee on Customs Valuation;

Decides as follows:

1. When a declaration has been presented and where the customs administration has reason to doubt the 
truth or accuracy of the particulars or of documents produced in support of this declaration, the customs administration may ask the importer to provide further explanation, including documents or other evidence, that the declared value represents the total amount actually paid or payable for the imported goods, adjusted in accordance with the provisions of Article 8. If, after receiving further information, or in the absence of a response, the customs administration still has reasonable doubts about the truth or accuracy of the declared value, it may, bearing in mind the provisions of Article 11, be deemed that the customs value of the imported goods cannot be determined under the provisions of Article 1. Before taking a final decision, the customs administration shall communicate to the importer, in writing if requested, its grounds for doubting the truth or accuracy of the particulars or documents produced and the importer shall be given a reasonable opportunity to respond. When a final decision is made, the customs administration shall communicate to the importer in writing its decision and the grounds therefor.

2. It is entirely appropriate in applying the Agreement for one Member to assist another Member on mutually agreed terms.

\title{
II. DECISION ON TEXTS RELATING TO MINIMUM VALUES AND
}

\author{
IMPORTS BY SOLE AGENTS, SOLE DISTRIBUTORS
}

AND SOLE CONCESSIONAIRES

The Committee on Customs Valuation,

Decides to adopt the following texts:

Where a developing country makes a reservation to retain officially established minimum values within the terms of paragraph 2 of Annex III and shows good cause, the Committee shall give the request for the reservation sympathetic consideration.

Where a reservation is consented to, the terms and conditions referred to in paragraph 2 of Annex III shall take full account of the development, financial and trade needs of the developing country concerned.

II

1. A number of developing countries have a concern that problems may exist in the valuation of imports by sole agents, sole distributors and sole concessionaires. Under paragraph 1 of Article 20, 
developing country Members have a period of delay of up to five years prior to the application of the Agreement. In this context, developing country Members availing themselves of this provision could use the period to conduct appropriate studies and to take such other actions as are necessary to facilitate application.

2. In consideration of this, the Committee recommends that the Customs Co-operation Council assist developing country Members, in accordance with the provisions of Annex II, to formulate and conduct studies in areas identified as being of potential concern, including those relating to importations by sole agents, sole distributors and sole concessionaires. 


\title{
Annex J \\ GATT/WTO Valuation Committee Decisions
}

World Trade Organization

G/VAL/5

13 October 1995

Committee on Customs Valuation

\section{DECISIONS CONCERNING THE INTERPRETATION AND ADMINISTRATION OF THE AGREEMENT ON IMPLEMENTATION OF ARTICLE VII}

\author{
OF THE GATT 1994 (CUSTOMS VALUATION)
}

The following Decisions concerning the interpretation and administration of the Agreement were adopted by the WTO Committee on Customs Valuation at its meeting of 12 May 1995. These decisions, contained in sections A and B of document G/VAL/W/1, were originally adopted by the Tokyo Round Committee on Customs Valuation. The decisions contained in Section A were adopted by the WTO Committee without any amendments, while the text of the decisions in Section B was adapted to the WTO situation. The Committee decided not to take any action on the Procedures for the derestriction of documents set out in section B.3 of document G/VAL/W/1, until the General Council would take a decision on this question.

\section{A. DECISIONS CONCERNING THE INTERPRETATION OF THE AGREEMENT}

\section{A.1 Meaning of the word "undertaken" in Article 8.1(b) (iv) of the English text of the Agreement}

\section{Adopted by the Tokyo Round Committee on 3 March 1983 (VAL/M/6, paragraph 18)}

The Committee agreed that in the context of Article 8.1(b) (iv) of the Agreement, the English word "undertaken" was to be understood as meaning "carried out". It noted that the French and Spanish texts of the Agreement were not affected.

\section{A.2 Linguistic consistency of the item "development" in Article 8.1(b)(iv) of the Agreement (VAL/M/13)}

The Chairman made the following statement at the Tokyo Round Committee meeting of 9-

10 May 1985:

"Consultations have taken place and in the light of these I suggest that the matter be settled by 
including the following statement in the minutes of the meeting, on the understanding that this would be without prejudice to rights and obligations under the Agreement and that members of the Committee can revert to the matter should the need arise.

"The Parties to the Agreement considered that the terms "development" in English, "travaux d'étude" in French and "creación y perfeccionamiento" in Spanish in Article 8.1(b) are understood to exclude "research" in English, "recherche" in French and "investigación" in Spanish, as stated in paragraph 6 of VAL/W/24/Rev.1. However, one signatory, Argentina, considered that, as used in

Article 8.1(b), the Spanish expression "creación y perfeccionamiento" could not be interpreted as allowing any part of the value to be excluded from the "creación y perfeccionamiento"."

\section{A.3 Decision on the treatment of interest charges in the customs value of imported goods (VAL/6/Rev.1)}

Adopted by the Tokyo Round Committee on 26 April 1984 (VAL/M/9, paragraph 38) and rectified (French and Spanish texts only) by the Committee on 24 September 1984 (VAL/M/10, paragraph 17)

The Parties to the Agreement on Implementation of Article VII of the GATT agree as follows:

Charges for interest under a financing arrangement entered into by the buyer and relating to the purchase of imported goods shall not be regarded as part of the customs value provided that:

(a) the charges are distinguished from the price actually paid or payable for the goods;

(b) the financing arrangement was made in writing;

(c) where required, the buyer can demonstrate that

such goods are actually sold at the price declared as the price actually paid or payable, and

- the claimed rate of interest does not exceed the level for such transactions prevailing in the country where, and at the time when the finance was provided.

This Decision shall apply regardless of whether the finance is provided by the seller, a bank or another natural or legal person. It shall also apply, if appropriate, where goods are valued under a method other than the transaction value.

Each Party shall notify the Committee of the date from which it will apply the Decision.

\section{A.4 Decision on the valuation of carrier media bearing}




\section{software for data processing equipment (VAL/8)}

\section{Adopted by the Tokyo Round Committee on 24 September 1984 (VAL/M/10, paragraph 7)}

The Committee on Customs Valuation DECIDES as follows:

1. It is reaffirmed that transaction value is the primary basis of valuation under the Agreement on Implementation of Article VII of the General Agreement on Tariffs and Trade (the Agreement) and that its application with regard to data or instructions (software) recorded on carrier media for data processing equipment is fully consistent with the Agreement.

2. Given the unique situation ${ }^{1}$ with regard to data or instructions (software) recorded on carrier media for data processing equipment, and that some Parties have sought a different approach, it would also be consistent with the Agreement for those Parties which wish to do so to adopt the following practice:

In determining the customs value of imported carrier media bearing data or instructions, only the cost or value of the carrier medium itself shall be taken into account. The customs value shall not, therefore, include the cost or value of the data or instructions, provided that this is distinguished from the cost or the value of the carrier medium.

For the purpose of this Decision, the expression "carrier medium" shall not be taken to include integrated circuits, semiconductors and similar devices or articles incorporating such circuits or devices; the expression "data or instructions" shall not be taken to include sound, cinematic or video recordings.

3. Those Parties adopting the practice referred to in paragraph 2 of this Decision shall notify the Committee of the date of its application.

4. Those Parties adopting the practice in paragraph 2 of this Decision will do so on a most-favourednation (m.f.n.) basis, without prejudice to the continued use by any Party of the transaction value practice.

\section{A.5 Rectification of the French text of paragraph 1 of the Note to Article 2 and the Note to Article 3}

Refer to the Tokyo Round Committee meeting of 20 March 1990 (VAL/M/26, paragraph 24)

No objections were raised to the proposed rectification of the French text of paragraph 1 of both the Note to Article 2 and the Note to Article 3 which suggested replacing "la vente" in the first sentence by "celui" and to change the second sentence to read "En l'absence d'une telle vente....differente" (VAL/W/49/Add.4).

\section{B. DECISIONS CONCERNING THE ADMINISTRATION OF THE AGREEMENT AND WORKING PROCEDURES OF THE COMMITTEE}




\section{(The Decisions have been adapted to the WTO situation)}

\section{B.1 Reservations under the Agreement on Customs Valuation}

\section{Adopted by the Tokyo Round Committee on 13 January 1981 (VAL/M/1, paragraph 36 and}

Annex 2)

1. A reservation made under Article 21 of the Agreement by a Member accepting the WTO Agreement before 1 January 1995 shall be deemed to be accepted by the other Members unless the Committee is notified (through the Secretariat) by a particular Member to the contrary before 1 February 1995. Upon request of a Member or Members notified to the Secretariat before 1 February 1995, the time-limit shall be extended for another thirty days.

2. Members that accept the WTO Agreement on or after 1 January 1995 shall be deemed to accept all reservations previously accepted by the Members. Reservations made by Members which accept the WTO Agreement on or after 1 January 1995 shall be deemed to be accepted by the other Members unless the Committee is notified (through the Secretariat) to the contrary by a particular Member before expiry of thirty days following the date on which the WTO Agreement enters into force for the Members making the reservation. Upon request of a Member or Members notified to the Secretariat before the expiry of the period referred to in the preceding sentence, the time-limit shall be extended for a further thirty days.

3. For reservations made under paragraph 2 of Annex III, the Member having made the reservation shall communicate to the Committee (through the Secretariat) in due course a proposal containing the terms and conditions under which it wants to retain the minimum customs values (or similar schemes). This proposal would be discussed by the Committee with the aim of reaching an agreement on the terms and conditions of such reservation. Agreement should be reached as quickly as possible and at any rate not later than the date at which the Member having availed itself of the possibility of Article 20.1 starts implementing the provisions of the Agreement.

4. A reservation shall not come into force if:

- $\quad$ in the case of a reservation made under Article 21 of the Agreement another Member objects to the reservation within the time-limits as specified in paragraphs 1 and 2 or,

- $\quad$ in the case of a reservation made under paragraph 2 of Annex III, no agreement has been reached on the content (terms and conditions) of the reservation by the time that the Agreement is implemented by the Member in question.

Cases where a minority view about the acceptability or non-acceptability of a reservation exists would be examined in the Committee, at the request of the Member wishing to enter the reservation, with a view to seeking a mutually acceptable solution.

5. Reservations made by a developing country Member in conformity with paragraphs 3 or 4 of Annex III to the Agreement shall be deemed to be consented to by the other Members. 


\section{B.2 Notification and circulation of national legislation in accordance with Article 22 of the Agreement}

\section{Adopted by the Tokyo Round Committee on 13 January 1981 (VAL/M/1, paragraph 37)}

Members will submit the complete texts of their national legislation (laws, regulations, etc.) on customs valuation in one of the three official WTO languages as soon as possible to the

Secretariat which will circulate them as Committee documents to the other Members in the language submitted. If a general interest is expressed in the Committee that the text of a particular Member be available also in other official WTO languages, this text will be translated and circulated as a Committee document. In those cases where the national legislation is not in an official WTO language, the original texts shall also be submitted to the Secretariat where they will be open for inspection.

(ii) It is understood that the texts of the national legislation of developing country Members availing themselves of the provisions of Article 20, paragraphs 1 and 2 of the Agreement will be supplied to the Committee before the developing country Members begin the application of the provisions of the Agreement.

(iii) At its meeting of 12 May 1995 the WTO Committee decided that in cases of Members who were Tokyo Round signatories and whose legislation had already been examined, a communication from those Members could be sent to the WTO Secretariat indicating that legislation notified under the Tokyo Round Customs Valuation Agreement remained valid under the WTO Customs Valuation Agreement with a specific reference to the document containing the legislation. The Secretariat would then proceed to circulate this notification in a WTO document $(\mathrm{G} / \mathrm{VAL} / \mathrm{M} / 1$, paragraph 29-35).

\section{B.3 Checklist of issues}

\section{Adopted by the Tokyo Round Committee on 5 May 1981 (VAL/M/2, paragraph 52)}

(i) "The Committee decided that Members should respond in writing to the points contained in the checklist."

(ii) At its meeting of 12 May 1995 the WTO Committee decided that in cases of Members who were Tokyo Round signatories and whose legislation had already been examined, a communication from those Members could be sent to the Secretariat indicating that their responses to the checklist of issues remained valid under the WTO Customs Valuation Agreement (G/VAL/M/1, paragraph 36-39).

\section{ANNEX}




\section{CHECKLIST OF ISSUES}

1. Questions concerning Article 1:

(a) Sales between related persons:

(i) Are sales between related persons subject to special provisions?

(ii) Is the fact of intercompany prices prima facie considered as grounds for regarding the respective prices as being influenced?

(iii) What is the provision for giving the communication of the afore-mentioned grounds in writing if the importer so requests? (Article 1.2(a))

(iv) How has Article 1.2(b) been implemented?

(b) Price of lost or damaged goods:

Are there any special provisions or practical arrangements concerning the valuation of lost or damaged goods?

2. How has the provision of Article 4 to allow the importer an option to reverse the order of application of Articles 5 and 6 been implemented?

3. How has Article 5.2 been implemented?

4. How has Article 6.2 been implemented?

5. Questions concerning Article 7:

(a) What provisions have been made for making value determinations pursuant to Article 7 ?

(b) What is the provision for informing the importer of the customs value determined under Article 7?

(c) Are the prohibitions found in Article 7.2 delineated?

6. How have the options found in Article 8.2 been handled? In the case of f.o.b. application, are exfactory prices also accepted?

7. Where is the rate of exchange published, as required by Article 9.1?

8. What steps have been taken to ensure confidentiality, as required by Article 10? 
9. Questions concerning Article 11:

(a) What rights of appeal are open to the importer or any other person?

(b) How is he to be informed of his right to further appeal?

10. Provide information on the publication, as required by Article 12, of:

(a) (i) the relevant national laws;

(ii) the regulations concerning the application of the Agreement;

(iii) the judicial decision and administrative rulings of general application relating to the Agreement;

(iv) general or specific laws being referred to in the rules of implementation or application.

(b) Is the publication of further rules anticipated? Which topics would they cover?

11. Questions concerning Article 13:

(a) How is the obligation of Article 13 (last sentence) being dealt with in the respective legislation?

(b) Have additional explanations been laid down?

12. Questions concerning Article 16:

(a) Does the respective national legislation contain a provision requiring customs authorities to give an explanation in writing as to how the customs value was determined?

(b) Are there any further regulations concerning an above-mentioned request?

13. How have the Interpretative Notes of the Agreement been included?

14. How have the provisions of the Decision on the Treatment of Interest Charges in the Customs Value of Imported Goods been implemented?

15. For those countries applying paragraph 2 of the Decision on the Valuation of Carrier Media Bearing Software for Data Processing Equipment, how have the provisions of this paragraph been implemented?

For all questions listed above, an indication of the references is requested. 


\section{B.4 Information on technical assistance}

Agreed by the Tokyo Round Committee on 9-10 May 1985 (VAL/M/13, paragraph 8)

"...In regard to the point raised at the Committee's last meeting about whether there was need to ensure greater transparency of technical assistance activities so as to give interested developing country Members further information and also to help Members in their planning (VAL/M/1, paragraph 18), the Committee agreed that the information documents prepared for the Technical Committee on such activities were also made available as a WTO document..." 


\section{Annex K \\ WCO TCCV List of Instruments}

\section{Advisory Opinions}

1.1 The concept of "sale" in the Agreement. (Adopted, 2nd Session, 2 October 1981, 27.960)

2.1 Acceptability of a price below prevailing market prices for identical goods. (Adopted, 2nd Session, 2 October 1981, 27.960)

3.1 Meaning of "are distinguished" in the Interpretative Note to Article 1 of the Agreement: duties and taxes of the country of importation. (Adopted, 2nd Session, 2 October 1981, 27.960)

4.1 Royalties and licence fees under Article 8.1 (c) of the Agreement. (Royalty that the seller requires the importer to pay to a third party (the patent holder) (Adopted, 2nd Session, 2 October 1981, 27.960

4.2 Royalties and licence fees under Article 8.1 (c) of the Agreement. (Royalty that the laws of the country of importation require the importer to pay to a third party (the copyright holder) when he resells the imported records.) (Adopted, 3rd Session, 23 March 1982, 28.560)

4.3 Royalties and licence fees under Article 8.1 (c) of the Agreement.

(Royalty that the importer is required to pay to a third party (the patent holder), under a separate contract, for the right to use a patented process for the manufacture of certain products.) (Adopted, 2nd Session, 2 October 1981, 27.960)

4.4 Royalties and licence fees under Article 8.1 (c) of the Agreement.

(Royalty that the importer is required to pay to a seller (the patent holder), as a condition of sale, for the right to incorporate or use the patented concentrate in products intended for resale.) (Adopted, 3rd Session, 23 March 1982, 28.560)

4.5 Royalties and licence fees under Article 8.1 (c) of the Agreement.

(Royalty that the importer is required to pay to a trademark holder for making and selling under that trademark six types of cosmetics irrespective of whether he uses the ingredients imported from the trademark holder or not.) (Adopted, 3rd Session, 23 March 1982, 28.560)

4.6 Royalties and licence fees under Article 8.1 (c) of the Agreement.

(Royalty that the importer is required to pay to a seller (the trademark holder), as a condition of sale, when he resells the imported goods (the concentrate) with the trademark.) (Adopted, 5th Session, 11 March 1983, 29.960

4.7 Royalties and licence fees under Article 8.1 (c) of the Agreement. 
(Royalty that the importer is required to pay to a seller, who has been assigned world-wide reproduction, marketing and distribution rights by a rights holder, for the marketing and distribution rights in the country of importation.) (Adopted, 26th Session, 8 October 1993, 38.480)

4.8 Royalties and licence fees under Article 8.1 (c) of the Agreement. (Royalty that the importer is required to pay to a third party the licence holder) for the right to use the trademark.) (Adopted, 26th Session, 8 October 1993, 38.480)

4.9 Royalties and licence fees under Article 8.1 (c) of the Agreement. (Royalty that the importer is required to pay to a seller (the trademark holder) for the right to manufacture, use and sell the "licensed preparation" in the country of importation and for the right and licence to use the trademark in connection with the manufacture and sale of licensed preparations in the country of importation) (Adopted, 26th Session, 8 October 1993, 38.480)

4.10 Royalties and licence fees under Article 8.1 (c) of the Agreement. (Licence fee that the importer is required to pay to a seller(the trademark holder)for the right to resell the imported garments containing trademarked material.) (Adopted, 26th Session, 8 October 1993, 38.480)

4.11 Royalties and licence fees under Article 8.1 (c) of the Agreement. (Royalty that the importer is required to pay to a related party the trademark holder), who is also related to a seller (manufacturer), for the right to use the trademark which is affixed to the imported goods.) (Adopted, 26th Session, 8 October 1993, 38.480)

4.12 Royalties and licence fees under Article 8.1 (c) of the Agreement. (Licence fee that the importer is required to pay to a seller for the right to use the patented process, which is performed through a technology incorporated in the imported goods.) (Adopted, 26th Session, 8 October 1993, 38.480)

4.13 Royalties and licence fees under Article 8.1 (c) of the Agreement. (Royalty that the importer is required to pay to a related party (the trademark holder) for the right to use the trademark.) (Adopted, 26th Session, 8 October 1993, 38.480)

4.14 Royalties and licence fees under Article 8.1 (c) of the Agreement. (Royalty or licence fees that are paid to the licensor in the country of importation.) (Adopted, 22th Session, 7 April 2006, VT0499)

4.15 Royalties and licence fees under Article 8.1 (c) of the Agreement. (Royalty paid to a third party licensor) (Adopted, 36th Session, 19 April 2013, VT0875E1c)

4.16 Royalties and licence fees under Article 8.1 (c) of the Agreement. (Tax withheld on royalty that the laws of the country of importation require) (Adopted, 40th Session, 8 May 2015, VT0967E1c)

4.17 Royalties and licence fees under Article 8.1(c) of the Agreement. 
(Royalties paid under a franchise agreement) (Adopted, 44th Session, 12 May 2017, VT1075E1c)

5.1 Treatment of cash discount under the Agreement.

(The case that payment for the goods has been made before the time of valuation.) (Adopted, 3rd Session, 23 March 1982, 28.560)

5.2 Treatment of cash discount under the Agreement.

(The case that payment for the goods has not yet been made at the time of valuation: the requirements of Article 1.1 (b) of the Agreement.) (Adopted, 3rd Session, 23 mars 1982, 28.560)

5.3 Treatment of cash discount under the Agreement.

(The case that payment for the goods has not yet been made at the time of valuation: the transaction value under Article 1 of the Agreement.) (Adopted, 5th Session, 11 March 1983, 29.960)

6.1 Treatment of barter or compensation deals under the Agreement. (Adopted, 3rd Session, 23 March $1982,28.560)$

7.1 Acceptability of test values under Article 1.2 (b) (i) of the Agreement. (Adopted, 3rd Session, 23 March 1982, 28.560),

8.1 Treatment under the Agreement of credits in respect of earlier transactions. (Adopted, 3rd Session, 23 March 1982, 28.560),

9.1 Treatment of anti-dumping and countervailing duties when applying the deductive method.

(Adopted, 4th Session, 24 September 1982, 29.260),

10.1 Treatment of fraudulent documents. (Adopted, 6th Session, 16 September 1983, 30.480),

11.1 Treatment of inadvertent errors and of incomplete documentation. (Adopted, 7th Session, 2 March 1984, 31.460),

12.1 Flexible application of Article 7 of the Agreement. (Adopted, 6th Session, 16 September 1983, 30.480),

12.2 Hierarchical order in applying Article 7. (Adopted, 6th Session, 16 September 1983, 30.480)

12.3 Use of data from foreign sources in applying Article 7. (Adopted, 6th Session, 16 September $1983,30.480)$

13.1 Scope of the word "insurance" under Article 8.2 (c) of the Agreement. (Adopted, 6th Session, 16 September 1983, 30.480)

14.1 Meaning of the expression "sold for export to the country of importation". (Adopted 9th Session, 8 March 1985, 32.350) 
15.1 Treatment of quantity discounts. (Adopted, 12th Session, 10 October 1986, 33.590)

16.1 Treatment of a situation where the sale or price is subject to some condition or consideration for which a value can be determined with respect to the goods being valued. (Adopted, 15th Session, 17 March 1988, 34.628)

17.1 Scope and implication of Article 11 of the Agreement. (Adopted, 15th Session, 17 March 1988, 34.628)

18.1 Implications of Article 13 of the Agreement. (Adopted, 15th Session, 17 March 1988, 34.628)

19.1 Application of Article 17 of the Agreement and paragraph 6 of Annex III. (Adopted, 15th Session, 17 March 1988, 34.628)

20.1 Conversion of currency in cases where the contract provides for a fixed rate of exchange. Adopted, 17th Session, 17 March 1989, 35.250) and four examples (18th Session, 21 November 1989, Doc. 35.650) adopted

21.1 Interpretation of the expression "partners in business" in Article 15.4 (b). (Adopted, 2nd Session, 8 March 1996, 40.210)

22.1 Valuation of imported technical documents relating to design and development of an industrial plant. (Adopted, 28th Session, 3 April 2009, VT0686E1c)

\section{Commentaries}

1.1 Identical or similar goods for the purpose of the Agreement. (Adopted, 3rd Session, 23 March $1982,28.560)$

2.1 Goods subject to export subsidies or bounties. (Adopted, 3rd Session, 23 March 1982, 28.560) (Amended and approved, 6th Session, 1 May 1998, 42.359)

3.1 Goods sold at dumping prices. (Adopted, 3rd Session, 23 March 1982, 28.560)

4.1 Price review clauses. (Adopted, 3rd Session, 23 March 1982, 28.560)

5.1 Treatment of goods returned after temporary exportation for manufacturing, processing or repair. (Adopted, 5th Session, 11 March 1983, 29.960)

6.1 Treatment of split shipments under Article 1 of the Agreement. (Adopted, 6th Session, 16 September 1983, 30.480)

7.1 Treatment of storage and related expenses under the provisions of Article 1. (Adopted, 6th Session, 16 September 1983, 30.480) 
8.1 Treatment of package deals. (Adopted, 7th Session, 2 March 1984, 31.460)

9.1 Treatment of costs of activities taking place in the country of importation. (Adopted, 8th Session, 5 October 1984, 31.900)

10.1 Adjustment for difference in commercial level and in quantity under Article 1.2 (b) and Articles 2 and 3 of the Agreement. (Adopted, 8th Session, 5 October 1984, 31.900)

11.1 Treatment of tie-in sales. (Adopted, 9th Session, 8 March 1985, 32.350)

12.1 Meaning of the term "restrictions" in Article 1.1 (a) (iii). (Adopted, 10th Session, 4 October 1985, 32.940)

13.1 Application of the decision on the valuation of carrier media bearing software for data processing equipment. (Adopted, 14th Session, 8 October 1987, 34.380)

14.1 Application of Article 1, paragraph 2. (Adopted, 18th Session, 21 November 1989, 35.650)

15.1 Application of deductive value method. (Adopted, 18th Session, 21 November 1989, 35.650)

16.1 Activities undertaken by the buyer on his own account after purchase of the goods but before importation. (Adopted, 20th Session, 12 October 1990, 36.280)

17.1 Buying commissions. (Adopted, 20th Session, 12 October 1990, 36.280)

18.1 Relationship between Articles 8.1 (b) (ii) and 8.1 (b) (iv). (Adopted, 24th Session, 23 October 1992, 37.860)

19.1 Meaning of the expression "right to reproduce the imported goods" within the meaning of the Interpretative Note to Article 8.1 (c). (Adopted, 28th Session, 7 October 1994, 39.000)

20.1 Warranty charges. (Adopted, 7th Session, 9 October 1998, 42.620)

21.1 Cost of transportation: Free-on-board system of valuation. (Adopted, 7th Session, 9 October 1998, 42.620)

22.1 Meaning of the expression "sold for export to the country of importation" in a series of sales. (Adopted, 24th Session, 26 April 2007, VT0564)

23.1 Examination of the expression "circumstances surrounding the sale" under Article 1.2 (a) in relation to the use of transfer pricing studies. (Adopted, 31st Session, 29 October 2010, VT0774E1c) 
24.1 Determination of the Value of an Assist under Article 8.1(b) of the Agreement. (Adopted, 31st Session, 29 October 2010, VT0774E1c)

25.1 Third party royalties and licence fees - General commentary. (Adopted, 32nd Session, 15 April 2011, VT0800E1c)

\section{Explanatory Notes}

1.1 Time element in relation to Articles 1, 2 and 3 of the Agreement. (Adopted, 2nd Session, 2 October 1981, 27.960)

2.1 Commissions and brokerage in the context of Article 8 of the Agreement. (Adopted, 3rd Session, 23 March 1982, 28.560)

3.1 Goods not in accordance with contract. (Adopted, 3rd Session, 23 March 1982, 28.560)

4.1 Consideration of relationship under Article 15.5, read in conjunction with Article 15.4. (Adopted, 10th Session, 4 October 1985, 32.940)

5.1 Confirming commissions. (Adopted, 23th Session, 20 March 1992, 37.420)

6.1 Distinction between the term "maintenance" in the Note to Article 1 and the term "warranty. (Adopted, 1st Session, 6 October 1995, 39.790)

\section{Case Studies}

1.1 Report on a case study with special reference to Article 8.1 (b) (iv): engineering, development, artwork, etc. (Adopted, 3rd Session, 23 March 1982, 28.560)

2.1 Application of Article 8.1 (d) of the Agreement. (Adopted, 5th Session, 11 March 1983, 29.960)

2.2 Treatment of proceeds under Article 8.1 (d). (Adopted, 5th Session, 11 March 1983, 29.960)

3.1 Restrictions and conditions in Article 1. (Adopted, 9th Session, 8 March 1985, 32.350)

4.1 Treatment of rented or leased goods. (Adopted, 12th Session, 10 October 1986, 33.590)

5.1 Application of Article 8.1 (b).

(Assists in relation to armored vehicles: the basic vehicles.) (Adopted, 18th Session, 21 November 1989, 35.650)

5.2 Application of Article 8.1 (b).

(Assists in relation to the manufacture of racing cars: the carburetors; the electronic checking equipment; the fuel for the racetrack tests; and the plans and sketches.) (Adopted, 18th Session, 21 November 1989, 35.650) 
6.1 Insurance premiums for warranty. (Adopted, 20th Session, 12 October 1990, 36.280)

7.1 Application of the price actually paid or payable. (Adopted, 26th Session, 8 October 1993, 38.480)

8.1 Application of Article 8.1.

(Adjustments in relation to the garments: the licence fee that is required to be paid for the right to use the paper patterns.) (Adopted, 28th Session, 7 October 1994, 39.000)

8.2 Application of Article 8.1.

(Adjustments in relation to the video laser disc : the licence fee that is required to be paid for the right to use the music video clips and master tape.) (Adopted, 28th Session, 7 October 1994, 39.000)

9.1 Sole agents, sole distributors and sole concessionnaires. (Adopted, 1st Session, 6 October 1995, 39.790)

10.1 Application of Article 1.2. (Adopted, 3rd Session, 4 October 1996, 40.710)

11.1 Application of Article 15.4 (e) - related party transactions. (Adopted, 8th Session, 1 April 1999, VT0034)

12.1 Application of Article 1 of the Valuation Agreement for goods sold for export at prices below their cost of production. (Adopted, 11th Session, 3 November 2000, VT0164)

13.1 Application of Decision 6.1 of the Committee on Customs Valuation.

(Declared value of imported goods lower than identical goods) (Adopted, 13th Session, 19 October 2001, VT0225)

13.2 Application of Decision 6.1 of the Committee on Customs Valuation

(Declared value of imported goods lower than raw materials.) (Adopted, 26th Session, 4 April2008, VT0626E1b)

14.1 Use of transfer pricing documentation when examining related party transactions under Article 1.2 (a) of the Agreement. (Adopted, 42th Session, 22 April 2016, VT0920E1c)

\section{Studies}

1.1 Treatment of used motor vehicles. - Supplement to Study 1.1. (Adopted, 4th Session, 24 September $1982,29.260)$

2.1 Treatment of rented or leased goods. (Adopted, 11th Session, 7 March 1986, 33.180). 


\section{Annex L}

\section{WCO TCCV Conspectus}

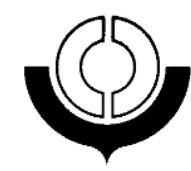

TECHNICAL COMMITTEE

ON CUSTOMS VALUATION

$33^{\text {rd }}$ Session

WORLD CUSTOMS ORGANIZATION

ORGANISATION MONDIALE DES DOUANES

ORGANIZACIÓN MUNDIAL DE ADUANAS
VT0815E1a

$(+$ Annex $)$

O. Eng.

Brussels, 14 June 2010.

\section{REVIEW OF THE CONSPECTUS OF TECHNICAL VALUATION QUESTIONS}

(Item VII (c) on the Agenda)

Reference document:

VT0748E1a (TCCV/31)

VT0774E1a (TCCV/31 Report)

1. The Conspectus of Technical Valuation Questions, which is used to record items of a technical nature raised within the Technical Committee on Customs Valuation, was last updated at the Technical Committee's $31^{\text {st }}$ Session. It consists of three parts: Part I contains the instruments or other questions and studies adopted or concluded by the Technical Committee; Part II includes work currently being considered and Part III contains questions previously raised that have not yet been considered or have been put aside for later recall, both of which may then form part of the Technical Committee's future work. The Secretariat has, in accordance with established procedure, updated the Conspectus, which is at the Annex to this document.

2. It is important to notice that Members' comments, made during the $31^{\text {st }}$ Session, regarding drafting changes, typographical corrections, online availability, layout improvements and inclusion of details related to the status Part III items, are registered for 
future proposals by the Secretariat.

3. Any observations or comments on the attached Conspectus should be submitted in writing to the Secretariat by $\mathbf{5}$ September 2011 . Comments submitted in response to this document will be published and circulated to Members of the Technical Committee for consideration at its $33^{\text {rd }}$ Session in October 2010. 


\section{CONSPECTUS OF TECHNICAL VALUATION QUESTIONS}

\section{TABLE OF CONTENTS}

PART I : Questions concluded (unless a new aspect arises)

- Work of the Technical Committee established under the Agreement on implementation of Article VII of the GATT 1947 (From March 1981 to September 1995)

- Work of the Technical Committee established under the Agreement on implementation of Article VII of the GATT 1994 (Since October 1995)

PART II : Questions on the Technical Committee's programme of work

PART III : Questions raised pending future work

Note: At its first Session in October 1995, the Technical Committee, established under the Agreement on the implementation of Article VII of the GATT 1994, adopted all of the work and decisions of the Technical Committee established under the Agreement on the implementation of Article VII of the GATT 1947. 
$\overline{\text { Part I. Questions concluded (unless a new aspect arises) }}$

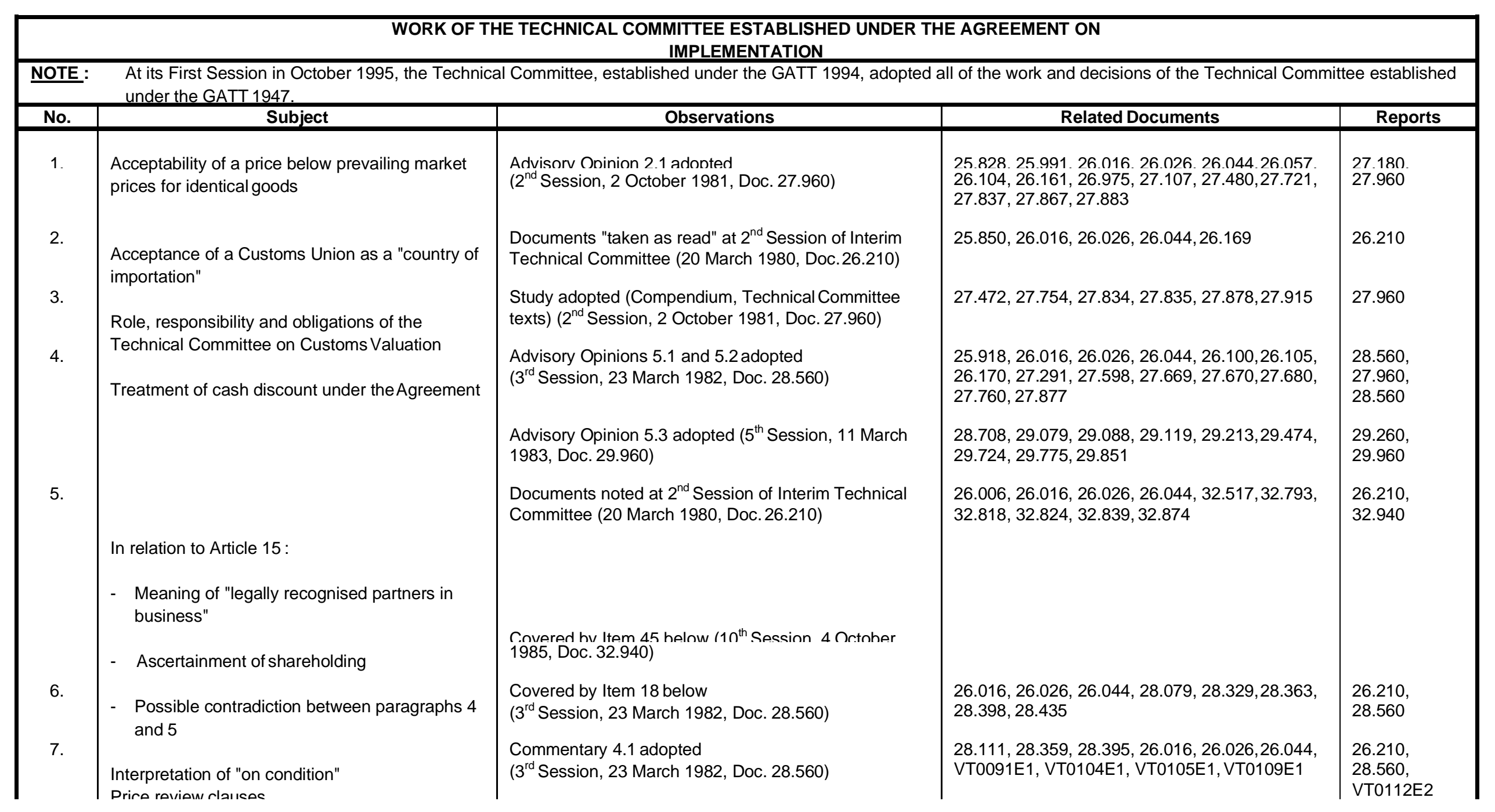




\begin{tabular}{|c|c|c|c|c|}
\hline \multicolumn{5}{|c|}{$\begin{array}{l}\text { WORK OF THE TECHNICAL COMMITTEE ESTABLISHED UNDER THE AGREEMENT ON } \\
\text { IMPLEMENTATION }\end{array}$} \\
\hline NOTE: & \multicolumn{4}{|c|}{$\begin{array}{l}\text { At its First Session in October 1995, the Technical Committee, established under the GATT 1994, adopted all of the work and decisions of the Technical Committee established } \\
\text { under the GATT } 1947 .\end{array}$} \\
\hline No. & Subject & Observations & Related Documents & Reports \\
\hline 8 & Timo olomant in ralatinn th $\Delta$ rtirloc 1 o and 2 & $\begin{array}{l}\text { Funlanstnn, Nonta } 11 \text { arnntar } \\
\left(2^{\text {nd }} \text { Session, } 2 \text { October 1981, Doc. } 27.960\right)\end{array}$ & 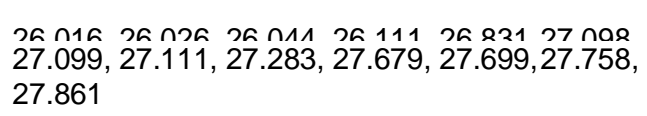 & $\begin{array}{l}26.210 \\
27.180 \\
27.960\end{array}$ \\
\hline 9. & $\begin{array}{l}\text { Treatment of goods not in accordance with } \\
\text { contract (including damaged goods) }\end{array}$ & $\begin{array}{l}\text { Explanatory Note } 3.1 \text { adopted } \\
\left(3^{\text {rd }} \text { Session, } 23 \text { March 1982, Doc. 28.560) }\right.\end{array}$ & $\begin{array}{l}25.991,26.016,26.026,26.044,27.448,27.701, \\
27.718,27.759,27.887,28.051,28.131,28.314, \\
28.445,28.610\end{array}$ & $\begin{array}{l}26.210 \\
27.960 \\
28.560\end{array}$ \\
\hline 10. & Goods subject to export subsidies or bounties & $\begin{array}{l}\text { Commentary } 2.1 \text { adopted } \\
\left(3^{\text {rd }} \text { Session, } 23 \text { March 1982, Doc. } 28.560\right)\end{array}$ & $\begin{array}{l}26.789,27.024,27.035,27.059,27.104,27.122, \\
27.429,27.467,27.471,27.566,27.719,27.885, \\
28.122,28.315,28.418,28.443,28.454\end{array}$ & $\begin{array}{l}27.960 \\
28.560\end{array}$ \\
\hline 11. & Goods sold at dumping prices & $\begin{array}{l}\text { Commentary } 3.1 \text { adopted } \\
\left(3^{\text {rd }} \text { Session, } 23 \text { March 1982, Doc. } 28.560\right)\end{array}$ & $\begin{array}{l}\text { 26.789, 27.024, 27.035, 27.059, 27.104,27.122, } \\
\text { 27.429, 27.467, 27.471, 27.566, 27.719,27.885 } \\
\text { 28.122, 28.315, 28.418, 28.443,28.454, } \\
\text { VT0086E1, VT0094E1, VT0098E1, VT0101E1 }\end{array}$ & $\begin{array}{l}27.960 \\
28.560 \\
\text { VT0112E2 }\end{array}$ \\
\hline 12. & Royalties and licence fees under Article 8.1 (c) & $\begin{array}{l}\text { Six Advisory Opinions }(4.1,4.2,4.3,4.4,4.5 \text { and } 4.6) \\
\text { adopted } \\
\left(2^{\text {nd }}, 3^{\text {rd }} \text { and } 5^{\text {th }} \text { Sessions, Docs. } 27.960,28.560 \text { and }\right. \\
29.960)\end{array}$ & $\begin{array}{l}26.044,26.839,27.098,27.100,27.108,27.121, \\
27.454,27.832,27.866,27.886,27.917,28.128, \\
28.358,28.444,28.457,29.377,29.652,29.721, \\
29.781,29.854\end{array}$ & $\begin{array}{l}27.180 \\
27.960 \\
29.260 \\
28.560 \\
29.960\end{array}$ \\
\hline 13. & $\begin{array}{l}\text { Commissions and brokerage in the context of } \\
\text { Article } 8\end{array}$ & $\begin{array}{l}\text { Explanatory Note } 2.1 \text { adopted } \\
\left(3^{\text {rd }} \text { Session, } 23 \text { March 1982, Doc. } 28.560\right)\end{array}$ & $\begin{array}{l}26.832,27.103,27.430,27.476,27.563,27.600, \\
27.720,27.862,28.057,28.290,28.326,28.367, \\
28.393,28.399,28.432\end{array}$ & $\begin{array}{l}27.960 \\
28.560\end{array}$ \\
\hline 14. & $\begin{array}{l}\text { Treatment of credits in respect of earlier } \\
\text { transactions }\end{array}$ & $\begin{array}{l}\text { Advisory Opinion } 8.1 \text { adopted } \\
\left(3^{\text {rd }} \text { Session, } 23 \text { March 1982, Doc. } 28.560\right)\end{array}$ & $28.047,28.312,28.348,28.366,28.396,28.437$ & 28.560 \\
\hline 15. & Treatment of used motor vehicles & $\begin{array}{l}\text { Study } 1.1 \text { adopted } \\
\left(4^{\text {th }} \text { Session, } 24 \text { September } 1982 \text {, Doc. } 29.260\right)\end{array}$ & $\begin{array}{l}27.459,27.700,27.761,27.833,27.865,27.977, \\
28.082,28.317,28.369,28.394,28.428,28.653 \\
28.696,28.910,29.082,29.087,29.169\end{array}$ & $\begin{array}{l}27.960 \\
28.560 \\
29.260\end{array}$ \\
\hline 16. & Application of Article 8.1 (d) & $\begin{array}{l}\text { Case Study } 2.1 \text { adopted } \\
\left(5^{\text {th }} \text { Session, } 11 \text { March } 1983 \text {, Doc. } 29.960\right)\end{array}$ & $\begin{array}{l}28.828,29.094,29.181,29.346,29.653,29.727 \\
29.773,29.834,29.855\end{array}$ & $\begin{array}{l}27.960, \\
29.960\end{array}$ \\
\hline & & Case Study 2.2 adopted ( $9^{\text {th }}$ Session, 8 March 1985 & $32.113,32.251,32.306,32.321,32.349$ & 32.350 \\
\hline
\end{tabular}




\begin{tabular}{|c|c|c|c|c|}
\hline \multicolumn{5}{|c|}{$\begin{array}{l}\text { WORK OF THE TECHNICAL COMMITTEE ESTABLISHED UNDER THE AGREEMENT ON } \\
\text { IMPLEMENTATION }\end{array}$} \\
\hline NOTE: & \multicolumn{4}{|c|}{$\begin{array}{l}\text { At its First Session in October 1995, the Technical Committee, established under the GATT 1994, adopted all of the work and decisions of the Technical Committee established } \\
\text { under the GATT } 1947 .\end{array}$} \\
\hline No. & $\begin{array}{c}\text { Subject } \\
\end{array}$ & Observations & Related Documents & Reports \\
\hline & & Doc. 32.350) & & \\
\hline 17. & Acceptability of test values under Article 1.2 (b) (i) & $\begin{array}{l}\text { Advisorv Opinion } 7.1 \text { adopted } \\
\left(3^{\text {rd }} \text { Session, } 23 \text { March 1982, Doc. 28.560) }\right.\end{array}$ & $\begin{array}{l}25.828,25.991,26.016,26.026,26.044,26.057 \\
26.104,26.161,28.004,28.137,28.266,28.277 \\
28.370,28.423,28.439\end{array}$ & $\begin{array}{l}26.210 \\
28.560\end{array}$ \\
\hline 18. & Treatment of barter or compensation deals & $\begin{array}{l}\text { Advisory Opinion } 6.1 \text { adopted } \\
\left(3^{\text {rd }} \text { Session, } 23 \text { March 1982, Doc. 28.560) }\right.\end{array}$ & $28.079,28.329,28.363,28.398,28.435$ & 28.560 \\
\hline 19. & $\begin{array}{l}\text { Treatment of goods returned after temporary } \\
\text { exportation for manufacturing, processing or } \\
\text { repair }\end{array}$ & $\begin{array}{l}\text { Commentary } 5.1 \text { adopted } \\
\left(5^{\text {th }} \text { Session, } 11 \text { March } 1983 \text {, Doc. } 29.960\right)\end{array}$ & $\begin{array}{l}28.090,28.310,28.417,28.438,28.827,29.074 \\
29.095,29.168,29.297,29.662,29.750,29.777 \\
29.856\end{array}$ & $\begin{array}{l}28.560 \\
29.260 \\
29.960\end{array}$ \\
\hline 20. & $\begin{array}{l}\text { Treatment of anti-dumping and countervailing } \\
\text { duties when applying the deductive method }\end{array}$ & $\begin{array}{l}\text { Advisory Opinion } 9.1 \text { adopted } \\
\left(4^{\text {th }} \text { Session, } 24 \text { September 1982, Doc. } 29.260\right)\end{array}$ & $28.729,29.081,29.085,29.170$ & 29.260 \\
\hline 21. & $\begin{array}{l}\text { Treatment of split shipments under Article } 1 \text { of } \\
\text { the Agreement }\end{array}$ & $\begin{array}{l}\text { Commentary } 6.1 \text { adopted } \\
\left(6^{\text {th }} \text { Session, } 16 \text { September } 1983 \text {, Doc. } 30.480\right)\end{array}$ & $\begin{array}{l}29.475,29.699,29.722,29.726,29.761,29.766 \\
29.831,29.852,30.028,30.332,30.337,30.348 \\
30.422\end{array}$ & $\begin{array}{l}29.960, \\
30.408\end{array}$ \\
\hline 22. & $\begin{array}{l}\text { Treatment of storage and related expenses } \\
\text { under the provisions of Article } 1\end{array}$ & $\begin{array}{l}\text { Commentary } 7.1 \text { adopted } \\
\left(6^{\text {th }} \text { Session, } 16 \text { September } 1983 \text {, Doc. } 30.480\right)\end{array}$ & $\begin{array}{l}\text { 29.376, 29.654, 29.702, 29.725, 29.752,29.768, } \\
\text { 29.843, 30.107, 30.319, 30.325, 30.338,30.346, } \\
\text { 30.355, 30.379, 30.418, VT0214E1, VT0223E1, } \\
\text { VT0225E2, VT0240E1 }\end{array}$ & $\begin{array}{l}29.960 \\
30.480 \\
\text { VT0225E2, } \\
\text { VT0254E2 }\end{array}$ \\
\hline 23. & Treatment of fraudulent documents & $\begin{array}{l}\text { Advisory Opinion } 10.1 \text { adopted } \\
\left(6^{\text {th }} \text { Session, } 16 \text { September } 1983 \text {, Doc. } 30.480\right)\end{array}$ & $30.015,30.317,30.333,30.347,30.370,30.422$ & 30.480 \\
\hline 24. & Hierarchical order in applying Article 7 & $\begin{array}{l}\text { Advisory Opinion } 12.2 \text { adopted } \\
\left(6^{\text {th }} \text { Session, } 16 \text { September } 1983 \text {, Doc. } 30.480\right)\end{array}$ & $\begin{array}{l}30.029,30.014,30.331,30.369,30.382,30.402 \\
30.422\end{array}$ & 30.480 \\
\hline 25. & $\begin{array}{l}\text { Use of data from foreign sources in applying } \\
\text { Article } 7\end{array}$ & $\begin{array}{l}\text { Advisory Opinion } 12.3 \text { adopted } \\
\left(6^{\text {th }} \text { Session, } 16 \text { September } 1983 \text {, Doc. } 30.480\right)\end{array}$ & $30.038,30.336,30.367,30.380,30.401,30.422$ & 30.480 \\
\hline 26. & Flexible application of Article 7 of the Agreement & $\begin{array}{l}\text { Advisory Opinion } 12.1 \text { adopted } \\
\left(6^{\text {th }} \text { Session, } 16 \text { September } 1983 \text {, Doc. } 30.480\right)\end{array}$ & $\begin{array}{l}29.572,29.764,29.827,29.833,29.861,30.037 \\
30.321,30.326,30.400,30.422\end{array}$ & $\begin{array}{l}29.960 \\
30.480\end{array}$ \\
\hline 27. & $\begin{array}{l}\text { Scope of the word "insurance" under Article } 8.2 \\
\text { (c) of the Agreement }\end{array}$ & $\begin{array}{l}\text { Advisory Opinion } 13.1 \text { adopted } \\
\left(6^{\text {th }} \text { Session, } 16 \text { September } 1983 \text {, Doc. } 30.480\right)\end{array}$ & $30.063,30.316,30.341,30.381,30.399,30.422$ & 30.480 \\
\hline
\end{tabular}




\begin{tabular}{|c|c|c|c|c|}
\hline \multicolumn{5}{|c|}{$\begin{array}{l}\text { WORK OF THE TECHNICAL COMMITTEE ESTABLISHED UNDER THE AGREEMENT ON } \\
\text { IMPLEMENTATION }\end{array}$} \\
\hline \multirow{2}{*}{ NOTE: } & \multicolumn{4}{|c|}{$\begin{array}{l}\text { At its First Session in October 1995, the Technical Committee, established under the GATT 1994, adopted all of the work and decisions of the Technical Committee established } \\
\text { under the GATT 1947. }\end{array}$} \\
\hline & Subject & Observations & Related Documents & Reports \\
\hline 28. & Treatment of package deals & $\begin{array}{l}\text { Commentarv } 8.1 \text { adonted } \\
\left(7^{\text {th }} \text { Session, } 2 \text { March } 1984 \text {, Doc. } 31.460\right)\end{array}$ & $\begin{array}{l}29.476 .29 .728 .29 .765 .30 .014 .30 .345 .30 .422 \\
30.792,31.291,31.326,31.347,31.381,31.417\end{array}$ & $\begin{array}{l}29.960 \\
30.480 \\
31.460\end{array}$ \\
\hline 29. & $\begin{array}{l}\text { Meaning of the term "at or about the same time" } \\
\text { in Articles } 2 \text { and } 3 \text { of the Agreement }\end{array}$ & $\begin{array}{l}\text { Text inserted in Explanatorv Note } 1.1 \text { as } \\
\text { paragraphs } 12 \text { and } 13 \text { (see Item } 8)\left(7^{\text {th }} \text { Session, }\right. \\
2 \text { March 1984, Doc. } 31.460)\end{array}$ & $\begin{array}{l}29.961 .30 .254 .30 .259 .30 .273 .30 .334 .30 .421 . \\
30.783,31.290,31.324,31.366,31.382,31.418\end{array}$ & $\begin{array}{l}30.480 . \\
31.460\end{array}$ \\
\hline 30. & Treatment of inadvertent errors and of & $\begin{array}{l}\text { Advisory Opinion } 11.1 \text { adopted } \\
\left.\text { ( } 7^{\text {th }} \text { Session, } 2 \text { March 1984, Doc. } 31.460\right)\end{array}$ & $30.798,31.226,31.292,31.365$ & 31.460 \\
\hline 31. & $\begin{array}{l}\text { incomplete documentation } \\
\text { Time standard for test values under Article } 1.2 \\
\text { (b) of the Agreement }\end{array}$ & $\begin{array}{l}\text { Text inserted in Explanatory Note } 1.1 \text { as } \\
\text { paragraphs } 6,7 \text { and } 8 \text { (see Item } 8)\left(7^{\text {th }} \text { Session, }\right. \\
2 \text { March } 1984 \text {, Doc. } 31.460)\end{array}$ & $\begin{array}{l}28.042,28.227,28.264,28.325,28.365,31.041, \\
31.342,31.367,31.415\end{array}$ & $\begin{array}{l}28.560 \\
29.260 \\
29.960 \\
31.460\end{array}$ \\
\hline 32. & & $\begin{array}{l}\text { Case Study } 1.1 \text { adopted } \\
\left(3^{\text {rd }} \text { Session, } 23 \text { March 1982, Doc. } 28.560\right)\end{array}$ & $27.567,27.831,27.875,28.206,28.446$ & $\begin{array}{l}27.960 \\
28.560\end{array}$ \\
\hline 33. & $\begin{array}{l}\text { Terms in Article } 8.1 \text { (b) (iv) : Engineering, } \\
\text { artwork, etc. } \\
\text { The concept of "sale" }\end{array}$ & $\begin{array}{l}\text { Advisory Opinion } 1.1 \text { adopted }\left(2^{\text {nd }} \text { Session, } 2 \text { October }\right. \\
\text { 1981, Doc. } 27.960)\end{array}$ & $\begin{array}{l}\text { 25.826, 25.991, 26.016, 26.026, 26.039,26.044, } \\
\text { 26.058, 26.102, 26.783, 27.034, 27.098,27.101, } \\
\text { 27.106, 27.118, 27.123, 27.427, 27.702,27.731, } \\
27.755,27.860\end{array}$ & $\begin{array}{l}26.210 \\
27.180 \\
27.960\end{array}$ \\
\hline & & $\begin{array}{l}\text { Text inserted situation VII ( } 3^{\text {rd }} \text { Session, } 23 \text { March } 1982 \text {, } \\
\text { Doc. 28.560) }\end{array}$ & $28.008,28.263,28.305,28.318,28.368,28.397$ & 28.560 \\
\hline 34. & - Additional situation & $\begin{array}{l}\text { Advisory Opinion } 3.1 \text { adopted with respect to the } \\
\text { treatment of duties and taxes of the country of } \\
\text { importation }\left(2^{\text {nd }} \text { Session, } 2 \text { October } 1981 \text {, Doc. } 27.960\right)\end{array}$ & $\begin{array}{l}\text { 25.962, 25.991, 26.016, 26.026, 26.044,26.099, } \\
\text { 26.103, 26.874, 27.110, 27.458, 27.758,27.838, } \\
27.868,27.884,27.916\end{array}$ & $\begin{array}{l}26.210 \\
27.180 \\
27.960\end{array}$ \\
\hline 35. & $\begin{array}{l}\text { The meaning of "are distinguished" in } \\
\text { Interpretative Note to Article } 1\end{array}$ & $\begin{array}{l}\text { Commentarv } 1.1 \text { adopted ( } 3^{\text {rd }} \text { Session. } 23 \text { March } 1982 . \\
\text { Doc. 28.560) }\end{array}$ & $\begin{array}{l}25.991,26.158,26.811,27.102,27.112,27.705 \\
28.048,28.313,28.337,28.436,28.442\end{array}$ & $\begin{array}{l}27.180 \\
27.960 \\
28.560\end{array}$ \\
\hline & Application of Articles 2 and 3 : & Four examples added ( $4^{\text {th }}$ Session, 24 September & $25.991,26.158,26.811,27.102,27.112,27.705$ & 27.180 \\
\hline
\end{tabular}




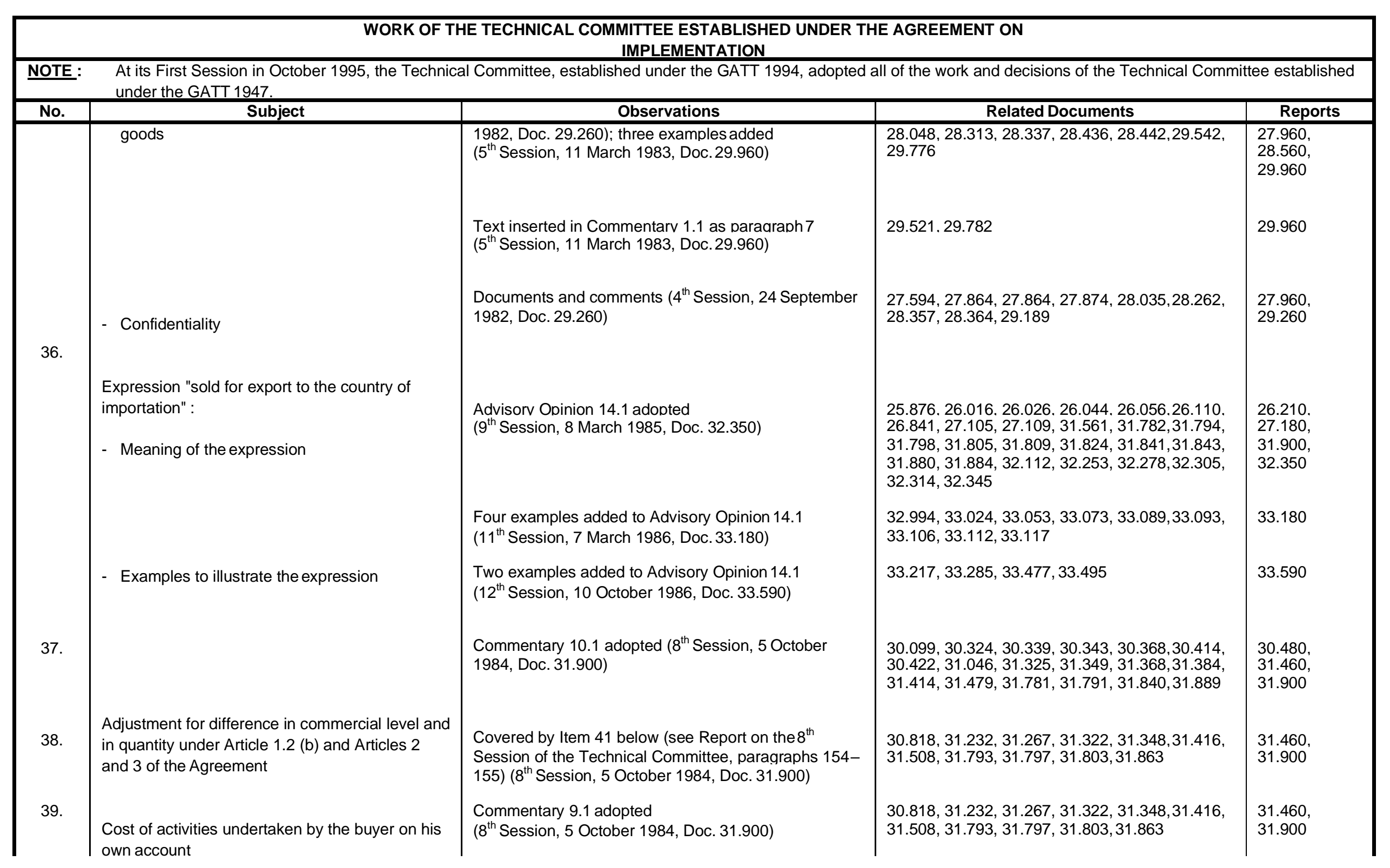




\begin{tabular}{|c|c|c|c|c|}
\hline \multicolumn{5}{|c|}{$\begin{array}{l}\text { WORK OF THE TECHNICAL COMMITTEE ESTABLISHED UNDER THE AGREEMENT ON } \\
\text { IMPLEMENTATION }\end{array}$} \\
\hline NOTE: & $\begin{array}{l}\text { At its First Session in October 1995, the Techn } \\
\text { under the GATT } 1947 .\end{array}$ & Committee, established under the GAT & of the work and decisions of the Technica & established \\
\hline No. & $\begin{array}{c}\text { Subject } \\
\end{array}$ & Observations & Related Documents & Reports \\
\hline 40. & Treatment of tie-in sales & $\begin{array}{l}\text { Commentary } 11.1 \text { adopted } \\
\left(9^{\text {th }} \text { Session, } 8 \text { March } 1985 \text {, Doc. } 32.350\right)\end{array}$ & $30.792,31.787,32.102,32.319$ & $\begin{array}{l}31.900 \\
32.350\end{array}$ \\
\hline 41. & Conditions and restrictions in Article 1 & $\begin{array}{l}\text { Case Study } 3.1 \text { adopted ( } 9^{\text {th }} \text { Session, } 8 \text { March } 1985 \text {, } \\
\text { Doc. } 32.350 \text { ) }\end{array}$ & $\begin{array}{l}31.562,31.785,31.790,31.792,31.802,31.806 \\
31.825,31.861,31.881,31.888,32.130,32.260 \\
32.276,32.320,32.341\end{array}$ & $\begin{array}{l}31.900 \\
32.350\end{array}$ \\
\hline 42. & Importation of vintage cars & $\begin{array}{l}\text { Technical Committee's conclusion recorded inthe } \\
\text { Report on the } 9^{\text {th }} \text { Session (paragraph 253) }\left(9^{\text {th }} \text { Session, }\right. \\
8 \text { March 1985, Doc. } 32.350)\end{array}$ & 32.244 & 32.350 \\
\hline 43. & Consideration of relationship under Article 15.5, & $\begin{array}{l}\text { Explanatory Note } 4.1 \text { adopted } \\
\left(10^{\text {th }} \text { Session, } 4 \text { October } 1985 \text {, Doc. } 32.940\right)\end{array}$ & $\begin{array}{l}26.006,26.016,26.026,26.044,32.517,32.793 \\
32.818,32.824,32.839,32.874\end{array}$ & $\begin{array}{l}26.210 \\
32.940\end{array}$ \\
\hline 44. & read in conjunction with Article 15.4 & $\begin{array}{l}\text { Commentary } 12.1 \text { adopted } \\
\left(10^{\text {th }} \text { Session, } 4 \text { October } 1985 \text {, Doc. } 32.940\right)\end{array}$ & $\begin{array}{l}32.111,32.252,32.277,32.322,32.645,32.677 \\
32.817,32.858,32.809,32.879,32.880,32.884\end{array}$ & $\begin{array}{l}32.350 \\
32.940\end{array}$ \\
\hline 45. & $\begin{array}{l}\text { Meaning of the term "restrictions" in Article } 1.1 \\
\text { (a) (iii) } \\
\text { The effects of false invoicing on customs } \\
\text { valuation }\end{array}$ & $\begin{array}{l}\text { Technical Committee's Report to the Committee on } \\
\text { Customs Valuation (Annex to the Report on the } \\
10^{\text {th }} \text { Session of the Technical Committee) } \\
\left(10^{\text {th }} \text { Session, } 4 \text { October 1985, Doc. 32.940) }\right.\end{array}$ & $\begin{array}{l}32.581,32.668,32.737,32.794,32.801,32.816 \\
32.828,32.838,32.849,32.857\end{array}$ & 32.940 \\
\hline 46. & & $\begin{array}{l}\text { Documents noted at the } 10^{\text {th }} \text { Session of the Technical } \\
\text { Committee }\left(10^{\text {th }} \text { Session, } 4 \text { October } 1985 \text {, }\right. \\
\text { Doc. } 32.940)\end{array}$ & $32.039,32.239,32.250,32.637,32.820,32.868$ & $\begin{array}{l}32.350 \\
32.940\end{array}$ \\
\hline 47. & $\begin{array}{l}\text { Application of test values : Adjustment for } \\
\text { difference in level, quantity and the other } \\
\text { elements mentioned in Article } 1.2(\mathrm{~b})\end{array}$ & $\begin{array}{l}\text { A studv published as Secretariat Doc. } 33.236 \\
\left(12^{\text {th }} \text { Session, } 10 \text { October } 1986, \text { Doc. } 33.590\right)\end{array}$ & 32.980 .33 .084 .33 .104 .33 .236 & $\begin{array}{l}33.180 \\
33.236 \\
33.590\end{array}$ \\
\hline 48. & $\begin{array}{l}\text { Organisational requirements for the } \\
\text { implementation of the GATT valuation code }\end{array}$ & $\begin{array}{l}\text { Studv } 2.1 \text { adopted }\left(11^{\text {th }} \text { Session, } 7 \text { March } 1986,\right. \\
\text { Doc. } 33.180)\end{array}$ & $\begin{array}{l}\text { 32.524, 32.738, 32.780, 32.813, 32.819,32.846, } \\
32.991,33.063,33.067,33.086,33.111,33.116\end{array}$ & $\begin{array}{l}32.940 \\
33.180\end{array}$ \\
\hline 49. & $\begin{array}{l}\text { Rented or leased goods : } \\
\text { - Treatment of rented or leased goods }\end{array}$ & $\begin{array}{l}\text { Case Study } 4.1 \text { adopted }\left(12^{\text {th }} \text { Session, } 10 \text { October }\right. \\
\text { 1986, Doc. } 33.590) \\
\text { Advisory Opinion } 15.1 \text { adopted }\end{array}$ & $\begin{array}{l}\text { 33.111, 33.213, 33.292, 33.479, 33.481, 33.554, } \\
\text { 32.979, 33.054, 33.069, 33.087, 33.092,33.110, }\end{array}$ & $\begin{array}{l}33.590 \\
33.180\end{array}$ \\
\hline
\end{tabular}




\begin{tabular}{|c|c|c|c|c|}
\hline \multicolumn{5}{|c|}{$\begin{array}{l}\text { WORK OF THE TECHNICAL COMMITTEE ESTABLISHED UNDER THE AGREEMENT ON } \\
\text { IMPLEMENTATION }\end{array}$} \\
\hline \multirow{2}{*}{ NOTE: } & $\begin{array}{l}\text { At its First Session in October 1995, the Techn } \\
\text { under the GATT } 1947 .\end{array}$ & I Committee, established under the GATT 1994, adopted & II of the work and decisions of the Technical Cc & e established \\
\hline & $\begin{array}{c}\text { Subject } \\
\end{array}$ & Observations & Related Documents & Reports \\
\hline & & $\left(12^{\text {th }}\right.$ Session, 10 October 1986, Doc. 33.590) & $33.115,33.358,33.433,33.508$ & 33.590 \\
\hline 50. & Practical application of Article 7 & $\begin{array}{l}\text { Examples on application of Article } 7 \text { publishedas } \\
\text { Secretariat Doc. } 33.237\left(12^{\text {th }} \text { Session, } 10 \text { October }\right. \\
\text { 1986, Doc. 33.590) }\end{array}$ & $\begin{array}{l}30.030,30.327,30.403,30.531,30.577,31.220 \text {, } \\
31.345,31.477,31.668,31.770,32.038,32.234, \\
32.254,32.323,32.496,32.781,32.799,32.941 \text {, } \\
33.039,33.055,33.068,33.237\end{array}$ & $\begin{array}{l}30.480, \\
31.460 \\
31.900 \\
32.350 \\
32.940 \\
33.180 \\
33.590\end{array}$ \\
\hline 51. & Treatment of quota charges under Article 1 & $\begin{array}{l}\text { Technical Committee's conclusion on a Swedish } \\
\text { example recorded in the Report on the } 12^{\text {th }} \text { Session } \\
\text { (paragraphs } 128 \text { and } 129)\left(12^{\text {th }} \text { Session, } 10 \text { October }\right. \\
\text { 1986, Doc. } 33.590)\end{array}$ & $33.050,33.235,33.447,33.462,33.496,33.536$ & $\begin{array}{l}32.350 \\
32.940 \\
33.180 \\
33.590\end{array}$ \\
\hline & & $\begin{array}{l}\text { Two Advisory Opinions adopted at the } 15^{\text {th }} \text { Session of } \\
\text { the Technical Committee. } \\
\left(15^{\text {th }} \text { Session, } 17 \text { March } 1988 \text {, Doc. } 34.628\right)\end{array}$ & $\begin{array}{l}\text { 33.659, 33.766, 33.789, 33.818, 33.828,33.852, } \\
33.853,33.858,33.872,34.146,34.264,34.286 \text {, } \\
34.292\end{array}$ & $\begin{array}{l}33.930 \\
34.380 \\
34.628\end{array}$ \\
\hline 52. & $\begin{array}{l}\text { Application of the decision on the valuation of } \\
\text { carrier media bearing software for data } \\
\text { processing equipment }\end{array}$ & $\begin{array}{l}\text { Commentary } 13.1 \text { adopted } \\
\left(14^{\text {th }} \text { Session, } 8 \text { October } 1987 \text {, Doc. } 34.380\right)\end{array}$ & $\begin{array}{l}33.049,33.216,33.366,33.431,33.476,33.509, \\
33.538,33.685,33.814,33.857,33.874,33.956, \\
34.190,34.251,34.394,34.454,34.456,34.566\end{array}$ & $\begin{array}{l}33.180 \\
33.590 \\
33.930 \\
34.380\end{array}$ \\
\hline 53. & $\begin{array}{l}\text { Treatment of a situation where the sale or price } \\
\text { is subject to some condition or consideration for } \\
\text { which a value can be determined with respect to } \\
\text { the goods being valued }\end{array}$ & $\begin{array}{l}\text { Advisory Opinion } 16.1 \text { adopted }\left(15^{\text {th }} \text { Session, } 17 \text { March }\right. \\
\text { 1988, Doc. } 34.628)\end{array}$ & $\begin{array}{l}\text { 33.694, 33.834, 33.845, 33.859, 33.875,34.019, } \\
\text { 34.195, 34.245, 34.395, 34.462, 34.521,34.568, } \\
\text { VT0242E1, VT0252E1 }\end{array}$ & $\begin{array}{l}33.930 \\
34.380 \\
34.628 \\
\text { VT0254E2 }\end{array}$ \\
\hline 54. & $\begin{array}{l}\text { Scope and implication of Article } 11 \text { of the } \\
\text { Agreement }\end{array}$ & $\begin{array}{l}\text { Advisory Opinion } 17.1 \text { adopted } \\
\left(15^{\text {th }} \text { Session, } 17 \text { March } 1988, \text { Doc. } 34.628\right)\end{array}$ & $34.386,34.569$ & 34.628 \\
\hline 55. & Implications of Article 13 of the Agreement & $\begin{array}{l}\text { Advisory Opinion } 18.1 \text { adopted } \\
\left(15^{\text {th }} \text { Session, } 17 \text { March 1988, Doc. } 34.628\right)\end{array}$ & $34.387,34.567$ & 34.628 \\
\hline 56. & $\begin{array}{l}\text { Application of Article } 17 \text { of the Agreementand } \\
\text { paragraph } 7 \text { of the Protocol ( } 6 \text { of Annex III) }\end{array}$ & $\begin{array}{l}\text { Advisory Opinion } 19.1 \text { adopted }\left(15^{\text {th }} \text { Session, } 17 \text { March }\right. \\
\text { 1988, Doc. } 34.628)\end{array}$ & $34.388,34.582$ & 34.628 \\
\hline 57. & $\begin{array}{l}\text { Conversion of currency in cases where the } \\
\text { contract provides for a fixed rate of exchange }\end{array}$ & $\begin{array}{l}\text { Advisory Opinion } 20.1 \text { adopted }\left(17^{\text {th }} \text { Session, } 17 \text { March }\right. \\
1989 \text {, Doc. } 35.250) \text { and four examples }\left(18^{\text {th }} \text { Session, }\right.\end{array}$ & $\begin{array}{l}\text { 33.686, 33.813, 33.853, 33.846, 33.854,33.864, } \\
33.873,33.957,34.186,34.252,34.285,34.449,\end{array}$ & $\begin{array}{l}34.380 \\
34.628\end{array}$ \\
\hline
\end{tabular}




\begin{tabular}{|c|c|c|c|c|}
\hline \multicolumn{5}{|c|}{$\begin{array}{l}\text { WORK OF THE TECHNICAL COMMITTEE ESTABLISHED UNDER THE AGREEMENT ON } \\
\text { IMPLEMENTATION }\end{array}$} \\
\hline \multirow{2}{*}{ NOTE: } & \multicolumn{4}{|c|}{$\begin{array}{l}\text { At its First Session in October 1995, the Technical Committee, established under the GATT 1994, adopted all of the work and decisions of the Technical Committee established } \\
\text { under the GATT 1947. }\end{array}$} \\
\hline & Subject & Observations & Related Documents & Reports \\
\hline & & 21 November 1989, Doc. 35.650) adopted & $\begin{array}{l}34.575,34.583,34.595,34.662,34.754,34.758, \\
34.884,34.885,34.886,34.893,34.895,34.902, \\
34.909,34.914,34.937,34.941,34.954,35.075, \\
35.091,35.108,35.175,35.209,35.216,35.313, \\
35.383,35.533,35.546,35.637,35.385,35.532, \\
35.546,35.547,35.637\end{array}$ & $\begin{array}{l}35.000 \\
35.250 \\
35.650\end{array}$ \\
\hline 58. & Application of deductive value method & $\begin{array}{l}\text { Commentary } 15.1 \text { adopted } \\
\left(18^{\text {th }} \text { Session, } 21 \text { November } 1989 \text {, Doc. } 35.650\right)\end{array}$ & $\begin{array}{l}\text { 33.697, 33.833, 33.843, 33.862, 33.870,34.001, } \\
\text { 34.094, 34.221, 34.244, 34.262, 34.269,34.397, } \\
\text { 34.482, 34.519, 34.592, 34.756, 34.889,34.894, } \\
\text { 34.916, 34.939, 34.810, 34.904, 34.922,34.955, } \\
\text { 35.081, 35.082, 35.109, 35.198, 35.208,35.235, } \\
\text { 35.286, 35.298, 35.395, 35.543 }\end{array}$ & $\begin{array}{l}33.930 \\
34.380 \\
34.628 \\
35.250 \\
35.000 \\
35.650\end{array}$ \\
\hline 59. & Application of Article 8.1 (b) & $\begin{array}{l}\text { Case Studv } 5.1 \text { adopted } \\
\left(18^{\text {th }} \text { Session, } 21 \text { November } 1989 \text {, Doc. } 35.650\right)\end{array}$ & $35.382,35.534,35.554,35.640$ & 35.650 \\
\hline & & $\begin{array}{l}\text { Case Study } 5.2 \text { adopted }\left(19^{\text {th }} \text { Session, } 16 \text { March } 1990 \text {, }\right. \\
\text { Doc. } 35.970)\end{array}$ & $35.756,35.866,35.884$ & 35.970 \\
\hline 60. & Application of Article 1, paragraph2 & $\begin{array}{l}\text { Commentary } 14.1 \text { adopted } \\
\left(18^{\text {th }} \text { Session, } 21 \text { November } 1989 \text {, Doc. } 35.650\right)\end{array}$ & $35.058,35.315,35.390,35.537,35.553,35.639$ & $\begin{array}{l}35.250 \\
35.650\end{array}$ \\
\hline 61. & Transport costs & $\begin{array}{l}\text { Comments of the Technical Committee recorded inthe } \\
\text { Report on the } 18^{\text {th }} \text { Session (paraaraphs 203-216) } \\
\left(18^{\text {th }} \text { Session, } 21 \text { November 1989, Doc. 35.650) }\right.\end{array}$ & $35.476,35.635$ & 35.650 \\
\hline 62. & $\begin{array}{l}\text { Meaning of the expression "activities undertaken } \\
\text { by the buyer on his own account after purchase } \\
\text { of the goods but before importation" }\end{array}$ & $\begin{array}{l}\text { Commentary } 16.1 \text { adopted }\left(20^{\text {th }} \text { Session, } 12 \text { October }\right. \\
\text { 1990, Doc. } 36.280)\end{array}$ & $\begin{array}{l}33.698,33.728,33.816,33.832,33.844,33.863 \\
33.871,33.998,34.405,34.515,34.588,34.663 \\
34.888,34.896,34.920,35.090,35.107,35.215 \\
35.225,35.285,35.312,35.384,35.538,35.557 \\
35.638,35.742,35.867,35.882,35.988,36.191\end{array}$ & $\begin{array}{l}33.930 \\
34.380 \\
34.628 \\
35.000 \\
35.250 \\
35.650 \\
35.970 \\
36.280\end{array}$ \\
\hline 63. & Buying commissions & $\begin{array}{l}\text { Commentary } 17.1 \text { adopted ( } 20^{\text {th }} \text { Session, } 12 \text { October } \\
\text { 1990, Doc. } 36.280)\end{array}$ & $\begin{array}{l}34.445,34.479,34.531,34.576,34.593,34.665 \\
34.856,34.883,34.908,34.917,35.051,35.204\end{array}$ & $\begin{array}{l}34.628, \\
35.000\end{array}$ \\
\hline
\end{tabular}




\begin{tabular}{|c|c|c|c|c|}
\hline \multicolumn{5}{|c|}{$\begin{array}{l}\text { WORK OF THE TECHNICAL COMMITTEE ESTABLISHED UNDER THE AGREEMENT ON } \\
\text { IMPLEMENTATION }\end{array}$} \\
\hline \multirow{2}{*}{ NOTE: } & $\begin{array}{l}\text { At its First Session in October 1995, the Techni } \\
\text { under the GATT } 1947 .\end{array}$ & Committee, established under the GATT 1994, adopted & II of the work and decisions of the Technical $\mathrm{Cc}$ & established \\
\hline & Subject & Observations & Related Documents & Reports \\
\hline & & & $\begin{array}{l}\text { 35.211, 35.227, 35.287, 35.297, 35.381,35.535, } \\
35.555,35.636,35.686,35.869,35.887,36.036, \\
36.187,36.211,36.235\end{array}$ & $\begin{array}{l}35.250 \\
35.650 \\
35.970 \\
36.280\end{array}$ \\
\hline 64. & Organisation of Technical Committee's work & $\begin{array}{l}\text { Text inserted in previously adopted Study (see No. } 3 \text { of } \\
\text { this Part) as paragraphs } 8 \text { to } 13\left(19^{\text {th }} \text { Session, }\right. \\
16 \text { March 1990, Doc. } 35.970)\end{array}$ & $\begin{array}{l}35.146,35.394,35.536,35.552,35.594,35.641 \\
35.688,35.823,35.870,35.886\end{array}$ & $\begin{array}{l}35.250 \\
35.650 \\
35.970\end{array}$ \\
\hline 65. & Insurance premiums for warranty & $\begin{array}{l}\text { Case Study } 6.1 \text { adopted }\left(20^{\text {th }} \text { Session, } 12 \text { October }\right. \\
\text { 1990, Doc. } 36.280)\end{array}$ & $\begin{array}{l}35.232,35.407,35.544,35.645,35.783,35.868 \\
35.883,36.017,36.186,36.198\end{array}$ & $\begin{array}{l}35.250 \\
35.650 \\
35.970 \\
36.280\end{array}$ \\
\hline 66. & $\begin{array}{l}\text { Relationship between the price actually paid or } \\
\text { payable under Article } 1 \text { and Article } 8.1 \text { (c) }\end{array}$ & $\begin{array}{l}\text { Comments of the Technical Committee recorded inthe } \\
\left.\text { Report on the } 21^{\text {st }} \text { Session (paraqraphs } 74-89\right) \\
\left(21^{\text {st }} \text { Session, } 15 \text { March 1991, Doc. } 36.607\right)\end{array}$ & $36.383,36.529$ & 36.607 \\
\hline 67. & $\begin{array}{l}\text { The meaning of the term "on his own account" in } \\
\text { the Note to Article } 1\end{array}$ & $\begin{array}{l}\text { Comments of the Technical Committee recorded inthe } \\
\left.\text { Report on the } 22^{\text {nd }} \text { Session (paragraphs } 155-170\right) \\
\left(22^{\text {nd }} \text { Session, } 11 \text { October 1991, Doc. } 37.020\right)\end{array}$ & $36.611,36.961,36.979,37.001$ & 37.020 \\
\hline 68. & $\begin{array}{l}\text { Determination of the value and apportionment of } \\
\text { an assist under Article } 8.1 \text { (b) }\end{array}$ & $\begin{array}{l}\text { Comments of the Technical Committee recorded inthe } \\
\left.\text { Report on the } 22^{\text {nd }} \text { Session (paraqraphs } 189-199\right) \\
\left(22^{\text {nd }} \text { Session, } 11 \text { October } 1991, \text { Doc. } 37.020\right)\end{array}$ & $36.618,36.965,36.981$ & 37.020 \\
\hline 69. & $\begin{array}{l}\text { Correlation between the Note to Article } 1 \text { and } \\
\text { paragraph } 8 \text { of the Protocol } 7 \text { (of Annex III) }\end{array}$ & $\begin{array}{l}\text { Comments of the Technical Committee recorded inthe } \\
\left.\text { Report on the } 22^{\text {nd }} \text { Session (paragraphs } 171-188\right) \\
\left(22^{\text {nd }} \text { Session, } 11 \text { October } 1991, \text { Doc. } 37.020\right)\end{array}$ & $36.663,36.967,36.989,36.991$ & 37.020 \\
\hline 70. & $\begin{array}{l}\text { Examination of forms of payment for royalties } \\
\text { and licence fees }\end{array}$ & $\begin{array}{l}\text { The Technical Committee took note of Doc. } 37.105 \\
\left(23^{\text {rd }} \text { Session, } 20 \text { March 1992, Doc. } 37.420\right)\end{array}$ & $37.105,37.362$ & 37.420 \\
\hline 71. & Definition of the terms royalties and licencefees & $\begin{array}{l}\text { The Technical Committee took note of Doc. } 36.437 . \\
\text { Comments of the Technical Committee recorded inthe } \\
\text { Reports on the } 21^{\text {st }}, 22^{\text {nd }}, 23^{\text {rd }} \text { and } 24^{\text {th }} \text { Sessions } \\
\left(24^{\text {th }} \text { Session, } 23 \text { October } 1992 \text {, Doc. } 37.860\right)\end{array}$ & $\begin{array}{l}36.305,36.437,36.463,36.541,36.545,36.642, \\
36.966,36.983,37.093,37.288,37.351,37.545 \\
37.695,37.780\end{array}$ & $\begin{array}{l}36.607 \\
37.020 \\
37.420 \\
37.860\end{array}$ \\
\hline 72. & Treatment of confirming commissions & $\begin{array}{l}\text { Explanatory Note } 5.1 \text { adopted ( } 23^{\text {rd }} \text { Session, } 20 \text { March } \\
\text { 1992, Doc. } 37.420)\end{array}$ & $\begin{array}{l}29.417,29.681,29.701,29.723,29.759,29.767 \\
29.774,29.853,30.013,30.282,30.328,30.351\end{array}$ & 29.960 \\
\hline
\end{tabular}




\begin{tabular}{|c|c|c|c|c|}
\hline \multicolumn{5}{|c|}{$\begin{array}{l}\text { WORK OF THE TECHNICAL COMMITTEE ESTABLISHED UNDER THE AGREEMENT ON } \\
\text { IMPLEMENTATION }\end{array}$} \\
\hline \multirow{2}{*}{ NOTE: } & $\begin{array}{l}\text { At its First Session in October 1995, the Technic } \\
\text { under the GATT } 1947 .\end{array}$ & I Committee, established under the GATT 1994, adopte & II of the work and decisions of the Technical Con & ee established \\
\hline & Subject & Observations & Related Documents & Reports \\
\hline & & & $\begin{array}{l}\text { 30.371, 30.415, 30.419, 30.576, 31.219,31.223, } \\
31.313,31.346,31.472,31.769,31.807,35.556, \\
35.804,35.911,36.042,36.197,36.216,36.304, \\
36.536,37.092,37.289,37.358,36.613,36.962, \\
36.978,37.002\end{array}$ & $\begin{array}{l}30.480, \\
31.460, \\
31.900 \\
35.650, \\
35.970, \\
36.280, \\
36.607 \\
37.020 \\
37.420\end{array}$ \\
\hline 73. & $\begin{array}{l}\text { Relationship between Articles } 8.1 \text { (b) (ii) and } 8.1 \\
\text { (b) (iv) }\end{array}$ & $\begin{array}{l}\text { Commentary } 18.1 \text { adopted } \\
\left(24^{\text {th }} \text { Session, } 23 \text { October } 1992 \text {, Doc. } 37.860\right)\end{array}$ & $\begin{array}{l}36.443,36.614,36.963,37.003,37.089,37.360 \\
37.546,37.692,37.781\end{array}$ & $\begin{array}{l}36.607 \\
37.020 \\
37.420 \\
37.860\end{array}$ \\
\hline 74. & Application of Article 8.1 (c) & $\begin{array}{l}\text { Advisory Opinions } 4.7 \text { to } 4.13 \text { adopted } \\
\left(26^{\text {th }} \text { Session, } 8 \text { October } 1993 \text {, Doc. } 38.480\right)\end{array}$ & $\begin{array}{l}36.305,36.465,36.533,36.644,36.968,36.982 \\
36.996,37.555,37.696,37.782,37.874,38.079 \\
38.203,38.305,38.391,38.421\end{array}$ & $\begin{array}{l}36.607 \\
37.020 \\
37.420 \\
37.860 \\
38.130 \\
38.480\end{array}$ \\
\hline 75. & Application of price actually paid orpayable & $\begin{array}{l}\text { Case Study } 7.1 \text { adopted } \\
\left(26^{\text {th }} \text { Session, } 8 \text { October } 1993 \text {, Doc. } 38.480\right)\end{array}$ & $\begin{array}{l}37.096,37.364,37.542,37.693,37.783,37.849 \\
38.071,38.130,38.374,38.436\end{array}$ & $\begin{array}{l}37.420 \\
37.860 \\
38.130 \\
38.480\end{array}$ \\
\hline 76. & $\begin{array}{l}\text { Study on legislation, regulations and } \\
\text { administrative practices }\end{array}$ & $\begin{array}{l}\text { General conclusions adopted (Annex to the Reporton } \\
\text { the } 27^{\text {th }} \text { Session of the Technical Committee) } \\
\left(27^{\text {th }} \text { Session, } 25 \text { March } 1994 \text {, Doc. } 38.800\right)\end{array}$ & $37.725,38.476,38.631,38.631 /$ suppl, 38.714 & $\begin{array}{l}37.860 \\
38.800\end{array}$ \\
\hline 77. & $\begin{array}{l}\text { Meaning of the expression "right to reproducethe } \\
\text { imported goods" within the meaning of the } \\
\text { Interpretative Note to Article } 8.1 \text { (c) }\end{array}$ & $\begin{array}{l}\text { Commentary } 19.1 \text { adopted } \\
\left(28^{\text {th }} \text { Session, } 7 \text { October } 1994 \text {, Doc. } 39.000\right)\end{array}$ & $\begin{array}{l}\text { 35.832, 36.012, 36.189, 36.215, 36.312,36.535, } \\
36.617,36.964,36.984,37.094,37.290,37,564, \\
37.694,37.777,37.836,38.070,38.201,38.304, \\
38.390,38.517,38.652,38.712,38.751,38.952, \\
39.004\end{array}$ & $\begin{array}{l}35.970 \\
36.280 \\
36.607 \\
37.420 \\
37.020 \\
37.860 \\
38.130 \\
38.480 \\
38.800\end{array}$ \\
\hline
\end{tabular}




\begin{tabular}{|c|l|l|l|}
\hline \multicolumn{4}{|c|}{ WORK OF THE TECHNICAL COMMITTEE ESTABLISHED UNDER THE AGREEMENT ON } \\
IMPLEMENTATION
\end{tabular}


Part I. Questions concluded (unless a new aspect arises)

\begin{tabular}{|c|c|c|c|c|}
\hline \multicolumn{5}{|c|}{$\begin{array}{l}\text { WORK OF THE TECHNICAL COMMITTEE ESTABLISHED UNDER THE AGREEMENT ON IMPLEMENTATION } \\
\text { OF ARTICLE VII OF THE GATT } 1994 \text { (Since October 1995) }\end{array}$} \\
\hline NOTE & \multicolumn{4}{|c|}{$\begin{array}{l}\text { At its First Session in October 1995, the Technical Committee, established under the GATT 1994, adopted all of the work and decisions of the Technical Committee } \\
\text { established under the GATT 1947. }\end{array}$} \\
\hline No. & Subject & $\begin{array}{c}\text { Observations } \\
\end{array}$ & Related Documents & Reports \\
\hline 1 & $\begin{array}{l}\text { Sole anents snle distrihı ıtors and snle } \\
\text { concessionaires }\end{array}$ & $\begin{array}{l}\text { Sase Stı Idv } 91 \text { adnnted } \\
\left(1^{\text {st }} \text { Session, } 6 \text { October } 1995 \text {, Doc. } 39.790\right)\end{array}$ & 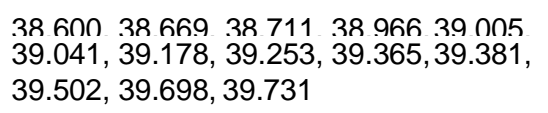 & $\begin{array}{l}38.800 .3 .9 \text { กกก } \\
39.390,39.790\end{array}$ \\
\hline 2. & $\begin{array}{l}\text { Scope of the term "maintenance" in the Note to } \\
\text { Article } 1\end{array}$ & $\begin{array}{l}\text { Explanatory Note } 6.1 \text { adopted } \\
\left(1^{\text {st }} \text { Session, } 6 \text { October } 1995 \text {, Doc. } 39.790\right)\end{array}$ & $\begin{array}{l}39.110,39.314,39.361,39.471,39.699 \\
39.733\end{array}$ & $39.390,39.790$ \\
\hline 3. & $\begin{array}{l}\text { Interpretation of the expression "partnersin } \\
\text { business" in Article } 15.4 \text { (b) }\end{array}$ & $\begin{array}{l}\text { Advisory Opinion } 21.1 \text { adopted } \\
\left(2^{\text {nd }} \text { Session, } 8 \text { March 1996, Doc. } 40.210\right)\end{array}$ & $\begin{array}{l}39.317,39.503,39.701,39.732,39.822 \\
40.098,40.163\end{array}$ & $\begin{array}{l}39.390,39.790 \\
40.185,40.210\end{array}$ \\
\hline 4. & Application of Article 1.2 & $\begin{array}{l}\text { Case Study } 10.1 \text { adopted } \\
\left(3^{\text {rd }} \text { Session, } 4 \text { October } 1996 \text {, Doc. } 40.710\right)\end{array}$ & $40.388,40.597,40.681$ & 40.710 \\
\hline 5. & $\begin{array}{l}\text { Consideration of relationship under Article 15.5, } \\
\text { read in conjunction with Article } 15.4\end{array}$ & $\begin{array}{l}\text { A revised Explanatory Note } 4.1 \text { adopted } \\
\left(6^{\text {th }} \text { Session, } 1 \text { May } 1998, \text { Doc. } 42.360\right)\end{array}$ & $\begin{array}{l}39.894,40.016,40.162,40.386,40.581 \\
40.702,40.965,41.042,41.084,41.216 \\
41.656,41.889,42.301,42.353\end{array}$ & $\begin{array}{l}40.185,40.710 \\
41.120,41.740 \\
42.360\end{array}$ \\
\hline 6. & Goods subject to export subsidies or bounties & $\begin{array}{l}\text { An amended Commentary } 2.1 \text { approved } \\
\left(6^{\text {th }} \text { Session, } 1 \text { May 1998, Doc. } 42.360\right)\end{array}$ & $41.852,42.326$ & 42.360 \\
\hline 7. & $\begin{array}{l}\text { Cost of transportation : Free On Board system of } \\
\text { valuation }\end{array}$ & $\begin{array}{l}\text { Commentary } 21.1 \text { adopted } \\
\left(7^{\text {th }} \text { Session, } 9 \text { October } 1998 \text {, Doc. } 42.620\right)\end{array}$ & $41.886,42.327,42.594,42.605,42.615$ & $42.360,42.620$ \\
\hline 8. & Warranty charges & $\begin{array}{l}\text { Commentary } 20.1 \text { adopted } \\
\left(7^{\text {th }} \text { Session, } 9 \text { October } 1998 \text {, Doc. } 42.620\right)\end{array}$ & $\begin{array}{l}40.307,40.578,40.632,40.941,41.044 \\
41.086,41.190,41.614,41.654,41.731 \\
41.873,42.294,42.354,42.596,42.608 \\
42.616\end{array}$ & $\begin{array}{l}40.710,41.120 \\
41.740,42.360 \\
42.620\end{array}$ \\
\hline 9. & Study on the use of value declaration forms & $\begin{array}{l}\text { Study adopted } \\
\left(8^{\text {th }} \text { Session, } 1 \text { April } 1999 \text {, Doc. VT0034) }\right.\end{array}$ & $\begin{array}{l}\text { 41.952, 42.334, 42.358, 42.612,42.752, } \\
\text { VT0002E1, VTO014E1, VTO020E1, } \\
\text { VT0030E1, VT0031E1, VT0058E1 }\end{array}$ & $\begin{array}{l}\text { VT0034E2, } \\
\text { VT0076E2 }\end{array}$ \\
\hline 10. & Scope of the term "control" in Article 15.4 & $\begin{array}{l}\text { Documents and comments on the subject } \\
\left(8^{\text {th }} \text { Session, } 1 \text { April } 1999 \text {, Doc. VT0034) }\right.\end{array}$ & $\begin{array}{l}39.894,40.016,40.162,40.386,40.581 \\
40.702,40.965,41.042,41.084,41.392 \\
41.659,41.733,41.888,42.302,42.597\end{array}$ & $\begin{array}{l}40.185,40.710 \\
41.120,41.740 \\
42.360,42.620\end{array}$ \\
\hline
\end{tabular}




\begin{tabular}{|c|c|c|c|c|}
\hline \multicolumn{5}{|c|}{$\begin{array}{c}\text { WORK OF THE TECHNICAL COMMITTEE ESTABLISHED UNDER THE AGREEMENT ON IMPLEMENTATION } \\
\text { OF ARTICLE VII OF THE GATT } 1994 \text { (Since October 1995) }\end{array}$} \\
\hline \multirow{2}{*}{ NOTE: } & \multicolumn{4}{|c|}{$\begin{array}{l}\text { At its First Session in October 1995, the Technical Committee, established under the GATT 1994, adopted all of the work and decisions of the Technical Committee } \\
\text { established under the GATT 1947. }\end{array}$} \\
\hline & Subject & $\begin{array}{l}\text { Observations } \\
\end{array}$ & Related Documents & Reports \\
\hline 11 & Rolatad narty trancantinne & $\begin{array}{l}\text { Cogca Ctırı } 111 \text { arnntar } \\
\left(8^{\text {th }} \text { Session, } 1 \text { April } 1999 \text {, Doc. VT0034) }\right.\end{array}$ & 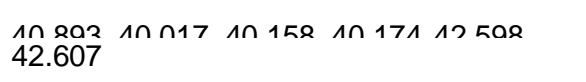 & $\begin{array}{l}\text { An } 18540 \text { a)ก } \\
\text { VT0034E2 }\end{array}$ \\
\hline 12. & $\begin{array}{l}\text { Meaning of the expression "as a condition of sale } \\
\text { of the goods being valued" in connection with } \\
\text { Article } 8.1 \text { (c) }\end{array}$ & $\begin{array}{l}\text { Documents and comments on the subject } \\
\left(10^{\text {th }} \text { Session, } 29 \text { May 2000, Doc. VT0112) }\right.\end{array}$ & $\begin{array}{l}35.978,36.076,36.184,36.185,36.210, \\
\text { 40.818, 41.046, 41.088, 41.854,42.331, } \\
\text { 42.593, VT0011E1, VT0021E1, VT0046E1, } \\
\text { VT0069E1, VT0072E1, VT0082E1, } \\
\text { VT0089E1, VT0089E1, VT0103E1, } \\
\text { VT0110E1 }\end{array}$ & $\begin{array}{l}36.280,41.120, \\
42.360,42.620, \\
\text { VT0034E2, } \\
\text { VT0076E2, } \\
\text { VT0112E2 }\end{array}$ \\
\hline 13. & $\begin{array}{l}\text { Meaning of the expression "related to the goods } \\
\text { being valued" in connection with Article } 8.1 \text { (c) }\end{array}$ & $\begin{array}{l}\text { Documents and comments on the subject } \\
\left(11^{\text {th }} \text { Session, } 3 \text { November } 2000 \text {, Doc. VT0164) }\right.\end{array}$ & $\begin{array}{l}\text { 35.978, 36.076, 36.184, 36.185, 36.210, } \\
\text { 40.862, 41.047, 41.087, 41.872,42.295, } \\
\text { 42.593, VT0011E1, VT0021E1, VT0046E1, } \\
\text { VT0069E1, VT0072E1, VT0082E1, } \\
\text { VT0089E1, VT0103E1, VT0110E1, } \\
\text { VT0125E1, VT0151E1, VT0156E1 }\end{array}$ & $\begin{array}{l}36.280,41.120, \\
42.360,42.620, \\
\text { VT0034E2, } \\
\text { VT0076E2, } \\
\text { VT0112E2, } \\
\text { VT0164E2 }\end{array}$ \\
\hline 14. & $\begin{array}{l}\text { Practical Case Study "Application of Article } 1 \text { of } \\
\text { the Valuation Agreement to goods imported } \\
\text { below production cost" }\end{array}$ & $\begin{array}{l}\text { Case Study } 12.1 \text { adopted } \\
\left(11^{\text {th }} \text { Session, } 3 \text { November } 2000 \text {, Doc. VT0164) }\right.\end{array}$ & $\begin{array}{l}\text { VT0096E1, VT0100E1, VT0107E1, } \\
\text { VT0126E1, VT0130E1, VT0147E1, } \\
\text { VT0157E1 }\end{array}$ & $\begin{array}{l}\text { VT0112E2, } \\
\text { VT0164E2 }\end{array}$ \\
\hline 15. & $\begin{array}{l}\text { Meaning of the expression "sufficientguarantee" } \\
\text { under Article } 13 \text { of the Valuation Agreement }\end{array}$ & $\begin{array}{l}\text { Documents and information on the subject } \\
\left(11^{\text {th }} \text { Session, } 3 \text { November } 2000 \text {, Doc. VT0164) }\right.\end{array}$ & $\begin{array}{l}\text { VT0047E1, VT0081E1, VT0092E1, } \\
\text { VT0127E1, VT0138E1, VT0146E1 }\end{array}$ & $\begin{array}{l}\text { VT0112E2, } \\
\text { VT0164E2 }\end{array}$ \\
\hline 16. & $\begin{array}{l}\text { Practical application of the Valuation Aareement } \\
\text { with respect to Decision } 6.1\end{array}$ & $\begin{array}{l}\text { Case Studv } 13.1 \text { adopted } \\
\left(13^{\text {th }} \text { Session, } 19 \text { October 2001, Doc. VT0225) }\right.\end{array}$ & $\begin{array}{l}\text { VT0129E1. VT0139E1. VT0143E1. } \\
\text { VT0149E1, VT0155E1, VT0161E1, } \\
\text { VT0162E1, VT0185E1, VT0190E1, } \\
\text { VT0210E1, VT0216E1 }\end{array}$ & $\begin{array}{l}\text { VT0164E2. } \\
\text { VT0198E2, } \\
\text { VT0225E2 }\end{array}$ \\
\hline 17. & $\begin{array}{l}\text { Study on the valuation treatment of rented or } \\
\text { leased goods }\end{array}$ & $\begin{array}{l}\text { Documents and information on the subject } \\
\left(15^{\text {th }} \text { Session, } 24 \text { October 2002, Doc. VT0290) }\right.\end{array}$ & $\begin{array}{l}\text { VT0238E1, VT0247E1, VT0250E1, } \\
\text { VT0268E1, VT0286E1 }\end{array}$ & $\begin{array}{l}\text { VT0254E2, } \\
\text { VT0290E2 }\end{array}$ \\
\hline 18. & $\begin{array}{l}\text { Terms of reference for the work of the Technical } \\
\text { Committee on Customs Valuation in connection } \\
\text { with concerns on the accuracy of the declared } \\
\text { value }\end{array}$ & $\begin{array}{l}\text { Technical Committee Response to the Terms of } \\
\text { Reference adopted } \\
\left(16^{\text {th }} \text { Session, } 2 \text { May 2003, Annex D to Doc. VT0328, }\right. \\
\text { Doc. VT0330) }\end{array}$ & $\begin{array}{l}\text { VT0295E1, VT0301E1, VT0303E2, } \\
\text { VT0304E1, VT0312E1, VT0313E1, } \\
\text { VT0314E1, VT0315E1, VT0316E1, } \\
\text { VT0317E1, VT0323E1, VT0324E1, } \\
\text { VT0325E1, VT0330E1 }\end{array}$ & VT0328E3 \\
\hline
\end{tabular}




\begin{tabular}{|c|c|c|c|c|}
\hline \multicolumn{5}{|c|}{$\begin{array}{l}\text { WORK OF THE TECHNICAL COMMITTEE ESTABLISHED UNDER THE AGREEMENT ON IMPLEMENTATION } \\
\text { OF ARTICLE VII OF THE GATT } 1994 \text { (Since October 1995) }\end{array}$} \\
\hline NOTE & $\begin{array}{l}\text { At its First Session in October 1995, the Techn } \\
\text { established under the GATT } 1947 .\end{array}$ & I Committee, established under the GATT 1994, adopte & of the work and decisions of the Tech & ittee \\
\hline No. & Subject & Observations & Related Documents & Reports \\
\hline 10 & $\begin{array}{l}\text { Gulino th tho Fvehanno of C.ıctnme V/alıation } \\
\text { Information }\end{array}$ & $\begin{array}{l}\text { Givita arnntar } \\
\left(16^{\text {th }} \text { Session, } 2 \text { May 2003, Annex E to Doc. VT0328) }\right.\end{array}$ & 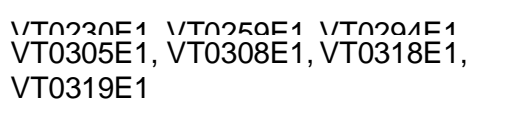 & $\begin{array}{l}\text { V/TกशムЕ? } \\
\text { VT0290E2, } \\
\text { VT0328E3 }\end{array}$ \\
\hline 20. & $\begin{array}{l}\text { Guidelines on the Development and Use of a } \\
\text { National Valuation Database as a Risk } \\
\text { Assessment Tool }\end{array}$ & $\begin{array}{l}\text { Guidelines adopted } \\
\left(18^{\text {th }} \text { Session, } 2 \text { April 2004, Annex D to Doc. VT0388) }\right.\end{array}$ & $\begin{array}{l}\text { VT0258E1, VT0259E1, VT0290E3, } \\
\text { VT0295E1, VT0313E1, VT0314E1, } \\
\text { VT0324E1, VT0328E2, VT0330E1, } \\
\text { VT0343E1, VT0349E1, VT0356E1, } \\
\text { VT0361E2, VT0372E1, } \\
\text { VT0372E2, VT0379E1 }\end{array}$ & $\begin{array}{l}\text { VT0361E3, } \\
\text { VT0388E3 }\end{array}$ \\
\hline 21. & $\begin{array}{l}\text { The valuation treatment of price influenced } \\
\text { importations from related parties }\end{array}$ & $\begin{array}{l}\text { Documents and comments on the subject } \\
\left(19^{\text {th }} \text { Session, } 21 \text { October 2004, Doc. VT0420E3) }\right.\end{array}$ & $\begin{array}{l}\text { VT0140E1, VT0175E1, VT0186E1, } \\
\text { VT0194E1, VT0211E1, VT0217E1, } \\
\text { VT0236E1, VT0241E1, VT0246E1, } \\
\text { VT0345E1, VT0358E1, VT0377E1, } \\
\text { VT0387E1 }\end{array}$ & $\begin{array}{l}\text { VT0164E2, } \\
\text { VT0198E2, } \\
\text { VT0225E2, } \\
\text { VT0254E2, } \\
\text { VT0328E3, } \\
\text { VT0361E3, } \\
\text { VT0388E3, } \\
\text { VT0420E3 }\end{array}$ \\
\hline 22. & $\begin{array}{l}\text { Study on the treatment of importations by sole } \\
\text { distributors and sole concessionaires }\end{array}$ & $\begin{array}{l}\text { Documents and comments on the subject } \\
\left(21^{\text {st }} \text { Session, } 21 \text { October 2005, Doc. VT0470E1c) }\right.\end{array}$ & $\begin{array}{l}\text { VT0225E2, VT0237E1, VT0269E1, } \\
\text { VT0272E1, VT0279E1, VT0302E1, } \\
\text { VT0306E1, VT0360E1, VT0374E1, } \\
\text { VT0382E1, VT0401E1, VT0430E1a, } \\
\text { VT0461E1a }\end{array}$ & $\begin{array}{l}\text { VT0254E2, } \\
\text { VT0290E2, } \\
\text { VT0361E3, } \\
\text { VT0388E3, } \\
\text { VT0420E3, } \\
\text { VT0440E1c, } \\
\text { VT0470E1c }\end{array}$ \\
\hline 23 & $\begin{array}{l}\text { Royalties and licence fees } \\
\text { under Article } 8.1 \text { (c) of the Agreement }\end{array}$ & $\begin{array}{l}\text { Advisory Opinion } 4.14 \text { adopted } \\
\left(22^{\text {nd }} \text { Session, } 7 \text { April 2006, Doc. VT0499E1c) }\right.\end{array}$ & VT0464E1a, VT0465E1a, VT0480E1a & $\begin{array}{l}\text { VT0440E1c, } \\
\text { VT0470E1c, } \\
\text { VT0499E1c }\end{array}$ \\
\hline 24. & $\begin{array}{l}\text { Meaning of the expression "sold for export to the } \\
\text { country of importation in a series of sales" }\end{array}$ & $\begin{array}{l}\text { Commentary } 22.1 \text { adopted } \\
\left(24^{\text {th }} \text { Session, } 26 \text { April 2007, Doc. VT0564E1c) }\right.\end{array}$ & $\begin{array}{l}\text { VT0225E2, VT0237E1, VT0269E1, } \\
\text { VT0272E1, VT0279E1, VT0302E1, } \\
\text { VT0306E1, VT0360E1, VT0375E1, } \\
\text { VT0376E1, VT0402E1, VT0406E1, } \\
\text { VT0414E1, VT0417E1, VT0431E1a, } \\
\text { VT0435E1a, VT0462E1a, VT0463E1a, }\end{array}$ & $\begin{array}{l}\text { VT0254E2, } \\
\text { VT0290E2, } \\
\text { VT0361E3, } \\
\text { VT0388E3, } \\
\text { VT0420E3, } \\
\text { VT0440E1c, }\end{array}$ \\
\hline
\end{tabular}




\begin{tabular}{|c|c|c|c|c|}
\hline \multicolumn{5}{|c|}{$\begin{array}{l}\text { WORK OF THE TECHNICAL COMMITTEE ESTABLISHED UNDER THE AGREEMENT ON IMPLEMENTATION } \\
\text { OF ARTICLE VII OF THE GATT } 1994 \text { (Since October 1995) }\end{array}$} \\
\hline \multirow{2}{*}{$\begin{array}{l}\text { NOTE: } \\
\text { No. }\end{array}$} & \multicolumn{4}{|c|}{$\begin{array}{l}\text { At its First Session in October 1995, the Technical Committee, established under the GATT 1994, adopted all of the work and decisions of the Technical Committee } \\
\text { established under the GATT 1947. }\end{array}$} \\
\hline & Subject & Observations & Related Documents & Reports \\
\hline & & & $\begin{array}{l}\text { VT0479E1a. VT0489E1a. VT0511E1a. } \\
\text { VT0526E1a, VT0542E1a, VT0556E1a }\end{array}$ & $\begin{array}{l}\text { VT0470E1c. } \\
\text { VT0499E1c, } \\
\text { VT0534E1c, } \\
\text { VT0564E1c }\end{array}$ \\
\hline 25 & $\begin{array}{l}\text { Application of Decision } 6.1 \text { of the Committee on } \\
\text { Customs Valuation }\end{array}$ & $\begin{array}{l}\text { Case Study } 13.2 \text { adopted } \\
\left(26^{\text {th }} \text { Session, } 4 \text { April 2008, Doc. VT0626E1c) }\right.\end{array}$ & $\begin{array}{l}\text { VT0469E1a, VT0485E1a, VT0494E1a, } \\
\text { VT0517E1a, VT0548E1a, VT0560E1a, } \\
\text { VT0531E1a, VT0548E1a, VT0560E1a, } \\
\text { VT0581E1a, VT0597E1a, VT0616E1a, } \\
\text { VT0616E1b, VT0624E1a }\end{array}$ & $\begin{array}{l}\text { VT0440E1c, } \\
\text { VT0470E1c, } \\
\text { VT0499E1c, } \\
\text { VT0534E1c, } \\
\text { VT0564E1c, } \\
\text { VT0598E1c, } \\
\text { VT0626E1c }\end{array}$ \\
\hline 26 & $\begin{array}{l}\text { Valuation of imported technical documents } \\
\text { relating to design and development } \\
\text { of an industrial plant }\end{array}$ & $\begin{array}{l}\text { Advisory Opinion } 22.1 \text { adopted } \\
\left(28^{\text {th }} \text { Session, } 3 \text { April 2009, Doc. VT0686E1c) }\right.\end{array}$ & $\begin{array}{l}\text { VT0527E1a, VT0550E1a, VT0562E1a, } \\
\text { VT0580E1a, VT0588E1a, VT0613E1a, } \\
\text { VT0622E1a, VT0644E1a, VT0660E1a, } \\
\text { VT0674E1a, VT0681E1a }\end{array}$ & $\begin{array}{l}\text { VT0534E1c, } \\
\text { VT0564E1c, } \\
\text { VT0598E1c, } \\
\text { VT0626E1c, } \\
\text { VT0663E1c, } \\
\text { VT0686E1c }\end{array}$ \\
\hline 27 & $\begin{array}{l}\text { Examination of the expression "circumstances } \\
\text { surrounding the sale" under Article } 1.2(\mathrm{a}) \text { in } \\
\text { relation to the use of transfer pricing studies }\end{array}$ & $\begin{array}{l}\text { Commentary } 23.1 \text { adopted }\left(31^{\text {st }} \text { Session, } 29 \text { October }\right. \\
\text { 2010, Doc. VT0774E1c) }\end{array}$ & $\begin{array}{l}\text { VT0587E1a, VT0604E1a, VT0647E1a, } \\
\text { VT0662E1a, VT0736E1a, VT0675E1a, } \\
\text { VT0676E1a, VT0682E1a, VT0683E1a, } \\
\text { VT0703E1a, VT0712E1a, VT0726E1a, } \\
\text { VT0736E1a, VT0757E1a, VT0769E1a }\end{array}$ & $\begin{array}{l}\text { VT0598E1c, } \\
\text { VT0626E1c, } \\
\text { VT0663E1c, } \\
\text { VT0686E1c, } \\
\text { VT0715E1c, } \\
\text { VT0740E1c, } \\
\text { VT0774E1c }\end{array}$ \\
\hline 28 & $\begin{array}{l}\text { Determination of the Value of an Assistunder } \\
\text { Article } 8.1(\mathrm{~b}) \text { of the Agreement }\end{array}$ & $\begin{array}{l}\text { Commentarv } 24.1 \text { adopted }\left(31^{\text {st }} \text { Session. } 29 \text { October }\right. \\
2010 \text {, Doc. VT0774E1c) }\end{array}$ & $\begin{array}{l}\text { VT0713E1a, VT0727E1a, VT0738E1a, } \\
\text { VT0758E1a, VT0770E1a, }\end{array}$ & $\begin{array}{l}\text { VT0715E1c, } \\
\text { VT0740E1c, } \\
\text { VT0774E1c }\end{array}$ \\
\hline
\end{tabular}




\begin{tabular}{|c|c|c|c|c|}
\hline \multicolumn{5}{|c|}{$\begin{array}{c}\text { WORK OF THE TECHNICAL COMMITTEE ESTABLISHED UNDER THE AGREEMENT ON IMPLEMENTATION } \\
\text { OF ARTICLE VII OF THE GATT 1994 (Since October 1995) }\end{array}$} \\
\hline NOTE: & $\begin{array}{l}\text { At its First Session in October 1995, the Technical } \\
\text { established under the GATT } 1947 .\end{array}$ & Committee, established under the GATT 1994, adopted al & f the work and decisions of the Technica & ittee \\
\hline No. & Subject & Observations & Related Documents & Reports \\
\hline 29 & $\begin{array}{l}\text { Third Party Royalties and Licence Fees - } \\
\text { General Commentary }\end{array}$ & $\begin{array}{l}\text { Commentary } 25.1 \text { adopted }\left(32^{\text {nd }} \text { Session, } 15 \text { April 2011, }\right. \\
\text { Doc. VT0800E1c) }\end{array}$ & $\begin{array}{l}\text { VT0433E1a, VT0465E1a, VT0467E1a, } \\
\text { VT0481E1a, VT0491E1a, VT0513E1a, } \\
\text { VT0514E1a, VT0528E1b, VTO529E1b, } \\
\text { VT0544E1a, VT0545E1a, VT0557E1a, } \\
\text { VT0558E1a, VT0575E1a, VT0576E1a, } \\
\text { VT0589E1a, VT0590E1a, VT0608E1a, } \\
\text { VT0609E1a, VT0619E1a, VT0620E1a, } \\
\text { VT0639E1a, VT0640E1a, VT0648E1a, } \\
\text { VT0649E1a, VT0655E1a, VT0656E1a, } \\
\text { VT0663E1c, VT0670E1a, VT0678E1a, } \\
\text { VT0699E1a, VT0711E1a, VT0722E1a, }\end{array}$ & $\begin{array}{l}\text { VT0440E1c, } \\
\text { VT0470E1c, } \\
\text { VT0499E1c, } \\
\text { VT0534E1c, } \\
\text { VT0564E1c, } \\
\text { VT0598E1c, } \\
\text { VT0626E1c, } \\
\text { VT0686E1c, } \\
\text { VT0715E1c, } \\
\text { VT0740E1c, } \\
\text { VT0774E1a, }\end{array}$ \\
\hline
\end{tabular}

Part II. Questions on the Technical Committee's programme of work

\begin{tabular}{|c|c|c|c|c|c|}
\hline \multicolumn{6}{|c|}{$\begin{array}{c}\text { WORK OF THE TECHNICAL COMMITTEE ESTABLISHED UNDER THE AGREEMENT ON IMPLEMENTATION } \\
\text { OF ARTICLE VII OF THE GATT } 1994 \text { (From October 1995) }\end{array}$} \\
\hline \multicolumn{6}{|c|}{ NOTE } \\
\hline No. & Subject & When raised & Observations & Related Documents & Reports \\
\hline 1. & Rovalties and licence fees & $\begin{array}{l}\text { U.R. } 19^{\text {th }} \text { Session of the } \\
\text { Technical Committee }\end{array}$ & $\begin{array}{l}\text { Information dociuments were summitted for the Technical } \\
\text { Committee's consideration at the } 19^{\text {th }}, 20^{\text {th }}, 21^{\text {st }}, 22 n d, 23^{\text {rd }} \text { and } \\
24^{\text {th }} \text { Sessions. } \\
\text { Brazil, Canada, Colombia and Japan provided casestudies. }\end{array}$ & $\begin{array}{l}\text { VT0432E1a, VT0433E1a, } \\
\text { VT0467E1a, VT0481E1a, } \\
\text { VT0482E1a, VT0483E1a, } \\
\text { VT0490E1a, VT0491E1a, } \\
\text { VT0492E1a, VT0497E1a, } \\
\text { VT0513E1a, VT0514E1a, } \\
\text { VT0515E1a, VT0528E1b, } \\
\text { VT0529E1b, VT0543E1a, } \\
\text { VT0544E1a, VT0545E1a, } \\
\text { VT0546E1a, VT0557E1a, } \\
\text { VT0558E1a, VT0575E1a, } \\
\text { VT0576E1a, VT0577E1a, } \\
\text { VT0578E1a, VT0589E1a, }\end{array}$ & $\begin{array}{l}\text { VT0440E1c, } \\
\text { VT0470E1c, } \\
\text { VT0499E1c, } \\
\text { VT0534E1c, } \\
\text { VT0564E1c, } \\
\text { VT0598E1c, } \\
\text { VT0626E1c, } \\
\text { VT0663E1c, } \\
\text { VT0686E1c, } \\
\text { VT0715E1c, } \\
\text { VT0740E1a }\end{array}$ \\
\hline
\end{tabular}


Determination of the value of assist under article $8.1(\mathrm{~b})$ of the Agreement
U.R. $25^{\text {th }}$ Session of the Technical Committee

U.R. $29^{\text {th }}$ Session of the Technical Committee
Information documents were submitted for the Technical Committee's consideration at the $25^{\text {th }} .26^{\text {th }} .27^{\text {th }}$ and $28^{\text {th }}$ Sessions.

Information documents were submitted for the Technica Conmmittee's conscideration at the $29^{\text {th }}$ and $30^{\text {th }}$. Sessinns
VT0590E1a, VT0608E1a VT0609E1a, VT0610E1a VT0611E1a, VT0619E1a,

VT0620E1a, VT0639E1a

VT0640E1a, VT0641E1a

VT0648E1a, VT0642E1a,

VT0649E1a, VT0655E1a,

VT0656E1a, VT0657E1a,

VT0658E1a, VT0670E1a,

VT0671

VT0671E1a, VT0672E1a,

VT0679E1a

VT0587E1a, VT0662E1a,

VT0604E1a, VT0675E1a,

VT0676E1a, VT0647E1a,

VT0682E1a, VT0683E1

VT0703E1a, VT0712E1a,

VT0703E

VT0726E1a, VT0736E1a,

VT0757E1a, VT0769E1a

VT0713E1a, VT0727E1a VTn738F1a
VT0598E1c, VT0663E1C. (26) VT0663E1c, VT0686E1c VT0715E1c, VT0740E1a

VT0715E1c,

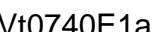

\begin{tabular}{|c|c|c|c|c|c|}
\hline \multicolumn{6}{|c|}{$\begin{array}{c}\text { WORK OF THE TECHNICAL COMMITTEE ESTABLISHED UNDER THE AGREEMENT ON IMPLEMENTATION } \\
\text { OF ARTICLE VII OF THE GATT } 1994 \text { (From October 1995) }\end{array}$} \\
\hline \multicolumn{6}{|c|}{ L 1005 T } \\
\hline No. & Subject & When raised & Observations & Related Documents & Reports \\
\hline 4. & $\begin{array}{l}\text { Valuation of industrial waste } \\
\text { : proposed by Belarus }\end{array}$ & $\begin{array}{l}\text { U.R. } 30^{\text {th }} \text { Session of the } \\
\text { Technical Committee }\end{array}$ & $\begin{array}{l}\text { Information documents were submitted for the Technical } \\
\text { Committee's consideration at the 30th Sessions. }\end{array}$ & - & VT0740E1a \\
\hline 5. & $\begin{array}{l}\text { Interpretation of "condition of } \\
\text { sale" in Article } 8.1 \mathrm{c}- \\
\text { Request by Singapore }\end{array}$ & $\begin{array}{l}\text { U.R. } 32^{\text {nd }} \text { Session of the } \\
\text { Technical Committee }\end{array}$ & $\begin{array}{l}\text { Information documents were submitted for the Technical } \\
\text { Committee's consideration at the } 32^{\text {nd }} \text { Sessions. }\end{array}$ & VT0793E1a & VT0800E1a \\
\hline 6. & $\begin{array}{l}\text { Application of Article } 8.1 \mathrm{~d} \\
\text { with respect to payments } \\
\text { based on projected net } \\
\text { profits - Request by } \\
\text { Singapore }\end{array}$ & $\begin{array}{l}\text { U.R. } 32^{\text {nd }} \text { Session of the } \\
\text { Technical Committee }\end{array}$ & $\begin{array}{l}\text { Information documents were submitted for the Technical } \\
\text { Committee's consideration at the } 32^{\text {nd }} \text { Sessions. }\end{array}$ & VT0794E1a & VT0800E1a \\
\hline
\end{tabular}


Part III. Questions raised, pending future work

\begin{tabular}{|c|c|c|c|c|c|}
\hline \multicolumn{6}{|c|}{$\begin{array}{l}\text { WORK OF THE TECHNICAL COMMITTEE ESTABLISHED UNDER THE AGREEMENT ON IMPLEMENTATION } \\
\text { OF ARTICLE VII OF THE GATT } 1994 \text { (Since October 1995) }\end{array}$} \\
\hline NOTE & $\begin{array}{l}\text { At its First Session in October 1995, } \\
\text { established under the GATT } 1947 .\end{array}$ & Technical Committee & tablished under the GATT 1994, adopted all of the $\mathrm{n}$ & rk and decisions of the Technic & ittee \\
\hline No. & Subject & When raised & Observations & Related Documents & Reports \\
\hline 1. & $\begin{array}{l}\text { Scope of the term "activities" in the Note } \\
\text { to Article } 1\end{array}$ & $\begin{array}{l}\text { T.R. } 19^{\text {th }} \text { Session of } \\
\text { the Technical } \\
\text { Committee }\end{array}$ & $\begin{array}{l}\text { After havina discussed Secretariat Doc. } 35.833 \text {. } \\
\text { the Committee decided to include this item in Part } \\
\text { III in the context of the phrase "activities } \\
\text { undertaken by the buyer on his own account" } \\
\text { (T.R. } 19^{\text {th }} \text { Session, } 16 \text { March 1990) }\end{array}$ & 35.833 & 35.970 \\
\hline 2. & $\begin{array}{l}\text { Scope of the expression "materials } \\
\text { consumed in the production of the } \\
\text { imported goods" under the terms of } \\
\text { Article } 8.1 \text { (b) (iii) }\end{array}$ & $\begin{array}{l}\text { T.R. } 19^{\text {th }} \text { Session of } \\
\text { the Technical } \\
\text { Committee }\end{array}$ & $\begin{array}{l}\text { After having discussed Secretariat } \\
\text { Doc. } 36.009 \text {, the Committee decided not to } \\
\text { pursue the issue due to lack of practical } \\
\text { experience } \\
\left.\text { (T.R. } 20^{\text {th }} \text { Session, } 12 \text { October } 1990\right)\end{array}$ & $36.009,36.188,36.199$ & 36.280 \\
\hline 3. & Application of Articles 1.1 (b) and 8.1 (c) & $\begin{array}{l}\text { T.R. } 22^{\text {nd }} \text { Session of } \\
\text { the Technical } \\
\text { Committee }\end{array}$ & $\begin{array}{l}\text { After having reviewed Secretariat } \\
\text { Doc. } 38.614 \text {, the Committee decided to place the } \\
\text { Case Study in Part III } \\
\text { (T.R. } 27^{\text {th }} \text { Session, } 25 \text { March 1994) }\end{array}$ & $38.202,38.315,38.614,38.713$ & $38.480,38.800$ \\
\hline 4. & $\begin{array}{l}\text { Implications of loan arrangements in } \\
\text { terms of Article } 15.4(\mathrm{e})\end{array}$ & $\begin{array}{l}\text { T.R. } 28^{\text {th }} \text { Session of } \\
\text { the Technical } \\
\text { Committee }\end{array}$ & $\begin{array}{l}\text { After having discussed Secretariat } \\
\text { Doc. } 39.508 \text {, the Committee decided to place the } \\
\text { issue in Part III } \\
\text { (U.R. } 1^{\text {st }} \text { Session, } 6 \text { October 1995) }\end{array}$ & $39.508,39.697,39.730$ & 39.790 \\
\hline 5. & Related party transactions & $\begin{array}{l}\text { T.R. } 29^{\text {th }} \text { Session of } \\
\text { the Technical } \\
\text { Committee }\end{array}$ & $\begin{array}{l}\text { After having discussed the Secretariat's } \\
\text { Doc. } 39.501 \text {, Annex II was placed in Part III } \\
\text { pending consideration of the term "control" with } \\
\text { Article } 15.4 \\
\left.\text { (U.R. } 1^{\text {st }} \text { Session, } 6 \text { October } 1995\right)\end{array}$ & $\begin{array}{l}39.501,39.676,39.754,40.388 \\
40.597,40.681\end{array}$ & $39.790,40.710$ \\
\hline 6. & $\begin{array}{l}\text { Relationship between paragraphs (c) } \\
\text { and (d) of Article } 8.1\end{array}$ & $\begin{array}{l}\text { T.R. } 22^{\text {nd }} \text { Session of } \\
\text { the Technical } \\
\text { Committee }\end{array}$ & $\begin{array}{l}\text { After having discussed the Secretariat's draft } \\
\text { Commentary in Doc. } 41.368 \text {, the Committee } \\
\text { decided to move this Agenda Item to Part III } \\
\text { (U.R. } 5^{\text {th }} \text { Session, } 6 \text { October } 1997 \text { ) }\end{array}$ & $\begin{array}{l}37.113,37.363,39.108,39.118, \\
39.489,39.704,39.718,39.734, \\
39.839,40.119,40.175,40.387, \\
40.596,40.633,40.817,41.043, \\
41.085,41.368,41.626,41.653, \\
41.853,42.329,42.340,42.352\end{array}$ & $\begin{array}{l}37.420,39.390 \\
39.790,40.185 \\
40.710,41.120 \\
41.740,42.360\end{array}$ \\
\hline 7. & $\begin{array}{l}\text { Documents associated with discussion } \\
\text { on "Relationship between paragraphs (c) }\end{array}$ & $\begin{array}{l}\text { T.R. } 23^{\text {rd }} \text { Session of } \\
\text { the Technical }\end{array}$ & $\begin{array}{l}\text { After having discussed Doc. VT0001, the } \\
\text { Committee decided to place all associated }\end{array}$ & $\begin{array}{l}37.113,37.363,39.108,39.118 \\
39.489,39.704,39.718,39.734\end{array}$ & $\begin{array}{l}\text { 42.620, } \\
\text { VT0034E2 }\end{array}$ \\
\hline
\end{tabular}




\begin{tabular}{|c|c|c|c|c|c|}
\hline \multicolumn{6}{|c|}{$\begin{array}{c}\text { WORK OF THE TECHNICAL COMMITTEE ESTABLISHED UNDER THE AGREEMENT ON IMPLEMENTATION } \\
\text { OF ARTICLE VII OF THE GATT } 1994 \text { (Since October 1995) }\end{array}$} \\
\hline \multicolumn{6}{|c|}{ NOTE : } \\
\hline No. & Subject & When raised & Observations & Related Documents & Reports \\
\hline & $\begin{array}{l}\text { and }(d) \text { of Article } 8.1: \text { Examples } \\
\text { submitted by Australia and the EC" }\end{array}$ & Committee & $\begin{array}{l}\text { documents in Part III } \\
\text { (U.R. } 8^{\text {th }} \text { Session, } 1 \text { April 1999) }\end{array}$ & $\begin{array}{l}\text { 39.839, 40.119, 40.173, 40.390, } \\
40.387,40.596,40.633,40.817, \\
41.043,41.085,41.368,41.653, \\
41.626,41.853,42.329,42.340, \\
\text { 42.352, 42.592, 42.606, 42.751, } \\
\text { VT0001E1, VT0018E1, } \\
\text { VT0033E1 }\end{array}$ & \\
\hline 8. & $\begin{array}{l}\text { Practical Case Study : Treatment under } \\
\text { the Valuation Agreement of accrued } \\
\text { credits }\end{array}$ & $\begin{array}{l}\text { U.R. } 9^{\text {th }} \text { Session of the } \\
\text { Technical Committee }\end{array}$ & $\begin{array}{l}\text { After having discussed the Secretariat's draft } \\
\text { Case Study in Doc. VT0128, the Committee } \\
\text { decided to place this Agenda Item in Part III } \\
\text { (U.R. } 11^{\text {th }} \text { Session, } 3 \text { November 2000) }\end{array}$ & $\begin{array}{l}\text { VT0083E1, VT0090E1, } \\
\text { VT0099E1, VT0106E1, } \\
\text { VT0128E1 }\end{array}$ & $\begin{array}{l}\text { VT0112E2, } \\
\text { VT0164E2 }\end{array}$ \\
\hline 9. & $\begin{array}{l}\text { Explanatory Note 1.1: Time element in } \\
\text { relation to Articles } 1,2 \text { and } 3 \text { of the } \\
\text { Agreement }\end{array}$ & $\begin{array}{l}\text { U.R. } 12^{\text {th }} \text { Session of } \\
\text { the Technical } \\
\text { Committee }\end{array}$ & $\begin{array}{l}\text { After having discussed Doc. VT0184, the } \\
\text { Committee decided to place this Agenda Item in } \\
\text { Part III } \\
\text { (U.R. } 12^{\text {th }} \text { Session, } 1 \text { June } 2001 \text { ) }\end{array}$ & VT0184E1, VT0192E1 & VT0198E2 \\
\hline 10. & $\begin{array}{l}\text { Advisory Opinion } 14.1 \text { : Meaning of the } \\
\text { expression "sold for export to the country } \\
\text { of importation" }\end{array}$ & $\begin{array}{l}\text { U.R. } 13^{\text {th }} \text { Session of } \\
\text { the Technical } \\
\text { Committee }\end{array}$ & $\begin{array}{l}\text { After having discussed Doc. VT0213, the } \\
\text { Committee decided to place this Agenda Item in } \\
\text { Part III } \\
\text { (U.R. } 13^{\text {th }} \text { Session, } 19 \text { October 2001) }\end{array}$ & VT0213E1, VT0222E1 & VT0225E2 \\
\hline 11. & Valuation for perfume testers & $\begin{array}{l}\text { U.R. } 23^{\text {rd }} \text { Session of } \\
\text { the Technical } \\
\text { Committee }\end{array}$ & $\begin{array}{l}\text { After having discussed Doc. VT0533, the } \\
\text { Committee decided to place this Agenda Item in } \\
\text { Part III } \\
\text { (U.R. } 27^{\text {th }} \text { Session, } 24 \text { October 2007) }\end{array}$ & $\begin{array}{l}\text { VT0533E1a, VT0551E1a, } \\
\text { VT0563E1a, VT0614E1a, } \\
\text { VT0623E1a, VT0645E1a }\end{array}$ & $\begin{array}{l}\text { VT0534E1c, } \\
\text { VT0564E1c, } \\
\text { VT0598E1c, } \\
\text { VT0626E1c, } \\
\text { VT0663E1c }\end{array}$ \\
\hline 12 & Valuation of cinematographic films & $\begin{array}{l}\text { U.R. } 24^{\text {th }} \text { Session of } \\
\text { the Technical } \\
\text { Committee }\end{array}$ & $\begin{array}{l}\text { After having discussed Doc. VT0552, the } \\
\text { Committee decided to place this Agenda Item in } \\
\text { Part III } \\
\text { (U.R. } 27^{\text {th }} \text { Session, } 24 \text { October } 2007 \text { ) }\end{array}$ & $\begin{array}{l}\text { VT0552E1a, VT0584E1a, } \\
\text { VT0615E1a, VT0625E1a, } \\
\text { VT0646E1a, VT0661E1a }\end{array}$ & $\begin{array}{l}\text { VT0564E1c, } \\
\text { VT0598E1c, } \\
\text { VT0626E1c, } \\
\text { VT0663E1c }\end{array}$ \\
\hline 13 & Customs valuation of imported electricity & $\begin{array}{l}\text { U.R. 20th Session of } \\
\text { the Technical } \\
\text { Committee }\end{array}$ & $\begin{array}{l}\text { After having discussed Doc. VT0437, the } \\
\text { Committee decided to place this Agenda Item in } \\
\text { Part III } \\
\text { (U.R. 30th Session, } 16 \text { April 2010) }\end{array}$ & $\begin{array}{l}\text { VT0437E1a, VT0466E1a, } \\
\text { VT0484E1a, VT0493E1a, } \\
\text { VT0516E1a, VT0547E1a, } \\
\text { VT0559E1a, VT0579E1a, } \\
\text { VT0596E1a, VT0612E1a, }\end{array}$ & $\begin{array}{l}\text { VT0440E1c, } \\
\text { VT0470E1c, } \\
\text { VT0499E1c, } \\
\text { VT0534E1c, } \\
\text { VT0564E1c, }\end{array}$ \\
\hline
\end{tabular}




\begin{tabular}{|l|l|l|l|l|}
\hline \multicolumn{5}{|c|}{ WORK OF THE TECHNICAL COMMITTEE ESTABLISHED UNDER THE AGREEMENT ON IMPLEMENTATION } \\
OF ARTICLE VII OF THE GATT 1994 (Since October 1995)
\end{tabular}

Note : T.R. $=$ Technical Committee established under the Agreement on implementation of Article VII of the GATT 1947 U.R. $=$ Technical Committee established under the Agreement on implementation of Article VII of the GATT 1994 


\section{Bibliography}

Abbott, P., and Borot de Battisti, A. (2009). Recent Global Food Price Shocks: Causes, Consequences and Lessons for African Governments and Donors, Paper presented at the International Agricultural Trade Research Consortium.

Akhtar, M. and R. Spence Hilton. (1984). Effects of Exchange Rate Uncertainty on German and U.S. Trade, Federal Reserve Bank of New York, Quarterly Review, Vol 9, 7-16.

Aristotle \& Ellis, W. (2006). Politics, Echo Library.

Asakura, H., \& World Customs Organization. (2003). World history of the customs and tariffs. Brussels: World Customs Organization.

Auboin, M., and Ruta, M., (2011), The relationship between exchange rates and international trade: a literature review. World Trade Organisation, Economic Research and Statistics Division. Pdf file available at: https://www.wto.org/english/res_e/reser_e/ersd201117_e.pdf. [accessed 22 June 2017]

Aquinas, S. T. (2013). Summa Theologica, Volume 3 (Part II, Second Section). Cosimo Classics. ISBN 9781602065581. Pdf file available at: https://books.google.com.br/books?id=A7Cf9Bt1DWsC. [accessed 22 June 2017].

Attalus. Roman Customs Laws at Ephesus. Available at http://www.attalus.org/docs/other/inscr_10.html. [accessed 22 June 2017]

Babili, M., (2009), Ad Valorem Equivalent in the WTO, Working Paper No. 34, Pdf file available at: http://ageconsearch.umn.edu/bitstream/48586/2/43_ad_valorem_mb_en.pdf. [accessed 22 June 2017]

Barford, Vanessa and Holt, Gerry. (2013). BBC News Magazine. Google, Amazon, Starbucks: The rise of 'tax shaming'. Available at: http://www.bbc.com/news/magazine-20560359. [accessed 22 June 2017].

Bhatia, Ujal Singh. (2017). The Problems of Plenty: Challenging Times for the WTO's Dispute Settlement System. WTO Release of the Appellate Body Annual Report 2016. Pdf file available at: https://www.wto.org/english/news_e/news17_e/ab_08jun17_e.pdf. [accessed 22 June 2017]

Baudrillard, J., (1994). Simulacra and Simulation, University of Michigan Press.

Baudrillard, J., (1996c), The System of Objects, London: Verso. 
Brandstetter, L., (2014). Do Corporate Tax Cuts Reduce International Profit Shifting?, Freie Universität Berlin, http://edocs.fuberlin.de/docs/servlets/MCRFileNodeServlet/FUDOCS_derivate_000000003504/discpaper20 14_10.pdf?hosts $=$. [accessed 22 June 2017]

Brandt, Karl. (1964). The Failure of International Commodity Agreements. Foundation for Economic Education. Available at: https://fee.org/articles/the-failure-of-internationalcommodity-agreements/. [accessed 1 March 2018].

Buchan, David. (2017). Commodities Demystified. A Guide to Trading and the Global Supply Chain. Trafigura. Pdf file available at: https://www.trafigura.com/media/3663/commoditiesdemystified-guide-en.pdf. [accessed 4 August 2017].

Cantens, Thomas. Mirror Analysis and Revenue Fraud. WCO Research Paper No. 35. April 2015. Available at http://www.wcoomd.org/en/topics/research/activities-andprogrammes/ /media/9F730547EF794600ADB7B2012BB5EE63.ashx [accessed 16 July 2020].

Carbaugh, Robert (2008). International Economics. Cengage Learning, 576 pages.

Cline, W. (2017). Estimates of Fundamental Equilibrium Exchange Rates. Peterson Institute for International Economics, Washington, DC.

Coe, N., Hess, M., Yeung, H. W., Dicken, P., \& Henderson, J. (2004). Globalizing regional development: A global production networks perspective. Transactions of the Institute of British Geographers, 29(4), 468-484.

Cottier, M. et al. (2008). The Customs Law of Asia. Oxford.

Daniel, J., (2001), “Hedging Government Oil Price Risk," IMF Working Paper 7. Pdf file available at: https://www.imf.org/external/pubs/ft/wp/2001/wp01185.pdf. [accessed 22 June 2017]

Debreu, G., (1959), Theory of Value: An Axiomatic Analysis of Economic Equilibrium, New York: Wiley. Reprint. New Haven: Yale University Press, 1971.

Dischinger, M. and N. Riedel (2007), Economies of Scope in International Profit Shifting and Multinational Headquarter Location, mimeo, University of Munich.

Downes, J. and Goodman, J. E. (1985). Dictionary of Finance and Investment Terms. Barron’s Financial Guides.

Duran, P. and Sokol, José B. (2005). Customs Modernization Handbook. Chapter 6 - Policy and Operational Lessons Learned from Eight Country Case Studies. World Bank (WB). 
Ebrahim, Z., Inderwildi, O., Kimg, A., (2014), "Macroeconomic Impacts of Oil Price Volatility: Mitigation and Resilience," Frontiers in Energy, Higher Education Press and Springer-Verlag Berlin Heidelber.

Ebrill, Liam P. and others (1999). Revenue implications of trade liberalization. International Monetary Fund (IMF) Occasional paper 180. Washington DC.

Elms, Deborah K. and Low, Patrick. (2013). Global value chains in a changing world. Edited by Deborah K. Elms and Patrick Low. Fung Global Institute (FGI), Nanyang Technological University (NTU), and World Trade Organization (WTO).

Erickson, Jeff. (2019). Algorithms. Independently Published. Book available for download at http://jeffe.cs.illinois.edu/teaching/algorithms/

European Central Bank. (2014). Global Value Chains Surveying Drivers and Measures, Working Paper Series, No. 1739.

European Commission (EC). (2012). Tax Reforms in EU Member States Tax Policy Challenges for Economic Growth and Fiscal Sustainability, Working Paper 34, Pdf file available at http://ec.europa.eu/taxation_customs/resources/documents/taxation/gen_info/economic_analy sis/tax_papers/taxation_paper_34_en.pdf. [accessed 22 June 2017]

European Central Bank (ECB), (2012), Virtual Currency Schemes, https://www.ecb.europa.eu/pub/pdf/other/virtualcurrencyschemes201210en.pdf. [accessed 22 June 2017]

European Central Bank (ECB), (2015), Virtual Currency Schemes - A Further Analysis. Pdf available at: http://www.ecb.europa.eu/pub/pdf/other/virtualcurrencyschemesen.pdf. [accessed 22 June 2017]

European Commission (EC), (2005), AVE-Ad Valorem Equivalents, Directorate-General for Agriculture and Rural Development, Brussels. Pdf available at: http://ec.europa.eu/agriculture/trade-analysis/map/brief1.pdf. [accessed 22 June 2017]

European Union (EU) (2007). Treaty of Lisbon Amending the Treaty on European Union and the Treaty Establishing the European Community, 13 December 2007, 2007/C 306/01, Available at: http://www.refworld.org/docid/476258d32.html [accessed 22 June 2017]

European Union (EU) (2018). WTO modernisation - introduction to future EU proposals concept paper. Pdf available at:

https://trade.ec.europa.eu/doclib/docs/2018/september/tradoc 157331.pdf [accessed 14 January 2020] 
Filippini, Massimo. (2012) Elements of the Swiss Market for Electricity. Springer Science \& Business Media. 229 pages.

Fuest, C./Hebous, S./Riedel, N. (2011), "International Debt Shifting and Multinational Firms in Developing Economies," Economics Letters, pp. 135-138.

Fuest, C., Spengel, C., Finke, K., Heckmeyer, J., Nusser, H., (2013), "Profit Shifting and 'Aggressive' Tax Planning by Multinational Firms: Issues and Options for Reform," ZEW Center for European Economic Research. Pdf available at: http://ftp.zew.de/pub/zewdocs/dp/dp13044.pdf. [accessed 22 June 2017]

Fulton, R. and Buterbaugh, K. (2007). The WTO Primer: Tracing Trade's Visible Hand Through Case Studies. Palgrave Macmillan. 230 pages.

Fung, Victor K. (2013). Governance through partnership in a changing world. Global value chains in a changing world. Edited by Deborah K. Elms and Patrick Low. Fung Global Institute (FGI), Nanyang Technological University (NTU), and World Trade Organization (WTO).

G20 China. (2016). Leaders' Communique, Hangzhou Summit, 4-5 September 2016. Available at: https://www.g20.org/Content/DE/_Anlagen/G7_G20/2016-09-04-g20kommuniqueen.html;jsessionid=29EF225E4A19ABD291972F80BD904D64.s1t1?nn=2068780). [accessed 22 June 2017].

G20 Germany. (2017). Shaping an Interconnected World. Questions and Answers on the G20. Available at:

https://www.g20.org/Webs/G20/EN/G20/FAQs/faq.html;jsessionid=D3A229EB3BB07E8F00 8EB6BA8A5C04E4.s1t1. [accessed 22 June 2017].

GATT (1978). Agreement on Implementation of Article VII of the General Agreement on Tariffs and Trade. MTN/NTM/W/206. 14 December 1978. Available at: https://docs.wto.org/gattdocs/q/TR/MTNNTM/W206.PDF. [accessed 21 February 2018].

GATT (1986). Multilateral Trade Negotiations, The Uruguay Round. Ministerial Declaration on the Uruguay Round, NIN.DEC (September 20, 1986).

GATT (1990). Group of Negotiations on Goods. Negotiating Group on MTN Agreements and Arrangements, Communication from India, MTN.GNG/NG8/W/73 (19 March 1990). p.1-2

Gerber, David. (2012). Global Competition: Law, Markets, and Globalization. OUP Oxford. 416 pages.

Gereffi, G. and Korzeniewicz, M. (eds) (1994) Commodity Chains and Global Capitalism, Westport: Praeger. 
Gereffi , G., Humphrey, J., Sturgeon, T. (2005). The governance of global value chains, Review of International Political Economy, 12(1), 78-104.

Gereffi, G. (2014). Global Value Chains in a Post-Washington Consensus World. Review of International Political Economy, 21(1).

Gilbert, C., (2010), "How to Understand High Food Prices," Journal of Agricultural Economics, 61(2). p. 398-425.

Gilbert, C.L., and Morgan, C.W., (2010), “Has Food Price Volatility Risen?” revised version.

Golt, Sidney. (1974). The GATT negotiations, 1973-75: a guide to the issues. Publications of the British-North American Committee, British-North American Committee.

Goorman, Adrien and Luc De Wulf. (2005). Customs Valuation in Developing Countries and the WTO Valuation Rules. Customs Modernization Handbook. World Bank.

Haberler, Gottfried von. (1936). The Theory of International Trade. W. Hodge, 408 pages.

Hersken, M., Mas, M., Lucas, O, IBDF, (2009), edited by Bakker, A., Obuoforibo, B., Transfer Pricing and Customs Valuation: Two Worlds to Tax As One.

Hicks, J. R., (1961). Value and Capital: An Inquiry Into Some Fundamental Principles of Economic Theory, Clarendon Press.

HM Revenue \& Customs. (2018). Air transport costs to be included in the customs value, Pdf available at: https://www.gov.uk/government/publications/air-transport-costs-to-be-includedin-the-customs-value [accessed 14 January 2020].

Hooper, P., \& Kohlhagen, S. W. (1978). The effect of exchange rate uncertainty on the prices and volume of international trade, Journal of International Economics, 8, 483-511.

International American Conference (IAC) (1890). Report and Recommendations on Customs Regulations, 1889. Classic Reprint Series.

International Chamber of Commerce (ICC). (2014). ICC raises concerns at WTO about the misuse of customs valuation databases. Available at:

http://www.iccwbo.org/News/Articles/2014/ICC-raises-concerns-at-WTO-about-the-misuseof-customs-valuation-databases/. [accessed 22 June 2017]

International Monetary Fund (IMF) et al. (2016). Enhancing the Effectiveness of External Support in Building Tax Capacity in Developing Countries. Available at http://www.oecd.org/tax/enhancing-the-effectiveness-of-external-support-in-building-taxcapacity-in-developing-countries.pdf . [accessed 18 July 2020]. 
International Monetary Fund (IMF) (2017). IMF Primary Commodity Prices. Available at: http://www.imf.org/external/np/res/commod/index.aspx. [accessed 22 June 2017]

International Monetary Fund (IMF) (2020). Tax Revenues in Fragile and Conflicted-Affected States - Why Are They Low and How Can We Raise Them?. Prepared by Bernardin Akitoby, Jiro Honda, and Keyra Primus.

International Tropical Timber Organization (ITTO) (2016). Intra-African Trade in Tropical Timber and Timber Products and Options for Trade Facilitation. Pdf file available at: http://www.itto.int/files/itto_project_db_input/3134/Technical/PD-700-13-R2-I-PhI-St1Technical-Report-1-Study\%20on\%20Tariff.pdf. [accessed 25 February 2018]

Jackson, John H. (1997). The World Trading System: Law and Policy of International Economic Relations, Second edition, MIT Press, Cambridge.

Jovanovich, J. (2000). Customs Valuation and Transfer Pricing: Is It Possible to Harmonize Customs and Tax Rules? Institute of Comparative Law, McGill University of Montreal.

Kautilya's Arthashastra. (1915). Translated into English by R. Shamasastry. Pdf file available at http://www.patheos.com/blogs/hindu2/2014/10/arthashastra-of-kautilya-by-r-shamasastry/. [accessed 03 August 2017]

Kerr, William Alexander and Gaisford, James D. (2007) Handbook on International Trade Policy. Edward Elgar Publishing. 543 pages.

Keynes, J. M. 1973 (1936). The General Theory of Employment, Interest, and Money. New York: Macmillan.

Khan, K. R. (1982). The Law and Organisation of International Commodity Agreements. BRILL, 416 pages.

Kilian, L., (2010). Oil Price Volatility: Origins and Effects, Available at: https://www.wto.org/english/res_e/publications_e/wtr10_forum_e/wtr10_kilian_e.htm. [accessed 22 June 2017]

Kroll, Joshua A. and Huey, Joanna and Barocas, Solon and Felten, Edward W. and Reidenberg, Joel R. and Robinson, David G. and Yu, Harlan. (2016). Accountable Algorithms. University of Pennsylvania Law Review, Vol. 165, 2017 Forthcoming, Fordham Law Legal Studies Research Paper No. 2765268, Available at SSRN: https://ssrn.com/abstract=2765268

Kurzweil, Ray. The Singularity Is Near: When Humans Transcend Biology. New York : Penguin, 2006. 
Landon, Stuart and Constance, Smith (2013). Government Revenue Volatility in Alberta in Boom and Bust Again: Policy Challenges for a Commodity-Based Economy. University of Alberta.

Levett, Benjamin Arthur. (1923) Through the customs maze. Customs Maze Publishing Co., 189 pages.

Liu, Ping (2010). "Agreement on Customs Valuation" in WTO - Trade in Goods : Max Planck Commentaries on World Trade Law: Volume 5. / Wolfrum, Stoll, Hestermeyer (Editors). Martinus Nijhoff Publishers.

Love, Patrick and Lattimore, Ralph. (2009). International Trade. Free, Fair and Open? OECD Insights. OECD publishing.

Marsilla, Santiago Ibáñez (2011). Towards customs valuation compliance through corporate income tax. World Customs Journal, Volume 5, Number 1.

Majumder, S. Dutt. (2001) Customs Valuation - Law \& Practice, Centax Publications PVT.Ltd. New Delhi - 110 003, India.

Marx, K., Engels, F. 1867 (2007), Capital: A Critique of Political Economy - Vol. I-Part II: The Process of Capitalist Production, Cosimo.

Meerhaeghe, M. A. G. van. (1992). The Commodity Agreements. The United Nations Conference on Trade and Development (UNCTAD). In International Economic Institutions. Springer Netherlands.

Mill, J. S. (1870). Principles of Political Economy: With Some of Their Applications to Social Philosophy. London; Longmans, Green and Co.

Mittelstadt, B. D., Allo, P., Taddeo, M., Wachter, S., \& Floridi, L. (2016). The ethics of algorithms: Mapping the debate. Big Data \& Society.

https://doi.org/10.1177/2053951716679679

Northrup. (2003). Encyclopedia of Tariffs and Trade in U.S. History: The encyclopedia.

Organization for Economic Cooperation and Development (OECD). (2003). Working Party of the Trade Committee. Analysis of Non-Tariff Measures: The Case of Export Duties. TD/TC/WP(2002)54/FINAL. Pdf file available at: http://www.oecd.org/officialdocuments/publicdisplaydocumentpdf/?doclanguage=en\&cote=td /tc/wp(2002)54/final. [accessed 5 August 2017]

Organization for Economic Cooperation and Development (OECD). (2005). Looking Beyond Tariffs: The Role of Non-Tariff Barriers in World Trade. OECD Trade Policy Studies. 
Organisation for Economic Cooperation and Development (OECD). (2013a). Interconnected Economies: Benefitting from Global Value Chains, Paris: OECD.

Organisation for Economic Cooperation and Development (OECD). (2013b). Addressing Base Erosion and Profit Shifting. OECD Publishing, Available at: http://dx.doi.org/10.1787/9789264192744-en. [accessed 22 June 2017]

Organisation for Economic Cooperation and Development (OECD). (2014), Standard for Automatic Exchange of Financial Account Information in Tax Matters, OECD Publishing, Paris. Available at: http://dx.doi.org/10.1787/9789264216525-en. [accessed 08 July 2017].

Organisation for Economic Cooperation and Development (OECD). (2015a). Policy Brief. Pdf file available at http://www.oecd.org/ctp/policy-brief-beps-2015.pdf [accessed 22 June 2017].

Organisation for Economic Cooperation and Development (OECD). (2015b). OECD/G20 Base Erosion and Profit Shifting Project 2015 Final Reports - Executive Summaries. Pdf file Available at http://www.oecd.org/tax/beps/beps-actions.htm. [accessed 22 June 2017].

Organisation for Economic Cooperation and Development (OECD) (2015c). About BEPS and the inclusive framework. Available at http://www.oecd.org/tax/beps/beps-about.htm. [accessed 22 June 2017].

Organisation for Economic Cooperation and Development (OECD) (2017). Transfer Pricing Guidelines for Multinational Enterprises and Tax Administrations. Available at https://www.keepeek.com//Digital-Asset-Management/oecd/taxation/oecd-transfer-pricingguidelines-for-multinational-enterprises-and-tax-administrations-2017_tpg-2017en\#.Wp7nmOjwaUk\#page12 [accessed 06 March 2018].

OECD (2019). Global Forum on Transparency and Exchange of Information for Tax Purposes. The AEOI Implementation Report. Available at http://www.oecd.org/tax/transparency/AEOI-implementation-report-2019.pdf [accessed 10 January 2020].

Oxford English Dictionary (OED) online. (2016). "valuation". Oxford University Press. http://www.oxforddictionaries.com/us/definition/american_english/valuation. [accessed 22 June 2017].

Ozturk, I. (2006). Exchange rate volatility and trade: a literature survey, International Journal of Applied Econometrics and Quantitative Studies Vol.3-1

Ping, L., Silberztein,C., (2007), Transfer Pricing, Customs Duties and VAT Rules: Can We Bridge the Gap? Pdf available at: http://www.oecd.org/tax/transfer-pricing/39265412.pdf. [accessed 22 June 2017]. 
Prévost, Denise. (2009). Balancing Trade and Health in the SPS Agreement: The Development Dimension. Wolf Legal Publishers. ISBN: 978-90-5850-419-7.

Rapsomanikis, G., Sarris, A., (2010). Commodity Market Review, Food and Agriculture Organization in the United Nations, Rome.

Ravenhill, J. (2014). Global value chains and development, Review of International Political Economy, 21(1), 264-274.

Ricardo, David. (1821). On the Principles of Political Economy, and Taxation, London: John Murray.

Rodriguez, C., (2011). Mexico Subsidizes 40 Percent of Corn Hedging Costs. Bloomberg, January 15, 2011.

Ruessmann, Laurent and Willems, Arnoud (2009). 'Revisiting the First Sale for Export Rule: an Attempt to Remove Fairness in the Interests of Raising Revenues, Without Improving Legal Certainty', in World Customs Journal, Volume 3, Number 1.

Samani, R.; Paget, F. and Hart, M., (2013). Digital Laundry. An Analysis of Online Currencies, and their Use in Cyber-Crime, White Paper, McAfee.

Sawyer, W. Charles and Sprinkle, Richard L. (2015). Applied International Economics. $4^{\text {th }}$ edition revised. Routledge, 570 pages.

Shaffer, Gregory and Winters, L. Alan. (2016). FTAs as Applicable Law in WTO Dispute Settlement:

Was the Appellate Body Wrong in Peru-Additional Duty (DS457)? Pdf file available at: http://www.law.uci.edu/faculty/fulltime/shaffer/pdfs/2016\%20FTAs\%20as\%20Applicable\%20Law\%20in\%20WTO\%20Dispute \%20Settlement.pdf. [accessed 22 June 2017].

Sherman Saul L. and Glashoff H. (1988). Customs Valuation Commentary on the GATT Customs Valuation Code. International Chamber of Commerce, 2nd Edition.

Smith, A., (1776). Wealth of Nations: An Inquiry Into the Nature and Causes of The Wealth of Nations. Pennsylvania: Pennsylvania State University 2005.

Sturgeon, T. (2008). From commodity chains to value chains: Interdisciplinary theory building in an age of globalization. In J. Bair (Ed.), Frontiers of commodity chain research. Palo Alto, CA: Stanford University Press.

Stawowy, W. (2001). Calculation of Ad Valorem Equivalents of non-ad valorem tariffs Methodology notes. Division on International Trade in Goods and Services, and Commodities, UNCTAD, Draft paper. 
Stiglitz, Joseph E. (2002). Globalization and its discontents. New York: W.W. Norton.

Tax Administration Diagnostic Assessment Tool (TADAT) (2015). Field Guide. Available at: http://www.tadat.org/ [accessed 22 February 2018]

Tax Administration Diagnostic Assessment Tool (TADAT) (2016). Performance Assessment Report. Hashemite Kingdom of Jordan. Available at: http://www.tadat.org/ [accessed 17 August 2018]

Tax Administration Diagnostic Assessment Tool (TADAT) (2016). Performance Assessment Report. Liberia. Available at: http://www.tadat.org/ [accessed 17 August 2018]

Tutt A (2016) An FDA for algorithms. SSRN Scholarly Paper, Rochester, NY: Social Science Research Network. Available at: http://papers.ssrn.com/abstract=2747994 [accessed 25 August 2020].

Trump, Donald. (2017). 7 Point Plan to Rebuild the American Economy by Fighting for Free Trade, Available at https://www.donaldjtrump.com/policies/trade, Jan. 26, 2017 [accessed 22 June 2017].

United Nations (UN). (1969). Treaty Series. Vienna Convention on the Law of Treaties, done at Vienna, 23 May 1969, Vol. 1155, p. 331. Available at: https://treaties.un.org/doc/publication/unts/volume\%201155/volume-1155-i-18232english.pdf. [accessed 22 June 2017].

United Nations (UN). (2011a). Transfer Pricing Methods, Chapter 5, Pdf available at: http://www.un.org/esa/ffd/tax/2011_TP/TP_Chapter5_Methods.pdf. [accessed 22 June 2017].

United Nations (UN). (2011b). Chapter IV - The global food crises. Book: The Global Social Crisis. Pdf file available at: http://www.un.org/esa/socdev/rwss/docs/2011/chapter4.pdf. [accessed 22 July 2017].

United Nations (UN) and World Trade Organization (WTO) (2012). Chapter 2: Quantifying trade policy. A Practical Guide to Trade Policy Analysis. WTO Publications. Pdf file available at: https://www.wto.org/english/res_e/publications_e/wto_unctad12_e.pdf. [accessed 20 July 2017].

United Nations (UN). (2015). Transforming our world: the 2030 Agenda for Sustainable Development. Resolution A/RES/70/1 of 25 September 2015 (p.14).

United Nations (UN). (2015). Addis Ababa Action Agenda of the Third International Conference on Financing for Development (Addis Ababa Action Agenda). Pdf available at: https://sustainabledevelopment.un.org/content/documents/2051AAAA_Outcome.pdf. [accessed 08 July 2017]. 
United Nations Conference on Trade and Development (UNCTAD). (2003), Dispute Settlement, World Trade Organization, Pdf available at:

http://unctad.org/en/docs/edmmisc232add33_en.pdf. [accessed 22 June 2017].

United Nations Conference on Trade and Development (UNCTAD) (2006). Trade

Misinvoicing in Primary Commodities in Developing Countries: The cases of Chile, Co te d'Ivoire, Nigeria, South Africa and Zambia. UNCTAD/SUC/2016/2. Pdf available at: http://unctad14.org/Documents/UNCTAD_SUC_2016_2_en_Advance_Copy.pdf. [accessed 21 February 2018].

United Nations Conference on Trade and Development (UNCTAD), (2012). Don't Blame the Physical Markets: Financialization is the Root Cause of the Oil and Commodity Price Volatility. 2012-09, Pdf file available at: http://www.ourenergypolicy.org/wpcontent/uploads/2012/10/presspb2012d1_en.pdf. [accessed 22 June 2017].

United Nations Conference on Trade and Development (UNCTAD). (2013). Global Value Chains and Development: Investment and Value-Added Trade in the Global Economy UNCTAD/DIAE/2013/1, Geneva: UNCTAD.

United Nations Department of Economic and Social Affairs (UN DESA), (2017). International Migration. Available at: http://www.un.org/en/development/desa/population/theme/international-migration/. [accessed 22 June 2017].

United Nations Development Program (UNDP) (2010). The Path to Achieving the Millenium Development Goals: A Synthesis of MDG evidence from around the world. Available at: http://www.undp.org/content/dam/aplaws/publication/en/publications/MDG/the-path-toachieving-the-mdgs/Synthesis\%20Report_21\%20Jul\%202010.pdf?download. [accessed 22 June 2017].

United States (US). American State Papers: Documents, Legislative and Executive, of the Congress of the United States. (1834). Volume 11, Congress, ISBN 1575884046, 9781575884042, Gales and Seaton.

United States (US). (1919). Senate. Ninety-Sixth Congress. First Session. Hearings before the Subcommittee on International Trade of the Committee on Finance, February 21 and 22, 1919.

United States (US). (1922). Congress. Senate. Committee on Finance. American valuation; Dyes embargo. U.S. Government Printing Office. p. 218.

United States (US) House of Representatives (1966), Committee on Foreign Affairs, Subcommittee on Foreign Economic Policy, August 9, 1966. 
United States (US). (2010). Federal Register, Vol. 75, nr.188, Wednesday, September 29, 2010, Notices.

United States Tariff Commission (USTC) (1972). Congress. Senate. Committee on Finance. Subcommittee on International Trade. Customs valuation; staff report on investigation no. 332-68 under section 332 of the Tariff act of 1930. Washington.

Van den Bossche, Peter and Zdouc, Werner. (2013). The Law and Policy of the World Trade Organization. Third Edition. Cambridge University Press.

Wolffgang (2010). "Agreement on Customs Valuation” in WTO - Trade in Goods : Max Planck Commentaries on World Trade Law: Volume 5. / Wolfrum, Stoll, Hestermeyer (Editors). Martinus Nijhoff Publishers.

World Bank (WB) (2016). Expanding the Global Tax Base: "Taxing to Promote Public Goods: Tobacco Taxes". Panel Session Held as Part of "Winning the Tax Wars: Global Solutions for Developing Countries Conference", May 23-24, 2016, Available at: http://pubdocs.worldbank.org/en/799981480947591462/Taxing-to-Promote-Public-Goodstobacco-taxation-chapter-conference-25-nov-2016-final-version-pmarquez-002.pdf. [accessed 31 March 2020].

World Customs Organization (WCO) (2003). Guide to Exchange of Customs Valuation Information. Available at:

http://www.wcoomd.org/ /media/WCO/Public/Global/PDF/Topics/Valuation/Instruments\%2 0and\%20Tools/Guides/guide_exchange.ashx?db=web. [accessed 08 July 2017].

World Customs Organization (WCO) (2004). Guidelines on the Development and use of a National Valuation Database as a Risk Assessment Tool. Available at:

http://www.wcoomd.org/en/topics/valuation/instruments-andtools/ /media/WCO/Public/Global/PDF/Topics/Valuation/Instruments\%20and\%20Tools/Gui des/guidelines_national_db.ashx. [accessed 22 June 2017].

World Customs Organization (2006a). The Harmonized System: A Universal Language for International Trade. Part 7 of Customs compendium. 51 pages.

World Customs Organization (WCO). (2006b). Customs Valuation Control Handbook. Available at: http://www.wcoomd.org/en/topics/key-issues/cep/instruments-and-tools.aspx. [accessed 08 July 2017].

World Customs Organization (WCO) (2014). Customs Valuation Compendium. Available at: http://wcoomdpublications.org/valuation/e-valuation-en-douane-acces-1-an-pour-1utilisateur.html. [accessed 08 July 2017]. 
World Customs Organization (WCO) (2015a). 2014-2015 Annual report. Pdf file available at http://www.wcoomd.org/-/media/wco/public/global/pdf/media/annualreports/wco_annrep_en_2014_2015.pdf. [accessed 03 August 2017].

World Customs Organization (WCO) (2015b). Revenue Package Phase II. Overview and Introduction to New Materials. Pdf file available at: http://www.wcoomd.org//media/wco/public/global/pdf/topics/key-issues/revenue-package/common-infrastructure/1__overview-and-introduction-to-new-materials-_2015_final_en.pdf?db=web. [accessed 08 July 2017].

World Customs Organization (WCO). (2016). Guidelines for Strengthening Cooperation and the Exchanging of Information between Customs and Tax Authorities at the National Level. Pdf file available at: http://www.wcoomd.org/ /media/wco/public/global/pdf/topics/facilitation/instruments-andtools/tools/customs-tax-cooperation/customs_tax_guidelines_en_final2.pdf?db=web. [accessed 22 June 2017].

World Customs Organization (WCO). (2017a). List of 207 countries, territories or customs or economic unions applying the Harmonized System. Pdf file available at http://www.wcoomd.org/-/media/wco/public/global/pdf/topics/nomenclature/overview/hscontracting-parties/list-of-countries/countries_applying_hs.pdf?db=web. [accessed 03 August 2017].

World Customs Organization (WCO) (2017-2018). Annual report. Pdf file available at http://www.wcoomd.org/en/about-us/what-is-the-wco/annual-reports.aspx. [accessed 03 August 2017].

World Health Organization (WHO). Report on the Global Tobacco Epidemic (2015).

World Health Organization (WHO). Framework Convention on Tobacco Control. Available at: http://www.who.int/fctc/en/. [accessed 03 March 2018].

World Trade Organization (WTO) (1968). Agreement Relating Principally to Chemicals, Supplementary to The Geneva (1967) Protocol to The General Agreement on Tariffs and Trade. Available at: https://www.wto.org/english/docs_e/legal_e/kennedy_e.pdf. [accessed 22 June 2017]

World Trade Organization (WTO). (1998). Ad valorem, Specific and other Tariffs:

Background Paper by the Secretariat. WTO, AIE/S5.

World Trade Organization (WTO). (1999). The Legal Texts: The Results of the Uruguay Round of Multilateral Trade Negotiations. Cambridge University Press.

World Trade Organization (WTO). (2001), Market Access: Unfinished Business, Special Studies Series 6. 
World Trade Organization (WTO). (2003). Incidence of Non-Ad Valorem Tariffs in Members' Tariff Schedules and Possible Approaches to the Estimation of Ad Valorem Equivalents. Paper by the Secretariat. WTO, TN/MA/S/10.

World Trade Organization (WTO). (2004). Calculation of Ad Valorem Equivalents (AVEs) Data Requirements and Availability, TN/AG/S/11/Add.1, 29 November 2004.

World Trade Organization (WTO). (2005). Negotiating Group on Market Access - Incidence of Non-Ad Valorem Tariffs in Members' Tariff Schedules and Possible Approaches to the Estimation of Ad Valorem Equivalents, TN/MA/S/10/Rev.1, dated 18 July 2005.

World Trade Organization (WTO). (2008). Revised Draft Modalities for Agriculture. TN/AG/W/4/Rev.1. Pdf file available at:

http://www.wto.org/english/tratop_e/agric_e/agchairtxt_dec08_a_e.pdf. [accessed 21 February 2018].

World Trade Organization (WTO). (2010) World Trade Report 2010. Geneva. Pdf file available at:

http://www.wto.org/english/res_e/booksp_e/anrep_e/world_trade_report10_e.pdf. [accessed 5 August 2017].

WTO. (2012). Analytical Index - Guide to GATT Law and Practice, Article VII - Valuation for Customs Purposes, Pdf available at:

https://www.wto.org/english/res_e/booksp_e/gatt_ai_e/art7_e.pdf. [accessed 22 June 2017]

World Trade Organization (WTO). (2013). Switzerland and Liechtenstein Trade Policy Review, 2013. Swiss Customs Administration, WT/TPR/G/280. Available at: http://www.ezv.admin.ch/zollinfo_firmen/04020/04256/04257/04506/index.html?lang=en, 2015. [accessed 22 June 2017].

World Trade Organization (WTO). (2014a), Technical Information on Customs Valuation, Available at: http://www.wto.org/english/tratop_e/cusval_e/cusval_info_e.htm. [accessed 22 June 2017].

World Trade Organization (WTO). (2014b). WTO OMC Report on G-20 Trade Measures, WTO website, www.wto.org/english/news_e/news13_e/g20_wto_report_dec13_e.pdf. [accessed 22 June 2017].

World Trade Organization (WTO). (2015a). World Trade Report 2015. Available at: https://www.wto.org/english/res_e/booksp_e/world_trade_report15_e.pdf. [accessed 22 June 2017]. 
World Trade Organization (WTO). (2015b). Chile. Trade Policy Review (TPR). Report by the Secretariat. WT/TPR/S/315. Available at:

https://www.wto.org/english/tratop_e/tpr_e/tp415_e.htm. [accessed 22 June 2017].

World Trade Organization (WTO). (2017). Annual Report. Available at:

https://www.wto.org/english/res_e/booksp_e/anrep_e/anrep17_e.pdf [accessed 11 January 2019]

World Trade Organization (WTO). (2018). Annual Report. Available at:

https://www.wto.org/english/res_e/booksp_e/anrep18_e.pdf [accessed 11 January 2019]

World Trade Organization (WTO) (n.a.). Introduction to Market Access in Trade in Goods in the WTO. WTO E-Learning 12. My Course series. Pdf file available at: https://ecampus.wto.org/admin/files/Course_385/Module_1578/ModuleDocuments/MA-L1R1-E.pdf. [accessed 17 August 2018].

World Trade Organization (WTO) (n.a.). Detailed Presentation of Tariffs and Tariff Negotiations. WTO E-Learning 12. My Course series. Pdf file available at: https://ecampus.wto.org/admin/files/Course_385/Module_1579/ModuleDocuments/MA_Tarif f-L2-R1-E.pdf. [accessed 24 July 2017].

World Trade Organization (WTO). (n.a.) (b). Trade Policies and Practices by Measure. Trade Policy Review.

World Trade Organization (WTO) (n.a.). WTO Schedules of Concessions and Renegotiation of Concessions. Pdf file available at:

https://ecampus.wto.org/admin/files/Course_417/Module_757/ModuleDocuments/NAMAM4-R3-E.pdf. [accessed 20 July 2017].

Wulf, L., \& Sokol, J. B. (2004). Customs modernization initiatives: Case studies.

Washington, DC: World Bank (WB).

Yeung, H.W. (2014). Governing the Market in a Globalizing Era: Developmental States, Global Production Networks and Inter-Firm Dynamics in East Asia. Review of International Political Economy, 21(1).

Ziewitz, M. (2016). Special Issue Introduction: Governing Algorithms: Myth, Mess, and Methods. Science, Technology, \& Human Values, 41(1), 3-16. Retrieved August 30, 2020, from http://www.jstor.org/stable/43671280 


\section{Valorization Addendum}

\section{Social and economic relevance}

Revenue is essential to providing public goods and services, increasing equity and helping manage macroeconomic stability. It is a central component of financing sustainable development goals (SDGs) across the United Nations (UN). In this context, there is a strengthened awareness of the link between taxation and international trade.

Assuming a scenario of global fiscal debt, low inflation and slow economic growth, this dissertation investigates the adoption of AV tariffs in association with the WTO rules on customs valuation for countries' revenue needs. It questions beliefs about sustainable international trade liberalization based on the perspective of converting all types of tariffs into $\mathrm{AV}$, which are applied in combination with customs valuation rules.

In this regard, the dissertation takes a critical view of the WTO policies of converting NAV into AV tariffs and setting customs valuation rules based on free market assumptions. It argues that AV tariffs and the WTO rules for customs valuation may be suitable for many categories of goods and countries, but not for all.

Goods with high import tariffs, countries lacking the capacity to check declared import prices, unknown export prices, regulated markets, and an increasing importance of services in the value of traded goods are some elements for consideration when debating the pros and cons of AV tariffs.

Due to government 's fiscal weaknesses, it is thus important to discuss the role of tariffs and customs valuation for taxation in various fora, including the United Nations (UN), the World Trade Organization (WTO), the World Customs Organization (WCO), the Organisation for Economic Co-operation and Development (OECD), the International Monetary Fund (IMF), the World Bank, and several regional development banks, such as the European Investment Bank (EIB), the Islamic Development Bank (IsDB), the Asian Development Bank (ADB), European Bank for Reconstruction and Development (EBRD), the Inter-American Development Bank Group (IDB), and the African Development Bank (AfDB).

The social and economic relevance of the revenue function of tariffs is thus the understanding that $\mathrm{AV}$ tariffs can bring risks for countries in need of the revenue resources from tariffs. Revenue instability and uncertainty result in undesired outcomes for sustainable economic and social policies, as well as for international trade liberalization.

After decades of GATT tariff negotiations, WTO schedules of concessions and Members national tariffs mainly use the AV tariff type. Over the years, different NAV were converted into AV. The present dissertation thus contributes to revisiting AV conversion on the multilateral level in relation to the relevant provisions of WTO law. As such this dissertation challenges the status quo of AV tariffs for schedules of concessions and national tariffs lists.

\section{Target groups}

This dissertation should be of interest to various actors operating in the areas of customs, international taxation, trade finance, trade negotiations, economic development, and policy making, among others. These actors can be found within several international 
organizations, countries economy and trade ministers, relevant international consulting companies, industry associations, and large business corporations.

Particularly WTO Members may be interested in the topic of the dissertation in order to gain a better understanding of the challenges of working with AV tariffs. These Members might also get a better understanding of their existing rights with respect to the use of other tariff types rather than AV, according to the WTO rules of law. This particularly concerns less developed economies, as well some developing economies that struggle to audit declared values in international trade. It is argued in the conclusions of this dissertation that AV simplification to monitor and negotiate tariff preferences puts the revenue function of tariffs at risk.

Moreover, this dissertation concludes that the further development of the WTO negotiations with regard to tariffs and customs valuation should promote more flexibility to use NAV types of tariffs instead of AV, as well as to link the trade liberalization agenda of less developed countries with the revenue function of tariffs. The WTO, however, is a Member-driven organization and the flexibilization expected from WTO Members in this regard would thus only be possible if there is a consensus among the Members regarding the challenges posed by the proliferation of AV tariffs for all types of goods and economies.

The results of this dissertation should be of direct interest to several Customs administrations, such as those WCO Members. These Customs administrations face daily challenges in the field of taxation when applying AV tariffs and WTO customs valuation rules. In addition, the dissertation results may be considered in academic papers prepared by the 200 members and affiliates of the International Network of Customs Universities (INCU), which supports research in Customs matters, and others such as the Society of International Economic Law (SIEL) and International Customs Law Association (ICLA).

Finally, the results of the present research should be useful and interesting for international trade and tax academic researchers, legal practitioners, policy experts, and policy makers who are active in the field of international trade, international economic law and international taxation.

\section{Activities and products}

This study will result in a published book. It will, as a result, be publicly available for consultation at libraries and for purchase by academic researchers, legal practitioners, policy experts, policy makers, governmental officials, international civil servants, and other stakeholders or persons interested in the challenges posed by tariffs and WTO customs valuation rules. As was mentioned already, this dissertation presents a number of considerations and proposals concerning the understanding on the use of different tariff types, the complexities of WTO customs valuation rules, WTO customs valuation disputes, the interpretation of the existing relevant norms of WTO law, and ideas for the possible further development of WTO law in the area of tariffs and valuation.

The author thus hopes that at least some of these outcomes and proposals will influence the policies pursued by WTO and WCO Members and their relevant authorities when deciding about the suitable tariff type and flexibility rules for groups of goods and/or countries. The author also anticipates that his considerations and proposals will be considered by private consulting companies, industry associations and business corporations.

As concluded at the end of the study, more research is necessary to understand various aspects of tariffs types for revenue purposes, the flexibility issues as well as the options available to address the challenges from a tax planning and services perspective. Finally, of 
course, I am planning to be actively involved into the ongoing discussions and research on this fascinating topic.

\section{Innovation}

Although there are a number of reports, research papers and publications on tariffs and customs valuation, their effects on international trade in goods, and the implications of WTO law for their regulation, a critical legal dissertation on the need to revisit the tariffs theory and the complexities associated with the WTO customs valuation rules has not been undertaken to date.

The present dissertation thus contributes to the existing body of literature and research on this important topic. In fact, this dissertation, through its analysis of tariff types and WTO customs valuation rules, together with an examination of historical documents and the WTO disputes, helps to clarify the overall "picture" of the alternatives for tariffs.

Moreover, the study contributes to exploring the possible ways of using tariffs and further linking the WTO objective of trade liberalization with the challenges such as fiscal stability and predictability for long-term planning. In this respect, the dissertation presents several innovative recommendations and proposals.

\section{Planning and implementation}

The author hopes that the results of this dissertation will be considered in the ongoing discussions for tariffs and revenue taking place in the WTO, WCO, IMF, World Bank, regional development banks, customs unions, and other relevant bodies. The dissertation results may also be considered by the panelists, Appellate Body Members and WTO Secretariat staff dealing with tariffs. This would be particularly useful when a dispute related to the use of tariffs and customs valuation is brought to the WTO dispute settlement system by a WTO Member.

The author also expects that the research results will be considered in upcoming reports and papers prepared and issued by Members of academic bodies such as the International Network of Customs Universities (INCU), the Society of International Economic Law (SIEL) and International Customs Law Association (ICLA).

The author will endeavor to promote the results of this study among the customs and international trade community, academics and practitioners, as well as to participate actively in the on-going discussions on legal and economic issues related to tariffs and customs valuation. This will be done through further publications on the topic, participation in scientific conferences, roundtables, and other meetings organized by universities, international organizations, scientific societies, NGOs, and other organizations active in the field. 


\section{Curriculum Vitae}

Leonardo Correia Lima Macedo was born on 26 November 1972, in Santos, Brazil. He finished high school in 1991 and spent a year abroad in Haarlem as a Rotary exchange student. After returning from the exchange, he went to University Federal da Paraiba (UFPB) from 1991 to 1995 and obtained a bachelor's degree in economics. Subsequently, from 1995 to 1999 he did a masters in economic law at the same university.

In 1997, after passing competitive public exams, he was admitted as a tax and customs auditor of the Ministry of Economy. From 1997 to 2010, he worked in different positions at the tax and customs administration, including managing teams up to 30 employees on both local and national levels to implement proper WTO customs valuation procedures and trade facilitation measures. From 2001 to 2004, he went to University Centre of the Federal District (UDF) and obtained a bachelor's degree in law.

From 2006, Leonardo started doing technical assistance missions on customs matters for the WCO and the WTO. He holds accreditations for customs modernization projects, trade facilitation and customs valuation. As a customs expert, he has a comprehensive understanding of customs modernization and trade facilitation reforms, including risk management, customs regulations, post clearance audits, and customs appeals systems. From 2010 to 2013, he moved to Brussels and worked as a technical officer for the WCO. At this position, he was part of the tariffs and trade directorate, advising countries on policy issues for customs valuation and other tariffs-related matters. During this time, he also attended meetings at the WTO and was involved in transfer pricing discussions with the OECD.

During his career, Leonardo gave several courses and lectures at various universities/schools (FGV, FESP, ESAF, IPOG) and international organizations (WCO, IDB, UNDP, OIE). He is a Member of the International Network of Customs Universities (INCU).

From 2014 to 2017 he worked as an advisor for the Customs Directorate. From 2017 to 2020 he served as administrative judge at Brazilian Federal Court for Customs and Tax Appeals. In 2020 he was appointed Tax and Customs attaché for Brazil in Argentina and now works in Buenos Aires. 